THE

\title{
WATER SUPPLY OF TOWNS
}

AND THE

CONSTRUCTION OF WATERWORKS 


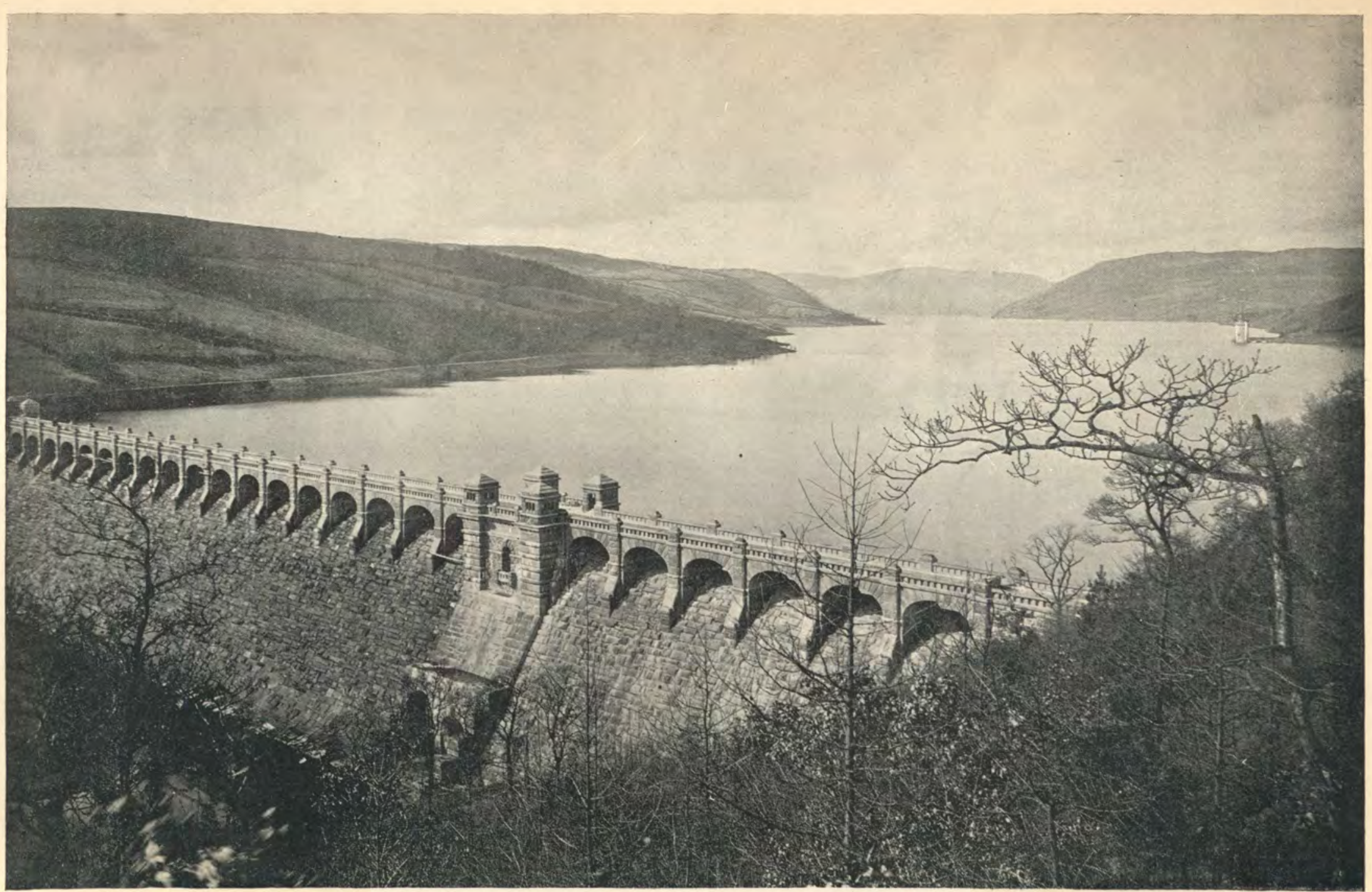

Reproduced by permission from THE ENGINEER.] 


\section{WATER SUPPLY OF TOWNS}

AND THE

\section{CONSTRUCTION OF WATERWORKS}

A PRACTICAL TREATISE FOR THE USE OF ENGINEERS AND STUDENTS OF ENGINEERING

BY

W. K. BURTON, Assoc. Memb. Inst. C.E. PROFESSOR OF SANITARY ENGINEERING IN THE IMPERIAL UNIVERSITY, TOKYO, JAFAN CONSULTING ENGINEER TO THE TOKYO WATERWORKS

ENGINEER TO THE SANITARY BUREAU, HOME DEPARTMENT, JAPAN

TO WHICH IS APPENDED

A PAPER ON THE EFFECTS OF EARTHQUAKES ON WATERWORKS BY PROFESSOR FOHN MILNE, F.R.S.

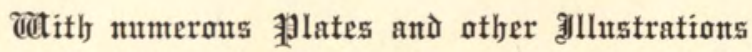

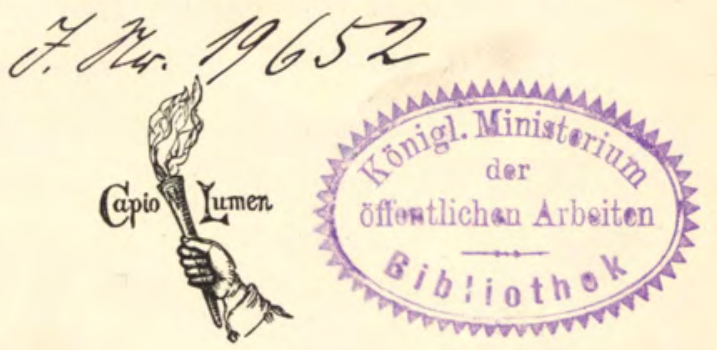

L O N D O N

CROSBY LOCKWOOD AND SON

7, STATIONERS' HALL COURT, LUDGATE HILL

I 894 


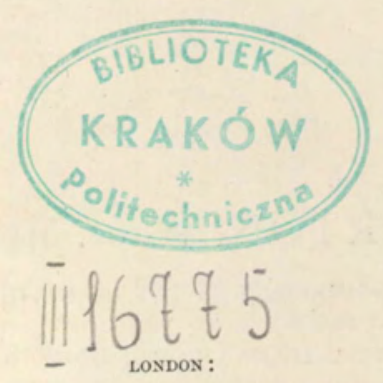

BRADBURY, AGNEW, \& CO. LD., PRINTERS, Whiterriars, 


\section{PREFACE.}

The present volume being largely based upon my own practice in the particular branch of Engineering with which it is concerned, and the conclusions expressed therein being the result of careful study of the various questions dealt with, I venture to hope that it may be found in some respects useful as a book of reference by many of my brother Engineers. In writing it, however, I have specially kept in mind the requirements of those Students of Engineering to whom the subject of Water Supply may be a novel one.

It would be impossible, even were it desirable, to write such a book without making frequent use of what has already been written and published; and I have not hesitated to quote from, or to give the sense of, any writings on the subject that I have had access to. But I have been careful, as far as possible, to acknowledge the sources of any information that has not arisen out of my own practice; and if in any case I have failed to do so the omission is due to oversight, not to intention, and I shall be glad to be told of it.* Such standard works as those of Humber and Fanning (it need not be said) I have freely used. I do not pretend that every piece of information which has been

* This book had been written nearly a year before I had an opportunity of seeing the excellent work, "The Principles of Waterworks Engineering," by Mr. J. H. Tudsbery Turner, B.Sc., and Mr. A. W. Brightmore, M.Sc. 
gained from these works is individually acknowledged, and I therefore make this general acknowledgment.

For obvious reasons, I hope that the work may prove of special interest, as well as utility, to Japanese Students; and I have for this reason inserted here and there matter that applies to Japan alone. Such matter, however, has been relegated to the position of foot-notes, so that it need not interrupt the course of what is of interest to the general reader.

It would be impossible to mention even the names of all those personal friends who in one way or another have kindly rendered me assistance in regard to the work, although acknowledgments of the help received from many of them will be found scattered through the text. I cannot help, however, particularly mentioning here my colleagues Dr. E. Divers, F.R.S.; Professor Charles Dickinson West, M.A. ; Professor A. Inokuchi; and Professor John Milne, F.R.S. To the first of these I am indebted for advice in matters connected with Chemistry, as well as for revising what I had written touching that subject, and for having himself written several paragraphs which are duly acknowledged in their places. Mr. West, and Mr. Inokuchi, I have to thank for assistance and advice in all matters connected with Mechanical Engineering; and Mr. Milne for his interesting paper on the Effects of Earthquakes on Waterworks, which is printed as an Appendix.

W. K. BURTON.

College of EngineeriNg,

IMPERIAL UNIVERSITY,

TOKYO, JAPAN. 


\section{CONTENTS.}

\section{CHAP'TER I.}

CHAPTER II.

Different Qualities of Water

\section{CHAP'TER III.}

Quantity of Water to Be Provided

\section{CHAP'TER IV.}

On Ascertaining Whether a Proposed Source of Supply is Sufficient

\section{CHAP'TER V.}


CHAPTER VI.

CHAPTER VII.

IMPOUNDING RESERVOIRS

\section{CHAPTER VIII.}

Earthwork DaMs

\section{CHAPTER IX.}

Masonry Dams

CHAPTER $\mathrm{X}$.

The Purification of Water

CHAPTER XI.

Settling Reservoirs .

CHAPTER XII.

Sand Filtration

\section{CHAPTER XIII.}

Purification of Water by action of Iroin-Softening of Water by action of Lime-Natural Filtration 


\section{CHAP'TER XIV.} Service or Clean Water Reservoirs-Water Towers-Stand PIPES

PAGE

\section{CHAPTER XV.}

The Connection of Settuing Reservoirs, Filter Beds, and Service ReservoIrs

\section{CHAPTER XVI.}

PUMPing Machineri .

CHAPTER XVII.

Flow of Water in Conduits-Pipes and Open Channels 167

\section{CHAPTER XVIII.}

Distribution Systems

CHAPTER XIX.

Special Provisions for the Extinction of Fire . 205

CHAPTER XX.

PIPES FOR WATERWORKS 218

CHAP'TER XXI.

Prevention of Waste of Water . . . . . . . . . . . 239 


\section{CHAPTER XXII.}

\section{APPENDIX I.}

Considerations concerning the Probable Effects of Earthquakes on Waterworks, and the Special Precautions to be taken in Earthquake Countries. By Professor John Milne, F.R.S. 


\section{LIST OF ILLUSTRATIONS.}

Fig.

PAGE

Lake Vyrnwy Reservoir (Liverpool Water Supply) . . . Frontispiece

1, 2. Weir or Notchboard for Gauging Streams . . . . . . $\quad 25$

3. Metal Plate for do. do. . . . . . . . . 26

4. Section across River showing depth of Stream at various points . . 28

5. (Plate I.) Impounding Reservoir: Diagram illustrating required Storage Capacity (Yearly rainfall) . . . . . . . facing 38

6. (Plate II.) Impounding Reservoir: Diagram illustrating required Storage Capacity (Daily rainfall) . . . . . . facing 40

7-12. (Plates III., TV., V.) Forms of Gravitation and Pumping Systems of Waterworks . . . . . . . . . facing 44

13. Contour of Sides of Valley forming Site for Reservoir . . . . . 46

14. Do. do. do. (Streams Meeting) 47

15. Diagram illustrating Mean Depth of Reservoir with Sloping Side _ . 49

16. Do. do. $\quad$ with Steep Sides . . 49

17. Do. Method for determining Necessary Depth of Reservoir 50

18. (Plate VI.) Section of Earthwork Dam . . . . facing 54

19. Cross-section of Puddle Trench . . . . . . . . . . . 55

20. Do. do. (another form) . . . . . 56

21. Position of Valve Tower with Culvert in Trench . . . . . 58

22. Do. $\quad$ with Tunnel under Dam . . . . 58

23-28. (Plate VII.) Sections of Culverts and Tunnels . . . . . facing 58

29. (Plate VIII.) Section of Puddle Trench . . . . $\quad$, 60

30-34. (Plate IX.) Masonry Valve Tower: Sections . . . . . , 62

35-38. (Plate X.) Do. Sections of Air-collecting Vessel

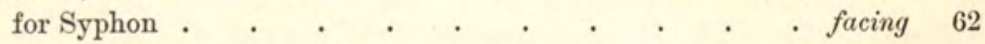

39-43. (Plate XI.) Cast-iron Valve Tower: Sections . . . $\quad$ " 64

44. Diagram of Main Pipe divided for Meters and Sluice Valves . . . 63

45. Waste Weir for Water passing over Dam (Fanning) . . . . 64

46. (Plate XII.) Impounding Reservoir in Plan, with Waste Weir and

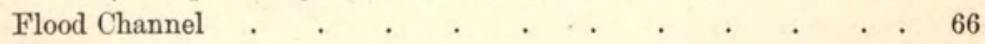


Fig. $\quad$ PAGE

47. Arrangement for Directing Flow into Reservoir . . . . . 68

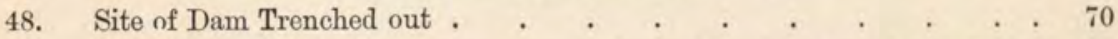

49. (Plate XIII.) Masonry Dams: Comparison of Rankine's with the Theoretical Profile . . . . . . . . f facing

50. (Plate XIV.) Masonry Dams: Wergmann's Theoretical Profile for Stone of different gravities . . . . . . . . facing 72

51-53. (Plate XV.) Masonry Dams: Wergmann's Practical Profiles $\quad$, 74

54. (Plate XVI.) Section of Tytam Dam, Hong-Kong ～. 76

55. (Plate XVII.) Section of Vyrnwy Dam (Liverpool Water Supply) , 76

56. (Plate XVIII.) Section of Tytam Dam through Valve Wall . , , 76

57. Settling Tanks: Plan . . . . . . . . . . . . 86

58. Do. Side and Cross Channels _ . . . . . . 86

59. Do. Cross Channel Weir Box in Section . . . . . 86

60-63. (Plate XIX.) Forms of Settling Reservoirs . . . . facing 90

64. Arrangement of Partition Walls in Reservoir to divert Flow of Water . 89

65. Diagram of Settling Reservoir: Inlet and Outlet at Surface level . . 90

66. $\quad$ Do. $\quad$ Inlet and Outlet at Floor level . . . . 90

67. Do. Inlet at Surface level, and Outlet at Floor level 91

68. Do. Inlet at Floor level, and Outlet at Surface level 91

69-73. (Plate XX.) Settling Reservoirs: Arrangement of Inlet Pipes facing 92

74-76. (Plate XXI.) Do. do. Draw-off Pipe ,, 92

77-79. (Plate XXII.) Do. Drawing-off by Stand Pipe and by Floating Pipe . . . . . . . . . facing

80-83. (Plate XXIII.) Settling Reservoirs: Drawing-off by Stand Pipe and by Floating Pipe. Details . . . . . . . . . 92

84. (Plate XXIV.) Do. Overflow and Drain Pipe combined facing 94

85-91. Arrangement of Filter Beds: When three, four, six, eight, nine, twelve,

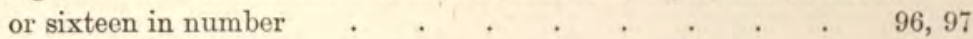

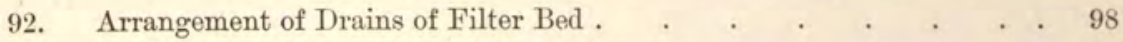

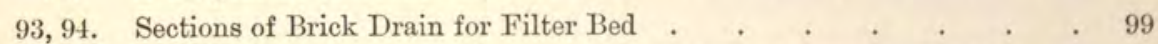

95. Cellular Brick Floor for Filter Beds (New River Company, London) 99 96-100. (Plate XXV.) Arrangement of Filter Beds shown in section (New River Company, London) . . . . . . . facing 100

101. Diagram illustrating the Filtering Head . . . . . . . . 103

102-105. (Plate XXVI.) Arrangement for Regulating Speed of Filtering Beds (J. P. Kirkwood) . . . . . . . . . facing 106

106. (Plate XXVII.) Arrangement for Regulating speed of Filtering Beds (Henry Gill) . . . . . . . . . fucing

107-113. (Plate XXVIII.) Arrangement for Regulating Speed of Filtering Beds (Telescopic Tubes) ..$\quad$. . . . . . . facing 110

114-119. (Plate XXIX.) Arrangement for Regulating Speed of Filtering Beds (Automatic) . . . . . . . . . . facing 112

120, 121. Valve for Regulating Flow of Water (Section and Plan) . . . 111

122. Sand Washer . . . . . . . . . . . . . . 113 
123, 124. Walker's Patent Sand Washing Apparatus . . . . . . 114

125-127. "Canal" Sand Washer . . . . . . . . . . . 114

128-131. (Plate XXX.) Cylinder for Purifying Water with Metallic Iron facing 120

132-136. (Plate XXXI.) Water Softening and Filtering Apparatus for Locomotive Purposes . . . . . . . . facing

137-141. (Plate XXXII.) Covered Reservoir: Brick or Concrete Arches on Columns . . . . . . . . . . facing 132

142. (Plate XXXIII.) Reservoir with Tile or Slate Roof . . , 134 143-145. (Plate XXXIV.) Water Towers at Liverpool and Shanghai . , , 136

146. Diagram illustrating Action of a Stand Pipe . . . . . . 141

147. (Plate XXXV.) Typical Arrangement for Waterworks . . facing 144

148. Section of Open Channel (Curvilinear) . . . . . . . 172

149. Do. (Semi-hexagonal) . . . . . . 172

150. $\quad$ Do. $\quad$ (Embanked) . . . . . . . . 173

151. Do. (on Slope) . . . . . . . . 174

152-168. (Plate XXXVI.) Cross-sections of Covered Conduits . . facing 176

169-172. (Plate XXXVII.) Aqueduct Bridge on line of Loch Katrine Waterworks (Glasgow). . . . . . . . . facing 178

173. Diagram illustrating Hydraulic Grade Line . . . . . 178

174. Diagram illustrating Calculation of Hydraulic Grade Line . . 185

175-177. Diagrams illustrating Systems of Distribution _ . . . . 191-193

178. Diagram illustrating Multiplication of Sluice Valves . . . . . 194

179, 180. Diagrams illustrating Arrangement of Distributing Mains ～～～196, 199

181-183. Diagrams illustrating Systems of Centres of Distribution . 200, 201

184. (Plate XXXVIII.) Waterworks of Tokyo: Distribution System facing 204

185. (Plate XXXIX.) Do. Part of Distribution System in detail . . . . . . . . . . . facing 204

186, 187. (Plate XL.) Pillar Hydrant: English form . . . . . , 210

188. Pillar Hydrant: American form (Fanning) . . . . . . 209

189. Merryweather's Hydrant . . . . . . . . . 210

190. Ball Hydrant and Stand Pipe . . . . . . . . . 211

191, 192. Sluice Valve Hydrant · c c . c c c . . 212

193. Stand Pipe for Sluice Valve Hydrant . . . . . . . . . . 212

194, 195. Screw-down Hydrant (two examples) . . . . . . . 213, 214

196, 197. Sunk Hydrant: American form (Fanning) . . . . . . 215

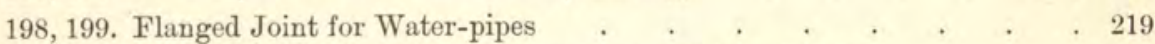

200-202. Spiggot and Socket Pipes, with Turned and Bored Joints . . . . 220

203, 204. Tools used for Caulking Joints of Pipes . $\quad$ c c c c c c . 222

205-208. Spiggot and Socket Pipes, with Joints run with Lead ․ . . . 223

209. Water Pipe, with Ball and Socket Joint (Fanning) _ . . . . 224

210-215. (Plate XLI.) Pipes for Distribution Systems: Forms of Special

Castings . . . . . . . . . . facing 230

216, 217. Pipe Testing Machine . . . . . . . . . . . 233

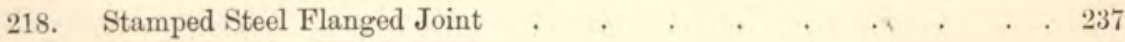


Fig.

219. The Duncan Patent Joint . . . . . . . . . 237

220. The Riley Patent Joint . . . . . . . . . . 238

221. Diagram illustrating Results of Experiments to Test Extent of Waste of Water (Hope) . . . . . . . . . . . . . 241

222. Arrangement of Pulleys in Waste Meter . . . . . . . 247

223. Mr. G. F. Deacon's "District" Waste Meter . . . . . . 249

224-231. (Plates XLII. and XLIII.) Diagrams illustrating Supply and Waste of Water (Deacon) . . . . . . . . . facing 252

232. Kennedy's Patent Water Meter, in section . . . . . . 258

233, 234. Siemens and Halske's Patent Water Meter. ․ . . . . . . 259

235, 236. (Plate XLIV.) Sluice Valve, in section and elevation . . facing 264

237, 238. Gear for Opening Sluice Valves . . . . . . . . . . 263

239. Air Valve for Water Pipe . . . . . . . . . . 264

240-242. Spring and Screw-down Safety Valve . . . . . . . . 265

243. Large Safety Valve for use on Water Mains . . . . . . . 266

244. Blakeborough's Stand Pillar . . . . . . . . . 267

245, 246. Tapered Ferrules for Connecting Water Pipes. . . . . . . 268

247, 248. Screwed Ferrules for Connecting Water Pipes . . . . . . . 268

249. Screwed Ferrule attached to Water Pipe . . . . . . . . 269

250-252. Gear for Connecting Pipes to Mains . . . . . . . . 270

253, 254. Patent Stop Valve Ferrule . . . . . . . . . . 271

255. Diagram illustrating Formula for Strength of Wall . . . . . 277

256. Illustration of Dr. Divers' Theory of Sand Filtration . . . . 280

257. Diagram illustrating System of Distribution for Small District . . . 284 


\section{LIST OF PLATES.}

FACING PAGE

I. Impounding Reservoir: Diagram illustrating required Storage Capacity (Yearly Rainfall).

II. Impounding Reservoir : Diagram illustrating required Storage Capacity (Daily Rainfall) . . . . . . . . . 40

III.-V. Forms of Gravitation and Pumping Systems of Waterworks . 44

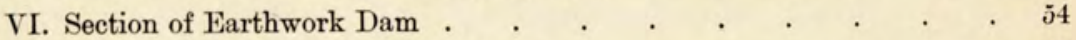

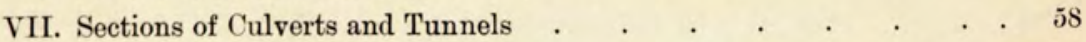

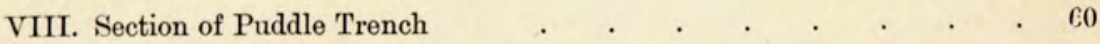

IX. Masonry Valve Tower: Vertical and Horizontal Sections _ . . . $\quad 62$

X. Do. Sections of Air-collecting Vessel for Syphon 62

XI. Cast-iron Valve Tower: Vertical and Horizontal Sections 64

XII. Impounding Reservoir in Plan, with Waste Weir and Flood Channel . 66

XIII. Masonry Dams: Comparison of Rankine's with the Theoretical Profile 72

XIV. Do. Wergmann's Theoretical Profile for Stone of different gravities . $. \quad . \quad . \quad . \quad . \quad . \quad . \quad . \quad 72$

XV. Masonry Dams: Wergmann's Three Practical Profiles . . . . . 74

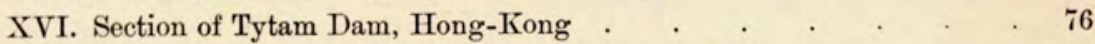

XVII. Section of Vyrnwy Dam (Liverpool Water Supply). . . . 76

XVIII. Section of Tytam Dam through Valve Well . . . . . . 76

XIX. Forms and Modes of Construction of Settling Reservoirs . $\quad . \quad$. $\quad 90$

XX. Settling Reservoirs: Arrangement of Inlet Pipes . . . . . . 92

XXI. Do. do. Draw-off Pipe $\quad$. $\quad$. $\quad . \quad .92$

XXII. Do. Drawing-off by Stand Pipe and by Floating Pipe. 92

XXIII. Do. do. do. do Details 92

XXIV. Do. Overflow and Drain Pipe combined . $\quad$ - 91

XXV. Do. Arrangement of Filter Beds shown in Section . . 100

XXVI. Arrangement for Regulating Speed of Filtering Beds (J. P. Kirkwood) 106

XXVII. Do. do. do. (Henry Gill) . 108

XXVIII. Do. do. do. (Telescopic Tubes) 110

\begin{tabular}{llll} 
XXIX. & do. & do. & (Automatic) \\
\hline
\end{tabular} 
XXX. Cylinder for Purifying Water with Metallic Iron . . . . . 120

XXXI. Water Softening and Filtering Apparatus for Locomotive Purposes

(Fitzherbert Pullen) . . . . . . . . . . . . 122

XXXII. Covered Reservoir: Brick or Concrete Arches on Columns . . . 132

XXXIII. Reservoir with Tile or Slate Roof . . . . . . . . . . 134

XXXIV. Water Towers at Liverpool and Shanghai _ . . . . . . . 136

XXXV. Typical Arrangement for Waterworks _ . . . . . . 144

XXXVI. Cross-sections of Covered Conduits . . . . . . . . . . . 176

XXXVII. Aqueduct Bridge on line of Loch Katrine Waterworks (Glasgow) 178

XXVIII. Waterworks of Tokyo: Distribution System . . . . . 204

XXXIX. Do. Part of do. in detail . . . . 204

XL. Pillar Hydrant (English form) . . . . . . . . 210

XLI. Pipes for Distribution Systems : Forms of Special Castings . . . 230

XLII., XLIII. Diagrams illustrating Supply and Waste of Water (Deacon) . . . 252

XLIV. Sluice Valve, in section and elevation . . . . . . . . . 264 


\section{WATER SUPPLY OF TOWNS.}

\section{CHAPTER I.}

\section{INTRODUCTORY.}

IT is superfluous, at the present day, to expound at any great length the necessity for a plentiful supply of pure water wherever people are closely congregated together in towns or villages, for the necessity is known to all. Indeed, although it is only of late years that the influence of water-supply on the health of a community has come to be thoroughly understood, the necessity for a supply of water has been felt from the earliest times, and the sites of towns and villages have been determined as much by the possibility of obtaining a supply of water, as by other considerations. It has often been pointed out how the congeries of villages that now form London were at first isolated from each other, each being built over a patch of water-bearing gravel, and how the filling up of the interstices between them became possible only when some more general supply of water than that from wells in the gravel was provided.

Almost instinctively there must have been selected as a site for a habitation one where water could readily be obtained either from a stream or a spring, or by digging to no great depth in the ground, and, as long as houses were isolated, or only in very small groups, such a supply of water was in many cases all that was necessary. It was probably plentiful, and likely to be pure in the sense of being free from dissolved organic matter, or the like impurities, that are known either to cause or to spread disease. Even the much despised shallow well will give a wholesome supply of water, if it is suitably situated: if, for example, it is at the foot 
of a hill, so that it intercepts the underground flow of the water from the hill side. A shallow well may, indeed, even in the case of a single isolated house be a source of danger when, for example, as is too often the case, a cesspool is excavated in the same porous soil at no distance from it. In this case the matter from the cesspool probably percolates into the well, with the result of rendering the water most unwholesome; but even here we are not likely to have the spreading of an epidemic such as we may have if a common source of water becomes contaminated.

It is when people begin to settle together in rude communities that the danger really becomes great, for it is then almost certain that there will be no efficient means of carrying off the filth that in modern cities and towns constitutes sewage. A part of it will probably sink into the ground, another part will find its way by natural channels to the nearest stream. If the supply of water be from shallow wells, the quality of the water is sure to get worse and worse till,-at last, the water-bearing stratum is saturated with sewage, and the wells are full of water that is nothing better than dilute sewage. If the inhabitants have built their houses on the banks of a stream relying on the water of this for a supply, it is certain that gradually more and more filthy matter will find its way into the stream and the community will suffer, especially the part that is downstream. In either case-that of the wells or of the streamnot only is the general health of the community sure to suffer, but, in the case of certain epidemics that are known to be communicated through water-notably cholera-it is likely that, if once the sickness enters the village or town, it will spread " like wild-fire." In one case the germs of disease, entering the soil, find their way into the wells; in the other they are carried into the stream. In either case the result will be much the same.

Where shallow wells are used, it is the lowest parts of the town that suffer most. The writer has knows cases in which the impurities in shallow wells within a town were just about inversely proportional to the heights of the sites of the wells. If a stream is relied on for supply, it is the down-stream people that will suffer the most.

Apart, however, from quality, it often happens that as a community increases in size the quantity of water begins to fall short, so that in times of long continued drought actual water famines occur, such famines being the more terrible because, in 
most countries, they are liable to take place when the weather is at its hottest.

Thus it comes to pass that, in every town that keeps increasing in size, a time is reached when it becomes necessary to construct special works either for getting water from a great depth, or from a distance, else the health of the community will suffer, and the death-rate increase.

The ancients well appreciated the necessity of a copious supply of water, and, moreover, seem to have known the bearing that a pure supply had upon health. The Romans especially, not only in their own country, but in the countries that they conquered, carried out works the magnificence of which testifies to this day to their boldness and skill as engineers.

After the fall of the Roman Empire, the question of water supply seems to have fallen into abeyance, and, indeed, there can be no doubt that the terribly high death-rate which, so far as statistics can be got at, existed during the middle ages, as well as the terrible epidemics that decimated, and much more than decimated, the populations of whole towns and even countries, were in great part due to an insufficient supply of water. It would seem that the supply of water in Mexico and in Peru was vastly superior to that of Europe till the Spaniards conquered these countries in the 16th century, and all the monuments of their early civilization were allowed to go to ruin. The ruins of some of their works for water supply are eclipsed in grandeur only by those of the Romans. Nor is the American continent the only country that has set the example to Europe. There can be no doubt that, from the time, nearly three centuries ago, that Tokyo, the capital of Japan, was supplied with water by the Tamagawa canal, supplemented by a complete system of ingenious wooden pipes of square section, till about the beginning of this century, it had a better supply of water than either London or Paris, or probably any town in Europe of which the natural supply was not exceptionally good.

Waterworks, as the term is now generally understood, for the supply of water to villages, towns, and cities, may be said to have originated only after the beginning of the present century. Wooden pipes for the distribution of water were used in London up to about 1820 .

There can be no doubt that, in the earlier days of waterworks, a great deal was done by "private enterprise," and that many waterworks were constructed by companies to which concessions 
were granted, that would not otherwise have been constructed at all for a long time to come. It is also true that in many cases the projectors either gained nothing, or had to wait a long time till they did gain anything. Even at the present time there are many who think that it is advantageous to entrust the supply of water in towns to private companies, and it may be that in certain places where the work has been so entrusted, supplies of water have been provided which would not otherwise have been available. There is, however, a growing feeling that the supply of water to towns should be municipal work; that a matter of such vast importance to the public health is not one which should be left in private hands ; and, indeed, that it is not a matter from which profit should be made at all-that is to say, a direct money profit for individuals or even a municipality. The profit, of a most solid kind, to the community, is undoubted.

There should, in fact, in connection with water supply be much less consideration than there is of pounds, shillings, and pence, except in the matter of prevention of the waste of water. The question should not be, "How cheaply can we get a supply of water?" but, "What is the very best supply of water that we can get at any price that it is practicable for us to pay?" This is so far as providing a plentiful supply of wholesome water for domestic purposes is concerned, so that the public health may be kept as good as possible. It is different in the case of supplying water for manufacturing purposes, or for purposes purely of luxury, such as gardens and fountains. There is no reason why the municipality should not make a profit out of water supplied for these and the like purposes.

Another matter in connection with which it is quite legitimate to consider the question of pounds, shillings, and pence in regard to water supply, is that of insurance against loss by fire. This is a question not generally sufficiently considered when new waterworks, or extension of existing waterworks, are proposed. It is not considered that, very often, the expense of the construction of waterworks will actually be repaid within a few years by the saving in the destruction of property by fire. This is probably owing, in Europe at any rate, to the fact that waterworks in most cities have, so to speak, grown up, having gradually been improved and extended, instead of being suddenly brought into existence, as well as to the fact that until quite recently very insufficient attention was given to so proportioning the system of distribution that the mains can throw plentiful streams of water on any building 
at which a fire may occur. And it is much to be regretted more attention is not given to this aspect of waterworks. In America, where cities grow up with mushroom-like rapidity, so that, very soon after only a small congregation of houses has arisen, there is a great town needing a water-supply system, the saving of loss of property from fire is better appreciated. The reduction of fire insurance premiums in towns and cities as soon as an efficient water-supply has been provided is the surest gauge of the saving.

It is probable that, in countries like Japan, in which fires are very frequent, the total expense of providing waterworks would be recouped in a few years-perhaps in from five to twenty years, according to the first cost of the work-by the saving of property from destruction by fire alone, to say nothing of other considerations. 


\section{CHAPTER II.}

\section{Different Qualities of Water.}

Quality of Water.-There are two things that have to be taken into consideration before a source of water is decided on for a town supply: one is quality of the water, the other is quantity.

Every one knows that the quality of different waters varies greatly; that some are pleasant to the taste and smell, and that some are not; and, what is much more important, that some are perfectly harmless, whilst others are liable to produce ill-health when habitually drunk, or even to spread epidemic diseases; that some are good for washing, and others not; that some are inferior to others for cooking, and so on. It is necessary, therefore, for the engineer who is to report on a proposed source of water, to have some knowledge of the causes of the difference in the qualities of water, although he need not have any deep knowledge of chemistry, far less be able to analyse water himself. $\mathrm{He}$ will find it much more convenient, if he wants an opinion on water, to hand a sample of it to a professional chemist, getting, if possible, the latter's opinion on the results of both a chemical and a biological examination.*

At the same time, I wish here to warn engineers against relying solely on the report of a chemist, either in adopting or in condemning a source of water. Should the report of the chemist be condemnatory, the water may be condemned out of hand, at any rate after a second analysis has confirmed the first; but, if the result of the analysis is to indicate a pure water, more care is necessary on the part of the engineer. He must make a personal examination of the source: if it is a river or a stream he should follow it to its beginnings, noting along both banks what possible

* The writer went through a special laboratory course to learn to make a thorough water analysis, and never afterwards applied the knowledge he had gained, finding it far more convenient to hand cver the analysis of water, on which he wanted an opinion, to a professional chemist. 
sources of pollution there may be. Whatever the result of a chemical examination may have been, the water of a river should be condemned if it is found that there is a copious discharge of sewage into it a mile or so above the proposed intake. The writer has known a case where chemical analysis, performed by a chemist of reputation, failed to discover any organic impurity in such water. Again, in the case of a mountain stream flowing over a clear, stony bottom, without either cultivation or habitations on the sides, a chemical analysis is almost unnecessary, except to determine the hardness of the water.

In any case it must be distinctly understood that no conclusion can be arrived at from a single analysis. Waters are nearly all liable to vary from time to time. This is particularly true of shallow well water, and of river water. In time of floods, river water is liable to have a large quantity of inorganic matter in suspension and perhaps in solution, whilst sewage having access to it is likely to be so much diluted, that the organic matter it contains cannot be detected. It is quite possible that such was the state of affairs in the case cited above. Again, in the case of rivers receiving the drainage of rice cultivation, there can be no doubt that the quality of the water must vary much. Just after the newly manured fields have begun to be irrigated, the drainage water must contain much organic matter of a highly dangerous nature, whilst, when the rice has grown tall and strong, towards the end of the time of irrigation, it is likely that the drainage water is practically as pure when it leaves the paddy fields as when it is discharged on to them, in fact it is quite possible that, in some cases, it is purer. No conclusion can be come to as to the fitness of a river for a water-supply from analyses, chemical or biological or both, unless these have been performed at short intervals, say of not more than one month each, during at least one year.

I do not wish it to be thought that I am decrying the usefulness of chemical, much less of biological, analysis. By no means so, but I say that a little intelligence must accompany the use of the reports of chemists. We do not want, any more, to have the reports of engineers beginning, "A sample of the water was taken from the source on such a day and was handed to Mr. — - for analysis. The following is the result of the analysis :-

It will

be seen that the water is one thoroughly suited for a domestic 
supply:" without anything indicating that an actual examination of the source has been made.

If a shallow well is on the lower side-in the sense of being on that side towards which the underground water is flowing-of a cesspool, midden heap, pig sty, or the like, from which filth is soaking into the ground, it could not be pronounced a safe source of supply though a thousand chemical analyses failed to detect contamination.

Taking Samples of Water.-If possible the chemist should draw his own sample of water, but this is often inconvenient. For this reason a word or two on the collection of samples of water may not be out of place here. Each sample should consist of about half a gallon, and should be collected in a clear glass bottle with a glass stopper. In England nothing is better than the "Winchester quart," holding eighty ounces, or just half a gallon. The bottle must be made scrupulously clean, and, before it is filled, it should be rinsed out two or three times with the water to be collected. Care should be taken not to stir up any mud on the banks of a stream, and if the proposed source is a large river or a lake, the water should be collected at some distance from the bank, from a boat, or, in the case of a river, from a bridge, if possible. The mouth of the bottle should be entirely submerged whilst the water is being collected. The stopper should not be luted down with any cementing material, but merely tied with string.

The sample of water should be handed over to the analyst as soon as possible, as changes are liable to take place. If it has to be kept for any length of time, it should be kept in a cool place away from any strong light.

The Self-purification of Natural Streams.-This may be the best place in which to discuss the question of the selfpurification of streams of water, when flowing for some distance.

Premising that the most dangerous contamination of water is from sewage and the like refuse, which adds decomposing organic matter to the water-not of itself necessarily dangerous to health, but forming the vehicle for the multiplication of micro-organisms, some of which are supposed to be the cause of disease, or at least to have the power to spread infectious disease-it is admitted on all hands that water thus contaminated at one point along the course of its flow becomes gradually purer and purer, the organic matter being changed into simple and harmless compounds, till 
it may seem, from chemical analysis, to be as fit for drinking as it was before it received the contaminating matter.

It has for long been known that the presence of oxygen was necessary for this change, and it was believed that the oxygen of the atmospheric air, a certain proportion of which dissolves in water, was the active agent. It would now appear that this is merely the passive agent, the active agent being micro-organisms, commonly called bacteria. The fact is that the bacteria exhaust the power of the organic matter to support them, after which it is harmless. It would appear that this organic matter is attacked first by a micro-organism that does not need oxygen for its work, but converts the nitrogenous organic matter into ammonia. This ammonia is then attacked by different kinds of micro-organisms, which, making use of the oxygen dissolved in the water, convert the ammonia into nitrites and nitrates, which are unable to support bacterial life. Whether this description be scientifically correct or not, the fact remains that the water is, to all intents and purposes, rendered pure again if it only flows long enough.

The question is, then, Shall water that is known to have received sewage, or the like filth, after it has flowed for a certain distance, be considered as fit for general use in towns? One great difficulty is the uncertainty of the time or distance taken for the completion of the process. Could it definitely be said that water will purify itself from decomposing organic matter by flowing ten miles, or by flowing twenty miles, or by flowing any particular distance, there would be a nearer approach to an answer to the question, but there is no such certainty. It is evident that several factors enter into the question. Thus the quantity and nature of the impurity are two; time is another; the extent that the water is exposed to the air is another; and temperature is still another. It will therefore happen that, in the case of a rapid running stream, the time taken for purification will be shorter than with a sluggish stream, but the distance flowed may, perhaps, be longer. Again, with the same average velocities, purification will take a shorter distance and a shorter time too in a stream that tumbles over a rough and bouldery bed, than in the case of one that flows over a smooth bottom. Further, the quantity of comparatively pure water that the contaminating matter flows into will certainly have something to do with the time of purification.

At the request of Professor von Pettenkofer, Drs. Pfeiffer and Eiselohr investigated the action in the case of the river Isar, which 
receives large quantities of sewage at Munich. This stream is immortalized as "rolling rapidly;" and the doctors came to the conclusion that it practically purified itself within about ten miles. There are, however, many cases in which a river flows a much greater distance than this, without purifying itself.

The attitude of those best able to give an opinion on this question may, perhaps, be summed up as follows :-Water of a stream that receives a considerable quantity of sewage or the like impurity, at any part of its course, should not be used for the supply of a town, even though chemically and bacteriologically it appears pure, if a water that receives no such contamination can be got at even considerably greater cost. On the other hand, the engineer should avoid being fanatical in the matter. It should be borne in mind that it is often better to select a water that is not ideally perfect, when no better can be had, than to put up with a distinctly bad water, or a scanty supply. Further, it should be borne in mind that there is no such thing in existence as natural stream water that receives no excremental matter. Every river receives the excrements of fish, birds, and other animals, and occasionally their dead bodies. It would be absurd to condemn the water of a large river because there are a few scattered cottages about the upper parts of the streams feeding it, although it is almost certain that these cottages will contribute a little sewage to it. Such sewage will constitute a minute fraction only of the decomposing organic matter that will inevitably reach the water.

Nevertheless, in elaborating a scheme for water supply the abolition of even these causes of minute contamination should, if possible, be provided for by buying up the necessary properties.

Common Impurities in Water.-From an engineer's point of view the following rough classification of the common impurities met with in water may be useful :-

(1) Dissolved inorganic matter.

(2) Suspended inorganic matter.

(3) Dissolved organic matter.

(4) Suspended organic matter.

(5) Micro-organisms.

Dissolved inorganic matter is not generally hurtful unless it is present in very large quantities, except inasmuch as it is liable to lead to the hardness of water. In great quantities it may render 
water unfit for general purposes. We have the extremes of such waters in natural mineral springs, often of use medicinally, but always unfit for general purposes. Apollinaris and Hunyaniyados waters are good examples. All dissolved inorganic matter can be removed by distillation, but this process is not applicable to the large quantities of water used for the supply of towns.

Hardness in water is that property which causes it to decompose a certain quantity of soap, forming insoluble compounds, before a lather can be formed. In fact, the quantity of soap so decomposed is generally taken as a measure of hardness; the origin of the term being the water's "hardness" to soap. Hardness is chiefly due to the presence of the carbonates of lime and magnesia, also to the sulphates and nitrates of lime and magnesium. Hardness is either temporary or permanent. Temporary hardness is due to the presence of the carbonates above mentioned. These carbonates are not soluble to any material extent in water, but are soluble in the carbonic acid that nearly all natural water contains in solution. This carbonic acid can be driven off by boiling the water, and, in this case, the carbonates are precipitated. It is these precipitated carbonates that form the incrustation and sediment so commonly seen in kettles and other cooking vessels that have been long in use for the boiling of water, and that form a large part of the incrustations of steam boilers.

Another method of removing temporary hardness is known as Clark's process. In this process caustic lime, in the form of limewater, is added to the water to be softened. This combines with the carbonic acid, forming carbonate of lime. The carbonates originally in the water, and this new carbonate, have now no solvent, and are precipitated. This is a very interesting process, involving the apparent paradox that, by adding carbonate of lime to water, we get rid of carbonate of lime! When it is said that water is of a certain number of degrees of hardness (Clark's scale) it is meant that a gallon of water will precipitate as much soap as would be precipitated by a gallon of pure water in which that number of grains of carbonate of lime had been dissolved. Thus water of ten degrees of hardness will precipitate as much soap as would pure water to which carbonate of lime to the amount of ten grains per gallon had been added. The hardness that is left after the carbonates have been precipitated is permanent hardness.

It is possible to tell roughly whether water is "hard" or 
"soft" by noticing the feeling of it whilst washing the hands with soap.

Excessive hardness of water leads to great waste of soap, makes the water unfit for dyeing and some other manufacturing processes, and gives great trouble to steam users. Much permanent hardness makes water objectionable for cooking, tea making, \&c. The old idea that a certain quantity of hardness is necessary in potable waters to provide the carbonates used for building up animal tissue, is now exploded. it having been shown that the food contains more than enough carbonate, and it is now considered by many that hard water is often detrimental to health. Another idea that waters owe their agreeable taste to dissolved salts, such as produce hardness, has been shown to be erroneous. These salts need to be present in much larger quantities than they ever are in water suitable for domestic supply before they can be detected by the sense of taste. It is now generally believed that the superior palatability of some waters over others is due to dissolved gases, especially carbonic acid gas. This would account for the old idea that the palatableness was due to salts producing hardness, these being generally associated with carbonic acid.

Water for a town supply should not have more than about eight, or at the outside, ten degrees of total hardness, three to four degrees of permanent hardness.

The lime process for removing temporary hardness may be used where no soft water can be got, but the trouble and expense of working it are very considerable.

Poisonous metallic salts, such as those of lead, are sometimes met with in water supplied to houses by waterworks, but they are almost always due to contamination in the pipes or other parts of the works.*

Suspended organic matter can be removed by settlement and ordinary sand filtration. It is, therefore, not objectionable unless it is present in very large quantity, or in an extremely fine state of division, when the expense of removing it may be considerable.

Dissolved organic matter may or may not in itself be dangerous to health, but is always a possible source of danger in water because it forms the vehicle for the multiplication of pathogenic bacteria. Dissolved organic matter can be removed, or rendered innocuous, only by processes too expensive for general

$$
\text { * See Note 1, Appendix II. }
$$


adoption. It is the worst form of contamination of water. Suspended organic matter can be removed by filtration, but it is scarcely ever-probably never-totally unassociated with dissolved organic matter.

Micro-organisms. - As has been stated already, certain forms of micro-organisms perform the useful function of decomposing organic matter so that it is no longer capable of supporting microorganisms. The bacteria that accomplish this seem to be harmless, but the danger of water containing them in large quantities, is that it also likely contains some of the specific micro-organisms that produce or spread certain diseases, and that the presence of a large number of bacteria of any kind indicates the presence of the wherewithal to support pathogenic bacteria.

With due precautions bacteria can be removed to a very great extent from water by sand filtration. It is stated that as many as 97 to 98 per cent. have been removed, but it has always to be borne in mind that, if there is a supply of dissolved organic matter, which is not removed by filtration, there is the means for an indefinite process of increase and multiplication in the bacteria that have passed the filter beds, and that, if the water is stored long enough, it will certainly become as bad, so far as number of bacteria is concerned, as if it had not been filtered at all. Hence the modern practice of "hurrying on" to the consumer water that has been filtered with the chief object of removing bacteria.

In cases where water is softened by Clark's process, already mentioned, the carbonate of lime precipitated in a very fine state of division carries with it a large percentage of any bacteria there may be in the water.

On a small scale bacteria can be removed entirely by Pasteur's filters, or by boiling. It is always advisable to boil water that is to be drunk, unless it is exceptionally pure. By repeated boiling water can be "sterilized," so that no further bacteria will appear in it, unless they reach it from the outside.

Purity of Water. - The purity of water cannot be judged by its taste. It has even been stated that the particular palatability of some waters has been due to an admixture of sewage. Whether this be true or not it is certain that a very appreciable quantity of sewage may be present without rendering water in any way unpalatable. There is the now very famous case of the old-time London well which held so high a reputation for the purity of its 
water that people sent from great distances for it, till an epidemic was traced to the well, when it was found that one of the public sewers leaked into it!

The following table, issued by the Rivers Pollution Commissioners (item eight added by the writer) has almost become classical :-

\begin{tabular}{|c|c|c|}
\hline \multirow{3}{*}{ Wholesome } & (1. Spring water & Verv \\
\hline & 2. Deep well water & palatable. \\
\hline & 3. Upland surface water & Moderately \\
\hline \multirow{3}{*}{ Suspicious } & (4. Stored rain water & palatable. \\
\hline & 5. Surface water from cultivated land & \\
\hline & $\left\{\begin{array}{l}\text { 6. River water to which sewage gains } \\
\text { access } \\
7 \text { Shallow well water }\end{array}\right.$ & Palatable. \\
\hline Dangerous & $\begin{array}{l}\text { 7. Shallow well water } \\
\text { 8. Water from paddy fields. }\end{array}$ & \\
\hline
\end{tabular}

The statements as to water being "very palatable," "moderately palatable," and " palatable," must, of course, be taken as approximations only.

Spring Water is generally very free from organic matter, and from any kind of matter in suspension. It often, however, contains dissolved inorganic matter, in the form of mineral salts, in such quantities as to make it objectionably hard, or in some other way unfit for domestic use. We have the extreme of this in medicinal springs.

Deep Well Water:-A deep well may perhaps be best defined as a well penetrating an impervious stratum into a water-bearing stratum below, in distinction from a shallow well which merely penetrates a surface water-bearing stratum. Although it may appear a contradiction in terms, it may thus occur that, measured by feet, a "shallow" well will be deeper than a "deep" well. With the exception of possible mineral salts present in objectionable quantities, deep-well water is generally looked on as the purest that can be obtained on any large scale. The mineral salts present are likely to depend more on the nature of the stratum from which the water is drawn than on the original source of the water. The red sandstones and chalk formations are famous as giving particularly pure water, especially the latter; and, strange to say, the water from deep-lying chalk is generally rather soft than otherwise. Deep well water is liable to be somewhat deficient in aëration.

Upland Surface Water.-This may be defined as the water from 
springs, streams, and rivers above the line of cultivation and of human habitation. All mountain water is of this nature, and so is the water of such valleys as, from the precipitous nature of their sides, do not allow of cultivation or residence. Whether high or low, unless actually swampy, all water from entirely uninhabited tracts of land should come under this head. Such water is a very common source of supply, and, especially if from really high land, as, for example, in the form of mountain streams, is one of the most desirable of waters. Water of this class is sometimes very pure, and it is seldom that it is not pure enough to be selected as a source of supply; but, within these limits, the purity varies considerably. "Peatiness," giving a brown colour, is a characteristic of the water from many mountain and moorland districts. This peatiness does not appear, when present to a moderate extent, to be harmful.*

Stored Rain Water.-All water whatever is, in a certain sense, rain water; that is to say, it has been over and over again evaporated and precipitated in the form of rain since the world began. What is meant here is water stored immediately after it has fallen, as, for example, when it is collected from the roofs of houses. The purity of such water varies greatly. In large cities, it may be very impure, collecting foreign matter both as it falls through the air, and as it washes the roofs of the houses. In the pure air of the country, rain water may be nearly as free from the presence of foreign matter as distilled water, but never quite. The chief characteristic of rain water is its absolute softness. On account of this it is very valuable for washing purposes. It is the custom, in many country houses in England, to collect the water from the roofs, and to store it specially for washing.

In the experience of the writer rain water, even collected remote from towns, is far from palatable.

Surface Water firm Cultivated Land.-Of this water very little further can be said than that it is to be looked on with suspicion. The assumption being that there is no paddy-field cultivation, or sewage farming, the water may be fairly good, but it may be far from good, and there is the great danger of frequent variation in the quality. Such water cannot be looked on as desirable for a source of supply.

River Water to which Sewage has gained access.-Water of this class has been so fully treated of under the head of the "self- 
purification of water" (page 8 et seq.) that it seems unnecessary to say anything further about it here.

Shallow Well Water.-This water is always to be looked on with suspicion if the wells are within towns and villages, if they are near farms with byres, pig-sties, \&c., or, indeed, if they are near any possible source of contamination of the ground water. On the other hand, it is a mistake to condemn the water of all shallow wells out of hand. If the direction of the flow of underground water, which generally follows the slope of the land, be ascertained by making trial borings, or by observing the level of the surface of the water in existing wells from which no water has been drawn for some little time, and if it be ascertained that there is no possible source of contamination in the direction from which the water is flowing, shallow well water may well be classified with upland surface water.

Water from Paddy Fields.-This kind of water must be looked on as highly dangerous. It may be classed with riverwater to which sewage gains access. The principal difference is that the impurity of river water into which sewage discharges varies chiefly with the amount of dilution it is subject to, being, therefore, greatest after long-continued dry weather. The impurity of water from paddy fields, on the other hand, varies with the season of the year.

The writer has not had the curiosity to test the palatableness or otherwise of water from paddy fields, and has not, as yet, met with any one who could speak with authority on the subject. 


\section{CHAPTER III.}

\section{Quantity of Water to be Provided.}

Standard of Measurement.-Before saying anything about the quantity of water it is found necessary to provide in towns, let me advocate the cubic foot, in preference to the gallon, as a standard of measurement [ 1 cubic foot $=6 \cdot 24$ (or about $6 \frac{1}{4}$ ) gallons]. The gallon has a certain advantage in cases where weights of water have to be converted into volumes, or vice versâ, in English measurement, as one gallon of water weighs just $10 \mathrm{lbs}$; but this conversion is seldom necessary in connection with waterworks, and there are two distinct disadvantages in the gallon as a standard. In the first place there are two gallons, the Imperial gallon of Great Britain, and the U. S. gallon, used in the United States, which differ in capacity as five to four. Then there is the fact that neither gallon is an even fraction of a cubic foot. This fact involves a deal of unnecessary calculation which, albeit of the most simple arithmetical nature, adds greatly to the trouble of all problems in connection with discharge ; velocities of flow being always reckoned in feet, and cross sections-whether those of pipes, weirs, or other openings through which water flows -in square feet and inches. It is therefore a much less troublesome thing to get out discharge in cubic feet * than in gallons.

Quantity of Water Required per head.-Twenty-four hours is the period most convenient to reckon for, but it is difficult to come to any conclusion as to the quantity which in any given case it will be necessary to provide per head in the twenty-four hours. In some cases, where large quantities of water are used for trade or manufacturing purposes, it is possible to make some

* In Japan the cubic shaku may, for all waterworks purposes, be taken as equivalent to the cubic foot. 
estimate of these, but the somewhat indefinite "domestic supply" is very difficult to estimate. In fact, although certain attempts to estimate the quantities of water needed in dwelling-houses have been made from consideration of the different items of consumption, it is now generally conceded that it is better to make use of past practice than to depend on such estimates.

Of late years large reductions in the consumption of water per head have been made by careful arrangements for saving waste. Waste has been saved in several ways, for example (1) by the use of district meters, (2) by the use of house meters, and (3) by insistance on the use of house-fittings of good quality only, and on their frequent inspection. The matter of meters will be treated fully further on. I may say, at present, concerning the third item, that the difficulty in preventing waste in waterworks has seldom been felt to any great extent in connection with the street mains, or the larger appliances belonging directly to the proprietors of the waterworks. These are fixed under the charge of skilled engineers, and are under their supervision afterwards. It thus occurs that leakage is not very likely to occur in them, and that, if it does, it is soon stopped. In the case of house-fittings it is quite different. These are put in by the builder or the householder, who employs whomsoever he likes. It is not in the least to the advantage of the former of these to be sure that no water-waste takes place, and it is to the reverse of the interest of the latter to prevent leakage-except when he pays for his water by meter--because he has nothing to pay for leakage, while he has to pay for preventing it.

Very stringent regulations have been introduced in most English and many Continental towns for the prevention of waste in houses, and these have been put efficiently in force in at least a considerable number of cases. It has thus, in some cases, been possible to reduce the mean consumption, even in water-closet towns, for all except special trade purposes, to as little as 2 cubic feet per head per day, or even to a trifle less in the case of some European towns. We have to contrast with this the case of American towns in which water is used-or wasted-in quantities approaching, or perhaps actually equalling, 20 cubic feet per head per day. It is found that the quantity of water that has to be supplied per head is commonly rather greater in large towns or cities, than in small towns or villages, but this cannot be taken as by any means a fixed rule. 
Perhaps the following estimates will be found fairly correct, for towns in which a fair amount of care is taken in preventing waste. The quantities of water are for all purposes except what are known as trade and manufacturing purposes :-

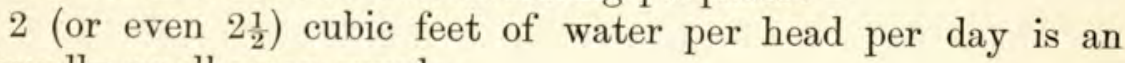
unusually small mean supply ;

3 (or at the most $3 \frac{1}{2}$ ) cubic feet mean supply per head per day ought to be sufficient in nearly all cases ;

4 cubic feet per head per day is a very ample mean supply.

To this there is to be added the water used for trade and manufacturing purposes, and the quantity of this naturally varies very greatly. Thus, in the case of purely manufacturing towns it may equal or even exceed the quantity needed for all other purposes. This is very exceptional, however, and it is much more common for it not to exceed about 25 per cent. of the water needed for other purposes. An additional supply at the rate of 1 cubic foot per head will generally be ample for towns that are not known specially as manufacturing towns. For American towns and cities it appears necessary to supply at least double these quantities, even if excessive waste be checked.

This information may seem meagre enough, and, to tell the truth, it is. It might readily enough be supplemented by long lists of the consumption of water in different towns, but this consumption is constantly varying. As indicated above, the quantities used are, at present, in many cases undergoing reduction by prevention of waste, and therefore such lists might, in a very little time, prove misleading. Moreover, the writer thinks it best to state plainly that it is not possible to give any exact information as to the quantity of water needed in any particular circumstances. The engineer should make use of all local knowledge that he can arrive at-that is to say, as to the consumption of water in towns adjacent to the one for which a new supply is contemplated-and this especially if the towns are at all alike in situation, trade, wealth, and so forth, and then see that he makes provision for an unnecessarily large supply, rather than for one too small.

Fluctuation in Consumption of Water.-The quantities just given are to be understood as being the mean daily consumption during the whole year, but this consumption is by no means uniform. As is natural, water is consumed more largely in hot summer weather than in cold weather. Again, in countries where 
the weather is very severe in winter, it is sometimes found necessary to allow a continual stream of water to run from hydrants, \&c., to prevent them from freezing up. Of course this adds much waste to the consumption.

Then again, there is, of course, a great variation in the quantity of water used during different parts of the twenty-four hours. Domestic consumption falls nearly to zero during some hours of the night, and is much above the mean during some hours of the day.

Commonly the maximum consumption for any one whole month rises to 10 to 20 per cent. above the mean consumption for the whole year, and there are cases where it may rise to 30 per cent. above the mean. For a few days at a time, during intensely hot and dry weather, the consumption may rise to 50 per cent. above the mean, and it is necessary to provide for a possible consumption at this rate.

The rate of consumption in the daytime may rise to about 50 per cent. above the mean rate of consumption for the whole twenty-four hours. This means that the total consumption for any one day may be mean consumption for one day $\times 1.5$, whilst the consumption for (say) one hour may be the mean hourly consumption for one hour $\times 1.5$.

Multiplying these two figures together we get 2.25 - that is to say, the rate of consumption for a short time during some parts of some day may be $2 \frac{1}{4}$ times as much as the mean annual consumption. It is not very likely, however, that the days on which the daily consumption is greatest will just correspond with those on which the hourly consumption is, in relation to the daily consumption, the greatest. It is, therefore, not really necessary to provide for a maximum consumption more than equal to twice the mean annual consumption, though there can be no harm in making some additional allowance.

This is without taking into consideration the provision for fire extinctions, a subject that will be treated separately.

Allowance for Increase of Population.-If it is difficult to make an estimate approaching to exactness of the quantity of water that is needed per head per day at the time that waterworks are started, it is much more difficult to make an estimate

* Analysis from statistics of a number of German waterworks gives the following figures:- If mean consumption $=1$, maximum daily consumption $=$ mean daily consumption $\times 1.4$; absolute maximum rate of consumption $=1.4 \times$ $1 \cdot 5=2 \cdot 1$. 
of the amount of margin that ought to be allowed for increase in the population. Naturally, in any particular case, the best estimate can be made by taking into consideration increase in the past, and assuming that increase in the future will be at a proportionate rate. This is a fair guide in the case of old countries where conditions have been fairly stable for a length of time, but it is scarcely any guide at all in new countries where towns may suddenly, after increasing at a moderate rate for a certain length of time, begin to " boom," as it is expressively put in America.

Even in an old country, the making or finishing of a railway, canal, or harbour - the finding of unexpected mineral wealth - the starting of new industries - or any one of many things, may cause a sudden increase that could not possibly have been foretold. In such cases engineers and others are often very unfairly blamed, the non-technical public seeming to think that an engineer ought to have, in many matters, a prescience that, if it existed, would be simply supernatural. The writer remembers a case in point-it was not, however, a case of waterworks, but it very well might have been-where an engineer was persistently badgered by members of a board to which he had sent estimates, for not foreseeing a certain difficulty that no human being could have foreseen. "And you call yourself an engineer?" asked one of the blockheads that constituted the board. "Yes, that's just it," was the reply. "If I called myself a prophet, I might be expected to foresee such things."

The best that can be done then is to look back on the past increase, and to take every circumstance into consideration that can be thought of in estimating the probable future increase. In the simplest possible case, let it be assumed that it has been decided that the water-works should need no augmentation for the next twenty years, and it is found that in the past twenty years the population has increased 22 per cent. It will be advisable to construct the works for a population say 25 per cent. greater than the present population.

Besides this, however, the greatest attention should be paid to so arranging all parts of the system to be established that, when augmentation does become necessary, it may be carried out at the least possible cost. Even supposing, for example, that it is decided that the whole of the works are to be constructed on the scale for a population 25 per cent. greater than the present, there will be some parts that may, with advantage, be made on a still 
greater scale than this. These are parts which ean be made, at first, on a large scale at a comparatively small additional cost, but which are expensive to augment afterwards.

Take the simple case of a long pipe line, laid in a difficult position. It should always be borne in mind that of two pipes having diameters in the ratio of 3 to 4 -say 12 -inch and 16-inch pipes--the larger will deliver more than twice the quantity the smaller will deliver. The price of the pipes, however, will vary only as about two to three, while the price for jointing will not vary so much, and the price for trenching and filling in will be very little more in one case than in another; the same may be said of bridges or other supports that may have to be put up at different places. It may, then, possibly happen that a pipe to give twice as much water as is needed for present population, will cost only about 20 per cent. more than one to carry 25 per cent. more than is necessary for the present population. On the other hand, if the original pipe has to be taken up and be replaced by a larger one, or if a second pipe has to be laid alongside the first (no special provision having been made for this from the beginning) the additional expense will probably be very great. In such a case, it will very often be the best policy to put in the big pipe from the first.

The case of open channels for carrying water is another in which a great augmentation of water may often be had at a comparatively low first cost, but in which the price of afterwards increasing the quantity carried may be very great.

Of the very opposite nature is the case of filter-beds. It is customary, in the case of works of any considerable size, to have several filter-beds, all but one at work together, one generally being empty of water for sand clearing. If land be provided, or the possibility of being able to buy land be secured from the beginning, additional filter-beds can be constructed at practically the same cost as the first ones. It is, therefore, customary to allow but little margin in the case of filter-beds, making, however, all provision for adding new beds one at a time as they may be needed.

The case of pumping machinery for large works is somewhat similar. There are generally several sets of pumps, one for "stand by," the others to work together. If due provision of space be made from the beginning, new pumping machinery may be added as it becomes necessary at about the same rate as the first.

Reservoirs, especially when covered, come somewhere between 
these two cases. Still it is generally possible to arrange that additional reservoir capacity can be provided at a rate not very much in excess of that of those first constructed.

In designing distribution systems great attention should be paid to the possibility of augmenting the supply not only as a whole, but in particular directions-that is to say, in certain districts of the town, and in certain directions of extension-at as small an additional expenditure as may be.

The likelihood that each part of a waterworks system may have to be augmented, ought, however, to be borne in mind from the first and in designing it the means of augmentation at the least possible cost should never be absent from the mind. 


\section{CHAPTER IV.}

On Ascertaining whether a Proposed Source of Supply is Sufricient.

Conditions of Supply.-If a source of water supply is investigated to discover whether it is sufficient in quantity, one of three things will always be found :-

(1) The minimum supply equals or is greater than the quantity demanded.

(2) The minimum supply is less than the quantity demanded, but the average supply is equal to or greater than the quantity demanded.

(3) The average supply is less than the quantity demanded.

(1) This is commonly the case when the supply is from rivers or from large natural lakes. It may also be the case with deep wells and, in the case of towns of moderate size, with large upland streams. Naturally this is the case that offers the least trouble to the engineers.

(2) In this case, which is commonest with upland streams, it is necessary to have recourse to storage of the water in impounding reservoirs, and the only question-if a storage reservoir be practicable - is what storage capacity has to be provided, as, in some cases, only a few days' supply to tide over specially dry weather may be necessary ; while in others-namely, those where the demand about equals the average supply-such a storage capacity is necessary as will in effect convert a fluctuating stream into one of nearly constant discharge.

(3) This is a case in which the supply is wholly insufficient, and in which it is necessary to search for another, either to supplement it, or to take the place of it.

Gauging Springs, Streams, and Rivers.-In the case of most springs, and of small streams, the gauging may be done by 
damming back the flow to form a pool of some depth, across which one or more boards are laid, so that one man or more can readily lift out the water with pails. A stake is driven into this ground through the water, a mark being made on the stake a little below the level at which the water will overflow the dam. Pails of known capacity are used, and the water is lowered some distance below the mark. Operations are then stopped to allow the surface of the water to become smooth, and the water is allowed to rise to the mark when time is taken. The water is then rapidly removed till the level of the surface falls somewhat

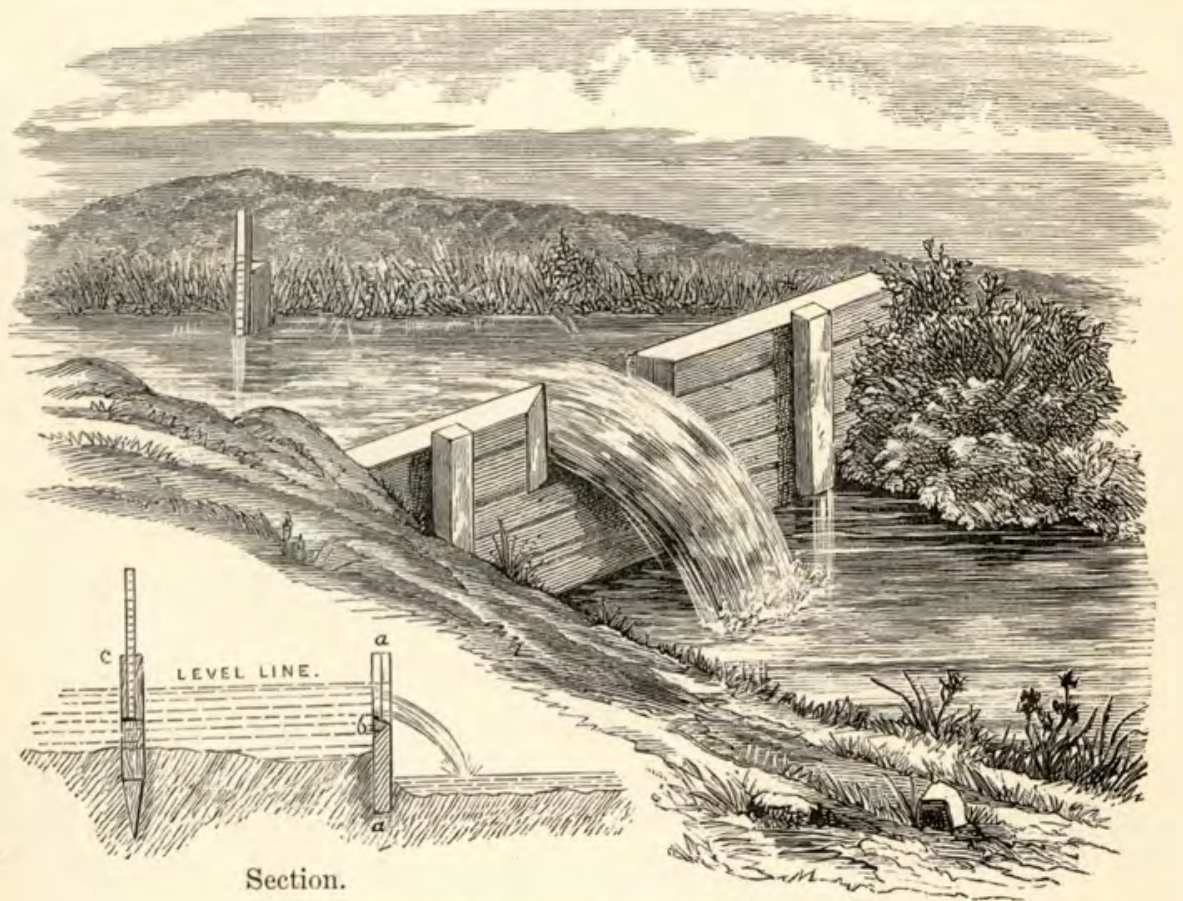

Figs. 1 and 2.-Weir or notchboard for gauging streams.

below the mark. The level is kept at this, the number of pailsful of water being counted for a considerable time, say approaching an hour. Operations then cease to let the surface of the water become again smooth, and the time is carefully watched till the water surface reaches the mark again, when it is taken.

Cubic feet of water removed by the buckets Number of minutes between the two times the surface $=$ discharge in cub. ft. per min. of the water reached the mark

This may seem a very crude method of gauging, and, indeed, it is not a very delicate one, but it must be borne in mind that 
nearly all water-gauging appliances give only approximate results. The writer does not put much faith in gaugings of water either by notch boards, or by observing the pressure necessary to force water through an aperture of known area, which profess to be within a very minute fraction of absolute accuracy. There are far too many elements of possible error, and it is likely that most gaugings of the kind just indicated are really as much in error as the common pail method, if this latter be carefully carried out. It is not, however, even with several assistants, commonly applicable to quantities of over five or six cubic feet a minute, and it is
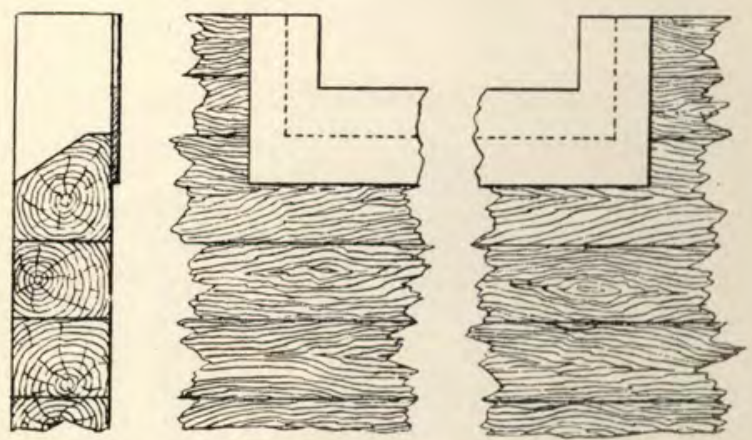

Fig. 3.-Metal plate for weir or notchboard for gauging streams.

difficult even when such quantities are measured. These quantities correspond about to a supply for a population of 3,000 people.

For larger streams the common method of gauging is that of the weir or notchboard illustrated in Figs. 1 and 2.*

The principle of the notch board is that, if the breadth of a rectangular opening such as that shown in the cut is known, and the depth of water is also known - the depth being, in this case, the difference of level between the lower edge of the notch and that of still water at some distance behind the notch-the discharge of water can be discovered by the application of a comparatively simple formula.

For very rough measurements an actual board may be used, the notch being carefully made, and the wood being chamfered or bevelled away on the down stream side. For more accurate work a metal plate, not more than about one-tenth of an inch thick, is fastened with screws to the wooden board, as shown in the accompanying sketch (Fig. 3). Sheet brass is the best material to use.

* The illustration is taken from "Our Homes and How to Make them Healthy," edited by Shirley F. Murphy. (By permission of the Publishers. London: Cassell \& Co.) 
The dam must, of course, be watertight, and it should, if possible, be of such a size and in such a position that there is a pool of practically still water behind it. If the pool be so small that the water approaches the dam with appreciable velocity, not only is the calculation more troublesome, but the results will probably be less accurate than with still water. The plane of the opening must be truly vertical, and the bottom and sides of the notch must be truly horizontal and vertical. The width of the notch should be such that the depth of water will be a quarter or less of the length, the depth being, however, not the actual depth of water on the weir, but the difference of level mentioned above.

Amongst the many formulæ* which have been given, that due to Mr. James B. Wood, C.E., is to be recommended, as giving results accurate enough for nearly all waterworks purposes, whilst it is not very complicated. It is :-

Where

$$
\mathrm{Q}=3 \cdot 33(l-0.2 \mathrm{H}) \mathrm{H}_{\frac{3}{2}}
$$

$\mathrm{Q}=$ Quantity of water in cubic feet per second,

$l=$ Length of weir in feet,

$\mathrm{H}=$ The observed depth of water in feet, that is to say, the difference in level between the bottom of the weir and the surface of still water in the pool behind the weir.

In cases where water approaches the weir at an appreciable velocity-that is to say, when it is moving in the pool before it comes close to the notch-a corrected formula is used, as follows :-

$$
\mathrm{Q}=3.33\left(l-0.2 \mathrm{H}_{1}\right) \mathrm{H}_{1} \frac{3}{2}
$$

In which $\mathrm{H}_{1}=\mathrm{H}+h$.

In this case $\mathrm{H}$ has the same value as before.

$h$ is an addition to be made on account of the velocity of the approaching water :

$$
h=\frac{v^{2}}{64 \cdot 4}
$$

Where

$v=$ the velocity of the approaching water in feet per second.

Table IV. in "Hydraulic and other Tables for purposes of Sewerage and Water-Supply,” by Thomas Hennell, M.Inst.C.E., is a most handy one for facilitating calculations of the flow of water over weirs. In it is given (unfortunately in gallons) the discharge of weirs per inch of length (or width) for depths from $\frac{1}{4}$-inch to five feet. This table gives results sufficiently approximate for rough gauging of streams.

* This subject is very completely treated by Mr. J. F. Fanning, C.E., in his treatise on "Hydraulic Water-supply Engineering," and all who want to go into the theory of the flow of water over weirs should read Chapter xIv. of that work. 
Gauging Streams too large to be gauged by Notchboards. - In the case of rivers which discharge over dams, it is generally possible to gauge the rivers at a dam with considerable accuracy and without much trouble, but readers are referred to works purely on hydraulics, or on river engineering, for the methods of such gauging. In ordinary cases the cross-section of the flow of the river is to be discovered, also the velocity of flow, when the two multiplied together equal the discharge.

To gauge roughly a river, a part is selected where the flow is fairly even for some little distance, say a few hundred yards for rivers of moderate size, a greater distance for large rivers. The section is to be taken at several places, say at least four, along the distance to be used for gauging. The section is taken by measuring the depth at a number of equally distant points across the stream as shown in the subjoined sketch (Fig. 4).

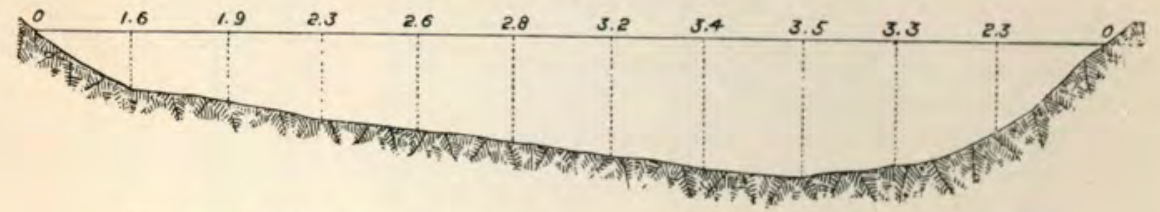

Fig. 4.--Section across river showing depth of stream at various points.

The depths at each end are taken as zero,* and the mean depth $\times$ length is taken as the section. For example, the depths in the sketch may be taken as $0,1 \cdot 6$ feet, $1 \cdot 9$ feet, $2 \cdot 3,2 \cdot 6,2 \cdot 8$, $3 \cdot 2,3 \cdot 4,3 \cdot 5,2 \cdot 3$ and $0:-$

$\frac{0+1 \cdot 6+1 \cdot 9+2 \cdot 3+2 \cdot 6+2 \cdot 8+3 \cdot 2+3 \cdot 4+3 \cdot 5+3 \cdot 3+2 \cdot 3+0}{12}=2 \cdot 242 \mathrm{ft}$.

Suppose the width to be 30 feet, the section in square feet = $2 \cdot 242 \times 30=67 \cdot 260$.

Several sections are thus taken, and the mean of them is assumed to be the section of the river.

The next thing is to determine the surface velocity at the centre of the stream. This is done by taking the time necessary for a floating body to pass two marks at a known distance apart, the body having been placed in the water some distance above the higher mark, so that it may have acquired the full velocity of the water before it reaches this mark. Three operators are thus necessary. One places the floating body in the water. In the

*- It is obvious that, if the banks be vertical, this would give inaccurate results. In such a case the actual vertical depth would be taken. 
case of a small river or stream this may simply be thrown from the bank, but in the case of a large river it should be thrown from a bridge or from a boat anchored about the centre of the stream. Two observers at a measured distance apart stand by upright stakes, there being other stakes exactly opposite on the other side of the stream, so that the floating object is sighted as it passes between the two stakes. Either one or other of the observers should have a stop watch, or each may have one with advantage, that they may check each other. In any case the passing of the floating body is signalled by one observer to the other by a rapid raising of the arm, or by some other pre-arranged signal. A number of observations is made, and the mean is taken as the surface velocity.

The best floating object is one of specific gravity just a little less than water, that is to say, a body that will float all but submerged. Slices of turnip are excellent for the purpose; they only just float, and their white colour makes them conspicuous. The surface velocity is greater than the mean velocity of a stream, and for rough estimations of discharge the mean velocity may be taken as three-fourths the surface velocity.*

Thus in the case we have imagined, if the surface velocity were estimated at 4.8 feet per second, we should take the mean velocity at $4.8 \times \frac{3}{4}=3.6$ feet per second, and the discharge at $67 \cdot 260 \times 3 \cdot 6=242 \cdot 136$ cubic feet per second.

More exact measurements can be made by the use of current meters or tachometers. These are generally in the form of fans, or, more strictly, of screw propellers, being, in fact, the exact converse of screw propellers. The revolutions of the fans are registered by trains of wheel-gearing just as in the case of water or gas meters, and from the number of revolutions the velocity of the water can be deduced.

Other tachometers depend on the fact that, if a pipe bent at right angles, so that one part is vertical, another horizontal be placed in flowing water, the horizontal part with its open mouth up stream, the water in the vertical part of the pipe will rise above the surface of the water in the stream, the difference of level varying as the square of the velocity.

* This only holds good, even approximately, when, as is generally the case in natural streams, the width is much greater than the depth-say not less than twelve times the mean depth. In very deep streams the mean velocity may be a considerably larger fraction than 75 of the surface velocity. Thus when the depth is half the width, the mean velocity may equal $\cdot 920$ of the surface velocity (Fanning), but $\frac{3}{4}$ is a very safe fraction to take, as it is likely to be exceeded rather than the reverse. 
With any of these current-meters, velocities may be taken at different depths at different distances across the stream, and the mean of all these observations may be taken as the mean velocity.*

The Minimum Flow of Streams and Rivers. - In cases where a river or a large stream is proposed as a source of water supply, it is often easy, by a mere glance, and by making use of local information that can readily be obtained, to say definitely that the minimum capacity of the river will be ample for the supply, but there often occur cases where it is quite doubtful whether the minimum will be sufficient or not. In these cases it is necessary to do all that is possible to find out what the minimum discharge is likely to be, and it is as well to admit that it is often difficult or impossible to do much more than guess at the minimum discharge of a stream, from all the data that can be obtained before a report has to be made.

In the rare case where, when a stream is first proposed for a source of water supply, it is found that systematic gauging has been carried on for a long series of years, the question is a simple one; but it is not often that such cases are met with.

Whenever a stream that has not been gauged is proposed as a source of supply, steps should be taken to begin systematic gaugings at once. There is almost always a good deal of delay before proposed waterworks get actually taken in hand, and during the interval it is likely that information may be obtained that will be very useful.

If the flow of streams varied directly as the rainfall it would generally be easy to calculate the minimum flow of any stream, or rather no calculation would be necessary, for, as it ceases to rain at times in all places-even in the Highlands of Scotlandthe rainfall is at times zero, and the minimum flow of all streams would be zero. We know, of course, however, that it is exceptional for any stream, save a small one draining a non-absorbent surface, to become totally dry at any time of the year.

If there were any constant ratio between the mean and the minimum discharge of a stream, the minimum might be discovered with fair accuracy with comparative ease, for the mean discharge may be estimated fairly exactly by gaugings spread

* For a description and drawings of several current-meters, see Chap. xvi. of Fanning's "Hydraulic and Water-Supply Engineering." Indeed, the whole of that chapter (on the Flow of Water in Open Channels) should be read. 
over a comparatively short time, the rainfall being taken into consideration, and the mean of the gaugings assumed to be above or below the mean flow of the stream, in the same proportion that the mean rainfall during the time of observation was above or below the mean rainfall for a number of years.

There is, however, no fixed ratio between mean flow and minimum flow, these varying not only with the rainfall, according as it is very variable or pretty evenly distributed the year round, but also varying with the nature of the ground-being less the more absorbent this is-and with the area of the catchment basin being less the greater this area is.

We have the extreme case of variability in the drainage from the roof of a house. Here we have a small catchment area, one practically non-absorbent, and the flow of water ceases a few minutes after the rain stops falling. We have the opposite case in a great river draining large areas of flat or gently sloping absorbent land, which remains navigable all the year round, and does not rise in excessive flood at any time.

The following is part of a table given by Fanning, showing the minimum, mean, and maximum flow of streams in the average Atlantic coast basins * of the United States :-

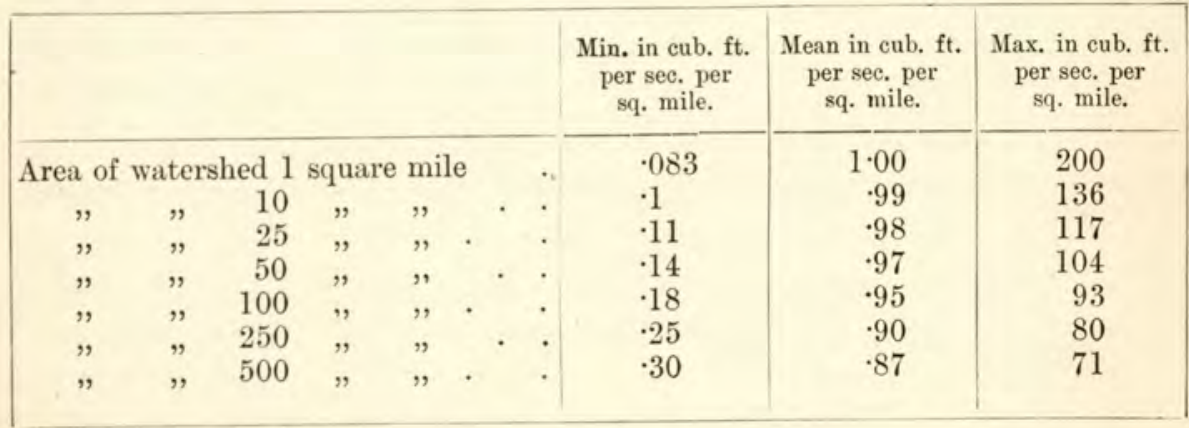

It is not likely that there will be any question of the minimum being insufficient for the water supply of a town, with catchment areas of over 500 square miles : so the rest of the table is omitted.

It will be seen from this table that the mean discharge becomes somewhat less per square mile as the catchment area increases, but that the maximum discharge becomes rapidly less.

* In some parts of England the variations are greater than those given, in others less. In Japan, on account of the long dry winter season and the wet summer season-sometimes with rainfalls almost phenomenal, a foot in twenty-four hours having been more than once observed, and on one occasion more than double that quantity - the variations are generally greater. 
The variation also becomes much less. Thus with a catchment area of only 1 square mile the minimum flow of a stream will be only about $\frac{1}{12}$ of the mean, with an area of 500 square miles it will be more than $\frac{1}{3}$ *

Even here the "minimum " refers to a fifteen days' period of least summer flow, so it is likely that the minima for a day or two at a time fall even below those given, especially for very small catchment areas ; but very small storage capacity, such as that of a settlement reservoir of fair size, would be sufficient to tide over these few days.

In making enquiries as to the minimum flow of streams, advantage should always be taken of the local knowledge of farmers and others who are likely to be observant of the quantity of water in streams, especially in countries where water is used for irrigation. Too implicit faith must not, however, be placed on their testimony. Repeatedly the writer has been told that a stream "has never been known to be lower than it is at present," when a glance at tables of the rainfall of the district for a few years showed conclusively that it must have been lower even within a comparatively short period of time.

* In the case of the Kobe waterworks, so far as can be ascertained from the many gaugings that have been made, and the observations of rainfall over a long period, it would appear that, whilst the total quantity of water available during the year, is probably more than $\frac{1}{3}$ of the whole rainfall, the quantity available during the dry months of winter is much less than $\frac{1}{3}$ of the total rainfall. During the cold dry months, a great part of the ground of the catchment area must be frozen, and a large proportion of the very small quantity of "precipitation" must be in the form of snow. 


\section{CHAPTER V.}

\section{On Estimating the Storage Capacity Required to be Provided.}

Phenomena of Rainfall.-It may be well to begin by noting that the result of observations on rainfall is to show that, in many countries with climates otherwise very different, two phenomena are repeated with remarkable regularity :-

(1) It is found that the minimum rainfall for a year is less than the mean rainfall by $\frac{1}{3}$, or 33 per cent., whilst the maximum rainfall for a year exceeds the mean by $\frac{1}{3}$, or 33 per cent.

(2) There may be expected to occur, at considerable intervals, sets of three consecutive years during which the average yearly rainfall is only 80 per cent. of the mean yearly rainfall over a number of years.

An Ideal Reservoir.-It has been stated that when the average discharge of a stream equals or is greater than the average consumption, a water supply is practicable, by the aid of storage reservoirs, even when the minimum discharge is less than the average consumption.

The case of an average discharge and an average consumption (including loss by evaporation from the reservoir surface, leakage, \&c.), absolutely equal to each other, is not one met with in practice, although it is hypothetically possible. It would involve a reservoir of such dimensions that, when the flow of the stream, after the longest possible drought had just come, from the first rain, to equal the supply, the reservoir should be exactly empty, or empty down to the lowest allowable level; while on the other hand the reservoir must be such that after the greatest possible flood it should be exactly full, but should not overflow a drop. It is evidently beyond the possibility of human calculation to proportion a reservoir that would just fulfil these conditions. 
If the average discharge exactly equalled the average consumption, it would be quite possible to make a reservoir so large that it would never overflow, so that it would not waste a drop of water in this way, and that a stream of varying discharge should thus be converted into one of absolutely constant discharge. Apart, however, from the fact that in some cases it is advisable to let storm water pass the reservoir, on account of the detritus it would otherwise deposit, it is never economical to make the reservoirs of such a size as to absolutely equalize the flow of water. They are always made of such a size that some of the storm water will either pass them or cause them to overflow. The most that is generally done is to so proportion the reservoir that it will equalize the flow during a set of three dry years, when the average rainfall is 20 per cent. less than the mean rainfall over a number of years, the reservoir, during such three years, neither becoming quite empty, nor losing water by overflow.

Capacity of Reservoirs, how Determined.-It is customary to state the capacity of reservoirs in days' consumption. Thus if it is said that a reservoir has a capacity of one hundred days' consumption, this means, that the reservoir holds, between the lowest level at which it is intended the water should be drawn off and the edge of the overflow, enough water to supply the town for one hundred days, at mean rate of consumption, without receiving any additional water.

Even to secure the averaging mentioned above, it has been found necessary occasionally to make reservoirs of a capacity of 250 days' supply, although 150 to 200 days' is commoner.

It is evident that the capacity needed is greater, the greater the irregularity of the flow, and that it is increased to the maximum if a season of maximum demand is just finishing when the season of maximum rainfall is beginning. This is the case in some parts of the United States of America,* where more water is consumed in July, August, and September than during any other months, whilst the season of maximum rainfall begins in December.

The following is a formula by Sir John Hawksley for determining the quantity of storage necessary when the mean rainfall is known :-

$$
\mathrm{C}=\frac{1000}{\sqrt{r}}
$$

* Almost the exact opposite holds in Japan, where the greatest rainfall is during the warm months, and the cold months are intensely dry. 
Where

$\mathrm{C}=$ The capacity in terms of one day's average consumption,

$r=$ The average rainfall during three consecutive dry years $=\cdot 8$ of the mean rainfall.*

Example. The mean rainfall is 45 inches. $45 \times 8=36$, therefore $\mathrm{C}=\frac{1000}{\sqrt{36}}=\frac{1000}{6}=166^{\circ} 6$, say 167 . That is to say, a storage capacity equal to an average consumption for 167 days must be provided.

It is difficult to see how this formula provides for differences in the irregularity of rainfall. It would give, for example, the same storage capacity, did the rain fall evenly through the whole year, or did it all fall at one rainy season. It has, however, undoubtedly been found to apply with approximate accuracy in England.

Where neither a record for a number of years of the gauging of a stream, nor of the rainfall of a district has been kept, it is impossible to do much more than guess at the storage capacity necessary. When either has been kept, the writer strongly recommends the simplified graphic method described hereafter.

If actual gaugings of a stream have been kept for a number of years, the matter is comparatively simple, but, as has been said, it is the exception to find that such gaugings have been kept. When they have not, it is necessary to make an estimation of the probable flow of the stream from the rainwater. To do this it is assumed that, for any period of time

\section{Where}

$$
d=a \times r \times c .
$$

$d=$ The discharge of the stream during that period of time in cubic feet.

$a=$ The area of the catchment area in square feet.

$r=$ 'The rainfall during that period of time in feet.

$c=\mathrm{A}$ co-efficient which gives, as a fraction, the total quantity of water that is available, that is to say, the total quantity of rain that falls within the catchment area minus such as is lost by evaporation, and by absorption, not being returned within the catchment area in the form of springs.

It will be seen that the assumption cannot be taken as correct except for long periods of time. We see this distinctly if we consider that for short periods of time the rainfall is often zero, while the discharge of the stream is probably never zero. The error of

* In the original formula the average rainfall for three consecutive dry years was taken as five-sixths of the mean rainfall. A more extended examination of rainfall records shows, however, that the average rainfall for three consecutive dry years not infrequently falls to four-fifths of the mean rainfall. In some very few cases it has fallen even below this. (See Tables X., XI., and XII. in Hennell's "Hydraulic and other Tables," for many details of rainfall records, arranged in such a form that a number of useful facts may be deduced from them at a glance. Here we learn, for example, that, during the years $1854-5$, and 6 , the average rainfall at Exeter was less than $\frac{3}{4}$ the mean rainfall of that town for fifty-two years.) 
one short period of time tends, however, to compensate that of others, so that, for the purpose of calculating the storage capacity necessary in any particular case, the assumption is safe. The difficulty lies in getting a fairly accurate value for $c$. Fanning gives the following approximate values for different kinds of ground :*-

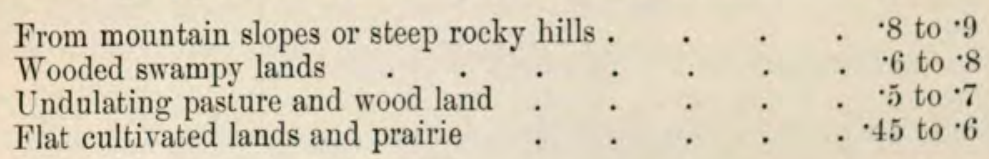

These figures are only intended to be taken as very rough approximations, and they are liable to variation even in the case of the same catchment area. Thus during dry seasons $c$ is less for the same catchment area than during wet seasons. That is to say, during dry seasons proportionately less of the rainfall is available for storage than during wet. The reason of this will be evident if it is considered that the total evaporation for any season is more nearly a constant than a fixed fraction of the rainfall as used to be assumed.

Again, $c$ will be greater where the rain is in the habit of falling violently for short periods of time than when the rainfall is spread fairly uniformly over the whole year. This fact, it is true, so far as practice is concerned, is likely to be more than compensated for by loss of storm water, as explained above. $\dagger$

In any case, if it is necessary to assume $c$ from the above table the smaller of the two values should always be taken.

If the stream can be gauged for even a moderately long time, a very fair estimate of $c$ can be made on the principle that

$$
c=\frac{d}{r}
$$

Where

$c$ is the co-efficient as before ;

$d=$ the total discharge of the stream, in cubic feet, during the whole period of time;

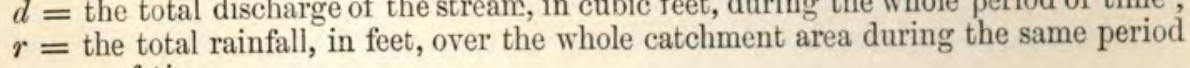
of time.

The longer the period during which the observations have been made, the more accurate, it may be assumed, is the value of $c$. Could the observations be made during a period of three consecutive dry years, the value of $c$ thereby obtained would be a very safe one. Even, however, with gaugings extending over a few months, a very fair approximation of $c$ may be got, if the weather during these gaugings has been fairly typical, and if the results of the gaugings be used with intelligence. Thus, if the

* See Note 3, Appendix II.

+ See Note 4, Appendix II. 
weather during the whole of the time has been on the wet side, some considerable deduction (say 10 per cent.) should be made. Even if the weather has been normal - the average rainfall equal to the mean rainfall for a long period, and the rain falling at about the usual intervals - a small deduction should be made. If the weather has been on the dry side, no deduction need be made. No conclusion can be arrived at if the weather has been continuously much more wet than usual, or much more dry. It is very desirable to let the observations cover a complete year if possible.

Reservoir Capacity as determined at Nagasaki.-The method that the writer recommends, $c$ having been estimated, will best be illustrated by taking a specific case - the case of Nagasaki. Waterworks were designed for this town by Mr. C. Yoshimura, these including an impounding reservoir. Some doubt was expressed as to the sufficiency of the capacity of the proposed reservoir, and the writer's advice was asked on the subject in 1889. Plates J. and II. (Figs. 5 and 6) are copies, on a reduced scale, of the diagrams then made to decide what storage capacity it was desirable to provide.

The following are particulars about the works:-It was proposed to provide for a population of 60,000 ; the quantity of water proposed per head per day was twenty gallons.* It was assumed that the consumption would be uniform during the whole year, the rains occurring in Japan, and particularly in Kiushu, during the hot weather, the cold weather being, for the most part, very dry. Of course, such an assumption can in no case be absolutely correct, but experience since the waterworks were opened has shown that, with an ample allowance for average consumption, it was a safe one. The catchment area was 865 acres.

There was a monthly and a daily record of rainfall from the beginning of 1879 to the end of 1888 . It had been found, by gauging of the stream, that $\frac{2}{3}$ or $\cdot \dot{6}$ was a very safe value for $c$. In other words, more than two-thirds of the total rainfall were found to be discharged by the stream.

It was necessary, during one-half of the month of June, and the whole of the months of July, August, September, and October, to supply water for irrigation at the rate of five-eighths of an inch depth in twenty-four hours over an area of about twenty-five acres.

Description of the Diagrams.-Beginning at the bottom, the

* These were figures supplied to the writer, not suggested by him, otherwise this should have been stated in cubic feet. 
first two columns need no explanation. The third and fourth columns are headed "Consumption" and "Rainfall." In a case where the diagram is worked out from actual gaugings of the stream for a number of years, these will be in cubic feet, and, indeed, it would be more consistent to state them in cubic feet in any case, the column headed "Rainfall" being headed "Discharge," and discharge being taken as the total rainfall over the catchment area $\times c$. In practice this involves much trouble, as it is necessary to multiply, for each month, a large figure (the catchment area in square feet) by an odd fraction (the rainfall in parts of a foot), and then by $c$.

To save this trouble the figures in the "Consumption" column are taken as the depth of rainfall that would be necessury to provide this supply. This is got as follows:-

Where

$$
r=\frac{q}{a \times c}
$$

$r=$ the rainfall in one day that would be necessary, allowing for loss by evaporation and absorption, to supply the consumption for one day ;

$q=$ the actual consumption of water for one day ;

$a=$ the area of the catchment basin ;

$c=$ the coefficient of total rainfall arailable.

Thus it was found that a rainfall of $\cdot 102$ inch per day would be sufficient to provide the necessary supply of water for the town consumption alone.

It was found that, when water had to be provided for irrigation, as mentioned above, a rainfall of $\cdot 126$ inch per day would be sufficient for both the town supply and what the farmers needed. The monthly requirements were found by multiplying these figures by $28,29,30$, or 31 , according to the number of days in the several months of the year.

The fifth column gives the difference between the rainfall necessary to supply water for any one month and the actual rainfall. In other words, it is the algebraical sum of the third and the fourth columns, taking the figures in the third column as minus quantities, those in the fourth as plus.

The sixth column gives, at any place, the algebraical sum of all the figures in the fifth column up to that place.

The curve is constructed by drawing ordinates, to any convenient scale, in accordance with the figures in the sixth column.

The resulting curve shows, at a glance, what would have been the conditions of a reservoir at any time during the years covered by the investigation. The rising of the curve shows that a 
Plate I.

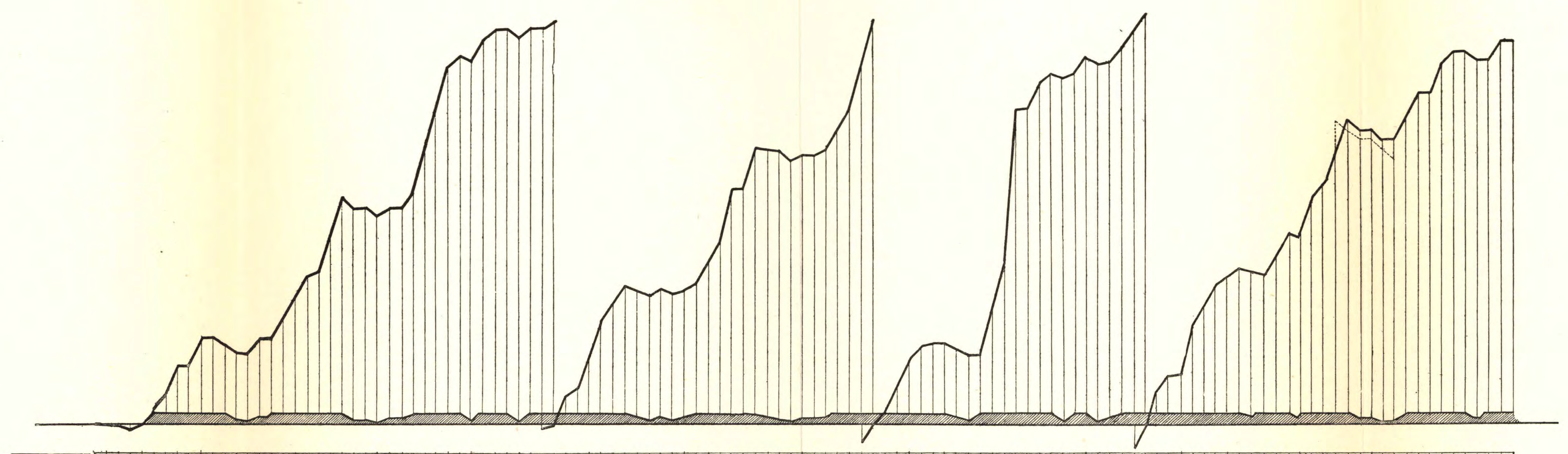

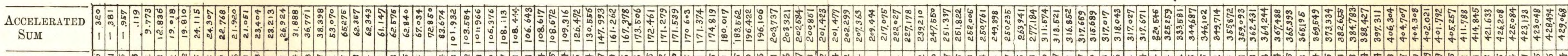

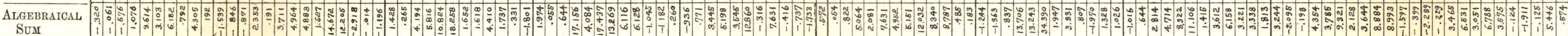

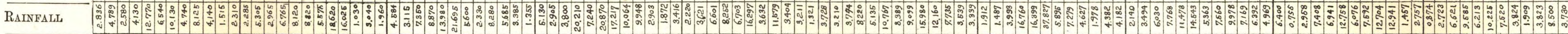

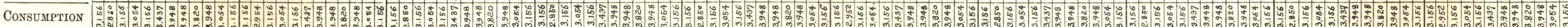

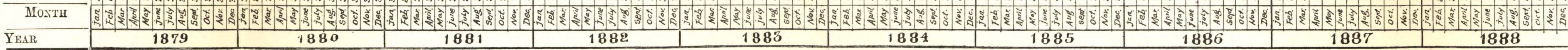


reservoir would have been filling or overflowing; the falling curve shows that it would have been becoming more and more nearly empty.

The depth of any depression is a direct measure of the minimum necessary capacity of the reservoir.

It will be seen how regularly there have been depressions in the winter months. It will be seen that the depression lasting from the beginning of November, 1887, to the end of March, 1888, is a good deal greater than any other. It is found to correspond with a little over forty-four days' supply. That is to say, according to this graphic solution the reservoir would need to hold a minimum of somewhat over $60,000 \times 20 \times 44=$ $52,800,000$ gallons.

The results of the monthly curve are only approximate. On the assumption that all the rain fell during one short period of time every month, and that a similar time, say the first, or the middle, or the last day of the month, the results would be quite exact; but of course no such conditions are met with. The rain is spread more or less unevenly over each month. It is just conceivable, for example, that, in the particular case we have before us, the whole of the rain of October had fallen on the first day of that month, and the whole of the rain of February had fallen on the last day. It is evident that, on this assumption, the depression would be much deeper than it is shown. In fact, it would be as deep as is shown in the dotted lines, or fully 50 per cent. deeper than the actual curve.

To get over this probable error, a curve should be worked out from the daily rainfalls for the deepest depression, or for several if there are several nearly equally deep.

Plate II. shows the result of working out the depression corresponding to the months from October 22nd, 1887, to March 28 th, 1888, from the daily rainfall record; and it will be seen that the necessity is made evident for considerably more storage than was indicated by working out from the monthly records. In fact, a storage capacity for a consumption of over fifty-two days is indicated.

Estimation of Contingencies.--There are various reasons why, even when such a result as this is got, it is necessary to make a considerable addition to cover contingencies. Thus (1) it is never desirable to entirely empty reservoirs except for cleaning out or for repairs that cannot be done with the reservoir full. 
Reservoirs should be so proportioned that they contain 10 to 15 per cent. of their water when they are reduced to the lowest.

(2) The results of the graphic method cannot be taken as other than approximate unless the rainfall record extends over a very considerable time, as there can be no certainty, if it extends over only a few years, that as long a spell of dry weather as is ever likely to occur is included within the time. If we have a record of forty to fifty years or longer to go upon, it is necessary to add only a small percentage on this account. If the record extends, say over only eight to twelve years, and we have no definite information that this time included a long spell of unusually dry weather, it is necessary to add a very considerable percentage.

(3) There is some loss from evaporation from the surface of the water in the reservoir. This cannot be even approximately estimated, as it varies not only with the climate but with the depth of water in the reservoir - with which, of course, varies the surface area. It is, fortunately, least when the water-level is lowest. It may amount to an equivalent of twenty inches over the mean surface area of the reservoir, or may be more or less. There is reason to believe that, in the case of climates in which hot weather is very damp, water is condensed on the surfaces of reservoirs with a rising thermometer. The writer has sometimes known weather during which, if water were taken from a reservoir and were poured into a bottle, the sides would immediately become bedewed, and water would be condensed to such an extent as even to trickle down them, before the temperature of the water within the bottle rose to that of the air outside. It is certain that, during such times, water is condensing over the whole surface of the reservoir to a very appreciable extent. It is quite conceivable that reservoirs, natural or otherwise, fed with very cold water, such as that from glacier streams, rather gain water by condensation than lose it by evaporation.

(4) A certain amount of leakage or percolation has to be anticipated. With careful work it should be reduced to a very small percentage, but there is probably always a little.

Taking all this into consideration, it may be said that 30 to 40 per cent. should be added to the estimated capacity of the reservoir according as the time over which rain-water records extend has been short or long.

In the case for which the diagrams on Plates I. and II. were prepared it will be seen that it was found that a minimum capacity 


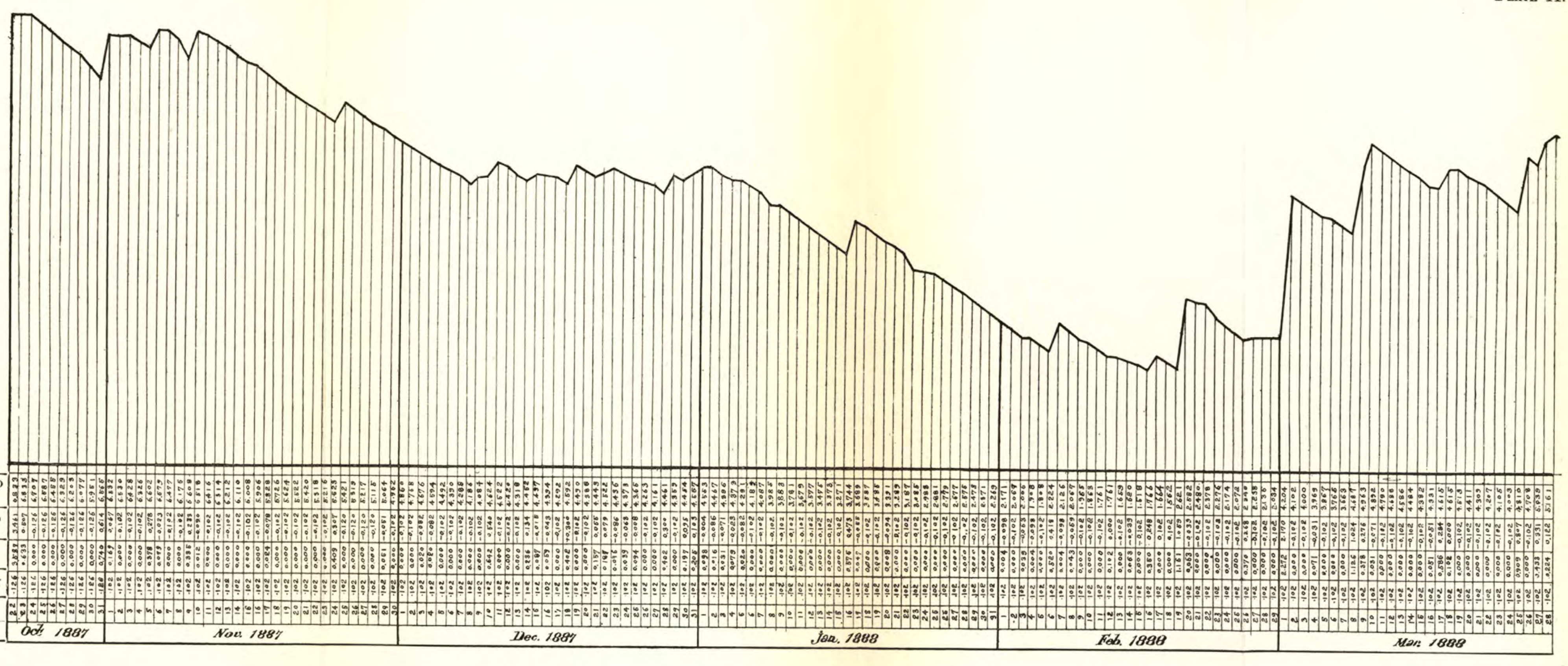

Fig. 6.-Diagram illustrating Required Storage Capacity (Daily Rainfali). 
of somewhat over fifty-two days' consumption would have been necessary to cover the winter of 1887-88. The capacity that had been proposed was one for sixty-five days. It was thought advisable in this case to add 40 per cent. to the estimated capacity, the rainfall record extending over only ten years. The capacity of the reservoir was increased to one of about seventy-five days' consumption by excavating all the material for the dam from the site of it. This is just about 40 per cent. more than the estimated quantity. So far as experience goes this allowance has been quite ample.

The lower shaded portion of the diagram in Plate I. shows what would have been the condition of a reservoir of the size first proposed during the years 1879 to 1888 inclusive. Where the line is horizontal it indicates that the reservoir would have been full or full and overflowing. A falling line indicates emptying of the reservoir; a rising one, filling. The distance of the line above the axis of the curve - that is to say, the length of an ordinate at any place-is a direct measure of the quantity of water that there would have been in the reservoir at the time corresponding to the ordinate. 


\section{CHAPTER VI.}

\section{Classification of Waterworks.}

WAтERWorks are generally classified into Gravitation Works and Pumping Works.

In gravitation works the pressure in the mains is that due to gravitation alone. In pumping works the pressure may he due directly to gravity, enough water being stored in a high-level reservoir to compensate for the fluctuation in consumption during the twenty-four hours, but this water has been pumped into the reservoir from a comparatively low level. In other cases, the water is pumped from a low-level reservoir directly into air vessels or "stand-pipes" acting as small accumulators to prevent undue shock or " ramming" in the mains.

The pumps are nearly always actuated by steam. In some few cases they are actuated by water power, especially when the works are on a very small scale, in which case the hydraulic ram may often be used.

Gravitation works to be complete must consist of (1) either a high-level impounding reservoir, or a high-level intake with a settling reservoir; (2) filter beds; (3) a service reservoir near the impounding or settling reservoir, or, if there is high land conveniently situated, a reservoir as near as possible to the town or within it, or one or more high-level tanks within the town; (4) a distribution system.

A pumping system may consist of :-A. (1) a comparatively low-level intake; (2) one or more settling reservoirs; (3) a set of filter beds; (4) a pumping station, with (5) a high-level reservoir or tank near or within the town, holding enough water to compensate for the inequality of the consumption during twenty-four hours ; (6) a distribution system.

B. Where there is no high land for a high-level reservoir, and 
a high-level tank on an artificial support to hold enough water to compensate for the variation in consumption during twenty-four hours is considered impracticable-(1) a comparatively low-level intake; (2) one or more settling reservoirs; (3) a set of filter beds; (4) a low-level service reservoir ; (5) a pumping station with engines pumping directly into (6) a distribution system.

C. Where the intake is so low that the water will not gravitate to any convenient place for settling reservoirs and filtering beds, and there is room for these only on the low ground-(1) a lowlevel intake; (2) an intake pumping station, with engines pumping into (3) one or more settling reservoirs ; (4) a set of filter beds ; (5) main pumping station, with engines pumping into (6) a highlevel reservoir or a tank on a high artificial support; and (7) a distribution system.

D. The same as before up to (5), but (5) a low-level service reservoir ; (6) pumping station with engines pumping directly into (7) a distribution system.

The last case, as that of B, occurs when there is no natural site for a high-level reservoir, and where the high-level tank of sufficient size on an artificial support would be too expensive, or is, for any other reason, impracticable.

Various combinations of these systems, or modifications of them, are met with in practice.

Plates III., IV., and V. (Figs. 7 to 12) are intended to show diagrammatically some of the forms of gravitation and pumping systems that are met with. The letters refer to the following terms :-

I. R. Impounding reservoir.

W. T. Water tower.

D. Dam.

F. B. Filter beds.

C. W. R. Clear water reservoir or service reservoir.

D. S. Distribution system.

S. R. Settling reservoir or reservoirs.

R. River, stream, or lake. In every case supposed to show low-water level.

P. S. Pumping station.

P. W. Pumping well.

I. P. S. Intake pumping station.

It is to be understood that no attempt has been made to keep to scale. The illustrations are of an entirely diagrammatic nature. They very nearly explain themselves, but a few words may be said of each.

In the first place attention is drawn to the difference between 
the systems illustrated in Fig. 7 and Fig. 8. It will be seen that the only difference is that, whereas in the case illustrated by Fig. 8 there has been, within the town, a position suitable for a service reservoir, in the case of Fig. 7 there has been no such position, and the service reservoir has had to be made close to the impounding reservoir. It might seem that it would make but little difference which arrangement was adopted. There is, however, a very considerable difference. In the case illustrated by Fig. 7 the main must be able to carry the maximum quantity of water consumed at any part of any day of the year. In other words, it must be able to carry at least twice the mean supply. In the case illustrated by Fig. 8, the main need only be able to carry the maximum daily supply - that is to say, not more than the mean supply $\times 1.5$. In this case the distribution system only has to carry the very maximum. The distribution system must always be capable of carrying the very maximum consumption.*

In both these cases, had the minimum discharge of the stream been capable of supplying the necessary quantity of water, instead of an impounding reservoir there would have been a high-level intake and a settling reservoir.

The difference between the cases illustrated by Figs. 9 and 10 is nearly the same as that between those illustrated by Figs. 7 and 8 , except that it applies to the pumping engines instead of to the mains.

In the case illustrated by Fig. 7, the engines need only be capable of pumping the maximum daily supply, or the mean supply $\times 1.5$; those illustrated by Fig. 10 must be capable of pumping the very maximum needed at any time - that is to say, at least the mean supply $\times 2 .+$

It is to be observed that, in the case illustrated by Fig. 9, the pumping station might be anywhere between the filter beds and the position in which it is shown according to the configuration of the land. It is, in fact, probably more nearly found near the filter beds than in any other position.

In the case illustrated by Fig. 10 it is advisable to have the clean water reservoir and the pumping station as near together as possible, because the pipe between the clean water reservoir

* Fig. 7 illustrates the case of the Nagasaki waterworks in Japan; Fig. 8 that of the proposed Shimonoseki works.

$\dagger$ Fig. 9 illustrates the proposed Fukwoka waterworks in Japan; Fig. 10 those proposed for Okayama. 
Plate III.

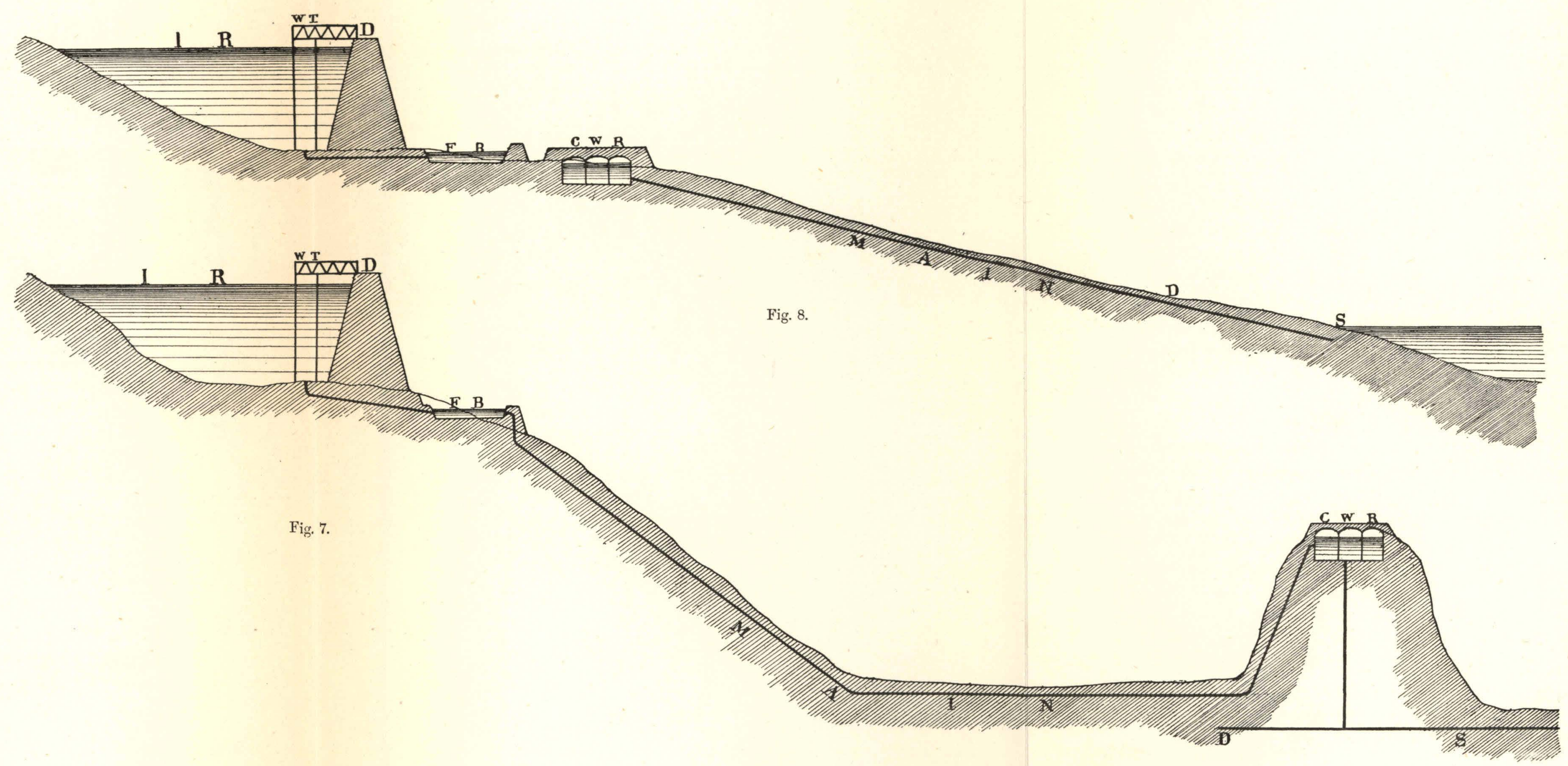

Diagrams illustrating Gravitation Systems of Waterworks.

[To face page 44. 
Plate IV.
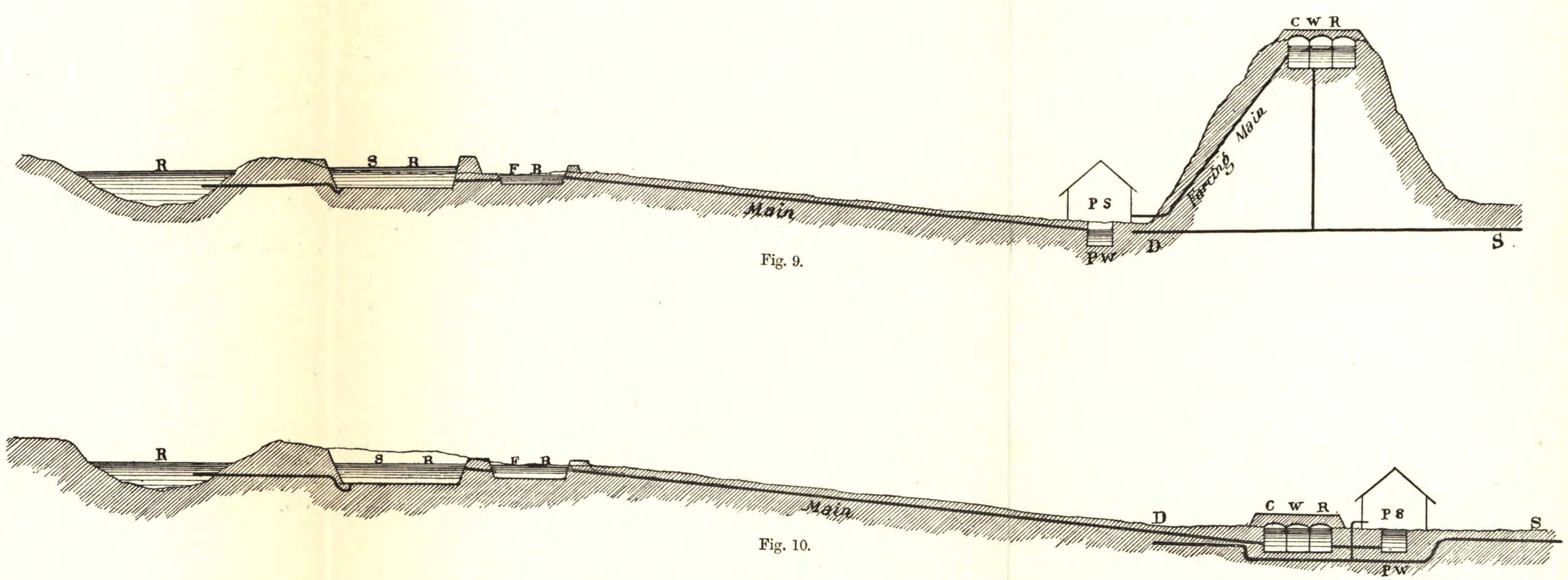

Diagrams illustrating Pumping Systems of Waterworks.

[To face page 44. 

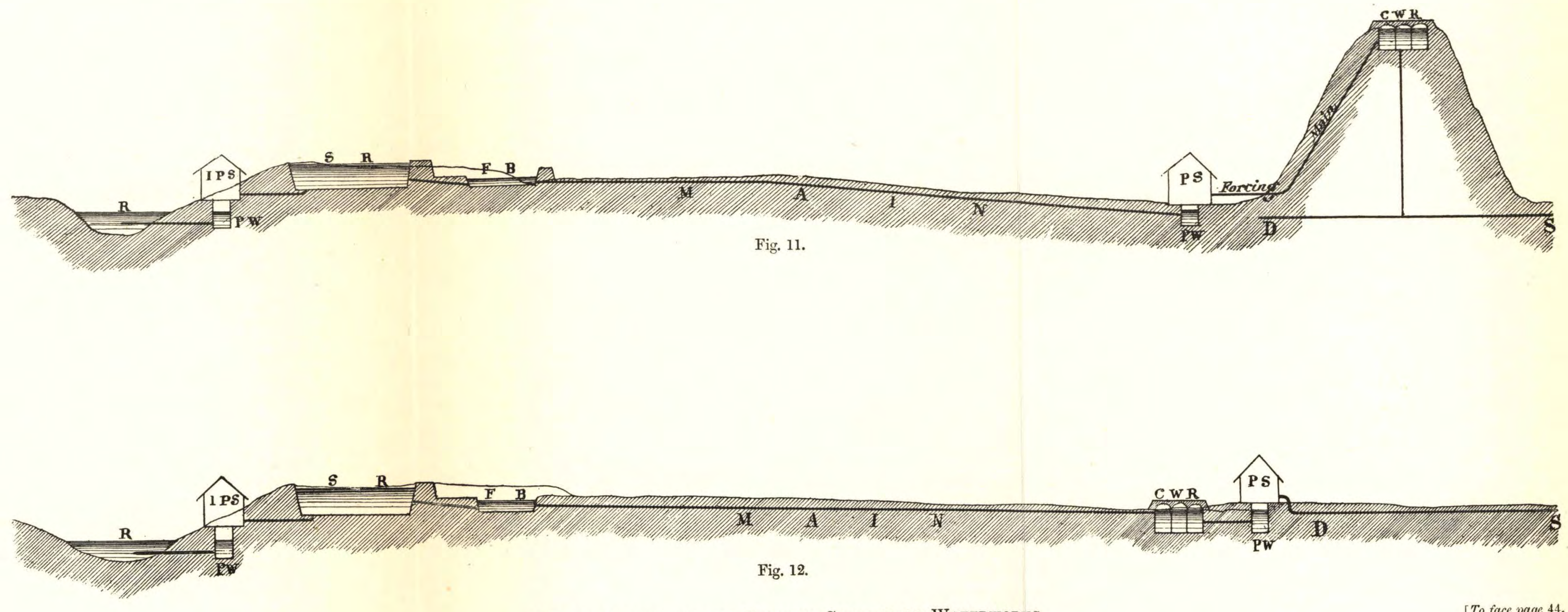

Diagrams illustrating Pumping Systems of Waterworks.

To face page 44. 
and the pumping well must be capable of carrying the very maximum of water that is needed, but there may be cases where they have to be some distance apart.

The same may be said of the case illustrated by Fig. 11 as of that illustrated by Fig. 9. The pumping station might be anywhere between the place where it is shown and the site of the filter beds.*

In the case illustrated here, the main pumping engines need only be able to do work at the maximum daily rate-that is to say, at the mean rate $\times 1 \cdot 5$. The intake pumping engines need hardly be able to do this, as it seldom happens for more than a day or two together that the daily consumption keeps up even nearly to the mean consumption $\times 1.5$, and the settling reservoirs hold, as a rule, two or three days' supply, some of which can, as settling reservoirs are generally arranged, be used up in case of emergency. Still it is safer to make these engines capable of doing the maximum daily work. This is apart from "stand by," which will be treated of hereafter. In the case illustrated by Fig. 11, the main pumping engines must be capable of doing the very maximum work, that is to say, at least twice the mean work. This ought to be without using the "stand by" engine or engines, but often these are used whenever the demand is unusually high.

The same may be said of the intake pumping engines in the case illustrated by Fig. 12 as of those in the case illustrated by Fig. 11.

* If the pumping station were shown close to the filter beds, this figure would illustrate the waterworks for Osaka, Japan, at present (1894) in progress. 


\section{CHAPTER VII.}

\section{Impounding Reservoirs.}

General Considerations.-If it is decided that it is desirable, in any particular case, to store water to supplement the supply during the dry seasons of the year-that is to say, if a deep-well supply be out of the question, and there are no streams of pure water at a convenient distance whose minimum discharge is sufficient for a supply-it is necessary to search for a site for an impounding reservoir, often for sites for several such reservoirs.

It is generally in a position high among valleys that suitable sites for impounding reservoirs are to be sought. Indeed one of the compensating advantages for the great expense of constructing

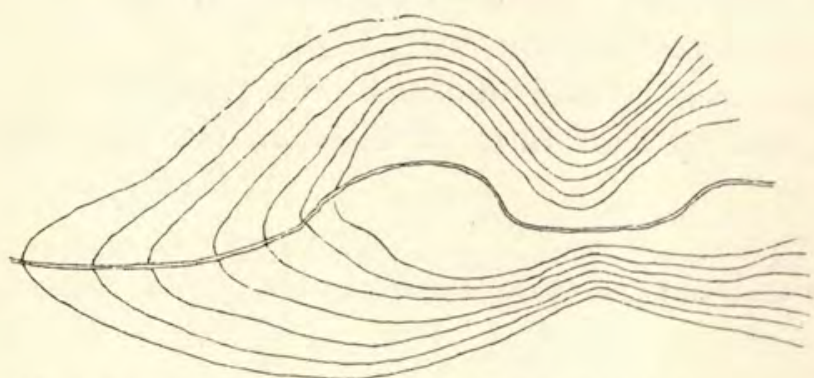

Fig. 13.-Contour of sides of valley forming site for reservoir.

impounding reservoirs is commonly that water can be got from them at sufficient pressure by gravitation. There are, however, cases where water, even from impounding reservoirs, has to be pumped to get sufficient pressure.* It need scarcely be said that, in searching for reservoir sites, any maps of the district that are available should be made use of. If there has been a complete survey of the ground, contour lines being inserted in the maps, the labour of the work will be greatly lessened.

The best site for a reservoir is one where a valley widens out

* In Japan this is the case in the proposed Moji waterworks. 
into a flat bottom bounded by steep sides, the sides coming close together, forming a contraction just below this flat bed. Thus the contour lines in Fig. 13 indicate a likely site for a reservoir.

The writer has noticed, both from the study of descriptions of work executed, and from his own practice in searching for probable sites for reservoirs, how commonly such a formation occurs just where two streams meet, a contraction of the valley occurring a little down stream from the junction. It, therefore, very often happens that impounding reservoirs are bifurcated.* The following contour lines (Fig. 14) indicate a likely site for a reservoir of this kind.

It will be understood, of course, that no impounding reservoir can be constructed unless there is an impervious bed under the

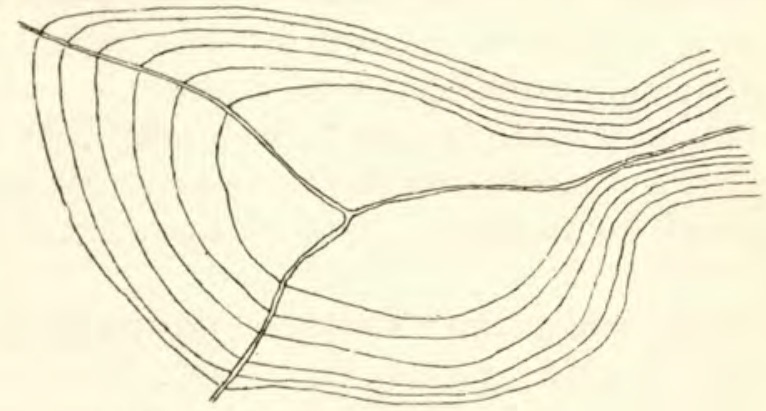

Fig. 14.-Contour of sides of valley (with meeting streams) forming site for reservoir.

site of it. Such an impervious bed is almost always to be found at a sufficient depth, but the depth may be so great as to make the construction of a dam-which must penetrate to the impervious stratum-impracticable. It has, in some cases, been considered advisable to construct dams where the watertight portion of them had to penetrate through as much as 100 feet of superficial porous material.

Preliminary Works.-A likely site for an impounding reservoir having been found, the following works are necessary :-

(1) Trial borings over the whole site of the proposed reservoir. These are particularly necessary along the site of the proposed dam as, on the results of them, depend not only the dimensions of the structure, but the material to be selected.

* The Nagasaki reservoir in Japan is bifurcated. So are the proposed reservoirs for Shimonoseki and for Moji. Some time ago the writer, in searching for a probable site for impounding water for a certain town, found three likely sites of nearly equal suitability, in each case at the junction of two streams. 
Great trouble has arisen when it has been found, after work had begun, that the porous soil penetrated at places to a much greater depth than had been supposed.

(2) A number of trial pits, exposing the surface of the supposed impervious bed, so that it may actually be seen and examined.

(3) Levels must be taken along the valley line, from the sea, or from some known datum at least as low as the lowest part of the town to be supplied. The pipe line will very commonly nearly coincide with the valley line.

(4) A survey, giving the limits of the catchment area. It is to be noted that the catchment area is nearly always bounded by the ridge lines of the surrounding hills. It may happen, however, in the case of nearly flat table lands, that the water is (in part at least) drained in a direction opposite to what would be expected, oblique porous strata carrying it in a direction opposite to that of the slope of the nearly flat ground. Such cases very rarely occur, however, and it is common practice to assume that the catchment area is bounded by the ridge lines of the surrounding hills or mountains.

(5) A careful and minute survey of the proposed site of the reservoir must be made, putting in contour lines at intervals of about 2 or 3 feet to a height above the greatest contemplated high-water level of the reservoir.

Of course, if the country has been accurately surveyed before, works nos. 3 and 4 need not be done afresh. The catchment area may be measured, by the planimeter or otherwise, from the maps.

In the case of country that has not been accurately surveyed, contour lines not being given, a good aneroid barometer is of much use; but, to get results even approximately correct, it is necessary that the fluctuation of a barometer at the sea level, if that is near, or at the place to which it is proposed to lead the water, be observed whilst the engineer is making his preliminary survey; otherwise his results are likely to be put entirely out by fluctuation of atmospheric pressure.

Depth of the Reservoir.-It is necessary, at this stage in the proceedings, to decide what depth of reservoir will be necessary.

The mean depth of reservoirs is roughly from somewhat less than one-third of the greatest depth to somewhat less than two- 
thirds. If the sides of the valley slope rapidly and evenly to the stream and the stream itself slopes rapidly, the mean depth will be at the minimum as compared with the greatest depth. If the reservoir consists of a nearly flat bottom bounded by steep sides, the mean depth will be at a maximum as compared with the greatest depth. The two cuts here given (Figs. 15 and 16), show types of the two cases.

A knowledge of the above fact makes it possible, a few
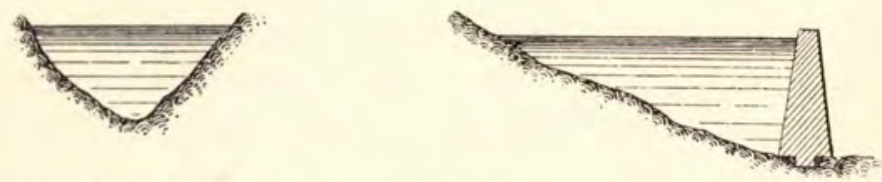

Fig. 15.-I)iagram illustrating mean depth of reservoir with sloping side.
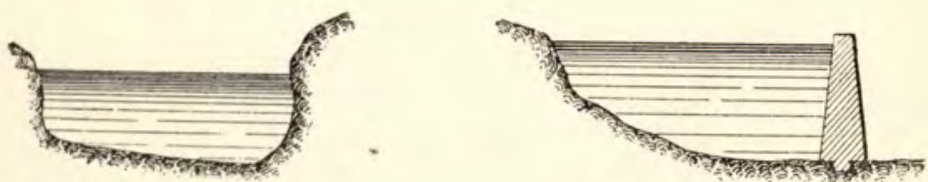

Fig. 16. -Diagram illustrating mean depth of reservoir with steep sides.

contour lines having been run, to decide very roughly what need be the size of the reservoir, and what its greatest depth.

The following very useful and interesting table is taken from "Water Engineering," by Charles Slagg : *

\begin{tabular}{|c|c|c|c|c|c|c|c|}
\hline No. & Ratio. & No. & Ratio. & No. & Ratio. & No. & Ratio. \\
\hline 1 & 612 & 20 & $\cdot 490$ & 39 & $\cdot 452$ & 58 & $\cdot 400$ \\
\hline 2 & 583 & 21 & $\cdot 487$ & 40 & $\cdot 450$ & 59 & $\cdot 400$ \\
\hline 3 & 580 & 22 & $\cdot 485$ & 41 & $\cdot 450$ & 60 & $\cdot 400$ \\
\hline 4 & $\cdot 572$ & 23 & $\cdot 473$ & 42 & $\cdot 447$ & 61 & $\cdot 400$ \\
\hline 5 & $\cdot 560$ & 24 & $\cdot 468$ & 43 & $\cdot 435$ & 62 & $\cdot 400$ \\
\hline 6 & $\cdot 543$ & 25 & $\cdot 468$ & 44 & $\cdot 431$ & 63 & $\cdot 496$ \\
\hline 7 & 537 & 26 & $\cdot 468$ & 45 & $\cdot 427$ & 64 & $\cdot 495$ \\
\hline 8 & 528 & 27 & $\cdot 466$ & 46 & $\cdot 422$ & 65 & $\cdot 494$ \\
\hline 9 & 526 & 28 & $\cdot 466$ & 47 & $\cdot 420$ & 66 & $\cdot 380$ \\
\hline 10 & $\cdot 525$ & 29 & $\cdot 465$ & 48 & $\cdot 420$ & 67 & 376 \\
\hline 11 & 515 & 30 & $\cdot 464$ & 49 & $\cdot 420$ & 68 & $\cdot 350$ \\
\hline 12 & 515 & 31 & $\cdot 463$ & 50 & $\cdot 420$ & 69 & $\cdot 350$ \\
\hline 13 & 514 & 32 & $\cdot 462$ & 51 & $\cdot 420$ & 70 & $\cdot 345$ \\
\hline 14 & $\cdot 510$ & 33 & $\cdot 460$ & 52 & $\cdot 420$ & 71 & $\cdot 340$ \\
\hline 15 & 504 & 34 & $\cdot 460$ & 53 & $\cdot 417$ & 72 & $\cdot 340$ \\
\hline 16 & 500 & 35 & $\cdot 460$ & 54 & $\cdot 407$ & 73 & $\cdot 336$ \\
\hline 17 & 500 & 36 & $\cdot 460$ & 55 & $\cdot 407$ & 74 & $\cdot 320$ \\
\hline 18 & $\cdot 496$ & 37 & $\cdot 458$ & 56 & $\cdot 405$ & 75 & $\cdot 281$ \\
\hline 19 & $\cdot 496$ & 38 & $\cdot 455$ & 57 & $\cdot 400$ & & \\
\hline
\end{tabular}

* London: Crosby Lockwood and Son. 
This table is the result of an examination of the dimensions of 75 reservoirs actually in existence. Here "ratio" is mean depth $\div$ maximum depth. It will be seen that the mean depth of most reservoirs is less than one-half their maximum depth, and that the average mean depth is less than half the maximum mean depth.

To get the depth and size of the reservoir much more exactly, we proceed as follows :-

Let $d=$ the depth of the bottom of the reservoir below the lowest contour line within the reservoir area.

Let $d_{1}=$ the vertical distance between contour lines.

Let $a_{1}, a_{2}, a_{3}, a_{4}, \& c .=$ the area enclosed by the first contour line, the area enclosed by the second contour line, the area

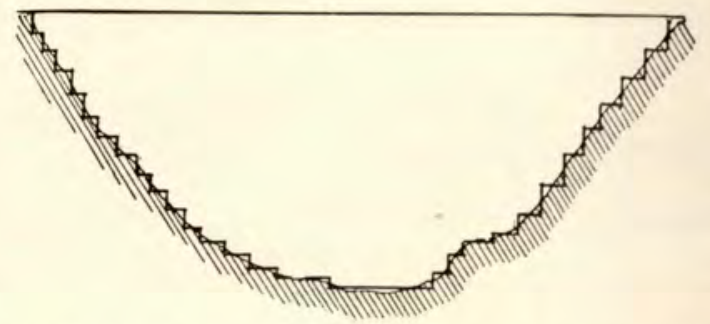

Fig. 17.-Diagram illustrating method for determining necessary depth of reservoir.

enclosed by the third contour line, the area enclosed by the fourth contour line, \&c.

It is assumed that the capacity below the first contour line $=\frac{d}{2} \times a$; that the capacity between the first and second contour lines $=\frac{a_{1}+a_{2}}{2} \times d$; that the capacity between the second and third contour lines $=\frac{a_{2}+a_{3}}{2} \times d$; that the capacity between the third and the fourth contour lines $=\frac{a_{3}+a_{4}}{2} \times d$; and so on.

It will be best to take the depths in feet, and the areas in square feet. The results will then be in cubic feet. The results are added together till the required capacity is reached, when we know the necessary depth of water in the reservoir.

This method gives a slight error on the side of safety-that is to say, the capacity of the reservoir is likely to be a little greater than that estimated in this way.

The only assumption here made is that the space in the accompanying illustration (Fig. 17) enclosed by the straight and the curved lines - the straight line representing the surface of the 
water and the curved line a cross section of the reservoir - is equal to the space enclosed by the same straight line and the stepped lines. If the curve is continuously concave towards the straight line-representing the usual form of the sections of reservoirs the area enclosed by it and the straight line will be somewhat more than that enclosed by the straight line and the stepped lines.

Some engineers go to the trouble of checking the results thus got by taking out the areas of vertical sections, sometimes taking the sections as close as a foot from each other. The writer cannot see the necessity of this-unless it is simply to check the arithmetic-as the results will be scarcely any more exact than by the method described, unless the data are more elaborate, and then the results would be improved by the other method also.

The depth of the water of course decides the height of the dam.

Material of Dam.-At least an approximate knowledge of the necessary height of the dam must be gained before material and form can be finally decided on.

Dams are of two kinds-earthen dams, and masonry or concrete dams.

Earthen dams are far the commonest, and in most cases the cheapest. They have the advantage that they can be founded on any impervious stratum-clay, gravel and clay mixed, \&c. Their disadvantage is that, unless they are very carefully made, water is apt to penetrate them, when the initial aperture will probably be rapidly enlarged by the rush of water, and the dam will be quickly burst; or, if the water overtops the dam during times of flood, it will begin to cut it away, when the rapidly increasing flow of water will lead to the total destruction of the dam. In any one of these cases, the results are likely to be disastrous, the whole volume of an artificial lake being suddenly sent rushing down the valley, sweeping everything before it. It is only necessary to mention the destruction of Johnstown, U.S.A., in 1890, by the bursting of the earthen dam in the valley above it, to enforce these considerations.

Masonry dams. - These are generally admitted to be superior to earthen dams when they can be founded on solid rock, but they are not suitable for soft foundations, however impervious. It is true that it needs quite as much care to make them water-tight as earthen dams, but the result of a leakage in a masonry dam is not so disastrous as in the case of an earthen dam, as the opening made does not tend to rapidly increase itself. Moreover, no harm 
need result if the water overtops the dam. In fact, in the case of the largest reservoir in England, or indeed in Europe, to be mentioned hereafter, the dam acts as its own by-wash, the water simply flowing over the top of it in flood-time.

As might be expected, the question as between earthwork and masonry dams is chiefly one of expense. Where suitable stone can be got in sufficient quantity, a masonry dam need not cost much more than an earthen one, especially if the clay for the puddle of the latter have to be brought from a considerable distance. In this case, if the foundation be suitable, a masonry dam would generally be preferred. 


\section{CHAPTER VIII.}

\section{Earthwork Dams.}

Order of Construction.-In most cases the works relating to the construction of earthen dams may be classified as follows. The order is as nearly as possible that of the actual progress, but in practice circumstances will often occur to alter the order, and with some works progress may be made concurrently :-

(1) The removal of the surface vegetable soil, generally extending to a depth of a foot or two.

(2) The excavation of a puddle trench passing through all pervious strata into the impervious bed below.

(3) The excavation of a trench or tunnel afterwards to be used as a gallery to hold one or more pipes to draw the water from the masonry.

(4) The filling, if the impervious stratum be of rock, of all fissures that there may be in the bottom or sides of the puddle trench with fine rich cement concrete, and the filling up of the trench with puddle in thin layers to the ground level.

(5) The building of the dam by continuing the puddle wall upwards, still in thin layers of puddle, whilst at the same time earth is laid at each side of it to make the body of the dam, this earth being generally laid in thicker layers than those of the puddle wall.

(6) Covering the inner face of the dam with stone pitching.

(7) Covering the outer face, and the top, if the latter is not to be used as a road, with turf.

(8) The construction of arrangements for regulating the flow of water from the reservoir, consisting generally of $(a)$ a watertower or valve tower within the reservoir, or at any rate within the puddle wall; $(b)$ the gallery above mentioned, generally with one or more pipes in it for drawing off the water; and $(c)$ a valve house at the end of this gallery - that is to say, at the outer toe of the dam, for controlling the discharge of the water.

(9) The construction of a by-wash, waste-weir, or overflow, to 
allow of the discharge of surplus water without over-topping the dam.

(10) The construction of works at the head of the reservoir for preventing silting up.

(11) The burning of all vegetable matter on the site of the reservoir before the water is allowed to rise.

Form of Section of Earthwork Dam.-Plate VI. (Fig. 18) shows a section of an earthwork dam reduced to the simplest form possible.

There is no question of the stability of an earthen dam as a whole - that is to say, of its resisting an overturning moment by its weight, the slope of the inner face being of necessity such that the vertical thrust of the water is much greater than the horizontal. The slopes are determined by the angle of repose of the material of which the dam is made, a considerable allowance being made for the sake of safety. The slope on the inner side is made less than that on the outer or lower side because, on the inner side, the earth becomes saturated with water, and the angle of repose is reduced in spite of the stone pitching. Even supposing the inner slope of an earthen dam to become so saturated with water, that the whole hydrostatic pressure due to the head of the water may be considered as acting directly on the inner face of the puddle wall, there need be no question of the stability if the outer slope of the dam be in accordance with English practice.

The proportions given here may be said to be English standard proportions. Dams are often made slighter than is shown in the plate, particularly in America, but it does not seem advisable to resort to a lighter section, although it must be admitted that, in the case of most failures of dams it does not seem as if the failure would have been permanently averted had greater thickness or smaller slope been adopted, unless certain other mistakes had also been corrected. In England, the slopes are often made even slighter than those shown on Plate VI.

Thickness of the Puddle Wall.--The puddle wall is shown with a thickness of eight feet at the top. There is no means of theoretically investigating the thickness of a puddle wall, and the only course is to depend on judgment and the results of past practice. Dams have been constructed with puddle walls thinner at the top than this, but the practice is not to be recommended. They have been made with walls much thicker too, but it is not 

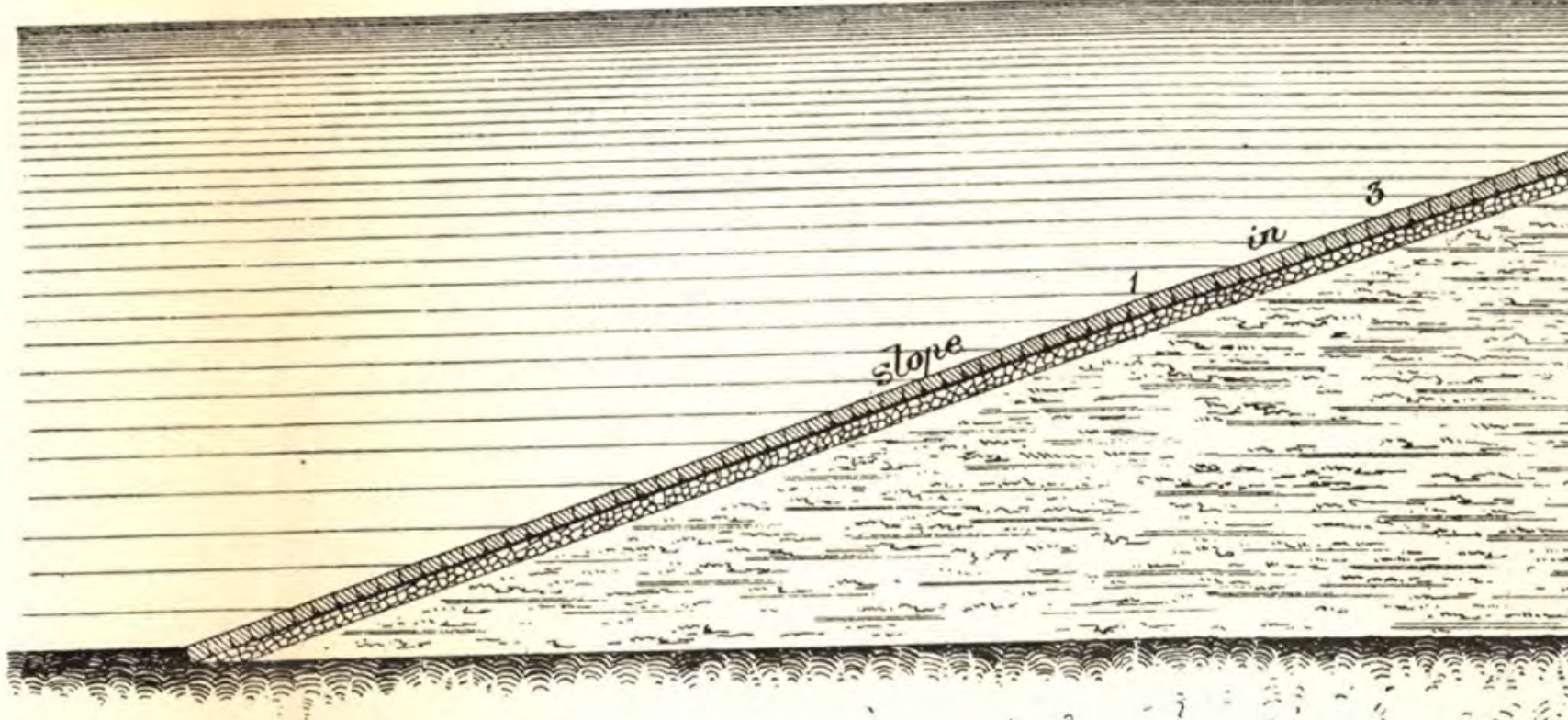

-
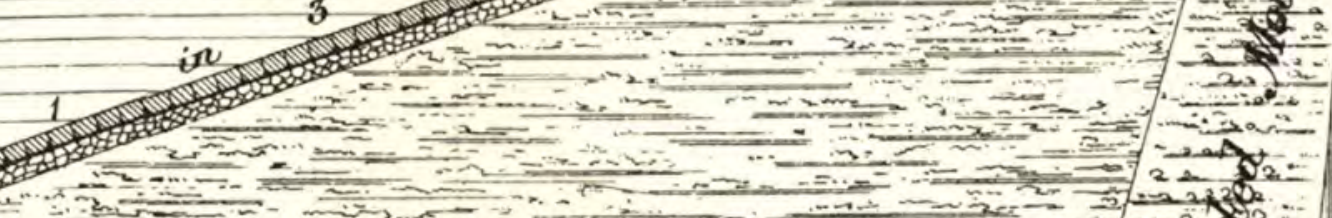

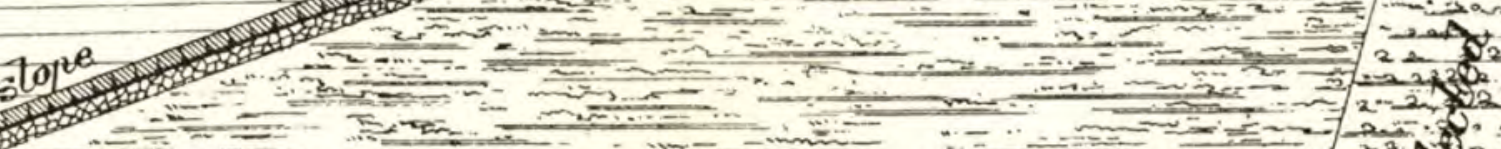

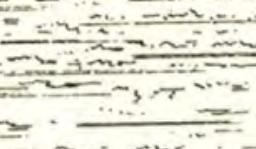

$x-3=-1$

(..,

(1).

$P_{0}^{2}=0, \quad Q=U$

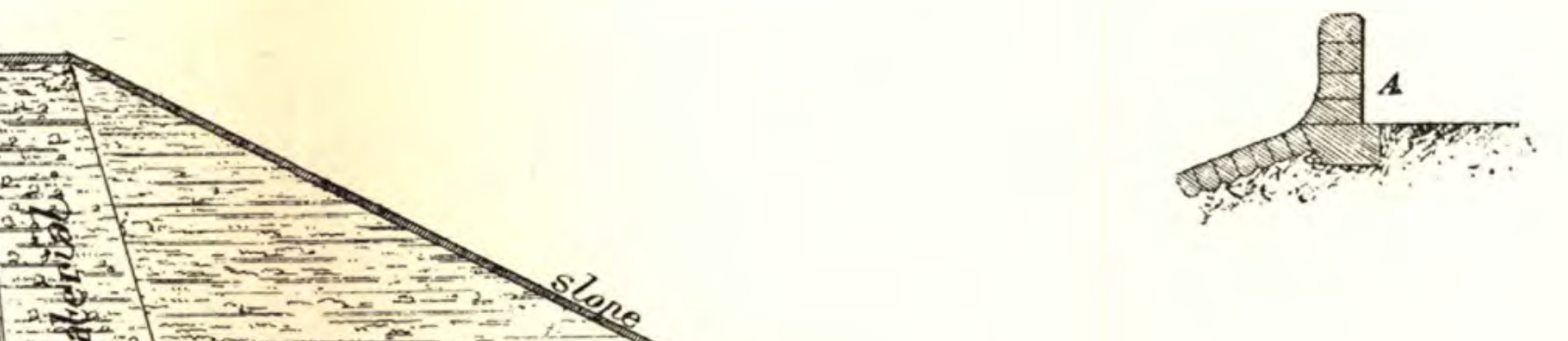

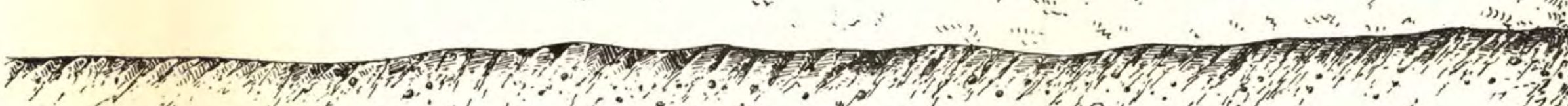

I $M$ P E R $R$

o.u's

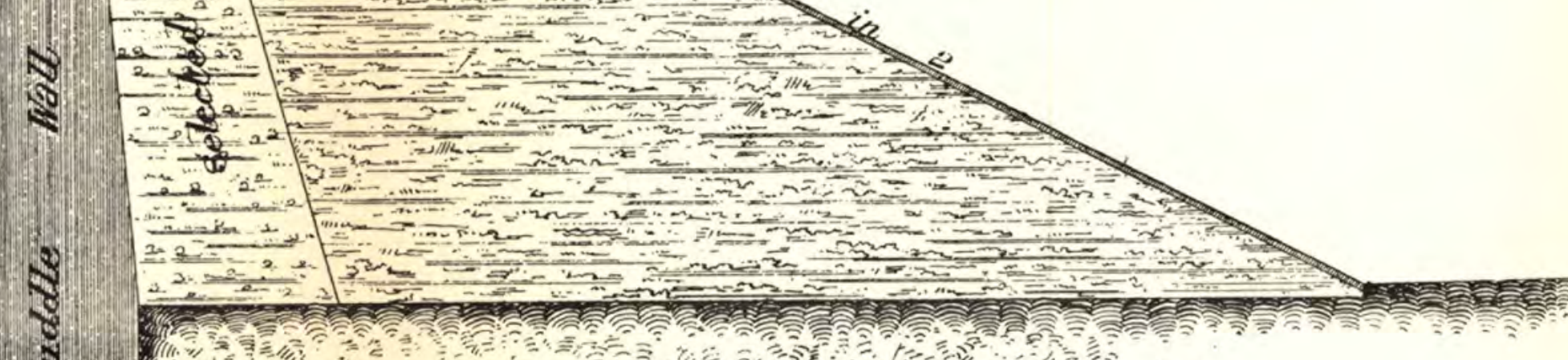

W.

$\because S “$ T R A A T U M

W

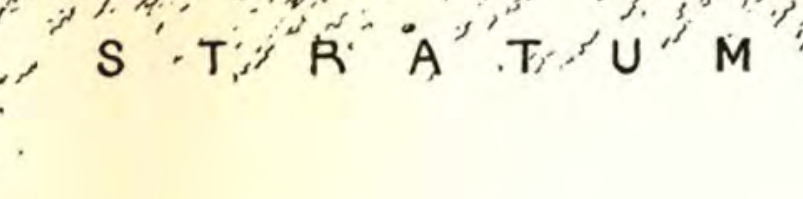

Fig, 18-Section of Earthwork DaM.

[To face page 54. 
evident that any benefit has resulted from the additional thickness.

Puddle walls may have any batten from one to two inches to the foot above the trench, but should nowhere be less in thickness than one-third the depth of water above them at flood time.

Through the pervious strata the puddle wall may have parallel vertical sides. The depth of the puddle trench in the impervious bed may equal the breadth of the bottom of the puddle wall.

Thickness of Selected Material.-It is common to sort the material that the body of the dam is to be made of, and to build up

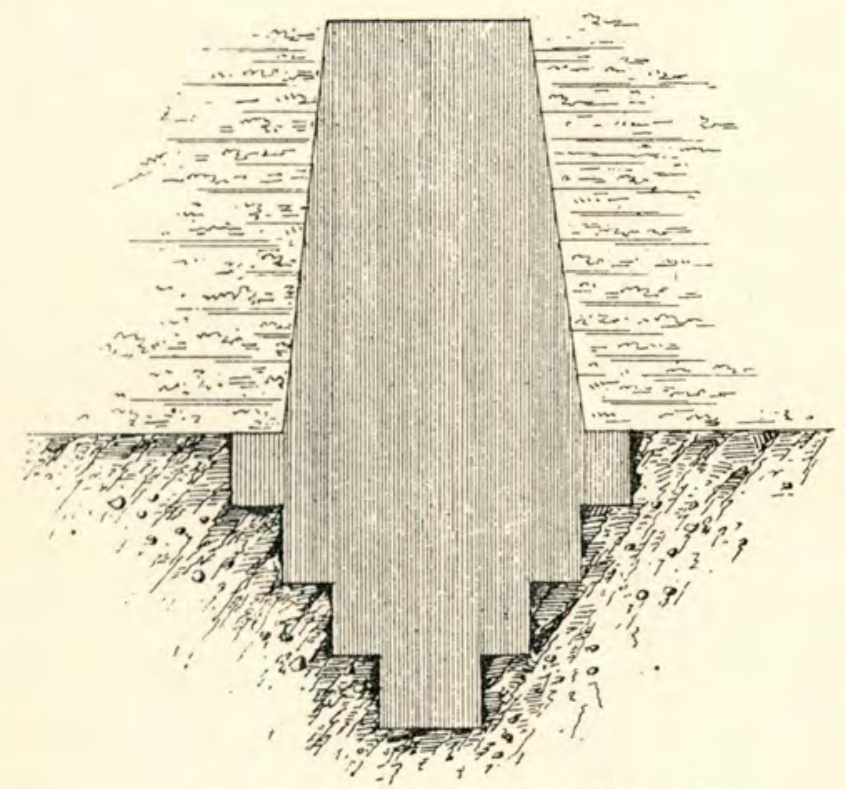

Fig. 19.--Cross-section of puddle trench.

the less pervious next the puddle wall, placing the heaviest material next the outer or lower slope. The thickness of the selected material may be the same horizontally as that of the puddle wall at all heights, or the thickness at the top may be made (say) four feet, and slopes of one vertical to one horizontal may be given.

The Removal of Surface Vegetable Soil.-This must include removal of tree roots and the like, even if they go deeper than the foot or two mentioned above. There is no object in leaving the ground very smooth. In fact, probably it is better to 
leave it rough. The whole idea of an earthwork dam is that it should be in perfect unity with the ground it is founded on.

The Puddle Trench.-The breadth and depth of the puddle trench have been given above. The shape of cross-sections varies considerably in the designs of different engineers. In the hands of some it is made a square; in the hands of others it has the form shown in Fig. 19; in others, that shown in Fig. 20.

The idea in adopting the former of these two sections is that there is less likelihood of water leaking under the puddle if it has

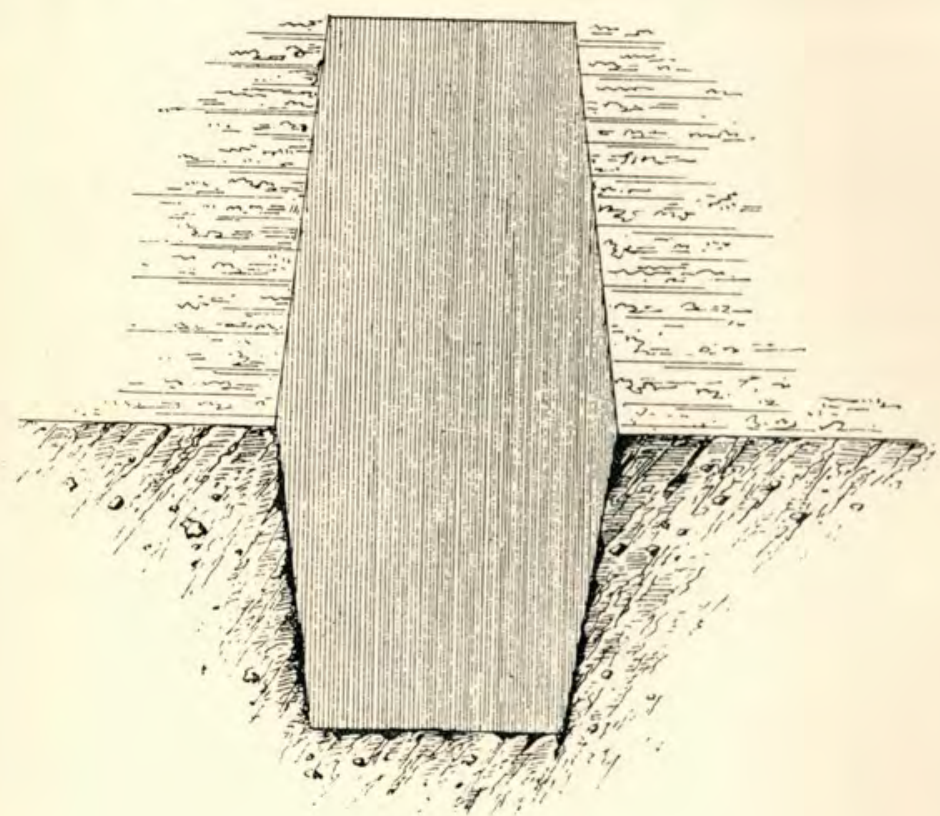

Fig. 20.-Cross-section of puddle trench (another form).

to pass a number of right angles than if it has to pass two only. This idea is probably more fanciful than anything else. The second section saves both puddle and excavation, and there appears to be no objection to it.

If springs be met with in excavating the puddle trench, pipes must be laid to carry the water to discharge at the toe of the outer slope of the dam.

The tunnel or trench that is afterwards to hold the culvert for the discharge pipes from the valve tower is a part of the work that needs considerable attention. At one time it was the custom to draw off water by cast-iron pipes sometimes laid in the dam, the discharge of the water being entirely regulated at the outer end of 
the pipe. This arrangement was faulty as, in case of any leakage from a pipe always of necessity under pressure, the water was liable to pass through the dam, weakening it till it ultimately failed ; or, if the pipes went through the made part of the dam water was liable to creep along their sides with the like disastrous results.

It was for this reason that water or valve towers were first designed, and that it was made a rule that the culverts from them should be founded on the solid ground. The water was admitted to the culvert by valves placed at different heights on the tower, connected with apertures penetrating its sides. Thus the water was under no hydrostatic pressure in the culvert which was always in compression.

It is now generally considered advisable to allow the culvert to act merely as a gallery in which are one or more cast-iron pipes, which are thus open to inspection and repairs. These pipes may be under pressure or not, according as it is considered advisable to regulate the discharge of water at a valve house at the toe of the dam, leaving a valve of the tower full open, or to regulate the flow at the tower by partly opening a valve, the water being allowed to escape freely at the toe of the outer slope of the dam, for immediate filtration or for delivery as compensation water.

Whether the culvert will be built in a trench passing under the dam, or shall form a tunnel passing the dam at one end, will depend on circumstances. If the valve tower is to be founded in the deepest part of the reservoir, as is common in the case of small reservoirs, the culvert will generally be built in a trench. There is the advantage that, the culvert being made large enough to carry off flood water, it may serve to carry the stream during the construction of the dam.

Where the culvert crosses the puddle trench, this latter should be filled in with cement concrete from the bottom to the culvert.

In the case of very deep reservoirs it is generally an object to keep the foundation of the valve tower at some height above the very lowest part of the reservoir. This may be done, without making it impossible to draw the reservoir to the bottom, should that ever become necessary, as the water may be syphoned from the deepest part of the reservoir. The utmost limit to which water can be syphoned is within thirty-four feet. In practice it is very troublesome to syphon it for more than twenty-eight feet, and it is inadvisable to fix syphons intended to draw more than twenty-five feet; but the base of the water tower may bo placed at such a height towards one side of the deepest part of the 
reservoir, that a syphon passing through it to the culvert will be anything up to twenty-eight feet above the bottom of the deepest part of the reservoir. Figs. 21 and 22 show the two positions of valve tower described.

With the tower in the position shown in Fig. 22, it may be con-

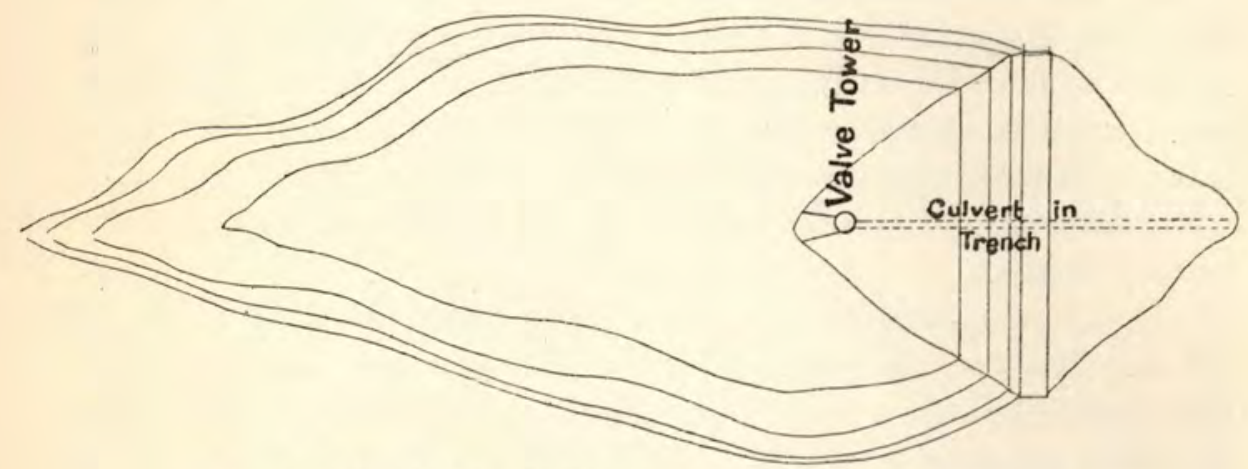

Fig. 21.-Position of valve tower with culvert in trench.

venient, especially if the valley be greatly contracted at the site of the dam, to make a tunnel, which may be short and often straight, through the solid ground, passing under the dam where the latter

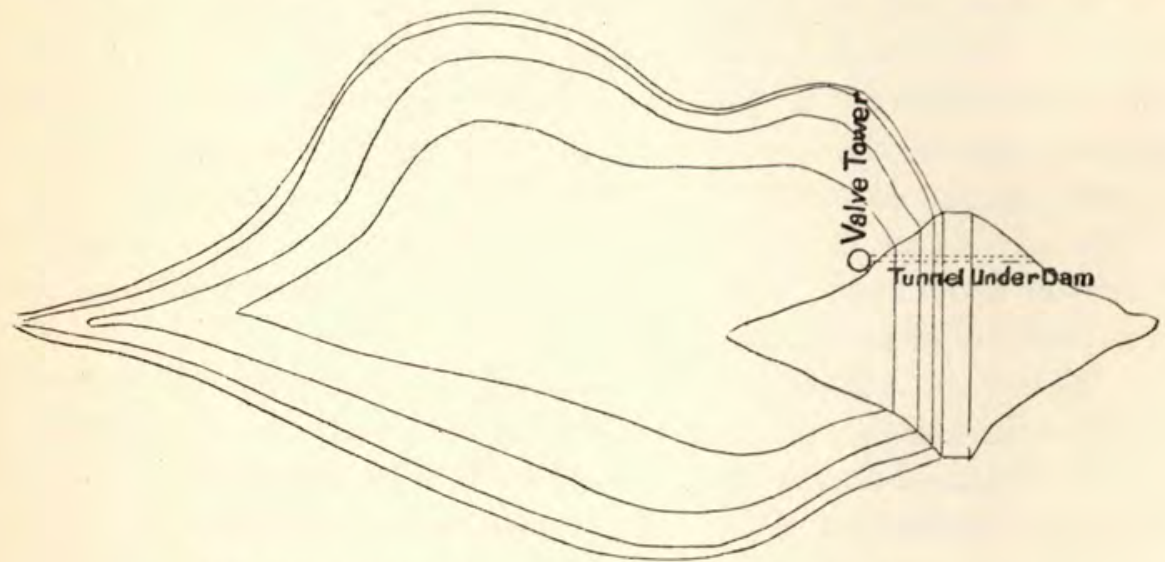

Fig. 22.-Position of valve tower with tunnel under dam.

is comparatively low. Sometimes the tunnel may, with advantage, be driven to a parallel valley through the intervening hill.

Various sections of culverts and tunnels are given on Plate VII. (Figs. 23 to 28).

The Puddle Wall.--It is customary to make the bottom of the puddle trench in the form of a series of steps, in longitudinal 


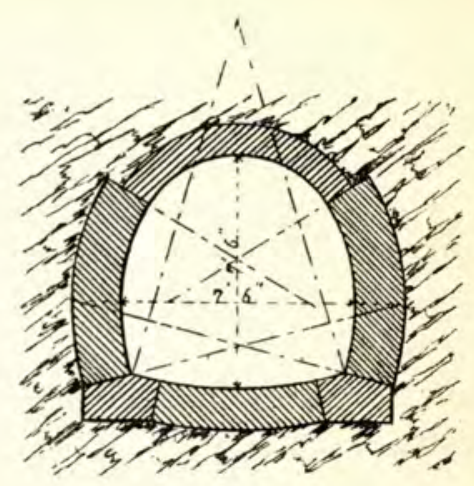

Fig. 23.

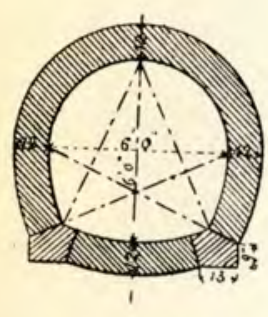

Fig. 24.

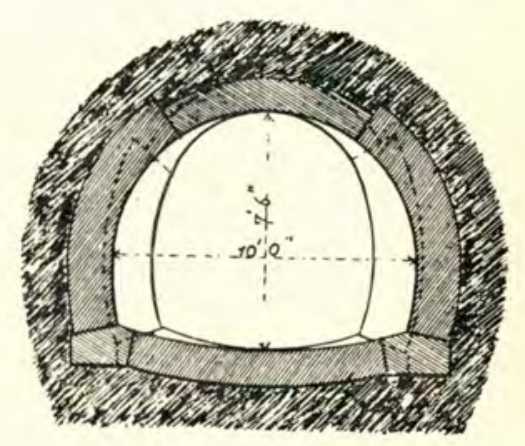

Fig. 25.

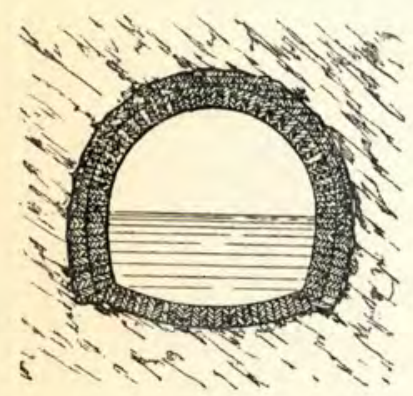

Fig. 26.

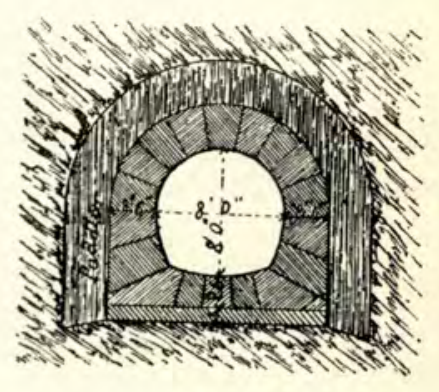

Fig. 27.

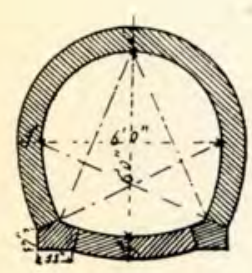

Fig. 28.

Sections of Culverts and Tunneis.

[To face page 58. 
section, rather than to make it parallel with the surface of the land. This will be seen on Plate VIII.

The puddle may be all clay, or gravel (well screened) may be added in any proportion up to one part of gravel to one of clay. Whatever proportion be adopted, the whole must be thoroughly mixed and worked up with just enough water to make a dense doughy mass. The puddle is laid in thin layers, as already indicated. It is common to specify that these be not more than six inches thick. Each layer must be thoroughly punned, and it should not be allowed to get dry on the surface before the next one is laid on it. The surface should not be made smooth, but should be left rough, so that the next layer will bond in with it.

It should be borne in mind that, although the wall is constructed in layers, the object is to make it into one solid mass.

Selected Material.-This may be laid in somewhat thicker layers than the puddle, but the layers should never exceed two feet in thickness, and it is not uncommon to specify that this material also be laid in layers of only six inches. The layers are better not laid level, but sloping towards the puddle wall. Nearly as much care should be taken in laying the selected material as in making the puddle wall, and it should all be thoroughly incorporated by punning.

The Body of the Dam.-Less care is generally devoted to the rest of the earthwork; but it should always be borne in mind, in connection with the dams of impounding reservoirs, that too much care can nowhere be taken, and this especially in the case of the puddle wall and all that lies between it and the impounded water. The heaviest material should be placed towards the lower slope.

The stone pitching may, with advantage, be about eighteen inches thick, and may lie on the like thickness of broken stones.

The Valve Tower.-The object of the valve tower is to allow water to be drawn from any one of a number of different levels, the reason being that water in an impounding reservoir is at its best a few feet below the surface. At its lower depths it may contain much suspended matter. At the surface it contains floating matter, and is liable to be warmed by the sun's rays.

A valve tower ought also to permit of examination of all the 
valves at any time, and of repairs to them if necessary, without stopping the flow of the water even for the shortest time. It may not be possible absolutely to secure this state of affairs for all conditions of the reservoir, but it will presently be seen that it is possible to secure them for nearly all.

The valve tower may be situated entirely within the reservoir, founded on its bottom, or it may pass through the inner slope of the reservoir anywhere within the puddle wall. In the latter case the pipes leading from the reservoir to the tower have to pass for a greater or less length through the material of the dam, according to their height from the bottom, and according to the distance of the tower from the puddle wall. This makes it comparatively troublesome to gain access to the ends of these pipes in case they have to be closed for the repair of the corresponding sluice valves within. For this reason it is generally advisable to construct the valve tower at the toe of the inner slope, a light foot-bridge connecting its top with that of the dam.

There are various descriptions of valve towers. Thus in some the water stands, within the tower, at the level of that in the reservoir, and the discharge of the water is controlled by a valve at the foot of the tower communicating with the culvert. With this arrangement it is possible to get at the valves below the level of the water, only by closing all openings between the reservoir and the inside of the tower and by letting off the water, the supply being, for the time, stopped. In other cases the water is allowed to flow into the valve tower by any of the valves, but is allowed to escape freely at the bottom by the culvert, thus not standing at the level of the reservoir water. This is some improvement, but still does not give free access to any valve at all times.

In yet another arrangement the tower is divided by a vertical partition into a "wet well " and a "dry well." In the former the water stands at the level of the reservoir. Through the partition there pass pipes at different heights, and opposite each is an opening from the wet well to the reservoir. From each opening through the partition a pipe, provided with a third valve, is carried to the culvert. There is provision for closing the openings in the partition from the wet well side. It is thus possible to get at any valve at all times for inspection or repair ; but this arrangement is a very expensive one. In the event of the lowest valve needing repair whilst the water lies low, the discharge would have to be stopped for a little time. 
Plate VIII.

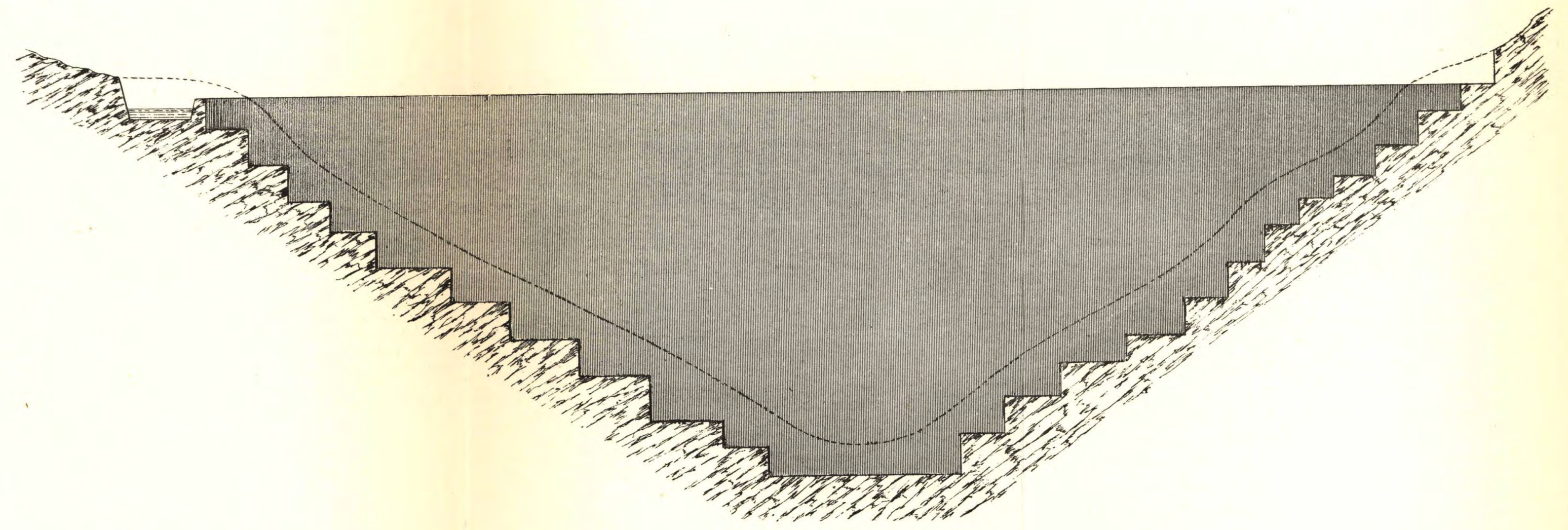

Fig. 29.-Section of Puddle Trench.

[To face page 60. 
There is one form of valve tower that has so much the advantage over others-in allowing perfect freedom of inspection at all times, in permitting of the repair of any valve under nearly all circumstances, and in simplicity of construction - that in the writer's opinion it is to be preferred to all others.

In a valve tower so constructed the water is drawn through the tower at different heights by pipes connected directly with a stand pipe, there being a sluice valve on each such pipe carrying water from the reservoir to the stand pipe, and also a means of closing the opening from outside the tower, the stand pipe being continued directly along the floor of the culvert or tunnel, which then becomes an inspection and repairing gallery merely. In fact, it is possible to enter this gallery at the toe of the outer slope of the dam, and to emerge at the top of the valve tower. The pressure due to the full head of the reservoir may be made use of, if it is considered necessary, by entirely opening a valve, or the discharge can be controlled at the tower by partly opening a valve. By the former arrangement gravitation works sometimes become possible that would not otherwise be so.

Valve towers, if high, are commonly made of ashlar masonry, or if only of moderate height, of cast iron. There should be openings to the reservoir water at intervals not greater than about ten feet in height.

Plate IX. (Figs. 30 to 34), drawn by Mr. K. Sakuma from hand sketches by the writer, shows a tower of the kind described made in masonry. An arrangement of flap valves, actuated by chains whereby it is possible to close any opening from without, is shown. By making these flaps of bronze it is extremely improbable that they should get out of order. In the improbable case of a flap below water level needing repairs, it would be necessary to send down a diver to repair it. The reason of the considerable leverage given to open the flaps is that, after they are once closed, a very considerable pressure on the back has to be overcome before they can be opened.

In the case of very large valves it would be advisable, in addition to this, to carry a filling pipe from the space between the valve and the sluice, so that, this space being filled, and a head of water being created in the filling pipe, there might be a pressure tending to open the flap.

Leaving the syphon out of the question for the meantime, it will be seen that any valve with the exception of the lowest could be removed without stopping the discharge for a moment. The 
lowest could be removed by allowing the discharge to take place by the syphon.

A syphon is not an essential part of a water tower. Indeed it ought to be the exception rather than otherwise, as there is always some trouble and uncertainty in its action. The trouble arises from the collection of air in the highest part. Unless means are taken to get rid of this air, the action is liable to stop altogether, especially when the water is lowest in the reservoir, and when, therefore, not only is there the greatest vacuum in the syphon, and hence the greatest tendency for air to be given off, but when there is a less vigorous action tending to carry the air down the long limb of the syphon. As long as the velocity is great, the water will carry the air with it, and discharge it in the syphon well.

Any leakage in the syphon above the level of the reservoir water is sure to cause stoppage by the drawing of air.

The syphon, in this case, is put into action in the following way. Whilst water is still flowing into the stand pipe by $\mathrm{A}$, but it is anticipated that the water in the reservoir will soon be below the level of $\mathrm{A}$, the sluice valve $\mathrm{B}$ is opened. The sluice valve $\mathrm{C}$ is then closed, when water will be drawn through the syphon without starting it by an air-pump, and with the arrangement shown at $\mathrm{D}$ for collecting the air, the syphon should work without stopping, till the water in the reservoir is drawn very nearly to the level of that in the syphon well.

The air-collecting vessel shown in Plate X. (Figs. 35 to 38) is very simple in action. It consists merely of a cylindrical vessel with a valve at the bottom communicating with the highest part of the syphon, one at the top, communicating with a filling cup, an emptying valve, and a glass gauge to show the height of the water in the vessel. The action is as follows: Before the syphon is brought into use the vessel is filled with water by the filling cup. If this be not done the air in the vessel will suddenly expand on opening communication between it and the syphon, and will partly fill the latter with air.

Whenever the syphon has been started, the communication between it and the air vessel (which communication must be of a fair diameter) is opened. All air will now rise into the air vessel, the height of the water in which will be indicated by the gauge glass. When the attendant finds that the vessel is nearly empty of water, he turns off communication between it and the syphon, opens the top valve, and fills the vessel again, when the 

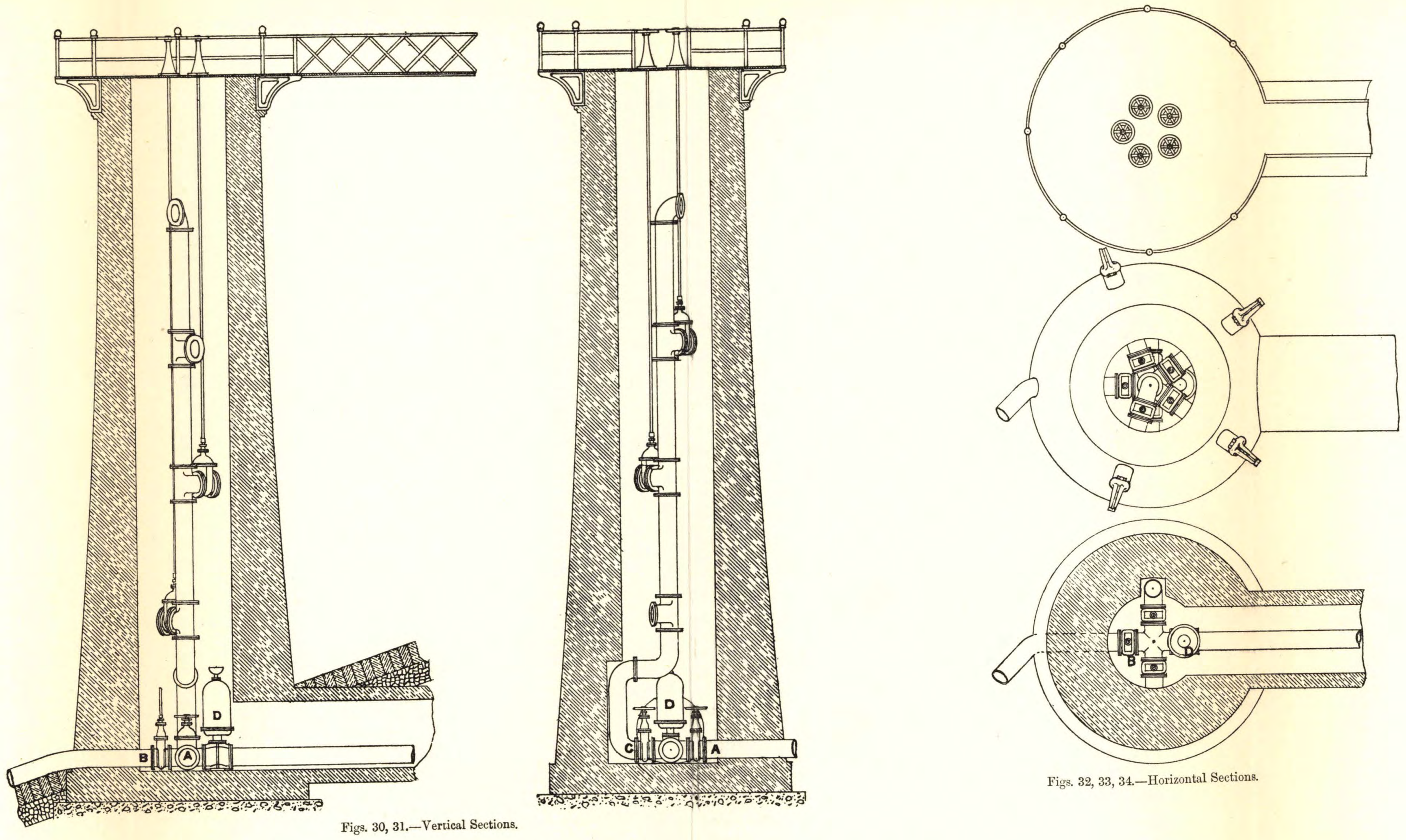

L 


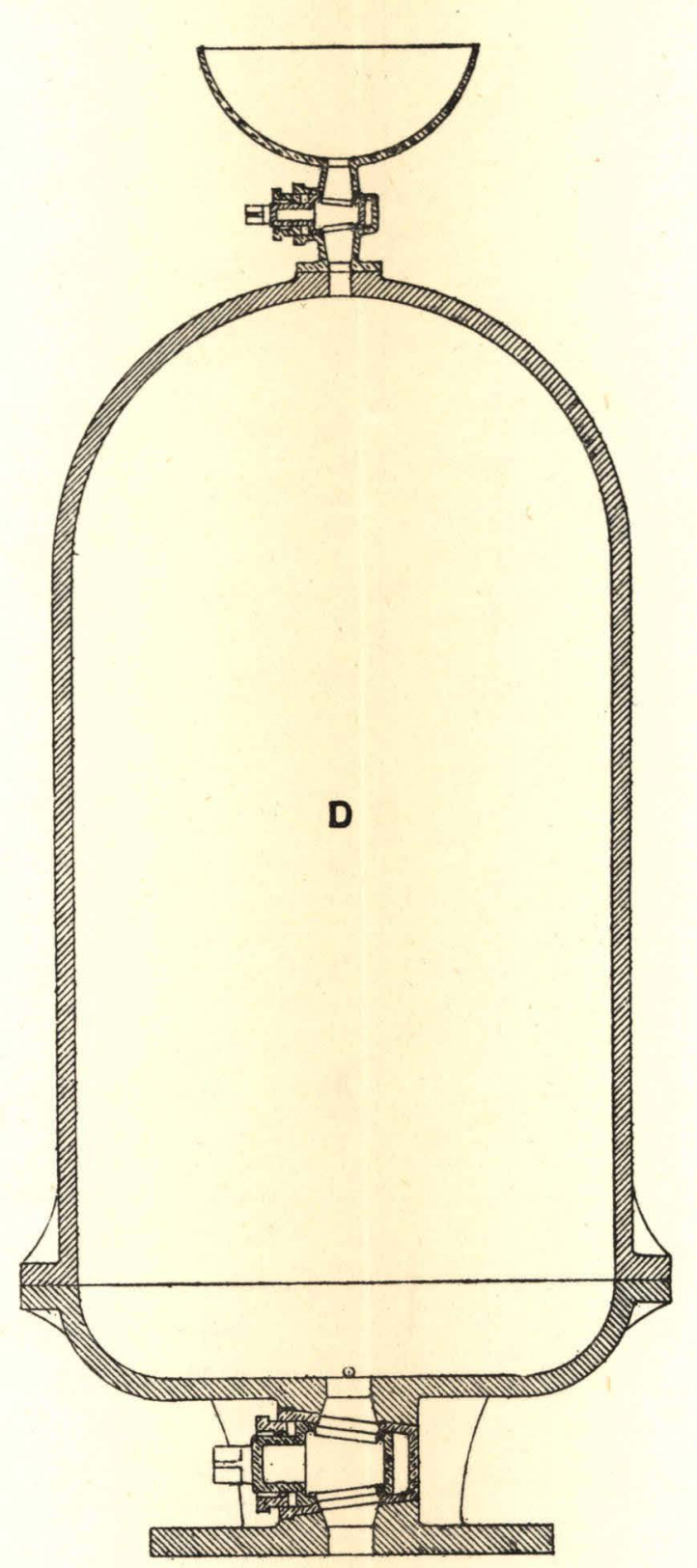

Figs. 35, 36.-Vertical Sections.

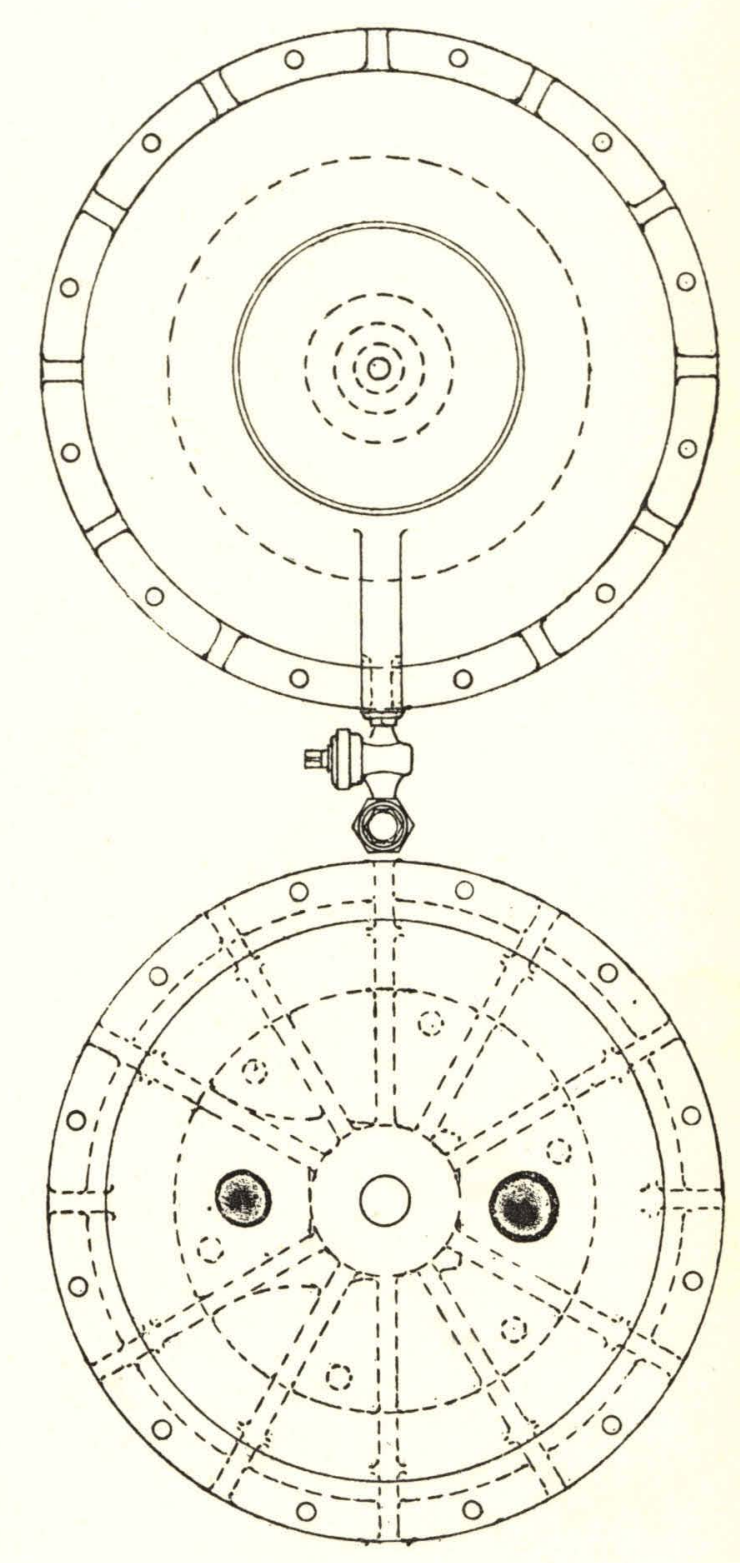

Figs. 37, 38.-Horizontal Sections.

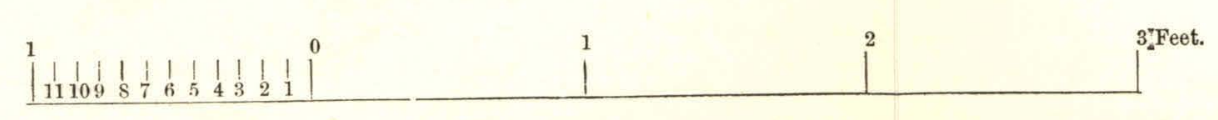


cycle of operations begins once more. When the syphon is not in use the vessel is emptied by the drain valve. It would be quite possible to make this apparatus automatic, but it would probably not be of advantage to do so. As has been said, the syphon ought not to cease to act if due care be taken in watching the air vessel, but an air-pump must, nevertheless, be provided, lest by any accident the syphon cease to act.

A "syphon well" has been mentioned more than once. This is a shallow well, with an overflow at a level of at least a foot or two below the lowest level to which it is intended to draw water from the reservoir by the syphon. The lower end of the long limb of the syphon dips into this well.

Plate XI. (Figs. 39 to 43 ) shows a smaller sized tower of castiron. No syphon is shown in this case.

Very often no particular provision is made for closing the

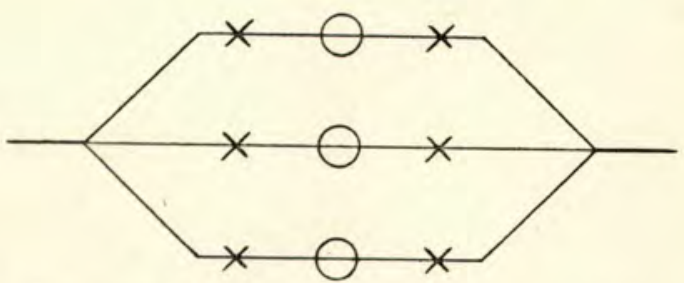

Fig. 44.-Diagram of main pipe divided for meters and sluice valves.

outer faces of the openings of valve towers other than so forming them that a diver can descend and close them with a temporary wooden partition. In the case of necessity, to close the lower end of the syphon shown in Plate IX. some such course would have to be pursued.

A Valve House or Meter House is sometimes constructed at the toe of the outer slope of the dam. It is particularly needed if, as is often the case, some of the water has to be deflected for compensation purposes. In this case it will generally be found convenient to have two pipes in the gallery, one for tower supply, the other for compensation water, the latter drawing water from the bottom of the reservoir and having a sluice valve both where it passes the valve tower and the valve house.

Sometimes the water is measured by meters in the valve house. In this case the main pipe is preferably divided into three branches with a meter and two sluice valves on each as 
shown diagrammatically in Fig. 44, where the meter is shown as $\mathbf{O}$, and the sluice valves as $\mathbf{X}$. Any two of the meters must be capable of measuring all the water, so that one may be removed for repairs or verification.

The By-wash, Waste Weir, or Overflow of a reservoir is of the greatest importance in all cases, but particularly in the case of a reservoir with an earthwork dam, as on its sufficiency depends entirely the safety of the dam, which is all but certain to burst if the overflow is too small and allows the water to overtop the dam.

The natural tendency, in designing a waste weir without much consideration, would be to make the waste water pass over a depression in the dam, and down a channel constructed on the

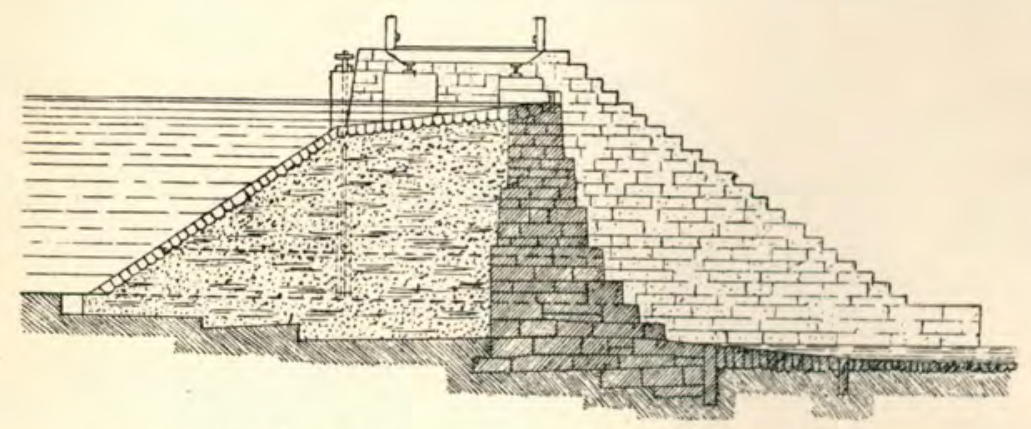

Fig. 45.-Waste weir for water passing over dam (Fanning).

down-stream slope, protecting the course of the flow of water with masonry; and, as a matter of fact, overflow weirs have, at times, to be constructed in this way. It is considered preferable, however, to carry the weir round the end of the dam in the solid ground, or to carry two weirs round the two ends of the dam rather than to have the best possible design of waste weir over the dam. The construction of a masonry weir over an earthwork dam spoils the whole homogeneity of the structure.

Fig. 45 (taken from Fanning) shows a form of waste weir that may be adopted when the waste water must pass over the dam. In this case there is no puddle wall, the whole dam being constructed of impervious material, as mentioned at the end of this chapter.

Plate VIII. (p. 60), which gives the longitudinal section of an earthwork dam, shows the by-wash or waste weir in transverse 

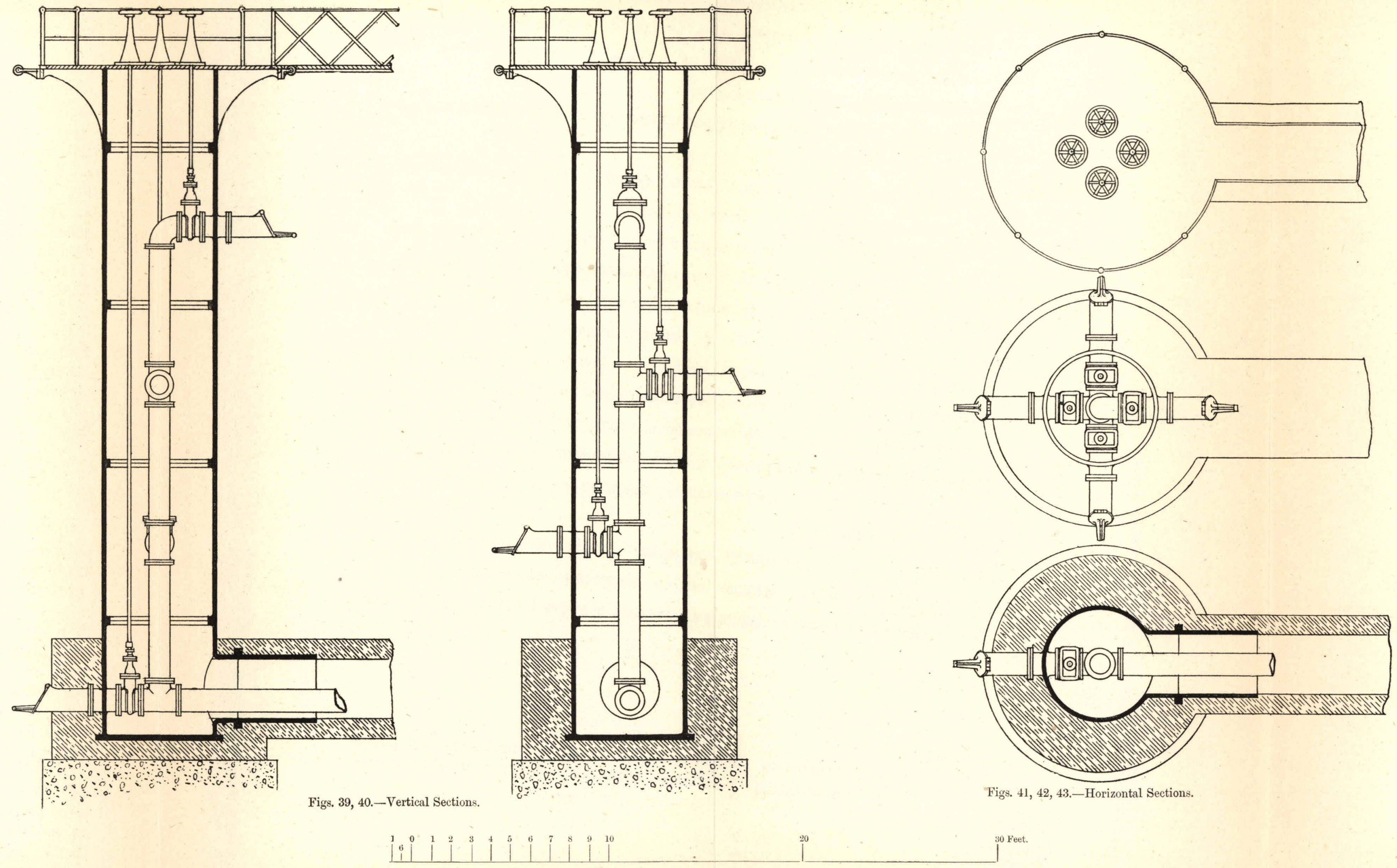
section; and Plate XII. shows a waste weir passing round the end of a reservoir dam, in plan.

It is objectionable to keep the sill of a waste weir low, because the result is to reduce the effective storage capacity of the reservoir, this capacity reckoning up to the level of the sill of the waste weir only. It is therefore necessary to get discharge capacity by considerable length of weir, and this especially as it is necessary to make a certain allowance for possible waves. That is to say, if it is decided that a certain length of weir will discharge the maximum storm water with a certain depth of water, the sill of the weir must not be made only this depth below the top of the dam, but this depth + the height of the highest wave that is likely to beat against the dam. This height is commonly taken as a minimum of 3 feet. This is for very small reservoirs ; for larger ones a greater allowance has to be made.

The maximum height of a wave is a function of the "fetch" of the reservoir - that is to say, of the longest straight line that can be measured from any part of the dam to any part of the shore of the reservoir, when the latter is fill and overflowing. Stevenson's formula for wave height is commonly used in this connection. It is as follows :-

Where

$$
\mathrm{H}=1 \cdot 5 \sqrt{\mathrm{D}}+(2 \cdot 5-\sqrt[4]{ } \overline{\mathrm{D}})
$$

$\mathrm{H}=$ the height of a wave in feet.
$\mathrm{D}=$ the fetch in miles.

The meaning of this really is that the allowance for waves in impounding reservoirs which an engineer is likely to have to do with, will vary from the minimum of 3 feet, established by practice, to a maximum of from 5 to 6 feet.

The height here given is the vertical height of a wave if it meets no resistance. A wave meeting a gentle slope will, however, as a rule, roll up it to a height considerably greater than its own height. For this reason it is desirable to continue the stone pitching 2,3 or 4 feet up in the form of a dwarf wall, as shown at A, Plate VI. This wall is not to be relied on to actually resist water pressure, but only to break waves that would otherwise roll over the top of the pitching.

If it were necessary to design waste weirs to carry the quantity of water that may fall over the whole catchment area for a few minutes at a time, they would have to be enormous in size-in fact they would generally be impracticably large. It is, 
however, the case, that the maximum flow of a stream never reaches this limit; and further, that the possible volume of water between the level of the sill of the weir and the highest level to which it is intended the water should ever be allowed to rise acts as an accumulator, so that it is not necessary to allow for an overflow equivalent to the maximum over the whole catchment area. The difficulty is how much to allow for. An old established English custom was to allow 3 feet length of weir for every 100 acres of catchment area, the depth of water over the sill of the weir being taken as from 2 to 3 feet. There is the great objection to this practice, that it takes no account of the fact that the maximum discharge of a stream is less, relative to the mean discharge, the greater the catchment area. The following table of length of weir and of depth of water over the weir-based on one by Fanning - will be found to be on the safe side for countries not liable to tropical rain storms.* The lengths and depths of water for intermediate areas may be taken as proportionate :-

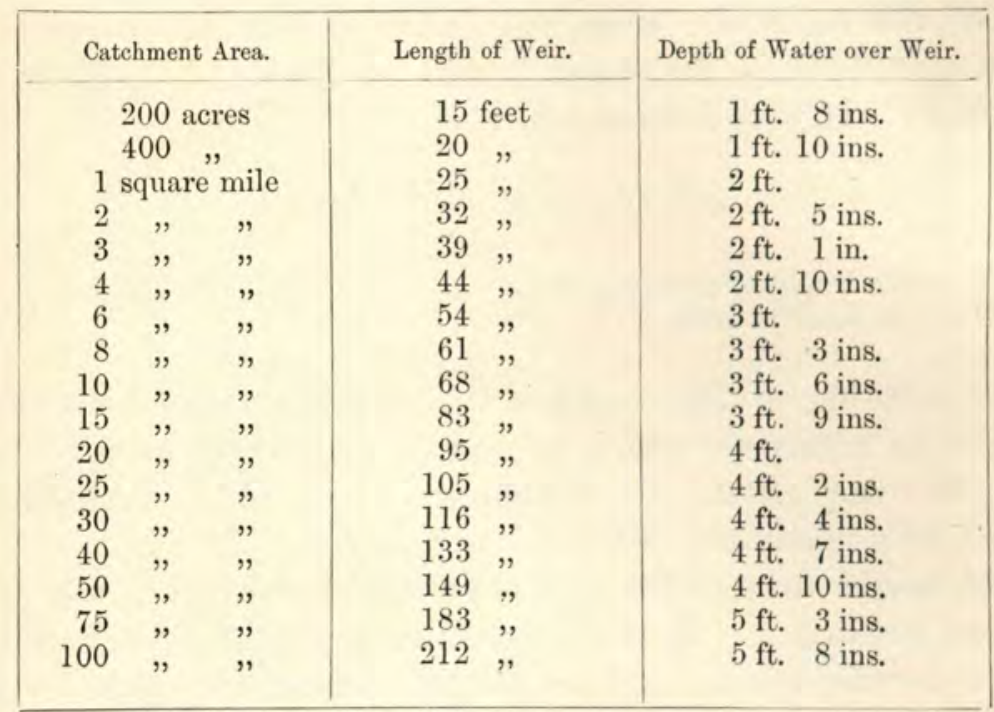

With the proportions given in Plate VI., every foot additional in height of dam gives an additional width of 5 feet to the base. It is, therefore, felt that it is a pity the capacity between the level of the sill of the weir and of the limit to which it is safe the water should rise is, with an ordinary weir, practically waste capacity. To overcome this waste to a certain extent-that is to

* In Japan it is advisable to allow double the length of weir, or at least for double the discharge of water that the weirs here mentioned will carry. 
Plate XII.

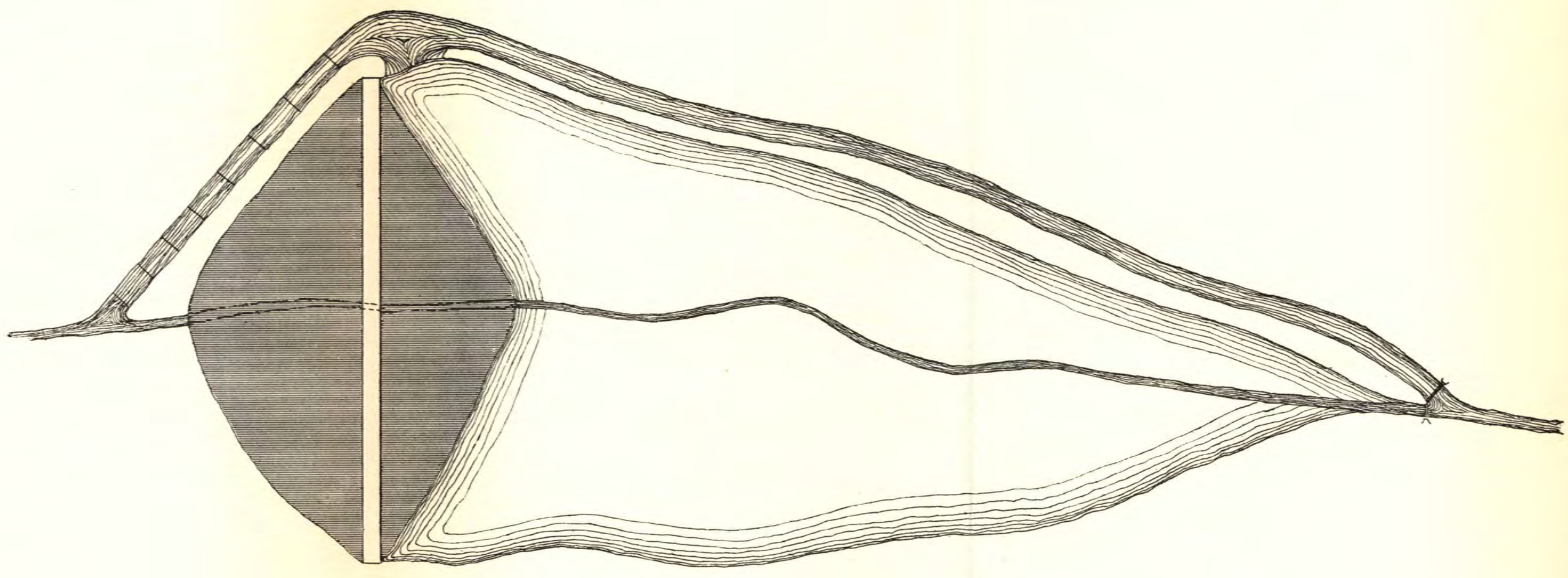

Fig. 46.-Impounding Reservoir, in Plan, with Waste Weir and Flood Channel.

[To face page 66. 
say, to so construct the waste weir that water may rise to the safe limit before overflow begins, no overflow at all taking place if it rises to any height short of this-and yet to secure safety, has been the object of various schemes.

The simplest, and perhaps the best, is to build a miniature dam of earth and sods on the weir, up to the level of the safe limit. If the safe limit is not reached this prevents waste of water. If the safe limit is reached, the miniature dam is overtopped and is washed away.*

This plan is successful so long as waves do not beat on the miniature dam. Should waves overtop it, it will certainly go in a short time. Waves can be provided against by constructing a screen opposite the weir, but there is always danger, if this be done, that the discharge of the weir will be diminished, especially if the stream brings down much floating matter at flood times.

In the case of short weirs, it can be arranged that a baulk of timber lies on the weir so as to be fairly water-tight at bottom and ends, and so that one end will give way on the striking of a bolt, the other end being held by a chain.

Works at the Head of the Reservoir.-The water of all natural streams contains some suspended matter that tends to settle, and this especially during the time of floods. It thus happens that all impounding reservoirs show some tendency to silt up. It is the case, however, that vastly the greater quantity of the silt is carried down at flood time. It is, therefore, distinctly

* Whilst writing of impounding reservoirs, the writer would like to say a word or two on a subject of much importance in Japan and other earthquake countriesnamely, the possible effect of an earthquake on a reservoir with an earthwork dam.

On the occasion of the great earthquake of 1891, in Japan, a strong partition wall of the service reservoir of the Yokohama waterworks, some 200 miles distant from the origin of the disturbance, was overturned by the lashing backwards and forwards of the water, although the reservoir was not otherwise damaged. Even the water in a small rectangular reservoir of the waterworks of the Imperial University of Japan (size $82 \times 25$ feet $\times 20$ feet deep) was thrown into waves about three feet high, and these effects were at places where the earthquake was but slightly felt. What would have been the fate of a large impounding reservoir had there been one in the part of the country most disturbed, it is impossible to say. Only two observations are to be made. The writer has not heard of the bursting, at the time of earthquakes, of any of the small reservoirs with earthwork dams, made by farmers to store water for irrigation. And further, if every engineering structure had to be made so that it would stand such shaking as that at the worst of the great earthquake of 1891 , no engineering structures would be made in Japan at all-nay, no structures of any kind, for what will stand when the very mountains are riven and partly overturned? The people would have simply to camp out in the cane brakes! (See remarks on this subject by Professor John Milne, F.R.S., in Appendix, p. 273.) 
objectionable to have flood water "passing through" a reservoir, as it is commonly put, that is to say, having floods pouring in at the head of the reservoir, while there is water overflowing by the waste weir. The result simply is to deposit a certain quantity of silt in the reservoir without any corresponding advantage.

As has been said, impounding reservoirs are never designed to take extreme floods. For this reason it is advisable, wherever practicable - that is to say, wherever the cost is not prohibitive - to construct a channel, or two channels, to carry flood water past the reservoir. Such an arrangement is shown in Plate XII. The waste weir discharges into this channel. By beginning the works

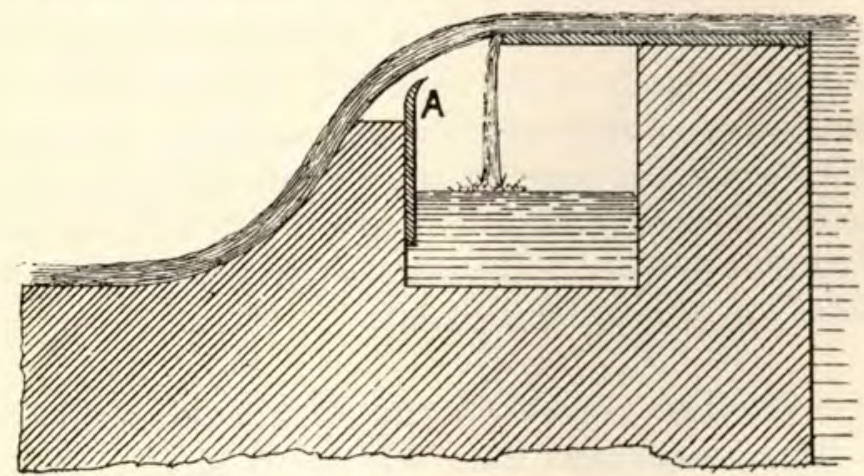

Fig. 47.-Arrangement for directing flow into reservoir.

by the construction of the channel and the tail race, the water is conveniently disposed of during the construction of the dam.

It is probably best to control the direction of the flow of the water by sluices worked by an attendant. The sluice to the reservoir is normally open, but, whenever the reservoir begins to overflow, or, if there is a dwarf dam on the waste weir, before this is overtopped, the water is deflected to the by-pass channel. By this arrangement the most is made of such a dwarf dam.

Various automatic arrangements have been designed for effecting the control of the direction of the flow of the water. The simplest is diagrammatically illustrated here (Fig. 47). The diagram is almost self-explanatory. The action depends on the fact that, the greater the volume of water the greater is its velocity, and the further it will leap over an open space. The plate $\mathrm{A}$ shown can be vertically adjusted. It is so adjusted that the water just overleaps it when the stream gets to such a height that the water is turbid. This arrangement can only be adopted when the total annual supply is considerably over the total annual 
consumption; for, although the plate $\Lambda$ can be regulated so that the normal flow of the stream will all enter the reservoir, whilst extreme floods will all enter the by-pass channel, there are intermediate states of the flow in which the plate will divide the water, sending one portion to the reservoir, and allowing another portion to run to waste.

If a by-pass channel is out of the question, and if the stream carries down much silt during floods, it is advisable to construct a small settling reservoir above the main reservoir by damming the valley with a masonry or wood crib-work dam, over the top of which flood-water is allowed to pass. Even if this hold only one day's mean discharge, it will hold at least some minutes' discharge of the extremest floods, and the detritus brought down by such floods being generally of a heavy nature, a large proportion of it will be deposited even in this short time. Part of the work consists of a by-pass channel capable of carrying normal discharges, and of a waste pipe allowing the water to be drawn from the little reservoir. The small reservoir may be cleared of deposit at any time when the stream is low, the stream being allowed to flow along the by-pass channel, and the water being drawn from the small reservoir slowly, so that it will not carry the detritus with it.

\section{Burning Vegetation within the Reservoir Area.-} The object of this is to reduce to a minimum the deterioration which the water impounded in a reservoir is liable to suffer for the first year or so from the decaying of vegetable matter. It is not by any means always carried out; but it should be if the vegetation is dry enough to burn at all readily.

Other Forms of Earthwork Dams.-Many modifications of the section of earth dams shown here are in use. For examples of these modifications the reader is referred to Humber's "Water Supply of Cities and Towns." Also in Fanning's "Treatise on Hydraulic and Water Supply Engineering," will be found very interesting descriptions of dams of much lighter section than that given in Plate VI. the whole, or the greater part of the structure being of impervious material.

Some engineers have suggested that, in place of a puddle wall, the puddle should be disposed in the form of a puddle apron protected by stone pitching on the inner slope of the dam. There does not appear to be any advantage in this arrangement. The 
writer thinks it is, at any rate, a mistake to have both a puddle wall and a puddle apron. If the latter is absolutely water-tight, the former is not needed. If it is not, the earth between the apron and the wall will become saturated with water if the reservoir stands full for any length of time; and on the lowering of the water of the reservoir there will be great danger that the internal pressure will cause a slip of the inner slope to take place.

Possibility of the Sliding of an Earthwork Dam.-As has been said, there is no question of the stability of a dam of the

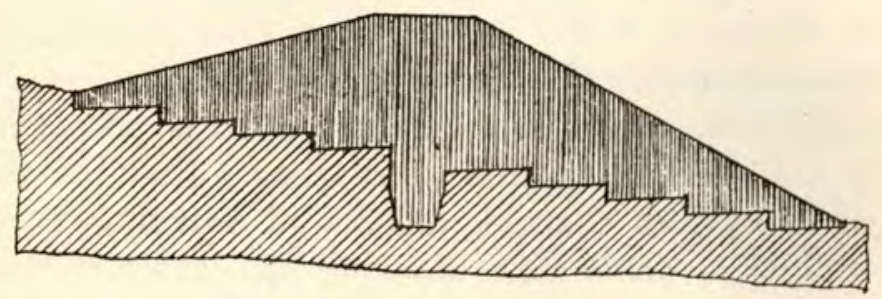

Fig. 48.- Site of dam trenched-out.

proportions recommended against overturning, but the possibility of the resistance of the dam to the horizontal thrust of the water tending to cause it to slide in its entirety down the valley has to be considered. It can easily be shown that, with the valley line nearly horizontal, the weight of an earth dam causes sufficient friction to prevent any sliding, and, indeed, the writer does not know of a case where an earthwork dam has failed by sliding as a whole.

With a valley having a steep slope, however, it is quite possible that such sliding might take place. To prevent the possibility of this it is advisable, when the slope of the valley is considerable, to trench out the ground on which the dam rests, as shown in Fig. 48. 


\section{CHAPTER IX.}

\section{Masonry- Dams.}

THE conditions that make a masonry dam preferable to an earthwork dam have already been described.

The problem of a masonry dam is entirely different from that of an earth dam, in which latter case other considerations than those of the stability of the whole mass determine the form of the section. The most likely way for an ill-proportioned masonry dam to give way, is by the overturning of the whole or a part of it from the pressure of the water in the reservoir.

The Stability of a Masonry Dam.-To be perfectly safe, a masonry dam should conform to the following conditions :-

(1) It must, by its weight alone, without considering either adhesions to the foundation, or such support* as it gets at the ends, be able to resist tendency to overturn by water pressure, wind, and waves.

(2) It must be able to do the same at any part of its height.

(3) It must be able, by friction alone, to resist all inclination to slide on its base.

(4) It must be able to do the same at any part of its height.

(5) No part of the masonry must be in tension.

(6) No part of the masonry may be under more than a certain pressure from the superincumbent weight.

To satisfy (5) it is necessary that the line of pressure, whether the reservoir be full or empty, be within the inner third of the masonry. "The line of pressure (called also the line of resistance) ${ }^{+}$ is the line intersecting each joint of a structure (whether it is real

* See post, p. 73, on Curved Masonry Dams.

$\dagger$ See "Design and Construction of Masonry Dams," by Edward Wergmann, Jr., C.E. (John Wiley and Sons, New York). This work treats most fully of masonry dams in a manner which, considering the difficulty of the subject, is remarkable for its clearness aud simplicity. 
or imaginary) at the point of application of the resultant of all the forces on that point." By the "inner third," is meant that part inclosed by two lines at every part of the height of the dam, dividing a horizontal line into three equal parts.

It may be shown that if conditions 5 and 6 be fulfilled, all others will be except in so much as it is necessary to give the top a certain thickness to resist waves, and for other reasons that will suggest themselves, all other conditions being fulfilled by a dam with zero thickness at the very top.

To find the best section of dam to fulfil all these conditions is a very complicated problem. The first solution of the problem which was at all successful was by M. Delocre, a French engineer. Rankine very much improved upon his method, and Rankine's profile has been the standard one, with English engineers at any rate, for a good many years back. Wergmann published, in 1889, the results of his investigations in connection with the proposed Quaker Bridge dam, a dam of 270 feet high intended to impound water for the supply of New York City-the highest dam in the world. In investigating the question of its design he worked out a "theoretical profile" suitable to all heights up to 200 feet.

The width of the top of a masonry dam cannot be calculated theoretically, as there are not sufficient data, but is a matter of judgment. Wergmann recommends a minimum of five feet, and a breadth equal to one-tenth the height of the dam for all dams over fifty feet high, and probably this practice is as good as can be recommended.

Professor Rankine's profile and Mr. Wergmann's do not differ much for heights not greater than about 150 to 160 feet, and Rankine's is, on paper at least, the more graceful of the two. For heights greater than those mentioned, Rankine's profile becomes very flat at the down stream slope, the thickness very rapidly increasing without apparent corresponding advantage. A comparison of the two profiles is given on Plate XIII.

Plate XIV. shows Wergmann's theoretical profile for different specific gravities of stone. The pressure on the masonry by superincumbent weight is never allowed to exceed 16,380 lbs. on the down-stream face, $20,480 \mathrm{lbs}$. on the up-stream face, per square foot. Masonry dams have been in existence for many years that have safely resisted a considerably greater pressure.

From this "theoretical profile" Wergmann deduces three "practical profiles," suitable for dams on different scales. These are shown on Plate XV. (Figs. 51 to 53). For dams lower 


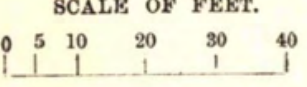

Professor Rankine's Profile.

Wergmann's Profile. 
Plate XIV.

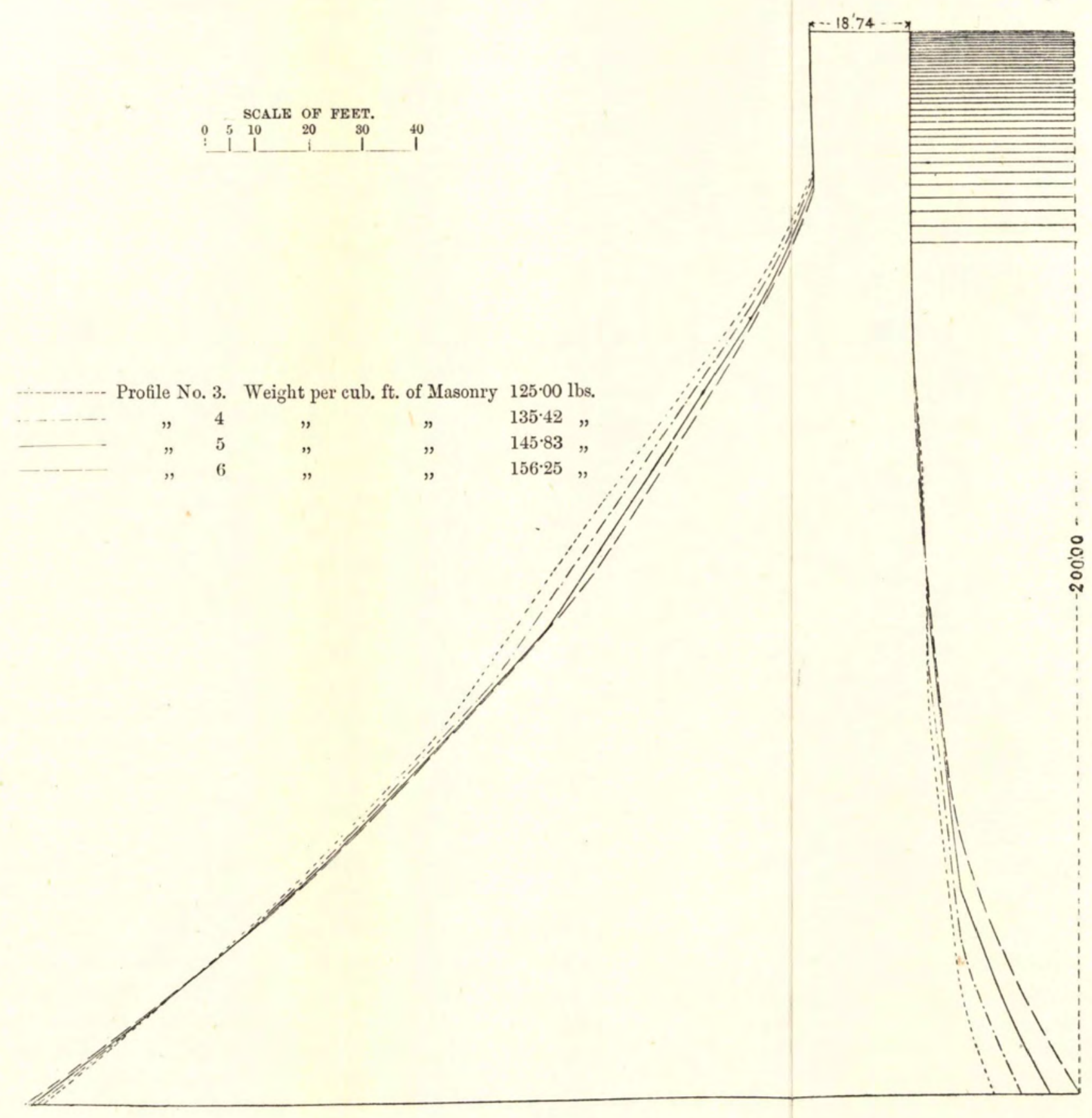

Fig. 50.-Masonry Dams: Wergmann's Theoretical Profile for Stone of Different Gravities. 
than fifty feet, all dimensions can be taken proportional to Profile 1, but keeping the width of the top always five feet. For those between fifty and a hundred feet, all dimensions can be taken proportional to Profile 2. For those above a hundred feet, the height wanted may be taken from Profile 3.

Curved Masonry Dams.-It must be evident that, in the case of a narrow gorge, a curved dam, convex up stream, would act as a horizontal arch abutting on the sides of the valley, and that the thickness might be reduced. It is evident, further, that there is a certain limit beyond which the arch principle would not come into operation, because the wall would be (partly or entirely) overturned, and distortion would probably take place, before the necessary compression to resist as an arch began to take place.

It has been found impossible to state any limit on one side of which a dam may be considered to act as a horizontal arch, and on the other side of which it cannot. The investigation is extremely complicated, and of necessity rests on data that are little better than pure assumption. For these reasons it is generally considered that, although the curved plan may, in some cases, especially when the valley is narrow, be adopted with advantage, the section should still be such that the dam is stable by its own weight.

On the other hand, Messrs. Joseph P. Daris, James J. R. Croes, and William F. Shunk, who were appointed Aqueduct Commissioners to the Quaker Bridge dam, stated their conclusions in connection with this matter as follows :-

" (1) That, in designing a dam to close a deep, narrow gorge, it is safe to give a curved form in plan, and to rely upon arch action for its stability; if the radius is short, the cross section of the dam may be reduced below what is termed the gravity section, meaning thereby a cross section or profile of such dimensions that it is safe, by the force of gravity alone, to resist the forces tending to overturn it, or to slide it on its base at any point.

"(2) That a gravity dam, built, in plan, on a curve of long radius, derives no appreciable aid from arch action, so long as the masonry remains intact; but that, in case of a yielding of the masonry, the curved form might prove of advantage.

"The division between what may be called a long radius, and what may be called a short radius, is, of course, indefinite, and depends somewhat on the height of the dam. In a general way, we would speak of a radius under 300 feet as a short one, and 
one of over 600 feet as a long one, for a dam of the height contemplated.

"(3) That, in a structure of the magnitude and importance of the Quaker Bridge dam, the question of producing a pleasing architectural effect is second only to that of structural stability, and that such an effect can better be obtained by a plan curved regularly on a long radius than by a plan composed of straight lines with sharp angular deflections.

" (4) That the curved form better adapts itself to changes of volume due to changes of temperature."

In another part of their report they state that "as to curved and straight plans generally, without reference to the Quaker Bridge location, all authorities agree that the same principles should be followed in designing of the profile, whatever the plan, unless the curve has a very short radius, not exceeding, say, 300 feet."

Material and Construction of Masonry Dams.-The best material for masonry dams is rubble, with Portland cement mortar. The size of the stones may be anything from a cubic foot or two to several cubic yards, according to the material available. The spaces between these stones are filled in with smaller stones and cement mortar, or with cement concrete.

In building the Vyrnwy reservoir dam for the supply of Liverpool with water, the mortar at the beginning of the work was made of one part of Portland cement to two parts of washed river sand. As the work progressed experiments were made, and it was found that, by pulverising the stone of which the dam was made (a grey slate rock), mixing two parts of this with one of sand, and two parts of the mixture with one of Portland cement, a stronger mortar resulted. This mortar was, therefore, adopted. For most cases, however, one part of Portland cement to two parts of clean, sharp sand, may be taken as a normal mortar.

In constructing a masonry dam, the first operation is to clear the rock on which it is to be founded, and to fill up all fissures or cracks with rich cement concrete. The actual building then begins, and this needs the utmost care at every stage. The stones must be most carefully bedded in mortar, and should not be moved or violently shaken after once they are bedded. No grouting should be allowed. The masonry should not be in regular courses, but should be built up in thick layers, making one most thoroughly bond with another. In fact, it should be 


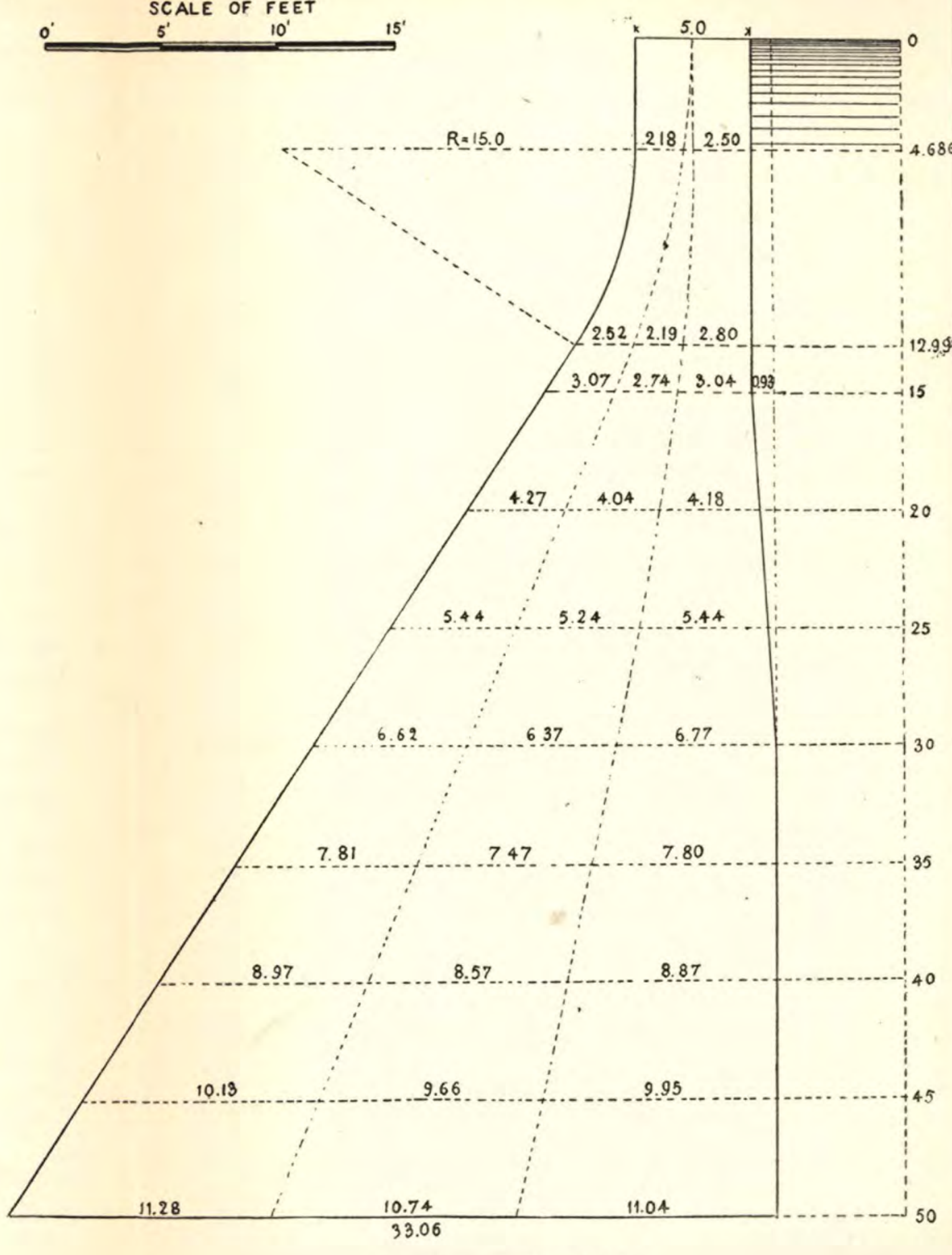

Fig. 51.-Practical Profile No. 1.
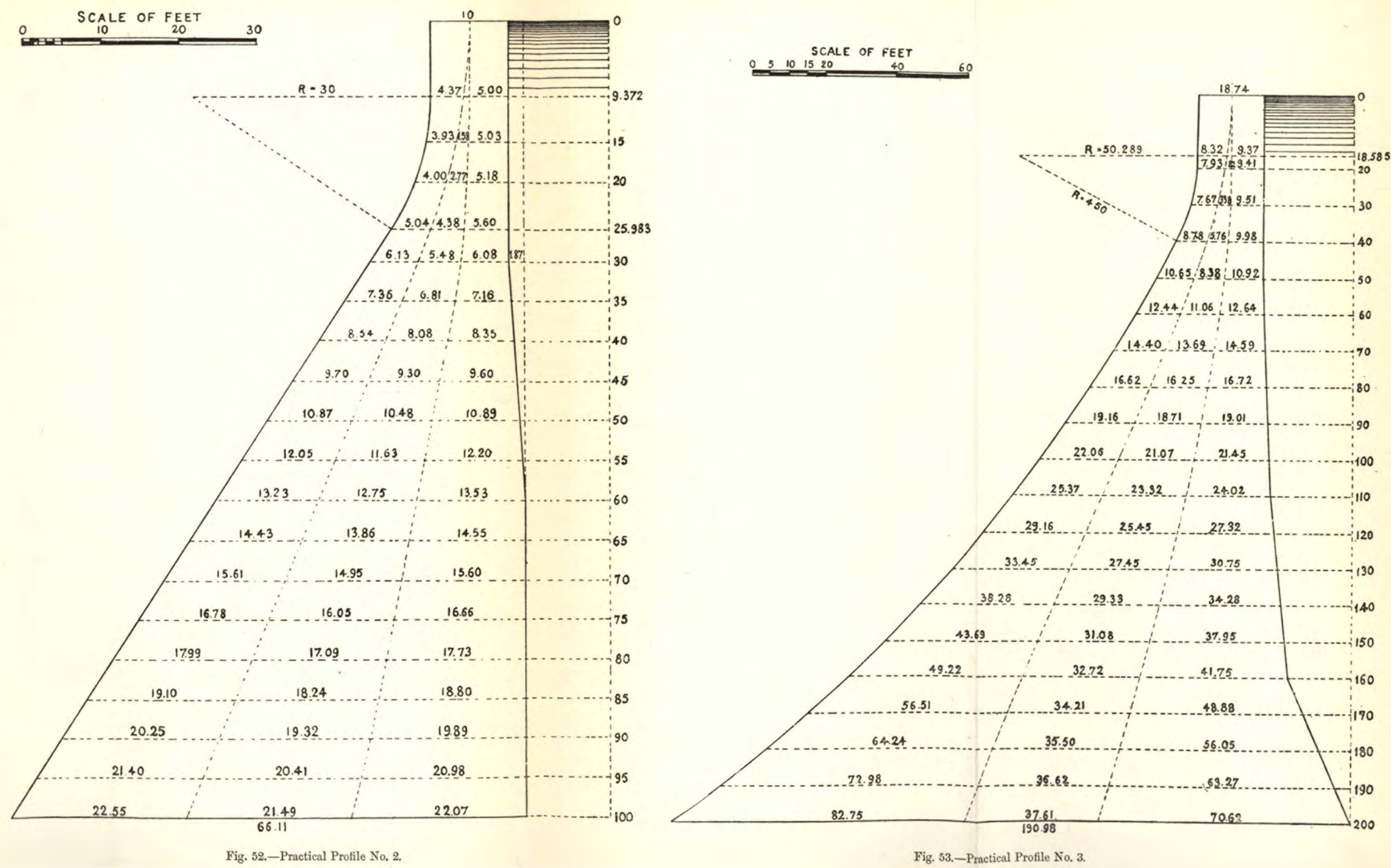
borne in mind throughout the work that the object is to produce as near an approach to a monolith as possible, and to so construct this monolith that leakage shall take place neither under it nor through it.

Concrete Dams.-Concrete has not often been used as the material for the bulk of a dam, but, in the cases where it has been used success has been met with, and it seems likely that the use of this material will spread.

In the case of the Tytam waterworks, Hongkong, the engineer, Mr. James Drange, finding Chinese masons untrustworthy, or unable to do a style of work of the excellence necessary for masonry dams, constructed a considerable dam entirely of rubble concrete with a cut stone facing. This has been in existence for several years, and has given all satisfaction. The section of this dam is shown in Plate XVI. For a full description of it, see Proceedings of the Institution of Civil Engineers, vol. c.

The By-wash or Waste Weir.-As has been said, there is not such great danger from the overtopping of water in the case of a masonry dam as in one of earth; yet this should be avoided unless the section of the dam is specially designed with a view to the flow of water over it, and to do this the waste weir should be made of the same proportions as those recommended for reservoirs with earthwork dams. As in the case of earthwork dams, so in the case of masonry, the overflow is generally made round one end of the dam. On the other hand, if a suitable profile be adopted, the water may be allowed to flow freely over the top of the dam, which in this case becomes its own by-wash.

One of the most extensive works in connection with modern water engineering is that of the dam of the Vyrnwy reservoir already referred to, of which Mr. G. F. Deacon, M.Inst.C.E., was engineer. This dam impounds water forming an artificial lake having a surface area of some 1,120 acres, and has a total height, including the viaduct, of 161 feet. Its section is shown in Plate XVII.

In the case of this dam, the flood water is intended to overtop the general section, the roadway being built above this on a series of arches. There is the great advantage in this arrangement that not an inch of the height of the dam is lost. The frontispiece, 
from a photograph,* shows the dam through nearly the whole of its length.

\section{Regulating the Discharge of Water from Reservoirs} with Masonry Dams.-This is done in a manner similar, in general principles, to that adopted for earthwork dams - that is to say, the water is drawn through a culvert or tunnel from a valve tower, and may be regulated at a valve house at the toe of the outer slope of the dam. There is this difference, however, that there is not the same objection to constructing this culvert in the body of the dam as there is in the case of an earthwork structure. Again, the batter of the inner face of a masonry dam being generally but slight, the valve tower may form an actual part of the wall. In Plate XVIII. is shown the valve tower of the Tytam reservoir, Hongkong. It will be seen that the tower is divided into a wet well and a dry well by a cast iron partition penetrated by short pipes to which are fixed sluice valves for controlling the flow of water. A valve tower on the principle here shown might be adopted with a masonry dam.

In all respects - such, for example, as works at the head of the reservoir-except those mentioned, the procedure is the same in the case of a reservoir with a masonry dam as in the case of one with an earthwork dam.

* Reproduced, by permission, from The Engineer of 15th July, 1892. 
Plate XVI.

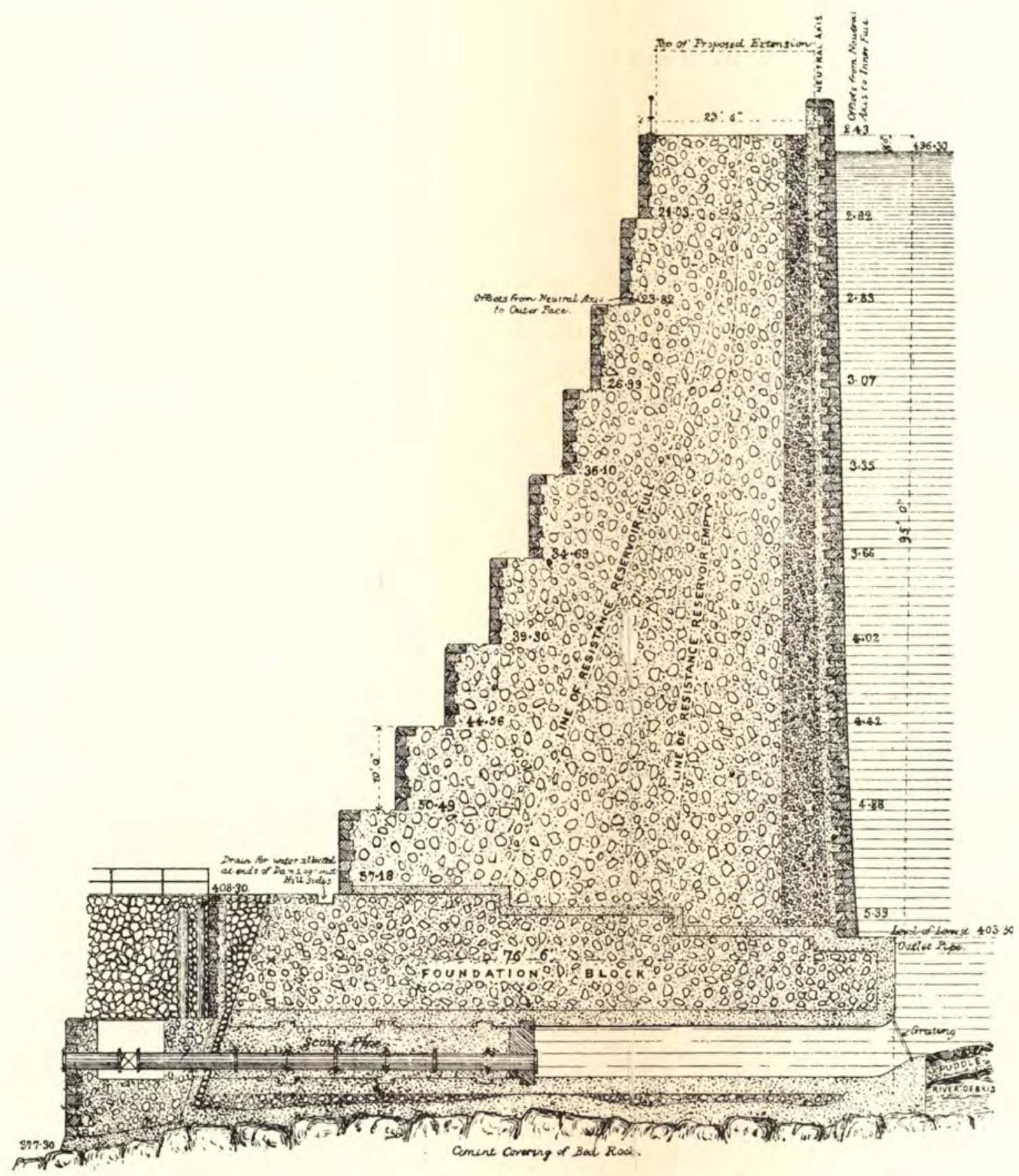

Fig. 54.-Tytam Dam, Hongkong: Section throvgh Scour Pipe. 


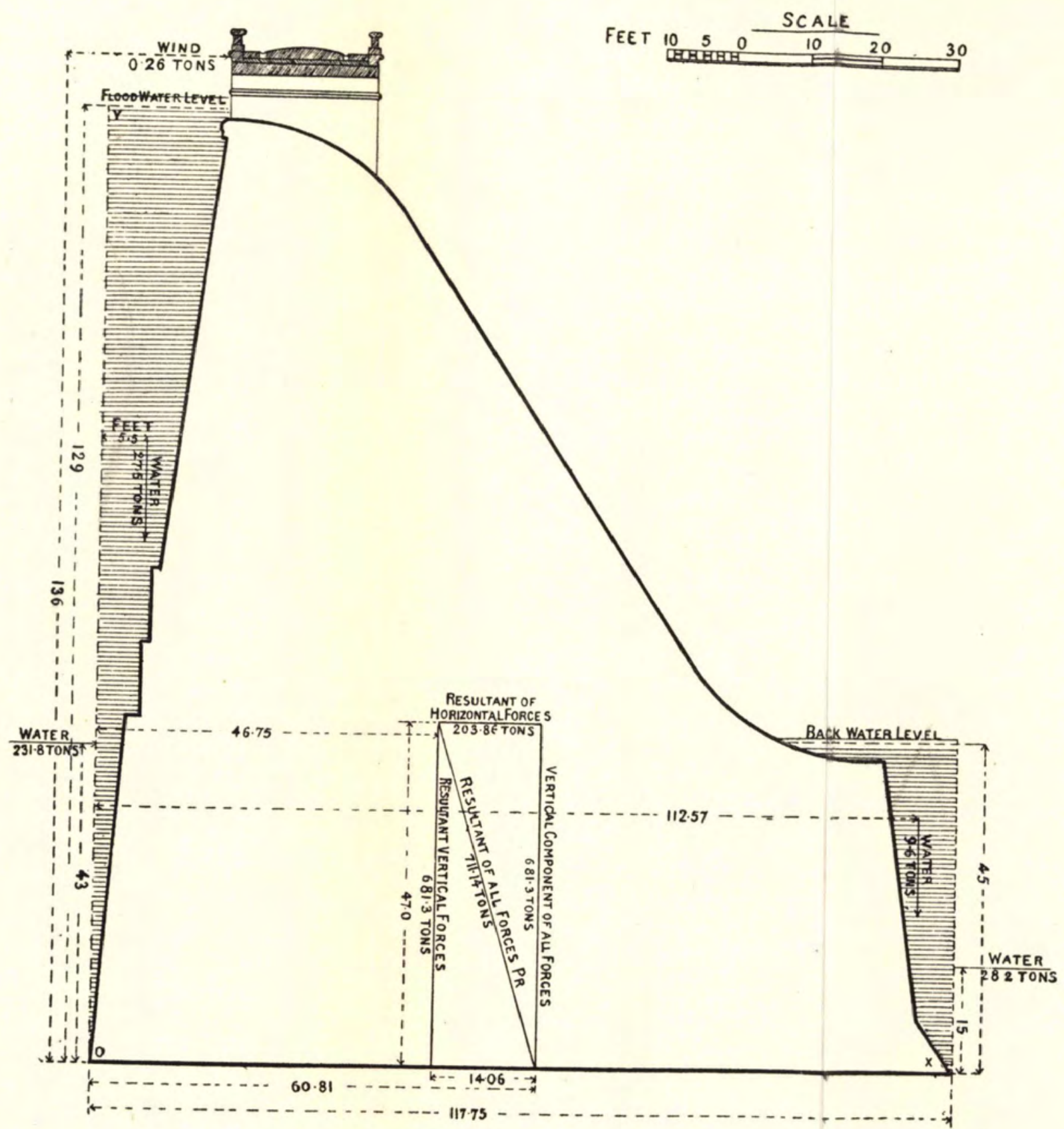

Fig. 55.-Section of Vyrnwy Dam (Liverpool Water SUpply). 
Plate XVIII.

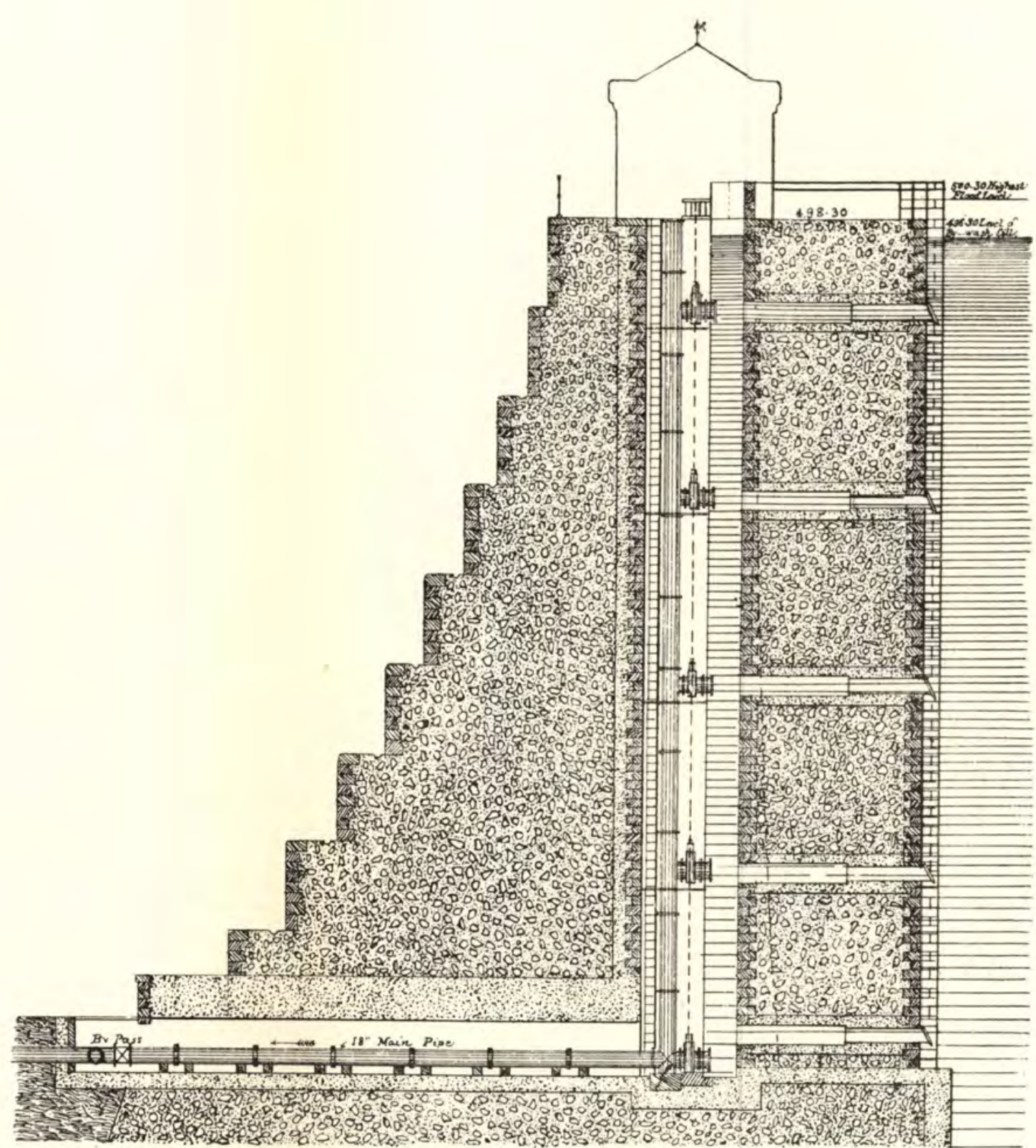

Fig. 56.-Tytam Dam, Hongkong: Section throdgh Vaive-Well. 


\section{CHAPTER X.}

\section{The Purification of Water.}

WATER, as found in nature, is never absolutely pure, and it is seldom that it is so pure but that it may not be improved by means so moderate in expense that they are applicable to the large quantities of water dealt with in the supply of cities.

Practically pure water can be got by distillation only, but such a process is, of course, quite out of the question on the large scale necessary for the supply of towns, although water is so purified for use on board ship.

Pasteur's filters of unglazed earthenware are said to remove all micro-organisms, but they, also, are not applicable on a large scale. In the case of some deep-well waters, and sometimes in the case of water that has been stored in impounding reservoirs, the degree of purity is so great that no improvement can be made by processes applicable on a large scale, or the improvement would be so slight that it is not considered worth the expense involved to establish purifying arrangements. This is the exception, however.

\section{Purification by Settlement and Sand-filtration.--By} far the commonest methods of purifying water on a large scale are by settlement and by sand-filtration.

Settlement consists simply in allowing the suspended particles to settle by their own weight. The possibility of such settlement assumes that these particles are of a higher specific gravity than water. The greater quantity of the suspended matter to be treated is of higher specific gravity than water, and only needs time enough to settle. A certain quantity is of less specific gravity than water. This rises to the surface, and can, therefore, also be separated from the water.

It is possible that some suspended matter is of precisely the 
same specific gravity as water, in which case it will incline neither to sink nor to rise. However this may be, there is generally some suspended matter in so fine a state of division that it takes an indefinite time to settle. It will readily be understood that, the finer the division of the suspended matter the longer it takes to sink. The reason is that the surface of similarly shaped particles, offering skin friction resistance to settlement, varies only as the square of any similar linear dimension: the volume, and therefore the weight, varies as the cube. In other words, the surface offering resistance by skin friction is relatively greater the smaller the particle.

In every case where there is an impounding reservoir this acts as a settling reservoir also, and, indeed, as a very efficient one; for in spite of the comparatively great depth of impounding reservoirs, they generally hold so many days' supply that settlement has ample time to take place. This is especially true if there is a by-pass channel for carrying the water of excessive floods.

Where there is no impounding reservoir, and the water of a stream is liable to be turbid at times, it is generally advisable to have one or more settling reservoirs. These are simply reservoirs of moderate size, which can be emptied occasionally for cleaning, and which hold the water long enough to allow the grosser particles of suspended matter to settle. The object of the settling reservoirs really is to spare fatigue to the filters, and no absolute rule has been evolved for the capacity of settling reservoirs. Without any settlement, filter beds are liable to become simply unmanageable at times, when the water is very turbid, becoming clogged more quickly than they can be cleaned. The greater the capacity of the settling reservoir, the less often have the filter beds to be cleaned. A capacity of from two to three days' mean consumption is a common one.

Sand-filtration is the almost universal method employed for completing the purification of water so far as it can be purified at a moderate cost on a large scale.

In a recent edition of a deservedly popular Encyelopædia, filtration is thus defined:- "The process of filtration consists in passing the liquid through some porous substance, the interstices of which are too small to admit the passage of the solid particles, the principle of the action being the same as that of a sieve." Now this is doubtless true of some kinds of filtration, such as that of liquids holding insoluble matter in suspension, through filtering 
paper, but the action in the case of sand-filtration is quite different from this-or, perhaps, it would be better to say that there is an additional action in the case of common sand-filtration.

There are two reasons for stating, with considerable positiveness, that the action of sand in filtration is different from the straining action of a sieve. One is that the sand found to be the best for filtration of water, is sand the grains of which are so large, that the interstices left must certainly be large enough to allow many of the particles that are actually filtered out to pass side by side. Another reason is that, whereas sand-filtration is efficient so long as a certain very slow velocity of the water is not exceeded, it rapidly becomes inefficient-fine suspended matter passing - if a velocity much below what would be perfectly permissible were the action merely a sieve-like straining action is reached.

We probably have the key to the action of sand in filtration if we consider the action that takes place if a glass filled with turbid water is allowed to stand for some length of time. It will be found that the matter constituting the turbidity will slowly deposit, but that it will deposit nearly as much on the vertical sides of the glass as on the bottom. There is, in fact, an adhesive action. This will be particularly noted if a ferruginous water, tending, after being exposed to the air for some time, to throw down the iron in the form of an insoluble compound, be used. It is probable that there is a similar action in the case of sandfiltration.* It would seem, however, that after a certain amount of fine filtrate has filled up the interstices of the upper inch or so of sand, the action is, in part at least, one of actual straining.

It has been stated that impurities in solution are not removed by sand-filtration, and this is true if the process be looked on as a continuous one; but it is a fact, not at all readily understood, that at the time a filter is first started, either with fresh sand, or with sand that has been thoroughly washed, a considerable quantity even of soluble matter is retained by the sand. This cannot, however, be said to be a fact having much bearing on waterworks practice, as after a little time the soluble matter begins to pass freely through the filter.

As has been already stated, sand-filtration will remove the greater number of micro-organisms from water so long as the velocity of the filtration is kept very moderate.

* See Note 5, Appendix II. 
Other Methods of Purifying Water.-As has been said, water that contains any appreciable quantity of dissolved organic matter ought not to be selected as a source of water supply, if any other source can be obtained. There occur, however, cases in which it is impossible to find any supply of water that is not more or less impregnated with dissolved organic matter. In such a case it becomes necessary to have recourse to some process that will remove the organic matter or, by oxidizing it, will render it innocuous. These methods are all somewhat expensive and cumbrous to work, but there are some of them that are not impracticable even on a large scale.

Animal charcoal had for long a high reputation as a purifier of water, and there can be no doubt that, given certain conditions, its action is wonderful, the organic matter of water passed through a layer of it being completely oxidized. There are some uncertainties, however, about the process, the charcoal in certain cases, after it has been at work for some time, actually making the water worse than it originally was. For this reason its use on any large scale is now discontinued.*

Various iron ores have a peculiar action on water, causing the rapid oxidation of organic matter. Notable amongst these is magnetic iron oxide. If water containing organic matter in solution be passed through a layer of some inches of any of these ores in a fine state of division, it is found that oxidation more or less complete takes place. Iron ores specially prepared for the purification of water are sold under such names as "Carfarel," "Carbide of Iron," and "Polarite." This last mentioned, which has been very favourably reported on in recent years, is said to be pure magnetic oxide of iron.

Metallic iron has a powerful action on water containing organic matter in solution. Thus if a handful of clean iron filings be placed in a vessel containing water with organic matter in solution, and the filings and the iron be violently agitated for two or three minutes, the organic matter will be carried down with the filings, when these are allowed to subside.

The action that takes place in this case is not very clearly understood, but the following is the explanation given to the writer by Dr. E. Divers, F.R.S. :-

"Water containing carbonic acid dissolves iron in the form of carbonate, at the same time liberating hydrogen when no deoxidis- 
able matters are present. One effect, well known, of depriving water of its dissolved carbonic acid, is to precipitate any calcium, magnesium, and iron carbonates, which the carbonic acid may have been keeping in solution. In this way spongy iron will become coated over and cemented together into a hard mass by some calcareous waters. What iron carbonate is not thus precipitated, becomes afterwards changed by atmospheric oxygen into ferric hydroxide and deposited as a rusty sediment. Oxygen, nitrite, nitrate, and no doubt some other of the oxygenous matters in solution in the water are consumed partly by contact with the metallic iron in presence of the carbonic acid, and partly afterwards by the iron dissolved as carbonate.

"It is not easy to admit that the action of iron upon water, holding carbonic acid in it, can be effective in destroying or precipitating dissolved albumenoid matters from the water. Rather must it be considered that the purification of water from matters indefinitely classed as albumenoid, consists in the removal of organisms living in the water. The activity of iron in depriving water of bacteria is just what might be expected, since a microbe in water holding carbonic acid gets into a field of powerful chemical action when it comes in contact with bright iron, and will naturally be paralysed if not killed outright. Further, water freed, as it is by iron, of both carbonic acid and oxygen, must be ill-fitted for bacterial life, while the dissolved ferrous carbonate will, even in the minute quantity of it present, be a powerfully poisonous agent, like all such reducing or deoxidising agents.

"In accordance with this account of the probable mode of action of the iron in killing and removing bacteria is the fact that it is only quickly after contact of the water with the iron that bacteria are so strikingly diminished in number, for towards the de-aërated water the iron becomes passive as glass, and new generations of bacteria may knock up against it with impunity if otherwise able to live in the water."

Spongy iron, obtained by calcining or reducing hæmatite by carbonic oxide, is really metallic iron, and if water containing organic matter in solution be filtered through this, the action above described will take place. The iron slowly rusts, and for this reason the method of agitating the water with metallic iron in the condition in which it is generally found in workshop turnings and borings, as described in a subsequent chapter, seems more suited 
to the purification of water on a large scale than filtration through spongy iron.*

Hardness of Water.-As in the case of dissolved organic matter, so with hardness: it is sometimes impossible to find a source of supply of water that is not much harder than is desirable. In this case a softening process ought to be applied, though it must be admitted that there is not the same real danger to health from even excessive hardness of water as there is from the presence of dissolved organic matter.

The general principle of Clark's process has been described already (p. 11). In practice the water is mixed, in settling tanks or reservoirs, with a certain quantity of lime water, which is merely a weak solution of caustic lime. Time is allowed for the insoluble carbonates formed to settle, when the clear water is drawn off. It is notable that the minute particles entangle with them a large percentage of any micro-organisms that there may be in the water, and carry them to the bottom of the tanks, though they do not kill them.

In a modified form the process is continuous. The water is mixed with a certain proportion of lime solution before entering a certain apparatus having a number of horizontal partitions, so arranged that the water has to pass slowly over the uppermost of these, then in the opposite direction over the next one below, and so on. The fine suspended particles haring comparatively a short distance to settle, the action is rapid, and at the same time a very large reservoir is avoided.

* See note 7 , Appendix II. 


\section{CHAPTER XI.}

\section{Settuing Reservoirs.}

Capacity and Number of Settling Reservoirs.--It has already been explained that the greater the capacity of settling reservoirs the less the fatigue of the filters, and the practice in the matter of proportioning the capacity of such reservoirs has varied greatly. Any capacity from that corresponding to a fraction of a day's consumption to one corresponding to ten or even twenty days' consumption has been recommended. The latter may be useful when a little storage capacity is thought desirable, there being fear that the minimum supply of water may fall a little below the consumption for a few days or even a few weeks at a time; but in ordinary cases a capacity of from two to four days' mean consumption is sufficient.

It is, of course, necessary to decide how many settling reservoirs there should be. If the intermittent system of settlement (see farther on in this chapter) be adopted, it is evident that there must be at least two reservoirs. With the constant system there need be only one; and in the case of small works it is often convenient, on account of cost, to have one reservoir only. In this case a by-pass channel has to be provided, so that the reservoir can be emptied for cleaning. A time for cleaning is selected when the water of the source is comparatively free from turbidity.

For any but small waterworks it will generally be found advisable to have two, three, four, or even a greater number of settling reservoirs. In such case one is emptied for cleaning at a time, the work proceeding in the case of the others.

Depth of Settling Reservoirs.-This has to be decided by various considerations. It will be evident at once that the greater the depth the longer the time taken for settlement. On the other hand, there are various objections to very shallow reservoirs. One of these is, of course, the great area of land they 
need; another is that for every capacity of reservoir there is a certain depth that is most economical to construct. It will be evident that, in the case of small reservoirs, the cost of the sides, especially if the retaining-wall construction be adopted, will form a greater proportion of the whole than in the case of large reservoirs of the same capacity, the capacity of a reservoir varying, with constant depth, as the square of the length of line enclosing it, assuming the shape to remain the same. It thus becomes economical to make small reservoirs shallow and large ones deep.

Against excessive shallowness there are other objections than those mentioned. Very shallow water is liable to be heated by the sun's action, and the growth of vegetation is likely to become excessively troublesome.

It may be said that standard depths for the water of settling reservoirs are from twelve feet to sixteen feet. In the case of very small works a less depth than twelve feet may at times be permissible. Thus reservoirs may be made as shallow as ten feet, or even perhaps eight feet in some cases. On the other hand, there are cases where the depth of sixteen feet may be exceeded, and a depth of eighteen or even twenty feet become economical; but this is to be anticipated only with very large works.

The depths given are those of the actual water. It is necessary, except in the case of very small reservoirs, to allow a depth beyond this of about two feet. Even in the case of very small reservoirs, an additional depth of about one foot six inches should be allowed.

\section{Constant Settlement and Alternating Settlement.-} Settlement may be in accordance with either of these two systems. In the case of constant settlement water is constantly flowing into a reservoir at one end, whilst it constantly flows out at the other. The reservoir may thus, indeed, be looked on as a canal with a very slow velocity of flow, one seldom exceeding a few feet an hour. The reservoir is only emptied for cleaning out.

In the case of intermittent settlement two or more reservoirs are necessary. The action is as follows. Let it be supposed there are three reservoirs. At any one time one is being filled up, the water is being drawn from another to within two or three feet of the bottom to flow to the filter-beds, and the third is in a perfectly quiescent state. Suppose then the capacity of each reservoir to be one day's supply. Any given reservoir is being filled during one day; it stands full during the next day; and water is being drawn from it during the third day. The two or three feet at the 
bottom are drawn off and run to waste only when the reservoir has to be cleaned out.

In the first place let it be stated that there are circumstances in which the first (or constant) system of settlement only is available. It is not always practicable to so adjust the various levels of the intake, the settling reservoir, and the filter-beds, that it is possible to draw off, say, three-quarters of the contents of the settling reservoirs into the filter-beds. It is sometimes, on the other hand, necessary to keep the level of the water in the filterbeds only as much below the level of the water in the reservoirs as will give a head sufficient to make the water flow from the latter to the former; that is to say, with only a few inches' difference of level. This state of affairs is illustrated in Plate XIX.

With this arrangement, when, as is sometimes the case, it is not possible to find a place to which the settling reservoir can be drained for cleaning, it is necessary to provide arrangements for occasionally pumping out the water. The pulsometer class of pump will be found useful for this purpose.

There is some difference of opinion as to which of the two systems described is the better, and it is certain that either of them, carried out with intelligence, results in great improvement of turbid water. The writer ventures to express a pretty decided opinion in favour of the constant system : he has more than one reason for expressing this opinion. Thus with the constant system there is a much longer time for settlement with water very nearly absolutely at rest than there is, with the same total capacity of reservoirs, in the case of the intermittent system, the water absolutely at rest. Thus - taking again the case of the three reservoirs of one day's capacity each, used as an example above-with the intermittent system the water remains in one reservoir for twenty-four hours absolutely at rest; with the constant system the water normally remains practically at rest for three days of twenty-four hours each; even when one reservoir is laid off for cleaning, it remains practically at rest for two days of twenty-four hours each in two settling reservoirs.

Then again, with the constant system, if the inlet and outlet pipes be in the proper position and of the proper form, the water is always drawn from a position where it is at its purest. With the intermittent system, on the other hand, when a reservoir is being emptied, there is a tendency for the settling matter near the inlet of the reservoir to be drawn towards the outlet, and as the level of the water gets low, to mix with the outgoing water. 
In the case of sewage precipitation, which is, in some respects, very similar to that of water settlement, the constant system has been found so much better than the intermittent that, in some cases, where works were first started on the intermittent system, the constant has been substituted for it: and this in spite of the fact that, in the case of sewage precipitation, the constant system has not the advantage that it has in the case of water settlement, that one reservoir, with a by-pass channel, is permissible.

The writer does not know whether, in the case of water settlement, a system that may be described as a set of settling reservoirs

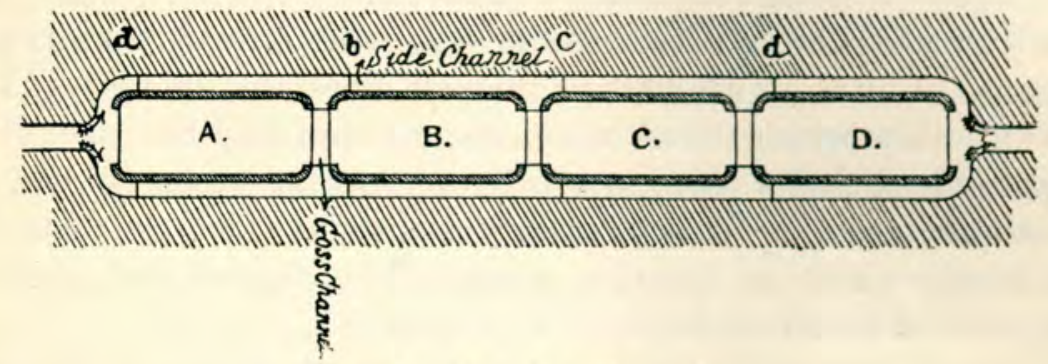

Fig. 57.-Plan of settling tanks.

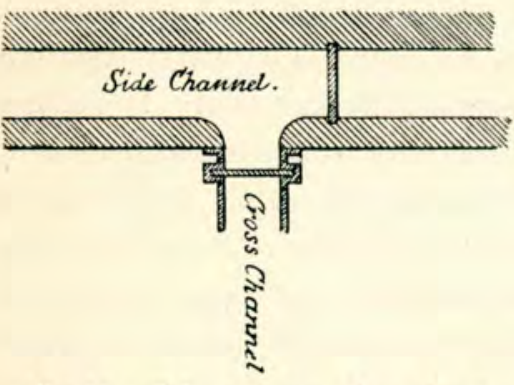

Fig. 58.-Side and cross channels of settling tanks.

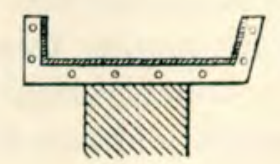

Fig. 59.- Section of cross channel weir box of settling tanks.

in series instead of parallelly arranged, which has been found useful in the case of sewage precipitation, has ever been attempted. The general principle is illustrated in Figs. 57 to 59 .*

In this case the water would flow normally through all the reservoirs, $\mathrm{A}, \mathrm{B}, \mathrm{C}$ and $\mathrm{D}$, the side channels remaining empty. At any time, however, any one of the reservoirs could be laid off for cleaning simply by closing the weir leading to and from it, and opening the sluice on the side channel past it. For example, the reservoir в could be laid off for cleaning by closing the weir to and from it, and by opening the sluices marked $b b$.

* From "Practical Sewage Purification," by Peter Spence and Sons. 
It is the opinion of the writer that, if, instead of allowing the water simply to flow over weirs, it were led to the bottom of the first reservoir, and afterwards from near the surface level of the first to the bottom of the second, and so on, very efficient settlement would result from the adoption of a system of this kind for clarifying water.

Form of Settling Reservoirs.-The form of a settling reservoir in plan will often be decided by the plan of the land that may be available for it. It may be said that a rectangle, with the length in the direction in which the water flows, several times that of the breadth, is a good form merely from the point of efficient settlement; and it may be an economical form where two or more settling reservoirs are constructed side by side. When there is only one reservoir, such a form is evidently not so economical in first cost as a square or circular reservoir, either of which, especially the latter, encloses a given quantity of water, with a shorter outline.

The circular form has, further, the advantage that in the case of small reservoirs, if it be decided to use vertical walls, or such as have but slight batter, the thickness may be considerably reduced from that needed in an actual retaining wall, resisting by its weight the whole wall acting as a circular arch. There is, however, in this case, a difficulty which often occurs in engineering works. It would be absurd to make the wall so thin as to depend on the resistance to crushing of the material only, as it would then be so slight that it would evidently be likely to give way by distortion-due to inequalities of radial pressure at different parts of the circle-which there are no possible data for calculating. The reduction of the thickness of a vertical reservoir, acting as an arch, thus becomes nearly entirely a matter of judgment. Again, as we get to larger sizes, it is a matter of judgment, with a given height of wall, up to what diameter of reservoir it is allowable to trust to the resistance as a circular areh at all.

In section the floor of a settling reservoir should have a slight slope, so as to facilitate cleansing. It is common to make the floor slope transversely in two directions towards a longitudinal drain in the middle of the reservoir, the floor with the drain also sloping slightly longitudinally. A slope of 1 in 150 or 1 in 200 towards the central drain, and a longitudinal slope of 1 in 250 or 300 is sufficient. 
The sides of settling reservoirs are either sloping, covered with stone pitching, or are in the form of retaining walls. The slope of sloping sides may be considerably greater than that for the inner face of the earthwork dam of an impounding reservoir, as, with the comparatively slight depth, the stone pitching may, to a certain extent, be said to act as retaining wall with a very great batter. Thus slopes of 2 horizontal to 1 vertical are common, and even somewhat steeper slopes are permissible.

If retaining walls are used, they are calculated from the usual engineering formulæ for retaining walls, to resist the earth pressure behind them. It is not necessary to take the water pressure into consideration, as this pressure will never force retaining walls outwards that are heavily enough proportioned to resist the thrust of the earth behind them; nor must any reduction in thickness be made, because the water pressure will greatly counteract the earth pressure when the reservoir is full. In fact, all calculations must be made for "reservoir empty."

It is common to give an inside batter of from $1 \frac{1}{2}$ inch to 2 inches to the foot to the retaining walls of settling reservoirs.

In comparing sloping sides with nearly vertical sides, it will be found as a rule that, so far as construction goes, reservoirs with sloping sides are the cheaper. It is evident that the additional price needed for the land in the case of sloping sides may balance, or more than balance, the saving in construction. A little consideration will show that, with the same depth, the addition at hand necessitated by sloping sides is relatively less the larger the reservoirs.

Where the first cost is about the same in both cases, preference is generally to be given to the retaining-wall structure, as the shallow water resulting from sloping sides is liable to include troublesome vegetation.

\section{Materials for the Construction of Settling Reservoirs.} -Until recently it was the universal practice to trust to puddle to secure watertightness for such structures as the reservoirs used in connection with waterworks, and puddle is still largely used. Increased knowledge of the powers of concrete and cement have, however, shown that these alone may be thoroughly relied on, ${ }^{*}$ if

\footnotetext{
* It does not seem advisable to rely alone on so inflexible a substance as concrete for reservoirs in earthquake countries. In the present state of our knowledge, it seems best in such countries to keep to the old practice of using puddle, at least as a stand-by, in case of the fracture of concrete.
} 
properly used, to make such structures as settling reservoirs and service reservoirs quite watertight, and the puddle is now commonly dispensed with.

Plate XIX. (Figs. 60 to $63 \mathrm{~A}$ ) shows two reservoirs-one a reservoir with sloping sides in which the puddle lining is retained, the other a reservoir with retaining wall in which no puddle is used.

Positions of Pipes for Settling Reservoirs.-A great deal of the efficiency of settlement in the reservoirs we are now dealing with depends on the manner in which the water is admitted to and drawn from the reservoirs. What is to be avoided is the water flowing in a direct line from the inlet to the outlet pipe with considerable velocity, without mixing with the

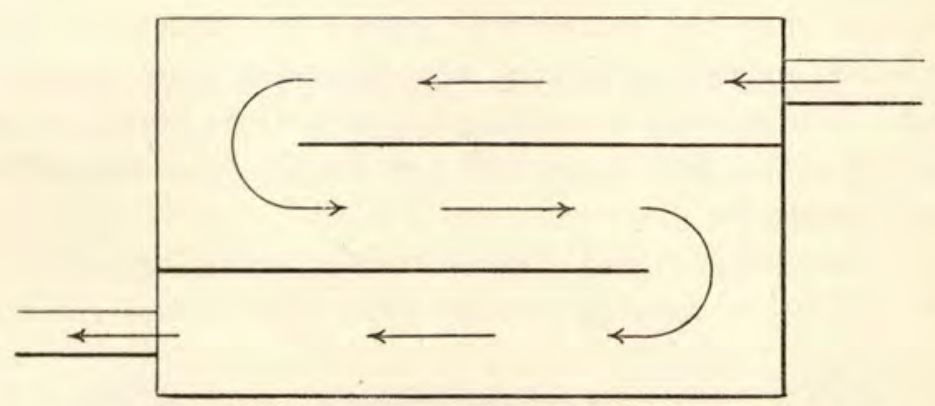

Fig. 64.-Arrangement of partition walls in reservoir to divert flow of water.

water already in the reservoir. It has been suggested that, to prevent this, there should be several partition walls longitudinally arranged in the reservoir, open at alternate ends, forcing the water to take a sinuous course, as shown in Fig. 64. This arrangement seems unnecessary if proper attention be paid to the admission and the drawing off of the water; and, moreover, it is likely to so increase the velocity of the flow of water in the reservoir, considered as a canal, that settlement will rather be impeded than the reverse.

It is probably seldom that water enters a settling reservoir for any length of time at exactly the same temperature as the bulk of the water in the reservoir. It is evident that currents may be produced, and the mixing of the water with that in the reservoir may be prevented, if the water entering the reservoir be at a different temperature from that in it, and that these conditions may influence the rapidity of settlement. 
It is interesting to consider briefly what would take place with outlets and inlets in different positions, and with the temperature of the incoming water either higher or lower than that of the water in the reservoir. First let us suppose both inlet and outlet at the level of the surface of the water, as shown diagrammatically in Fig. 65. Suppose first the incoming water warmer, and

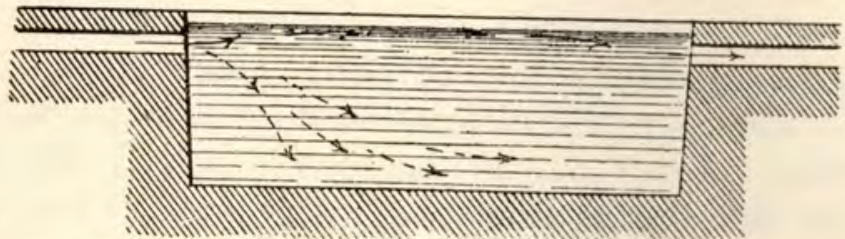

Fig. 65.-Diagram of settling reservoir : Inlet and outlet at surface level.

therefore of lower specific gravity than the water in the reservoir. It is evident that the water will travel, as shown by the full arrows, rapidly on the surface of the reservoir from the inlet to the outlet. During this travelling some of the suspended matter will certainly settle, but there will not be the time for settlement that there should be.

If, on the other hand, the entering water is colder, and, therefore, of higher specific gravity than that in the reservoir, it

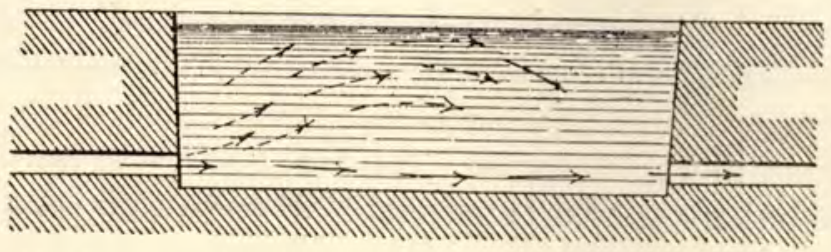

Fig. 66.-Diagram of settling reservoir : Inlet and outlet at floor level.

will tend to sink, as shown in the dotted arrows, and settlement will be much more satisfactory.*

Let us now take the opposite case, where both inlet and outlet are at the floor level of the reservoir, as shown in Fig. 66. Here, if the incoming water is colder than the water already in

* Those who have seen the Rhone flow into Lake Leman (or the Lake of Geneva) will have recognized a natural settling reservoir of this kind (the water entering and leaving at surface level, the entering water being colder than the water in the lake), produced by nature on a grand scale. The water of the Rhone carries down so much detritus that it is of a dull leaden gray colour. It is also mostly glacier water and is very cold. The dull leaden-coloured stream may be seen, so to speak, to plunge into the intensely blue waters of the lake and to disappear. This is, at any rate, the summer aspect of the lake and the river. 


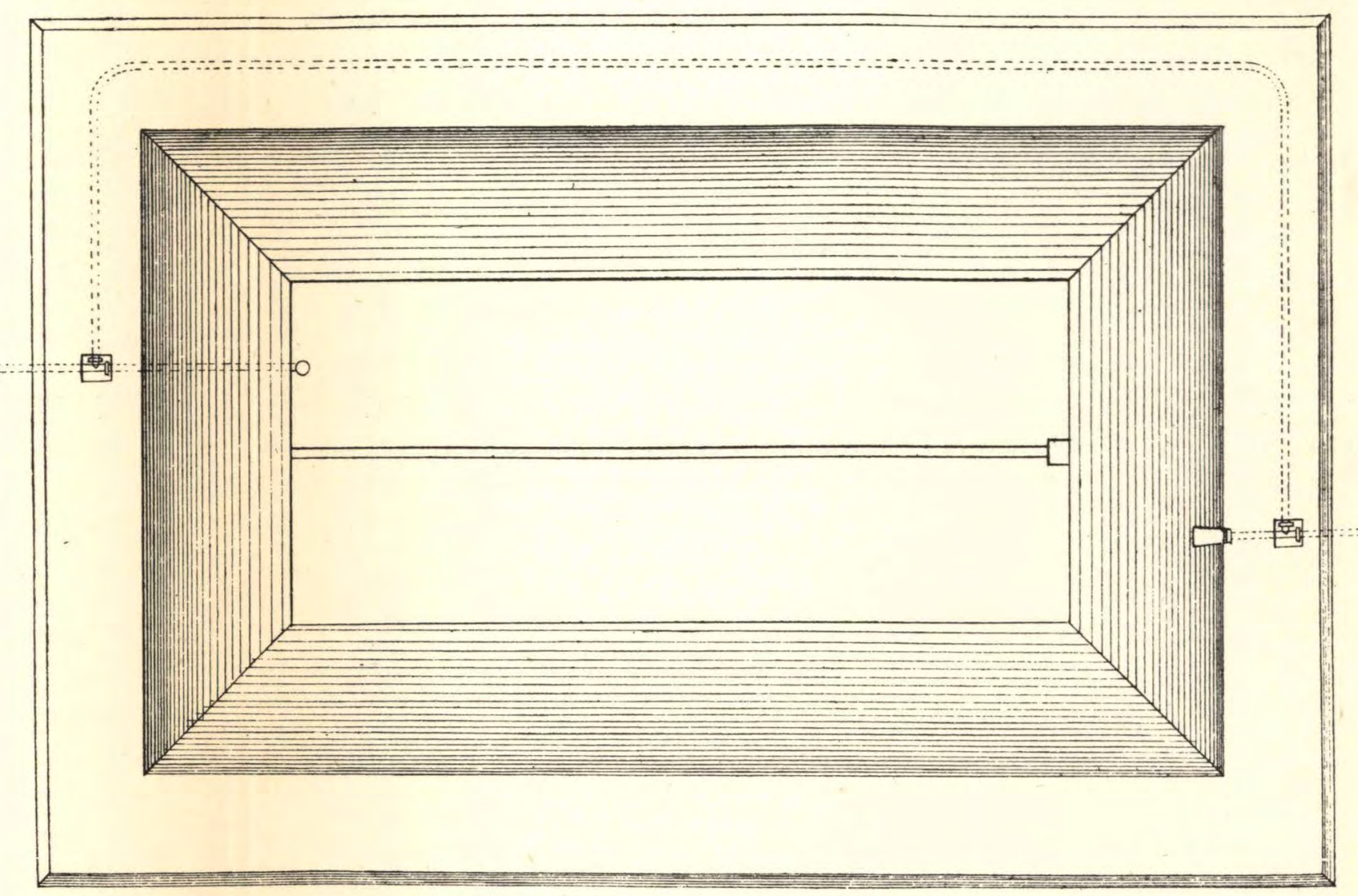

Fig. 60.

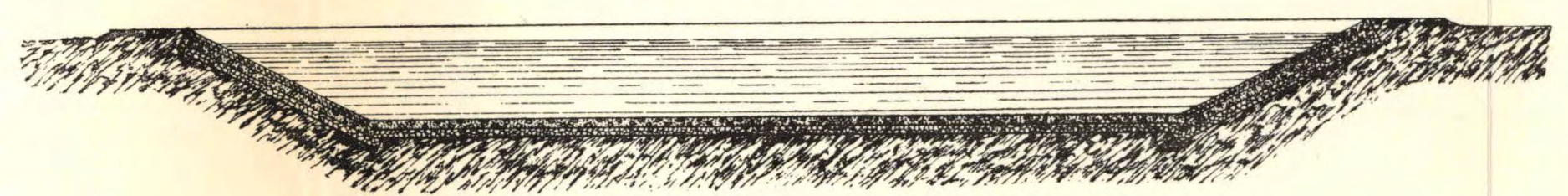

Fig. 61.

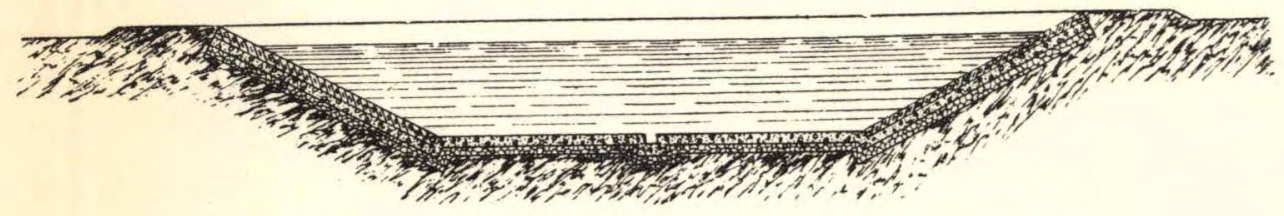

Fig. 61A.

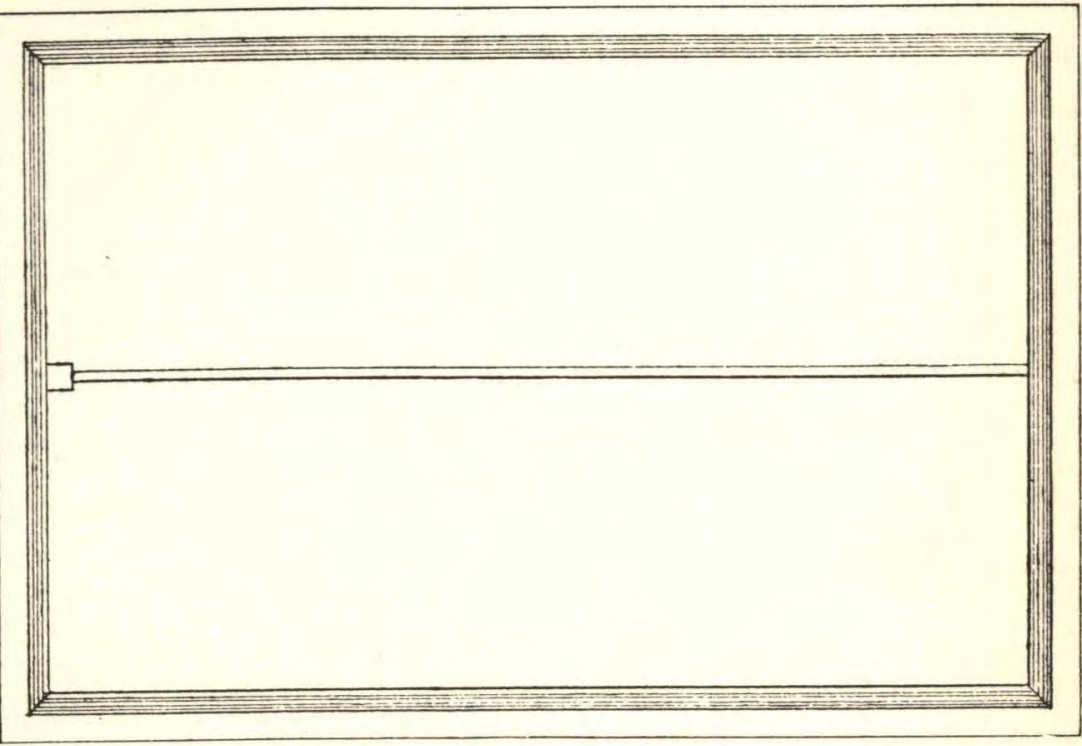

Fig. 62 .

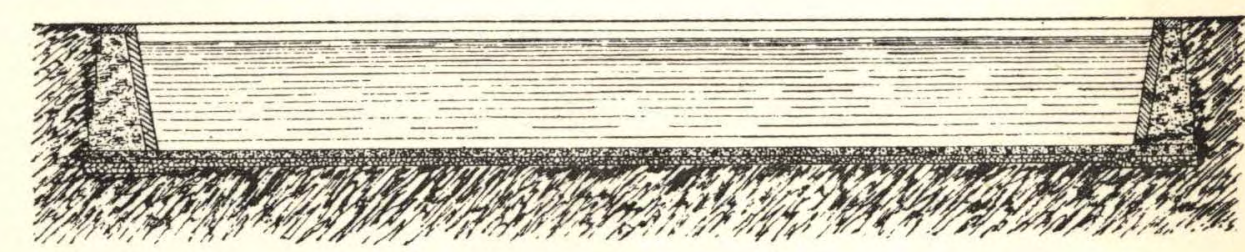

Fig. 63.

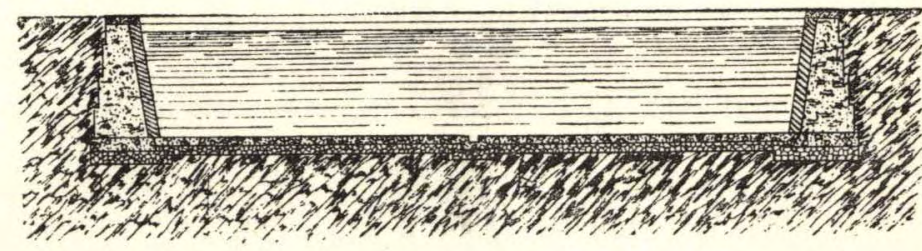

Fig. 63A. 
the reservoir, it will shoot straight across the floor, and the conditions will be the very worst possible. This state of affairs is shown in full arrows. If, on the other hand, it is warmer, the water will rise, as shown by the dotted arrows, and the suspended matter will have the greatest possible distance to settle.

The next possible supposition is that the water enters at the top, and has its exit at the bottom of the reservoir, as shown in Fig. 67. In this case, whether the entering water be colder or

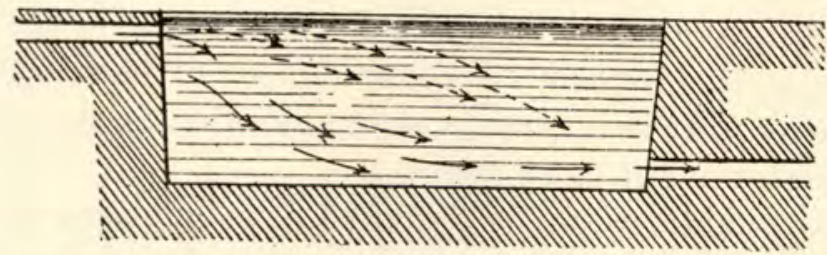

Fig. 67.-Diagram of settling reservoir : Inlet at surface level, and outlet at floor level.

warmer than that already in the reservoir, it tends to take too direct a course from the inlet to the outlet. If it is colder, it will take the course shown in the full arrows; if it is warmer, it will take the course shown by the dotted arrows. The former gives the better settlement.

The only other possible case is that where the water enters at the bottom of the reservoir and leaves at or near the surface level, as shown in Fig. 68. In this case, if the water is colder than that

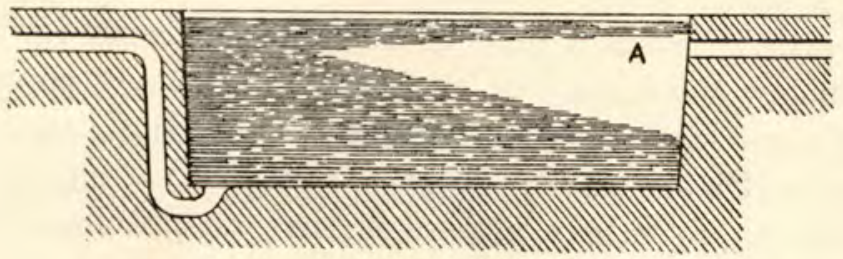

Fig. 68.-Diagram of settling reservoir : Inlet at floor level, and outlet at surface level.

already in the reservoir, it will incline to remain towards the bottom, gradually forcing upwards the water that has been for some time in the reservoir. These conditions give the very best possible settlement. If the water entering the reservoir be warmer than that already in it, it will tend to rise, and to take a somewhat direct course towards the outlet, but still the settlement is very fair; and these conditions of inlet and outlet-that is to say, in which the water enters the reservoir at the bottom and 
leaves it near the surface level of the water-are the best possible for settlement.*

The form of the inlet should be that of a bell mouth, so that the entering of the water may have the least possible tendency to cause currents by its velocity merely, and the bell mouth may with advantage point upwards. This is illustrated in Plate XX. (Figs. 69 to 73. )

With the position of the inlet and outlet as just described, it is evident that the settling and the floating matter will tend to take the positions shown by shading in Fig. 68, there being a certain part of the reservoir, marked $\mathrm{A}$, clear of both settling and floating matter. It is further evident that this is the place from which the water ought to be drawn.

If the constant system be adopted, it is sufficient to have the draw-off pipe situated with its top about a foot below the level of the water, and this arrangement may be adopted when the level of the ground is such that the settling reservoir can never be emptied into the filter beds. It is shown in Plate XXI. in the case of the reservoir with sloping sides (Fig. 74).

In the intermittent system (and in the constant system if it is intended occasionally to draw off the water into the filters), it is desirable to provide some means of drawing the water from a little below the surface, whatever may be the level of the water in the reservoir. There are two common methods of bringing this about. One is by a stand pipe with valves at different levels-a valve tower on a small scale, in fact; the other is by means of a "floating pipe." Such a pipe is kept floating with its mouth a foot or so below the surface of the water by floats of copper, or, in the case of very large sizes, of wrought iron. Both arrangements are shown in Plate XXII. (Figs. 77 to 79.) Except for the liability that there nearly always is that an automatic arrangement may get out of order, the floating pipe is the more efficient arrangement. Details of the floating pipe are shown in Plate XXIII. (Figs. 80 to 83 .)

In any case, the whole of the water in a settling reservoir is never run to the filter beds. In the case of the intermittent system the water is only drawn off to within 2 to 4 feet of the bottom, when the reservoir is filled up again, except when it

* It has been assumed throughout that the water does not fall below $39^{\circ} \mathrm{F}$. $\left(4^{\circ} \mathrm{C}\right.$. $)$, the temperature at which water is at its maximum density. With temperatures between this and the freezing-point, $32^{\circ} \mathrm{F}$. $\left(0^{\circ} \mathrm{C}\right.$.), the tendency of currents to rise or fall will be just the reverse of these indicated. 


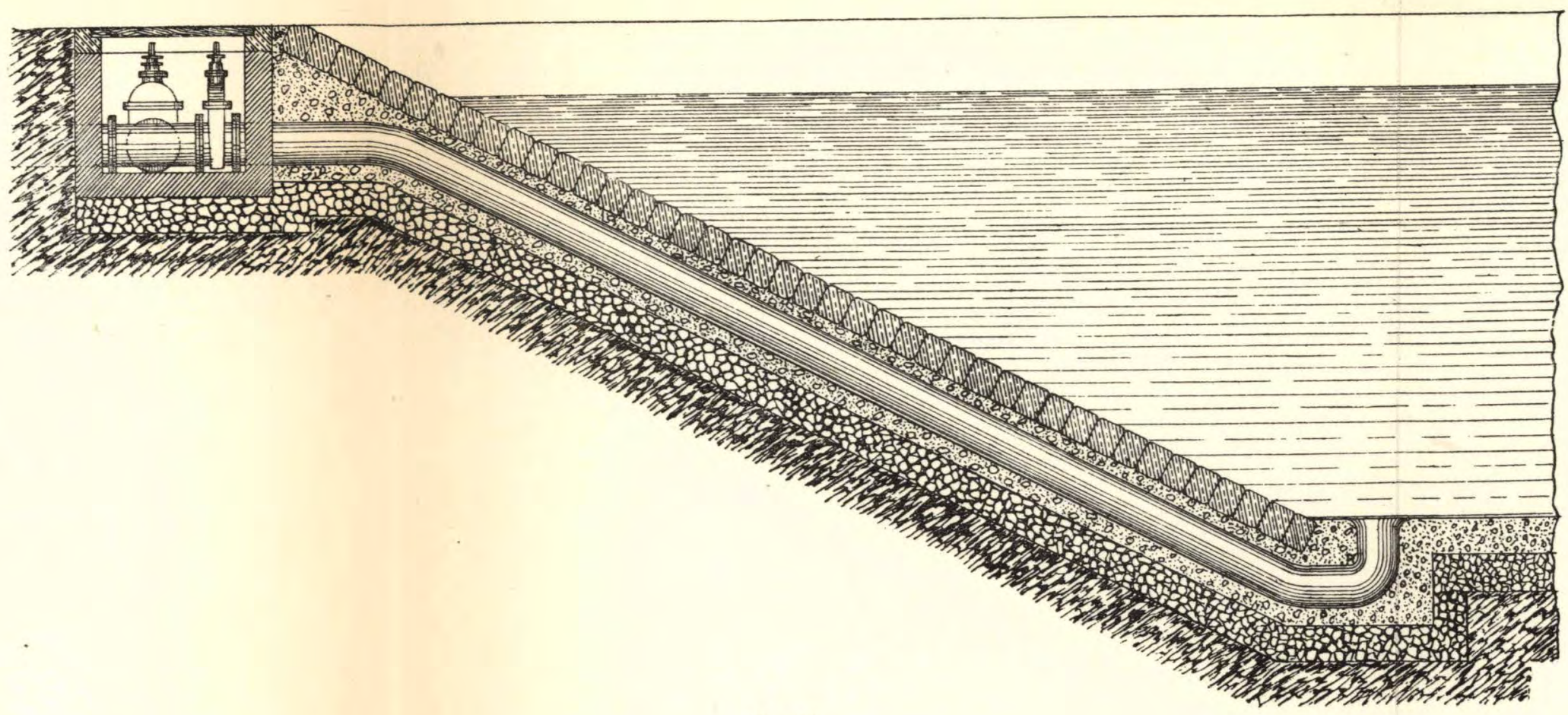

Fig. 69.

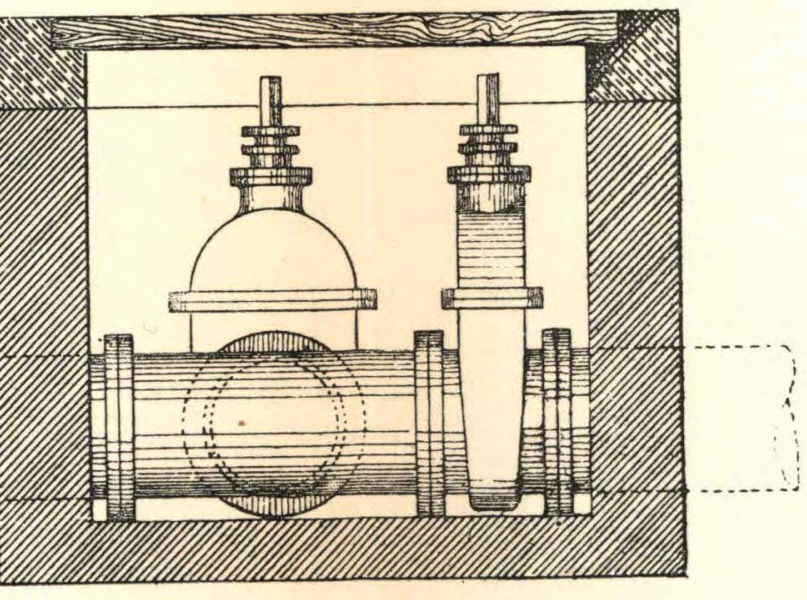

Fig. 70.

Fig. 71.

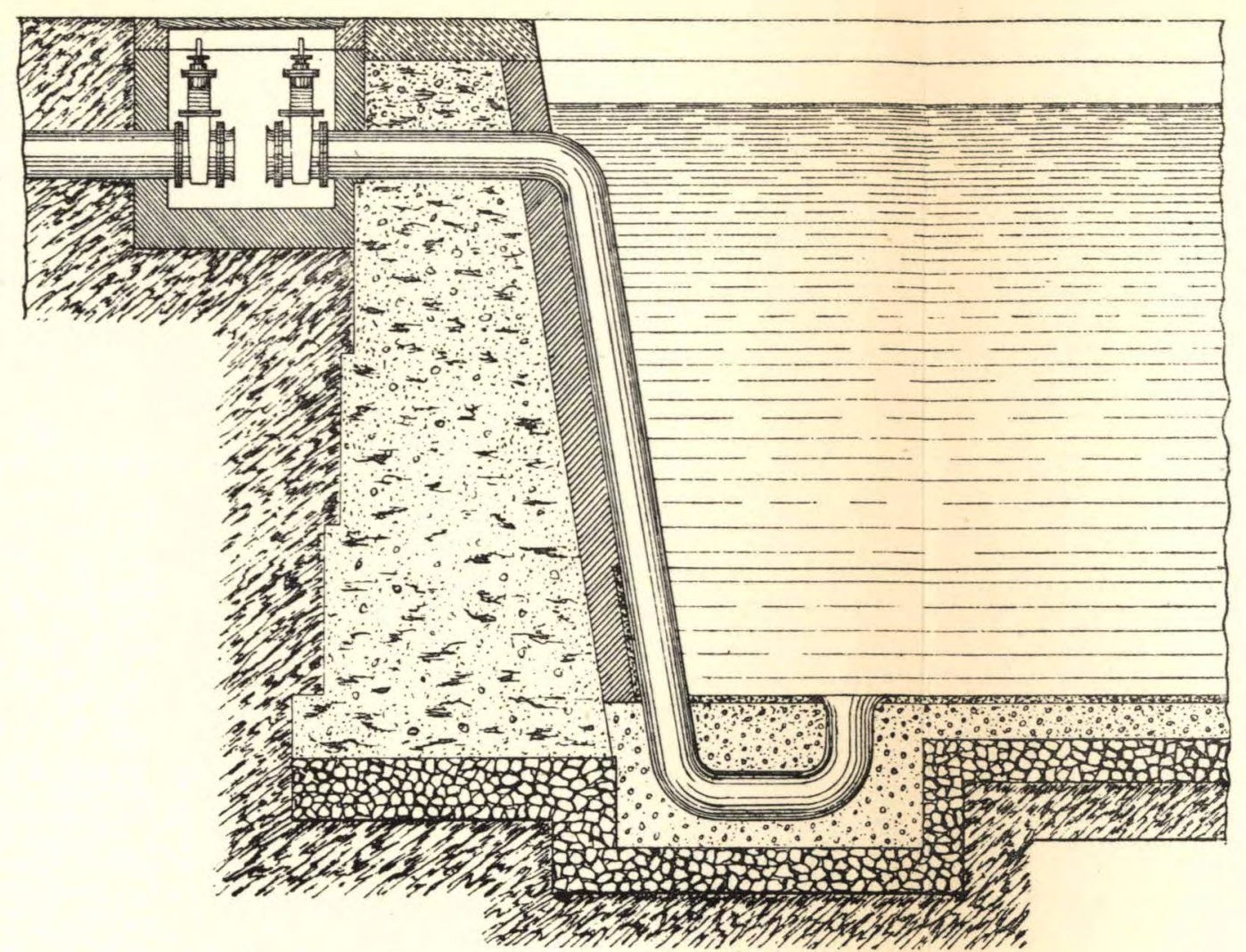

Fig. 72.

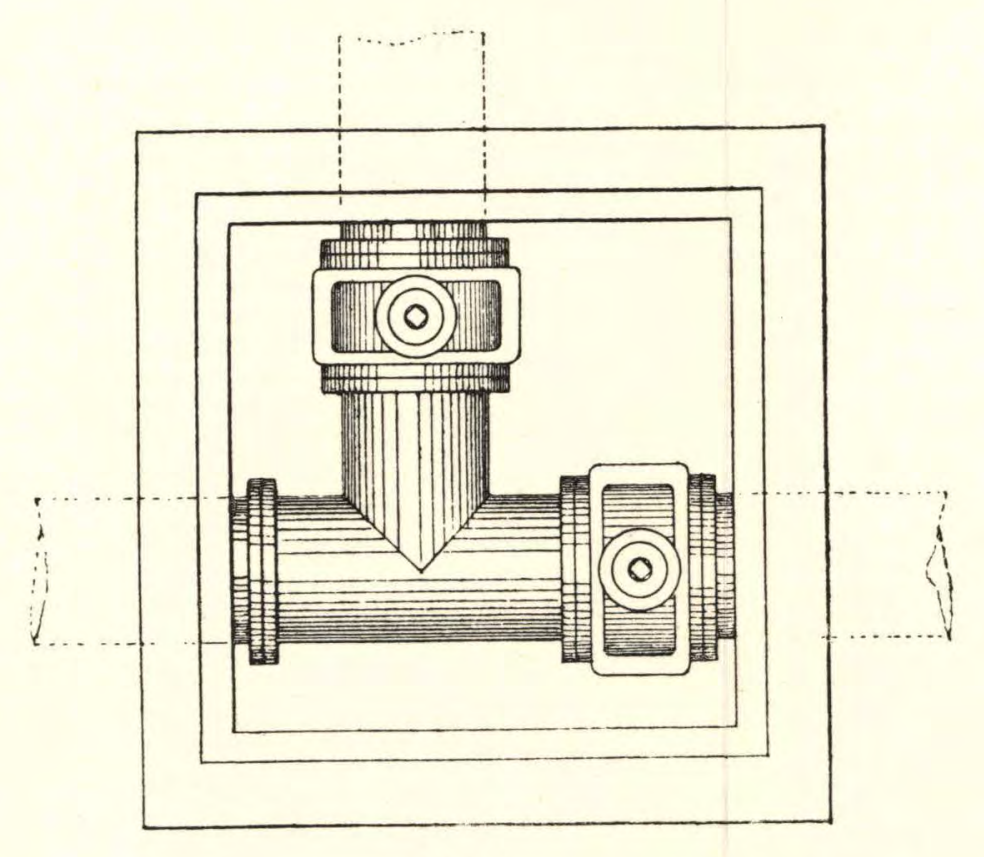

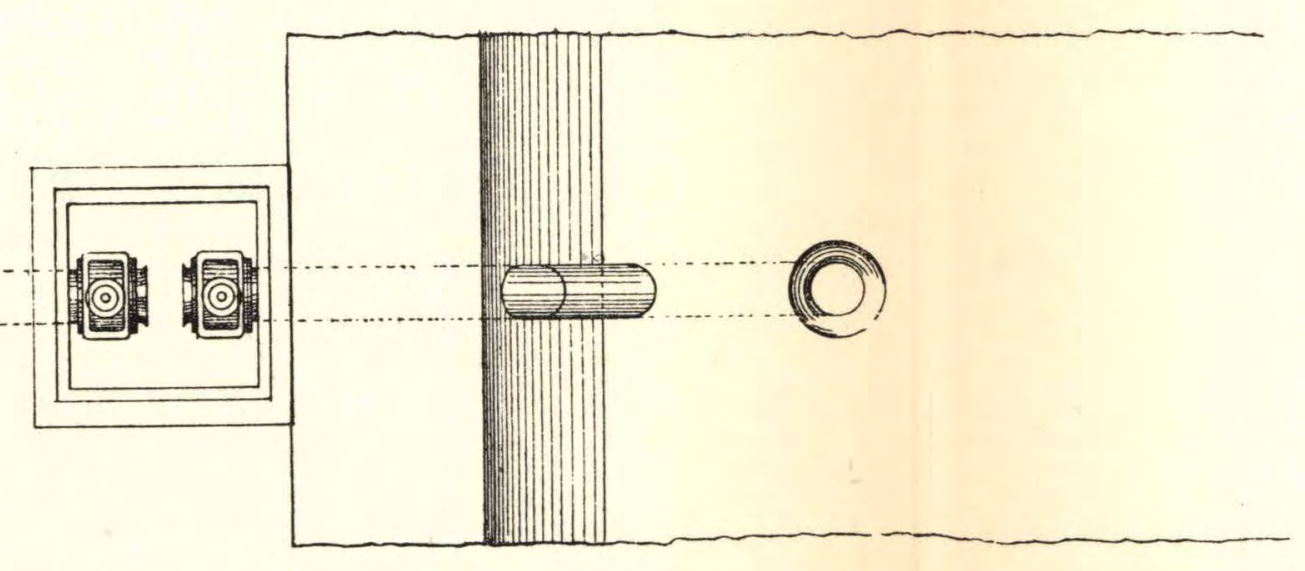

Fiv. 73. 
Plate XXI.
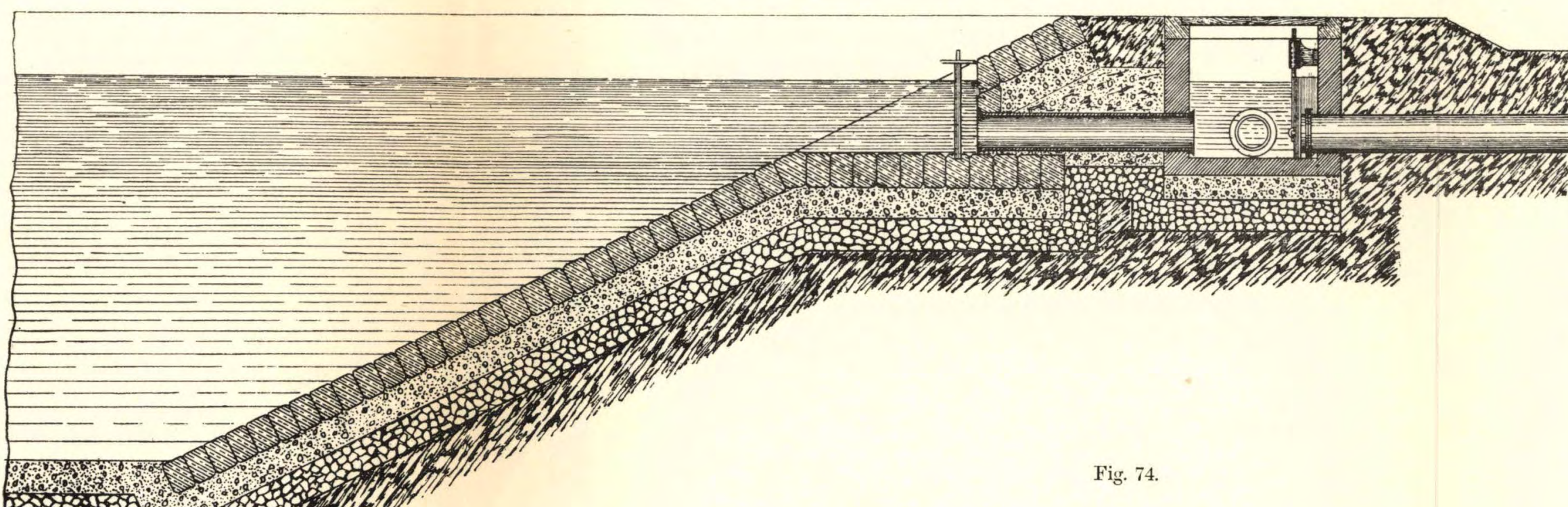

Fig. 74.

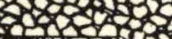

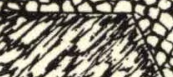

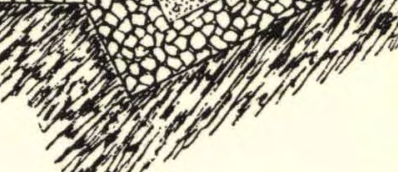

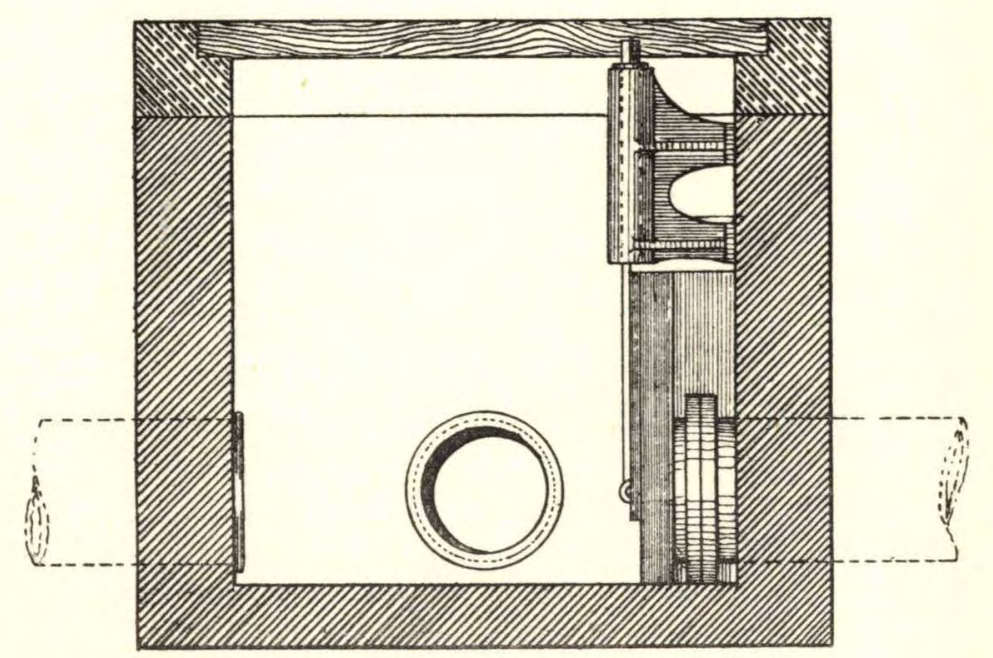

Fig. 75

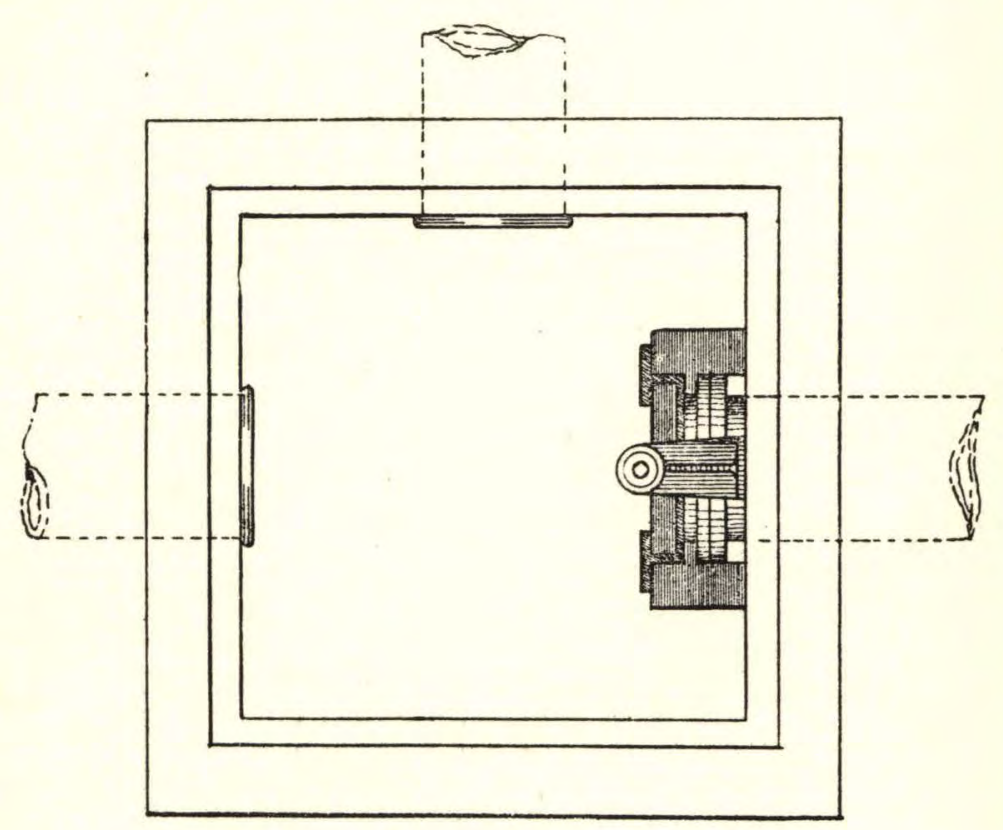

Fig. 76. 

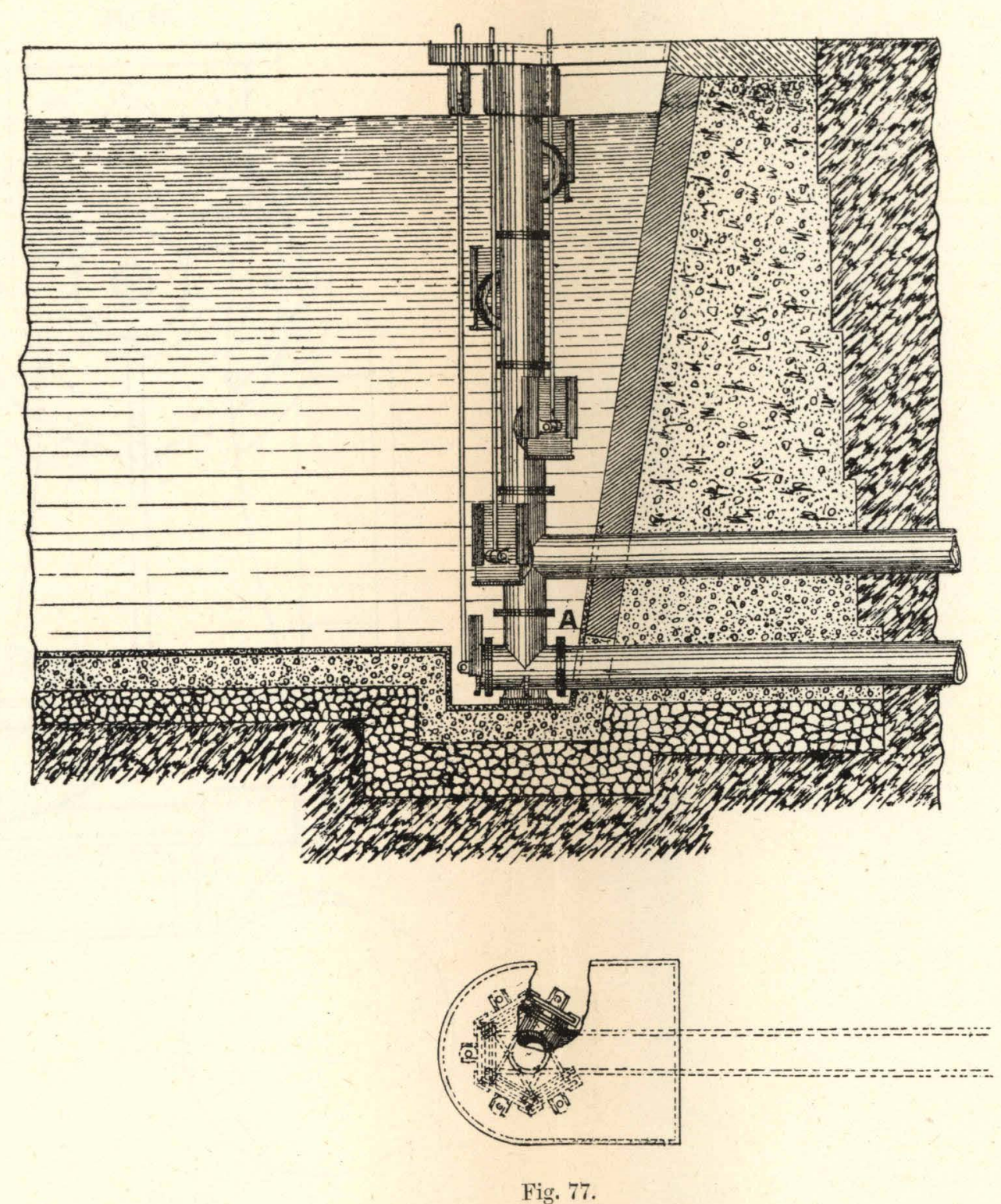

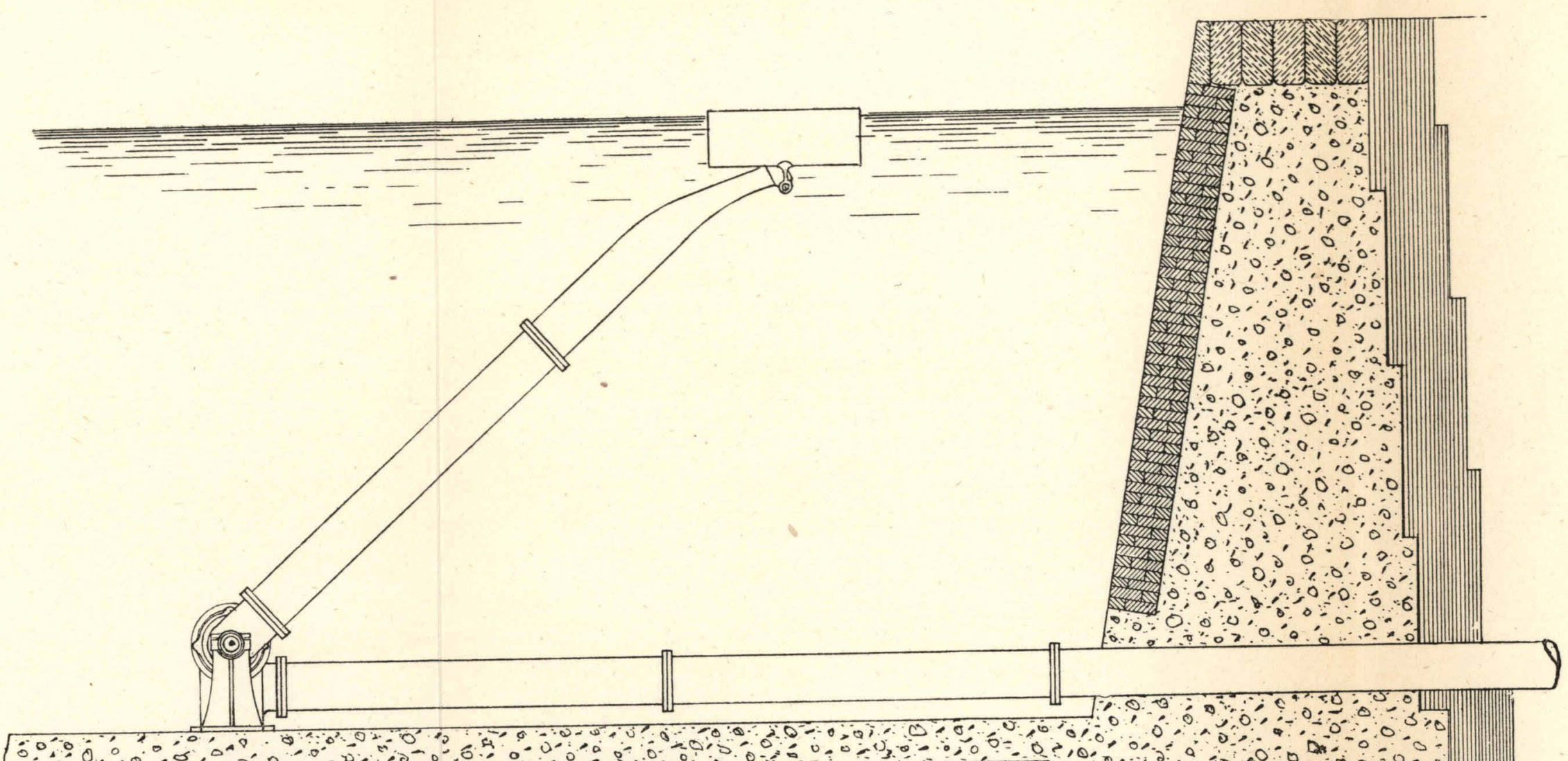

m ndm

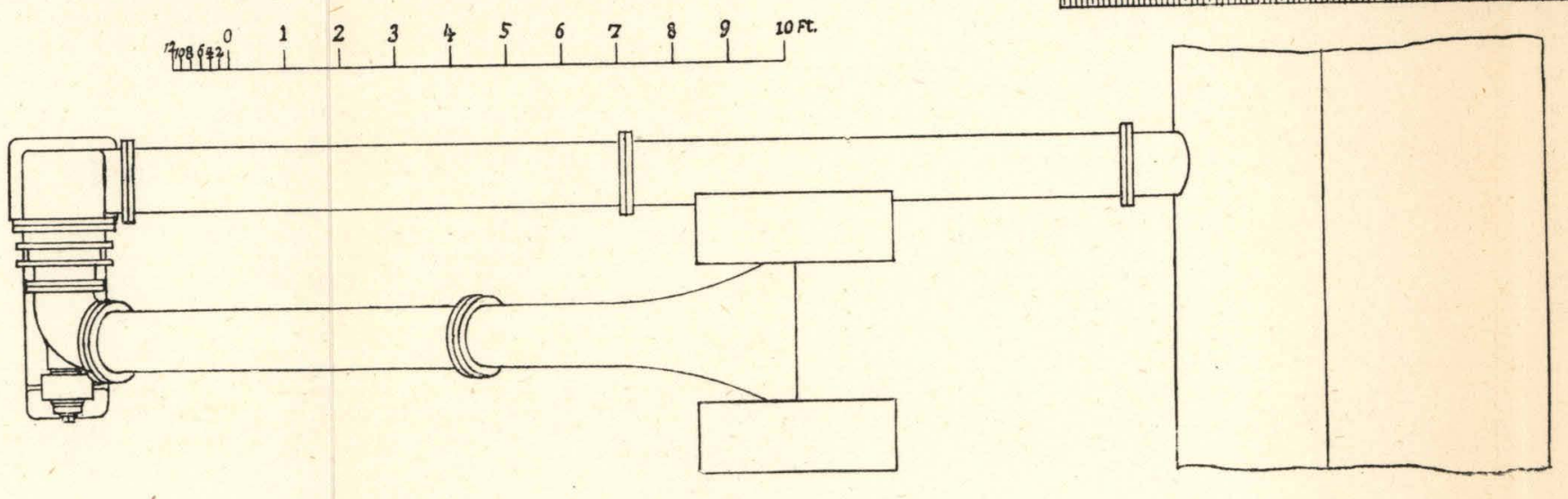

Figs. 78, 79 . 
Plate XXIII.

Fig. 80.
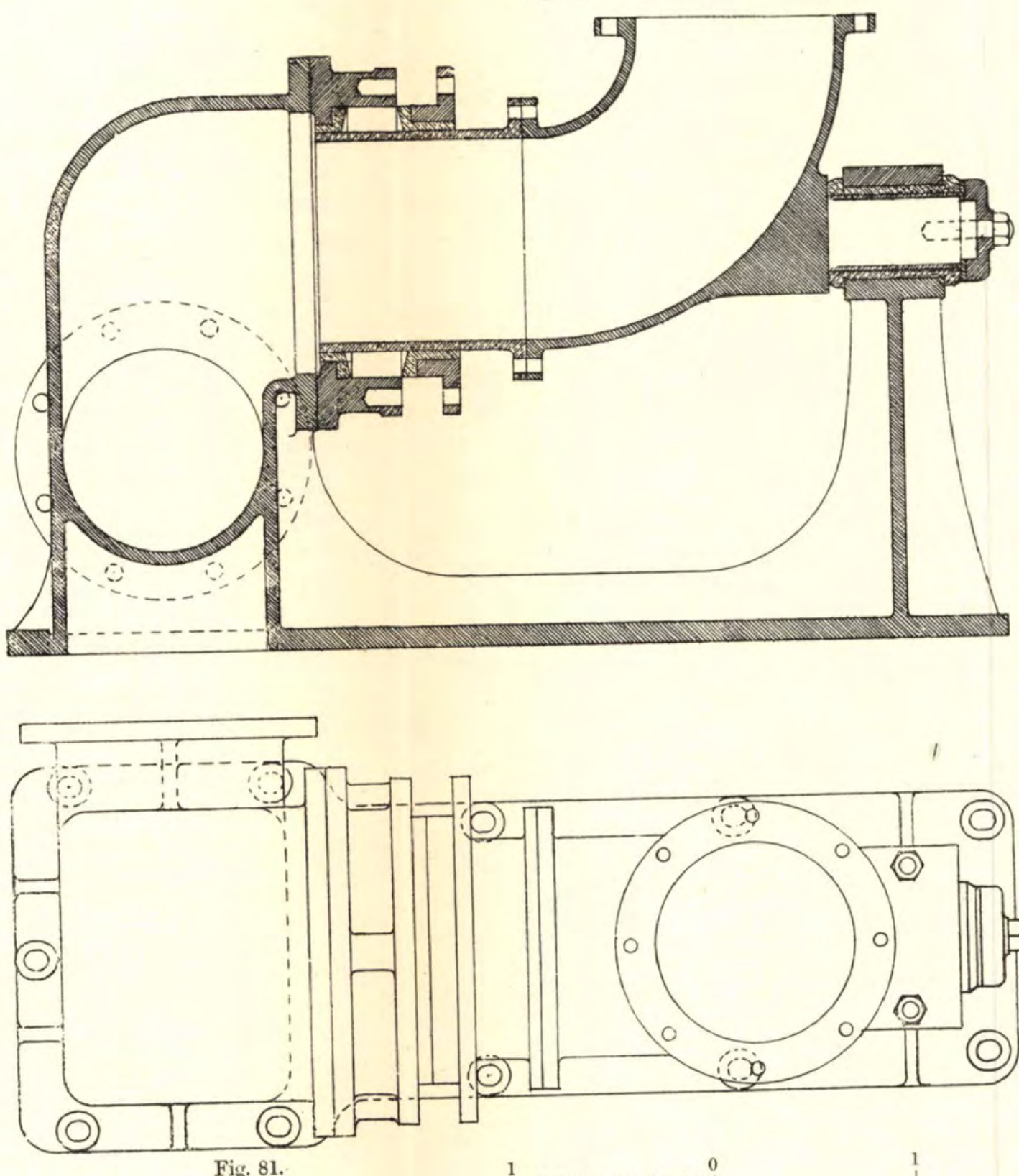

Fig. 82.
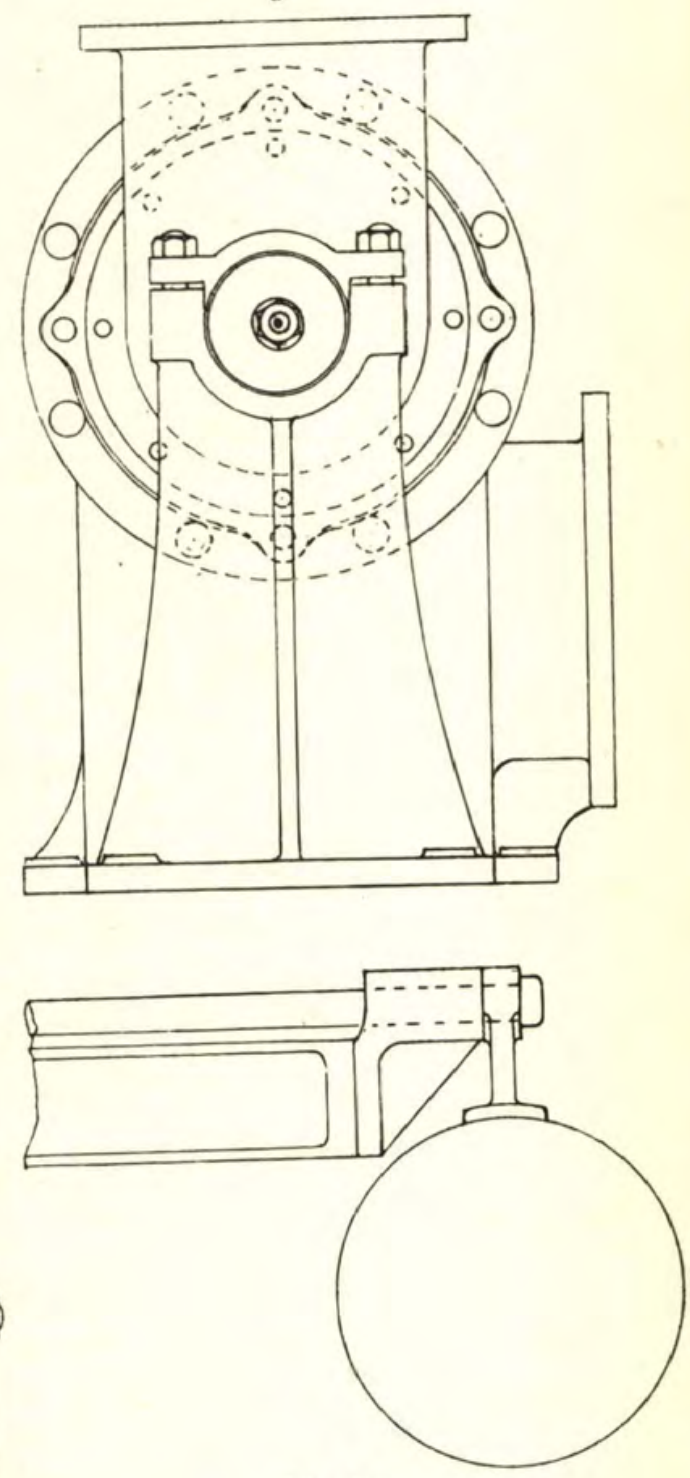

Fig. 83.

Settling Reservoirs: Detalls of Floating Pipe.

[To face page 92. 
needs cleaning. In this case the water is run to the filter beds, either till it begins to run off turbid, or till the lowest level is reached to which it is possible to run off to the filter beds. The rest is then run to waste. The same plan is pursued in the case of the constant system when a settling reservoir has to be cleaned.

The intervals of time between cleanings of settling reservoirs vary very much according to the nature of the water. They may be any period from a month or two to several years.

A drain pipe or scouring pipe, and in case of any danger of overfilling, an overflow pipe, are necessary adjuncts of settling reservoirs. When both are used, they are commonly made in conjunction, as shown in Plate XXIV. If no overflow is needed, the scouring pipe may form part of the stand pipe, by having a diaphragm across it below the lowest draw-off valve, as shown in Fig. 77, Plate XXII. Here there is a diaphragm at A which may consist either of a part of the bottom casting, or of the one immediately above it, or may be in the form of a wroughtiron plate bolted in between these two castings.

As already stated, where it is impossible to drain a settling reservoir by gravity, or where the cost makes it impracticable, it is necessary to provide a pump for draining it. 


\section{CHAPTER XII.}

\section{Sand Filtration.}

The Rate of Filtering Speed Allowable. - When it is thoroughly understood that sand filtration is not a mere straining, as by a sieve, but is effected by surface adhesion, it will readily be understood that it is of the utmost importance to estimate what filtering speed is allowable, and hence to estimate the necessary area of filter beds. By "filtering speed" is meant the velocity with which the whole of the water in a filter bed approaches the sand in a vertical direction. This velocity, multiplied by the area of sand surface, gives the quantity filtered.

When filter beds were first introduced, there were no data for filtering speed, and as the action was looked on merely as a straining action, it is probable that the only limit was taken as that speed which, if exceeded, would result in the washing away of the sand. After a time it became evident that it was not safe to approach such a limit, and it was found that, if certain very moderate velocities were exceeded, filtration rapidly became inefficient. Even after this, however, there was great difference of practice in the matter of the filtration speed allowed. Of late years great light has been thrown on the subject through the study of bacteriology, and an approach to uniformity is coming about. Even now, however, there is considerable variation in practice. Dr. Koch, the eminent bacteriologist, has (the writer understands) come to the conclusion that a filtering speed should never exceed $7 \frac{3}{4}$ feet in twenty-four hours. It seems unlikely that any such hard-and-fast rule can hold good for all cases," for there can be no doubt that the efficiency of filtration varies with many circumstances-with the purity or the reverse of the water, for example; with the nature of the sand ; and with the temperature.

* A series of experiments, both biological and chemical, carried on in connection with the Osaka (Japan) waterworks, gave very different results from this.

It has recently been discovered, at the Berlin waterworks, that covered filters are much less efficient than open. 
Plate XXIV.

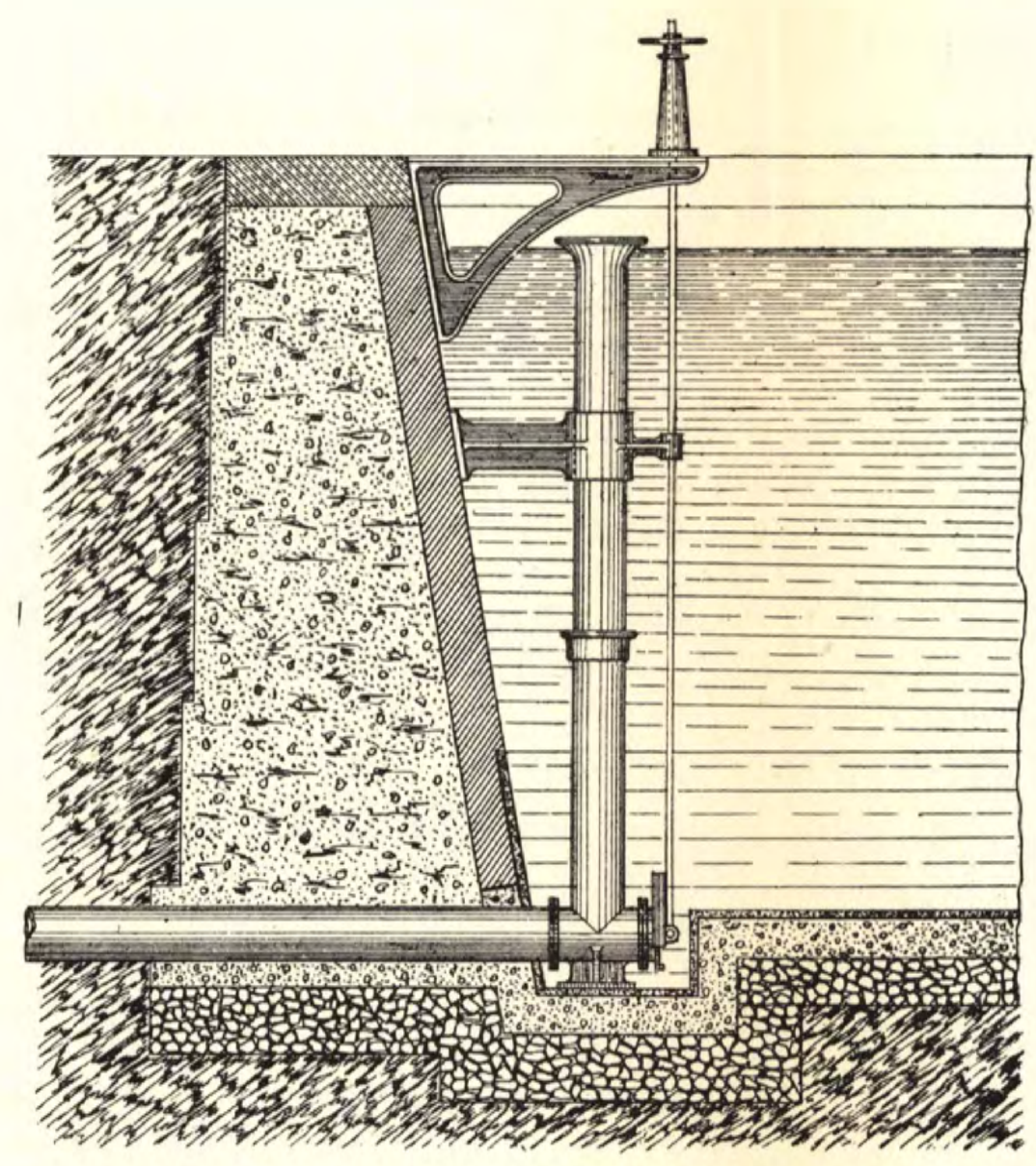

Fig. 84.-Overflow and Drain Pipe Combined.

[To face page 94. 
On the other hand, the much higher velocities - 16 feet in twentyfour hours or even more-adopted by some English engineers, are undoubtedly too high.

It is with some diffidence that the writer states the conclusion he has come to-namely, that a maximum filtering speed of 10 feet in twenty-four hours is quite permissible in the case of water already fairly good. That is to say, with arrangements properly made so that the daily filtering speed is constant, the area of the filtering beds need not be greater than will permit a filtering speed of 10 feet in twenty-four hours for maximum daily consumption, or, say, mean annual consumption $\times 1 \cdot 4$.

In this connection it should be borne in mind that a provision for additional filtering capacity always is, or ought to be, part of a waterworks scheme, and that, if filtration is found to be inefficient on account of too great filtering speed, it is very easy to add more filtering capacity. Nevertheless, the writer considers that there ought always to be, even from the first, such area of filter beds that the velocity need never exceed 10 feet in twenty-four hours.

The filtering speed once decided on, in order to get the total area of filter beds in use at one time, we have merely to take

Where

$$
a=\frac{q}{f}
$$

$q=$ maximum quantity of water consumed in one day in cubic feet ;

$f=$ filtering speed in feet ;

$a=$ area in square feet.

This naturally leads up to the question of the number of filtering beds to be provided.

Number of Filtering Beds.-Filtering beds have to be cleaned-an operation that will be described farther on-at periods which vary according to the condition of the water as it comes on for filtration. The period ought never to be less than ten days. A common interval between cleaning is about a month, although the writer knows of one case where water has been passing through a set of filter beds for several years without their having been cleaned or showing any approaching need of cleaning !* This, however, is a case where filtering beds were simply unnecessary, $\dagger$ the water being spring water of almost

* The small waterworks at Hatanomura Osumi Gori, Japan.

+ See note 8 , Appendix II. 
phenomenal clearness to begin with. To allow of cleaning it is necessary to provide at least one extra filter bed, that can be emptied, the filtering being done by the others. In small waterworks, it is never necessary to provide more than one additional filter bed, there being a total number of two to four beds. In very large works it is desirable to increase the number of beds, as very large beds become unwieldy. In this case it may be necessary to provide two or even three extra beds, especially if the water comes up for filtration somewhat turbid.

The following table is modified from Hennell. It is only intended as a very rough guide :-

$\begin{array}{cc}\text { With a Population up to } & \text { No. of Filter Beds. } \\ 2,000 & 2 \\ 10,000 & 3 \\ 60,000 & 4 \\ 200,000 & 6 \\ 400,000 & 8^{*} \\ 600,000 & 12^{*} \\ 1,000,000 & 16^{*}\end{array}$

Above this in proportion to the population.

These numbers include the filter beds out of use for cleaning.

Form of Filter Beds in Plan.-As in the case of settling

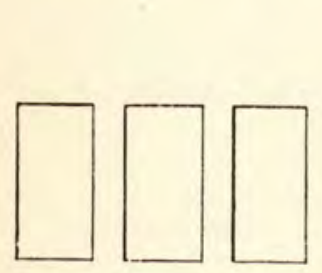

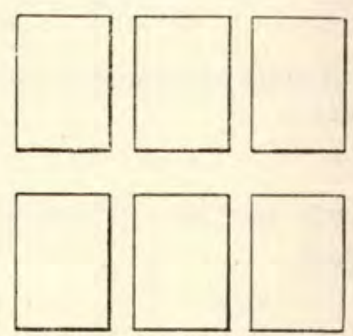

Fig. 86.-Arrangement for six filter beds.
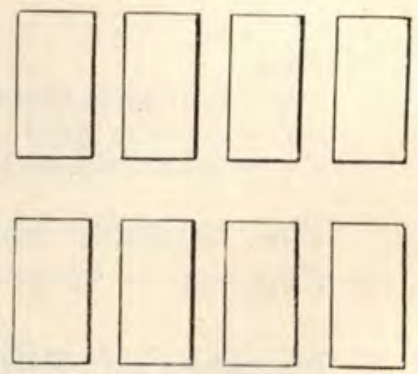

Fig. 87.-Arrangement for eight filter beds.

reservoirs, the form of filter beds in plan has often to be adapted to the shape of the available ground. When this is not the case, a rectangular form of plan is the commonest. When there are two or three filter beds they are commonly arranged side by side, as shown in Fig. 85, and it is generally most convenient to have the length greater than the breadth. The same applies to such numbers as 6, 8, and 12, as shown in Figs. 86, 87, 88.

* With these numbers it will probably be necessary to have two or more filtering beds of 9 at a time for cleaning. 
On the other hand, with such numbers as 4,9 , and 16 , it is generally convenient to have square beds arranged, as shown in Figs. 89, 90, 91.

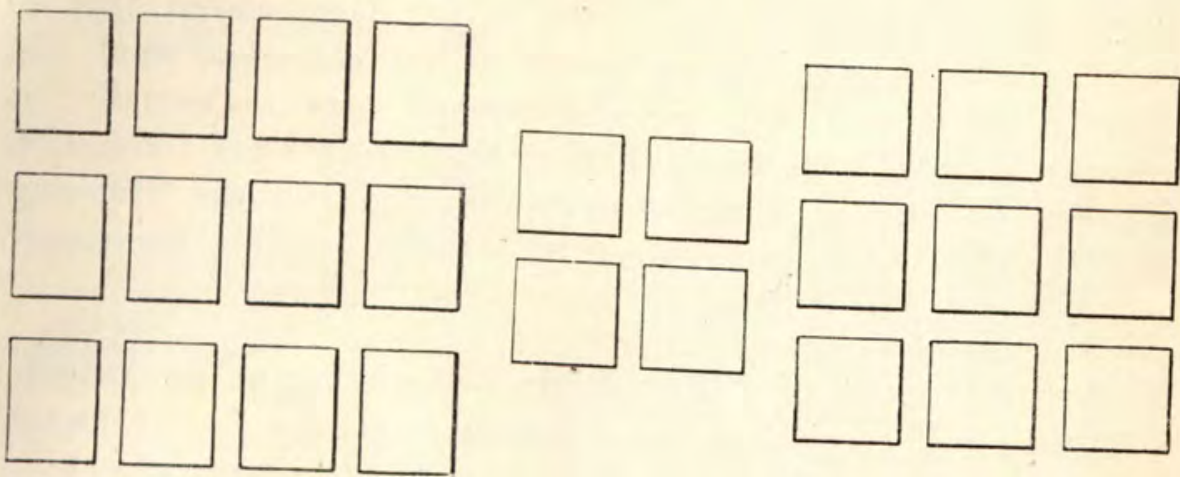

Fig. 89.-Arrangement for twelve filter beds.

Fig. 89.-Arrangement for Fig. 90.-Arrangement for four filter beds. nine filter beds.

Roughly, in fact, the whole area covered by the filter beds

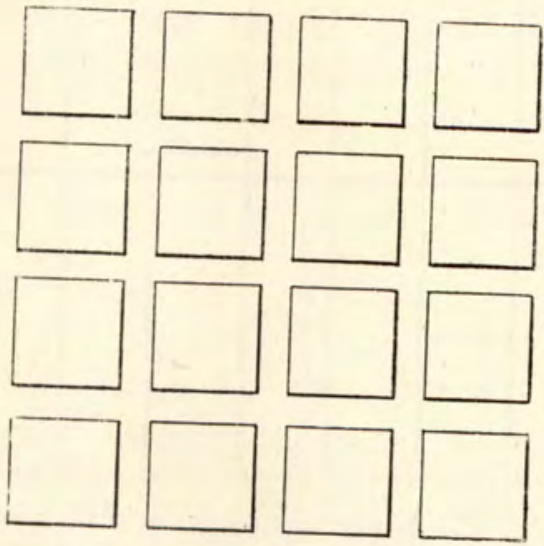

Fig. 91.-Arrangement for sixteen filter beds.

may conveniently approach a square, but in very many cases local circumstances will alter this form.

Depth of Filter Beds.-The cost of filter beds increases very rapidly with the depth, and it should be said at once that in designing a filter bed it is desirable to make it as shallow as is consistent with efficient filtration. Some of the older forms of filter beds show extraordinary depths, as much even as 14 feet, and we have such successions of material below the water, and working downwards, as Harwich sand, hoggin, fine gravel, coarse gravel, and boulders. 
These great depths were adopted on account of two misapprehensions. First, it was thought necessary to have a graduated series of particles, from fine sand to gravel, lest the sand be washed away. Now it has been shown that so long as a moderate filtering speed is not exceeded, sand laid directly on gravel will not be washed away. Secondly, it appears to have been thought that there was some connection between the depth of water over the sand and the "filtering head." As will be seen presently, no such relation necessarily exists.

Arrangement of Filter Beds.-Beginning at the bottom, a filtering bed consists of the following:-(1) the floor, (2) some draining arrangement, (3) a bed of sand, and (4) a layer of water.

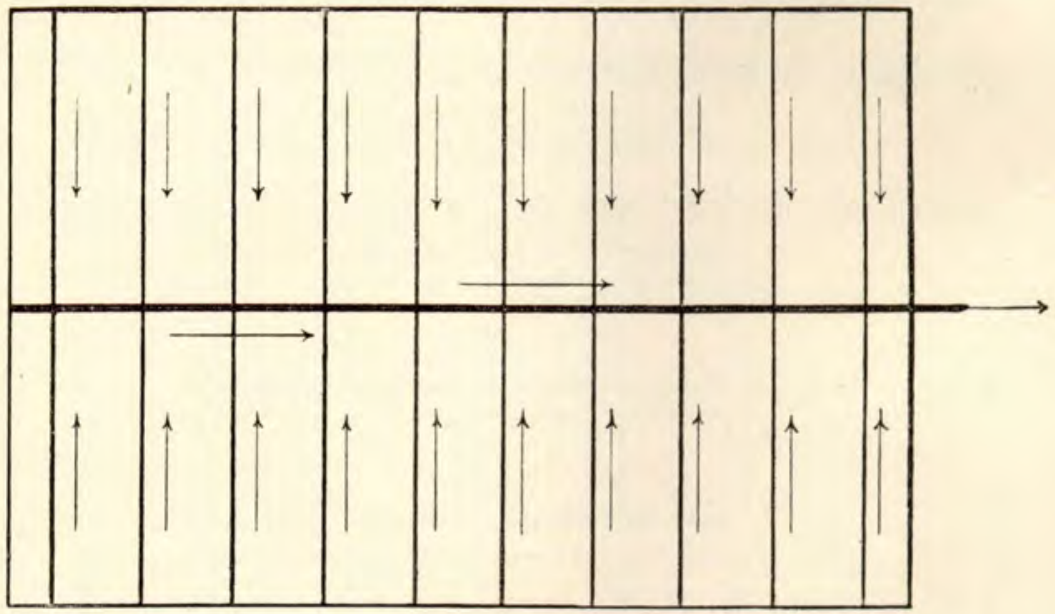

Fig. 92.-Arrangement of drains of filter bed.

The floor is commonly made of concrete, made watertight either by careful rendering in cement or by backing with puddle. For details as to thickness, \&c., Plate XXV. may be consulted.

Drainage Arrangement.-There is no difficulty in efficiently draining away the filtered water. Even the crudest of methodsnamely, that of filling the bottom of the filter bed with boulders, above which come broken stones, then gravel-is quite efficient, but what is wanted is an efficient method in itself inexpensive and taking up the least possible depth.

This puts all methods that the writer knows of, except two, out of court. These two methods are those in which a bed of gravel, supporting the sand, is underdrained, in the one case by 
a set of drains, in the other by a cellular brick false floor laid on the real floor.

In the former case the drains, of whatever section, will most naturally take the form shown diagrammatically in Fig. 92-that

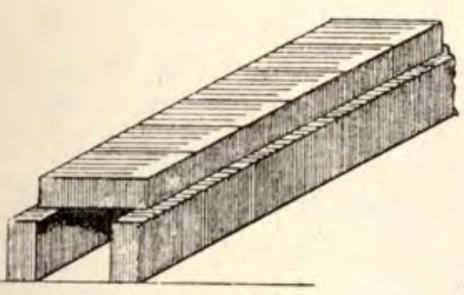

Fig. 93.--Section of brick drain for filter bed.

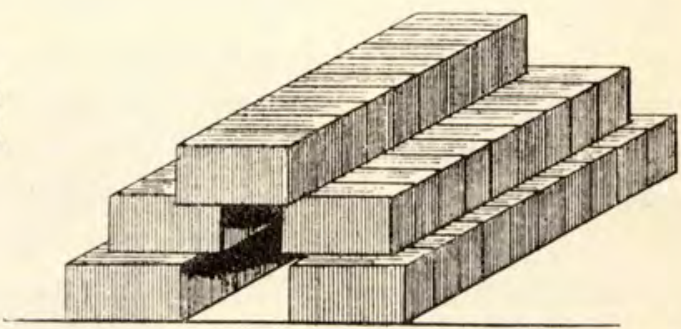

Fig. 94.-Section of brick drain for filter bed (another form).

is to say, a main drain down the centre of the filter bed, with branches junctioning into it at right angles from either side.

The drains are sometimes made of bricks, as shown in section in Figs. 93, 94, but stoneware pipes, such as are used for house drainage, are to be preferred. The size of the branch drains and their distance apart will be decided by the following considerations :-

(1) In no case should there be more than 6 feet distance

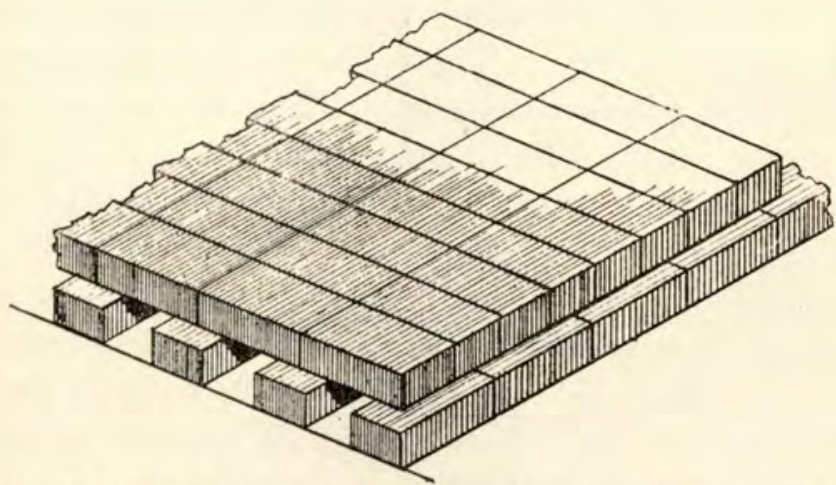

Fig. 95.-Cellular brick floor for filter bed (New River Company, London).

between branch drains, otherwise certain parts of the filter beds will do appreciably more work than others, and the efficiency of filtration will be reduced.

(2) The velocity of flow in the drain should not exceed 2 or, at the very most, 3 feet per second.

Whatever form or size of branch drain be adopted, there must be at least 6 inches of gravel over the top of it.

The cellular brick floor, first adopted by Mr. Muir for the New 
River Company (London), is, in the writer's opinion, by far the best method of draining a filter bed. The arrangement of the bricks is shown in isometric projection in Fig. 95, and in section in Plate XXV. (Figs. 96 to 100). The bricks are covered with a layer of fine gravel, which need not be more than 6 inches deep.

This method has the following advantages:-(1) it gives perfectly uniform drainage over the whole of the filter bed, (2) it takes up the least vertical space possible, and (3) it forms an arrangement as easily taken up for cleaning as possible.

The sand bed, as constituting the actual filtering material, is naturally the item that needs the most careful attention.

First, as to the sand itself. As has been said, the very finest sand is not the best. The coarseness should be such that the separate grains are quite distinctly visible to the naked eye. The sand should be pretty uniform in grain, and sharp. Of course it should be clean, * but if dirty only in the ordinary sense when found, it is sufficient to wash it. The nearer an approach the sand is to pure silica the better. $t$

The thickness given to the sand bed varies with different engineers. The actual filtration is done in a very thin film on the surface of the sand. When a filter bed has to be cleaned, it is necessary to remove only an inch or so of the upper surface of the sand. It might, therefore, appear that a very thin bed of sand only was necessary. There are reasons, however, for not having less than a fair thickness. Thus the very operation of cleaning would lead to the destruction of the bed were it very thin. Then it is the custom not to replace the film of sand that is removed for cleaning every time that this operation is performed, but to remove film after film till a foot or so has been removed. This is merely for the sake of convenience. On account of these various reasons, it would appear undesirable to have the sand bed of a thickness of less than about 2 feet 6 inches, and 3 feet may be said as about the standard thickness.

Depth of Water over the Sand.-So far as the mere filtration

* See note 9, Appendix II.

$\dagger$ Beautiful sands for filtration are found in Japan. Two sands in particular, from Niijima and Shikene, in the District of Idzu, are the most perfect sands for the purpose the writer has ever seen. These are pure white sands with occasiunal little black spots. When looked at with a magnifier, the white grains are seen to be as clear and transparent as glass, and the black spots consist of magnetic oxide of iron ! There is so much of this that, if a magnet be swept only once through either of these sands, it will pick up quite a considerable tuft of the magnetic oxide. The sands contain (the writer believes) about 97 per cent. of silica. They were discovered by $\mathrm{Mr}$. H. Yoshida about the year 1887 . 


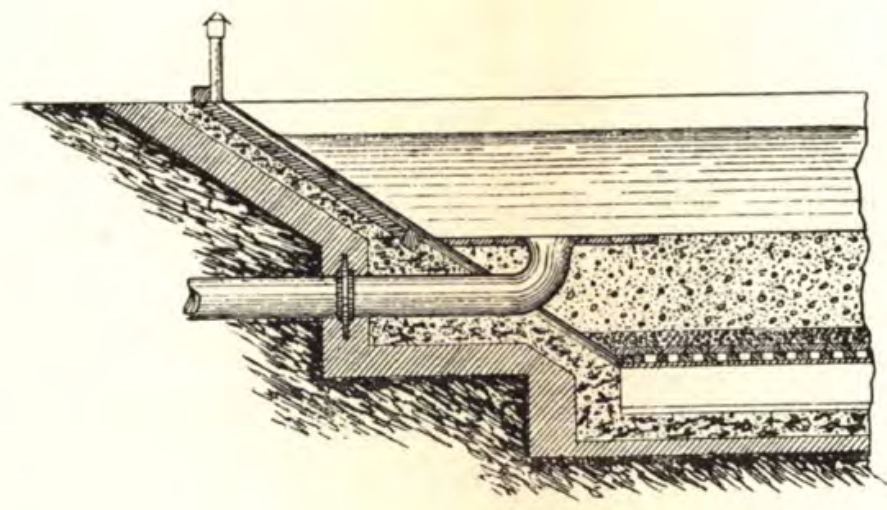

Fig. 96.

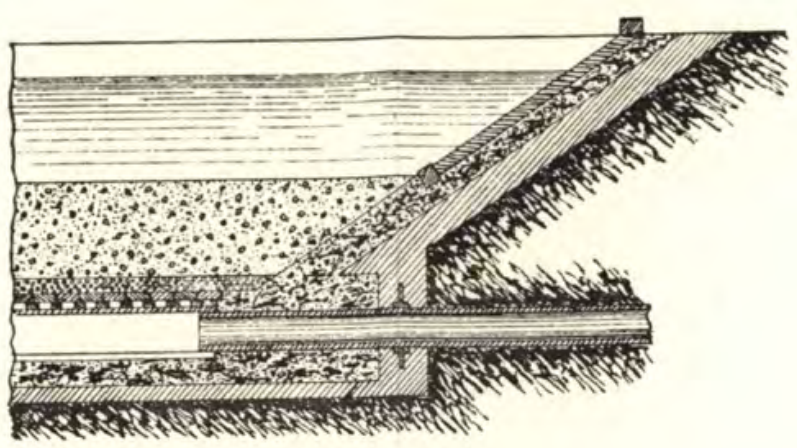

Fig. 97.

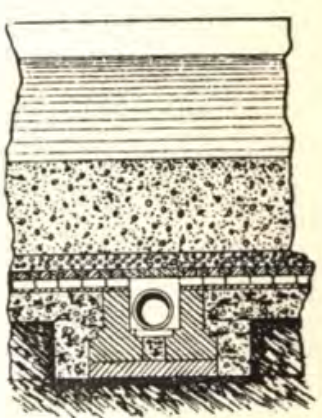

Fig. 98.

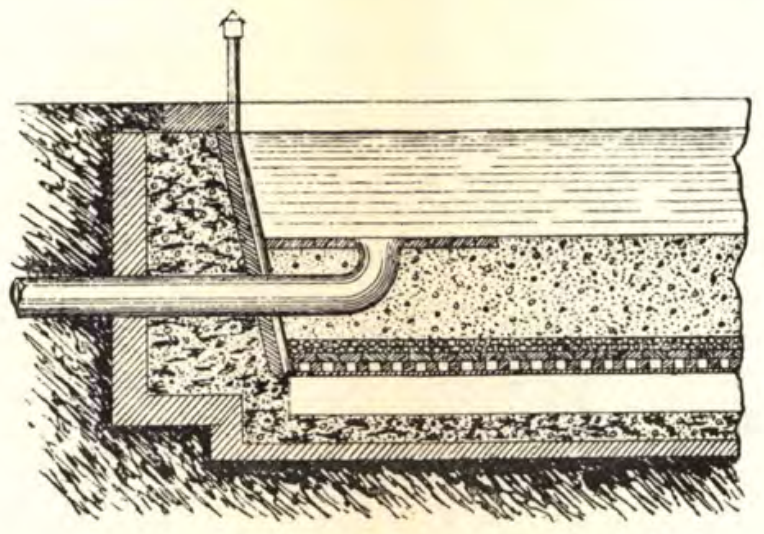

Fig. 99.

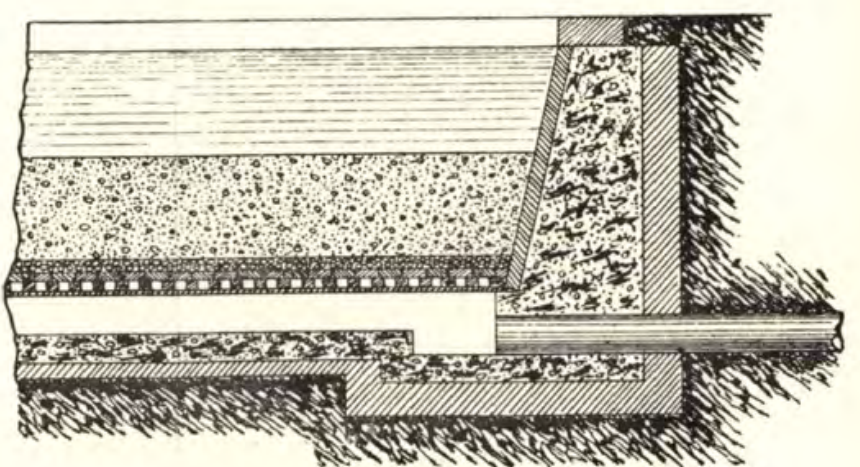

Fig. 100.

Arrangement of Filter Beds, in section (New River Company, London).

[To face page 100. 
goes, it is necessary to have only such a depth of water over the sand that it (the water) may be freely distributed over all parts of the bed, and it is evident that a very thin film of water would be sufficient for this. There are, however, certain practical considerations that make it advisable to have a depth of water much greater than is necessary merely to secure even distribution.

Certain opinions that have been held with regard to the necessity for a considerable depth of water appear to be delusions. The fallacy of the impression that there is a direct relation between the depth of water over the sand and the filtering head has already been mentioned. It seems, however, to the writer that there is not much more reason in an opinion often expressed at the present time-namely, that there is a direct relation between the depth of the water of a filter and the amount to which it will be heated by the rays of the sun, the heat being greater the shallower the water.

If the depth over the sand were such that the heat of the sun could not penetrate the water, there would be reason for such an assumption, as in this case the water would simply heat through the uppermost few feet, the heated water remaining stagnant and protecting the lower layers of water, which would remain cold and be distributed over the sand. This would, however, involve a depth of at least 7 or 8 feet, now never given to the water of filter beds. With the depths commonly given, and with water fairly clear, it is probable that the greater part of the heat of the sun's rays passes through the water, is absorbed by the sand, and is given up by the latter to the water, which becomes uniformly heated by convection.

This being so, it is simply a case of time multiplied by depth of water, and the efiect is the same whatever be this depth. Thus, for example, if there is 1 foot depth of water over the sand, it will, with a filtering speed of 8 feet in twenty-four hours, be exposed to the heat of the sun for three hours. If there be 3 feet of water, there will be three times the quantity to be heated, but it will be exposed to the sun for three times as long, or nine hours. General custom is, however, in favour of a fair depth of water over the sand, and there is the advantage of such depth, that it facilitates the filling of one filter, on first starting, with filtered water from others from below, as will be explained farther on. For these reasons the writer recommends a depth of water of about 3 feet.

There must be a height above the water level of, say, 6 inches for very small filter beds, to 1 foot or even 2 feet for 
large ones. Thus the total depth of filter, according to the system here recommended, will be from 7 feet to 8 feet 6 inches.

Form of Filter Beds in Vertical Section.-The floor of a filter bed may slope a little-say 1 in 100 to 200 - to the central drain and to the outlet, but this is by no means necessary, as it is the hydrostatic pressure of the filtering head that forces the water along the drains. The main central drain should be made of such a size that the velocity of flow of water in it is not more than 2 feet per second, or at the outside 3. Theoretically it might be tapered from nothing at one end to the full size necessary to carry all the water, at the velocities mentioned, at the other, but practically no advantage will be found in this, and it is best made of the same size throughout.

It is customary to ventilate the main central drain and the branch drains also, if the branch-drain system be adopted, by castiron pipes, about 3 inches in diameter, carried to the ground level. This ventilation is by no means necessary. It is intended to provide a free vent for the air on filling the filter beds, but the air will find its own way out without such special vents, particularly if the filling be done from below. The ventilating pipes can, however, do no harm.

As in the case of settling reservoirs, the sides of filter beds may be either nearly vertical, or sloping. In case they are sloping, the slope may be very considerably increased beyond that permissible even with settling reservoirs, at any rate if the depth be kept as small as possible. Thus the slope of the sides of filter beds is often made as great as 1 vertical to 1 horizontal.

The advantages and disadvantages of nearly vertical and of sloping sides are about the same in the case of filter beds as in that of settling reservoirs.

It is commonly laid down that the area of filter beds with sloping sides must be taken as that of the bottom of the sand bed. The writer considers, however, that, if only a reasonable filtering head be allowed to begin with, it is quite permissible to take the area of the filtering bed as that at half the depth of the sand before skimming off the surface for cleaning has begun. His reasons are that the whole of the actual filtration appears to be done in a very thin film of the uppermost part of the sand; and, further, that not more than about a foot-less than one-half of the thickness mentioned above-of the sand should be removed without filling in again with fresh or washed sand. 
Filtering Head.-This is the head of water necessary to force the water through the filter beds, overcoming the friction of the sand and of whatever draining arrangement is adopted. On it depends the speed of filtration, and it is therefore of the highest importance that it be accurately regulated.

For the speed of filtration given above, the filtering head will be only a few inches when the bed is new, or when the sand has just been washed. It gradually increases, however, as the sand gets clogged. When it reaches about 2 feet 6 inches, or, at the outside, 3 feet, the filter bed needs cleaning, and the head should never on any account be allowed to exceed this latter figure, otherwise the sand will be inconveniently compacted, and very likely fissured, allowing unfiltered water to pass.

The cut shows diagrammatically the drain from a filter and

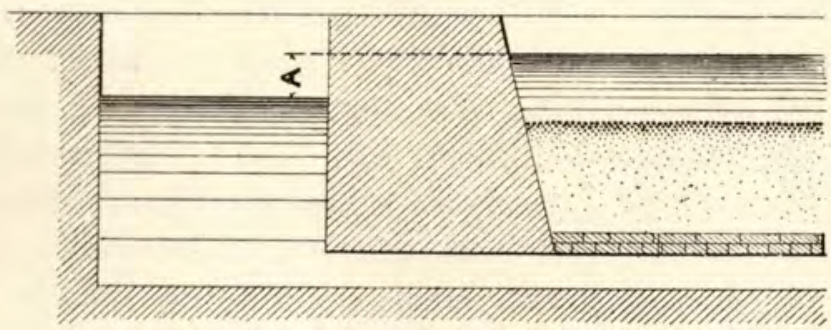

Fig. 101.-Diagram illustrating the filtering head.

a filter well. The level of the water in the filter well is that of the highest water in the clean-water reservoir plus the small head necessary to drive the water to this reservoir. The difference in level of this water in the well and that in the filter bed-that is to say, $\mathrm{A}$-is the " filtering head."

Were the arrangement merely that shown diagrammatically in the cut, there being no check for the water between the filter and the filter well, the action would be most imperfect. At first the water would flow through the filter with impetuous velocity, the filtering head being chiefly absorbed by the draining arrangement, and the filtration would be very inefficient. Soon the filter bed would clog, the velocity would be reduced, and the sand would get compacted, or very likely fissured.

The commonest arrangement for controlling the flow is merely a sluice valve between the filter bed and the well, which is openeri more or less, as may appear necessary. As, however, the friction of the bed is constantly varying, this arrangement is most 
imperfect, it being impossible to so regulate the opening of the valve that the flow can be kept uniform.

It is necessary to have some arrangement for regulating accurately the filtering head, and to have such arrangement attached to each filter.

Writing of this matter in 1866, Mr. James P. Kirkwood, C.E., ${ }^{*}$ says :-

"The English filters are all deficient as regards any arrangement for measuring" (or regulating) "the precise flow from each filter, or the precise" (filtering) "head of water on each filter while it is in action. . . . . In London, where the service of each company is effected by steam power, the daily or hourly delivery of the pumps forms the measure of the amount of water flowing through the filters. The engineer knows by this means when the filtering area is too small, because, in that case, the pumps are inefficiently supplied; and he would know if the water was passed through the filter too rapidly by the want of that perfect clearness that an efficient filtration always produces; but of the separate action of each individual filter bed he is ignorant, except by guess. The attendant can see when the filter bed has ceased to operate by its ceasing to pass the water thrown on it, and he can see when it passes the usual amount too rapidly, and can check this tendency by lowering his stopcocks and allowing the water to lower upon the filter bed; but his judgment may frequently be at fault in both cases, and there ought to be something more than the instincts of an intelligent labourer to regulate points of so much practical bearing on the proper working of those filter beds, as the varying amount of water delivered upon them, and the constantly varying head, required to pass that water under the changing conditions of the sand bed."

\section{Filling Filter Beds from below with Filtered Water.} -When filtering plant is first started, it is generally necessary to fill the filters cautiously from the upper side with unfiltered water, but once filtration has started, the beds should be filled

* "Report on the Filtration of River Waters, for the Supply of Cities, as practised in Europe, made to the Board of Water Commissioners of the City of St. Louis," by James P. Kirkwood, C.E. (New York: D. Van Nostrand). This bookalthough dated 1869 , and describing investigations made three years before that time - is the most complete, and in many ways the best, work on sand filtration of water that the writer knows. Most that has been written in text-books, encyclopædias, dictionaries, \&c., since the above-mentioned date, on sand filtration, is simply a repetition of what is in this report, generally used without acknowledgment. 
from below with filtered water. The reason is that otherwise the filtering speed is not in any way under control till the water has reached a level a little over that of the surface of the sand. The water simply spreads itself over the sand in the immediate vicinity of the inlet orifice, and then sinks through the bed at whatever speed it may, there being no control at all over this speed, so that the first water sent into the filter bed after cleaning is always imperfectly filtered. By filling from below with filtered water from the other filters this difficulty is overcome. Immediately that the water covers the sand for a depth of 2 or 3 inches, water may be admitted in the usual way.

There are several devices for regulating the filtering speed of filtering beds accurately, some of which also provide for filling from below. Plates XXVI., XXVII., XXVIII. and XXIX. illustrate several such arrangements. The first, shown in Plate XXVI., Figs. 102 to 105, is that of Mr. J. P. Kirkwood. It is exceedingly simple. It consists merely of a sluice, $\mathrm{s}$, that can be lowered so as to allow the water to flow over its top. By adjusting it from time to time so as to keep the depth of water over its top constant, the flow of water remains constant. After the water has been drained off, and the filter has been cleaned, it might be filled up from below by entirely lowering the sluice, when the water would "back up" the "gathering drain" from the "conduit to clear-water well;" the water, of course, actually coming from the other filters.

The next arrangement illustrated is that of Mr. Henry Gill, M.I.C.E., who has successfully employed it in connection with the Berlin waterworks. It is thus described by Gen. A. De C. Scott * (see Fig. 106, Plate XXVII.) :-

"Three small chambers had been constructed which he should call A, B, and C. A abutted against the outside wall of the filter, $\mathrm{B}$ abutted on the outside wall of $\mathrm{A}$, and $\mathrm{C}$ on that of $\mathrm{B}$, so that the chambers formed a row extending outwards from the filter. A pipe passed through the wall common to $\mathrm{A}$ and the filter, the mouth being just above the bed of the sand. The pipe after entering $\mathrm{A}$ was bent upwards and carried through the roof of $\mathrm{A}$ into a room built over $\mathrm{A}$ and $\mathrm{B}$; floats and rods were fitted to that pipe, to a second pipe in $\mathrm{A}$ open to the water, and to a similar pipe in chamber B. In the wall of $\mathrm{A}$, common to the filter, and at the floor level, was an aperture opening into the

* Proceedings of Institution of Civil Engineers, vol. c., page 292 et seq. 
latter at its base, and through which filtered water was free to pass.

"In the wall of $\mathrm{A}$ common to $\mathrm{B}$, and also at the floor level, was an opening into B that could be closed wholly or partially by a sluice shutter worked in the upper room. In the wall separating $\mathrm{B}$ and $\mathrm{C}$ was formed an aperture rectangular in elevation, with its sole about 1 metre 56 centimetres (5.12 feet) above the floor of chamber $\mathrm{s}$, and opening into c. To that aperture, and flush with the face of the wall in $\mathrm{B}$, was fitted a brass or gun-metal plate with bevelled edges. A pipe, controlled by a sluice valve, passed at floor level from chamber $\mathrm{B}$ to chamber $\mathrm{c}$, and gave the means of flushing out $\mathrm{A}$ and $\mathrm{B}$ when necessary. In $\mathrm{c}$ were outlets controlled by valves, and by which water passed to the filtered water or to waste, as the case might be.

"The object of the whole arrangement was to enable a constant head of water to be maintained in chamber $\mathrm{B}$, on the thin-lipped rectangular orifice, in the metal plate already referred to, and thus to secure a constant discharge from the filter. The constant head on the orifice was secured by the action of the shutter at the bottom of chamber $\Lambda$, regulated by the readings of the gauge rods and floats in chambers $A$ and $B$.

"The flow of water to the filter was also regulated by a sluicevalve, which was automatically controlled so as to automatically maintain a constant depth of water on the filter. As the filter became gradually foul, the flow through the material would gradually decrease, but by adjusting the valve in $A$ so as to increase the aperture into $\mathrm{B}$, the charge on the metal plate could be kept up, and also the water in A would fall, giving a greater head on the filter required to maintain the normal rate of flow through the sand. At last the water level in A would fall to the normal level of that in $\mathrm{B}$, when the regulated flow through the orifice could no longer be maintained. The supply was then shut off and the filter cleaned. The work of regulation was carried out with perfect ease and certainty, and the rate of flow through the orifice was not allowed to exceed 2 gallons per square foot per hour, or 432 gallons per square yard in twenty-four hours."

Nothing is said in this description of means of filling the filters with filtered water from below, but Mr. Gill is well known to be an advocate for so filling filters, and any engineer will be able readily to design means whereby with this "three chamber" arrangement water could be run under the sand to fill the filters. 

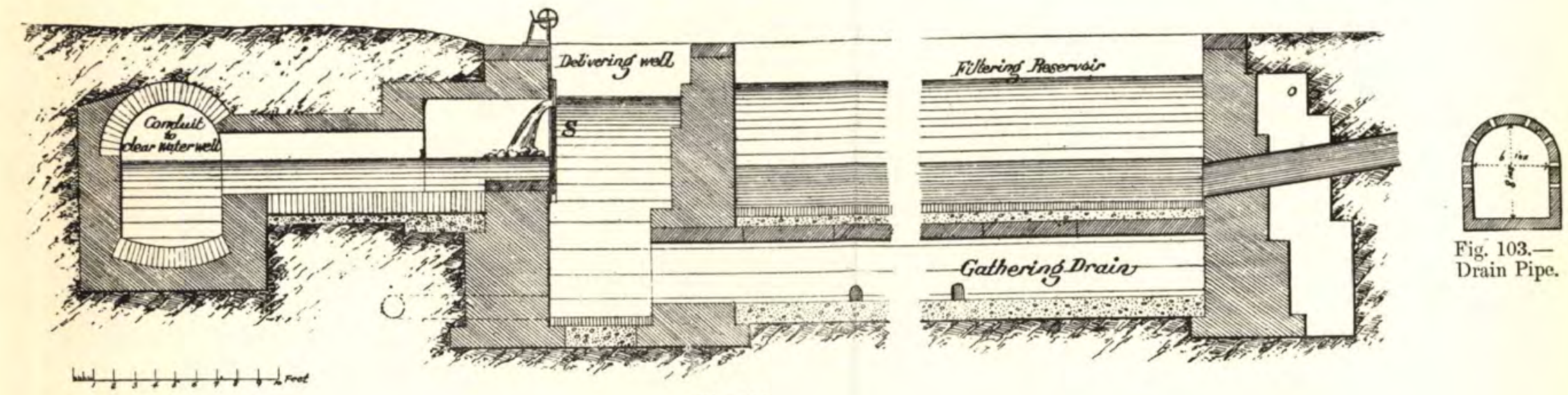

Fig. 102.
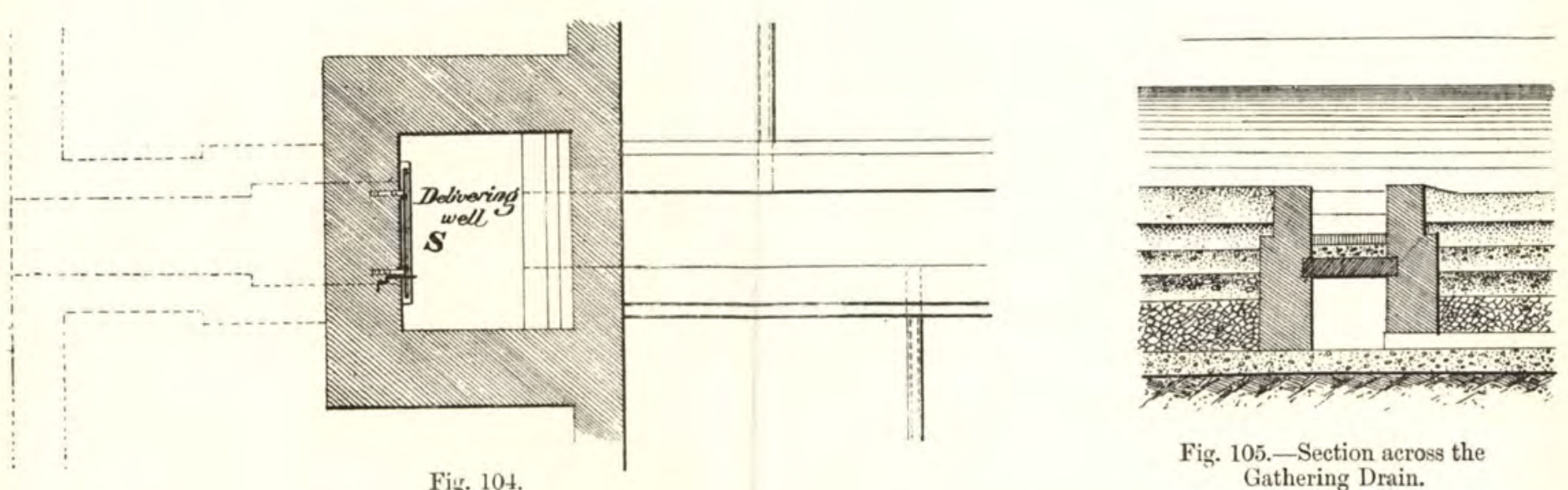

Fig. 105.-Section across the Gathering Drain.

Arrangement for Regulating Speed of Filtering Beds (J. P. Kirkwood).

[To tace page 106 . 
The next system illustrated is a very simple one, by the use of telescopic tubes. It is shown in Plate XXVIII., Figs. 107 to 113.*

The arrangement of having all the telescopic tubes from three (or more) filter beds in one filter well was designed by the writer, but he does not know that it has not been used before. It lends itself conveniently to the filling of the filters from below. The arrangement is so simple that a very brief description will suffice.

A, B, c are pipes from three filter beds. Each is turned upwards, and terminates in a trumpet-mouthed pipe within the filter well that can be raised or lowered by a screw. It is not essential that the joint between the trumpet-mouthed pipe and the one on which it slides be absolutely watertight. For this reason no packing is used, but the pipes are made to slide "brass to brass." E leads to the clean-water reservoir, and the level of the surface water shown in the filter well is that of the highest water level in the clean-water reservoir plus the small head necessary to cause the water to flow to that reservoir.

It will be evident that, if a trumpet-mouthed pipe be lifted to such a height that its upper lip is level with the water in the filter bed, or above it, no water will flow through the filter but the small quantity that may leak through the sliding joint. On the other hand, if the pipe be lowered, the water will overflow the trumpet mouth, and the discharge will be greater the more the pipe is lowered. By causing the height of the surface of the outflowing water over the lip of the trumpet mouth to remain constant the discharge remains constant. A very simple form of gauge may be attached to the trumpet mouth, with an indication of the height above the lip to which the water should rise.

It will readily be understood that, when a pipe has been lowered to such an extent that the difference in level of the water in the filter bed and that of the lip of the pipe amounts to the maximum filtering head that is to be permitted (say 2 feet 6 inches), the filter needs to be cleaned. The supply to it is stopped, and the water is allowed to flow away by the telescopic tube till the rate of flow becomes so slow that it is not worth the time necessary to allow the rest of the water in the filter bed to pass through the sand. The telescopic tube is then raised, and the drain pipe D, F, or Gt is opened to allow as much of the water to flow to waste as is necessary.

* A slight modification of the arrangement designed by the writer for the Nagasaki waterworks.

$\dagger$ In the plate these drain pipes are shown smaller than they should be. 
When it becomes necessary to fill the filter bed again from below, the corresponding telescopic tube is lowered as far as possible, and, if need be, the water flowing from the other filter beds is made to " head up " in the well by partially closing the sluice valve $\mathrm{E}$.

Figs. 114 to 119, Plate XXIX., illustrate a scheme designed by the writer in 1888 for the Tokyo waterworks, and afterwards adopted in the Osaka and other waterworks. The object of this arrangement is to do automatically what is done by hand in the case of the telescopic-tube system of Plate XXVII. Figs. 118 and 119 show the general arrangement, and this will be readily understood if it is perceived that, when not either opened or closed by hand, the valves $\mathrm{A}, \mathrm{B}$ and $\mathrm{C}$ are of such a nature that they automatically maintain a constant discharge of water through them, whatever may be the difference in the pressure at the entrance side and at the delivery side, so long as the difference does not fall below a certain small minimum.

The valve is shown in detail in Figs. 114 to 117 . The working drawings were made by Mr. J. Sakamoto from hand sketches by the writer.

The valve depends in its action on keeping a constant difference of pressure on the two sides of the diaphragm $a$, which has a circular opening in the middle of it. A constant difference of pressure in such a case results in a constant discharge.

The action is as follows. The water enters at $b$ and flows through the balanced valve $c c$, an outside view of which is shown in Fig. 117. It will be seen that water can pass the valve when its position is at all lower than that shown in Fig. 114, and that the lower the valve falls the freer will be the flow.

At starting the position of the valve will not be that shown in the drawing, but the valve will be resting on the bottom of the cast-iron casing. The water flowing through the valve first meets considerable resistance at the diaphragm, because the area of cross-section of flow is there first contracted, and there is produced a difference in pressure between the water within the valve-casing and that without. As the piston $d$ is in free communication with the inside of the casing on its lower surface, with the outside on its upper, the result of an increase of the pressure on the lower side, as compared with that on the upper, is to raise the piston, to reduce the flow of water through the valve $c c$, and to reduce the difference of pressure on the two sides of the diaphragm, and consequently on the inside and the outside of the valve-casing, and on the two sides of the piston. Thus a balance is reached, and the 


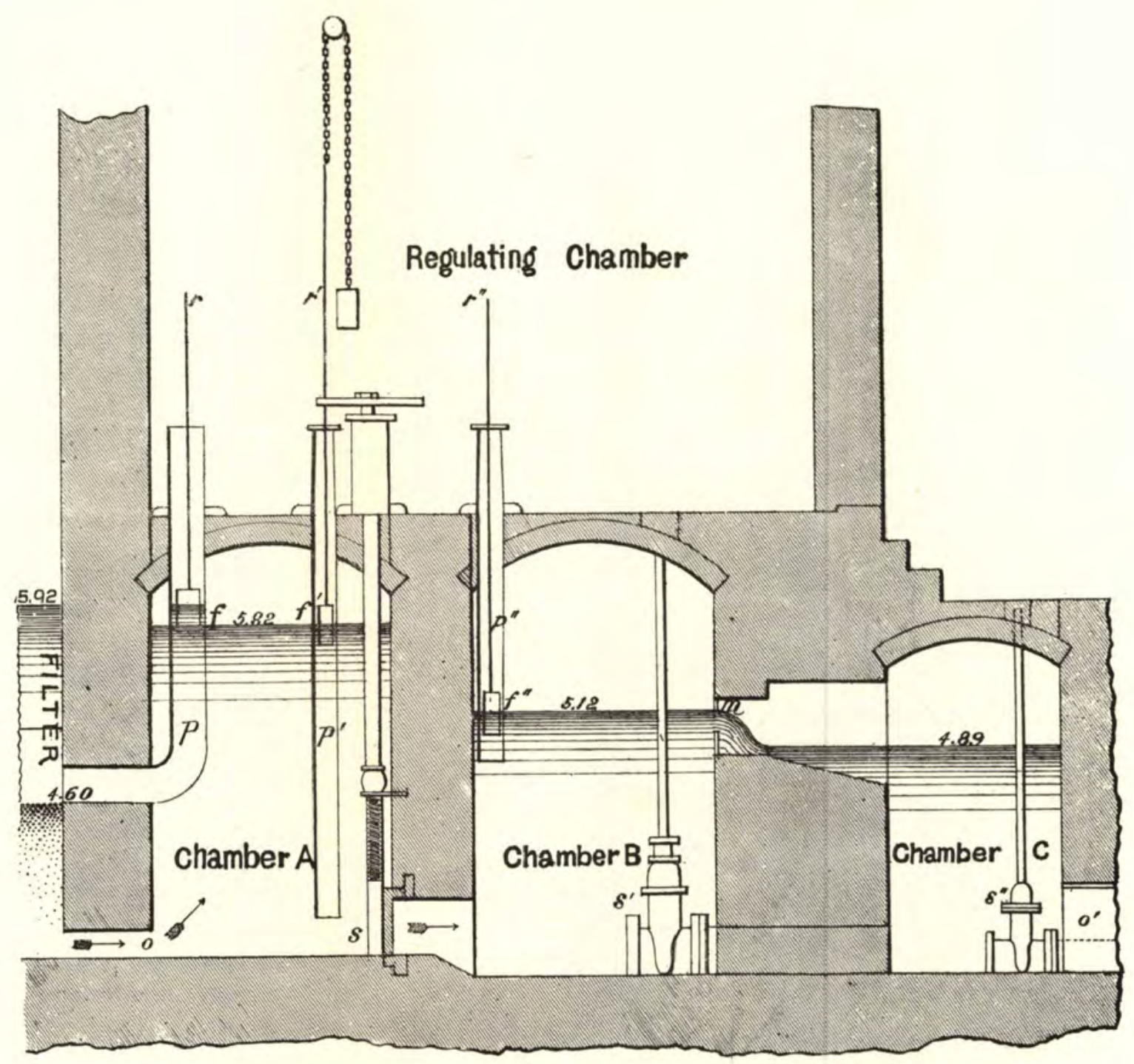

Fig. 106.-Arrangement for Regulating Speed of Filtering Beds (Henry Gill). 
piston and valve remain in a constant position, passing a constant quantity of water, unless the difference of head at $a$, and at $b$ the outlet, changes, when the piston immediately adjusts itself to a new position, and the discharge becomes again constant, and the same as before.

The pressures dealt with are very slight, and there is no reason that either the valves $c c$ or the piston $d$ be absolutely watertight. The friction may, therefore, be reduced to something quite inappreciable. It might, perhaps, be an advantage to turn rectangular sectioned grooves in the piston, but it has not been found necessary. In practice a small leakage hole has to be made at $d$, through the web of the piston, to allow air to escape which would otherwise interfere with the action of the valve.

The necessary flow of water being known, the required diameter of aperture in the diaphragm may very easily be found by a simple calculation after the other parts of the valve have been weighed. The whole piece constituting the piston, the balance valve, and the spindle that is rigidly attached to both, is weighed in water. Then taking

$w=$ this weight in lbs.,

$a=$ the area of the piston in square inches,

$p=$ the difference of pressure on the two sides of the diaphragm in lbs.

$$
p=\frac{w}{a},
$$

and it is only necessary to apply the formula for the flow of water through openings in thin plates to find the aperture necessary to give the flow needed with this difference of head.* With a design similar to that given, $p$ will be found to correspond to a head of only a few inches of water, say never over 6 inches.

It has been found that even great differences of head at the inlet to this valve do not result in any appreciable change of discharge. Indeed, even if a vertical glass tube, acting as a delicate gauge of the pressure of the water, be connected with the space within the casing, with which the under side of the piston is in communication, no difference of pressure is observable on varying the head at $a$ between wide extremes, unless it be varied very suddenly, when the

* The writer did not know, when he designed this valve, that a very similar valve had been designed by the late Prof. Fleeming Jenkin a number of years ago for a different purpose. The general principle-that of causing what is, to all intents and purposes, a reducing valve, to produce a constant difference of pressure on the two sides of a thin plate with an opening in it, and thus to produce a constant discharge - has, as a matter of fact, often been made use of, but the writer does not know that the principle has before been applied to regulating the flow of water through filter beds. 
inertia of the piston and attachments results in a momentary change of pressure. The change of discharge varies, moreover, only as the square root of any change in pressure that there might be.

When the filter bed becomes so foul that the friction absorbs so nearly the whole of the filtering head-that is to say, the whole of the difference in level of the water in the filter well and the filter bed-that there is not sufficient spare head to support the weight of the piston with its attachments, this latter suddenly drops on the cast-iron casing. Its so dropping shows that the filter in connection with this particular valve needs cleaning. It would be easy to add to the apparatus an indicator that would show conspicuously when the piston had dropped.

The piston having dropped, the process of draining the filter bed for cleaning the filter is very nearly the same as with telescopic tubes. The water is shut off from entering the filter bed, and what is in it is allowed to flow through the now completely open valve, till the discharge becomes so slow that it is not worth the time that would be necessary to save the rest of the water. The valve is then raised by hand, by the screw $e$, so as to close it, and the water is drained from the filter by one of the draining valves, D E F, till it is as low as is necessary for the cleaning of the filter bed. After cleaning the valve is forced downwards by the screw $e$ to open it, when the filter will begin to fill again from below. If necessary, the valve $\mathrm{G}$ is partly closed, so as to make the water " head up " in the filter-well, to increase the velocity of flow into the newly cleaned filter-bed. Whenever the sand has been covered with water a few inches deep, the admission valve is opened, and unfiltered water flows over the filtering sand in the usual way. When the level of the water over the sand rises to that in the filter-well, the screwed spindle is so adjusted that the valve is under control of the piston only, and, from that time, the discharge is, once again, automatically regulated.

\section{Admission of Water to Filter Beds.-The water must} be admitted to filter beds in such a way that the sand will not be disturbed. Sometimes the main central drain is built up to form a longitudinal channel above the level of the surface of the sand, and the water is allowed to flow into this channel, whence it spreads itself over the sand. This arrangement has the objection that it occupies a very considerable area which would otherwise be available for filtration.

Sometimes a channel is made in the thickness of the wall of 
Plat' XXVIII

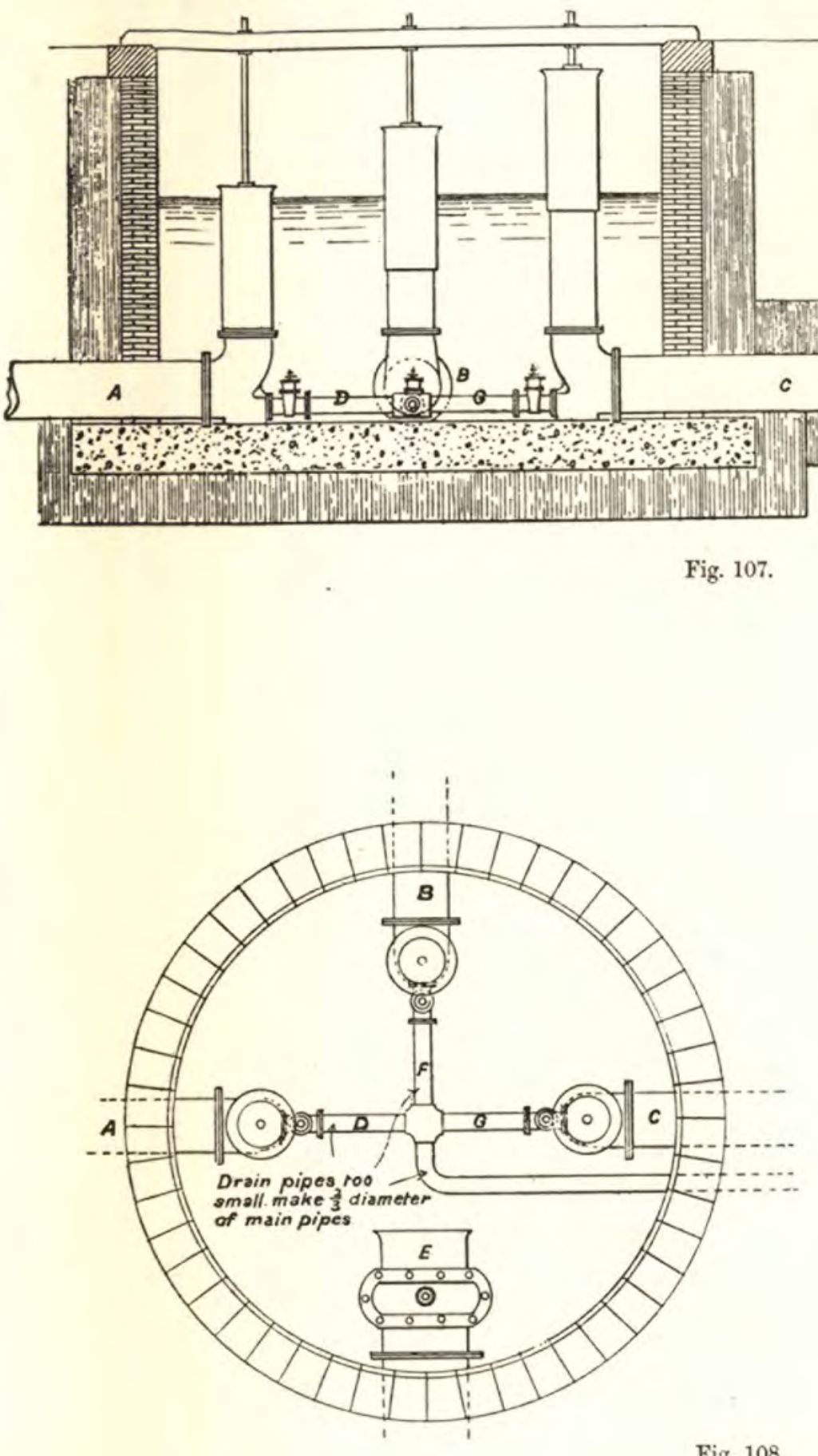

Fig. 108.

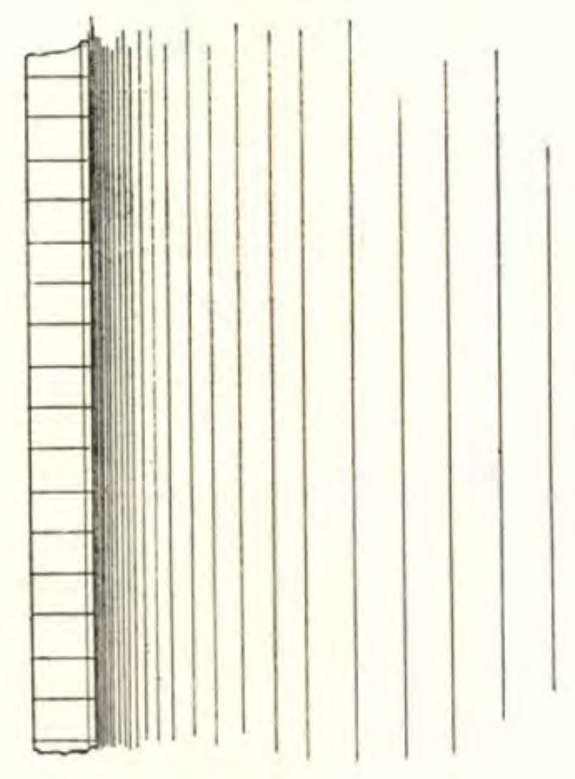

Arrangement for Regulativg Speed of Filtering Beds (Telescopic Tubes).
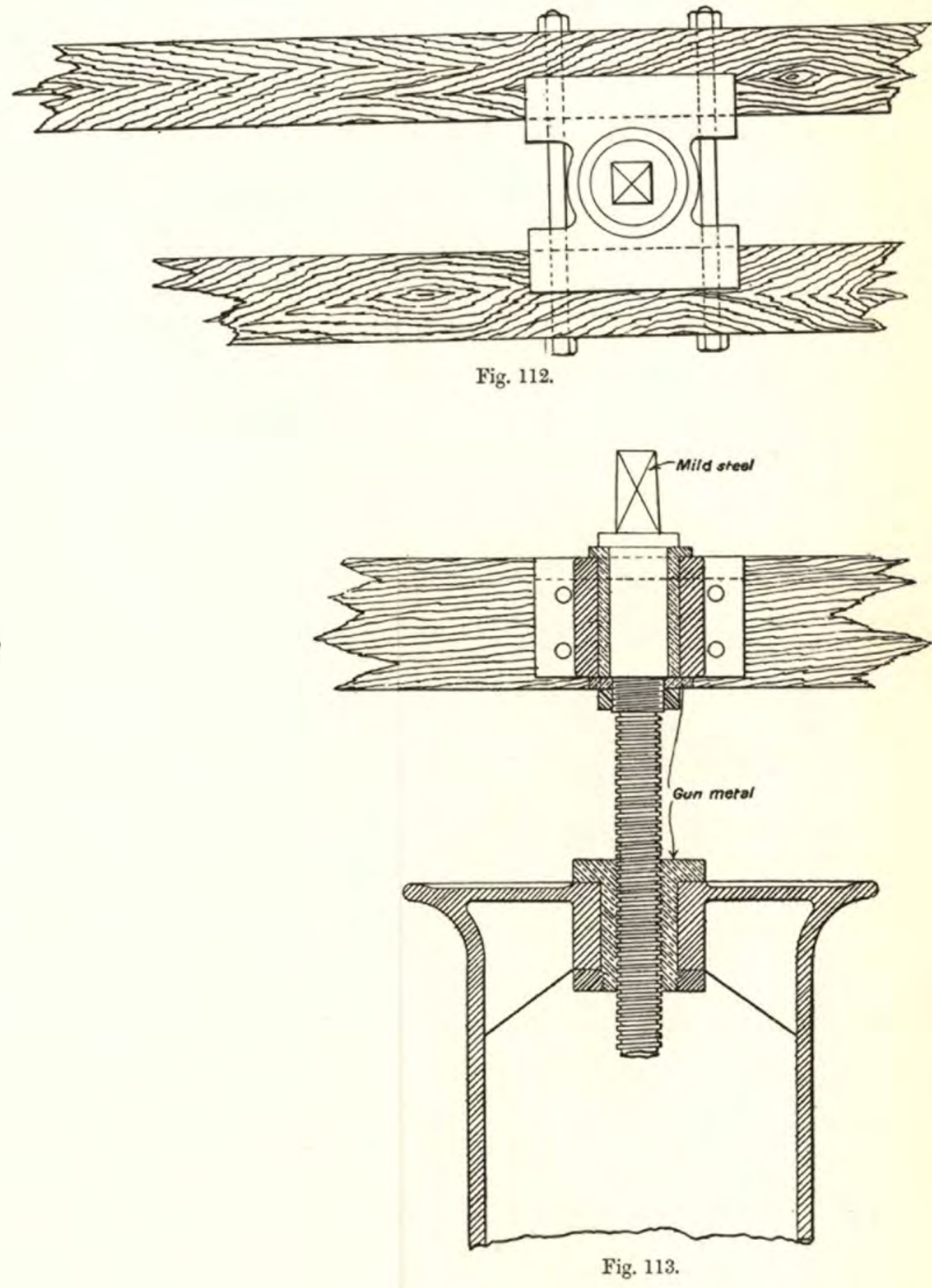

[To face page 110. 
the filter bed, contouring it at a level just above the sand surface, and having numerous openings into the filter through which water enters it. This arrangement certainly secures a very even distribution of the water, and is not open to the objection mentioned in connection with the others described, but it seems unnecessarily complicated. The simple bell or trumpet mouthed pipe, shown in Plate XXV., has been found to be quite efficient, if the sand, for

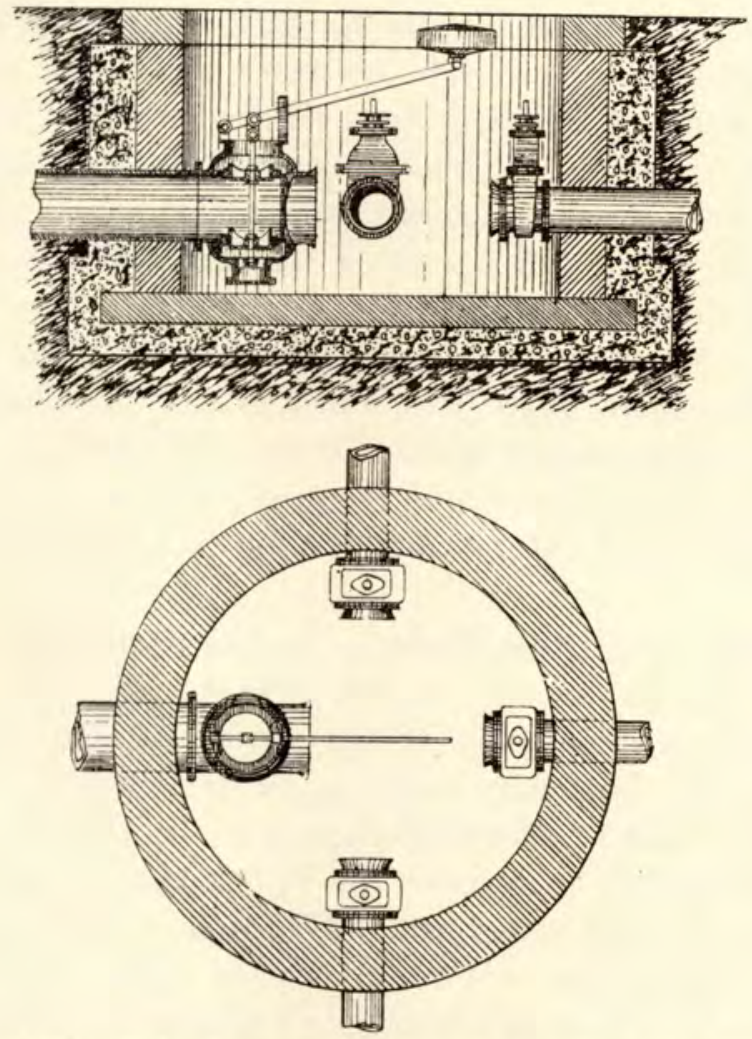

Figs. 120 and 121.-Valve for regulating flow of water (in section and in plan).

two or three feet around it, be covered with bricks, tiles, or stones, to prevent the rush of water from washing it away. The area of filter bed thus taken up is but trifling. The Plate illustrates two filter beds, one with sloping sides, the other with vertical walls.

The discharge into filter beds is commonly regulated by sluice valves, but there are various reasons why it is preferable to use an automatic valve to keep the water at a constant level in the filter bed. Such a valve is less needed if the automatic dischargevalves just described are used, than if the filtering head is regulated in any other way, as these valves compensate for varia- 
tion of head on either side. Still, even with these such an automatic arrangement is advisable.

Valves for so regulating the flow of water into a reservoir that the level will remain nearly constant are articles of commerce, and scarcely need description. Such a valve is illustrated in Figs. 120 and 121. It will be seen that it is, in fact, merely the familiar "ball valve," whereby the discharge of water into cisterns in houses is regulated, only that it is on a large scale.

There may be one such valve for each filter bed, but the writer prefers an arrangement whereby its water is admitted to one well, as shown at A, Plate XXXV. (p. 144), through a valve on the principle illustrated by Fig. 120. This valve secures a constant water level in the well, and, the sluice valves between this well and the filter beds in action being full open, the water level in each filter bed may be considered as being at the same level as that in the well, spite of the fact that there is a slight loss of head between the well and the nearest filter bed, and a greater loss between it and those that are somewhat more distant. If there are more than four filter beds, it will probably be an advantage to have one "dis. tribution well" with automatic valve for each three or four beds.

Cleaning of Filter Beds.-As has been said, the cleaning of a filter bed, at ordinary times, consists chiefly in removing a thin layer of an inch or so of the sand from the upper surface. Various details, however, have to be considered. The first of these is the quantity of water that is to be run off. It will be evident that merely to remove the upper film of sand it is necessary only to let the water run off to a level immediately below this film. Sometimes this is all that is done, but it is believed that there is a distinct advantage in running the filter dry; as, if this is done, a certain amount of oxidation of the whole sand bed is supposed to take place, this oxidation being beneficial to the after purification of the water.

However this may be, it is advisable, after removing the surface layer of completely clogged sand, to stir up and loosen, with a fork or other pronged instrument, a depth of eight inches to a foot of the upper surface of the sand. The water should be run off to a level at least below this depth.

To replace the thin layer of sand removed at every single cleaning of this kind would involve too much labour; and it is customary to allow a foot or so of the thickness of the sand to be thus removed in parings before it is replaced. 

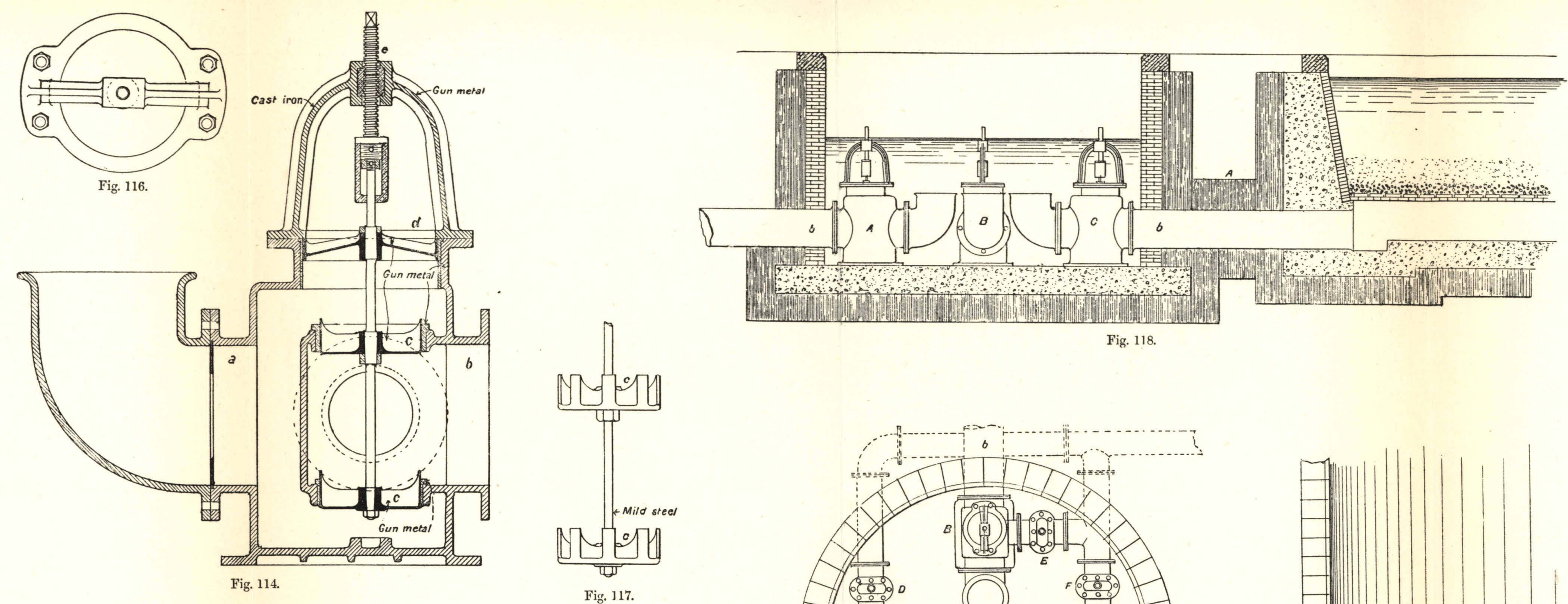

Fig. 118.
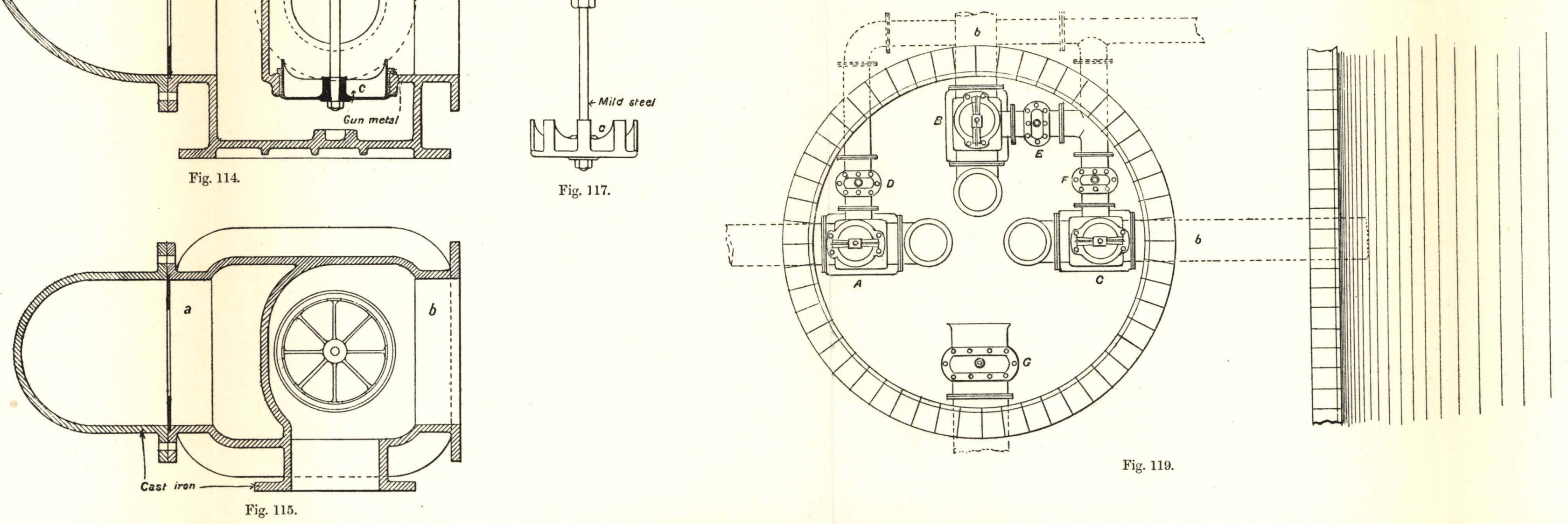
Occasionally clean sand is so near at hand, and so readily and cheaply got, that the dirty sand may be thrown away altogether; but this is rarely the case, as, even if sand is as cheap as may be, it is seldom in such condition that it is not improvable by washing, and it takes little or no more trouble to wash the sand that has already been used than to wash new sand.

The sand that has been removed for washing from filter beds is always more or less foul, and often smells badly, sometimes having a peculiarly offensive "fishy" smell.* It can, however, be effectually cleaned simply by thorough scouring with water, which ought to have been filtered.

Various contrivances have been invented for washing sand

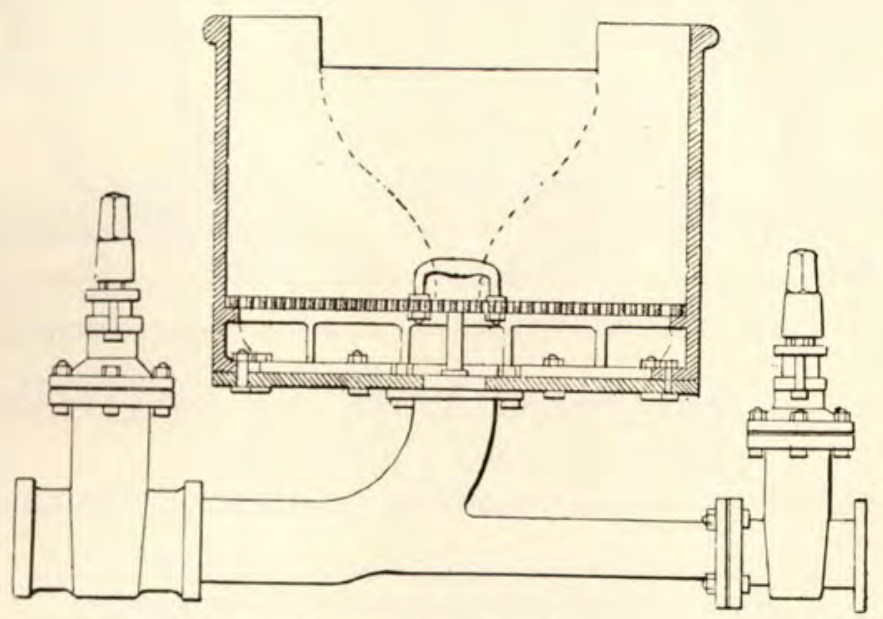

Fig. 122.-Sand-washer.

One of the most popular is illustrated in Fig. 122. Dirty sand is shovelled into the upper part of this contrivance, water is turned on from below, and is allowed to flow till that leaving the upper receptacle, at first thoroughly dirty, becomes quite clear, when the now purified sand is removed, and another lot is treated.

The next illustration (Figs. 123 and 124) shows Walker's patent sand-washing apparatus. The writer has no practical knowledge of the working of this machine, but has heard it highly praised by those who certainly had no interest in its sale. The washer, as will be seen, is hopper- or funnel-shaped, and is hung on trunnions. Water is admitted by a rubber pipe, c, connected with the main at the lower end, and, during the washing, escapes by the spout, в. The rubber pipe permits of the tipping of the vessel, without 
making any disconnection with the main. When the water comes off clear, it is an indication that the sand has been sufficiently washed; the flow is stopped, and the hopper-shaped vessel is
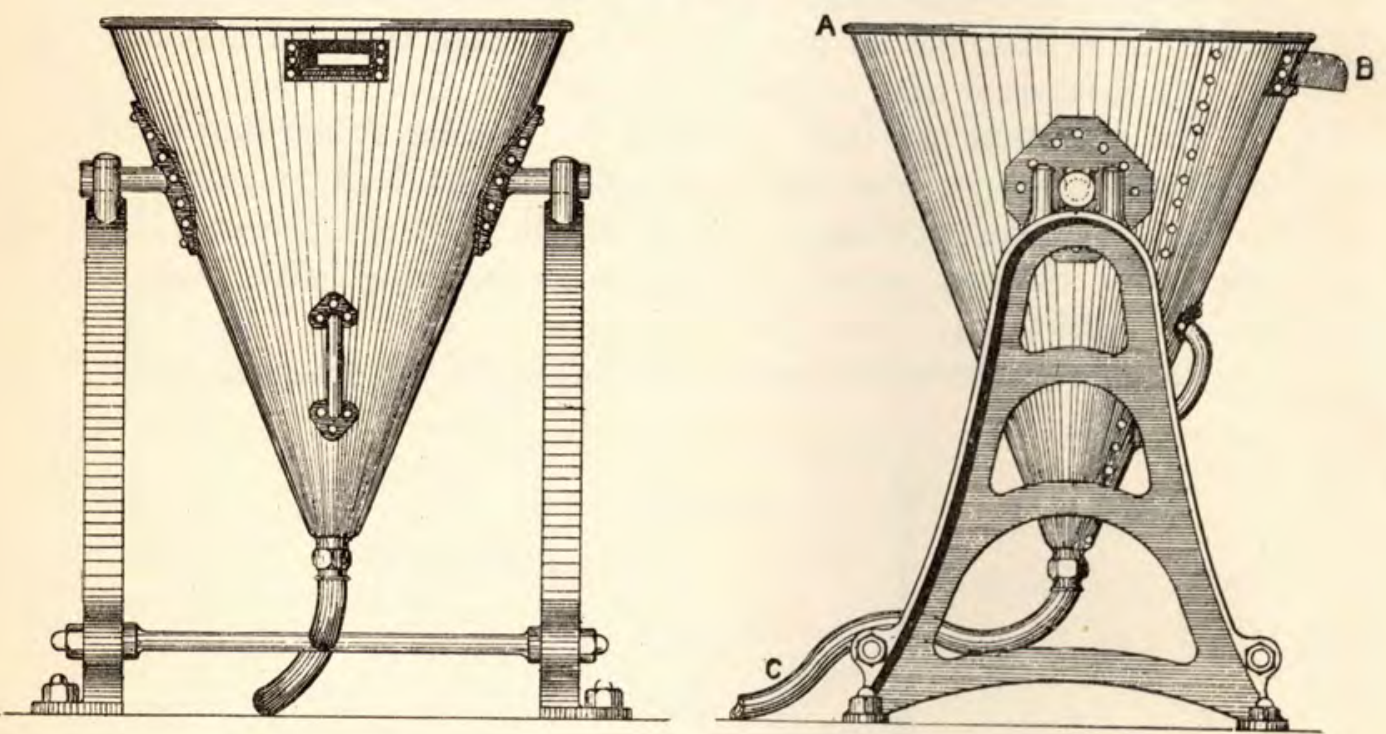

Figs. 123 and 124.-Walker's patent sand-washing apparatus.

tipped over in the direction $\mathrm{A}$, the sand being received in a wheel barrow or truck.

These sand-washers are made in "batteries," a trunnion frame
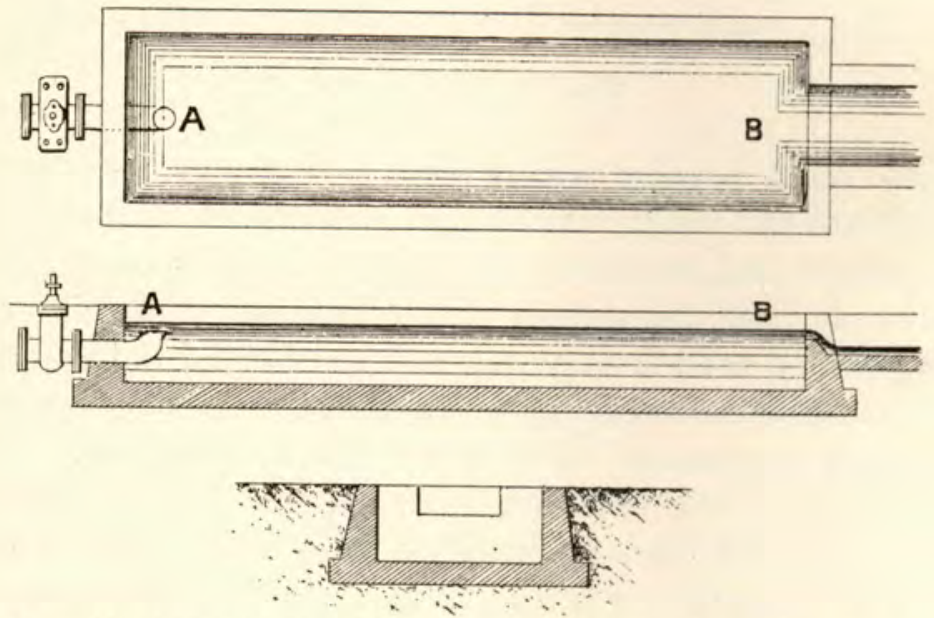

Figs. 125, 126 and 127.- "Canal" sand-washer (in plan and sections).

being, in this case, common to the hopper-shaped vessel on each side of it, except at the two ends of the battery. 
Another arrangement, still more simple than this, consists of a short, narrow, shallow canal, as illustrated in Figs. 125, 126 and 127. Water is allowed to How continuously into the canal at $A$, whilst dirty sand is continuously introduced at the opposite end B. This sand is raked by hand towards $\mathrm{A}$, and from $\mathrm{A}$ is continuously removed. A canal of about 30 feet long will, with a flow of water not likely to wash away the sand, readily serve for waterworks with a population up to 100,000 . For larger works, larger canals may be made, or several may be used instead of one. The flow of water, the feeding with sand, and the rate at which the sand is raked along the bottom of the canal should all be so regulated that, whilst no sand is washed away at the end $\mathrm{B}$, no visible dirt is washed out of the sand for several feet before it is raked up to $\mathrm{A}$.

Such is the routine of cleaning the sand of filter-beds; but, besides this, at long intervals, varying from six months to several years, according to the nature of the water-and probably, also, somewhat according to that of the sand - the whole of the material constituting the filter-bed, right down to the floor, should be removed and be thoroughly cleaned. 


\section{CHAPTER XIII.}

Purification of Water by action of Iron-Softening of Water by action of Lime-Natural Filtration.

The principles of these processes have already been described, It only remains to give a short description of the way in which they may be used in practice.

So far as the use of iron is concerned, it would appear that until recent years, it was believed that the action of oxides of iron - such as magnetic iron oxide, for example - was the same as that of metallic iron. It would now appear that, although both have the effect of purifying water containing organic matter in solution, the action is different in the two cases-may, in fact, be described as diametrically opposite-for magnetic oxide of ircn seems to act as an oxidizer, metallic iron is a reducer.

Use of Magnetic Oxide of Iron for Purifying Water.* -Magnetic oxide of iron, in a fine state of division, may be used as a filtering medium, either alone, or mixed with sand. Its expensiveness has led to the practice of mixing it with a certain proportion of sand. The following is a quotation from a pamphlet issued by a company that sells, by name of "Polarite," a substance professing to be a porous magnetic oxide of iron. Of the use of this substance the writer has had no experience, but he has both read and heard good reports of it :-

"The polarite bed, including layers of sand and gravel, need never exceed three feet in depth . . . . . The granules of polarite being very porous, water filters through them as well as around them. Hence about twice the quantity of water will filter in a given time through a polarite bed than through an ordinary sand filter-bed of the same size . . . . At the same time polarite . . . . will do what sand cannot do ; will purify water by oxidizing the . . organic matter in solution, and

* See note 11, Appendix II. 
making them innocuous . . . A good plan of a polarite filter is to place at the bottom rows of three-inch or four-inch agricultural drain tiles at suitable distances apart, filled in between with large shingle or broken stones, then a layer of gravel four to six inches thick, above that four inches of sharp coarse sand, then polarite mixed with sharp, coarse sand in proportion to suit the quality of water to be purified, but so as to form a layer twelve inches in thickness; and lastly at the top nine to twelve inches of sand, making a total depth of filter of two feet nine inches to three feet two inches. Space must be provided above the sand for a sufficient depth of water according to the speed of filtration required.* Such a filter will effectually purify from 100 to 1,000 gallons a square yard in twenty-four hours, according to the quality of the water to be purified. Every square yard of filter should contain about 360 pounds of polarite . . . . The top layer of sand acts as a strainer and arrests floating particles suspended in the water. . . . The lower layer of sand merely acts as a cushion to keep the finer particles of polarite from being washed out of the filter."

Use of Metallic Iron for Purifying Water.-The theory of the action of metallic iron on water which contains organic matter in solution has already been touched on. Professor Gustav Bishof has the chief credit of introducing the use of metallic iron for the purification of water, and to him is due the application of "spongy iron." On a small scale, for domestic filters, this substance has been highly successful. It has also been used with some success on a large scale. The water is first filtered through sand to remove ordinary matter in suspension; it then passes through a layer of spongy iron; when it is exposed for some time to the action of the air to reduce any iron dissolved to an insoluble oxide of iron, that can be removed by a second sand-filtration.

Spongy iron was thus used by Mr. William Anderson, M.Inst.C.E., for the Antwerp waterworks, and its effect, so far as purification was concerned, seems to have been excellent; $\dagger$ but after a time there was trouble on account of the clogging up - the rusting up,,+ in fact - of the layer of spongy iron.

These difficulties caused Mr. Anderson to search for some way of utilizing the remarkable effect of the action of metallic iron on

* There would seem to be some confusion, here, between the depth of water over the sand and the filtering head.

$\dagger$ Proceedings of the Institution of Civil Engineers, vol. LxII., pp. 24 et seq.

‡ See note 7 (to page 81) in Appendix II. 
organic matter dissolved in water that would not carry with it the objections that there were in the filtering arrangement just described. The method ultimately adopted, which appears to have practical advantages over any others in which iron is made to act on water, was the outcome of a suggestion by Sir Frederick Abel, K.C.B., F.R.S. It consists simply in vigorously churning up the water for a comparatively short space of time with metallic iron in a fine state of division.

The following is an abstract of the description of the apparatus used by Mr. Anderson :*-

A wrought-iron cylinder, four feet six inches in diameter by six feet long, was arranged to revolve on hollow trunnions, and was fitted up internally with six shelves or ledges, to scoop up the charge of iron placed inside, and shower it down continuously amidst the water flowing slowly through. The inlets and outlets were at first two inches in diameter, the intention being to purify at the rate of twelve gallons per minute, which would give the supposed necessary contact of water with the iron for forty-five minutes. The cylinder was charged with nine hundredweight of iron, and set revolving at the rate of one-third turn per minute. The trial showed that vastly too much metal was being taken up by the water; the rate of flow was therefore increased to thirty gallons per minute, when 1.2 grains of iron per gallon was dissolved; and then to sixty gallons, when 0.9 grain was taken up, a quantity still far in excess of what experience showed to be sufficient. New trunnions with four-inch pipes were fitted to the cylinder, and the apparatus was put to regular work at the rate of 166 gallons per minute, giving a contact of three-and-a-half minutes only, which proved to be amply sufficient to purify the water. It was found that about $0 \cdot 1$ grain of pure iron per gallon only was taken up by the water.

The great advantage of using iron in the way described arises from the fact that the surfaces of the material are always kept clean and in an active condition by rubbing against each other and against the inner surfaces of the cylinder that contains them, as well as by continually falling through the mass of water. It is found that iron in almost any divided form is suitable for the process. The most active agents are cast-iron turnings - on account, no doubt, of the way in which each particle is cracked and fissured; next, probably, comes spongy iron; then cast-iron

* Proceedings of Inslitution of Civil Engineers, vol. Lxxxi., p. 280, et seq. 
granulated by being poured into water ; and lastly, wrought-iron and steel turnings.

The unexpected discovery that the time of contact between the iron and the water could, in practice, be reduced to one-twelfth of what had been held necessary, completely changed the aspect of affairs. At Antwerp it was decided to convert the spongy-iron filters into sand beds, and the arrangement shown in Plate XXX. (Figs. 128 to 131) was adopted for purifying the water with iron.

The apparatus consists of three revolving purifiers, together capable of dealing with 1,500 gallons per minute $(2,160,000$ gallons per day), a small wall engine and line of shafting for driving them, and a tank fitted with a fine screen for separating coarse particles.

Each purifier consists of a wrought-iron cylinder, 5 feet in diameter by 15 feet maximum length, supported longitudinally on hollow trunnions 10 inches in internal diameter, fitted with stuffing boxes, through which the inlet and outlet pipes pass.

For scooping up the iron and showering it down through the water, the inside of the cylinder is fitted with five curved ledges, 8 inches deep, and one ledge 6 inches deep, the latter formed of twenty blades 6 inches long, each attached to a $\frac{7}{8}$-inch shank, which passes through the cylinder, and is secured to it by a nut. The object of this arrangement is to give the means, by placing the blades askew, of throwing the iron back towards the inlet end of the cylinder, if the current of water passing along should tend to make it travel towards the outlet.

The inlet-pipe, where it opens into the cylinder, is covered by a disk of iron-plate 2 feet 8 inches in diameter, fitted within $\frac{5}{5}$ inch of the spherical end, so that the entering water is compelled to spread out radially in all directions into a disk $\frac{5}{8}$-inch thick. It having been ascertained that a velocity of 4 inches per second was incompetent to move any but the finest iron in a vertical tube the outlet pipe was expanded, inside the cylinder, into an inverted bell-mouth, of such diameter that the current upward would not exceed 4 inches a second. Experience shows that the iron has very little tendency to move bodily along the cylinder in the direction of the flow of water, the feeble current of only about $\frac{3}{4}$-inch per second having little or no power to move it.

The three revolvers are placed side by side and connected, on the inlet side, by 10-inch branches, fitted with sluice cocks to the 20 -inch delivery main. The outlet pipes all open into a wroughtiron tank, 15 feet long, 3 feet 6 inches wide, and 3 feet deep, fitted with an inclined screen, covered with galvanized wire netting, 
four meshes to the inch. The object of this screen is to catch the large quantity of moss and other impurities which, especially in summer, form in the inlet pipes and, becoming detached, find their way to the filter-beds. It is noteworthy that no such growths take place after the water has been purified.

The driving-gear consists of an annular spur-ring secured round one end of each cylinder, and driven by a train of gearing working on a self-contained frame, driven by a $2 \frac{1}{2}$-inch belt driven from a lay shaft, coupled direct to the crank shaft of a wall engine, having acylinder $6 \frac{1}{4}$-inch diameter, 9 -inch stroke. The total weight of each revolver, filled with water and with its charge of 22 ewt. of iron, is 14 tons, 6 cwt., and the power necessary to drive it at the rate of one-third of a revolution per minute is 0.4 H.P. The total capacity of the three revolvers is $15,000,000$ gallons per week.*

The cost of the establishment in England would be, including a house, $£ 2,300$, while the cost of working, after allowing 5 per cent. deterioration of the building, and 10 per cent. for that of the machinery, together with 5 per cent. interest on the outlay would be $9 s .9 d$. per million gallons; $\dagger$ the cost in wages and materials alone amounting to $2 s$. $6 d$. per million. The total quantity of iron in use is less than $3 \frac{1}{2}$ tons. Had the original filter beds been extended so as to do the same work, the weight of iron in them would have been 1,800 tons. The iron dissolved per week is about 2 cwt.

The water supplied to the town is reported to be exceptionally bright and clear, so that no doubt need exist as to the success of the new method of purification.

This is the end of the abstract of Mr. Anderson's interesting paper. It is to be understood that the water needs to be treated in the usual way by sand filtration after this treatment with iron. The iron is filtered off in the form of an insoluble oxide, and the whole or a great part of the carbonates are also removed, so that this process does not only purify the water of dissolved organic matter and remove or kill or paralyse micro-organisms, but also serves to soften it to a great extent.

Softening Water by the use of Lime.-As has already been stated, in the original process of Clark, a certain quantity of lime-water-or sometimes of a milky mixture of Jime held in suspen

* About 343,400 cubic feet in twenty-four hours.

$\uparrow$ Somewhat less than three farthings per 1,000 cubic feet. 
Plate XXX.
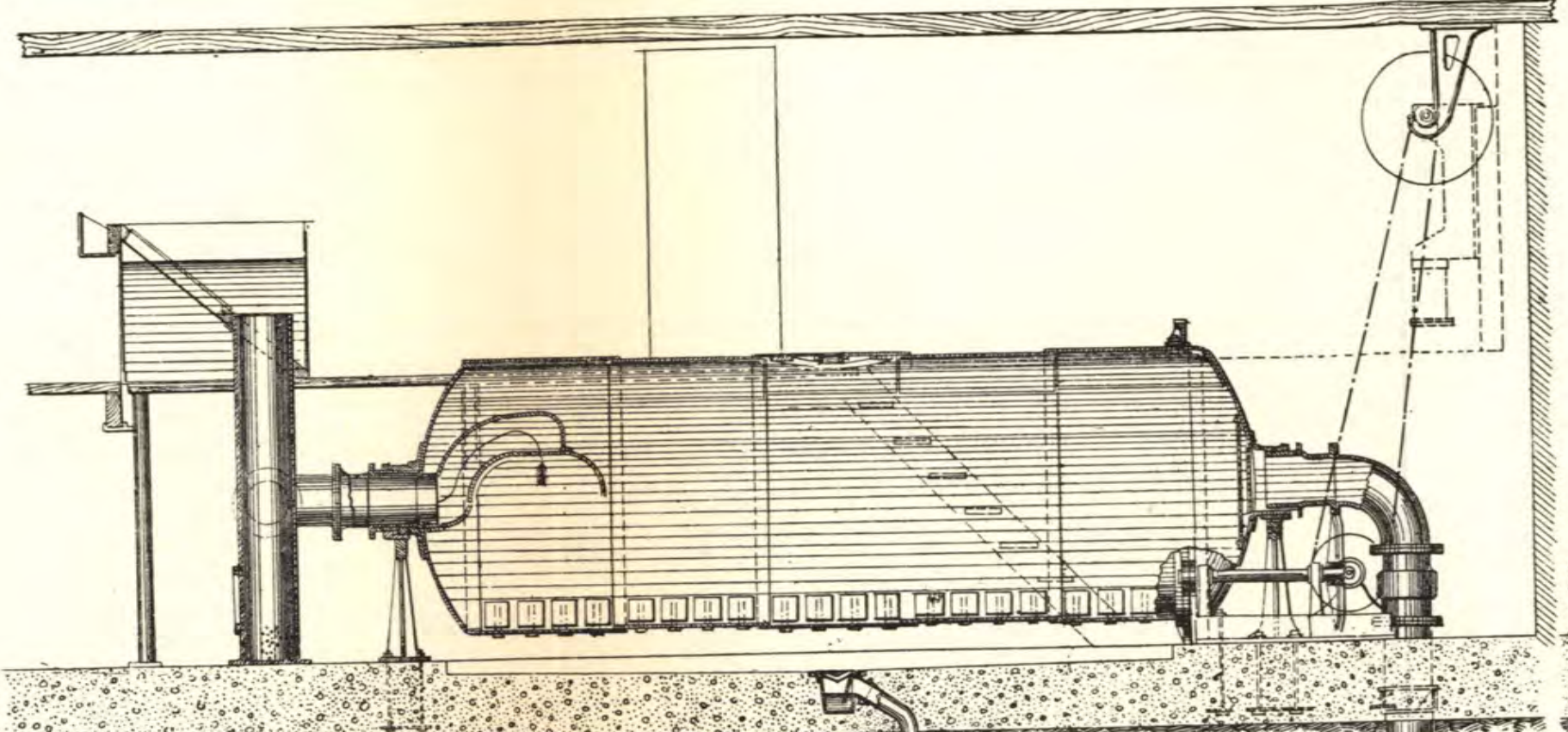

Fig. 128.

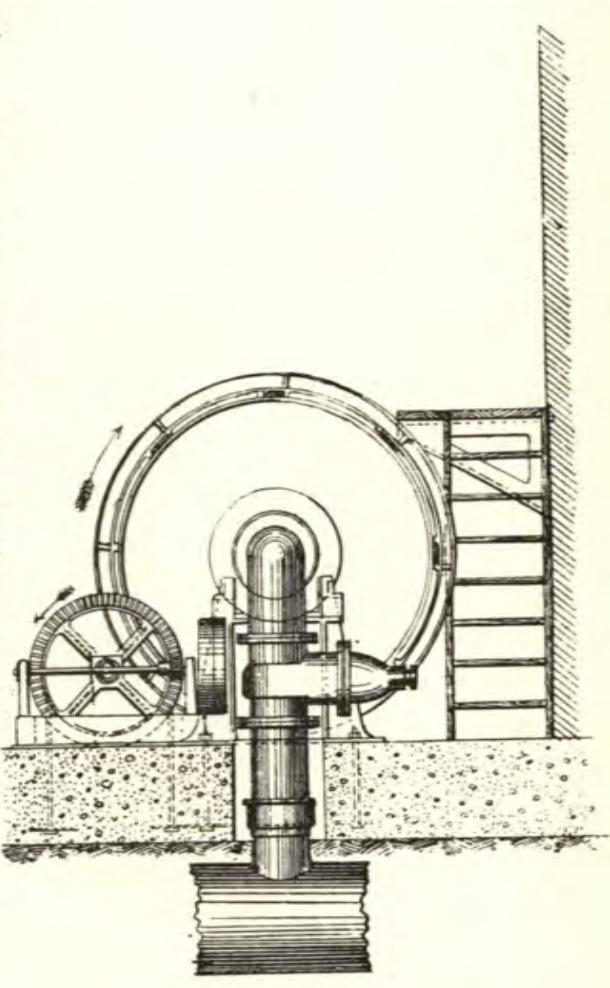

Fig. 129.
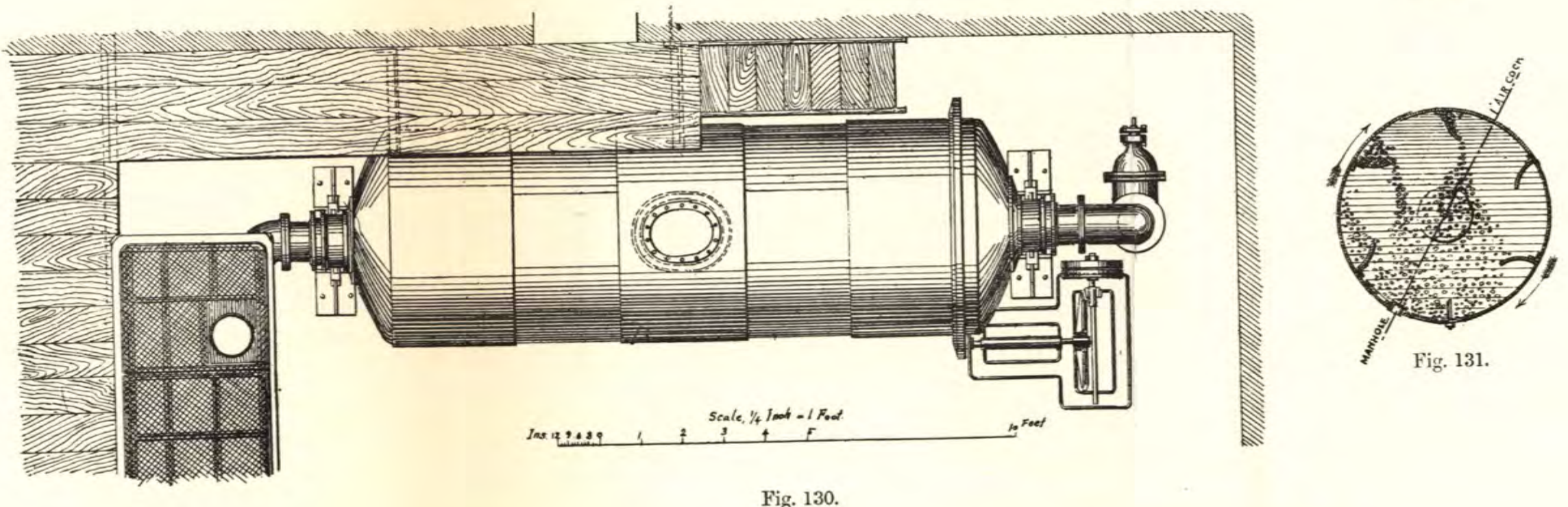

Cyimnder for Purifying Water with Metallic Iron.

[To face page 120. 
sion, but only partly dissolved in water-was added to the water to be softened in reservoirs, the resulting insoluble carbonate of calcium, which was in a fine state of division, being allowed to settle.

The objections to this arrangement were the long time taken for settlement, and consequently the large reservoir capacity that it was necessary to provide. This would not hold good where large settling reservoir capacity was needed for other reasons, as the lime could be mixed with the water before it entered the settling reservoirs, and the settlement of the calcium carbonate might take place along with that of the other suspended matter. Of late, however, various successful efforts have been made to soften water by a continuous process, without the use of large reservoirs.

In the Minutes of Proceedings of the Institution of Civil Engineers, vol. xcvir., there is a paper by Mr. W. W. Fitzherbert Pullen, C.E., on "Water-softening and Filtering Apparatus for Locomotive Purposes, at the Penarth Dock Station, near Cardiff, of the Taff Vale Railway Company."

The paper first treats very ably of the theory of water softening, and then goes on to describe an apparatus for continuous softening, that may, if it be desired, be worked under pressure. The apparatus described, although intended for softening water for use in locomotive boilers, could undoubtedly be applied to waterworks, certain modifications in design being, of course, introduced, if the works were on a large scale. Many cases are imaginable in which it might be of advantage to soften the water under pressure.

The part of the apparatus first described has, for its object, merely the production of a thoroughly saturated solution of caustic lime. Calcium hydrate $\left(\mathrm{C}_{\mathrm{a}} \mathrm{O}\right)$ is only slightly soluble in water, and has the somewhat unusual property of being less soluble in hot than in cold water. At ordinary temperatures, its solubility is very fairly constant, and may be taken to be about equivalent to one part of quicklime in 700 , about 10 grains in the $1 \mathrm{~b}$., or about $1 \frac{1}{4} \mathrm{oz}$. in the cubic foot. In all water-softening arrangements, the quantity of lime that is to be used must be accurately adjusted. If too little lime be added, the water is not sufficiently softened; if too much be added, there will be calcium hydrate in the water, which besides again hardening the water will be otherwise objectionable. Hence the necessity, if a saturated solution of lime is relied on as a standard solution, of using some arrangement that will insure complete saturation.

The apparatus described in the paper referred to, and shown in 
Fig. 132, Plate XXXI., for producing saturation, consists essentially of three vessels, in the first of which water and dry lime are mixed, and in the other two of which the "cream" thus produced is thoroughly churned up with part of the water to be softened, the arrangement being such that a saturated solution of hydrate of lime, but no undissolved lime, passes from the third vessel. Fig. 133, Plate XXXI., shows a section of two more tanks, in which the final softening takes place. These are each 20 feet high, 7 feet in diameter, and are constructed of $\frac{3}{8}$-inch plates.

The following is an abstract of a part of the paper referred to, describing the process of softening:-

The saturated lime water is allowed to enter the left-hand vessel at the bottom, near to where the hard water to be softened is entering. Here the chemical action takes place, and precipitation begins. The water and lime solution gradually rise in the tank, the course of the water being indicated by arrows in the figure; some of the precipitated calcium carbonate sinks through the slowly rising water, and finally rests upon the platforms, which are so arranged that very little of the precipitate reaches the bottom of the tank. The water flows from the left-hand tank, through the pipe marked " connecting pipe," to the bottom of the right-hand tank, where it slowly rises, passing between the platforms as represented by the arrows. Here the precipitation is completed, the insoluble calcium carbonate sinking through the liquid being caught by the platforms, as in the case of the lefthand tank. The precipitate resting upon the platforms is unaffected by the very slowly-rising stream of water, for the stream is deflected by the under-side of the platforms. The softened water passes out of the top of the right-hand tank.

Over each platform in each of the tanks (but shown in the cut only in the case of the left-hand one), is a pair of paddles, or rinsers, attached to a vertical shaft. When it is required to clean or scour the precipitating tanks, the rinsers are set in motion, and the precipitate is quickly removed from the platforms. Flushing valves at the bottom of the two tanks are opened, and the sediment is run to waste. This is done two or three times a week when the apparatus is in constant use.*

* In this abstract the use as a softener of lime only is mentioned, but in the original paper from which the abstract is made, the use of small quantities of sodium carbonate, to decompose the sulphates, and of a little alum to hasten the precipitation, are referred to. These are used because the water is to be softened specially for use in steam boilers. In softening water for domestic use, lime only is
commonly used. 
Plate XXXi

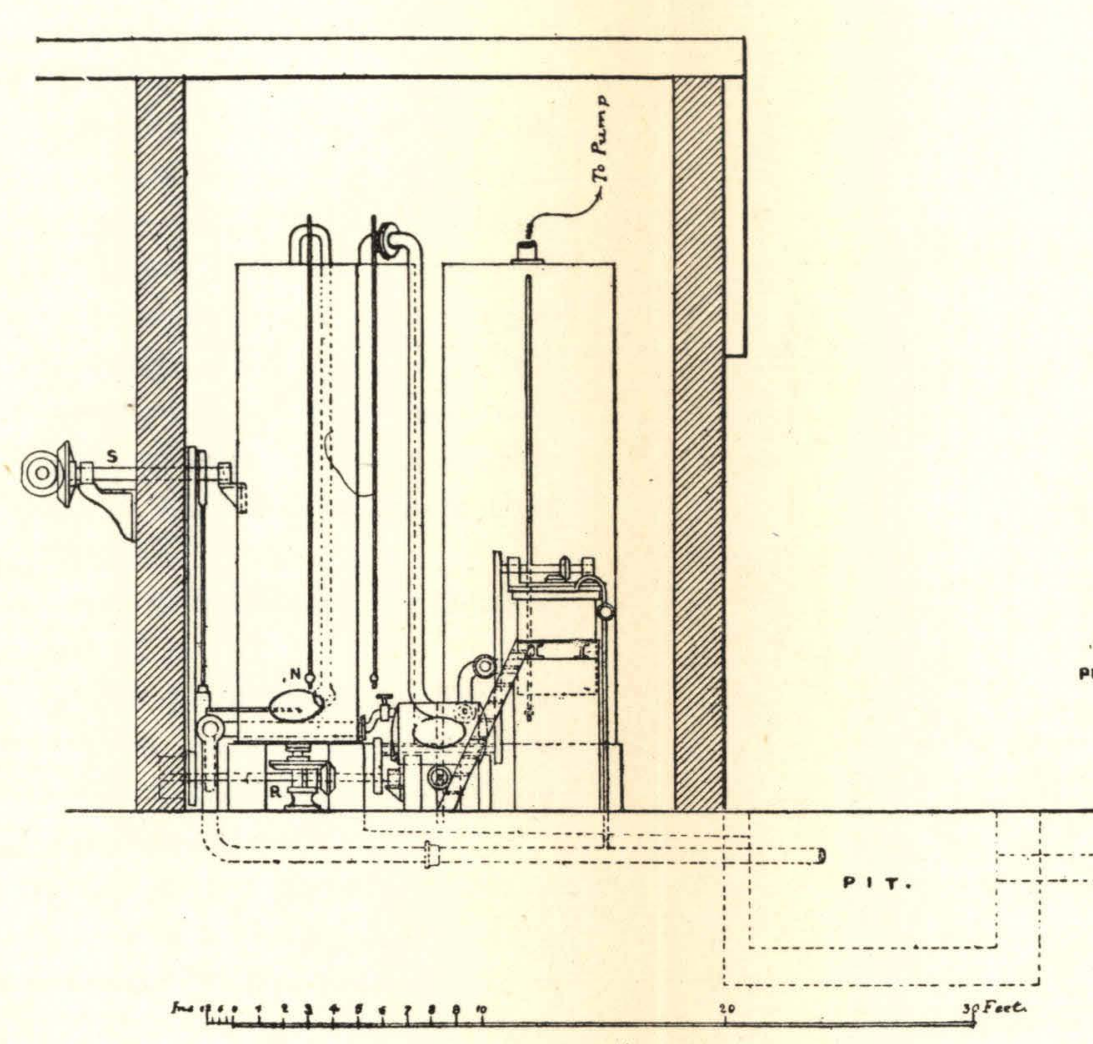

Fig. 132.-Side Elevation

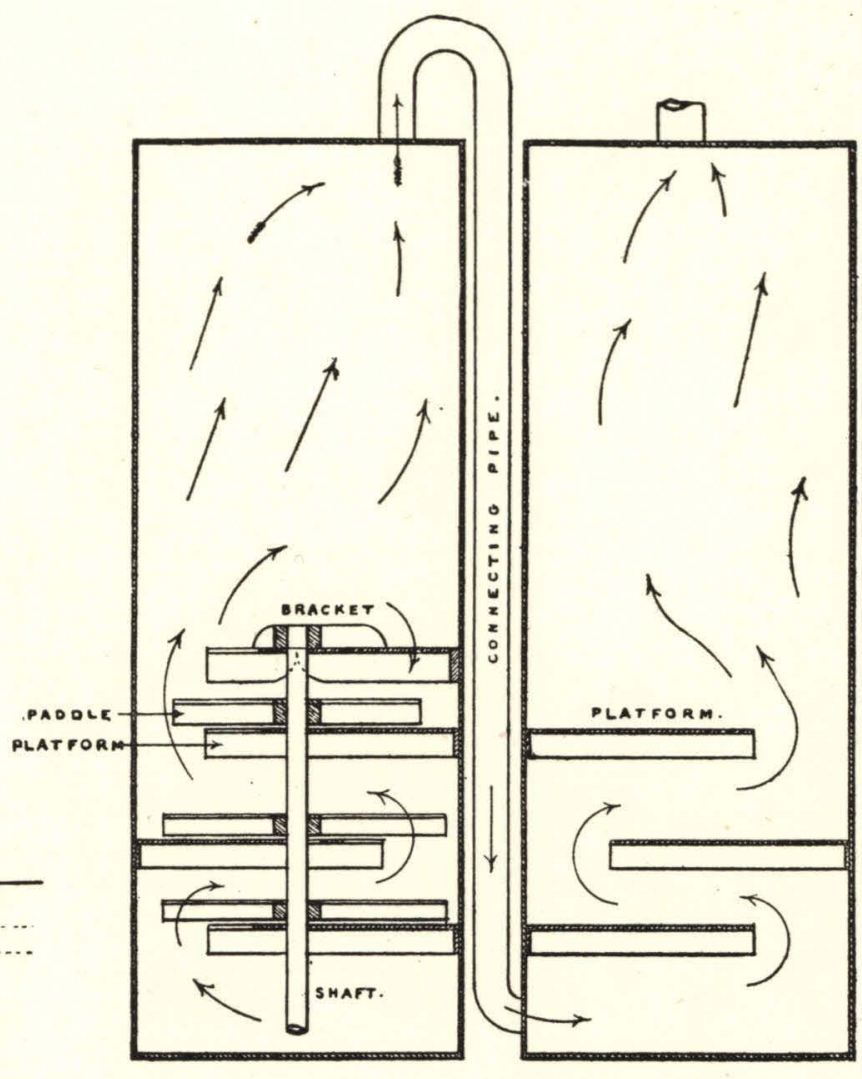

Fig. 133.-Longitudinal Section of Precipitating Tanks,

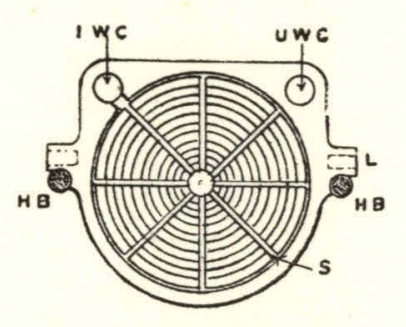

Fig. 134.-Filter-plate.

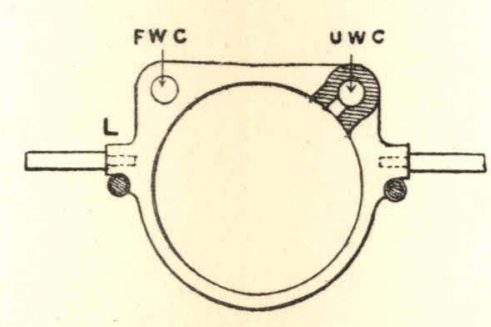

Fig. 135._Water-space Frame.

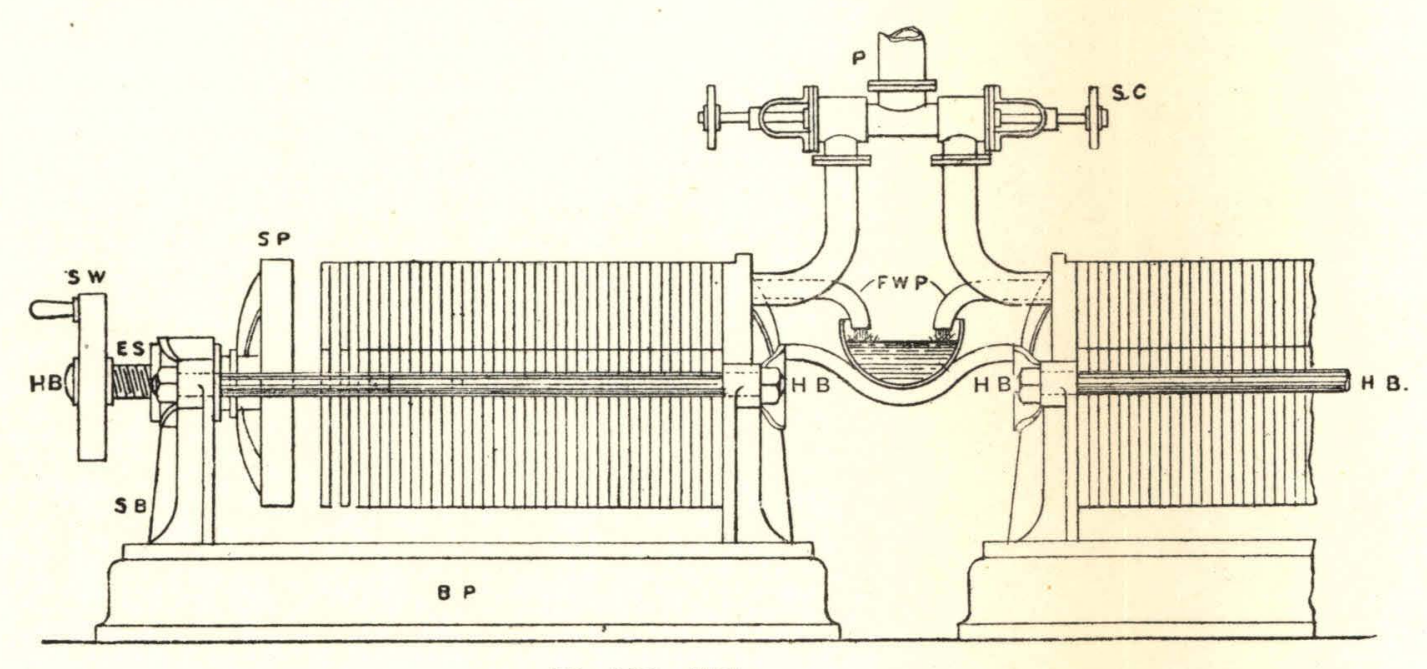

Fig. 136.-Filter-press 
The particular water treated in this case had a hardness varying from $15^{\circ}$ minimum in wet weather to over $21^{\circ}$ in very dry weather, $13^{\circ}$ of which were due to temporary hardness. In softening, the total hardness is reduced to between $6^{\circ}$ and $7^{\circ}$.* The cost of lime for hardening 1,000 cubic feet of water was less than $1 \frac{1}{4} d$.

To test whether the quantity of lime added is insufficient, sufficient, or too great.-By the use of a simple chemical test it may be discovered whether or not lime is being added to the hard water in the proper proportions. A solution of silver nitratet produces a yellow or brownish-yellow colour when it is added to water containing even a very minute trace of uncombined lime. A small quantity of water is taken from the large precipitating tanks, is placed in a white evaporating dish, and a few drops of a nitrate of silver solution are added. If a brownish colouration is produced, the lime is in excess; if the colour produced be a faint yellow only, barely perceptible, the proper proportion of lime has been added to the hard water. If the liquid continue colourless after the nitrate of silver has been added, it may be assumed that insufficient lime is being run into the tanks.

Filter presses are used in this case, and in others where there is not space available for precipitating tanks. $\ddagger$

The water and lime are mixed in due proportion, as for the tank precipitation, and the mixture is then allowed to flow, or is pumped under pressure into the filter presses (Fig. 134, Plate XXXI.), and comes out clear and comparatively soft.

"The filter press consists of a cast-iron bed plate BP, with a support or bracket sB at each end. Connecting and rigidly fastened to them are a couple of horizontal bars Hв, each of which is the same height above the bed plate. On these bars rest, the filter plates and water-space frames (Figs. 135, 136, Plate XXXI.).

"The filter plates are made of cast iron; each plate has two lugs L on its periphery for the purpose of support, and for the insertion of handles for removal. Upon its faces are turned a series of circular eccentric ribs for facilitating the filtration and supporting the cloths. A series of wide radial grooves s are cut in the plate to convey the filtered water to the annular space outside the ribs, from which it can flow into the channel Fwc, in the

* All degrees iu Clark's scale (the English standard). Water of $1^{\circ}$ hardness, Clark's scale, is water that will precipitate as much soap, as pure water in which 1 grain of calcium carbonate per gallon has been dissolved.

+ See note 12, Appendix iI.

\$ See note 13, Appendix II. 
left-hand top corner, and hence out of the press. In the righthand top corner is a hole, through which the unfiltered water passes into the water-space frames. The water-space frames (Fig. 136, Plate XXXI.) are similar to the filter plates, with the exception that the metal forming the circular ribs in the filter plate is removed, leaving an annular frame of metal. A passage is cast connecting the large central space with the hole ow in the right-hand top corner, to allow the unfiltered water to gain access to the filtering cloths.

"A number of filter plates and water space frames are placed alternately on the horizontal parallel bars $\mathrm{HB}$, and a cloth or towel of a superior quality of cotton twill is dropped over each filter plate (as a towel is placed on a horse), the cloth having holes worked in it corresponding with the holes in the top corners of the plates and frames. The frames and plates are tightly pressed together by a powerful end screw Es (Fig. 136, Plate XXXI.). Thus the holes Fwc, uwc, become collectively tubular channels of the length of the filter press, the channel on one side admitting its unfiltered water into the circular water press frames; whilst being inclosed and under pressure, the water can only escape through the cloths into the concentric grooves, passing from these along the radial grooves into the channel Fwc, and hence out of the press.

"After the process has been started, the unfiltered water will not only have to pass through the cloths, but also through the residue of carbonate of lime deposited upon the cloths. This acts as a very fine filtering agent, entirely removing all organic and mineral matter held in suspension by the water. On the average the cloths are changed after being used about twelve hours.

"The unfiltered water and lime are conveyed from the mixing tanks to the presses by the cast-iron pipe $P$, the flow being regulated by the stop-cocks sc. The softened water passes from the presses into a trough, FwP (Fig. 134), or into a pipe leading to the storage tank. A square foot of filtering surface will supply filtered water at the rate of 30 gallons [say 5 cubic feet] per hour, the amount varying according to the pressure under which the filtration takes place. The filter press (Fig. 134), contains about 100 square feet of filtering surface. The cloths are cleansed in a power washing machine, and are then ready for further use."*

Natural Filtration (so called).-If a tunnel or gallery be driven in the sandy and gravelly alluvial deposit that is found in

* See note 14, Appendix II. 
considerable depths along some parts of the courses of nearly all rivers, - especially such as have their sources amongst mountains, - parallel with the river, at a depth below that of the level of the water of the river, and be so constructed that the bottom, or the bottom and the sides, will allow water to enter, it will always be found that more or less water flows into the gallery. Commonly the quantity that enters is quite copious, and such sources of water have frequently been used for the supply of towns. Often (the bottom of the gallery only being left porous) water will flow continually upwards at the rate of from 20 to 30 lineal feet per day, sometimes much more, and this water is nearly always free from suspended matter, and is generally clear and sparkling.

It was commonly supposed, until comparatively recent timesand the supposition was a natural one-that the water entering these galleries was water that had infiltrated from the river. Recent investigations have shown that in some instances this is not the case, and it is probable that in most it is not. Thus it has been found that, if there were impurities in the water drawn from the gallery, these were not of the same nature as the impurities in the river water, but were rather of the nature of the impurities in the water of the land in which the gallery was driven, or between it and the higher ground. In fact the galleries did not seem to be filled by receiving water from the river, but by intercepting the underground water flowing slowly towards the river. In this connection it has to be borne in mind that a great part at least of all rain water reaches streams by soaking into the ground, and slowly moving in an underground flow towards the nearest stream, so that, when we see land gradually sloping towards a river, we have to imagine a water-bearing stratum under the surface of this sloping land, the water slowly working its way towards the river. Were it not for this underground water, the flow of a stream would cease very shortly after rain has stopped.

The most remarkable observations in this connection are, perhaps, those of Mr. Edward Easton, in the neighbourhood of Brighton (England). He observed that, over a large area of ground near that town, no stream of any kind was to be seen. $\mathrm{He}$ also noticed that along the sea-shore there were, especially at low water, innumerable rills of water passing through the sand, and he found that this was fresh water, the fact being that the ground is so porous that the rain all soaks into it, and makes its 
way underground to the sea. The form of the surface of this underground mass of water was even estimated by comparing the depth of water in wells, and it was found to slope steadily towards the sea. In this case, by driving a tunnel parallel with the seashore, and at the depth of low water, a plentiful supply of fresh water was obtained.

It is probable, in the case of galleries parallel with rivers, that the greater part of the water is, in most cases, intercepted water from the surrounding country, but that, in many cases, a part or the whole of the water is, at certain times, derived from the river. Thus it is quite conceivable, in some cases, that the water of the surrounding country is intercepted during rainy weather, whilst the river may be the source of supply during dry weather.*

However this may be, a gallery of the kind described must be looked on simply as a shallow well on an extended scale, and the water from it must be regarded with the same suspicion as is the water from a shallow well. As has already been said, the water from a shallow well is not of necessity bad. If there is no possible source of contamination near it, or above it in the direction from which the underground water is flowing, it may, in fact, be very good.

The case of the supply of Perth (Scotland) must be taken as one of actual natural filtration of river water. ${ }^{\dagger}$ This town is (or was until recently) supplied with water drawn from a gallery below an island in the middle of a river. Hence it may be assumed that the water all filtered from the river. It is stated that, although the water of the river contains much organic matter in solution, the water drawn from the gallery is remarkably pure. This is a particularly interesting case, where nature does what man has as yet failed to do by artificial means, even imitating her as closely as possible.

* In Japan - where, on account of continual embanking of rivers without removing detritus carried down by storms, the flood level of the rivers after they have left the mountains, is generally considerably above that of surrounding plains ; and, indeed where, at places, the very bed of the river is above the land through which it passes-very different conditions must prevail ; and it is probable that a gallery alongside such a river would generally be fed more or less by the river, entirely by
it at times.

$\dagger$ See note 15, Appendix II. 


\section{CHAPTER XIV.}

\section{Service or Clean Water Reservoirs-Water Towers-. Stand Pipes.}

Service Reservoirs.-The chief object of "service" reservoirs is to hold a reserve of water, so that, the supply remaining constant during the twenty-four hours, the consumption may vary according to the requirements of the consumers.

Were it not objectionable to vary the speed of filtration, and were there sufficient reserve either in settling reservoirs or in an impounding reservoir-or were the supply of water (say from a large upland stream) larger than the maximum consumption-there would, in most cases, be no particular object in having service reservoirs, and the town might be "served" directly from the filter beds. Indeed, this was by no means an unknown practice in somewhat earlier days. Enough has, however, been said already as to the desirability of keeping filtering speed uniform, or at least never permitting it to exceed a certain maximum. Seeing that it is sufficient to provide that it do not exceed a certain maximum, it is evident that service reservoirs might be dispensed with by increasing the filtration area. An increase of about 60 per cent. would be needed, and it is true that the cost of this might not, in some cases, be as great as that of the otherwise necessary service reservoirs, but the convenience of service reservoirs is so great for other reasons than that of permitting the filtering speed to remain uniform during the twenty-four hours, that the adoption of them may now be said to be all but universal.

Another use of service reservoirs will be more fully dealt with in treating of Distribution Systems; meantime it may be illustrated by a single case.

Let us suppose a town to be supplied by gravitation from an impounding reservoir at a considerable distance, such distances, in practice, amounting to anything up to sixty miles. It will be 
evident that, if the town is supplied directly by a main from the impounding reservoir, this main must be capable of carrying a quantity of water equal to the maximum consumption at any part of any day. In other words, it must be capable of carrying at least twice the mean consumption. If, on the other hand, there be within, or near the town-the best possible position is in the centre of the town-an elevated service reservoir into which the water can gravitate from the impounding reservoir, to be distributed from the service reservoir, it is evident that (assuming the service reservoir to have sufficient capacity) the main need only be capable of carrying the maximum daily supply, or, say, 40 per cent. more than the mean supply. Thus the main need have unly about two-thirds the capacity with the service reservoir that would be necessary without it.*

In the case of a long main from a reservoir at a considerable height, besides the objection of having to make the main capable of carrying absolute maximum consumption, and still give a fair pressure in the mains, it often happens that there is further trouble from excessive variation in pressure.

The Capacity of Service Reservoirs. - Until recently the practice of engineers commonly was to make service reservoirs of a very considerable capacity. Thus they were often made to hold two or three (or even more) days' consumption. There are decided advantages in having such a capacity for storing clean water, and this particularly in the case of pumping systems. Thus the pumping engines could, in the case of an emergency, be stopped for a day or two for repairs, so that there would be less necessity for "stand-by" pumping power than there is with only a small reservoir; or it could be so arranged that the pumping engines would have to work only during the day time, and this is a great advantage in the case of small instalments, where the

* In Japan, the waterworks of Hakodate and Nagasaki may be taken as typifying these two cases. The water for Hakodate is taken from an upland stream, with a discharge greater than the maximum daily consumption, the intake being at a very considerable distance from the town. There is, however, a service reservoir on the hill just at the back of the town, and, therefore, the main from the intake need carry only maximum daily supply. In the case of Nagasaki, on the other hand, the supply is by gravitation from an impounding reservoir at some distance from the town, and there is no elevation in, or very near, the town, suitable for an impounding reservoir. This being the case, it was necessary to make the main from the reservoir to the town capable of carrying the maximum quantity of water likely to be consumed at any time. It is true that, in this case, the advantage of a service reservoir would not be as great as it might be in many (ases; still, this case will serve to illustrate the point. 
firing and attendance constitutes the greater part of the expense of keeping a pumping station going. But above all there is the advantage of having a reserve in case of fire.

In spite of all these advantages of a large service reservoir, the modern tendency is to do with the smallest size of clean water reservoir that will serve its purpose.

This tendency is part of the outcome of the modern study of bacteriology, and the great weight now given to all sanitary conditions. It has, as has already been stated, been found possible, by careful sand filtration, or by any of one or two other means, to get rid of far the greater number of micro-organisms that all water contains. It is, however, found that, if the water thus freed from the greater quantity of the microscopic life that it contained is allowed to remain at rest for any considerable time, the number of bacteria may increase very rapidly, and, so far as organic life goes, the water will tend to become as bad as it was before filtration.

As the effect of a water supply on the health of the population supplied is now placed before all other considerations, the advantages that there are in a large service reservoir are commonly sacrificed for the sake of "hurrying through" the water to the consumer. The case of a great fire can commonly be provided for by a "by-pass" from the intake, the impounding reservoir, or the settling reservoirs, allowing, as a matter of fact, the river or the impounding or the settling reservoir to act the part of a service reservoir for the time being, the water flowing past the filter beds in the case of a great fire occurring. This arrangement is, of course, not without its objection, as, in case the by-pass comes into use, the result is to fill the mains with unfiltered water, which is not completely cleared away from them for some considerable time, so that the supply is really contaminated every time that the by-pass comes into operation. Still, it is now generally considered that the contingency of an occasional supply of altogether unfiltered water is to be preferred to the continual use of water deteriorated from too long storage after filtration.

Investigation has proved that, if a service reservoir has a capacity corresponding to seven hours' mean supply, ${ }^{*}$ it is capable of compensating for the inequality of the consumption during the twenty-four hours, even at times of maximum daily consumption, and some engineers recommend that the total capacity of the 
service reservoir be little or no greater than this. This (it seems to the writer) is a case of rushing to the opposite extreme of old practice. Nothing whatever is left for contingencies. Even in the case of a small fire taking place at the time when the service reservoir was nearly empty, it would be necessary to open the by-pass, or to put into operation whatever special provision had been made for fire extinction.

It is, of course, difficult to draw an even balance between the advantages of a large service reservoir, and one of the least capacity that will enable it to serve its purpose; but the writer ventures to suggest, tentatively at any rate, that a capacity of at least nine or ten hours' mean supply be adopted as a standard, apart from an ample provision for fire. It will readily be understood that a proportionately larger reserve for fires is desirable in the case of a small than of a large town, but this subject is fully treated in Chapter XIX., to which the reader is referred.

It is desirable to divide service reservoirs into several compartments, so that one may be cleaned at a time, and if a twelve hours' supply be taken as the capacity of the whole reservoir, it is evident that, if it be divided into three compartments, two of them will still hold enough water to compensate for the variation in consumption during the twenty-four hours. It is not, however, really necessary, in the case of service reservoirs, when one compartment is off for cleaning, that the other two should have a capacity sufficient to compensate for variation in the consumption during the twenty-four hours during a time of maximum daily consumption, because a clean water reservoir needs cleaning but seldom, and it is generally possible to select a time for cleaning when the daily consumption is not at its maximum, and when the discharge through the filter beds will equal the maximum daily discharge during the twenty-four hours, without exceeding the filtering speed determined on. It is thus possible, by having a by-pass that will allow the water to flow past the service reservoir, to manage the cleaning of a whole reservoir that has no parting division at all. In this case, however, there is, of course, at the time of cleaning, no reserve for fire at all, so far as the service reservoir is concerned. It is advisable, therefore, to have at least one division, dividing the reservoir into two compartments.

Form of Service Reservoirs in plan.-As in the case of settling reservoirs and filter beds, the form of service reservoirs is often determined by that of the land that may be available. If, however, there be no restriction, the form is generally rectangular. 
In some cases a circle has been selected as the form, because the walls, in the case of moderate-sized reservoirs, acting as horizontal arches, may be made thinner than they would have to be made if calculated as retaining walls, and, indeed, by adopting the circular form the total length of wall is, in any case, reduced to a minimum, as a larger area is included in a circle, than in a plane of any other form having the same length of bounding. line. A circular form, however, generally involves waste of land. Moreover, there is the question of covering with a roof-to be treated presently - and the difficulty of this in the case of a circular plan is much greater than in the case of a rectangular plan.

The rectangular plan may thus be considered the standard one, but the writer has known cases where the top of a small conical hill was the most suitable place for a service reservoir, and where the circular plan was the only one that was found practicable.

Under this heading of the form of clean water reservoirs in plan, may be considered the question of the motion of the water in the reservoir. Conceding that it is desirable that the water be stored for as short a time as possible in the clean water reservoir, it is evident that the object of this short storage will be defeated if the method of admitting and of drawing off the water be such that a part of the water passes direct from the inlet to the outlet, whilst another portion remains stagnant, or nearly so. For this reason it has been the custom in Germany, for some time past, to divide clean water reservoirs into several compartments by partitions, open at opposite ends of the reservoir, much as shown in Fig. 64 (page 89). The water has thus to travel the length of the reservoir several times, and stagnation is prevented. There is not the same objection to this construction in the case of clean water reservoirs as in that of settling reservoirs, because, in the case of the former a slight current is in no way objectionable.

It will be evident, if the system of piping diagrammatically represented in Plate XXXV. be adopted, and the pipes from the filter well to the clean water reservoirs, and those from the clean water reservoirs to the well delivering to the distribution system, be each made large enough to carry the whole of the water, that it will be possible to bring about the same result.

\section{Depth of Clean Water Reservoirs.-Although the} reason for the limitations in the depth is not exactly the same in both cases, the depths given for settling reservoirs (see page 84) may be taken as applying to clean water reservoirs also. 
Form of Clean Water Reservoirs in section.-Clean water reservoirs are always, or nearly always, made with sides vertical, or having only a moderate internal batter, say not more than 2 inches in the foot. The bottom, as with settling reservoirs, may with advantage have a slight slope towards a cleaning drain.

The Roofing of Clean Water Reservoirs. - There are several reasons why clean water reservoirs should be roofed over. One is that such roofing prevents the suspended dirt of the air from settling on the purified water, and this necessity has been so thoroughly realized for some time past that it has been enforced by law so far as reservoirs at all near towns are concerned, in Great Britain, for many years past. It has, moreover, become a nearly universal practice in Europe, and is a very common one in America.

Apart from the need of keeping the floating dirt of the air out of reservoirs, there is the further necessity of preventing the heating of the water by the sun's rays, and the vegetation that would certainly ensue. The necessity for preventing the sun's rays from heating the water, is, of course, specially felt in countries where the sun is for at least some part of the year nearly vertical. This will be readily understood if it is remembered the greatest draught of water is commonly in the morning, so that a service reservoir is partly empty by the time noon arrives, with the sun as nearly vertical as it will be during the day, and probably continues to empty during the early part of the afternoon, whilst the sun has still great heating power.

The form of roof used in Great Britain is in most cases that of a series of brick or concrete arches supported on columns, ${ }^{*}$ the arches being commonly covered with two or three feet of soil. Such a roof is practically impervious to heat, and keeps out all floating impurities. It is somewhat costly, even if it be taken into consideration that the side walls, acting as the abutments of the arches, may be made considerably thinner than if they had to sustain the whole thrust of the earth behind them as retaining walls. In Plate XXXII. (Figs. 137 to 141 ) a reservoir with a roof such as is described is illustrated. It is necessary, of course, to provide manholes for admission, and, if these be closed with perforated covers, the covers will act as ventilators.

Tile or slate roofs have not all the advantages offered by arched roofs of the kind that have just been described, but there may be cases where, for economical reasons, it is considered advisable to

\footnotetext{
* See note 16, Appendix II.
} 


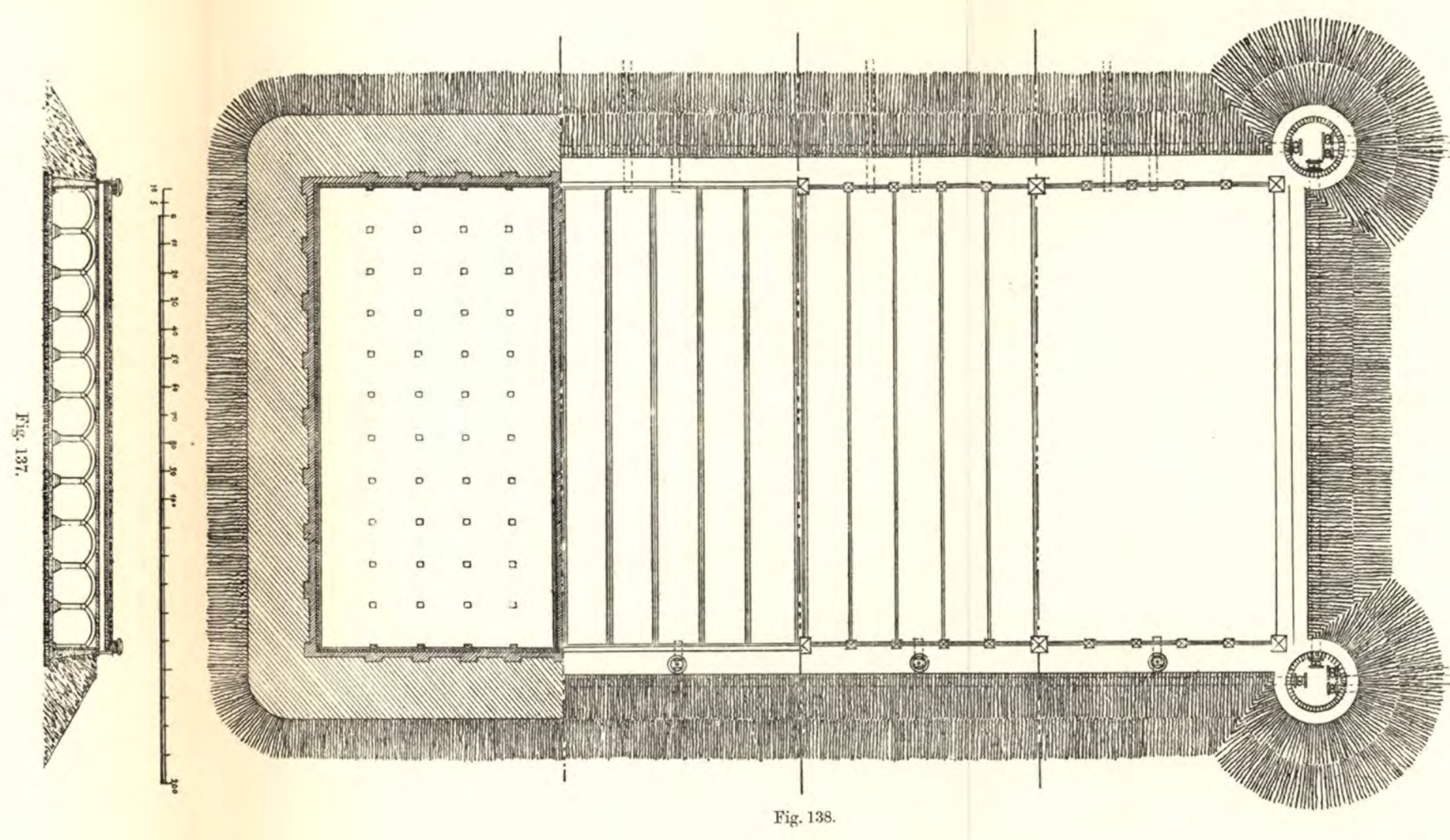

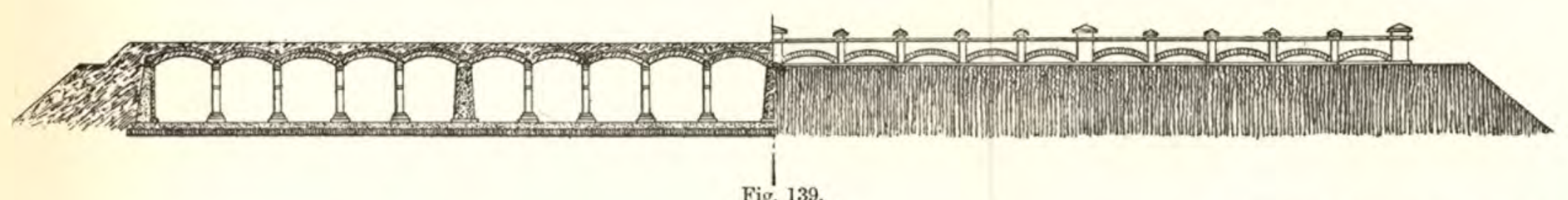
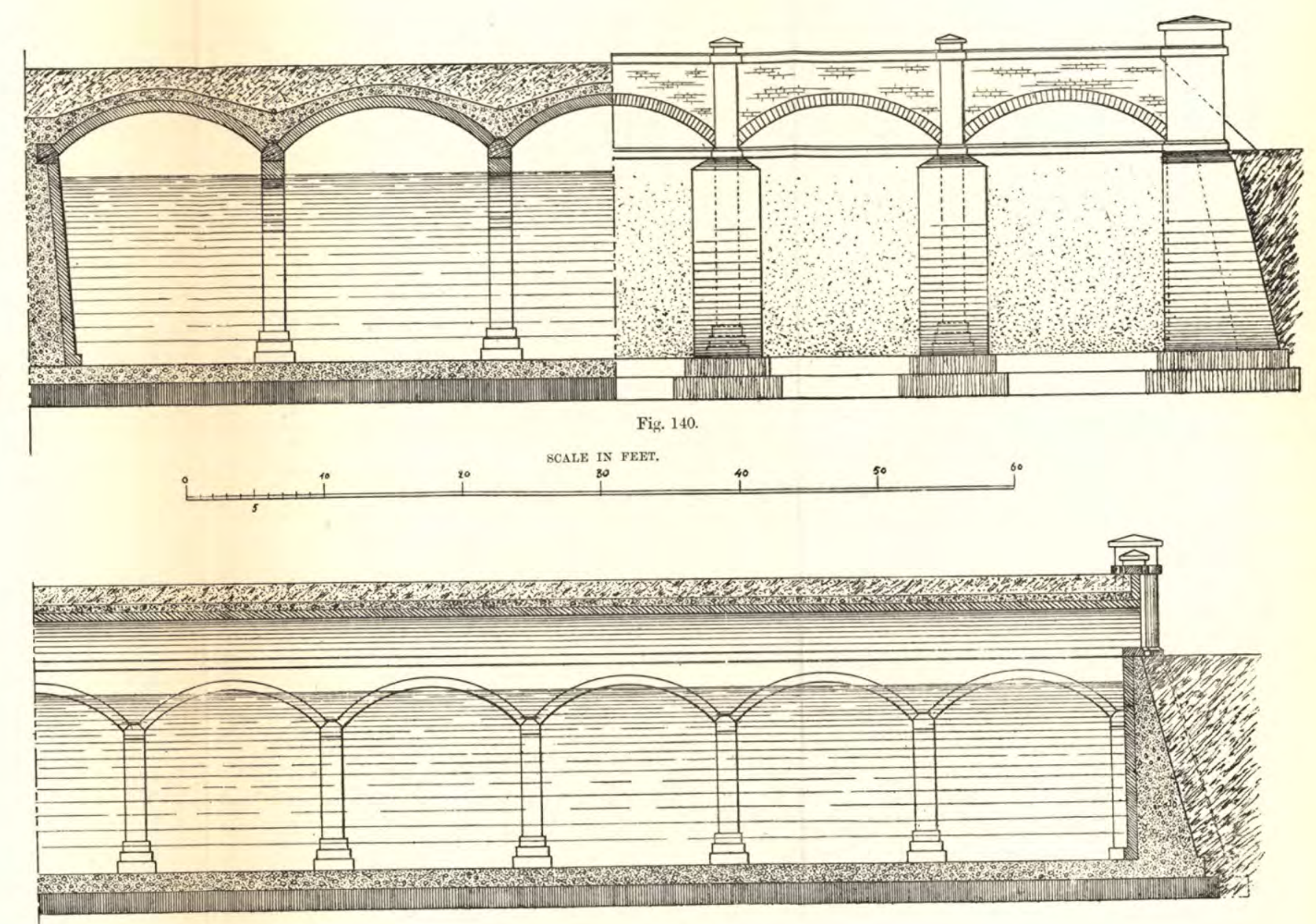

Fig. 141.

Tof face page 132 
adopt them. Plate XXXIII. (Fig. 142) shows the section of a reservoir with such a roof.

Materials for the Construction of Clean-Water Reservoirs.The bottoms of clean-water reservoirs are commonly made with concrete, rendered in cement; the side walls either with brick in cement, or concrete, generally with a brick facing. Until comparatively recently puddle was relied on for water-tightness, but, as in the case of settling reservoirs, the modern tendency is to do without clay. The following description of a service reservoir made entirely of concrete will be found of interest * :-

"Mr. Thomas Walker stated that in 1887-88 he constructed a covered service reservoir to hold 5,000,000 gallons of water on Addington Hill, near Croydon. It was made entirely of concrete, no puddle having been used; and, as the reservoir was perfectly water-tight, a few particulars might be of interest to the Institution.

"The hills were composed of the water-worn pebbles and fine sands of the Oldhaven beds, and these materials were chosen for the concrete, a portion of the sand being removed by screening. The contour of the ground necessitated the reservoir being oblong; the inside dimensions were 420 feet by 124 feet by $16 \frac{2}{3}$ feet deep. The floor, outer walls, and roof were of Portland cement concrete, 6 to 1 by measure ; and for the piers and arches of the longitudinal and cross walls, up to the springing level of the covering arches, the proportions were 5 to 1 , a little Thames sand being used. The concrete was hand-made, turned over twice dry, wetted from a rose on india-rubber tubing, and thoroughly mixed on wooden platforms. It was not dropped from a height into its final position, but placed there with a shovel in layers, not too thick, so that the coarse and fine parts of the concrete were laid or mixed together equally and well worked, ensuring solidity throughout. Water was rather freely employed, but not so as to stand on the surface of the concrete when in position. For joining up all old work when it was set, grout made of one part of cement to two of Oxted sand was used, and, when necessary, the old work was cleansed, roughed over with a pick, and brushed before the grout was applied.

"The floor was 18 inches thick, put down in two layers with overlapping joints. The inside of the outer walls (which required to be roughed) and the floor were carefully rendered,

* Proceedings of the Institution of Civil Engineers, vol. c. 
the first coat $\frac{1}{2}$ inch thick with cement and washed Thames sand in the proportion of one to one of each, and the finishing coat of $\frac{1}{4}$ inch thick was of neat cement put on before the first coat was quite set, and thoroughly trowelled to a hard face. A double thickness of rendering was laid under the piers and on the springing of the arches against the outer walls. The rendering might be said to line the floor and sides of the reservoir in every part to 6 inches above overflow level. Fifteen slight vertical cracks, that appeared in the outer walls before they were rendered, were cut in a $V$-shape, with a cross section of about 1 square foot, and filled in with good concrete.

"Careful examination after the reservoir had been in use failed to detect the slightest fracture in the rendering of any part of the work. The outside of the concrete arches forming the roof was covered with asphalt $\frac{3}{4}$ inch thick, in two coats, and was found to be water-tight. The spandrels of the arches were inclined from the centre to the ends of the reservoir, and had 3-inch land drains laid along them to carry off surface water. A partywall, 12 feet high across the reservoir, allowed the water on either side of it to be run off independently of the other. The main from the pumping station entereci each division at the springing level of the roof arches, which was also the overflow level, and a water cushion was formed on the floor under each inlet by walls 2 feet high inclosing a space 10 feet by 6 feet. The surface of the hills over the reservoir has been restored, and planted with heather as before."

Water Towers.-This name is given to tanks, almost always of wrought or cast iron, erected on the top of towers, either of masonry or ironwork, and acting as service reservoirs. Water towers are most commonly used in connection with pumping systems.

It is evident that, unless tanks of the kind here mentioned be of such a size that they will hold sufficient water to compensate for the variation in the consumption during the twenty-four hours, they do not really serve as service reservoirs, in the sense in which this term has been used up to the present. Even when they do not they are of very considerable use, for it is a great convenience, when pumping machinery has to be used, to have a tank holding a supply corresponding even with the consumption of an hour or two. Without this the speed of the engines must absolutely follow the consumption of the water. It 
Plate XXXIII.

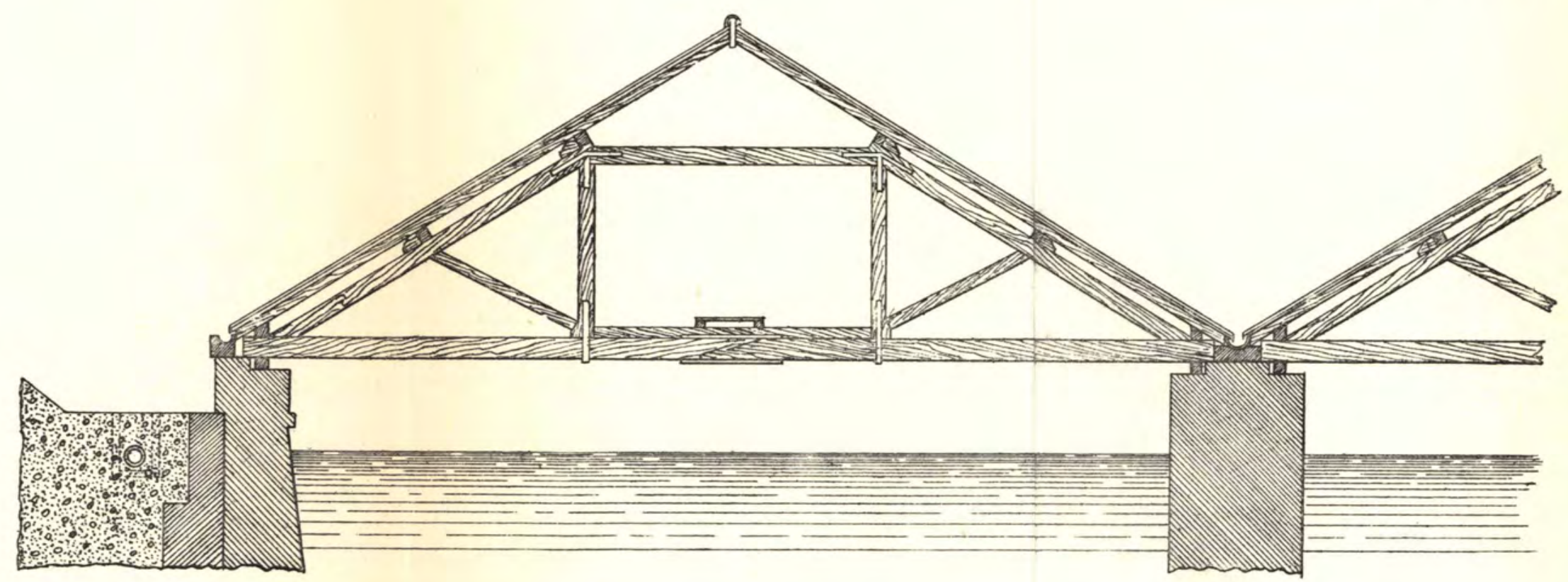

Seale in feet.

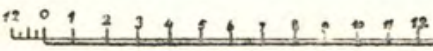

3

Fig. 142.-Reservoir with Tile or Slate Roof.

[To face page 134 . 
is true that, with any capacity of tank not as great as about seven hours' mean consumption, engines cannot work at a uniform speed during the twenty-four hours, but must have the speed of working varied from time to time. There is, however, in the practical working of pumping machinery, a great difference between varying the speed of an engine from time to time and in making it absolutely follow a consumption that is varying from second to second. Further than this-when, as is common in the case of large pumping plant, the power is divided up amongst several sets of pumping engines, of which one or more may have to work at a time, according to the consumption-it is a great convenience to have even a small service tank at the time that one engine is started to help those already at work, or when one is stopped, because the consumption is so slight that the engines at work are working at too slow a speed to work economically.

Pumping machinery has, however, been improved to such an extent of late years, that the tendency is to do away with water towers, unless it is feasible to make them of such a size that they will compensate for the variation in consumption during the twenty-four hours.

Another use of water towers is to store a reserve of water in case of fire. A little consideration will show that such a reserve storage is much more necessary in small towns than in large. The reason is that, in the case of a fire occurring, and beginning (as it always does) with a single house, the actual quantity of water wanted for extinction is the same in the case of a small as in the case of a large town, and is of course proportionately much greater in the case of the small town. So also the spread of the fire, up to a certain point, is likely to be as rapid in the case of a small as in that of a large town, so that still the same actual quantity of water is desirable in the small as in the large town, and proportionately much more. Thus it happens that, in the case of a small town, it should be possible to increase the supply of water, for a short time at least, to several times the maximum that is needed for ordinary purposes, to provide against fire; whereas, in the case of a very large town, a mere fractional increase on the ordinary maximum supply will be sufficient for the largest fire that is likely to occur. This can generally be provided for by setting the "stand-by" engines in motion.

From what has been said it will be gathered that water towers, to act as real service reservoirs, are desirable in the case of small towns, when the system is a pumping one; that they are 
matters of convenience in the case of large towns, even if they are not of so great a size as to act as actual service reservoirs, although the tendency in this latter case is to dispense with them, and to trust entirely to the pumping power.*

In any case, water towers are expensive structures. If made large enough to constitute actual service reservoirs, their cost will always form a large proportion of the whole cost of the works. The writer does not know of any case in which water-tower tanks have been made of capacity large enough actually to serve as service reservoirs, in the sense of compensating for variation in the consumption during the twenty-four hours, for waterworks on a large scale.

Two water towers are illustrated on Plate XXXIV. (Figs. 143, 144, 145). Fig. 143 shows a water tower used in connection with the recently opened Liverpool waterworks, of which $\mathrm{Mr}$. G. F. Deacon, M.Inst.C.E., was engineer. This water tower is not used to perform exactly the function above described as that of a water tower, but it very well might be. The tower itself is of masonry, and the design is one of real beauty. The design of the tank itself-a dish of wrought iron without support except at the edge - is a bold and admirable one.

The tower shown in Figs. 144 and 145, on the same Plate, is a composite structure of cast and wrought iron. It forms part of the Shanghai waterworks (Engineer, Mr. J. W. Hart, M.Inst.C.E.), and the design has been much admired. The following description of the tower, which stands on a foundation of solid concrete, is taken from the Proceedings of the Institution of Civil Engineers, vol. c., p. 223 :-

"The structure for supporting the tank is exclusively of iron ; 52 feet, octagonal in form, 52 feet 6 inches in diameter from centre to centre of the columns. There are twenty-four columns erected in the three tiers of eight each. They are 26 feet long from face to face of the flanges. The sole-plates for the columus are 3 feet 6 inches square and bed direct on the granite piers built in the brickwork. The sole-plate for supporting the centre tube is cast

* In earthquake countries water towers are to be avoided if possible. They are of necessity top-heavy structures, and specially likely to overset at the time of an earthquake. The destruction caused by the bursting of the tank at the top of a water tower, or by the upsetting or overturning of the tower, is likely to be very great. If water towers have to be erected in earthquake countries, it would seem that the supports of the tanks were best to be made of wrought iron only. A compound structure of wrought and cast iron is particularly to be avoided Masonry structures appear to be safer. 


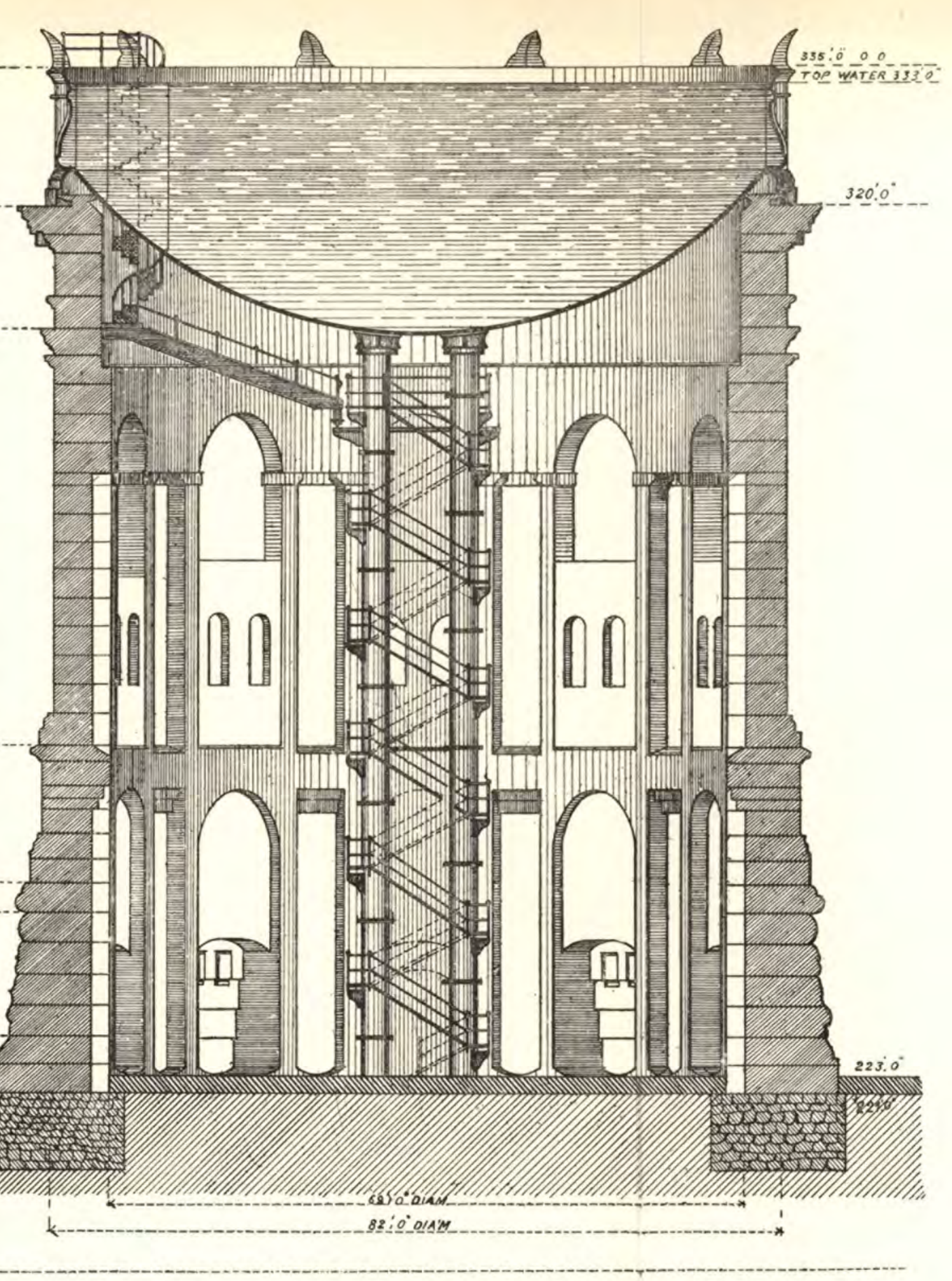

Fig. 143.-Water Tower (in Masonry) at Liverpool.
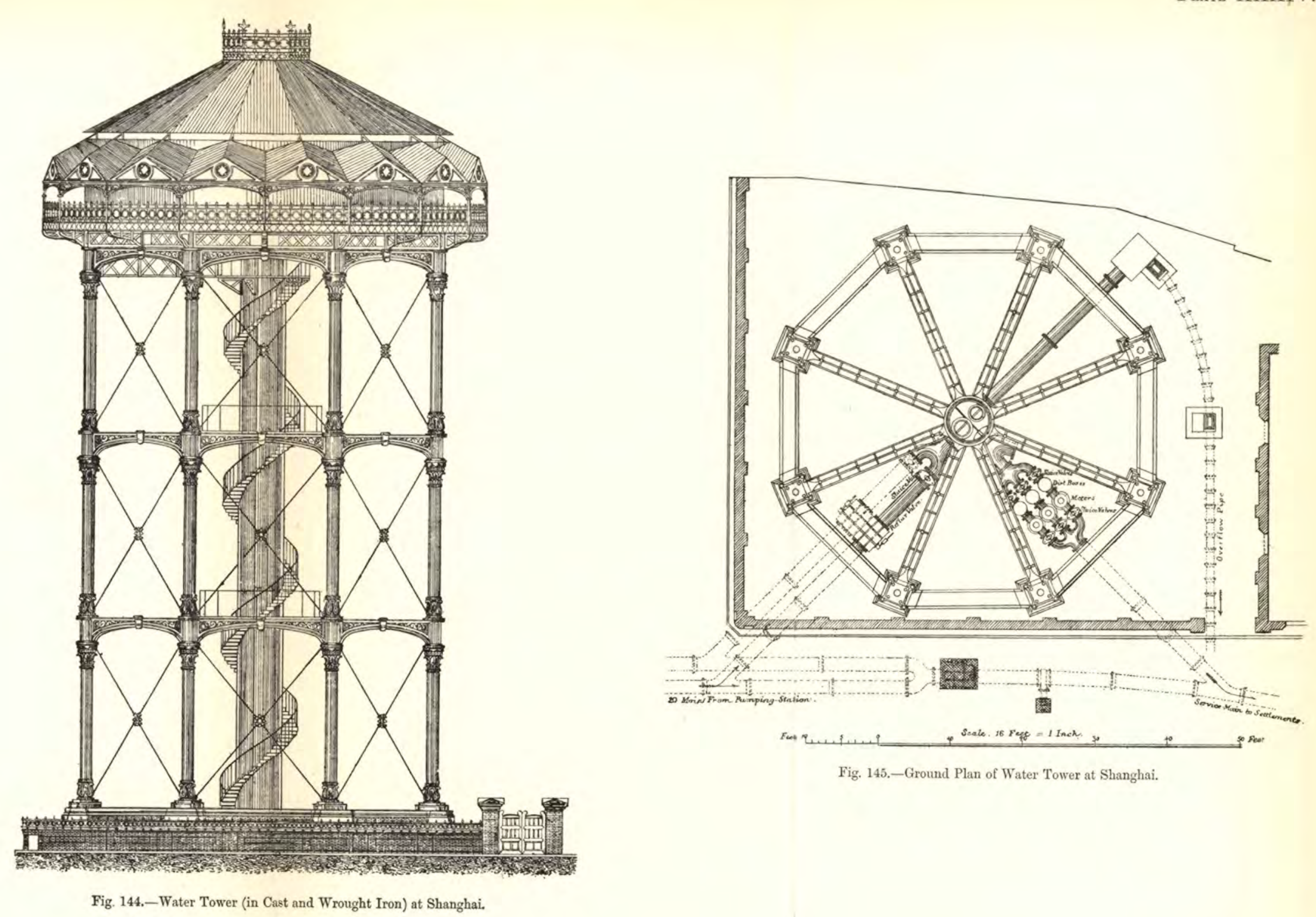
in one piece, with apertures and suitable flanges for the reception of inlet, outlet and overflow pipes. It weighs $5 \frac{1}{2}$ tons.

"The column sole-plates are connected with and bolted to the centre tube sole-plate by cast-iron radial girders bedded on the coping-stones of the radial wall of the foundation walls of the foundation. These walls radiate from the sole-plate for the central tube to each pier.

"The sole-plates and the radial girders are secured in position by $1 \frac{1}{2}$-inch foundation bolts built into the brickwork and piers. By connecting the sole-plates of each of the columns with the sole-plate of the central tube by means of the radial girders in the manner described, the whole weight to be supported is evenly distributed over the surface of the foundation, and the risk of the columns spreading or of inequality of pressure in case of settlement is in this manner reduced to a minimum. The centre tube is 6 feet in diameter, 82 feet 6 inches long, made of boiler-plate $\frac{3}{8}$-inch thick. At the base a strong angle flange-plate riveted to the tube is bolted to a corresponding flange cast on the sole-plate and a perfectly watertight joint is thus made. At the top end of the tube there is a similar flange-plate, to which are riveted the four plates of the tank. Eight vertical stiffening ribs of $\mathrm{T}$-iron, bedded into the tower and upper flange-plates, are riveted to the side of the tube, which thus forms a rigid central column, and does duty with the outer columns in supporting the tank and the water therein.

"It also serves the purpose of an ordinary stand-pipe, when it is found desirable to work with a variable head of water. This can be done during the greater part of the day, without reducing the pressure below what is necessary to meet the usual requirements of the highest building in the settlement.

"To secure the greatest rigidity, the columns of each tier are connected at the capitals with tie-girders made in halves, and bolted together in the centre, the ends being fastened to flanges cast on each column.

" Over the centre connecting joint of the girders an ornamental shield is placed in the form of a keystone to screen the flanges and bolts. Radial tie-girders of light wrought-iron lattice-work connect the centre tube and the columns, one end of the girders being bolted to the capitals of each of the columns in the same manner as the ornamental girders which connect the columns of each tier, while the other end is provided with a gusset-plate riveted to the vertical stiffening ribs of the central tube. The 
diagonal bracing consists of screw tie-rods $1 \frac{1}{2}$ inch in diameter in every bay between the columns, and radially in every bay between the columns and the central tube. There is an ornamental box for receiving the screw ends of the tie-rods; and by means of screw-nuts inside the box each rod is tightened and adjusted.

"The top or floor girders for supporting the tank and water are of steel, of the lattice type. The outer ends rest direct on the column flanges to which they are bolted, and to insure even settlement there is a sheet of lead $\frac{3}{8}$-inch thick between the bed-plate of the girders and the flange of each of the columns. The inner ends of the girders next the central tube have strong gusset-plates with cheek angle-irons, firmly riveted to the vertical stiffening bars of T-iron and to the sides of the central tube, so that the whole weight to be supported is transmitted between the outer cast-iron columns and the centre tube. In addition to the eight principal steel floor-girders, they are also connected with intermediate girders, the whole forming a suitable platform to receive the hard-wood joists upon which the floor of the tank rests.

"The tank is 50 feet diameter by 12 feet 3 inches deep, and contains 670 tons of water. It is made of boiler-plate, the floorplates being $\frac{3}{8}$-inch thick, and the side-plates $\frac{3}{8}$ - to $\frac{\pi}{16}$-inch thick. The floor-plates are riveted to, and connected with the upper flange of the central tube, and are bedded on hard-wood joists, resting on the steel floor-girders. The tank is staved inside with stiffening bars of $\mathrm{T}$-iron riveted to the side and the floor-plates, to which are secured diagonal gusset stay-plates. There are also screw stay-bolts from the side plates of the tank to the centre column which supports the roof.

"The roof is of light construction, the principal and intermediate rafters are of angle-bars, one end being riveted to the side-plates of the tank, while the other is bolted to a flange-plate on the top of the central column. This column rises from the floor-plates and supports the roof, bolted between another set of flanges of the centre column. There is a wrought-iron plate, and to this are fastened struts, which radiate at equal distances for stiffening and supporting the rafters. The roof is covered with corrugated galvanized iron, and closely resembles the structure of an ordinary umbrella when open. Round the tank there is a gallery 6 feet wide, supported by light cantilevers fastened to the ends of the steel floor-girders. To screen the water from the sun, the gallery roof is pitched at an acute angle.

"To approach the top and intermediate galleries from the 
foundation, there is a set of spiral steps fastened to the centre tube, and there are landings at the level of each tier of columns. These facilities for inspection place the tank and the whole superstructure at all times under immediate view, and render them accessible for painting and repairs.

$$
\text { * * * * }
$$

"The outlet aperture is cast on the sole-plate of the centre tube in the same way as the inlet aperture, and over the outlet, inside the centre tube, there is a large strainer, through which the water must pass before leaving the tower.

$$
\text { * * * }
$$

"To provide against the risk of flooding the tank by overpumping, there is, inside the centre tube, an overflow pipe, 20 inches in diameter, with a large bell-mouth at full-water level. The overflow water escapes through the aperture in the sole-plate of the centre tube, and is discharged into a well with a divisionwall to break the fall, and then runs to waste through the public drains.

"The total height of the water tower from the roadway to the crest of the terminal on the roof is 121 feet.

$$
\text { * * * * }
$$

"When the tank is full the total weight to be supported is 3,725 tons.

"The following sums represent the total cost of the water tower, exclusive of land :-

" Cost of construction of superstructure, including meters, reflux and other valves and other accessories, with freight and in, with reight and in- $£$

"Cost of foundations, earthwork, brickwork, and masonry * * 5,378

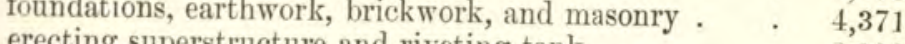
" erecting superstructure and riveting tank . . . 2,100

$£ 11,849$

"The tower has been subject to severe strains by several typhoons, and not a single defect has been discovered. Except as regards the cost of painting and cleaning, the cost of maintenance has been nil."

Stand-pipes.-It is not possible to draw any hard-and-fast line between water towers and stand-pipes. It will have been observed that, in the description of the water tower just given, it is mentioned that, in certain circumstances, the central tube may 
act as a stand-pipe. On the other hand, stand-pipes may act as water towers, in the sense that they may perform the functions ascribed above to water towers. If, in the case of the water tower just described, instead of there being a composite iron structure to carry a wrought-iron tank, there had been built up from the foundation block of concrete, a boiler-plate shell of the whole diameter of the tank, so arranged that the water could be pumped into it at the foot, and could rise to the level it is intended to rise to in the tank-if, in other words, the depth of the tank had been made from the present high-water level, right down to the foundation block--it is evident that, as holding a reserve of water, the arrangement would be as efficient as that actually used, in fact much more so, for although the whole of it could not be drawn off except at a gradually dininishing pressure, there would be a much larger reserve of water. Yet the structure now suggested would probably be called a stand-pipe rather than a water tower by many. In fact, a structure for storing a certain reserve of water may be called a stand-pipe when it is in the form of a tube or shell, with parallel sides from the level of the ground upwards. When the upper part is of comparatively large diameter, in practice needing some farther support than the mere tube forming the lower part, it is generally called a water tower.

There is another distinction in practice, however. A water tower generally includes a tank for holding a supply of water of such quantity that the engines pumping into it may be stopped for a short time if necessary, and ought when practicable to hold such a supply of water as will compensate for the irregularity in consumption during the twenty-four hours. A stand-pipe often holds only as much water as could be pumped by the engines in a few minutes, and acts merely as a "cushion" to the engines, preventing shocks on the pipes, and giving the engines time to get up speed when the demand for water increases, and to slow down " comfortably" when the demand decreases, instead of being quickly "drawn up."

The action of a stand-pipe as just described is diagrammatically illustrated in Fig. 146. Here s w stands for suction well, $\mathrm{P}$ for pumps, $\mathrm{E}$ for engines, $\mathrm{F}$ s for forcing main, s $\mathrm{P}$ for stand-pipe, and M for main to distribution system. It will be evident to anyone with the slightest knowledge of mechanics how a float within the stand-pipe might be caused to actuate a valve, or better, the lever controlling a differential expansion gear, on the pumping engines, so as to control their speed with the utmost nicety-exactly, in 
fact, as the "accumulator" controls the speed of the pumping engines in a high-pressure "hydraulic system" such as is commonly used in working cranes, coal hoists, capstans, \&c., around docks, and, in many cases, the greater part of the subsidiary machinery on board large steamships. Stand-pipes (socalled) may have any diameter from (say) 2 feet to 40 feet.*

The question of stand-pipes cannot be left without saying a word or two concerning one practice of engineers in connection with stand-pipes. These, especially when of moderate diameter, are sometimes made double, in the form of a "breeches-pipe," one leg being a rising pipe, another a falling, and there being a certain farther height of pipe above the junction.

It would seem that some engineers conceive that this arrangement offers some advantage over the single pipe shown diagrammatically in Fig. 146. But it is difficult to imagine, with modern

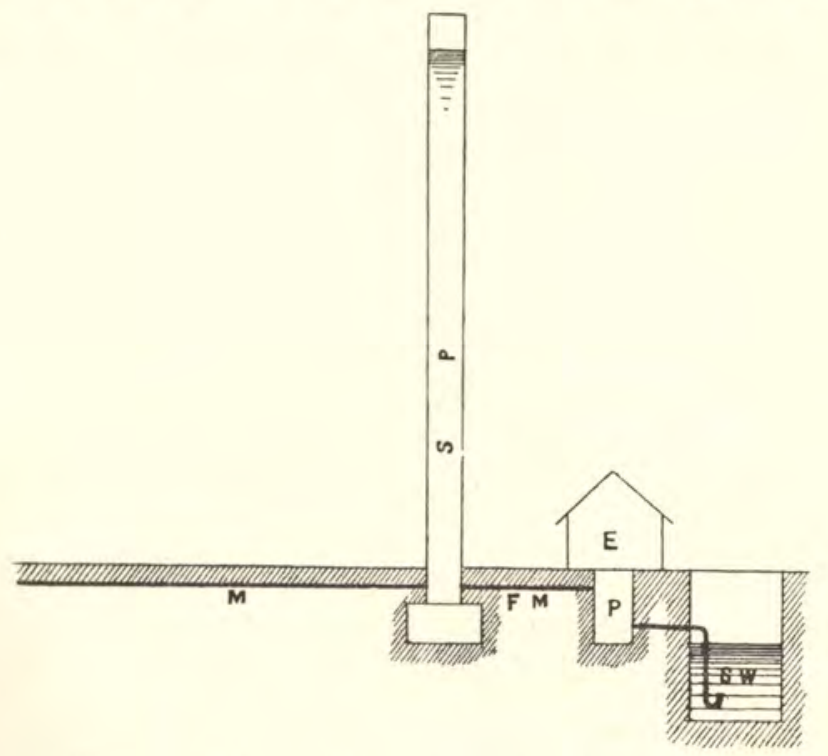

Fig. 146.-Diagram illustrating action of a stand-pipe.

pumping machinery, any advantage that can arise from the arrangement, whilst it is easy to point out many disadvantages that attach to it. Thus, in the case of a sudden demand for a large supply of water, the level of the water in the leg down which the water flows will fall below the junction, and the engines will merely be pumping water up to the junction to fall over it on the other side. In other

* See Fanning's “Treatise on Hydraulic and Water-Supply Engineering " (Fourth edition), in which a chapter, very fully dealing with the subject, is specially devoted to Stand-pipes. 
words, they are pumping up water for the sake of merely allowing it to fall down again in a cascade within a pipe! Further than this, the engines, pumping against a constant head, or, at any rate, a head whose minimum is up to the junction of the two pipes, will not respond to the demand for a large increase in the supply of water-most likely to occur in the case of a fire, when it ought to be met if it can by any possibility : whereas, were the stand-pipe arranged as shown in the diagram, the pressure against which the engine has to pump is reduced; the engine is able, within limits, to increase the quantity of water pumped; and yet the reduction of pressure in the mains is less than with the breeches-piece stand-pipe.

This double stand-pipe was necessary, or nearly so, with some of the older forms of pumping machinery, which would not work efficiently except against a constant head. It was probably adopted with somewhat more modern pumping machinery, to prevent an accident in case of a burst in the mains not very far from the engines, in which case the latter might "run away" and do serious damage. At the present time it is easy to provide against this contingency in any of various ways much less clumsy and expensive than that of providing a double stand-pipe, and double stand-pipes may be said to be relics of antiquity.

In the case of water towers it is common to have two pipes, one rising and the other falling, with a by-pass between them at the foot to be used when the tank at the top of the tower has to be put out of use for a time for cleaning or repairs, but even this is not at all necessary. A single tube will serve all purposes, as in the case of the tower for the Shanghai waterworks described in this chapter. During the time of cleaning or repairing the tank, the pumping can be regulated so that the level of the water in this tube-a stand-pipe in reality-does not quite reach the tank. The only inconvenience is a slight temporary reduction in the pressure on the mains.

The modern tendency is to substitute air-vessels for stand-pipes used merely for the purpose of " cushioning" pumping engines; the stand-pipes are always expensive structures. The air-vessels may be made of wrought-iron, as large as is necessary for preventing shocks in pipes, or the over-sudden increase or diminution in the speed of engines, however large the pumping plant may be.

More will be said about water towers and stand-pipes in the chapter on Distribution Systems. 


\section{CHAPTER XV.}

The Connection of Settling Reservoirs, Filter-beds, and Service Reservoirs.

A Typical System of Waterworks.-A typical waterworks system may be said to consist of (1) settling reservoirs; (2) filtering beds ; and (3) clean water (or service) reservoirs, although, as has been explained, there may be many departures from such a typical case. Even when such a case does occur, it will often happen that the conditions make it advisable that the various appliances be placed in localities somewhat separated from each other, and it seldom happens that a perfectly symmetrical arrangement, such as that shown in Plate XXXV. (Fig. 147), can be carried out in practice. Such a hypothetical case is taken, however, for the sake of illustrating certain points. The general arrangement will be understood without any explanation further than to say that s R stands for settling reservoir, F B for filtering bed, and $\mathrm{c} \mathrm{w} \mathrm{R}$ for clean water reservoir. The relative capacities and areas are taken as within the limits already laid down.

Mention has been made of by-passes and of overflow pipes, and although nothing häs specially been said about the connecting pipes, it will of course be understood that there must be such pipes * to carry water from settling reservoirs to filter-beds, and from filter-beds to clean water reservoirs. It seems necessary to give a few words of explanation about these different pipes.

In the first place, let it be understood that in Plate XXXV. connecting or distributing pipes are shown in full lines, by-passes in common dotted lines, and waste and overflow pipes in chaindotted lines. Further, that various letters have the following meanings:- $\mathrm{s} v$, sluice-valve, o, overflow, W $\mathrm{P}$, waste-pipe, $\mathrm{S}$ P, stand-pipe or floating pipe, в $\mathrm{v}$, ball valve, or valve actuated by a float to keep water at a constant level, and $\mathrm{F} \mathrm{H}$, an appliance for regulating the filtering-head.

\footnotetext{
* Note 17, Appendix II.
} 
Connecting or Distributing Pipes. - These may be arranged in various ways, but the writer thinks that by adopting the arrangement shown in Plate XXXV. the pipes are all conveniently under control, those for any one set of appliances being controlled at one or two "wells." It is, however, necessary to say a word or two about the diameters of the pipes.

In every case it would be possible to calculate the diameter of a pipe, taking as data (1) the quantity of water that has to pass through it in unit time, (2) the length of the pipe, and (3) the "head" of water that may be sacrificed in carrying the water through the pipe, using any standard formula for the discharge of water through "short pipes"; but if this be done, it is necessary to state what the "head" is to be, and practically such statement comes merely to assuming a certain head. Such being the case, it seems a reasonable course to take a certain velocity, such as is known to be thoroughly under control, and such as will not, in the lengths of pipe that are likely to occur in arrangements such as that illustrated in Plate XXXV., use up, or waste, any head that will interfere in any way with the general working of the system. Taking this into consideration, the writer has been in the habit of giving such diameters to the pipes at present under consideration, that the maximum velocity shall not exceed 3 feet per second. In other words, the area of cross section of a pipe may be made

$$
a=\frac{d}{3} .
$$

where

$a=$ the area of the cross section of the pipe in square feet.

$d=$ the maximum discharge in cubic feet per second.

From what has already been said, it will be understood that, if the water is to circulate through the various compartments of the clean water reservoirs, so as to prevent any likelihood of stagnation, it is necessary to make each pipe to and from each clean water reservoir of such diameter that it will satisfy these conditions.

By-passes. - The object of by-passes, or by-pass pipes, is to so arrange matters that in case of need the water may be allowed to pass by any single reservoir or filter-bed, or set of reservoirs or filter-beds. The reason why it is desirable to be able to put any single reservoir or filter-bed " out of circuit" will readily be understood, as all of these have to be put off work at times for cleaning. It will also be readily understood why it may, in case of fire, be 


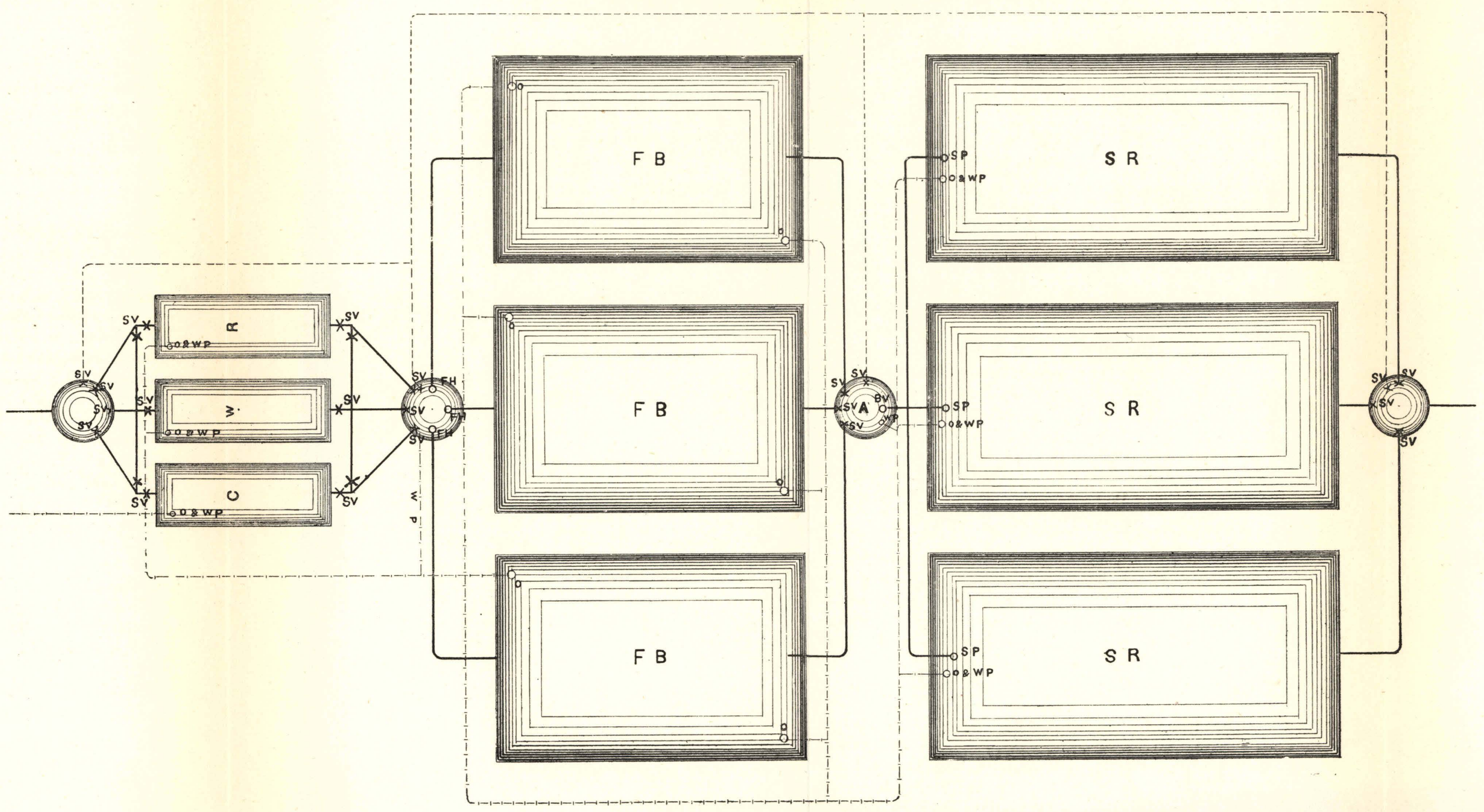

Fig. 147.-Typical Arrangement for Waterworks. 
desirable to allow the water to pass by any set of reservoirs or filter-beds. It need only be further added that it is well, in designing the pipe systems in connection with filter-beds and reservoirs, to so arrange them that any one, or any number, of either filter-beds or reservoirs may be "passed by" if this seems desirable at any time. * If the system diagrammatically illustrated in Plate XXXV. be examined, it will be readily understood how this can be done. Here (as has been said) the main supply pipes are shown in full lines, the pipes that are intended to act as by-passes only as dotted lines, and the pipes that act as overflow and waste-pipes as chain-dotted lines.

Overflow and Waste Pipes.-It is difficult to give any rule for the diameters of these pipes. Overflow pipes ought to be made of such a diameter that they will carry away the whole of the supply to the reservoir or filter-bed, in case the discharge from it be entirely shut off, but they are seldom made so large.

In the case of waste pipes we may be guided by the following considerations. It is undesirable to waste much time in running water away when an appliance has to be cleaned. On the other hand, it is seldom, or never, that the whole of the water is run off such an appliance by the waste pipe. As much as possible is allowed to go off by the discharge pipe, and then the remainder is allowed to run to waste. For example, in the case of a settling reservoir, or a clean-water reservoir, we may assume that it will never be necessary to run more than about 3 or 4 feet of water to waste. We should, therefore, make the waste pipe of such a diameter that this water may run to waste in, say, 3 hours. Of course the rate of discharge keeps changing as the appliance becomes emptier. For the sake of calculation, however, it will be near enough to assume the depth of water as constant at $\frac{2}{3}$ rds of the depth from which we begin to run to waste. For example, in the above case, we would assume water of a constant depth of 2 feet to 2 feet 8 inches. Any good formula for the velocity of the flow of water in short pipes may be used, or the diameters may be taken from tables. (See Chapter XVII.)

* The importance of this will be particularly appreciated in an earthquake country, where it is specially necessary to make provision against unknown seismic 


\section{CHAPTER XVI.}

\section{Pumping Machinery.}

IT is barely necessary even to mention that pumping machinery is one of the most important adjuncts of many waterworks; and that, as a breakdown of such machinery may mean a total stoppage of supply and a "water famine," it is of the utmost importance that the machinery be reliable. Further than this, as the consumption of coal, in the case of pumping systems, is one of the most considerable of the expenses of working, it is necessary that the machinery be efficient in the sense of raising the greatest possible quantity of water per unit of coal burned, or (as it would perhaps be better to put it) that the consumption of coal should be the smallest possible for the quantity of water that has to be raised.

For these reasons, it is most desirable that civil engineers should have some knowledge of the principles of pumping machinery, although it is not absolutely necessary that they should understand all details, these being a department of mechanical engineering. Indeed, however much a civil engineer may know about pumping machinery, the writer is of opinion that he should leave the details of construction to the makers of pumping engines, specifying with the utmost precision the work that the engines have to do, the position in which they are to be placed, and so forth. The makers of pumping machinery are certain to know more of the details of such machinery than most civil engineers. Elaborate specifications have generally the effect of hampering the makers, and result in machinery inferior to what would be got were the specifications confined to the general style of the engine, the work it is to do, the duty it is to develop per pound of coal, and the position it is to occupy, the makers being permitted to tender for the form of engines they prefer to make.

Number and Type of Pumping Engines.-It is always necessary to have a certain proportion of "stand-by" power. In 
other words, there must be more pumping engines than are at any time needed in actual work, so that at least one engine at a time may be laid off for cleaning and repairs, and may be ready to be put in action in the case of a break-down of any of the other engines. In the case of small waterworks it is common to have double the quantity of power needed, in the form of two pumping engines, either of which is capable of doing all the work. The reason for this is that the first cost would probably be rather increased than otherwise, by subdividing the work more, when the engines are very small, even although the total horse-power might be less. Thus suppose the total horse-power needed were six I.HP. Two engines of six I.HP. each would probably not cost more than three of three I.HP. each ; moreover, in work, the efficiency of the one pumping engine of six I.HP. would be greater than that of the two of three I.HP. each. Of course there is no hard-and-fast line between small and large works, but it may be very roughly said that it is not advisable to subdivide the pumping power into more than two engines if, by so doing, separate engines of less than ten I.HP. each have to be adopted.

In the case of large waterworks, the stand-by power need only equal one-third, one-fourth, or, in the case of very large works, perhaps one-fifth of the whole, there being, in such case, three, four, or five pumping engines.*

In the case of large works, it is most economical to pump during the whole twenty-four hours, but, in the case of small works it is not so, as the cost for attendance during the whole of this time would be proportionately excessive. In the case of small works it is generally advisable to have an engine considerably larger than is necessary to pump at the rate of maximum daily consumption, and to work it for only a portion of the twentyfour hours, pumping directly into a high-level reservoir or tankthat is, of course, one engine besides the stand-by.

The following table, giving the number of hours of working

* In the case of Tokyo, Japan, there are to be three pumping stations. Each pumping station is to have four pumping engines, and three of these working at
each station will be amply capable of supplying the present population of $1,200,000$.
There is, however, provision for fixing a fifth There is, however, provision for fixing a fifth set of engines at each station, when $1,600,000$.

In the case of Osaka there are to be three sets of centrifugal pumps for raising the water from the river to the settling reservoirs, any two of them being capable of supplying water enough for a population of 800,000 . There are also to be five sets of main engines, any four of them being capable of supplying the same
population. 
considered advantageous in the case of waterworks for towns, is slightly modified from Hennell, the towns being graded according to population :-

\begin{tabular}{|r|c|c|}
\hline Population. & $\begin{array}{c}\text { Hours during which } \\
\text { it is proposed to } \\
\text { pump. }\end{array}$ & $\begin{array}{c}\text { Net HP. for } \\
\text { 100 feet rise. }\end{array}$ \\
\cline { 1 - 2 } 1,000 & 4 & $1 \frac{1}{4}$ \\
2,000 & 6 & $1 \frac{3}{4}$ \\
3,000 & 10 & 2 \\
5,000 & 10 & 3 \\
6,000 & 10 & 5 \\
8,000 & 10 & 6 \\
10,000 & 10 & 8 \\
20,000 & 10 & $10 \frac{1}{8}$ \\
30,000 & 16 & $12 \frac{3}{4}$ \\
50,000 & 24 & $12 \frac{9}{3}$ \\
60,000 & 24 & 21 \\
80,000 & 24 & $25 \frac{1}{4}$ \\
100,000 & 24 & $33 \frac{1}{2}$ \\
500,000 & 24 & 42 \\
$1,000,000$ & 24 & 210 \\
& 24 & 421 \\
\hline
\end{tabular}

It may at first sight seem that, while going to the length of sixteen hours, it would be just as well to pump during the twenty-four hours, but there is a decided advantage in working for only sixteen hours, as this makes two reasonable "shifts" of men, whereas twenty-four hours is too long for two shifts. Further, the eight hours are convenient for small repairs.

General Style of Pumps.-For moderate lifts the centrifugal pump is very fairly efficient, and its great compactness, and (when by a good maker) the very small amount of repairing that it needs, recommend it strongly. It is not possible to give an exact limit to the lift up to which centrifugal pumps may with advantage be adopted, but it may be very roughly said that they are not to be recommended for lifts beyond about 25 feet, unless compactness of machinery is a first consideration and the consumption of coal only a secondary one. Of late years the "Archimedean" screw pump has been revived, and (the writer understands) has given great efficiency in the case of moderate lifts.

For high lifts either single-acting (plunger) or double-acting (piston, or bucket-and-plunger) pumps may be used, but the modern tendency is to adopt the latter rather than the former. In the plunger-pump, water is drawn during the up-stroke and is 
discharged during the down-stroke only, so that the delivery is intermittent, unless there are several pumps. The Cornish and Bull engines, often seen at the pit-mouths of mines, but not now very often manufactured, are examples of plunger pumps. They were, formerly, extensively used for waterworks, but (so far as the writer knows) are now never erected, although there are probably some old pumps still in use.

A piston pump needs no particular explanation, being simply a pump with a piston of the same character as in a steam engine. The bucket-and-plunger pump is really the equivalent of the piston pump. The cross section of the piston-rod or "plunger" has half the area of that of the cylinder and piston. At the down-stroke one-half the contents of the cylinder is forced into the main, the other half passes to the upper side of the piston or "bucket;" at the up-stroke the water on the upper side of the piston is forced into the main, and the cylinder fills with water again under the piston. The bucket-and-plunger has the advantage of reducing the number of pump-valves to one-half of those necessary with a double-action pump.

Pumps may be either horizontal or vertical, but the writer considers that there are distinct advantages in the vertical form. In the case of horizontal engines the "in-stroke" - that towards the cylinder-corresponds with the "up-stroke" in vertical pumps.

Types of Engines.--Steam Engines for working pumps may be divided into direct and crank-shaft with fly-wheel engines. In direct engines the piston-rod of the engine and the piston-rod of the pump, or the plunger, are continuous, and there is no crankshaft or fly-wheel. A typical direct engine is arranged in the following way. There are two cylinders side by side, the steam to each being controlled by an ordinary three-ported slide valve. We have to imagine steam admitted to the end of one cylinder, the piston of which is consequently moving towards the other end. When it comes to a certain distance from this end it strikes a lever which actuates the slide valve of the other cylinder. The other piston then begins to travel, and, when it has to a certain extent approached the other end of the cylinder, it in its turn strikes a lever that actuates the slide-valve of the first-mentioned cylinder, causing it to travel over, so as to admit steam to the opposite side of the piston from that which was supposed to be receiving steam at first. In fact, each piston actuates the slide valve that admits steam to actuate the other piston. This is a description of a very crude 
form of direct pump, but they all depend on the same principle. Often, however, one of the two cylinders is only a very small one, whose sole duty is to actuate the slide-valve of the large cylinder.

Direct engines of this kind are quite self-acting, and for this reason are very convenient. Up to their limit of capacity they pump just whatever quantity of water may be demanded of them, and they have the further advantage of being comparatively compact. They are, however, very uneconomical, simply "shoving" the water ahead, without any expansion of steam. Of late years, however, direct engines have been vastly improved in the matter of economy, firstly by "compounding," and afterwards by the introduction of "high-duty gear." This gear is of various forms, but the object is always the same-namely, to absorb a certain quantity of power at the beginning of the stroke, and to give it out again towards the end - so that the steam may work expansively in the cylinder. It is claimed for some of the most modern direct-engines, with high-duty gear, that they give the same duty as a fly-wheel engine of good design working at the same pressure, or even a higher duty.

The oldest form of crank-shaft and fly-wheel engine is the beam engine. This form of engine is still occasionally recommended, but it is gradually falling out of use, greatly because of the very expensive foundations that it involves. More commonly the crank-shaft is now placed between the cylinders of the pumps and the pumps, or beyond the end of the cylinders remote from the pumps, a tail rod being carried from the piston through the cylinder-cover remote from the pumps.

The advantage of the crank-shaft form of pumping engine is, of course, that the steam may be worked expansively. The disadvantage is to be found in space occupied.

A crank-shaft engine has nearly always at least two cylinders. The worst form of pumping engine with a crank-shaft is that in which there is only one single or double-acting pump, worked by the piston of one of the cylinders, the work of the other cylinder being all transmitted through the crank-shaft. In the first place, it is objectionable to transmit the whole of the work of one cylinder of an engine through the crank-shaft, on account of the violent strains set up : in the second place, a single pump is very unequal in its delivery of water.

With two pumps, as well as two cylinders, the cranks at right angles, as is commonly the case in all kinds of two-cylinder engines, the delivery of the water is much more uniform; but 
there is a great advantage in the use of what is known as a "three-throw" engine-that is to say, one in which there are three cylinders, each working a pump, preferably double-acting, with three cranks at angles of $180^{\circ}$. The delivery of water from such an engine is nearly quite uniform. This is specially important in the case of engines that have to pump directly into distribution-mains.

Steam pumping-engines may also be divided into condensing and non-condensing engines. The superior economy of condensing over non-condensing engines need not be dwelt on, and it is almost universal to have condensers with pumping-engines of any considerable size. In the case of very small pumping plant, it is scarcely advisable to go to the expense of condensers. The reason for this is that, in the case of small pumping plant, the actual price of coal forms only a comparatively small item in the working expenses, whilst the saving effected by a condenser is proportionably less than in the case of large plant. As already mentioned, it is not possible to draw any exact line between small and large plant, but the writer may state that he would scarcely consider it advisable to specify condensing engines, unless the total ten or more actual HP. were to be in use at one time.

Condensers are either "jet" or "surface." In the case of the former, the condensing water actually enters the condenser in the form of a jet, and has to be pumped out again, at the expenditure of some power, by the "air-pump." In the surface condenser, the condensing water and the steam do not come in contact, being separated by the large surface of a great number of small tubes. The jet condenser is considerably cheaper than the surface condenser, but it is not well suited to engines that have to work at a varying velocity. It should not, therefore, be used except in the case of pumping engines that can be run at a nearly uniform
speed.

When a surface condenser is used for pumping engines, it is not necessary to have a separate "circulating pump," as in the case of other forms of engines with circulating surface condensers, as the main water pumped by the engine itself may be allowed to act as circulating water. It will not be heated to any appreciable extent.

Pumping engines are further divided into simple, compound, triple expansion (or tri-compound), and quadruple expansion. The object of compounding is to permit of the use of a greater expansion of steam than can be utilised in the case of simple engines, without excessive strain on the working parts and the framing or bed-plate. 
As in the case of condensers, so in that of compounding. It is not generally worth the expense of compounding in the case of very small plant. The writer would incline to specify simple highpressure engines without condensers, unless there were more than a total of twenty I.HP. to be in use at one time, but of course this is an entirely empirical limit. (The subject of triple and compound and of triple-expansion engines will be treated later on in this chapter, in the paragraphs on the Duty of Pumping Engines.) So far as the writer knows, quadruple engines have not been used for pumping, and he thinks it scarcely likely they will be, for a very considerable time at least, although he knows of a case where they were proposed.

Yet again, pumping engines are divided into vertical and horizontal. There are advocates for both forms of engine, and probably each has its advantages. The writer is strongly in favour of vertical engines, but possibly this is a matter of prejudice.

\section{Length of Suction of Pumps. - In every technical} work in which pumps are touched on at all, we are told that the atmosphere will balance a column of water 34 feet high, somewhat more or less, according to the height of the barometer, but that in practice pumps will not satisfactorily draw more than about 26 or 28 feet. All this is true, but it would really seem that some engineers have come to the conclusion that all pumps ought to be given such suctions. Such a view is certainly a mistaken one. It is only with special precautions that a pump will work satisfactorily with such suctions; and it may be said that it is almost impossible to make a pump of a form that has a very variable discharge - such as, for example, is given by one doubleacting pump-work satisfactorily with such suctions except at a very slow rate. The probabilities are that, at any moderate rate, the pump will not fill, and at the turn of the stroke the piston will meet the rising column of water with a violent blow that will endanger the pump and the valve casings. The writer has known more cases of trouble, in connection with pumping machinery, to rise from too long suctions than from almost any other cause. It may be laid down as a rule, that every effort should be made to keep the suction of a pumping engine as short as possible; and further, that any kind of pumping engine will work most smoothly when the water actually gravitates into the pump.

It will of course be understood that when length of suction, or height of suction, is mentioned here, vertical height is referred to. 
Length horizontally is not nearly so detrimental, but it is to be avoided if possible, as it increases the weight of water that has to be set in motion and stopped at every stroke, or that, at any rate, has to have its velocity augmented and retarded. Especially when the vertical limit is nearly reached, every foot of horizontal length increases the trouble. For this reason pumping wells should, whenever possible, be immediately below the pumps.

It is to be observed that the suction is to be measured from the surface of the water to be pumped, to the highest point of the inside of the pump barrel, whether this be horizontal or vertical.

It will readily be seen that a vertical engine has an advantage over a horizontal one in this matter of suction. In the case of a vertical engine the pump may be, and, indeed, commonly is, fixed below the engine-room floor and, in fact, it may be placed as low as may be considered necessary or advisable.

If a long suction is inevitable, "three-throw" pumps should be adopted, as the variation in the velocity of the column of water in the suction pipe is so much less than with other forms of pump.

The Piston or Plunger Speed of Pumps. - The piston or plunger speed of pumps is limited by the capacity of the water to fill the pump during the time of a single stroke, violent "knocking" inevitably taking place, with the result of violent strains on the pumps and probable break-down. Naturally, the possible piston speed of pumps duly filling depends greatly on the size and form of the suction valves. It also depends to a considerable extent on the length of stroke. A great part of the success in designing pumping machinery depends on giving the pump valves, and especially the suction valves, a good form and size.

Other things being equal, the longer the stroke, the greater the piston speed permissible. This applies, at least, to crank-shaft engines. The reason is that, with a given piston-speed, the longer the stroke, the slower the acceleration of velocity at the beginning of each stroke. The shorter the suction, the greater the piston velocity than can be got in practice. Pumps of a form that give a comparatively uniform discharge of water, allow a higher pistonspeed than those that do not, if the suction pipes are properly arranged. With proper care, it should be easy to get a piston speed averaging 240 feet a minute, and it is even possible to reach a speed of 300 feet a minute in the case of well-designed pumps,
without knocking.

The comparatively slow speed at which engines working pumps 
directly have to be kept down to, is one reason why such engines will not develop quite as much power as some that work at a high piston speed, such as marine engines. In the case of the latter, the cylinder has not time to be cooled, at the time of exhaust, before steam is admitted again, and thus loss by condensation is saved. Until lately at any rate, even slower piston-speeds than these mentioned were considered advisable with pumping machinery. The consequence is that gearing has not infrequently been resorted to, so as to combine a high steam-piston speed, with a low pumppiston speed.

The Duty of Pumping Engines.-The duty of a pumping engine is the weight of water that it will lift one foot high per unit of coal used. The old unit of coal introduced by Watt was the bushel. As, however, the bushel is (strictly speaking) a measure of capacity and not a weight, the unit was found inconvenient, and the cwt. of 112 lbs. was substituted for it. It is now more common to use a cwt. of $100 \mathrm{lbs}$. As will be pointed out hereafter, the writer considers a water unit to be better than any coal unit.

Taking, in the meantime, the unit of $100 \mathrm{lbs}$, it was, until within the last twenty or thirty years, considered good work in practice, if a pumping engine developed $60,000,000 \mathrm{ft}$. lbs. of duty-or, as it was commonly put, had a duty of $60,000,000$. This duty has since then been greatly exceeded. There are two reasons for this : one has been the use of higher steam pressures, the other the introduction of compounding. The higher the initial pressure, and consequently the temperature of the steam, the greater the efficiency possible. This is in accordance with Carnot's now famous demonstration that the greatest quantity of work that can be got out of a heat engine-and, of course, a steam engine is a form of heat engine-is proportionate to $\frac{T-t}{T}$, where $T$ (in the case of the steam engine) is the temperature of the steam at admission, measured from absolute zero, and $t$ is the temperature of steam in the condenser, also measured from absolute zero.

It will readily be seen that the greater this difference can be made, the greater the efficiency; and, as the temperature in the condenser is very nearly fixed, the only way in which this difference can be increased is to increase the initial temperature, which is done, chiefly at least, by increased pressure, being sometimes also done to a certain extent by superheating the steam before admission to the cylinder. 
The pressures at which it is found practicable to work steam have been gradually increasing. Very high-pressure engines need much more care in designing and in construction, and more skilled attendance, than engines working at moderate pressures. It is only, therefore, in the case of very large installations that it is considered advisable to work at the highest pressures possible. It is perhaps approximately right to say that a pressure above the atmosphere of 150 to $160 \mathrm{lbs}$. per square inch is the most that it is advisable to recommend at the present time for pumping machinery, and this only in the case of boilers and engines that are in the hands of really skilled attendants. For many cases it will be found advisable to limit the steam pressures between 90 and $120 \mathrm{lbs}$. above atmospheric pressure. With pressures of less than $90 \mathrm{lbs}$. a high economy cannot be expected.

Apart from the cooling effect of the cylinder on the incoming steam, compounding with fly-wheel engines has no advantage, beyond that of reducing the strains on the working parts and on the frame-work and bed-plate. If the material from which the cylinder and the piston are made were of such a nature as not to absorb heat, the whole of the power of a compound engine could be developed in the low-pressure cylinder alone, without in any way increasing its dimensions. As a matter of fact, however, the cylinder and piston are of iron, which is a good conductor, and absorbs and gives off heat rapidly. With great differences of temperature, therefore, the steam would be condensed to a wasteful extent at the beginning of each stroke by the iron that had become cooled at the time of exhaust, and this would be particularly so with the comparatively slow speeds that pumping engines generally work at. By compounding, and still more by tri-compounding, the range of temperature in any one cylinder is greatly reduced.

Again, were an attempt made to do all the work of a compound engine, working at a high pressure, in the low-pressure cylinder only, the strains produced by admitting this high pressure to a cylinder of the large diameter of a low-pressure cylinder would be enormous. Other matters, such as loss by "clearance," would probably also reduce the efficiency.

It will be gathered from what has been said that, the higher the pressures, the greater the advantage of compounding; and that, further, a comparatively high initial pressure is essential to get the full advantage of compounding. Thus it may be said that the pressure should not be less than about $90 \mathrm{lbs}$. per square inch above atmospheric pressure, when compound engines are used. From 
$90 \mathrm{lbs}$. to $120 \mathrm{lbs}$. per square inch is a good economical pressure for compound engines. If pressures of $150 \mathrm{lbs}$. or thereabout be made use of, triple expansion, or tri-compound engines are more economical than compound engines, and have the advantage of lending themselves readily to the "three-throw" arrangement of pumps with crank-shaft engines. The "three-throw" arrangement can, however, readily be effected in compound engines, by having one high-pressure, and two low-pressure cylinders.

It is probable that, when steam of $200 \mathrm{lbs}$. pressure, and more, has been brought thoroughly under control, quadruple expansion engines may be applied with advantage to pumping work. Such engines have already been applied in marine work, but there appears to be some difference of opinion as to their usefulness.

As has been said, the unit of coal now commonly taken is 100 lbs. avoirdupois. The objection to taking coal as a standard is that coal is a very variable body. Even if, as is commonly done, it is specified that the coal to be used at the time of trials is " best Welsh coal," we are far from having an absolutely uniform substance. An attempt is sometimes made to get over this difficulty by weighing all the ash, clinkers, \&c., produced, taking only the difference between this and the coal as the actual consumption. This brings us very near an absolute standard, if our coal is nearly standard to begin with, but not if we take coal at random; for it is a fact not understood by all that-at any rate, when coal is burned in a steam boiler-less work is got out of a given weight of a poor coal, even after deducting all incombustible matter, than out of a rich coal that is nearly all combustible. Further than this, even assuming a perfectly standard coal, it is desirable to separate the performance of the boilers from that of the engines.

It is sometimes specified that the engine shall have so much duty per lb. of coal "on the basis of 10 lbs. of water evaporated by $1 \mathrm{lb}$. of coal." This seems to be bringing the thing to a reductio ad absurdum: for why bring in the coal at all? It is simply a very clumsy way of specifying that the engines must develop so much duty "for 10 lbs. of steam from the boilers." If it were put in that way it would, in the writer's mind, be a very sensible way of specifying duty. In fact, this is just what he recommends. The duty to be done should be stated in lbs. of water evaporated in the boiler. This, then, leaves the questions of the efficiency of the boiler and of the engines entirely separate 
- a thing which is particularly advisable when, as is very often the case, the boilers and the engines are by different makers.

It does not matter much what weight of water is taken as a unit. Ten pounds is as good a unit as another, and may be said to correspond with $1 \mathrm{lb}$. of coal, inasmuch as $1 \mathrm{lb}$. of the best coal will evaporate $10 \mathrm{lbs}$. of water in the best forms of boiler, the feed water being introduced at a temperature of $212^{\circ}$ Fahr. Taking, then, $10 \mathrm{lbs}$. of water evaporated as our unit, the water being fed into the boiler at the temperature of the boiling point at atmospheric pressure, let us consider what duty it is reasonable to expect from engines of different kinds.

In the first place, the highest duty that an engine is capable of doing cannot be expected, unless the engine works at a uniform speed. The duties mentioned here are, therefore, only to be expected in the case of pumping uniformly, as into a high-level reservoir. In working irregularly, as when pumping directly into a main, or even when pumping into a stand pipe holding only a few minutes' supply, or, indeed, any supply not sufficient to compensate for the variation in the consumption during the twenty-four hours, so high a duty need not be expected.

With compound engines, having working pressures of steam between the limits of about 90 and $120 \mathrm{lbs}$., it is fair to expect a duty of 1,000,000 for $10 \mathrm{lbs}$. of water evaporated. With triple expansion engines, working at a pressure of 150 or 160 lios., a duty of 1,200,000 ought to be obtainable. With large centrifugal pumps, and with a head not exceeding, say, 25 feet, a duty of 600,000 ought to be developed. With ordinary condensing, or very small compound, a duty of more than 400,000 to 500,000 need not be looked for; whilst small high-pressure engines, of only a few horse power, need not be expected to give a duty of over, perhaps, one half or one third of this.

Referring to the high duties of 1,000,000 to 1,200,000-which, it is stated, should be obtained by large compound condensing engines, pumping at a uniform speed-the writer is quite aware that, according to reports issued by the makers of pumping machinery, these duties have often been exceeded. He has seen duties stated as being anything up to 1,500,000 for $10 \mathrm{lbs}$. of water evaporated. All he can say is, that if the duties he has indicated in the last paragraph are got in practice, the engineer has every reason to be well satisfied.

Lest there should have been want of clearness in what has been stated above, it is here put in a different form. The duty for any 
engine, taking $10 \mathrm{lbs}$. of water evaporated as the unit, is got by the following formula :-

Where

$$
\mathrm{D}=\frac{\mathrm{H} \times \mathrm{W}}{\mathrm{W}} \text {. }
$$

$\mathrm{D}=$ duty in foot lbs. for every lb. of water evaporated in the boiler;

$\mathrm{H}=$ the height in feet to which the water is pumped;

$\mathrm{W}=$ the total weight of water in lbs. pumped during any interral of time;

$\mathrm{w}=$ the weight of water, in lbs., evaporated in the boiler, during the same interval of time.

A word or two ought to be said about $H$. It is properly the difference between the level of the water at the surface of the reservoir or pump-well from which the water is drawn, and the level of the reservoir or stand-pipe into which it is pumped. If, however, there is a long forcing main, the pressure necessary to overcome the friction in this main must be converted into the equivalent in feet of head of water, and be added to $H$. In fact, it is only in such a case as that shown diagrammatically in Fig. 146 (p. 141), where the engine pumps directly into a stand-pipe of such diameter that the friction in the pumping main can be entirely neglected. In the case of a long horizontal suction-pipe - a thing always to be avoided if possible - the head necessary to overcome the friction in it, should also be added to $H$, but the friction in the short vertical suction-pipe that ought always to be used is not commonly allowed for, as this pipe is, as a matter of fact, looked upon as part of the pump.

$\mathrm{W}$ is readily found, by seeing that the water level in the boiler is the same at the end of the trial as at the beginning, and measuring the quantity of water that has been fed into the boiler.

\section{Horse Power of Steam Pumping Engines.-The horse} power that ought to be stated in connection with pumping engines is the actual HP. as measured by a certain quantity of water lifted a certain height, the friction of the forcing main being taken into consideration, as explained above. In other words, it is measured by the quantity of water that could be pumped to a bigher level than the actual one, were the main frictionless. That is to say, the horse power $=\frac{\mathrm{W} \times \mathrm{H}}{33,000}$

Where

$W=$ the total weight of water in lbs., lifted in one minute of work, and

$\mathrm{H}=$ the height, in feet, to which the water is pumped, with addition for friction in pumping main, as described above.

Still it is sometimes (indeed, often) useful to be able to 
compare the indicated horse power-the horse power developed in the cylinders - with the actual work done in horse power; as it is only by so doing that we can ascertain where any loss of efficiency there may be in the engine is to be found. (It need scarcely be stated that the term "nominal horse power" is one now having no meaning at all. The sooner it is banished from all writings on engineering the better.)

The indicated horse power is the actual horse power $\times \frac{1}{c}$, where $c$ is the co-efficient of efficiency of the engine and pumps, and is always less than unity. The difference between $c$ and unity represents, in fact, that part of the work done in the cylinder that is used up by friction in the moving parts of the mechanism, and in the water passing through the pump valves and the passages leading thereto and therefrom. In good large engines $c$ should reach at the very least $\cdot 8$, and $\cdot 9$ is not too much to look for. The writer has seen a much higher figure than even this latter stated-one, in fact, very closely approaching unity-but he imagines there has been some error in the tests made. In fact, it is almost certain that this is the case, if it is borne in mind that I. HP. cannot be taken without a possible error of several per cent., even with the best indicators, and using all possible care.

Ninety per cent. of the work done in the cylinders, in water actually pumped, can, as has been indicated, be got in the case of high-class machinery; but it would not do to design engines capable of developing in the cylinders only the excess of about eleven per cent. over the work as measured by the water to be pumped, that is represented by the difference between $\cdot 9$ and 1 . In fact, even the largest engines should be made capable of developing in the cylinder at least fifty per cent. more power than that actually needed in lifting the water. This involves, for the greatest economy of working, that the high-pressure cylinder, at least, should be fitted with variable expansion-gear, to be linked up so as to reduce the I. HP., not by wire-drawing the steam, but by reducing the length of admission when, as ought always to be the ease in normal working, the whole fifty per cent. excess of power
is not being used.

Small engines, whether compound or high-pressure, should be made capable of developing, in the cylinders, twice the power that
will ever be actually used.

Taking what has just been said into consideration, it will be found that, if it is necessary to specify what I. HP. the engines have 
to be capable of developing, the following formulæ will be found to answer:-

In the case of large engines :-

$$
\text { I. HP. }=\frac{\mathrm{W} \times \mathrm{H} \times 3}{33,000 \times 2} \text {. }
$$

In the case of small engines :-

Where

$$
\text { I. HP. }=\frac{\mathrm{W} \times \mathrm{H} \times 2}{33,000}
$$

$\mathrm{W}=$ the weight of water in lbs. lifted during one minute, and

$\mathrm{H}=$ the height in feet lifted, with addition for friction of forcing main as described above.

We have here the very common difficulty that there is no hard and fast line between small and large engines. The engineer must, therefore, use some judgment. In any case, however, it is, as we have indicated, not advisable to specify the horse power of a pumping engine, but to specify, with all the precision possible, and giving every detail, the work that the engine has to do, the position that it has to be in, and so forth.

Whilst on the question of horse power, we may, perhaps, be allowed to give a figure which is to be taken as very roughly approximate only, but which we have found very useful at times. Leaving very small installations out of the question, it will be found that 1 I. HP. is sufficient for each 1,000 of population, pumping into a reservoir against a head of 100 feet, making ample allowance for friction, and also for stand-by and pumping. If pumping into the main direct, it is necessary to provide $1 \frac{1}{2} \mathrm{I}$. HP. per 1,000 of population, the other figures remaining the same.

\section{Pumping into Reservoirs and Pumping directly into} Mains. - There are many advantages in pumping into a reservoir or tank large enough to compensate for the variation of consumption during the twenty-four hours, and, in the case of small instalments, there is advantage in having a tank or reservoir so large, and engines so powerful, that the whole of the pumping may be done at a uniform speed during a part only of the twenty-four hours.

The difficulty in getting sites for elevated reservoirs, however, and the enormous expense, if not impracticability, of elevated tanks for large populations, has made it necessary, in many cases, to do without either reservoirs or tanks holding sufficient water to 
compensate for the variation in consumption during the twentyfour hours, and a system of pumping more or less directly into the mains has had to be adopted. The first stage in this direction is the use of elevated tanks that do not hold enough water to allow the engines to work at uniform speed during the twenty-four hours, but that hold a supply for, say, an hour's consumption, thus making it necessary to vary the speed of the engines from time to time. The next step is the introduction of a standpipe, holding a supply of only a few minutes' consumption. This can be looked on merely as a regulator, for preventing quite sudden changes in the working speeds of the engines. The last stage is that in which the engines pump directly into the main, there being no further cusion than that afforded by the air in one or more air-vessels. Such engines must follow exactly the consumption of water, the air-vessels being of use only to prevent undue shock on the machinery, and to increase the uniformity of the flow of water into the mains. It is oniy comparatively lately that pumping machinery has been brought to such perfection that it is possible to depend for a town supply on such a system, but it is now being adopted in various parts of
the world.*

If this system be adopted, it is to be observed that the engines, apart from the stand-by, must be capable of pumping at the rate of absolute maximum consumption $(+$ an allowance for fire extinction, to be treated of further on). The engines must be specially designed to work at variable speeds, and it is best to have an automatic contrivance for controlling the speed. A consideration of the manner in which the accumulator of hydraulic pumping-engines controls the speed of the engines, according to the number of machines at work, will readily suggest how pumping engines to pump directly into mains may be controlled. The most perfect arrangement is that in which the controlling gear actuates a differential expansion gear, varying the length of admission of steam to the high-pressure cylinder, or to all the cylinders, instead of wire-drawing the steam by a throttle valve. Of course, besides this, where there are several engines at work, at the time of maximum consumption there will be regulation by
hand also, the attendant seeing that there are never more engines at work than are necessary to do the pumping to correspond to the consumption without working at an excessive speed. It

* This system is being adopted for the Tokyo waterworks. 
would not be difficult to design gear for automatically effecting this stopping and starting of the engines, according to the demand for water; but it is likely that such a complication would not meet with the approval of many engineers. With engine power divided up into any number of engines common in connection with waterworks, there will never be more than one engine at work during the hours between midnight and early morning, unless there is great leakage from the mains or house services.

It is to be observed that, although the horse power of the engines must be sufficient to pump the maximum quantity of water needed at any time of the twenty-four hours, the whole duty of the engines during that time will be the same as if pumping into a reservoir, as the engines are nearly at rest for some of the time.

As has been said, so high a duty per unit of coal burned, or per unit of steam evaporated, cannot be expected in this case, as in the case where engines work at a uniform speed. It will be possible, according to the amount of variation and the efficiency of the controlling arrangement, to get 50 to 85 per cent. of the duty that can be got from engines working at a uniform speed.

In conclusion, with regard to steam pumping machinery, what an engineer will generally find it best to do is to specify exactly the work that the pumps are expected to do-giving their exact position, the level of engine-house floor above the level of the water to be pumped, whether the water is to pump into the main direct or into a reservoir, and in the latter case the length and diameter of the force-main, specifying the duty that the engines will be required to develop, and being very careful in this matter that there is no room for misinterpretation. If the engineer really has had considerable experience in estimating the duty of engines he may specify exactly how the test is to be carried out. Further than this (assuming the works to be on a considerable scale) he should generally specify high-pressure compound, or tri-compotind engines (mentioning certain limits of working pressure), with surface condensers, the main pumps to act as circulating pumps, double-acting pumps, and, if a crank-shaft design be adopted, the three-throw arrangement of cranks and pumps, the high-pressure cylinder to be steam-jacketed," also the intermediate cylinder in

* There is considerable difference of opinion as to the desirability, or not, of steam-jacketing low-pressure cylinders. In tri-compound engines, the intermediate cylinder at least should be steam jacketed. 
case the tri-compound design be adopted, the low-pressure cylinder and all steam jackets to be lagged with polished wood, \&c.

In fact, what is written above, with the usual additions about " best style of workmanship, the provision of all necessary fittings, etc.," would very nearly make a sufficiently complete
specification.

It is generally advisable to allow the makers of pumping engines to design foundations for the engines they propose.

The writer is tempted to give one or more designs of pumping engines, but refrains from doing so, as he feels that he might be falling into something like the fault of those engineers who merely place difficulties in the way of the makers of pumping machinery, by binding them to special designs, the more so as he holds pretty strong opinions as to what is the best form of pumping engine for general waterworks use. He will only say that it is one without complicated gearing, and one that is covered by no patents.

Pumps of the pulsometer type are useful for many purposes in connection with waterworks, as with so many branches of engineering, especially for temporary work or where it is necessary frequently to change the position of the suction-pipe, or even of the pump, but they are not to be recommended for constant work.

Boilers for Pumping Engines.-The boiler that will be efficient for any other kind of steam engine developing about the same amount of power, will be efficient for pumping engines, and this is not the place for a dissertation on boilers in general. A few general statements only will therefore be made.

Any really good boiler should be capable of evaporating at atmospheric pressure $10 \mathrm{lbs}$. of water fed into the boiler at a temperature of $212^{\circ}$ Fahr. per lb. of the very best coal. This is on the assumption that firing is not forced beyond the point at which the coal can be burned economically-the assumption, that is, that the boilers are as large as they should be, and that all other conditions are favourable. It is not unreasonable to specify that boilers shall do this duty, weighing only the portion of the coal actually consumed, that is to say, the difference in weight of the coal consumed, and of the ash, or even taking the actual weight of the best Welsh coal.

In the case of locomotive boilers, and to nearly the same extent in that of marine boilers, the object is to be able to evaporate the greatest quantity of steam possible, with a given 
capacity of boiler. The consequences are that a fierce combustion is maintained in the fire-boxes of these boilers, and that the quantity of water they contain is comparatively small. This makes it difficult to keep the pressure of steam constant, and causes the efficiency of the boilers to be less than it might be, unless the greatest care is exerted in firing, and in the care of the boiler.

In the case of boilers for pumping machinery for waterworks there is generally no great necessity to economise space, and the old Cornish or Lancashire boilers - which, after all, if properly arranged, give a greater economy than any other boiler-are commonly adopted. Still, the writer has known boilers of the marine type, and even of the locomotive type, used with great success to generate steam for pumping machinery.

Boilers of the "tubulous" or "water tube" kind, consisting of a number of tubes with water circulating through them, the firing being external, with a steam drum overhead to collect the steam, have the great advantage that they can be packed in small capacity, and are, therefore, easy of transportation. Moreover, the best of them are highly economical. They are, therefore, used with advantage in cases where boilers have to be imported from distant countries, or where there is, for any reason, great expense in getting heavy parts into position.

Manufacturers should be allowed to design chimneys and all brick-setting for their own boilers. It is quite unreasonable to expect them to guarantee any particular efficiency, unless they are allowed to do so.

Even if the engineer specify the type of boiler, he should also specify, with great exactness, the duty that it will be called on to perform. It is often convenient to get tenders for boilers and engines from the same firm, even if the firm does not itself manufacture boilers; as there is thus a certainty-or almost a certainty - that the boiler power will be properly proportioned to the work it has to do, and, at any rate, if it is not, the maker of the engine is responsible.

Other Forms of Motors for Pumping Water.-In not a few cases-especially, perhaps, in Holland-water-power is used for pumping water in large quantities for various purposes. It is evident that, where such power is available, there is a distinct advantage in using it. In the first place the machinery is not generally of a complicated nature, and, in the second, all consumption of coal is saved. 
Wherever there is even a moderate fall, and it is necessary to raise only a comparatively small portion of the water, this portion can be raised to a height above the top of the fall, the height that it can be raised being inversely as the quantity of water that has to be raised in terms of the whole water. Leaving friction out of the question, the height to which the water can be raised is expressed by the formula-

$$
\mathrm{H}=\frac{\mathrm{h} \times \mathrm{Q}}{\mathrm{q}}
$$

Where $\mathrm{H}=$ the height to which the water can be raised;

$\mathrm{h}=$ the head of water available for raising it;

$\mathrm{Q}=$ the total quantity of water,

$q=$ the quantity to be raised, $\}$ in the same terms.

This is on the assumption that the actual pump is at the bottom of the fall. There may be cases when it would be convenient to place it at the top of the fall, connecting it with connecting rods or other contrivances with a motor at the bottom of the fall. In this case $Q$ must be taken as the total quantity of water, less that to be raised. In either case the water will be raised to the same level.

The quantity of water that can be raised to a given height is expressed by the following formula, friction being again left out of consideration :--

$$
\mathrm{q}=\frac{\mathrm{Q} \times \mathrm{h}}{\mathrm{H}},
$$

the symbols having the same signification as before.

Overshot and breast wheels have probably been more used than any other kinds of motors for pumping water, and they have the advantage that, if of considerable size, they revolve slowly, or pumps may be connected to them through cranks and connecting rods only.

Of late years turbines have been used to some extent; and, although the writer does not know of any case of the use of it, there is no reason why the Pelton wheel, or "hurdy-gurdy," should not be used for pumping. The high velocity of either of these involves gearing between the spindle and the pump.

With any of the motors mentioned, an efficiency of about $\frac{2}{3}$ may be expected; that is to say, the water can be pumped to $\frac{2}{3}$ of the height got by the first of the two formulæ given, or $\frac{2}{3}$ of the water got by the second formula can be pumped.

It is not at all necessary that a water motor be employed in 
pumping part of the water of the same stream that actuates it. For example, the water of an impure stream may be used to actuate a motor pumping water from a pure spring.

The hydraulic ram is extensively used for raising water to a height considerably above the top of the fall available as motive power, although not for pumping very large quantities of water. In this ingenious mechanism, advantage is taken of the force of "ramming" that exerts itself when the flow of water in a pipe of some length is suddenly stopped. Water is allowed to flow along a pipe of considerable length with some fall. When the water is just approaching its maximum velocity the flow is suddenly automatically checked, when the pressure immediately rises, the augmentation of pressure being utilised to force a certain proportion of the water to a height above the top of the fall pipe.

The usefulness of hydraulic rams has been greatly increased since the introduction of those forms in which the water for the motive power may be from one source, that pumped from another.

Gas engines and hot-air engines are frequently used for pumping water, but on a small scale only. They do not, therefore, call for special description here. The same may be said of pumping by electric motors. 


\section{CHAPTER XVII.}

\section{Flow of Water in Conduits-Pipes and Open Channels.}

Channels for Water.-A conduit is properly any channel that serves to carry water from one place to another, but the term is, in engineering, only applied to artificial channels. Further than this, although in the widest engineering sense a pipe must be considered as a conduit, still in hydraulic engineering a distinction is generally made. Thus, by a pipe is understood a channel of circular section, constructed in lengths intended to be jointed together; and in the case of waterworks, pipes are nearly always intended to run full of water, which is frequently under pressure.

Conduits are structures excavated or built, or excavated and built, and are either open or closed, the former being in fact canals with a considerable velocity of flow. Covered conduits may be subdivided into (1) those made on the "cut and cover" principle, and (2) tunnels. In the case of the former a trench is made, the bottom being excavated, or built to the form of the lower half of the conduit, this being then covered, and the trench being filled in. Nearly all sewers are "cut and cover" conduits. The object of tunnelling is the same as in the case of railways, either to shorten the distance, or to get through obstacles that it is impossible to get round or over. Tunnels may be lined, or not, according as the strata they pass through are pervious or watertight. When conduits are of very large size they are commonly called aqueducts.

Many books, papers, and dissertations have been written about the laws regulating the flow of water in pipes and conduits, and innumerable formulæ have been deduced. It is not the writer's purpose to discuss the various merits of these at all, but rather to describe the way in which practical use may be made of them. They are to be found in every pocket-book of engineering, in all works on hydraulic engineering, \&c. Those given in books of 
established reputation are nearly always near-enough approximations to be used in practice.*

When water has to be carried under any considerable pressure, pipes are always used, and these are nearly always of metal. ${ }^{+}$ When water is to be carried without pressure, either pipes or conduits may be used. For small sizes pipes are generally to be preferred, as there are certain conveniences in connection with their use. Stoneware pipes are strongly to be recommended for small sizes, when it is intended that there shall be little or no pressure. They have the advantage of making a clean conduit that can be put down at a low price. The best quality of glazed and vitrified pipes only should be used, and, if they are to be subjected to even slight pressures, each pipe should be tested to at least twice the pressure that it is ever likely to be subject to. The trenches for pipes should be carefully excavated, a space being dug out under each socket, so that the pipes will bed through the whole of their length. The joints should be made by forcing a ring of spun yarn into the sockets, and carefully filling up with strong cement-mortar consisting of one part of Portland cement with not more than an equal part of clean sharp sand. Pipes with joints of the "Stanford" type may be used with advantage.

As regards built or excavated culverts, open or covered, it is not possible in the case of open, nor advisable in the case of covered, conduits, to allow the water to be at pressure. The " hydraulic grade line," in this case a line along the surface of the water, may change its inclination at certain points, where the area of the cross section of the flow of water is also changed, but between these points the grade line must be strictly followed. The consequences are that great expense is sometimes involved in contouring the land, or in constructing elevated conduits. With pipes even of stoneware it is permissible to have at least a slight pressure in the pipes, so that they need not strictly follow the hydraulic grade. They must not rise above it, but they may be allowed to fall somewhat below it, and this is sometimes a great convenience. It is quite possible, with due care, to lay stoneware

* Those who wish to see the merits of the various formulæ most commonly in use discussed, are recommended to read the chapters in Fanning's "Treatise on Hydraulic and Waterworks Engineering" on the subject. In these it is treated of at considerable length, and, so far as the writer is able to judge, with great acumen.

$\dagger$ The only exception that the writer knows is that of the small water-works of Hatanomura, Japan, designed by Mr. I. Iwata, C.E., where the pipes for the distribution are of stoneware, jointed with a composition, the invention of Mr. Iwata, and have pressure in them corresponding with a head of 70 feet. 
pipes so as to be water-tight under a pressure corresponding to a head of about 10 feet. This means that, when stoneware pipes are used for conveying water, the pipes may, at any part of their course, fall any depth up to 10 feet below the hydraulic gradeline, as will be seen further on, when the hydraulic grade-line is treated of in connection with water flowing under pressure in pipes.

The writer recommends the use of stoneware pipes, in preference to built conduits, up to a diameter of 24 inches.

Open Channels.-In connection with waterworks, open channels should be used only for water that is to be filtered, and even then should not be used in places where there is danger that the water may become polluted with organic matter. In other words, open channels should never be allowed through populous districts. Again, they are not, as a rule, to be recommended along the sides of steep slopes, as they are liable to become choked with accumulated snow, obstructed by falling boulders, and so forth: moreover, it is generally objectionable to allow them to intercept the surface rain-water, as they will, unless provision is made to carry it away; and such provision is sometimes more or less troublesome to make, involving considerable additional excavation along the upper side of the channel, to allow room for a rain-water channel, and arrangements at short intervals for carrying storm water over, or under the main channel.

Velocity of Flow of Water in Open Channels.-There are several factors to take into consideration in connection with the velocity of the flow of water in channels. In the first place, there is the very evident one that, the greater the velocity of flow, the smaller in cross section need be the channel, and, therefore, the more cheaply may it be constructed. There are many cases in which the fall is not at all restricted, and in which it would be quite possible to have very high velocities. It has been found, however, in practice, that mean velocities of over about 5 feet per second are objectionable. Higher velocities are liable to carry heavy matter along the bottom of the channel and to abrade it seriously, unless a very expensive construction is adopted. If the general fall is such that a higher velocity than this would result from following it, the channel must be carried for a certain distance with a moderate fall, and then be given a sudden drop over steps in the form of a tumbling bay. In some 
cases advantage may be taken of the power otherwise lost at such drops, by making the water pass over waterwheels, or through turbines, but great care must be taken that the water is not thereby subjected to any contamination.

There is an advantage in slow velocities, that parts of the channel that would otherwise have to be lined, not necessarily to prevent the leakage of water, but to prevent the erosion of the banks and sides, may go unlined. Thus with a mean velocity of not over about 2 feet a second, only fine clay and such like material is likely to be disturbed; whereas, if there be a velocity of only 1 to $1 \frac{1}{2}$ feet per second, no kind of ground that a channel is likely to be made through will be eroded.

On the other hand there is the objection to these low velocities, that vegetation is likely to flourish in the channels to such an extent as to seriously obstruct the flow of water. Such vegetation is entirely prevented by velocities of from 2 to 3 feet per second, according to the nature of the climate.*

The velocities most favoured by European and American engineers appear to be from a little under 2 feet a second, to a little over 3 feet a second.

Form of Cross-section of Open. Channels.-In every formula for determining the velocity of the flow of water in channels, either open or otherwise, it will be found that the "hydraulic mean depth" is a term in some form or other. The hydraulic mean depth $=\frac{\mathrm{a}}{\mathrm{p}}-$

\section{Where}

$a=$ the area of the cross section of the flow of water ;

$p=$ the " wetted perimeter," that is to say, the length of that part of the perimeter of the cross section of the channel that the water comes in contact with.

Both are, of course, in the same terms, so far as an area and a line can be in the same terms. If the area be in square feet, the wetted perimeter must be stated in linear feet, and the hydraulic mean depth will be in feet. If the area be taken in square inches, the two linear dimensions will be in inches.

The greater the hydraulic mean depth the higher the velocity for any given cross section, or the less need be the area of the cross section, or of inclination, or both, for any given velocity or discharge. It is generally, therefore, an object to give a channel such a form that the hydraulic mean depth may be as great as is

* In Japan, where the excessively hot and moist summers engender extremely rapid vegetation, it would seem that a velocity of at least 3 feet per second is necessary to prevent the obstruction of open channels with weeds. 
compatible with any form of construction at all economical; although, in cases where there is ample fall, it may be convenient to adopt sections that are of forms having the hydraulic mean depth considerably less than it could be made.

The hydraulic mean depth of a circle, or of a semi-circle, is one quarter the diameter, and the circular, or the semi-circular, section gives the greatest hydraulic mean depth that it is possible to get. This is simply because a circle is the figure in which a given area is bounded by the shortest possible line, and, in the case of the semicircle, the straight diameter line not being taken into consideration, the relation of area and length of line remains the same as in the circle.

From this it follows that a semicircular section is hypothetically the best to adopt for open channels. This section is, however, very seldom adopted, on account of the expense of construction. If a mere semicircle were sufficient, the section would not be so troublesome to use; but it is to be borne in mind that, to get advantage of this form, the semicircular section must be that of the water, not that of the actual channel, and, of course, it is not permissible to have the water flowing to the very top edge of the channel. There are several reasons for this. In the first place, it would be impossible to so regulate the flow of the water that, normally just touching the upper edge of the channel, it should never overflow it. Then there are waves to be taken into account.

It is, however, when we come to consider the possibility of the freezing of the channel that the necessity for some considerable height of bank above the level of the water is most evident. If ice forms on the surface of the water of an open channel, the section of flowing water is, of course, reduced by exactly the area of cross section of the ice. This can be compensated for by increasing the discharge of water, when the level of the ice surface rises. But there is much more than this to be taken into consideration. We saw that the "wetted perimeter" is that length of the boundary of the cross section that is wetted by the water. That part of the boundary that is in contact with the air, in the case of a semicircular section the diameter line, is not included in the wetted perimeter. The air offers a certain amount of resistance undoubtedly, but, in the case of the comparatively slight velocities of flow advisable in open channels, the resistance is so small that it may be left out of consideration. When, however, even the thinnest film of ice is formed on the surface of the water of an open channel, the under side of the ice forms part of the wetted 
perimeter, which is thus greatly increased, the flow being retarded to a very marked extent. This can only be compensated for by allowing the surface of the water bearing the ice to rise.

For these reasons the banks of open channels must rise for any height from 1 to 3 feet above the normal level of the water, according to the size of the channel and other considerations.

The form of a semi-circle with 2 or 3 feet of vertical sides, or

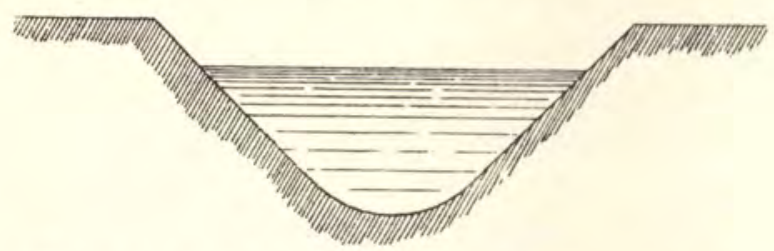

Fig. 148.-Section of open channel of curvilinear form.

even with the corresponding length of sloping sides, above it, would form a section very awkward and expensive to construct. An approximation to it, however - somewhat as shown in Fig. 148is sometimes adopted.

If the sides are to be straight, the greatest hydraulic mean depth is got by adopting half of a hexagon as a section, as shown in Fig. 149, and this is in some cases a very good section to adopt in practice, though it is generally better to give the sides a less steep slope.

A rectangular section is occasionally adopted, but not often. It is a convenient section in the not very common case where a channel is cut out of solid rock. When a rectangular section is

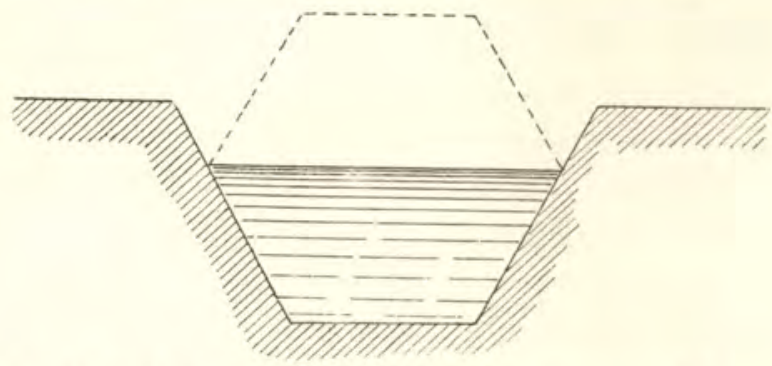

Fig. 149.-Section of open channel of semi-hexagonal form.

adopted, it should be of such proportions that the depth of the water is equal to one-quarter the width of the stream-that is to say, if it is wished to have the smallest area of channel possible.

\section{Construction of Open Channels.-When open channels}


are constructed through formations that are water-tight, and that are of such a nature that the water will not tend to wash them away, these channels may be without lining, but, as a rule, channels for conveying water have to be lined.

There are two separate objects in lining channels - one is simply to prevent erosion, the other is to prevent leakage of water through a porous soil. Very commonly the lining has as its object the prevention of both of these objectionable actions.

If lining is needed merely to prevent erosion, stone pitching is sufficient. If the bed of the channel is not water-tight, this stone pitching must be backed with puddle, or the bottom and sides of

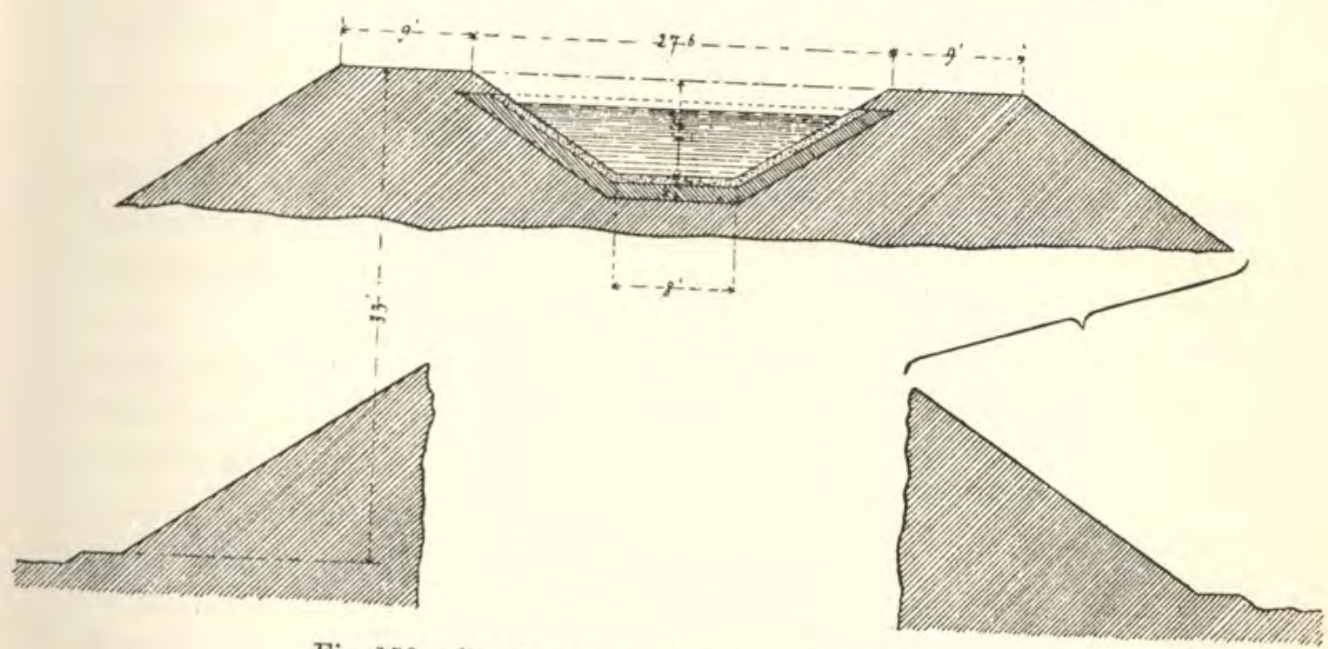

Fig. 150.- Section of open channel embanked-scale $\frac{1}{200}$.

the channel may be made of concrete lined with brick in cement mortar or rendered in cement.

Open channels have sometimes to be embanked above the natural surface of the ground. In this case the embanking must be done with the very utmost care, the earth being very closely rammed, to prevent danger of settlement, and it is probable that it is better to depend on puddle than on any other substance for material for making the channel water-tight, as leakage is less likely to take place, in the event of slight settlement, with puddle than with a non-yielding material such as concrete. Fig. 150 shows the form of canal on an embankment adopted for carrying water into Tokyo.

In the case of open channels carried along the side of a steep slope-as already stated, an arrangement not advisable in the case of conduits for waterworks---it is common to embank the lower 
side, the excavated material being used partly, or entirely, to construct this outer bank. An example of this construction is shown in Fig. 151. Sometimes a small puddle wall is constructed

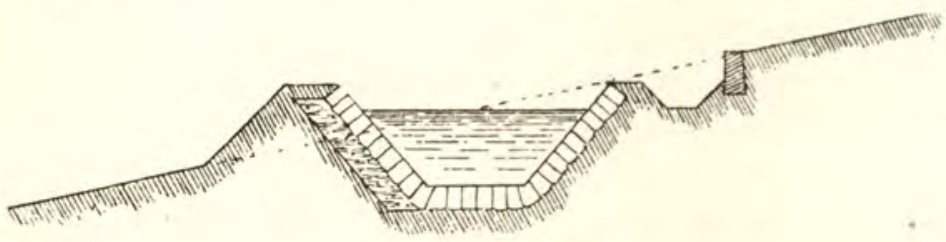

Fig. 151.-Section of open channel on slope.

in the middle of the bank, somewhat after the method adopted in the case of the dams of impounding reservoirs.

Covered Conduits.-Covered conduits are divided into those that are entirely excavated, and those that are constructed on the "cut and cover" principle. To these might be added culverts raised entirely above the surface of the ground.

Velocity of Flow in Covered Conduits.-The same considerations have to be taken into account here as in the case of open channels, except that the question of vegetation does not come in, for there is little or no tendency to vegetation in the darkness of covered conduits. The velocities most favoured by hydraulic engineers in covered culverts seem to be the same as in open-that is to say, from somewhat under 2 feet per second to somewhat over 3 feet.

Form of Cross-section of Covered Conduit.-The factors deciding the form of the cross-section of a covered conduit are extremely complicated, so many conditions having to be fulfilled. Thus, in the case of tumnelling, none of the considerations that go to make up the practice of that particular form of engineering can be left out of the question. Then, again, other things being equal, the form should be selected that gives the greatest hydraulic mean depth; but other things are not equal-if the expression may be allowedfor it is necessary not to leave out of consideration the greater facility of constructing certain sections than others. Moreover, in many cases-indeed, in most-we must take into consideration the form that is best calculated to resist external pressure, and the cross-section selected is commonly a compromise; but the writer is not aware that it is possible to give any general expression for the best form of compromise, especially as it must vary 
with the nature of the formation that the covered conduit passes through.

It is also necessary to take into consideration cases in which conduits have to be constructed above ground, and when it is necessary that the sides should be able to support not only the internal pressure of the water, but any thrust that they may be subjected to from the covering roof, generally in the form of an arch.

With conduits intended always to run full, a circular section has an advantage, so far as hydraulic mean depth is concerned, inasmuch as, taking a circular section, the area is reduced to the smallest possible. The circular section is sometimes adopted, but not often, for it is not the best section for resisting unequal external pressures; moreover, it is troublesome to construct, and it is seldom that it is desired to have culverts running quite full; and, indeed, it is impracticable to make them run quite full, unless the water in them is under pressure, for the highest velocity is attained even in a covered circular conduit when it is running only about $\frac{7}{8}$ ths full, and even the highest discharge is got when it is running not quite full. This is because the last stage in filling a circular conduit adds greatly to the wetted perimeter, and very little to the section of flow.

As the writer is unable to lay down any general principles to guide the engineer in designing cross sections suitable to all conditions, and doubts if it is possible to lay down such general principles, he is satisfied to give a series of drawings illustrating the cross-sections of large conduits that have actually been carried out or suggested by some of the most eminent engineers. These will be found in Plate XXXVI. (Figs. 152 to 168).

Fig. 152 shows the section adopted for the Loch Katrine waterworks, for supplying Glasgow, for tunnels that were through impervious rocks.

Fig. 153 shows the section adopted in the same waterworks, where the rock was not impervious.

Fig. 154 shows the section adopted for "cut and cover" where the rock was impervious.

Figs. 155 and 156 show forms of conduit used in connection with the Aberdeen waterworks.

Fig. 155 shows the section adopted for tunnels through impervious rock.

Fig. 156 shows a conduit raised above the natural level of the ground, and enclosed in an embankment. 
Figs. 157 and 158 show the sections proposed by Mr. Bateman in connection with the great scheme that was projected some twenty years ago for supplying London with water from North Wales.

Figs. 159, 160, and 161 show covered conduits proposed for the Cumberland lake scheme-one on an equally great scale projected at about the same time by Messrs. W. Hemans, M.I.C.E., and R. Hassard, M.I.C.E.

Fig. 162 shows the section of proposed covered conduit, raised above the natural level of the ground, proposed in connection with the same scheme.

Figs. 163, 164, and 165 show sections of the great culvert conduit of the New Croton works, for the supply of water to New York - the greatest works of the kind carried out in modern times, or perhaps at any time.

Fig. 166 shows a section of the same conduit where it has to be supported above the natural surface of the ground.

Figs. 167 and 168 show sections used at the Tytam waterworks, Hongkong, already referred to.

Materials used in the Construction of Covered Culverts.Masonry laid in cement mortar is a common material, and probably this is the best where stone is plentiful, but bricks in cement mortar are often used.

It will be seen from the figures in Plate XXXVI. that concrete is pretty freely used, and the tendency is, as in so many engineering works, to use it more and more freely. Indeed, conduits have, of late years, been made of concrete alone, and this construction can be recommended where stones suitable for masonry are not readily obtainable. Such conduits may be lined with brick in cement mortar, or may be rendered in cement.

Aqueduct Bridges. - When the ancients found it necessary to carry water across a valley in constructing the great waterworks, the remains of which form some of the grandest monuments of antiquity, they continued the hydraulic gradient, carrying the water in an open channel supported on arches of masonry. It has repeatedly been stated that the existence of these great aqueduct bridges shows that the ancients were ignorant of the rudimentary principle in hydraulics that "water tends to rise to its own level." It is highly improbable that this is so. The ancients did not have the necessarymaterials, or had not sufficient knowledge in working them, to construct "inverted syphons" to 
deal under high pressures with the very large quantities of water that were carried in their aqueducts.

At the present time, if water has to be carried across a valley, whatever be the quantity within the limits used for water supply, this is generally done simply in a pipe, laid a few feet under the ground, falling down one side of the valley, and rising on the other. Such a pipe has been somewhat inexactly termed an "inverted syphon." There is no difficulty whatever in proportioning such pipes. The end that the water is flowing to must be lower than the other end, by a sufficient height to give the " head" necessary to make the water travel through the pipe; the pressure at the different parts of the pipe must, of course, be taken into consideration, and the pipe must be made thick enough to bear them safely. Further than this, there should be a "scouring valve" at the lowest part of the pipe. This being opened occasionally, water will escape with a velocity due to the whole head, and any silt that may have been collected in the pipe will be carried with it.

Although water is generally, at the present day, so carried across valleys, there may be cases where an aqueduct bridge across a small valley may be cheaper than a pipe. Thus, in the case of a conduit of considerable size, and a narrow valley with declivitous sides, it would probably be cheaper to carry the conduit without interruption across the valley, on a bridge, than to make the necessary connection with a pipe, carry the pipe down one steep declivity and up another, and then to make another connection between the iron pipe and the conduit. This would be especially the case if solid rock had to be excavated to receive the pipe.

Plate XXXVII. (Figs. 169 to 172) shows such a short bridge crossing a small valley on the course of the Loch Katrine waterworks for Glasgow.

The Flow of Water in Pipes.-The flow of water in pipes differs from the flow of water in conduits, as the word "conduit" is generally understood in connection with waterworks, inasmuch as, in the case of pipes, the water is generally supposed to fill the whole of the pipe, while in the case of conduits it is seldom supposed to fill the whole conduit. There is no air surface in the case of the pipes: the water may be at some pressure; and it is not, therefore, necessary that the bottom of the pipe should be everywhere parallel with a surface of free-flowing water. In other words, a pipe does not need to follow the "hydraulic grade line" exactly, or often even nearly. 
The hydraulic grade line is the locus of a point to which water would rise, in vertical pipes with open tops connected with a pipe through which water is flowing. This will best be understood by taking a diagram. In Fig. 173, if we suppose $\mathrm{A}$ to be a vessel

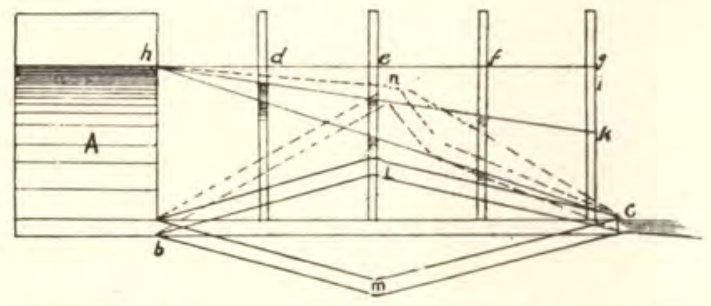

Fig. 173.-Diagram illustrating hydraulic grade line.

containing water, and $b c$ to be a pipe of uniform bore, freely open at both ends, water will of course escape from this pipe at $c$. If there be connected with this pipe $b c$, any number of vertical pipes, $d, e, f, g, \& c$, the water will rise in them to different heights, and a line drawn through the surfaces of the water in the pipes will be the hydraulic grade line. In the particular case that we have supposed, when there is no obstruction, the hydraulic grade line will be a straight line from a very little below the surface of the water in $\mathrm{A}$, to the free end of the pipe. For our present purpose we may suppose it as actually beginning at the surface of that water, and call $h c$ the hydraulic grade line.

Let there be a partial obstruction at $c$, however, and the hydraulic grade line, whilst still straight, and beginning at $h$, will not terminate at $c$, but at some point between $c$ and $i, i$ being level with the surface of the water. It will, for example, take the form $h k$.

With pipes of uniform bore, the hydraulic grade line is always straight, so long as the pipe does not rise above what would otherwise be the hydraulic grade line. Thus the hydraulic grade lines for the pipes $b l c$, and $b m c$, are the same as for the straight line pipe $b c$.

If, however, the pipe were to rise, as shown in dotted lines between $b$ and $c$, the hydraulic grade line would be $h n c$, also shown in dotted lines; or, to be more correct, there would be two hydraulic grade lines, one from $h$ to $n$, the other from $n$ to $c$.

Formula for the discharge of water through pipes.-In causing water to flow through pipes, the force of gravity has to overcome three different resistances. In first place, it has to overcome the mere inertia of the mass of the water; it has to put it in motion as 


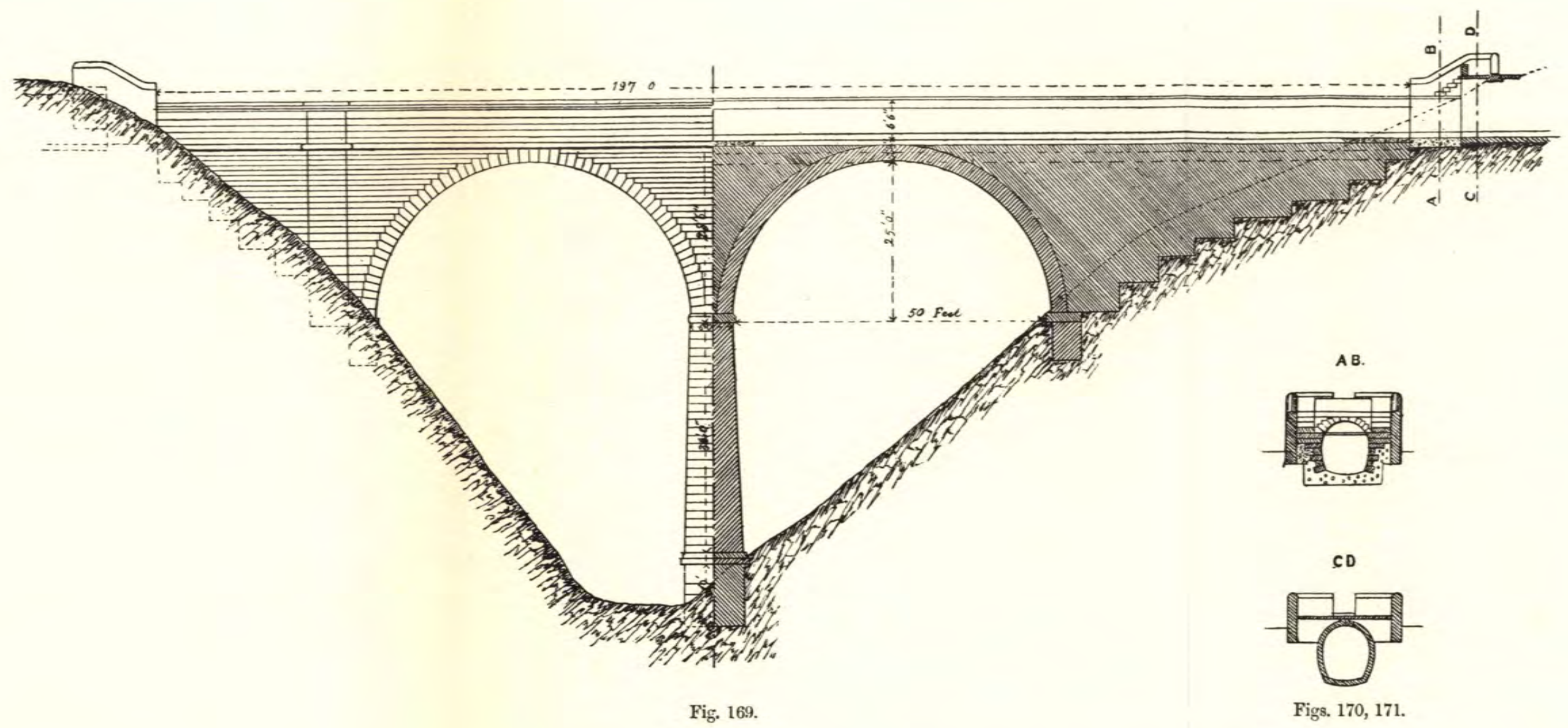

Aqueduct Bridge on line of Loch Katrine Waterworks (Glasgow).

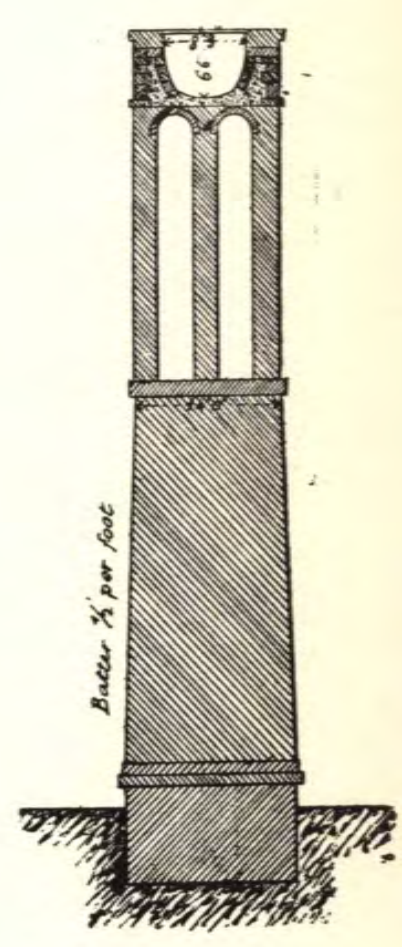

Fig. 172.

[To face page 178. 
a falling body is put in motion. This uses up an amount of "head" equal to the height that a falling body would have to fall, to acquire the velocity of the water in the pipe, and is expressed by the ordinary gravity formula-

$$
\mathrm{H}=\frac{\mathrm{v}^{2}}{2 \mathrm{~g}}
$$

Where-

$\mathrm{H}=$ the head consumed in overcoming the inertia of the water ;

$\mathbf{v}=$ the velocity of the water in the pipe ;

$\mathrm{g}=$ gravity $=($ say) $32 \cdot 2$ feet.

To take an example, suppose the velocity of the flow of water in a pipe is 4 feet per second. $\mathrm{H}=\frac{4^{2}}{64 \cdot 4}=\frac{16}{64 \cdot 4}=$ a very little over 25 , or (say) 3 inches. That is to say, if the velocity of the flow in a pipe is to be at the rate of 4 feet per second-a common one in the case of waterworks - 3 inches of the total head available for putting the water in motion in the pipe, will be consumed in overcoming the inertia only, and is not available for overcoming the two other resistances now to be mentioned.

The next resistance is that of entry to the pipe. When water flows from a reservoir into a pipe, the particles come from all directions towards the opening of the pipe, and something approaching a vortex motion is set up, with the effect that a certain resistance is offered to the flow of the water. This can be prevented altogether, or nearly so, by making the end of the pipe trumpet shaped; but this is not often done in practice, the amount of head lost by the resistance of entry to the pipe being very small. The head necessary to overcome this resistance is generally taken as one half that necessary to overcome the inertia of the mass of the water. Thus, in the case given above, it would be 1.5 inches, making the total head necessary to overcome the two resistances that have been considered, $4 \cdot 5$ inches.

The next resistance that has to be overcome is that of friction, and, except in the case of very short pipes, this resistance is far greater than both the others put together. In fact, so great is it comparatively that, with all other pipes of considerable length - say of lengths more than 500 times their diameters-all other resistances but that of friction become so insignificant that they may be left out of consideration.

Formulæ taking into consideration the head necessary to overcome the inertia of the mass of the water, and of the resistance of entry, are of necessity very complicated and cumbersome to work 
with. The formulæ most commonly in use do not take these factors into consideration at all, and can consequently never be quite accurate, whilst they generally become very inaccurate indeed, for short pipes. Even these formulæ may, however, be made to give very fairly accurate results by a very simple device.*

The form in which the problem of the flow of water in pipes most frequently presents itself is the following: Given a certain necessary discharge of water, and a certain available head to cause the water to flow through a pipe, what is the necessary diameter of the pipe? As has been said, if the pipe is long, it is not necessary to allow for overcoming the resistance of inertia, or that of entry to the pipe, as they are comparatively so insignificant, but they must be allowed for in the case of short pipes. This is done by finding, first, the approximate diameter of the pipe, and hence the approximate velocity of the flow of water, the velocity being, of course, the discharge of water $\div$ the area of cross section of the pipe. It is only necessary now to deduct from the total head available for giving motion to the water, that portion of the head that is necessary to overcome the inertia of the mass of the water, and the resistance of entry to the pipe. We may now make a closer approximation, taking as true diameters those that we get by the second trial.

For example, supposing that the total head of water available in the case of a comparatively short pipe were 7 feet, and that, by a first approximation, we found that the velocity of flow of water through the pipe would be at the rate of 8 feet per second: We will find, by the method already described, that as nearly as possible 1 foot of head is necessary to overcome the inertia of the water, to set it in motion that is to say. Again, as the head necessary to overcome the resistance to entry is one-half that necessary to put the water in motion, the total head consumed for overcoming these resistances will be 1 foot 6 inches.

* See Fanning on "Hydraulic and Water-Supply Engineering," for comparisons of the result of different formulæ in common use, when applied to pipes having lengths relatice to their diameters differing greatly. It will be seen that most of the results correspond very fairly, and with experimental results, when long pipes are concerned, but that they differ egregiously in the case of short pipes.

Those who are interested in the question of the theory of the flow of water in pipes, should also read the exceedingly thorough investigation of this matter by Fanning. The result of these investigations is a set of formulæ in some cases a little troublesome to handle, but, the writer believes, giving more accurate results than any formulæ that preceded them. They are not quoted here, as they can be used with adrantage only with the aid of a table of co-efficients for different diameters which it would not be fair to reproduce. 
7 feet -1 foot 6 inches $=5$ feet 6 inches. We therefore merely take 5 feet 6 inches as our available head instead of 7 feet.*

This may be put in another form by saying that the hydraulic grade line does not begin at the level of the surface of water from which the pipe is drawing, but from that level minus the head necessary to overcome the resistance of the inertia of the water added to that necessary to overcome the resistance of entry.

The following is one of the most commonly used formulæ, taking into consideration the frictional resistance of the pipe only. It is known as Eytelwein's formula :-

Where-

$$
\mathrm{D}=0.538 \sqrt[5]{\frac{\mathrm{L} \mathrm{W}^{2}}{\mathrm{H}}} .
$$

$\mathrm{D}=$ the diameter of the pipe in inches ;

$\mathrm{H}=$ the head of water in feet;

$\mathrm{L}=$ the length of the pipe in feet ;

$\mathrm{W}=$ the cubic feet of water discharged per minute.

Tables and diagrams of discharge.-Tables and diagrams for ascertaining the discharge of water in pipes, the diameters and falls being known, or for ascertaining the diameters, the discharges and falls being known, or, again, for ascertaining the necessary falls, the diameters and discharges being known, are now so common, so reliable, and so convenient, that in practice an engineer will seldom have recourse to formulæ, except to check the diameter of a long and important line of pipe.

The writer has made constant use for some years of " Hydraulic and other Tables for purposes of Sewerage and Water-supply," by Thomas Hennell, M.I.C.E., and can thoroughly recommend the little book. He has also used, within the last year or so, "Water Pipe Discharge Diagrams, showing the relation between the Diameters, Gradients, and Discharges of Water Pipes: together with Other Diagrams giving the proper Weights and Thicknesses of Pipes for various Pressures," drawn and compiled by E. Brough Taylor, M.I.C.E., and G. Midgley Taylor, Assoc.M.I.C.E. These diagrams are particularly convenient, as they give what tables cannot, diameters to any fraction of an inch, discharges to any fraction of a cubic foot, \&c. There is a certain slight inconvenience in the use of them. No steeper gradients are given than 5 in 1,000 , whereas in waterworks practice we often have

* The writer, when applying formulæ in this way, wishing to be on the safe side, takes the total head lost in overcoming inertia and the resistance to entry as the head necessary to overcome inertia $\times 2$. 
to deal with steeper gradients. This inconvenience is, however, readily overcome by remembering that the discharge is as the square root of the fall. Thus, if we have a fall of more than 5 in the 1,000 to treat of, we may divide our discharge by 2, and our fall by 4 , or even, if necessary, our discharge by 3 and our fall by 9 , when we get the result wanted.

Allowance for Incrustation of Pipes.-After a time the inner surfaces of pipes used as mains, sub-mains, or the like, for carrying water, nearly always get at least a thin film of deposit on the inner surface. This acts in two ways in reducing the discharge of water. In the first place, the actual diameter of the pipe is reduced; in the second place, the incrusted surface is always rougher than the clean surface of the pipe. Waters differ very materially in their tendency to incrust pipes. Some incrust them so rapidly that the pipes may become nearly full within a few years, others scarcely deposit anything at all on the inner surfaces. It seems difficult to predict whether a certain water will have a serious effect in this way or not. All that can be said is that hard waters incline to produce incrustation more readily than soft, as a rule. It is therefore naturally very difficult to say how much, in addition to the diameter got by tables or diagrams, ought to be added to allow for incrustation. The following rough rule has been found to work well with pipes above about a foot in diameter :-

Add one inch to the diameter got by formula, or from tables or diagrams, and take the next even inch above this as the actual diameter of the pipe.*

Pipes flowing with Open Ends.-In taking into consideration the question of hydraulic grade line, we considered the case of a pipe flowing without obstruction either at one end or the other, or along the course of the pipe. It does not often happen, in the case of waterworks, that water flows freely from the end of a pipe into the air, as shown in our diagrammatical cut, but we have the equivalent of this, when we have water flowing from an intake to a reservoir, from a reservoir to a filter-bed well, or from a filterbed well to another reservoir. In such cases the hydraulic grade line is drawn from the level of one surface of water to the level of the other, making, if it be considered necessary, the deduction already mentioned from the head, for overcoming the inertia of the water, and the resistance to entry to the pipe. Thus, for example, if there is a great distance between the filtering beds and the

* See note 18, Appendix II. 
clean water reservoir, so that we do not proportion the diameter of the pipe between the two simply to give a certain velocity of water, but to deliver the required amount of water with the available head, we take the surface of the water in the filtering well as the upper level of the upper end of the hydraulic grade line, and the level of the water in the clean water reservoir as the level of the lower end of the hydraulic grade line, making the deduction above mentioned in the difference of level, if it is likely appreciably to modify the result.

One thing we should bear in mind, however, and that is, to take the least favourable conditions that are likely to occur in actual working. Thus, in discharging from a reservoir, well, or the like, the level of the water in which is subject to variation, we should assume the water at the lowest level it is ever likely to be at in actual working. On the other hand, in discharging into a reservoir, well, or the like, with water at a variable level, we should assume the water at the highest level that it is likely to be at in actual working.

Flow of Water in Pipes Partly Closed at their Lower Ends.This is the condition always met with in distribution systems, and in mains leading to distribution systems. Indeed, this partial obstruction is an essential part of the working of distribution systems, as without it neither would water rise to the different levels that it has to rise to to supply the upper floors of houses, nor would it issue with any force from fire hydrants.

It thus comes to pass that, in the case of a main leading to a distribution system, the "head" used in calculating the diameter of the pipe is not the difference in level between the water in, let us say, the clean water reservoir and that of the pipes of the actual distribution system, but is the difference between the level of the water in the clean water reservoir and the level of the pipes under the streets plus the statical head that it is desirable to have in these pipes at the time when the consumption is at its greatest.

The first thing thus comes to be, to decide what pressure of water we wish to have in the pipes under the streets at all times. Several considerations have to be taken into account. Thus the water ought certainly to rise to the upper floor of the highest dwelling-houses. Further than this, it should, so far as possible, be possible to throw water direct from fire hose, without the intervention of a pump, over the highest buildings. But it is not, of course, possible to provide for this in all cases : 
the pressure through the whole of a distribution system cannot be doubled or tripled or multiplied 10 times, because of the existence of a single Eiffel Tower or even of a Strasburg Cathedral.

Apart from friction, water thrown from a jet would rise to the same height as it would rise to in a vertical pipe. In practice it will not rise nearly so high as this. In fact, it is not right to rely on being able to throw water to more than one half the height that it would rise to in a vertical pipe ; and, indeed, in the case of very high pressures, it will not rise so much as that. The reason why water can be thrown by a jet to a height equivalent to a proportionately less fraction of its statical head in the case of great than of slight pressures, would seem to be that with the high velocities due to great pressures the solid-like jet very soon breaks up into spray, and once so broken up the air offers a great surface of resistance.* It may be argued that the less relative efficiency in the matter of throwing to heights, with high than with low pressures, is merely due to the fact that the air resistance increases as the square of the velocity; but it must be borne in mind that the velocity of the water issuing from the jet varies only as the square root of the height to which it would, apart from pressure, rise.

Taking all things into consideration, it is evident that there are many advantages in a high pressure. There must, however, be a limit. Very commonly it is determined by the level of the source of supply, but there comes a point beyond which the rapidly-increasing difficulty in preventing wasteful leakage with high pressures imposes a limit. The difficulty is not so much with the street mains as with the house fittings. The rapid improvement of these is making higher pressures possible, but there must always be a limit. It is very difficult to state at what pressure this is reached, or even to say what head is the most desirable. Perhaps it will not, however, be very far wide of the mark to say that a pressure equivalent to a head of about 300 feet is about the greatest that is advisable with the fittings now in use. In the case of many towns that still have in the houses fittings of

* The writer has uften seen water thrown from $\frac{3}{8}$ ths inch nozzels under a pressure of 800 lbs. per square inch, equivalent to a head of over 1800 feet. The water broke into a spray almost as it left the nozzel, and would not rise more than about 100 feet. These diminutive fire hose were fitted up in connection with hydraulic systems erected by Messrs. Brown, Bros. and Co., of Rosebank Ironworks, Edinburgh. They are extremely efficient for extinguishing a fire at its beginning. They are attached to rubber hose which, strange to say, can be procured so strong that they will resist the enormous pressure mentioned. 
somewhat antiquated pattern, it would be quite impossible to increase the pressure to this amount without disastrous leakage immediately occurring.

In the case of towns on very uneven ground, it is inevitable that the pressure shall vary greatly in different places, and this even if there be a high level and a low level service, or if there be more than two services. It may, in such a case, be impracticable to avoid a pressure greater than one equivalent to 300 feet head. In such a case the greatest attention must be paid to the pipes and fittings in that part of the town where the pressure is the greatest. On the other hand, a town built on a level-or, still more, one built on ground gently sloping away from the centre of distribution-permits of a maximum pressure less than is needed in towns on any other form of ground. It is probably never advisable to have a pressure equivalent to a head of less than 100 feet in the mains.*

Fig. 174 will illustrate what is meant about the head that is to be used in calculating the diameter necessary for a main leading to a distribution system. Let us suppose $\mathrm{A}$ to be a clean water

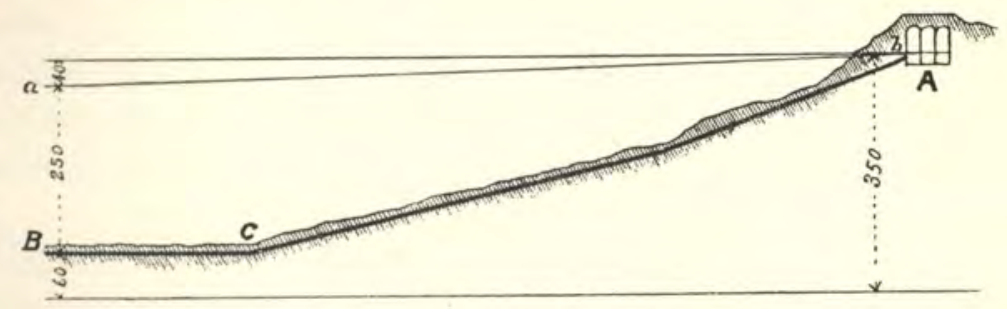

Fig. 174.-Diagram illustrating caleulation of hydraulic grade line.

reservoir, and the thick line to represent a main leading to a town on the site B C. We will suppose that we are given the following data :-

The town is 60 feet above datum; it is desirable to have a pressure equivalent to a head of not less than 250 feet in the mains; the level of low water in the clean water reservoir is 350 feet above datum.

We shall call $60+250 \mathrm{~h}$, and $350 \mathrm{~h}^{\prime}$. Then $\mathrm{H}=$ $\mathrm{h}^{\prime}-\mathrm{h},=350-310,=40$, when $\mathrm{H}$ is the head to be used in calculating the diameter of the main. That is to say, the main

* In Japan-the houses being very low, seldom over two stories in height-the maximum desirable pressure is equivalent to about 200 feet per head, and there are some towns in which a head of even 100 feet is unnecessary. 
must be made of such diameter that, with a head of 40 feet available for putting the water in motion, it shall be capable of carrying a quantity of water equal to the absolute maximum consumption at any part of the twenty-four hours.

In the sketch, $a b$ represents the hydraulic grade line. 


\section{CHAPTER XVIII.}

\section{Distribution Systems.}

THE working out of a distribution system is one of the most troublesome problems in connection with waterworks, as well as one on which most text-books are nearly silent, and that in general is barely referred to in papers describing the carrying-out of waterworks. It would seem that most engineers consider it a part of the works of quite minor importance. The writer would insist that it is of importance minor to no other part of the works, and that, in connection with that important function of modern waterworks - the extinction of fire-it is of the very first importance. Indeed it is only of late years that it seems to have been understood that the extinction of fires is one of the principal purposes of waterworks, and even now this fact seems to be fuliy appreciated only in America.

Constant and Intermittent Service.-Before discussing distribution systems, we must say a word or two about constant and intermittent service, but it will be only a word, as intermittent service may be looked on now as altogether a thing of the past.

Not many years ago a constant service was a thing scarcely known. All waterworks admitted water to the service-pipes of the houses during an interval of an hour or longer once a day. During this time, cisterns in the houses of sufficient capacity to hold a supply for at least twenty-four hours were filled up. During the rest of the day, the water was shut off from the houses and from the mains in the street. The owners or occupiers of houses found it imperative to prevent any very gross leakage in the houseservice system, for the simple reason that, if it continued to exist, the water in the cisterns would not last for the twenty-four hours.

The disadvantages of the intermittent system are very great. The very fact of storing water for a minimum of twenty-four hours in uncovered or imperfectly-covered cisterns is enough to condemn 
the system, as the water is certain to deteriorate. But there is worse than this. The cisterns are generally in inaccessible places, often between the ceiling of the upper rooms and the roof, and the actual householder seldom sees them. "Out of sight" is generally literally "out of mind" in such a case, and the cisterns are left uncleaned from year's end to year's end, so that water used for drinking purposes is drawn from storage tanks the sight of which would make the users of the cisterns sick.*

Further than this, there was the great inconvenience that, in case of fire, there was no pressure on the mains until the "turnkey" could be found to turn on the water.

When the advantages of a constant service were first pointed out, it was objected that such a service was impracticable, because the inevitable waste would be so enormous, and, indeed, when a constant-service was first attempted, the waste was found to be so great that it had to be abandoned. Since then, however, by improvements in house-fittings, by systems of regular inspection, and, in certain cases, by the general introduction of selling water by meter, waste has been so far reduced that the constant service system is now all but universal, and soon will certainly be the only system used, or, it is to be hoped, permitted.

In the constant service system water is admitted to the houseservice pipes during the whole twenty-four hours. The water ought, in all cases except for the use of water-closets, to be drawn from the service-pipes, under the town pressure, direct; but from what can only be called a sort of inveterate conservatism, it is quite common, in England at any rate, to find that, even where the constant service has been introduced, the evil cistern-system is still retained.

For the reasons here given, in treating of distribution systems, we assume a constant service.

\section{Distribution Systems and Extinction of Fire.--Until}

\footnotetext{
* If the writer could describe what he has seen, whilst making inspections of houses in London for the London Sanitary Inspection Association, he is pretty sure that no cistern would be allowed any more in any house in a civilised country. Dead rats are a trifle. He remembers once inspecting a house in which the cistern supplying drinking water was found to be situated under the floor of an attic used as a bedroom. There were quite unmistakable evidences that a certain unmentionable utensil had been upset on the very morning of the day of inspection, and that some of the contents had dropped into the cistern! This was in the house of a famous London physician! It was not at all uncommon to find cisterns in such positions that, on the washing of a floor, part of the washing water must inevitably enter them.
} 
recently, distribution systems were commonly designed to be capable simply of supplying so much water per head of population ; and-except inasmuch as a certain minimum size of pipe, much more than large enough to supply the water used in all the houses of any single street, was generally decided on-little consideration was given to the water desirable for the extinction of fire. Now it should be understood that, throughout the whole design of waterworks, the water desirable for fire extinction ought never to be left out of consideration, and that in the case of all mains it ought to be one of the determining factors of the diameter, whilst the diameter of all mains under a certain size ought to be determined solely with regard to their capacity to supply water for fire extinction.

It is not at all easy to decide what quantity of water it is necessary to provide for the extinction of fires. It is evident that it is in no way proportionate to the size of the town. Up to a certain point the water necessary for extinguishing a fire in a small village is as great as that needed in a great city. On the other hand, it is not possible to assign a definite quantity of water per minute as that necessary for fire extinction. whatever be the size of the town supplied, because, in the first place, a fire may spread to much greater limits in a large city than in a small town or village ; and, in the second, there is much greater probability of more than one fire at a time occurring in a large city than in a small town or village.

One thing that can be quite definitely stated is that the quantity of water that must be provided for fire extinction must be relatively larger in small towns than in large ones.

Fanning, in one part of his book, has the following:- "There is the possibility of two or three fires being in progress at the same time in even the smaller cities, requiring at least twelve hydrant streams, or, say, 300 cubic feet per minute of water for each fire." At another place he says :- "For fire supply we anticipate the possibility of two fires happening at the same time requiring ten hose-streams each. The minimum fire supply is, then, twenty hose-streams of, say, 20 cubic feet per minute, or a total of 400 cubic feet per minute." In another place he mentions that the average consumption for fire purposes in American cities is at the rate of one-tenth gallon per head per day. This is, however, a very different thing from the necessary provision, for this one-tenth gallon per day will be all consumed during a few hours of each year. 
It has been pointed out by Mr. Freeman-an American engineer who has given special attention to this subject, in the only country where the subject receives nearly the attention it deserves - that distribution systems should be designed with the object, so far as possible, of being able to concentrate the whole power of the waterworks on a fire occurring at any particular place; and he mentions a case where, on the occurrence of a large fire in an American city, as much water from hydrants alone was poured over the area of conflagration in a few hours as would have drowned it all by a depth of over 12 feet !

It is not generally possible, or at least practicable, to so arrange distribution systems that the whole power of the works can be concentrated on any one fire; but the system always can be and should be so arranged that, if a fire occurs at any one place, jets from several hydrants can be brought to bear on it, and that, if it spreads in spite of this, further jets can be brought to bear on it proportionate to its area.

It is necessary, too, that all this be effected without interfering with the general supply of water to the town; although we may bear in mind that, naturally, at the place where a fire is actually occurring, water is not being used for either "domestic" or manufacturing purposes. The water that would otherwise be thus constantly used is therefore available for fire extinction. The same applies partly to water that would naturally be used for domestic and other purposes in houses surrounding the site of a conflagration. For these reasons it is not necessary to specially supply quite all the water that would be necessary for fire extinction were the normal consumption going on. The question thus becomes greatly one of judgment.

The writer has no objection to the laying down of such large minimum quantities as have been mentioned above, but does not see much use in laying them down as minima not to be deviated from, as he feels sure that they will not be adhered to, at any rate, in the case of European cities. They represent a quantity of water that would supply the whole of the ordinary needs of a very fairly large town. As a compromise, he suggests, as a minimum, 200 cubic feet per minute. This is the quantity of water that will be carried by pipes of from 12 to 15 inches in diameter, with the hydraulic gradients common in the case of waterworks.

But let there be no mistake here. What is meant is, that all the principal mains of the distribution system of the waterworks 
of any fairly large city should be so proportioned, that they shall be capable of carrying water at the rate of 200 cubic feet per minute in addition to the absolute maximum consumption. Moreever, it is to be understood that this is suggested as a minimum. The more water, in addition to this, that is provided for fire extinction, the better. By all means, if the town can afford it, let there be provision for fire-extinguishing water at the rate of 400 cubic feet per minute, or even 600 feet. The latter quantity represents the whole of the water that would be carried by pipes of from about 20 to about 24 inches in diameter, with the hydraulic gradients usual in waterworks.

\section{"Dead-end" and “Interlacing" (or "Gridiron")} Systems of Distribution.--Systems of distribution may be subdivided in this way. The former is the system that naturally

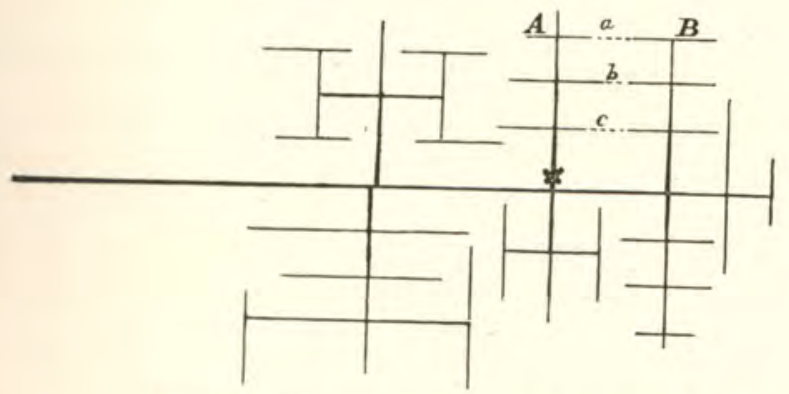

Fig. 175.--Diagram illustrating system of distribution.

first suggests itself, and it has certain advantages. It may be diagrammatically represented as a sort of tree-like arrangement of pipes, such as is shown in Fig. 175 .

This arrangement has the advantage that the necessary diameters of the pipes can be calculated with comparative ease, and further, that any part of the system can be isolated by closing a single sluice-valve, as at $\times$, for example. On the other hand, there are the disadvantages that the water is liable to remain stagnant for an indefinite length of time in the "dead-ends " of the pipes, with the result that it deteriorates in quality. This can be partly overcome by occasionally flushing out the pipes by hydrants at the dead-ends, but this involves waste of water, and the precaution is, moreover, liable to be neglected. Further, unless there is a great multiplication of sluice valves, it is necessary to shut off a district of considerable area entirely, in case of repairs 
being necessary to any pipe. This is inconvenient, and might be disastrous were a fire to occur.

Supposing, however, junctions made between the portions $\mathrm{A}$ and $B$ of the system, by junction pipes, $a b$ and $c$, shown in dotted lines, it will be evident that, to a considerable extent, stagnation would be reduced; for were water drawn from any of the pipes between $\mathrm{A}$ and $\mathrm{B}$, a motion of water would be set up in all the pipes common to the two portions $\mathrm{A}$ and $\mathrm{B}$. On the other hand, it will be evident that the closing of the single sluice valve $x$ will not permit of close water from any pipe of either of the parts $A$

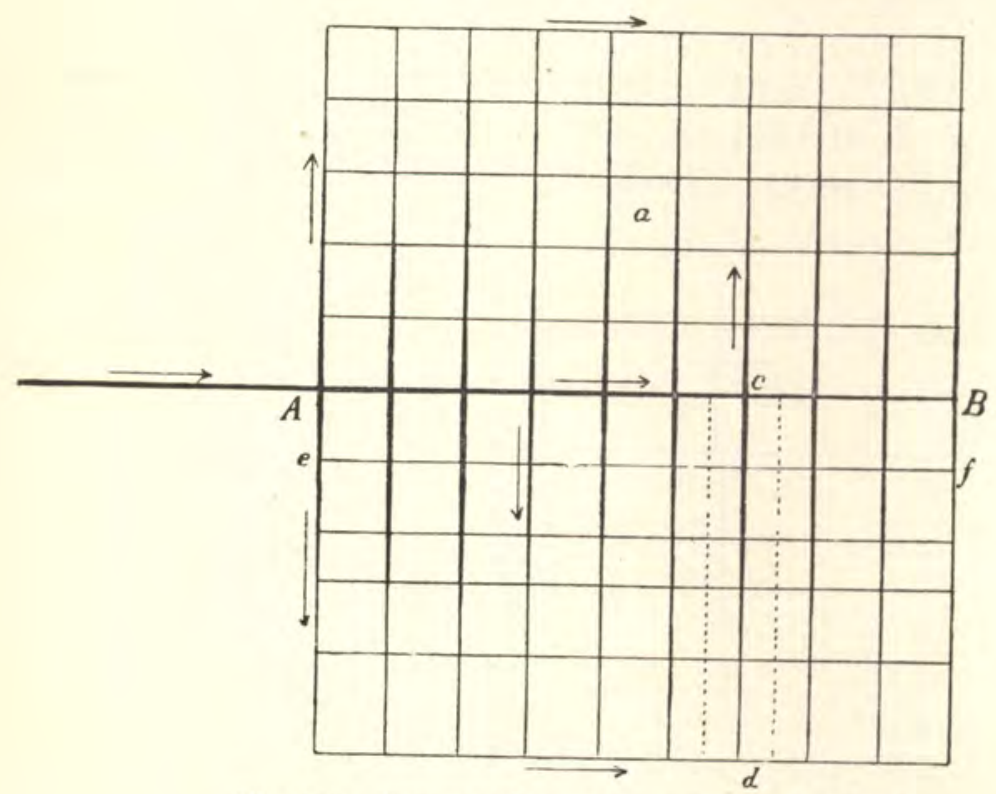

Fig. 176.-Diagram illustrating system of distribution.

and $\mathrm{B}$ of the system, and that it would be necessary to close at least two sluice valves.

This junctioning of the ends of mains into each other, is the beginning of the system which we have above entitled the "interlacing" or "gridiron" system. When this system is carried out in its integrity, the pipes cross each other, forming a complete network, and are junctioned into each other at every crossing. Such a system is illustrated diagrammatically in Fig. 176.

It will at once be seen that there is not likely to be much stagnation in the pipes, for the drawing of water at different places is certain to keep the whole mass of water in motion. The great advantage of this system is, however, the possibility of concen- 
trating the discharge of water at any particular part of the system, should this become desirable, as in the case of fire. Supposing, for example, that a fire occurs at $\alpha$, it is evident that the water will flow to hydrants opered around $a$, not only from the trunk main pipe, as would be the case with the "dead-end" system, but will, in fact, flow from all directions. It is true that it is not possible to calculate the necessary diameters of the pipes with any exactness, but we may at least be sure that they have diameter enough. Thus, for example, we may proportion a pipe $c d$, so that, drawing water from the trunk main A B, it would be large

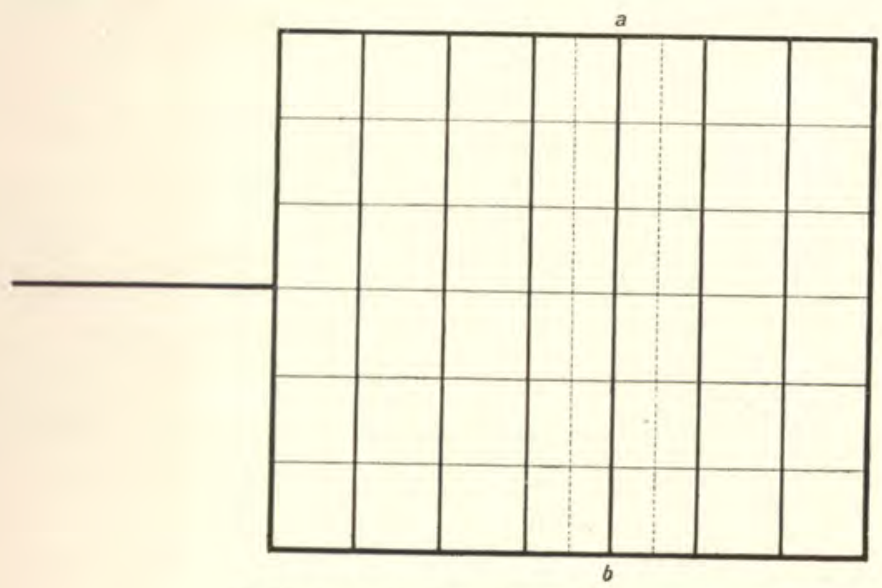

Fig. 177.-Diagram illustrating system of distribution.

enough to provide all the water needed for the part of the town shown as inclosed by dotted lines. All parallel pipes being proportioned in the same way, the pipes at right angles, such as $e f$, may be looked on merely as auxiliary pipes, serving to concentrate the water at any particular part of the system, should that become desirable ; and further, even in normal cases, serving to compensate for any error in the proper adjustment of the diameters of the pipes, or for any unlooked for excess in consumption in any part
of the town.

Again, there is another way of working out this interlacing system, which we attempt to illustrate diagrammatically in Fig. 177. Here the system--not generally the whole of a town system but that of a portion, say of a district of it is surrounded with a pipe capable of supplying the whole from both ends. That is to say, the "loop" pipe is of such a diameter throughout that it is capable of carrying one-half of all the water needed in the district, including 
allowance for fire-extinction. Any pipe, such as $a b$, is then made of such a diameter that, supplied from both ends, it is capable of supplying all the wants of the parts of the district enclosed in dotted lines. All parallel pipes are proportioned in the same way, and the pipes at right angles are made of the diameter necessary to supply one street only - that is to say, they will generally be the minimum diameter of pipe that is admitted in the system.*

It is, however, very difficult to say exactly how it is best to arrange the pipes. They would be arranged just as shown, only in the case of a typically American city, with " avenues " and streets at right angles to each other. In the case of towns of more or less irregularity in the matter of streets, the thing becomes very

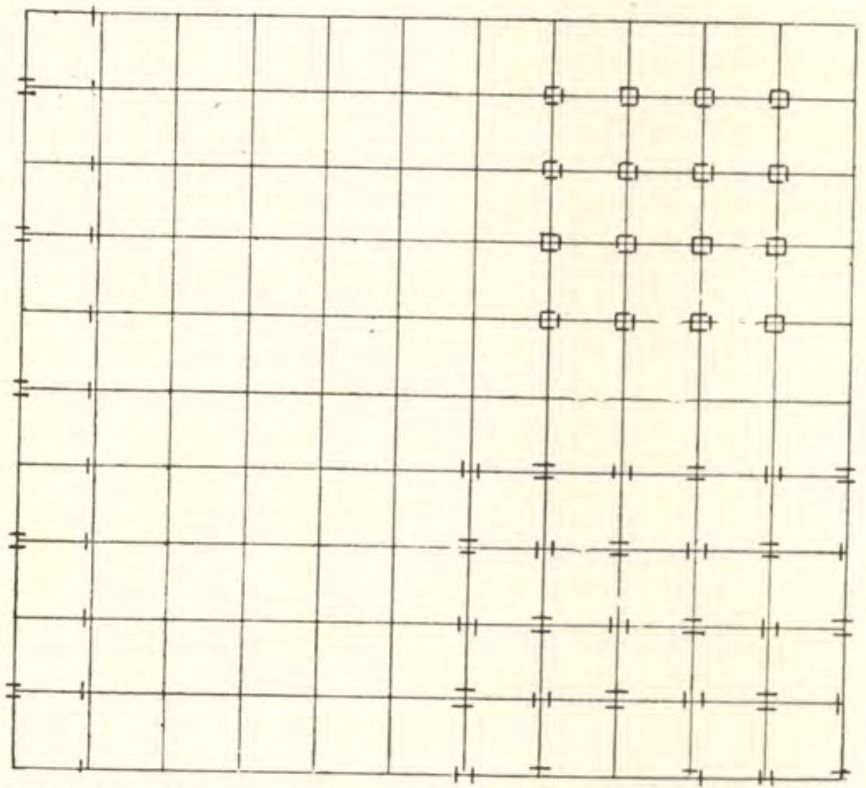

Fig. 178.-Diagram illustrating multiplication of sluice valves.

greatly one of judgment, and one in which practice leads to comparative facility. In the case of very irregularly arranged streets, it is seldom advisable to adopt the interlacing system in its completest form : it is generally advisable to make a sort of compromise between that and the dead-end system, merely taking care to have as few dead-ends as possible.

The real difficulty that is found in working out an interlacing system in its integrity, lies in the enormous multiplication of sluice valves necessary to be able to close off any one part of the system, in

* See note 19, Appendix II. 
case of repairs. It is never possible to shut off a single pipe without closing at least two sluices. This is liable to cause great confusion in case of a burst pipe. On the other hand, there is the fact that a small part of the system can be closed off without interfering with any of the rest of it.

The inevitable multiplication of sluice valves will be understood by reference to Fig. 178. In the upper part of this figure to the right is shown the only arrangement whereby it is possible to close off any one pipe by closing only two sluice valves. Sluice valves are represented by short lines intersecting the pipe mains. It will be seen that there are four such valves at every crossing of the pipes.

In the lower part of the figure is shown an arrangement whereby the number of sluice valves may be reduced to one half, but it will be seen that it is necessary to close no less than four valves, to isolate any one pipe from the general system. Further than this, a comparatively larger area has to be deprived of water in isolating any one pipe.

At the left-hand side is seen an arrangement that may be adopted at the edges of a distribution system, whereby three sluice valves have to be closed, to shut off any pipe.

A further difficulty in connection with the interlacing system is, that it makes it difficult to apply "district meters." This will be discussed in the chapter on Water-waste Prevention.

\section{Diameters of the Larger Mains of Distribution} Systems, - In working out the diameters of the large mains of a town, it is always necessary, first of all, to divide the area into a certain number of districts - the more the better-and to discover the approximate population of each. Perhaps a better idea of the way of setting to work will be got by imagining a definite case, with certain conditions; and describing this, setting about to work out the problem. Let us take the following for example:-

The town, or part of the town that is to be supplied, is long and narrow - the simplest case to deal with-and it is decided to supply it by a trunk main running down the chief street, which is in the midde of it. The population is 100,000. Provision is to be made for an increase of population of 50 per cent. Mean daily supply of water is to be taken at 3 cubic feet per head per day; water is to be provided, for the extinction of fire, at the rate of 200 cubic feet per minute. 
The town is on flat ground, and it has been decided that the pressure in the mains is at no time to fall below one equivalent to a head of 150 feet. Of course this minimum will be reached at the part of the town farthest from the source of supply.

Water is supplied from a clean-water reservoir, at some distance from one end of the town; low-water level in this reservoir is 200 feet above the level of the town. There is, therefore, 50 feet of head available for giving the water in the pipes motion; the distance from the clean-water reservoir to the remote end of the town is 12,000 feet.

The hydraulic gradient is, therefore, strictly $\frac{50}{12,000}$. To be on the safe side, and to make ample allowance for overcoming the inertia of the water and the resistance to entry, we shall take it at $\frac{48}{12,000}$, or four in a thousand.

We imagine Fig. 179 to represent the outline of the town, divided into 10 districts, having the prospective populations of $8,000,10,000$, $15,000,20,000,18,000,17,000,19,000,14,000,12,000,9,000$ and 8,000 , as duly marked on the figure. It is to be noted that these augmented populations may be proportionate to the present popu. lations, or may not be, according as the town shows a tendency to

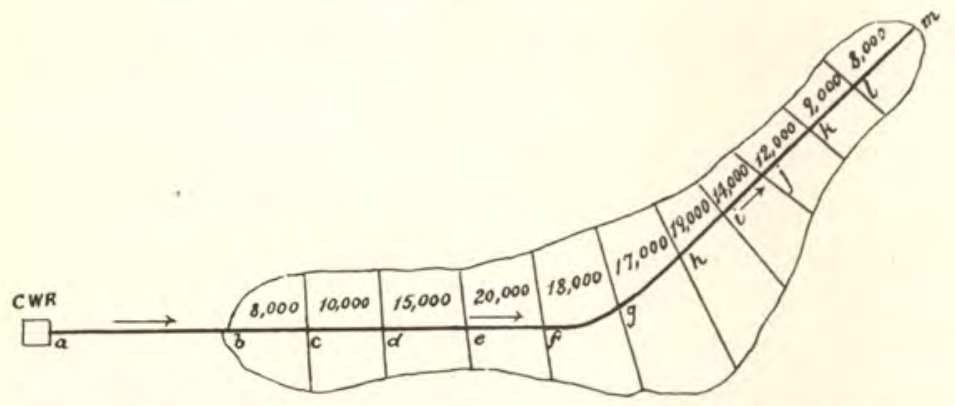

Fig. 179.-Diagram illustrating arrangement of distributing mains.

grow uniformly, or to grow in particular directions. Much judgment and local knowledge is necessary to determine whether a town is likely to grow uniformly, or more in certain directions than in others, and there is always something of mere speculation in the matter.

The augmented population - not the present one-is taken, for reasons given in an early chapter of this book, wherein it was explained that it is true economy to make certain parts of the system sufficient for a considerably increased population, from 
the beginning, instead of allowing for their subsequent enlargement.

Our problem now is to decide on the diameter of the pipe from $a$ to $c$, from $c$ to $d$, from $d$ to $e$, from $e$ to $f$, from $f$ to $g$, from $g$ to $h$, from $h$ to $i$, from $i$ to $j$, from $j$ to $k$, from $k$ to $l$, and from $l$ to $m$.

Theoretically the pipe might begin to taper from $b$, but in practice the full diameter of the main is carried on to the end of the first of the districts into which we have divided the town.

In this case we have to deal with absolute maximum con sumption. This, as has been seen, must be taken as at least equal to twice mean consumption. It will, therefore, be at the rate of 6 cubic feet in 24 hours in this case.

It is thus evident that the rate for domestic supply is represented by the following equation :-

$$
\mathrm{D}=\frac{150,000 \times 6}{24 \times 60} .
$$

Where

$$
\mathrm{D}=\text { discharge in cubic feet per minute. }
$$

This is found to be 625 cubic feet, and it is evident that the total that has to be provided for, including water for fire extinction, is $625+200$, or 825 .

We could apply a formula to find out the necessary diameter of the pipe, but prefer to refer to diagrams of Taylor's Water-pipe Discharge Tables, from which we gather in a moment that the pipe would need to have a diameter of, as near as may be, $23 \frac{3}{4}$ inches. On account of what has already been said about allowance for incrustation, we shall, in practice, give the pipe a diameter of 25 inches.

We next come to investigate the portion of pipe $c d$. Here our formula becomes :- $\mathrm{D}=\frac{142,000 \times 6}{24 \times 60}$, and the total quantity to be provided for $=792$ cubic feet per minute. We will find that the pipe to supply this would need to have a diameter of 23.3 inches, but again we should make it 25 inches in diameter in practice.

Next comes the portion of pipe $d e$. Here we will find that the total quantity that has to be provided for is 750 cubic feet per minute, and that the pipe must be $22 \frac{7}{8}$ inches in diameter, or allowing for incrustation, 24 inches in diameter. 
Taking our pipe in this way by sections, we may tabulate the results as follows :-

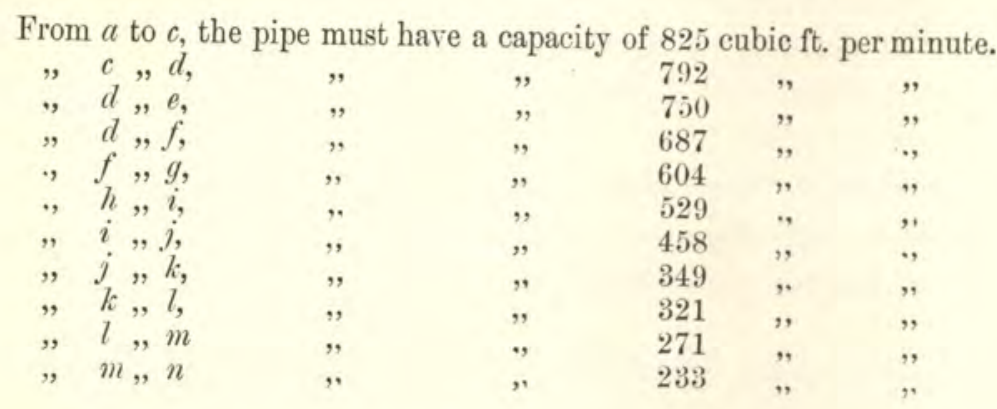
that-

Further, we shall find, referring to the diagrams mentioned,

\section{Erom-}

$a$ to $c$ the pipe must have a diameter of 233 ins. or, allowing for incrustation, 25 ins.

\begin{tabular}{|c|c|c|c|c|c|c|}
\hline$c, d$ & ", & , & $23 \cdot 3$ & , & , & \\
\hline$a, e$ & " & , & $22 \frac{7}{8}$ & , & ", & 24, \\
\hline${ }^{e}, g$ & $"$ & " & $\begin{array}{l}22 \frac{1}{4} \\
\end{array}$ & ", & " & 24, \\
\hline 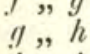 & " & $"$ & $\begin{array}{l}21 \frac{1}{4} \\
6\end{array}$ & , & , & 23, \\
\hline$h, i$ & " & $"$ & $20 \frac{1}{8}$ & ", & ", & 22, \\
\hline$i, j$ & , & ”, & $17 \frac{3}{4}$ & $"$ & $"$ & $\begin{array}{l}21 \\
19\end{array}$ \\
\hline & , & , & $16 \frac{3}{4}$ & ", & ". & 18 \\
\hline$k, l$ & , & , & $15^{\frac{3}{4}}$ & ," & , & $\begin{array}{l}10 \\
17\end{array}$ \\
\hline & $"$ & " & 15 & , & , & 16 \\
\hline
\end{tabular}

The last column gives the diameters of pipes that would be used were it considered desirable to use pipes of diameters rising an inch at a time. It is more common, in the case of waterworks, to have pipes of different sizes varying, at least in the case of pipes over 12 inches in diameter, 3 inches at a time. Thus it is common to jump from 12 inches to 15 inches, from 15 inches to 18 inches, from 18 inches to 21 inches, from 21 inches to 24 inches, and so on ; and, indeed, it is the practice in many cases, with pipes above 3 feet in diameter, to jump as much as 6 inches in diameter.

The question is merely one of expense. If the different sizes of pipe wanted do not aggregate any very great length, it may be cheaper to restrict the sizes to a few different diameters than to have small quantities of pipes of each of a number of different diameters, and this spite of the fact that, with the small number of different diameters, the aggregate weight of the pipes will be greater than with a number of different diameters. Naturally pipemakers will quote a cheaper price per ton for a quantity of pipe all of one diameter than for smaller quantities of pipes of several 
different diameters, aggregating the same length. Then there is the further necessity, when there are many different diameters, of a multiplication of bends and other special pipes, and of keeping a comparatively large number of straight pipes in reserve in case of breakage. On the other hand, the engineer should bear in mind that he has not to consider only the cost of the pipes, either at the foundry or delivered, but the cost of the pipes laid, and with unnecessarily large diameters the price of handling and laying is increased, as well as the cost price.

The writer is of opinion that, in the case of large works at least, pipes of intermediate sizes might be more freely used than they are, and he is confirmed in his opinion by a paragraph in the introduction to Messrs. Taylor's book of "Water-pipe Discharge Diagrams" (see ante, p. 181). The paragraph reads as follows :-

"With cast-iron pipes above 10 inches diameter, it is much too frequently the practice to adopt only those sizes whose diameters rise 3,4 , or 5 inches respectively, other diameters being much more rarely met with. To exemplify what is here referred to, suppose that in a certain case it was found that a main 34 inches in diameter would carry the volume required, it is probable that a main of 36 inches would be adopted, notwithstanding the fact that the latter would require over 100 tons of metal per mile more than the former."

Centres of Distribution.-In the particular case we have

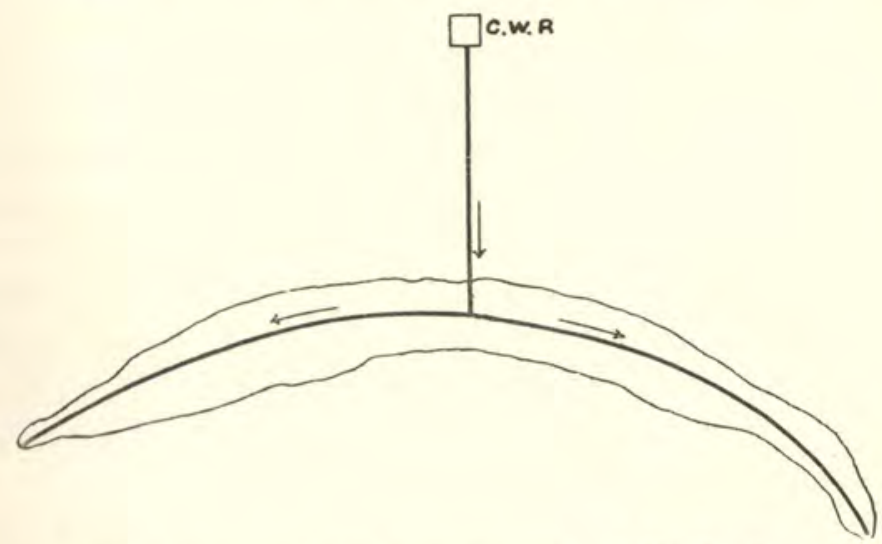

Fig. 180.-Diagram illustrating arrangement of distributing mains.

taken we have supposed that the water enters the town from outside at one end. Another common arrangement of the mains 
of distribution systems is shown in Fig. 180. By this arrangement, other things being equal, the size of mains within the town is very considerably reduced.*

In the case where there is a natural elevation in the middle of a town, suitable for the site of a clean water reservoir, an excellent distribution system is afforded. In the case of small towns it may even be worth the expense to erect an artificial elevated tank in such a position, to give an even distribution throughout the town. Edinburgh is a good example of a town with a central reservoir on a natural elevation. The reservoir is on the Castle Hill, which, as every one who has seen the "modern Athens" knows, is nearly
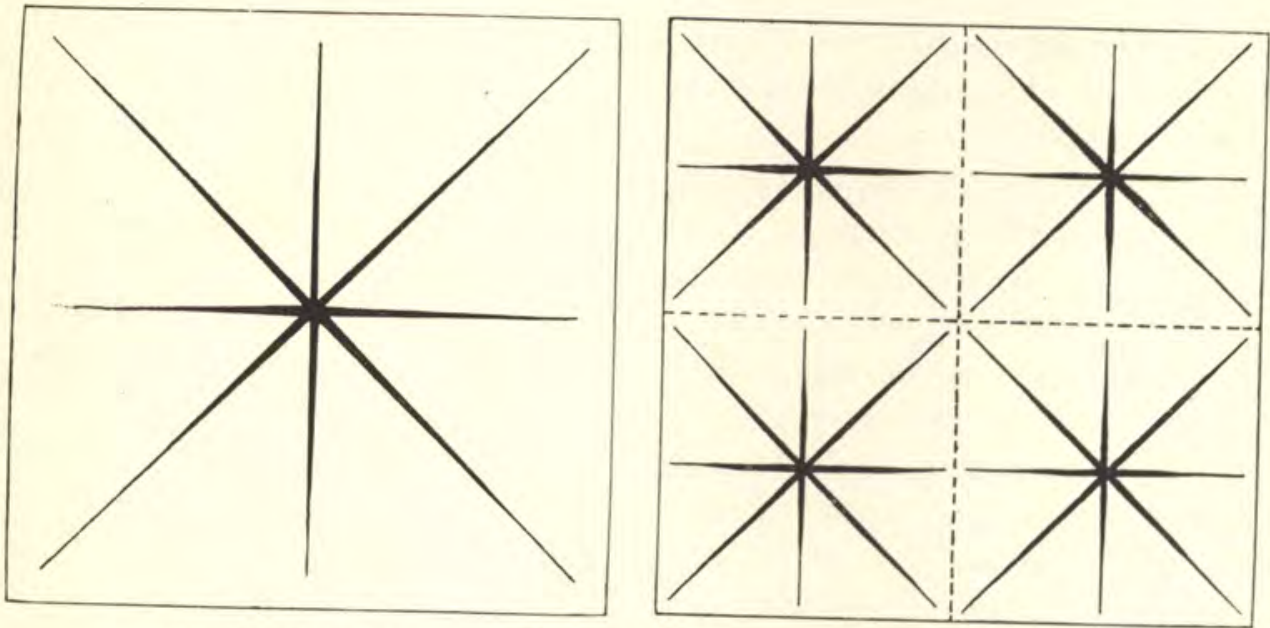

Figs. 181, 182.-Diagrams illustrating systems of centres of distribuiion.

in the middle of the town, or rather was before the town began to creep so far westwards as it recently has.

In the case of very large towns it is a great advantage to have several centres of distribution. The advantage is diagrammatically illustrated in Figs. 181 and 182

The hypothetical case of a perfectly square city is taken, and we imagine pipes in the first place radiating from one centre. It will be seen that the pipes have to taper from the extreme limits of the town to this one centre, and that they are of necessity of a very large size near the centre.

In the second case, we suppose the town divided into four districts, each with a centre of distribution. It will be seen that

* This is the arrangement proposed for the Kobe and the Shimonoseki waterworks, Japan. 
the pipes are much shorter, and a very little consideration will show that they are of much smaller size where they approach the centre of the four centres of distribution than are those pipes approaching the one single centre of distribution.

The fact is that the advantage is almost precisely the same as that gained by the use of "intercepting sewers " in the case of some sewerage systems, the advantage being commonly represented by a diagram something of the nature of Fig. 183. Here the whole large triangle represents the total weight of pipe that would be needed with one centre of distribution; the shaded part represents what would be needed with four. Of course, we do not mean to state that the unshaded portion is an actual measure of the saving that is effected in the weight of pipe. We merely mean to say that it diagrammatically represents the sort of saving to be expected.

It may be urged that with the four distribution centres, although there is a saving in the diameters of the actual distribution pipes, this is just compensated for by the fact that a greater length of pipe is necessary to the four centres from

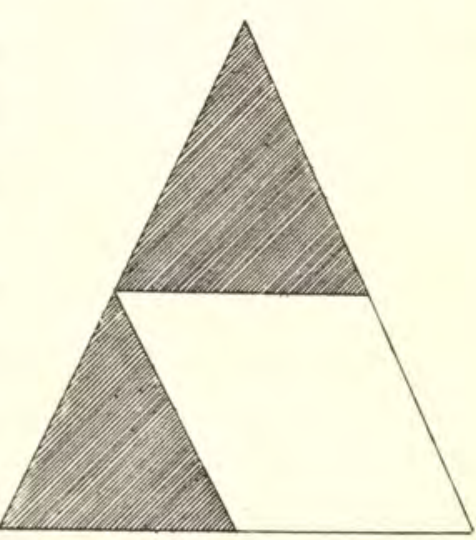

Fig. 183.-Diagram illustrating system of centres of distribution. the actual source of supply than in the case of the one centre. It will be found, however, that in nearly all cases there is an actual saving. It has to be borne in mind in this connection that the pipes to the centre or centres have to carry maximum daily consumption only, while those from the centres have to carry absolute maximum consumption.

It will be readily understood that, in cases where pumping machinery is used to pump either directly into the mains, into stand-pipes, or into elevated tanks not holding a sufficiency of water to compensate for the variation in consumption during the twenty-four hours, the pumping station or stations must be looked on as centres of distribution; and that, if it is permissible to have the station or stations within the town, it is best, other things being equal, to have one pumping station in the centre of a town of moderate size; several stations-two or more, according to the shape of the plan of the town and the size-in the case of large towns. 
Diameters of the Smaller Mains.-The first thing to be done in connection with the smaller mains is to decide on the minimum diameter of pipe to be used in the distribution system. In many cases a minimum of 3 inches has been allowed, but it is now generally agreed that this diameter is too small. It is certainly much too small in the case of pipes for waters that incline to produce incrustation quickly. A common minimum in English practice has been 4 inches. This the writer considers to be certainly the very smallest pipe that should be admitted in any distribution system ; indeed, he considers that it would be a good thing* if 5 inches were adopted as a minimum size for mains in European waterworks' distribution systems. In America it is not uncommon to have 6 inches as a minimum diameter for the pipes of distribution systems, and 8 inches has been suggested as a minimum by Fanning.

Whatever may be decided on as a minimum, the diameters of all the smaller mains should be determined entirely in consideration of their capacity to supply full streams of water at all the hydrants likely to be called upon for use at the same time.

To state this is simple enough, but two difficulties are met with at once. In the first place, At what particular diameters do the smaller mains begin? Secondly, How is it possible to tell what number of hydrants are likely to be called into use at one time?

So far as the first question is concerned, we have some data for answering it--namely, the allowance of water for fire extinction. We took that at 200 cubic feet per second as a minimum. We may, then, say that smaller mains are those that supply less than 200 cubic feet per second with the hydraulic gradient allowed in working. But in this connection it must be borne in mind that if the interlacing system be adopted most or all of the smaller mains will be supplied from both ends. Mains open at both ends will, then, come under the heading of smaller mains only when they are capable of supplying less than 100 cubic feet from each end. Thus, in the case illustrated in Fig. 179, with the data we assumed, it will be found that all mains supplied from one end only, under 16 inchest in diameter, will rank as smaller

* It is useful to remember, in this connection, that a 4 -inch pipe carries considerably more than twice as much water, with the same head, as a 3 -inch pipe, and a 5-inch pipe more than four times as much; a 6 -inch pipe carries not very much less than six times as much.

$\dagger$ A diameter of sixteen inches gives barely one inch allowance for incrustation; but it is only in the case of pipes of considerable diameter that it is considered essential to allow a full inch for incrustation. 
mains; those supplied from two ends, under 12 inches diameter, will be so classed.

As to how to come to any conclusion as to what number of hydrants are likely to be called into use at one time, it is not possible to say much more than that this is a matter of judgment, and that, as in nearly all engineering cases where judgment has to be relied on, it is right to make sure that any error there may be is on the safe side.

The first thing is to locate all the fire hydrants. Of this more is said in the next chapter. The next thing is simply to judge, to the best of one's ability, as the plotting down of the distribution pipes goes on, what number of these hydrants are likely ever to be called on at one time, on the occurrence of fires in any part of the district, and to proportion the pipes to be able to supply all these hydrants.

The following table is a modification of one given by Fanning. It is intended for European use, * and may be handy in determining the diameters to be given to the smaller mains:-

\begin{tabular}{|c|c|c|}
\hline No. of fire-hose. & $\begin{array}{c}\text { Diameter of mains if } \\
\text { supplied at one end. }\end{array}$ & $\begin{array}{c}\text { ciameter of mains if } \\
\text { supplied at both ends. }\end{array}$ \\
\cline { 2 - 3 } & $4^{\prime \prime}$ & $4^{\prime \prime}$ \\
\hline 1 & $5^{\prime \prime}$ & $4^{\prime \prime}$ \\
2 & $6^{\prime \prime}$ & $5^{\prime \prime}$ \\
4 & 8 & 6 \\
5 & 9 & 7 \\
6 & 9 & 7 \\
7 & 10 & 7 \\
8 & 10 & 8 \\
9 & 11 & 8 \\
10 & 12 & 9 \\
12 & 14 & 10 \\
\hline
\end{tabular}

A Japanese Distribution System.-In conclusion to this somewhat long chapter, we give a short description of the distribution system of the waterworks of Tokyo, the capital of Japan, in progress at the time of writing. Present population 1,200,000.

Plate XXXVIII. (Fig. 184) shows the great mains of the

* In Japan the houses are small (seldom more than two stories high), and of light construction ; and although fires happen very often, it is considered likely that a number of nozzles of moderate diameters will probably be more useful in the case of fire extinction than several of the very large diameters sometimes used in Europe, and more commonly in America. The diameters of the smaller mains need, therefore, not be more than about three-quarters of those given in the tables for given number of hydrants. 
whole system. The town is roughly divided into a plain and a plateau, shown separated by a dotted line, and there are the three distribution centres, marked on the plan A в and c.

The height of the water above sea level in the high-level reservoir at Yodobashi, marked $\mathrm{A}$, is 124 feet. This height is not sufficient to supply the plateau by gravitation, but is high enough to supply the service reservoirs at Hongo and Shiba, marked respectively $\mathrm{C}$ and $\mathrm{B}$. At $\mathrm{A}$ the water is pumped up to a head of 116 feet, to supply the plateau.

The level of high water in the reservoirs at Shiba and Hongo-. that is to say, B and c, is 90 feet. There are pumping stations at each of these places, and the pumps will pump against a head corresponding to 75 feet.

The distribution system for the plateau is more or less radial. That for the plain consists mainly in two large loop pipes, joining the two reservoirs at $\mathrm{B}$ and $\mathrm{c}$. These loops are marked $\mathrm{B}$ a $\mathrm{c}$, and в b с c, respectively.

The pipes from $\mathrm{A}$ to $\mathrm{B}$ and $\mathrm{c}$, and the main pipe of the distribution system for the plateau, are each 42 inches diameter. Each of the great loops, also, begins with a diameter of 42 inches, but is reduced down to 20 inches at the middle.

Plate XXXIX. (Fig. 185) shows a part of the distribution system. A part is selected that is somewhat thinly populated, but in which the streets are very irregularly arranged, so that a system of thorough reticulation is remarkably difficult to work out.

The attempt has been made to so arrange the pipes and sluice valves that it may never be necessary to shut more than four valves to isolate any part of the system, whilst, as a rule, any pipe can be isolated by closing three, or only two, sluice valves. It is certainly not possible to tell exactly, on this map, from the thicknesses of the lines only, the diameters of the mains, but a fair idea can be got; and as, in any case, the diameters would not apply to European or American practice, it is not necessary that they should be exactly known. 
Plate XXXVIII.

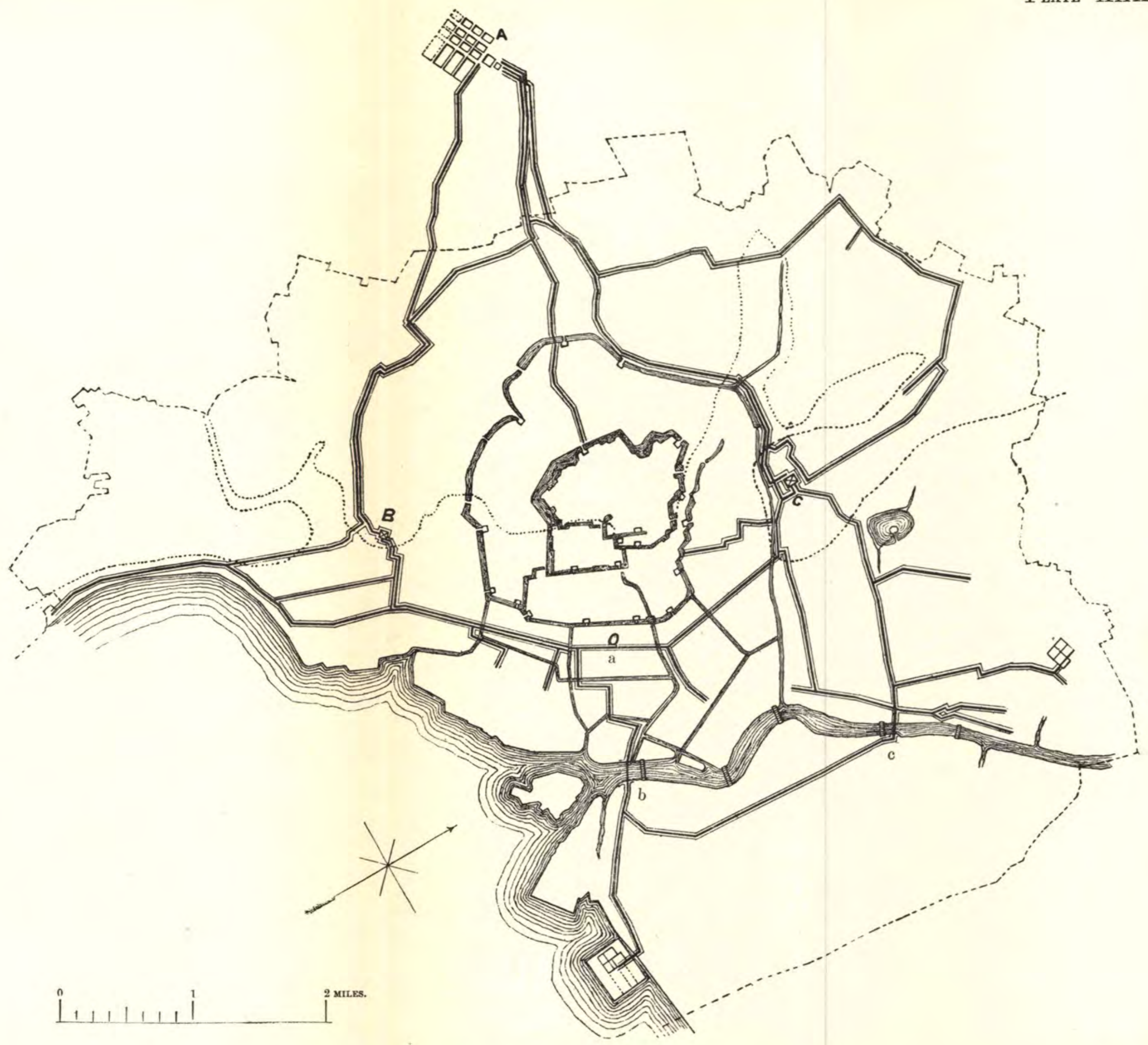

Fig. 184.-Waterworks of Tokyo: Distribution System.

[To foce page 204. 
(1) District Meters.

o Fire Hydrants.

* Sluice Valves.
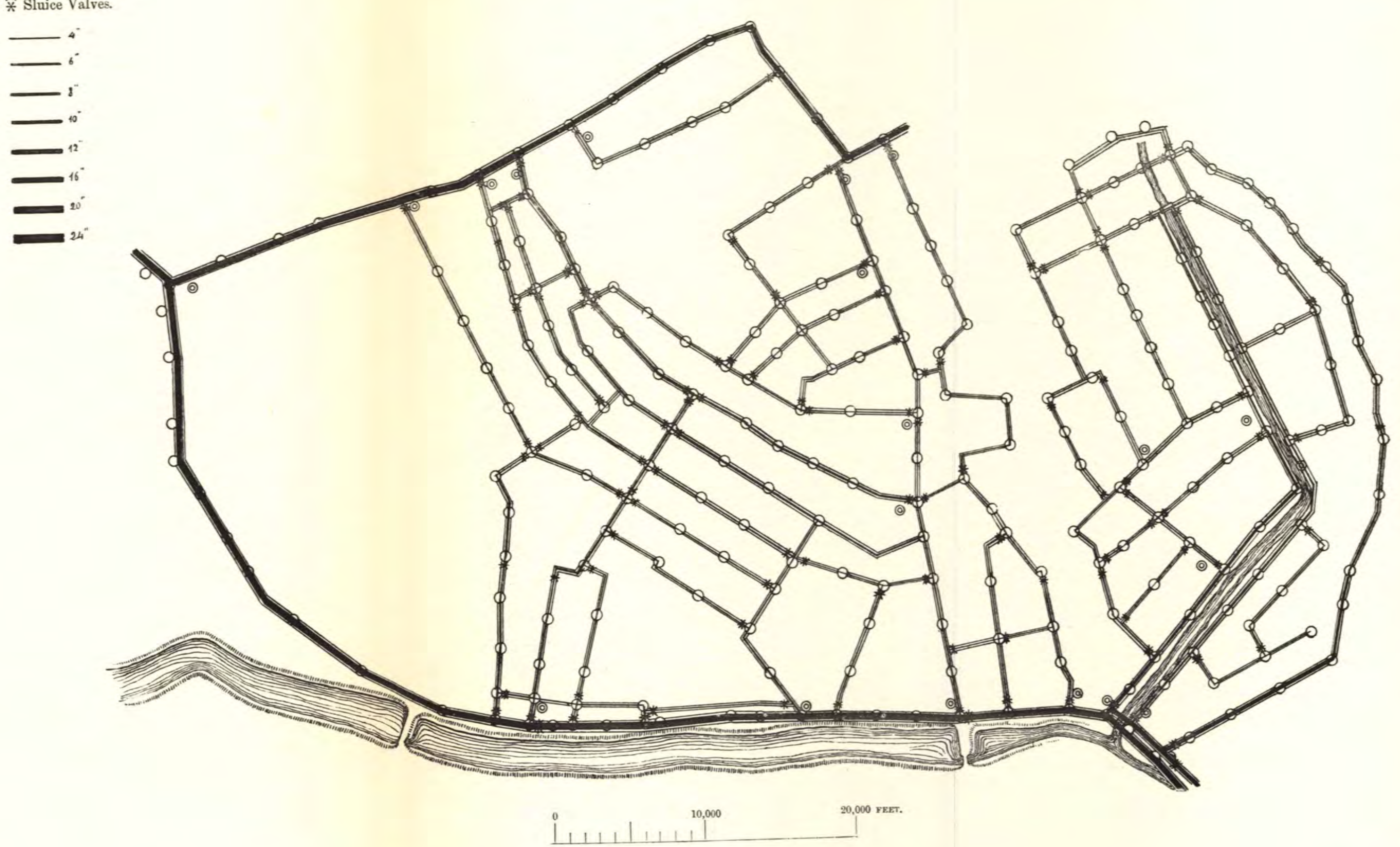

Fig. 185.-Waterworks of Tokyo: Part of Distribution System in detall. 


\section{CHAPTER XIX.}

Special Provisions for the Extinction of Fire.

A Goov deal has been said in the last chapter about providing mains amply large enough to supply all hydrants that are likely to be wanted in action at the same time, but it is necessary to say something more about the special precautions that should be taken to provide for fire extinction.

Extra Storage for Fire Extinction.- Mention has already been made of the necessity for making a provision, in the way of special storage, for fire extinction. At first sight, it might seem that the problem is nearly the same as that of providing a certain rate of discharge in mains for fire extinction, but it is really different.

It is true that, up to a certain point, a fire is likely to need as much water for extinction in the case of a small as of a large town, but there is a point beyond which a conflagration in a large town is likely to need more water than in a small. In the case of most large towns, it will generally be found that this is provided for, in the method of working out such distribution systems as we have described, for as a fire spreads in a large town there will soon, as a rule, be water available from more than one main, or even from more than one centre of distribution.

Further than this it is to be observed that a fire is likely to last for a longer time in a large than in a small town. It thus appears that, whereas so far as the provision in the matter of carrying power of mains is concerned, the amount may, for individual mains, be nearly constant for all towns above a certain very moderate size, the quantity of water stored as a precaution against fires must increase with the size of the town. On the other hand, it must be evident that this storage capacity, specially provided, does not need to increase proportionately with the size of the town as measured by population. 
It is difficult, probably impossible, to state just what storage capacity should be specially provided for fire extinction, in the case of a town of any particular size. It is therefore with much diffidence that the author suggests the following formula as fairly representing the minimum storage capacity that should be provided for fire extinction alone. He has arrived at it by observations and reasoning that it would take too long to discuss here, and that would probably be of no particular interest to the reader, the more especially as, at best, there has nowhere been more than approximation :-

when

$$
Q=200 \sqrt{P}
$$

$\mathrm{Q}=$ the minimum quantity of water, in cubic feet, to be stored for the special $\mathrm{P}=$ the population.

As has already been stated, this storage capacity may either be provided in the clean water reservoir, or in the settling reservoir or the impounding reservoir. In either of the two lastmentioned cases, a by-pass is provided, to be opened in the case of fire, so that the water shall not have to pass through the filterbeds.

It is evident that there are certain advantages in having the necessary reserve in the clean water reservoir. If the reserve is there, it is ready for instant use, without the opening of any by-pass valves, and, moreover, the objectionable practice of allowing unfiltered water to enter the mains is avoided. On the other hand, there is the objection that keeping the reserve mentioned involves storing a comparatively large quantity of water in the clean water reservoir, and we have seen that this is not advisable, as the water, kept stagnant for a considerable time after filtration, is liable to deteriorate. Measured in days' consumption, the necessary storage is much greater in the case of small towns than in that of large. Thus, in the case of a town of 10,000 inhabitants, it would be necessary to have a storage capacity equivalent to sixteen hours' mean supply to provide for fire extinction only. In the case of a city with a population of $1,000,000$, on the other hand, it would be necessary to keep a reserve corresponding to less than two hours' mean consumption.

Reserve of Pumping Power for Fire Extinction.-It is evident that, where pumping engines pump into clean water 
reservoirs, if these reservoirs be made large enough to hold the water that it is desirable to have in reserve in case of fires, as well as that necessary to compensate for variation in consumption during the twenty-four hours, there need be no special provision in the pumping machinery. True, the reservoir may be empty at the end of a fire, and will have to be filled up again, but this need only be done slowly, and pumping machinery will always work a little above its normal capacity, although generally at a sacrifice of efficiency. Moreover, the stand-by power may be brought into requisition in an emergency, although it is inadvisable so to use it.

In all cases where the nec cssary reserve for fire is not provided for in the elevated reservoir or tank, the engines ought evidently to be able to do additional pumping work corresponding to the quantity of water that may be needed for fire extinction. A minimum provision of 200 cubic feet per minute has been suggested, and there is no doubt that, in the case of all considerable towns, there ought to be engine power capable of pumping this quantity of water in addition to what is needed for maximum rate of consumption on ordinary occasions. This means an additional pumping power of nearly forty actual horse-power-that is to say, horse-power measured by the water actually pumped-per 100 feet of head against which the pumping is done ; and, strictly speaking, this ought to be provided in addition to the "stand-by." It is not very often, so far as the writer knows, that such a provision is made in practice. It is common to rely on the "stand-by" for the emergency of a fire, although, as has been said, the principle is not a good one, because one of the very reasons for having a eertain quantity of stand-by power is that one of the pumping engines may break down at any time, at the time of a fire, of course, as well as at any other time.

Sometimes delivery of water for the extinction of fire is provided for by specifying that, whilst the engines shall be eapable of delivering the normal quantity of water, whilst developing a certain "duty," they shall be capable of delivering a certain percentage more, say 20 per cent., regardless of efficiency - or at least without any specially-stated efficiency - as regards coal consumption.

There is no great objection to this arrangement, but that it is necessary to be very careful in providing ample boiler. reserve in such a case, for it must be borne in mind that, if the engines be run at a speed, say 20 per cent. in excess of the normal speed, it 
will be necessary to increase the steaming by more than 20 per cent., because the engines will probably not work as economically as at their normal rate.

In any case, however much spare boiler power has to be provided, there is always the trouble, in connection with pumping systems without a reserve of pumped water, that a sudden demand for an increased supply of water involves a sudden increase in steam, whereas it takes some time to increase the steaming of a set of boilers by bringing additional boilers into work. In this connection, it is worth remembering that steam can be got up much more rapidly in boilers of the marine or locomotive or of the "tubulous" or "water tube" kind, than in boilers of the Lancashire or Cornish type that hold a great mass of water that has to be heated.

Spacing and Position of Hydrants.--It is not easy to say anything very definite about the spacing of hydrants, farther than that the more there are the better, which of course means that the closer they are spaced the better. The question of expense is the only limiting quantity. The actual cost of hydrants themselves forms no small item in the price of waterworks, and there is no use in scattering hydrants thickly, unless the mains are of size enough to supply all that may be in the proximity of any building that may catch fire. It will be evident that the more dense the population and the more valuable the property the greater is the reason for thickly scattered hydrants.

Perhaps it may be said that, in thickly populated parts of cities, particularly in business centres, the spacing of hydrants should not be over 100 yards, though it may be less, and that it should be not more than 150 yards at any part of a city.

As to the position of hydrants, it is evident that there is a distinct advantage in a street-crossing as a position, for a hydrant there commands any one of two, three, four, or even more streets, without the necessity of bending the hose round a corner, and is in a position where the man actuating it can always see the site of conflagration. It is recommended, then, that a hydrant should be placed at every street-crossing, and that there be an intermediate hydrant wherever street-crossings are more than 150 yards apart.

Mr. Freeman, already mentioned (p. 190) as an authority on this subject, strongly recommends that the positions of hydrants be decided on the spot, rather than on a plan of the town, and there is much to be said for this. It is also advisable for the engineer to 
consult the Fire Brigade authorities, rather than to rely on his own judgment alone. The writer, indeed, in working out a distribution system, considers it most satisfactory to hand a clean map of the town to the Fire Brigade authorities, and to ask them to locate the hydrants. The mains, up to a certain limit of size, are then worked out solely with a view to supply these hydrants, and it is still possible to modify the proposed positions to a very considerable extent on the ground afterwards, and yet have a sufficient supply for all hydrants.

Form and Size of Hydrants.-One has only to look over the pages of any of the large catalogues of makers of waterworks appliances to see how many different forms of hydrant have been invented, and to be struck with the idea that some of them must have been invented surely rather for the sake of producing something new, and perhaps patentable, than on account of any really useful novel feature.

The requirements of a good fire-hydrant may be stated as follows:-(1) It must not be liable to get out of order, either by leaking, sticking, or in any other way. (2) It must allow a full and unobstructed flow of water on opening the valve. (3) It must be of such form that hose may be connected with it with the least possible trouble. (4) In countries where the frosts of winter are severe, it must be so constructed that it is not liable to freeze up. (5) The cost must be moderate, as the providing of fire-hydrants constitutes a considerable item in the first cost of waterworks.

Hydrants may be divided into two classes, pillar hydrants and sunk hydrants. Pillar

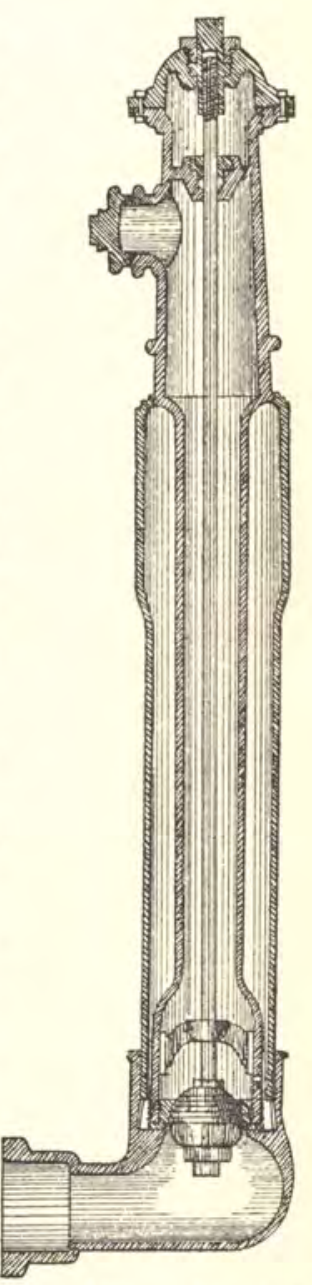

Fig. 188. - American form of pillar hydrant (Fanning). hydrants stand several feet above the street level, and are commonly fixed on the outside of the side-walk. Plate XL. (Figs. 186, 187) illustrates a form not uncommon in England. Fig. 188 (from Fanning) shows an American form of pillar hydrant.

The pillar hydrant has the advantage that it is a conspicuous object, and that the fire-hose can be attached to it without the 
intervention of a stand-pipe. It is, however, not commonly used except in towns of comparatively small size, presumably because it is considered that it would interfere with the traffic too much. It is, however, difficult to see how, placed on the outside of the footway, it should do so. It has, undoubtedly, the disadvantage of being more expensive than a sunk hydrant.

Sunk hydrants are fixed entirely below the level of the street, access being got to them by opening a small hinged door, and a short stand-pipe, generally of copper, has to be fixed to the hydrant,

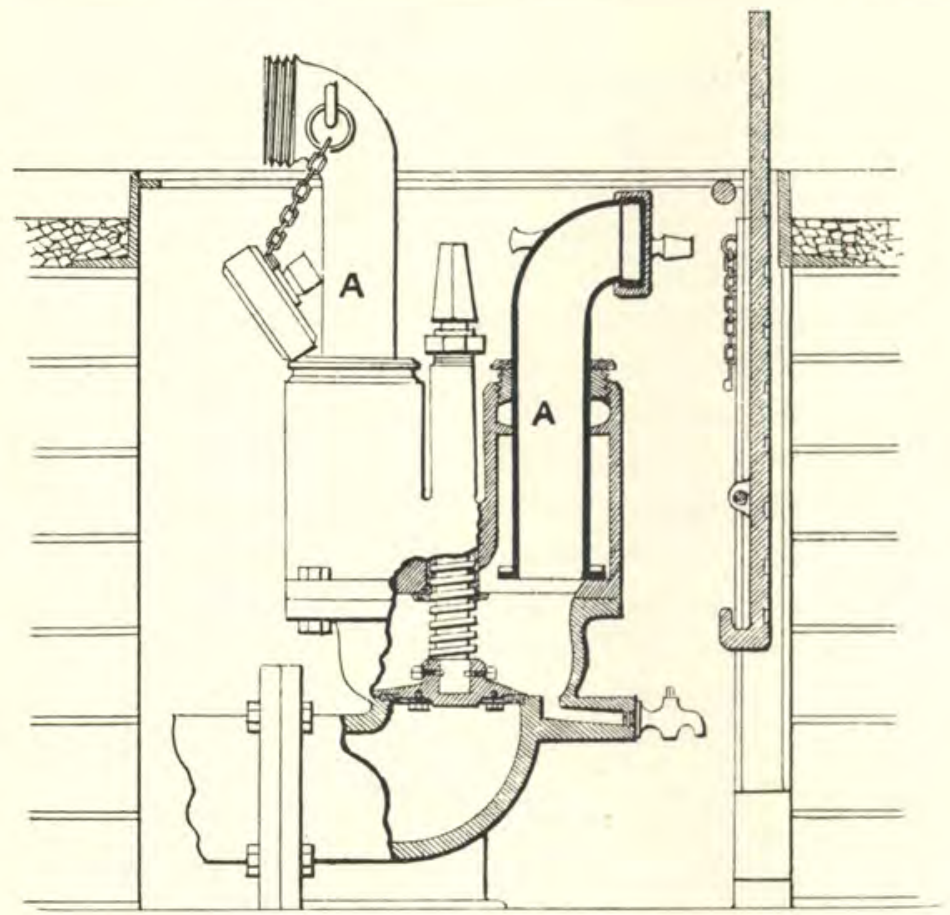

Fig. 189.-Merryweather's hydrant.

either by a screw or a bayonet joint, or a combination of both, for screwing the fire-hose to at the time of a fire. Here at once comes one of the inconveniences of sunk hydrants. At times the castiron cover is sure to be covered with mud or snow, and, in the hurry that there is at the time of a fire, especially at night time, there is often delay in finding the door and in opening it, even if its position be well marked. In every case the position of a sunk hydrant should be distinctly marked by conspicuous letters on the nearest wall, and it must be admitted that such letters are not always ornamental.

Fig. 189 illustrates an ingenious hydrant patented by Messrs. 
Plate XL.

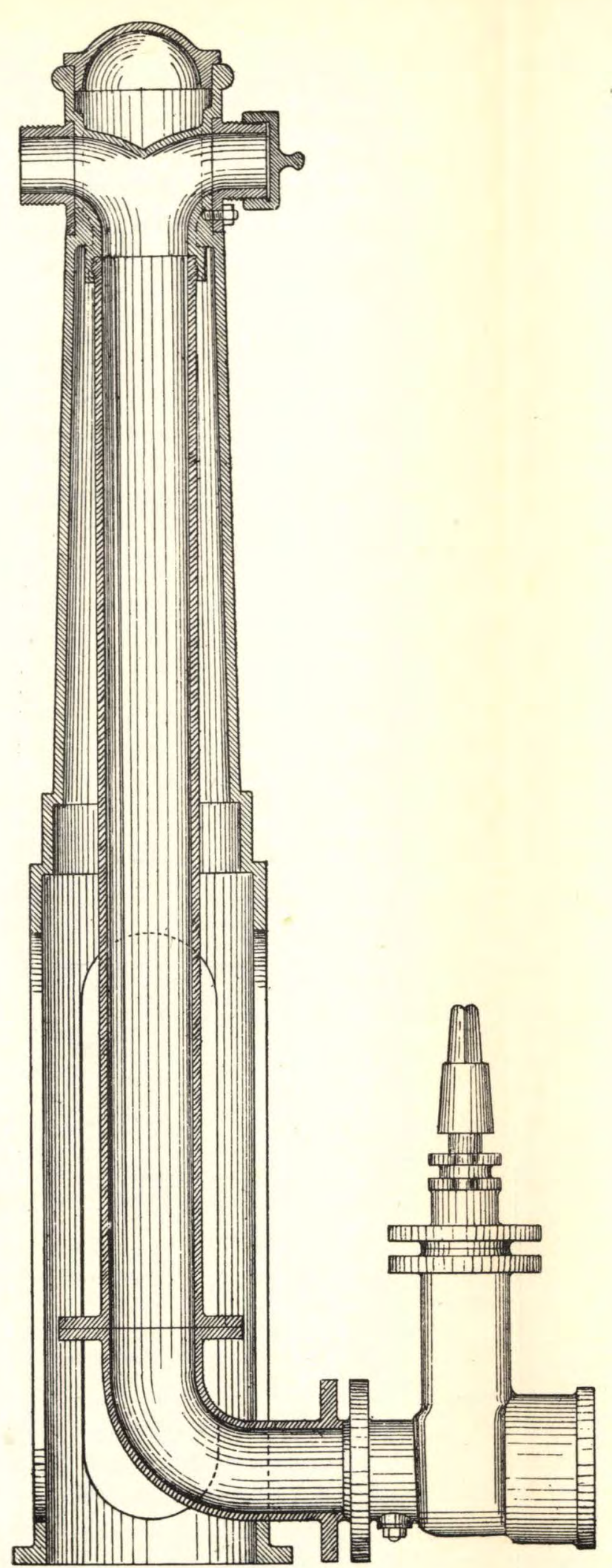

Fig. 186.

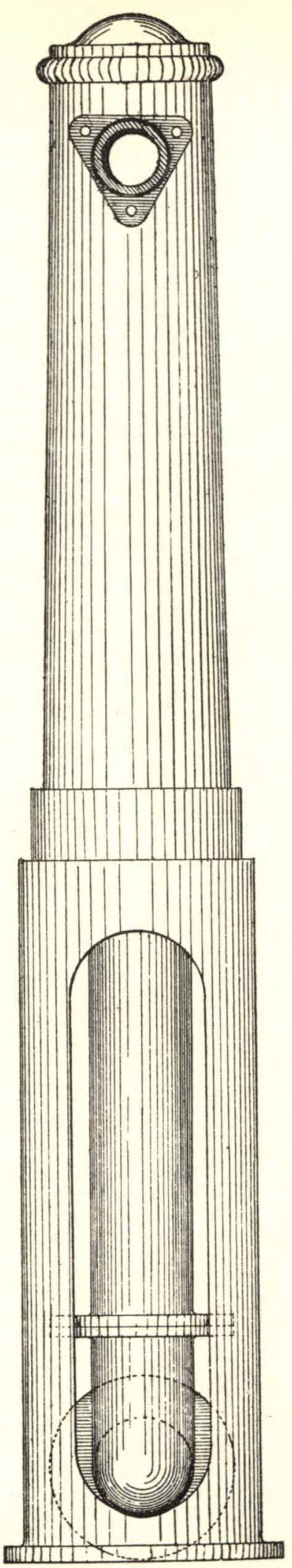

Fig. 187.

Pillar Hydrant (English Form).

[To face page 210. 
Merryweather and Sons, that possesses many of the advantages of both the pillar and the sunk hydrant. The tubes A, A are telescopic. When the hydrant is not wanted for use they are both in the position shown on the right - that is to say, they are under the street level. They can, however, be raised into the position shown on the

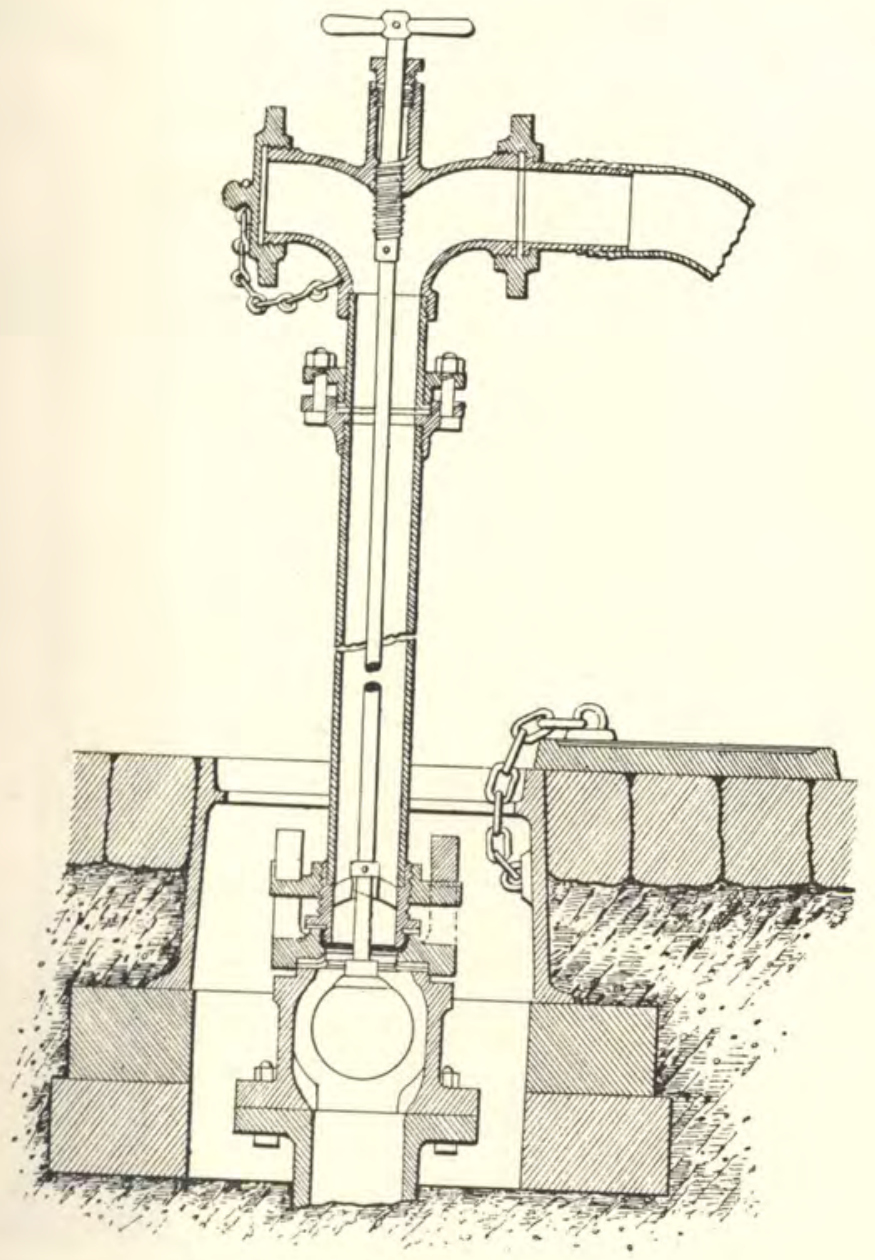

Fig. 190.-Ball hydrant and stand-pipe.

left, either by hand, or by opening the screw-down valve a little before the brass caps are removed.

This hydrant, as will be seen, gives a free water-way of considerable diameter, and does not exhibit the common absurdity of having two $2 \frac{1}{2}$-inch unions on one $2 \frac{1}{2}$-inch branch or stand-pipe. The only present objection to this form of hydrant is its high cost.

Besides classifying hydrants as pillar hydrants and surk 
hydrants, they may be divided into ball hydrants, sluice-valve hydrants, and screw-down hydrants.

Ball hydrant.-This is the simplest form of hydrant there is. It is illustrated, along with the stand-pipe that has to be used with it, in Fig. 190. The action is very simple. The stand-pipe is fixed
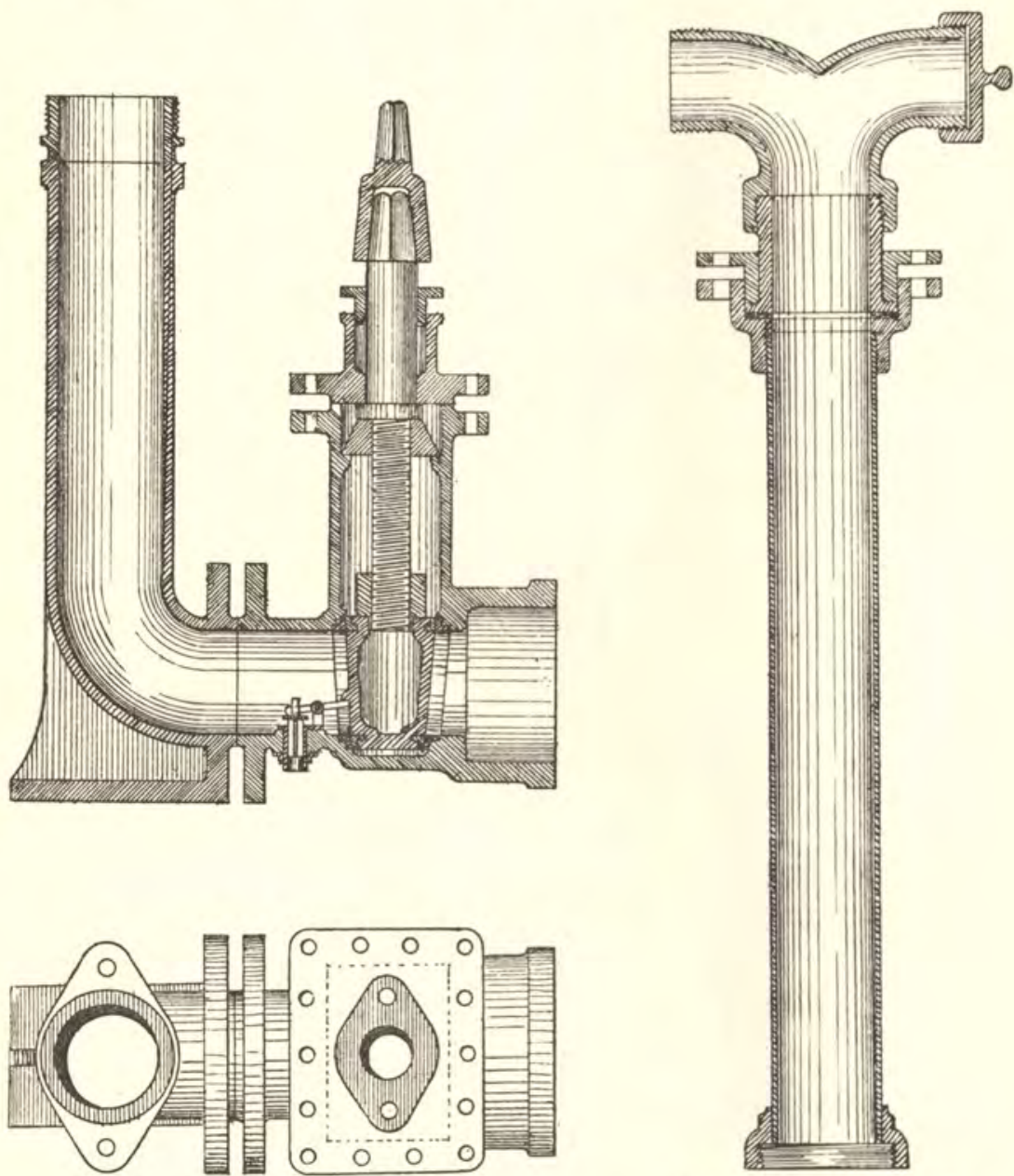

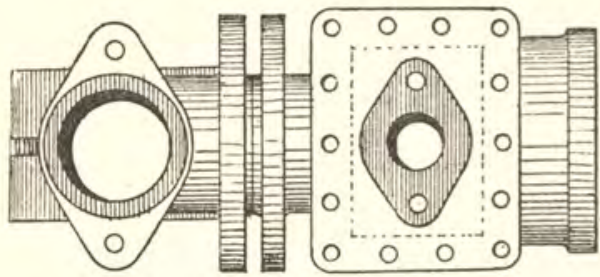

Figs. 191, 192.-Sluice-valve hydrant.
Fig. 193.-Stand-pipe for sluice-valve hydrant.

over the hydrant by allowing two projections on the bottom part of the stand-post to catch under the two lugs of the hydrant, and screwing the stand-pipe home, so that a watertight joint is made between it and the hydrant. To open the ball valve, the central spindle of the stand-pipe is screwed down, so as to push the ball from its seat.

Ball hydrants are more liable to leakage than those of other 
forms. Dirt is liable to lodge between the ball and the seat, and, in the case of very heavy pressures, the rubber-covered ball is liable to become distorted, or grooved, in form. Nevertheless considerations of economy often lead to the use of such hydrants, and, indeed, for moderate pressures-say equivalent to 100 , or at the very most 150 feet head - they appear to be fairly satisfactory.

A sluice-valve hydrant is illustrated in Figs. 191, 192 . It

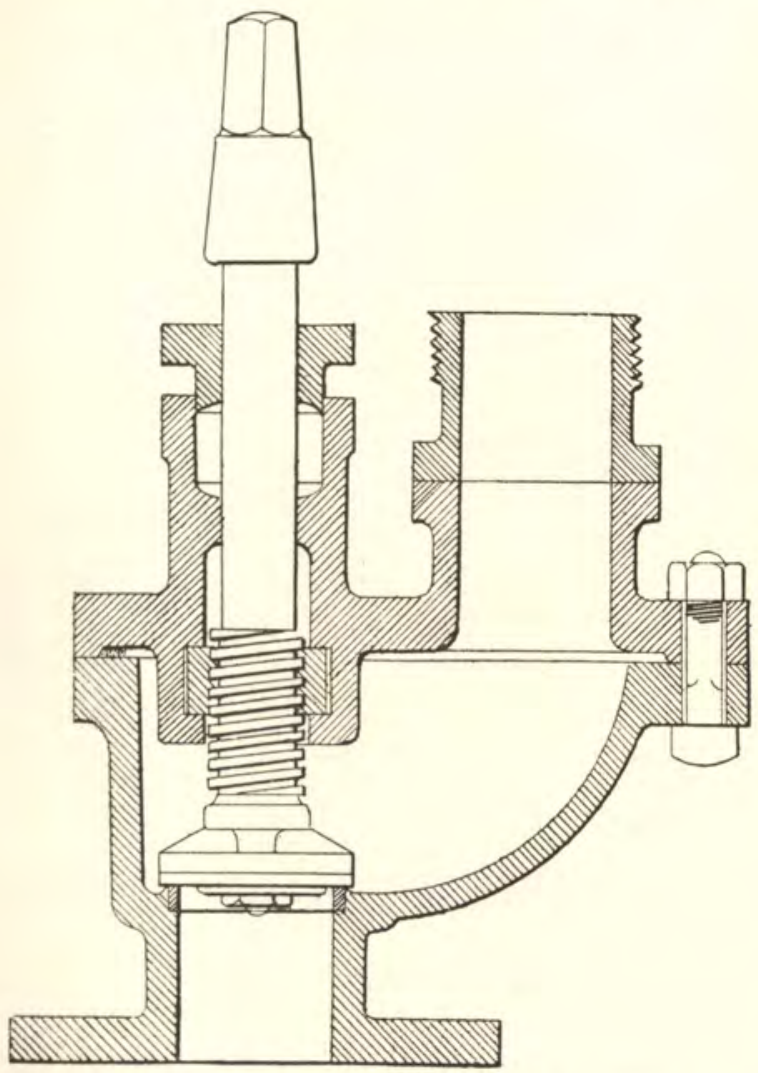

Fig. 194.-Screw-down hydrant (first example).

scarcely needs any explanation. This form of valve may almost be said to be the standard in England, where filtered water only is used. It is not suitable for use with any water that is not filtered, as the slightest grit is liable to corrugate the face of the sluice-valve, after which it will no longer be absolutely watertight, and the slightest leakage in a fire-hydrant is the greatest nuisance, especially at times of frost, even if only mild frost.

Fig. 193 shows the form of stand-pipe used with this hydrant for the fixing of hose pipes. 
There is great variety in the design of screw-down hydrants. Figs. 194, 195 show two good forms. They need no particular explanation.

In America screw-down hydrants are more commonly used than sluice-valve hydrants, and, moreover, whereas in England, where screw-down hydrants are used, the valves may work "brass to brass," in America the valves are always made of "sole

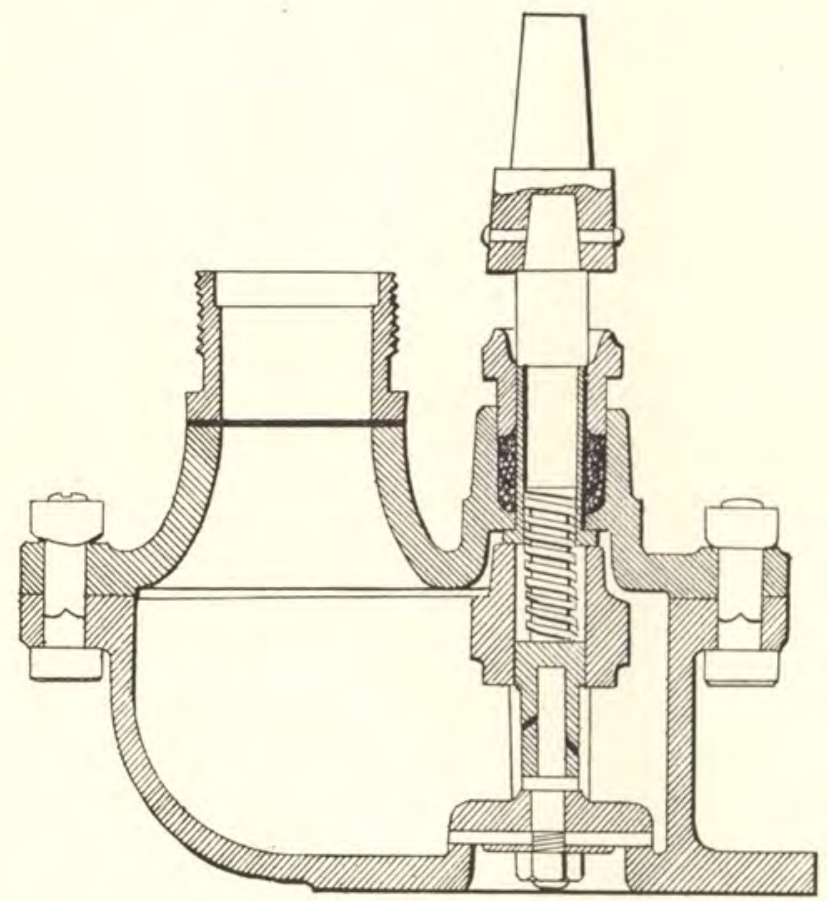

Fig. 195.-Screw-down hydrant (second example).

leather " or india-rubber, seating in brass. This appears to be on account of the prevalent use of unfiltered water in America.

Figs. 196, 197 (from Fanning) illustrate a form of American sunk hydrant that has several features to recommend it. In the first place it is intended to be fixed at the crossing or junction of two pipes in an "interlacing" system, so that it will get the full benefit of the flow of water from three or four different directions. The upper piece is portable, being made of brass, as light as is consistent with standing the pressure of the water. This is screwed to the lower casting if the hydrants have to be brought into action. It will be seen that there is a centre spindle controlling the main screw-down valve, and that there are smaller spindles, 
each controlling a sluice-valve closing one of the nozzles for the attachment of a hose pipe. There may be two, three, or four of these nozzles.
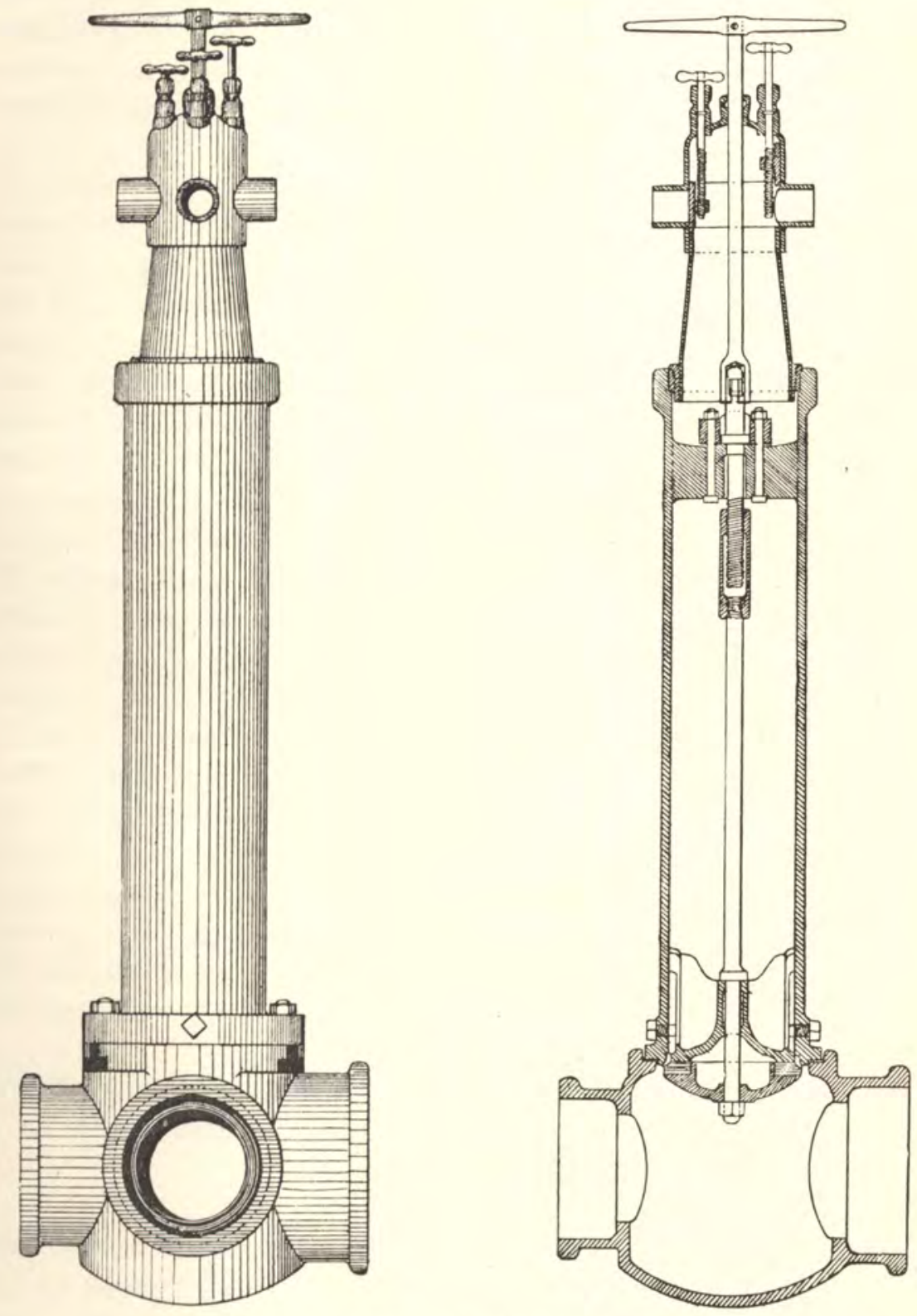

Figs. 19(i, 197.-Sunk hydrant: American form (Fanning).

Size of Fire Hydrants.-The commonest size of fire hydrants until recent years was $2 \frac{1}{2}$ inches internal diameter-and 
it is still only too common, in England at any rate, to adopt hydrants of this small size-that is to say, there was a clear internal space of that diameter throughout the hydrant.

Such hydrants will give a fair jet from one fire nozzle 1 inch in diameter, or even perhaps $1 \frac{1}{8}$ inch diameter, or two jets from fire nozzles $\frac{5}{5}$ or even $\frac{3}{4}$ inch in diameter, and these latter sizes used to be considered, and unfortunately still are considered, large enough for jets worked off the main.

At the present time, however, the tendency, especially in America, is to use larger and larger nozzles. 'The limit to the size of nozzle that can be used is the diameter of the hose, and that is limited by the facility of handling it. The common diameter of hose pipe is $2 \frac{1}{2}$ inches in diameter. In America 3-inch hose has been tried, but has been found very troublesome in handling. $2 \frac{3}{4}$ inches diameter has been suggested as a compromise, but the writer is not aware that hose of this diameter has come into general use anywhere. $2 \frac{1}{2}$ inches may, therefore, be taken as the standard diameter for hose pipes. Such hose will throw a good stream from a nozzle 1 inch in diameter; a fair jet from a nozzle $1 \frac{1}{8}$ inch diameter; and a poor one from a nozzle $1 \frac{1}{4}$ inch diameter, assuming a length of hose pipe that ought to be the maximum used in case of fire.

The commonest number of hose to work from one hydrant is, in England at least, two. With a hydrant $3 \frac{1}{2}$ inches diameter, two nozzles of a diameter of $\frac{7}{8}$ inch, or 1 inch, will give good jets ; with $1 \frac{1}{8}$ inch will give fair jets; and even with $1 \frac{1}{4}$ inch will give some sort of a jet. $3 \frac{1}{2}$ inches is, therefore, suggested as a minimum standard diameter. Larger sizes may be used for a greater number of streams, as 4 inches for three streams, $4 \frac{1}{2}$ inches for four streams. Even larger sizes than this last mentioned are often used in America.

Where a $3 \frac{1}{2}$-inch hydrant is used, it is recommended that it be fitted with a 4 -inch socket, and that the pipe supplying it be at least 4 inches in diameter.

Prevention of Freezing in Hydrants.-In countries where the winters are excessively cold-as, for example, in the Northern States of America-hydrants, at any rate pillar hydrants, have to be fitted with "frost cases" to prevent them from freezing hard. In climates such as that of England this is not necessary. In the case even of a pillar hydrant, there is no danger of freezing whilst even a small stream is passing through 
the hydrant. Freezing would, however, be liable to take place were the hydrant to remain for any length of time with the central tube full of water. The tube would naturally remain full of water after use, unless there were some special provision for emptying it.

In a climate such as that of England, water even a foot or so below the street level does not freeze in an ordinary winter, so that it is seldom that a sunk hydrant freezes, even if the water be allowed to remain in the bend and short upward piece of pipe belonging to it. There are winters, however, when even sunk hydrants will freeze if the water be allowed to remain in them. For this reason it is advisable to provide some drainage arrangement even for such hydrants. Very often this is merely a small valve or cock, to be opened by hand when the main valve has been closed. There is always a great chance that the draining in this way by hand may be forgotten, and an automatic arrangement is for this reason often introduced.

Such an arrangement is shown in Figs. 191, 192 (p. 212). There it is shown as applied to a sunk hydrant, but it is manifest that it would suit a pillar hydrant equally well. The means of adapting this principle to screw-down hydrants, as well as to sluice-valve hydrants, will suggest themselves to every engineer. In the particular case illustrated the closing of a sluice-valve opens a small "clack" valve, which allows the water to drain away. The opening of the sluice-valve closes the clack valve again. 


\section{CHAPTER XX.}

\section{Pipes for Waterworks.}

Material for Pipes.-In many countries the first material that has been used for pipes has been wood. The pipes have been made either by hollowing out the trunks of trees, or by building up of staves or planks. Recently in America there has been a return for certain purposes to the use of pipes built up of wooden staves, these staves being bound together by iron hoops.

In Eastern countries bamboos are largely used as water-pipes of small diameters. The partitions at the joints or nodes are knocked out with an iron tool, and a light convenient pipe that is capable of resisting some little internal pressure results.

The first improvement on wood as a material for pipes seems, in Britain at any rate, to have consisted in the use of lead, the pipes being either cast as pipes, or being made out of the sheet lead, which itself was cast until a comparatively recent date.

The standard material for pipes used for waterworks at the present time may undoubtedly be said to be cast-iron. Here we are referring to pipe conduits, and to the mains and sub-mains of distribution systems, not to house-service pipes, which are still principally made of lead. Cast-iron is much more perishable than lead, but it is very much cheaper and stronger. Moreover, it has probably a longer life, if properly treated, than any other metal that is really practicable for extensive use in making pipes of any size for waterworks.

Of late years wrought-iron and steel riveted pipes have been used to a very considerable extent. In the case of large sizes they have distinct advantages in respect of their lightness, on account of which they are easily handled. It is no trifling matter at all to handle cast-iron pipes of diameters of 3 feet and upwards.

In America, and also in France, what may be called " composite pipes" have been used to some extent. These consist of a shell of wrought-iron or steel, stiffened with a lining of cement, 
either inside or both inside and outside. The idea is to gain some of the lightness of wrought-iron or steel pipes, with some of the stiffness of cast-iron pipes, and also to avoid the likelihood of rusting.

The use of stoneware or fireclay pipes has already been mentioned in the chapter on the Flow of Water in Pipes and Conduits.

Cast-iron Pipes.-These pipes are of two different kinds, according to the nature of the joint used to connect one with the other. There are flanged joints and spiggot and faucet (or spiggot and socket) joints.

The flanged joint is illustrated here (Figs. 198,199). It is made
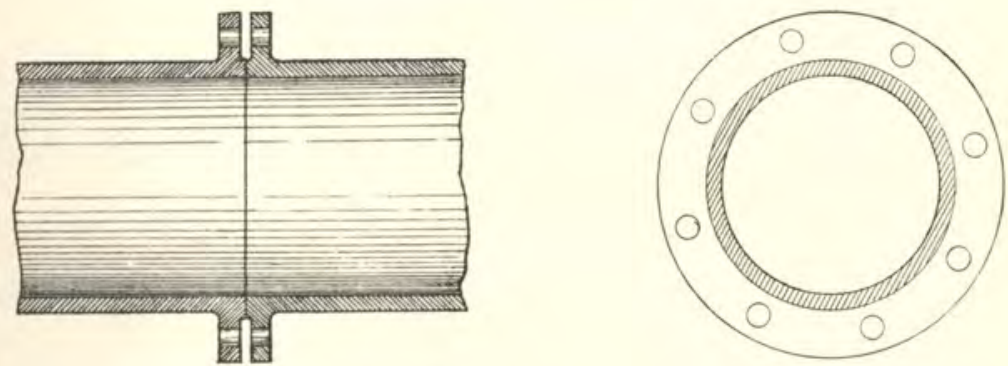

Figs. 198, 199.-Flanged joint for water pipes.

watertight by covering the face of the flange with red-lead putty (made by working up white lead in linseed oil with dry red lead), imbedding a piece of string for two or three turns, and screwing up; or by screwing up on a ring of gutta-percha or lead or soft copper wire. A rubber ring will also serve between the flanges. Flanged joints are used extensively in connection with waterworks for connecting pipes with valves and other special fittings. They are to be preferred in any case where it is likely that it may be necessary to break the joint at any time. A flanged joint can be taken apart and remade much more readily than a spiggot and socket joint. Flanged joints are not used on long lengths of straight pipes, because, for one thing (for no reason that is very evident), they are considerably dearer than socket pipes. The main objection to their use is, however, that they do not allow in any way for the contraction and expansion that take place in every long pipe on account of change in temperature. There is a further objection to them when they have to be shipped, that they do not pack so well as socket pipes. 
Spiggot and socket pipes again are divided into two kinds-namely, those with turned and bored joints, and those with joints to be run with lead. In the case of turned and bored joints the pipes are metal to metal, the turned spiggot fitting accurately into the bored socket. Several common forms of such a joint are shown in Figs. 200, 201, 202. Of course, it costs something to turn
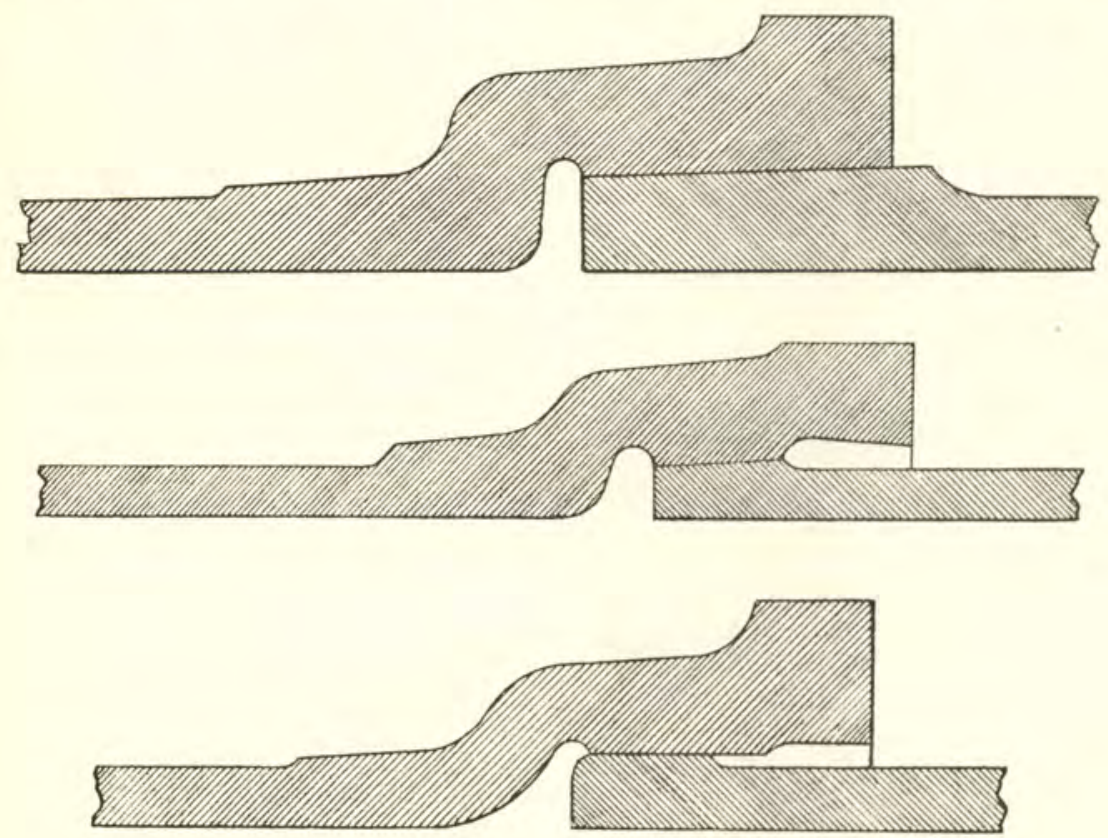

Figs. 200, 201, 202.-Spiggot and socket pipes with turned and bored joints.

and bore the pipes, but when there are large quantities the cost is not great, as machines can readily be arranged to turn the work out very quickly. There is saving in lead and in labour, and it thus results that it is cheaper to lay a pipe with turned and bored joints than with lead joints.

The process of laying pipes with turned and bored joints is as follows:- The turned and bored parts of the pipe are thoroughly cleaned, and are then smeared over with either a solution of salammoniac (chloride of ammonium), or with a mixture of tallow and resin. The spiggot is then entered in the faucet, and the pipe is well rammed home. This may be done by swinging the next pipe that is to be laid with a block and tackle, and using it as a battering-ram, a block of wood intervening to prevent any breakage. The motive for using sal-ammoniac is to "rust" the pipes together, practically making them one continuous piece. The 
tallow and resin of course actually prevent any rusting from taking place, but they make a joint that is watertight, at any rate unless the joint "draws" at all.

In this question of "drawing" we have the whole trouble of turned and bored joints. There is no allowance for expansion and contraction. If the pipes are laid in very cold weather they will get out of line with an increase of temperature, or will actually break. On a fall of temperature again the joints will "draw." If the pipes have been laid in warm weather the joints will "draw" in cold weather, or the first time that cold water passes through the pipes. Attempts have been made to get over this difficulty by having one lead joint to every five to ten turned and bored joints, or by having expansion joints at intervals, but these are clumsy expedients, and it may be said that turned and bored joints are not to be recommended for any length of straight pipes that it is essential should not leak.

Joints run with lead satisfy all the requirements of long straight pipes. In fact, they are suitable every where except where it is expected that the joint may have to be broken for repair of a valve or the like. As has been said, flanged joints are best in such cases. Joints run with lead are, if properly made, quite watertight, and they allow sufficient expansion and contraction, through the softness of the lead, to prevent leakage from "drawing."

A lead joint is made in the following manner:-The spiggot having been entered in the socket, a "gasket" of spun yarn, or a ring of lead, is caulked into the bottom of the socket. This keeps the two pipes concentric, and makes a joint so far "lead-tight" that if the rest of the socket be filled up with molten lead none will enter the pipe. Spun yarn is most commonly used on account of its cheapness, and because it is so easily handled. Lead is certainly to be preferred, inasmuch as it leaves nothing of a decomposable nature in contact with the water.

Next, the outer end of the socket is closed, to be "lead-tight." In the case of small pipes this is commonly done with thoroughly kneaded fireclay only, but in the case of large pipes an iron ring in halves is commonly used. In any case the object is to close the whole of the outside of the socket, except a hole at the top, by which it can be filled up with molten lead.

The socket is now run full with molten lead, and time is given for this to solidify. The ring is then removed and the lead is thoroughly " caulked" or "set up" with a short thick caulking 
tool. That is to say, it is compressed by hammering so as to bear outwards on the inside of the socket and inwards on the outside of the spiggot, and so as to fill up any interstices that there may be in either surface. Figs. 203, 204 illustrate the tools used for caulking in the ring of gasket or lead, and for caulking the joint after running with lead. It is sometimes specified that the joint must be trimmed entirely with the caulking tool, a chisel not being used at all. It is supposed that better caulking is thus insured than if the ragged edge of the joint be trimmed with a chisel. The lead used should be soft blue pig lead.

The form of the spiggot and socket is a thing that has received much attention, and the number of designs that have been made is legion. Each one is supposed to have some special advantage. The writer believes that these special advantages for the most part exist only in the imagination of the designer.

Certain things are to be borne in mind in either designing a
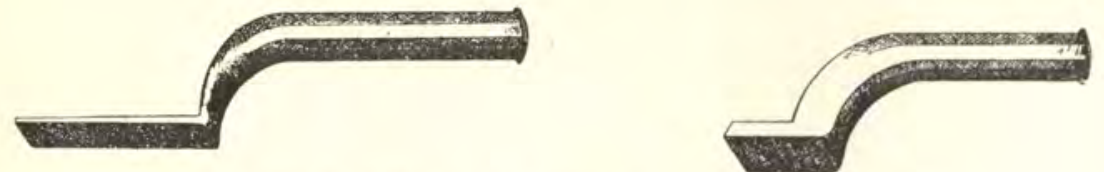

Figs. 203, 204.--Tools used for caulking joints of pipes.

spiggot and socket or in selecting one from the very many designs that already exist. One is that not more lead than is necessary is to be used; another, that the socket shall have such strength that it is not likely to be split by the very heavy internal pressure that is brought about by the caulking process. There are no data for calculating either the minimum quantity of lead that is needed to make an efficient joint, or the thickness of metal of the socket that is necessary to prevent danger of bursting during the caulking process. The matter of designing a spiggot and socket, or of selecting one, thus becomes a question of judgment only.

In Figs. 205 to 208 illustrated sections are given of several forms of spiggot and socket that have found favour. The writer does not pretend to find much advantage in one over any of the others. Sometimes a groove, either V-shaped or semicircular, is cast in the inside of the socket. The object of this is to prevent drawing of the joint. It is difficult to see wherein there is any advantage in the adoption of this groove. It has been amply shown that the resistance to drawing of pipes properly caulked with plain sockets is very great, and, indeed, it would seem to be a mistake to introduce 
additional resistance, as one of the advantages of the lead-caulked joint is that it "gives" sufficiently to allow for contraction and expansion due to change of temperature. Then again there is the possibility of a less perfect joint than would be got with a plain socket, through the imprisoning of air in the groove. In some
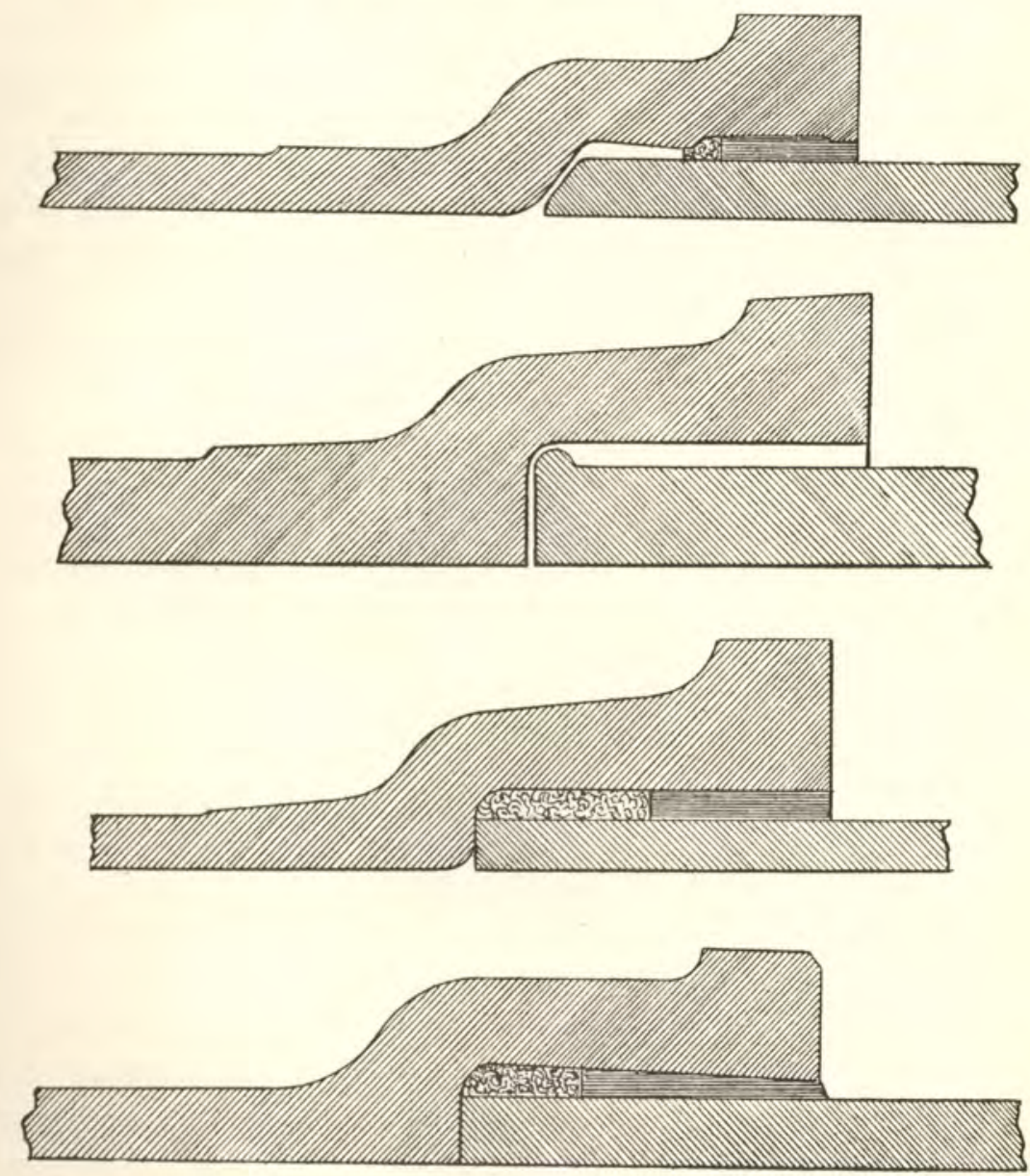

Figs. 205, 206, 207, 208.-Spiggot and socket pipes, with joints run with lead.

cases this has been provided against by boring a small hole into the groove, the pipe being so laid that this hole is at the top.

Various sockets have been designed, having their internal surface a part of a sphere. One such (from Fanning) is illustrated in Fig. 209. The object is to form a "ball and socket" joint, so as to allow of a large amount of play. Such joints are of use in special cases, as when a length of pipe, already jointed, has to be lowered on to an uneven bed-as, for example, on the bed of a 
river-but they have no advantage for general use. Ordinary leadcaulked joints will "give" for any amount of settlement that is not likely to "draw" the joints, and if there be such settlement as is likely to draw the joints, a cylindrical joint is likely to remain more watertight than a spherical joint.

Length of Cast-iron Pipes.-It is evident that there is an advantage in considerable length in straight cast-iron pipes. The greater the length of the individual pipes, the fewer the joints in any given length of main, and hence a reduction both in cost and in the possibility of leakage at joints. The limit in the length of pipes is found in the possibility of casting them straight and of uniform thickness throughout.

In English practice pipes of small diameter were, until a com-

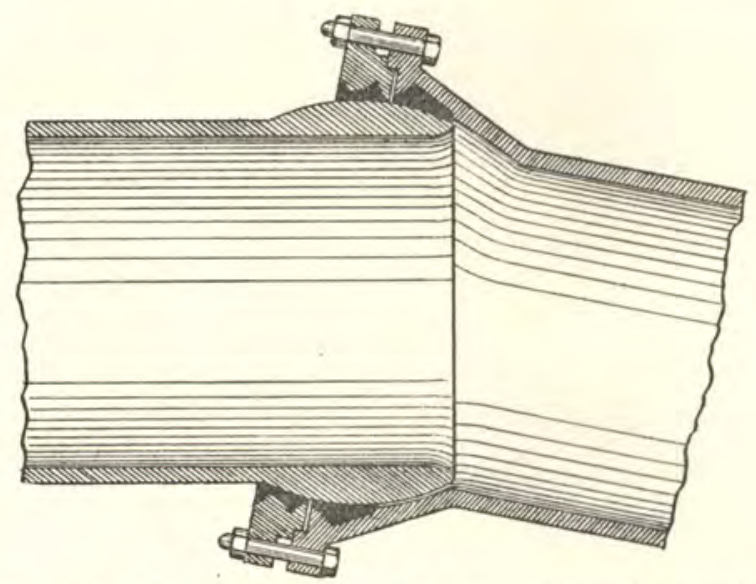

Fig. 209.-Waterpipe with ball and socket joint (Fanning).

paratively recent date, cast of 8 or 9 feet lengths (exclusive of the socket), of 10 feet lengths for larger pipes, and of 12 feet lengths for pipes of, say, 18 inches and upwards. It is now common to cast pipes from 4 inches diameter upwards of 10 feet lengths. Longer lengths than these mentioned have been adopted by some pipe manufacturers, notably by Belgian foundries.

Thickness of Cast-iron Pipes.-If cast-iron pipes were made only thick enough to resist the internal pressure that they are to be subject to in the mains and submains of waterworks, -even allowing for "ramming," and with an ample "factor of safety," let us say six - they would be so thin that they could not be handled with safety, and, moreover, would be liable to frac- 
ture from the ramming of the earth on the top of them, and from the slightest settlement of the ground. This is an all-sufficient reason for making pipes thicker than they would have to be according to any calculation based on the internal pressure that they are to be subject to alone; but there is another, namely, the necessity for providing against slight inequality of the thickness of pipes. It is evidently an impossibility to cast pipes of mathematically an equal thickness throughout all parts of their length and circumference.

Were no allowance made for the contingencies here mentioned, the formula for the thickness of cast-iron pipes would merely be

where

$$
t=\frac{p r f}{s},
$$

$t=$ the thickness of the pipe in inches.

$p=$ the pressure in lbs. per square inch.

$r=$ the internal radius of the pipe in inches.

$f=$ the factor of safety determined on.

$s=$ the tensile strength of the metal in lbs. per square inch of section.

If this formula were used, it would be found that-taking, for example, a diameter of 4 inches, a pressure of $200 \mathrm{lbs}$. per square inch, a tensile strength of iron of 18,000 lbs. per square inch, and a factor of safety of 5 -the thickness would be less than $\frac{1}{8}$-inch, a thing that is evidently absurd.

On the other hand, taking a pipe of 40 inches in diameter, the other conditions the same, it will be found that the thickness according to formula is nearly $1 \frac{1}{8}$ inch. This is not nearly so absurd a thickness for a 40 -inch pipe as $\frac{1}{8}$-inch is for a 4 -inch pipe. It is, therefore, evident that it is necessary to add much less proportionately in the case of large than of small pipes to cover the contingencies mentioned above, even if it is not necessary to add less actually.

Ramming of Water in Pipes.-If water be flowing in a long pipe with any considerable velocity, and the flow be suddenly stopped by closing a valve at the end of the pipe towards which the water is flowing, an action called "ramming" takes place. This consists in a sudden momentary increase of the pressure of water, which may be very considerable. In a short description of the hydraulic ram it has been explained how this ramming may aetually be made use of, to raise a portion of water to a greater height than the whole of the water gravitated from.

In all modern waterworks care is taken to minimise 
ramming by providing valves that can be closed only somewhat slowly, by providing safety valves at the lower ends of very long lengths of pipe, in which the water flows at any considerable velocity, \&c. Still it is necessary to make some provision against ramming in the strength of the pipes, and that not an inconsiderable one. It is to be borne in mind that the additional pressure due to ramming is a function not of the statical pressure in the pipes, but of the velocity of flow, so that, other things being equal, it is likely to be as great in a low-pressure system as in a highpressure. Fanning gives 100 lbs. per square inch as a sufficient allowance for ramming, and it seems to the writer that this is ample, if the precautions mentioned above be not neglected.

Bearing in mind what has been said above, we shall say a word or two about various formulæ that have been largely used.

Prof. Rankine gives the following rule for the minimum thickness of pipes:- "The thickness is never to be less than a mean proportional between the internal diameter and $\frac{1}{48}$-inch." Put in the form of an equation this rule is thus stated :-

Where

$$
t=\sqrt{\cdot 0208 d}
$$
$t=$ the thickness of the metal in inches ;
$d=$ the internal diameter in inches.

A formula from Molesworth that has been much used is as follows :-

Where

$$
t=\cdot 00125 \mathrm{P} d+x \text {. }
$$

$t=$ the thickness of the metal in inches;

$\mathrm{P}=$ the pressure of water in lbs. per square inch ;*

$d=$ the internal diameter of the pipe in inches ;

$x=\cdot 37$ inch for pipes of less than 12 inches diameter ;

$=5$ inch for pipes from 12 to 30 inches in diameter;

$=\cdot 6$ inch for pipes from 30 to 50 inches in diameter.

The following is the equation given by Fanning :-

Where

$$
t=\frac{(p+100) d}{4 \mathrm{~S}}+\cdot 338\left(1-\frac{d}{100}\right)
$$

$$
\begin{aligned}
& t=\text { the thickness of the pipe in inches ; } \\
& p=\text { the pressure of water in lbs. per square inch ; } \\
& d=\text { the internal diameter of the pipe in inches ; } \\
& \mathrm{S}=\text { the tensile strength of the metal in lbs. per square inch. }
\end{aligned}
$$

* It is not stated whether this $\mathrm{P}$ is to include an allowance for ramming; but the factor of safety involved in the formula, when $x$ is left out of consideration, is such as to indicate that P must include an allowance for ramming. That is to say, $\mathrm{P}$ should be taken as $p+r$, when $p$ is the actual maximum statical pressure in the pipes ; $r$ is an allowance for the extra pressure to be allowed for ramming, say, 100 lbs. per square inch. 
In this ease the figure 100 that appears in the upper line of the first part of the equation is allowance for ramming. It is, therefore, unnecessary to make any further allowance.

If the last two formulæ-that by Molesworth and that by Fanning-be examined, it will be seen that there is a remarkable discrepancy between them. Thus Molesworth makes a greater allowance in thickness for contingencies in the case of large than in that of small pipes; Fanning makes less. In fact, in the case of Fanning's formula the allowance would become nil in the case of a pipe of 100 inches in diameter-and pipes not so very short of that diameter are coming into use.

It does not seem very evident why there should be any point at which the allowance should cease altogether-leaving out of the question the minus allowance that would result if the formula were applied to pipes of over 100 inches in diameter. On the other hand, there is no very evident reason why the allowance should increase in the case of large pipes, for it is, if anything, easier to keep the thickness of metal uniform in large than in small pipe castings.

In any case, when two authorities such as those in question disagree, it seems safe to take a middle course. This the writer has done by adopting a constant allowance for all sizes of pipes. The following is the formula he has used :-

Where

$$
t=\frac{(p+100) r f f}{\mathrm{~S}}+\cdot 3 .
$$

$t=$ the thickness of the metal in inches ;

$p=$ the pressure in lbs. per square inch;

$r=$ the internal radius of the pipe in inches ;

$f=$ the factor of safety adopted;

$\mathrm{S}=$ the tensile strength of the iron in lbs. per square inch of section.

In this formula the figure 100 that appears is allowance for ramming, so that it is not necessary to make any further allowance. The figure 3 is the extra allowance in thickness of metal on account of contingencies.

The tensile strength of the cast-iron used in pipe-founding ought to run to about $20,000 \mathrm{lbs}$. per square inch, but not more than about 8 tons, or, say, 18,000 lbs., is to be counted on.

If ample allowances were not already made, by adding to the pressure in case of ramming, and by adding to the thickness of the metal to cover contingencies, it. would be necessary to adopt a factor of safety of about 6 . As, however, the allowances mentioned have been made, a factor of safety of 4 is sufficient. 
The subjoined table, compiled for the writer's own use, assumes an ultimate tensile strength of $18,000 \mathrm{lbs}$. per square inch and a factor of safety of 4 . The thicknesses are to the nearest $\frac{1}{32}$ of an inch above what is given by the formula. The pressures taken are 50, 100, and $200 \mathrm{lbs}$. per square inch. For pressures between any two of these, or for diameters between any two given in the table, it will be near enough, in practice, to take proportionate thicknesses, although this procedure is not strictly correct. The heads corresponding to these pressures are, respectively, 115, 230, and 460 feet.

The formula and table here given have been used in practice for some time past, and the writer therefore leaves them unaltered.

\begin{tabular}{|c|c|c|c|}
\hline \multirow{2}{*}{$\begin{array}{l}\text { Diameter in } \\
\text { inches. }\end{array}$} & \multicolumn{3}{|c|}{ Thickness of Pil' in inches. } \\
\hline & $\begin{array}{l}\text { For pressures up to } \\
50 \text { lbs. per sq. inch. }\end{array}$ & $\begin{array}{l}\text { For pressures up to } \\
100 \text { lbs. per sq. incl. }\end{array}$ & $\begin{array}{l}\text { For pressures up to } \\
200 \text { lbs. per sq. inch. }\end{array}$ \\
\hline $\begin{array}{r}4 \\
5 \\
6 \\
7 \\
8 \\
9 \\
10 \\
12 \\
15 \\
18 \\
21 \\
24 \\
27 \\
30 \\
33 \\
36 \\
42 \\
48 \\
54 \\
60 \\
66 \\
72\end{array}$ & 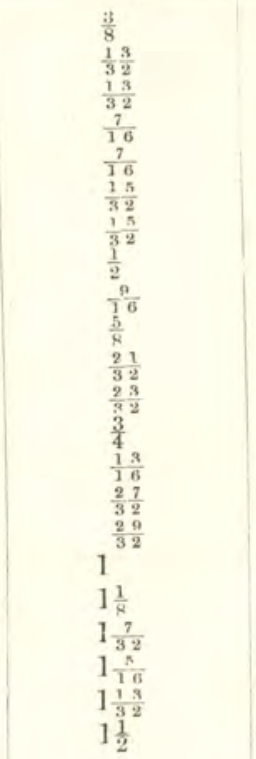 & $\begin{array}{l}\frac{13}{32} \\
\frac{7}{16} \\
\frac{7}{16} \\
\frac{7}{32} \\
\frac{1}{2} \\
\frac{1}{2} \\
\frac{1}{2} \\
\frac{17}{32} \\
\frac{19}{32} \\
\frac{21}{32} \\
\frac{23}{32} \\
\frac{2}{32} \\
\frac{27}{32} \\
\frac{29}{32} \\
\frac{21}{32} \\
1 \frac{1}{12} \\
1 \frac{1}{4} \\
1 \frac{1}{4} \\
1 \frac{3}{8} \\
1 \frac{1}{2} \\
1 \frac{3}{8} \\
1 \frac{9}{33} \\
1 \frac{29}{32}\end{array}$ & 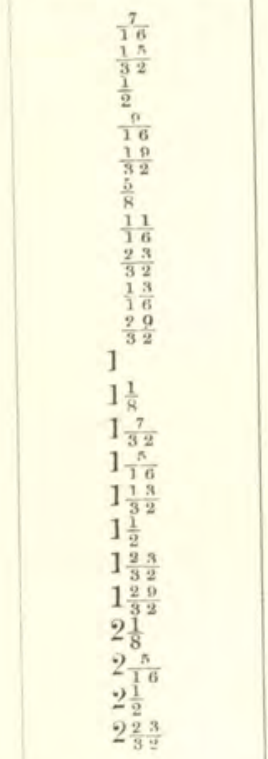 \\
\hline
\end{tabular}

It is very doubtful, however, if a slight modification might not be an improvement. The following is suggested:-

$$
\mathrm{T}=\frac{(p+100) 5 r}{18,000}+\cdot 25,
$$

the meaning of the terms remaining as before.

It will be seen that here 5 is taken as a factor of safety, whilst 
the thickness added to cover contingencies is reduced from a little less than $\frac{1}{3}$ rd of an inch to $\frac{1}{4}$ th of an inch. The result is to make small pipes for light pressures somewhat less in thickness than the table gives to make large pipes, especially those for high pressures considerably greater in thickness. For example, the thickness of 4,30 and 72 inch pipes, for the several pressures given in the above table would come out as follows :-

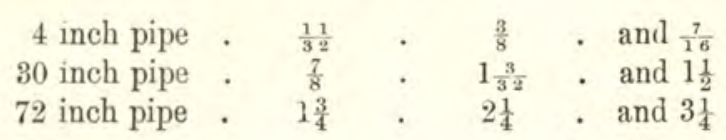

The reasons for thinking that this formula might, perhaps, be an improvement on the one from which the table is calculated, is that, with the great skill that has in the present day been acquired in pipe-casting, $\frac{1}{4}$ inch a side ought really to be an ample allowance for contingencies, whilst 4 is somewhat a small factor of safety. In the case of the small pipes the addition of $\frac{1}{3}$ rd of an inch added to cover contingencies, constitutes so large a proportion of the whole thickness of the pipe, that this is of no consequence. In the case of very large pipes it is otherwise. The $\frac{1}{3} r d$ in. added forms only a small fraction of the total thickness, and the factor of safety is low.

Against this it may be put that ramming to the extent of $100 \mathrm{lbs}$. on the square inch is practically impossible in very large pipes as used in waterworks, because the valves on such pipes can only be closed very slowly, whilst the sudden closing of a valve on a small branch from a large main does not retard the flow of water sufficiently to produce serious ramming.

On the other side, again, it may be argued that the danger from the bursting of a very large main is so serious, that every possible precaution should be taken to prevent it. On the whole it seems difficult to decide on one formula in preference to another.

Special Pipes.-Besides flanged pipes already mentioned, which may really be looked on as special pipes, many other special castings are needed in connection with distribution systems, besides valves and other fittings of that order. These are chiefly $\mathrm{T}$ pieces, bends, $Y$ pieces, and so forth. A set of these is illustrated in Plate XLI. (Figs. 210-215), and scarcely need explanation. The "sleeve," Fig. 215, is used for connecting two spigot ends together. It is occasionally convenient to do this when pipes are laid at first; it is often convenient, when a pipe has to be removed and replaced by a new one. With the regular spigot and socket, the 
new pipe cannot be put in place without removing several others, but by using a pipe with a spigot at both ends no other pipe need be disturbed. The sleeve is slipped on the new pipe, and, when the latter is in position, it is slipped over the two spigots that have to be jointed together, and these are both run and caulked. The sleeve is, in fact, a double socket.

Pipe Casting.-This is by no means the place in which to enter into a description of the details of pipe-founding. Much information on the subject is to be found in books treating of iron foundries, but there are many practical details that are known only by those who have had long practice in the work. It is not expected that a waterworks engineer should be acquainted with all the details of foundry work, but it is necessary that he should know the requisites of suitable pipes, be able to specify pipes so that they will possess these requisites if the manufacturers adhere to the specification, and that he should be able to tell, by testing in various ways, whether the pipes really fulfil the requirements.

A number of conditions are therefore generally laid down in specifications, all of which it is expected the manufacturer will comply with. The following are the principal of them. There are several, such as tests for the strength of the iron, that may be considered as alternative. It is right, however, to say, that not all engineers insist on all these conditions.

The iron to be used should, on fracture, show a close, smooth grain, gray in colour, should be tough, and of such a nature that it can readily be chipped with a chisel or filed with a file. It should be without any admixture of cinder-iron or other inferior metal.

The pipe-founder may be instructed, at any time, by the inspector, to cast a bar to be tested for transverse strength. These bars may conveniently be 3 feet 6 inches long, 2 inches deep, and 1 inch broad. These are to be supported on bearings placed 3 feet apart, and are to be loaded in the middle with weights till they break; or, at any rate, until they sustain some weight determined on. Iron fit for pipes ought to bear about 2 tons in this test.

On one of every number of pipes, a stud 8 inches long and $1 \frac{1}{4}$ inch in diameter should be cast. This stud should afterwards be sut from the pipe, and be turned down to an area of $\frac{1}{2}$ square inch, and be tested for tensile strength. These studs ought not to break in any case at less than about $3 \frac{3}{4}$ tons, and the average of a number of breakages should not be less than about 4 tons.

It is customary to give exact drawings of the sockets and 
Plate XILI.

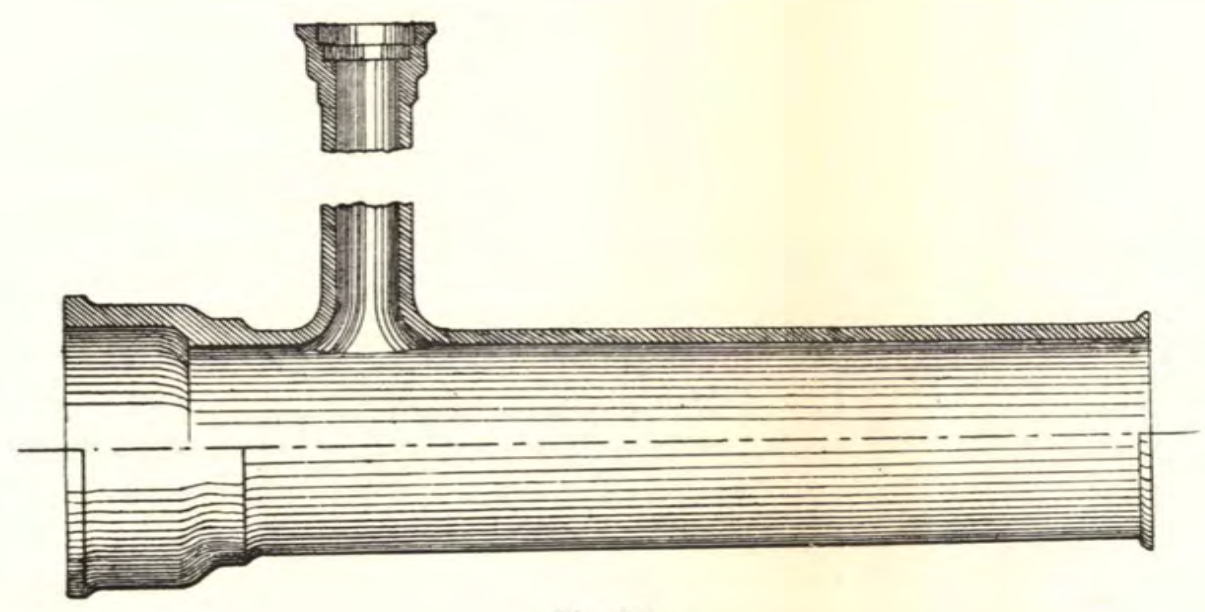

Fig. 210.

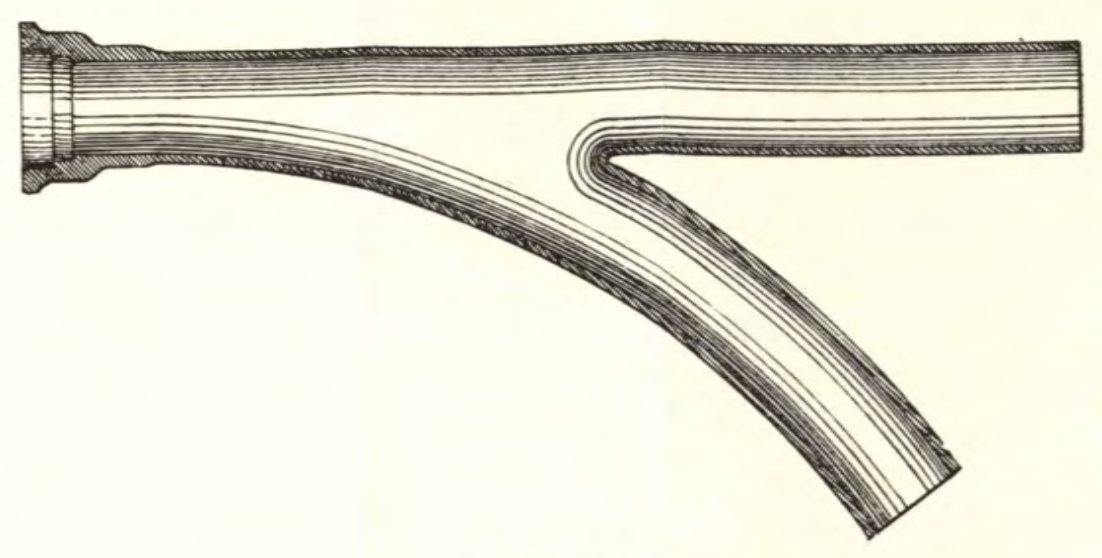

Fig. 212.

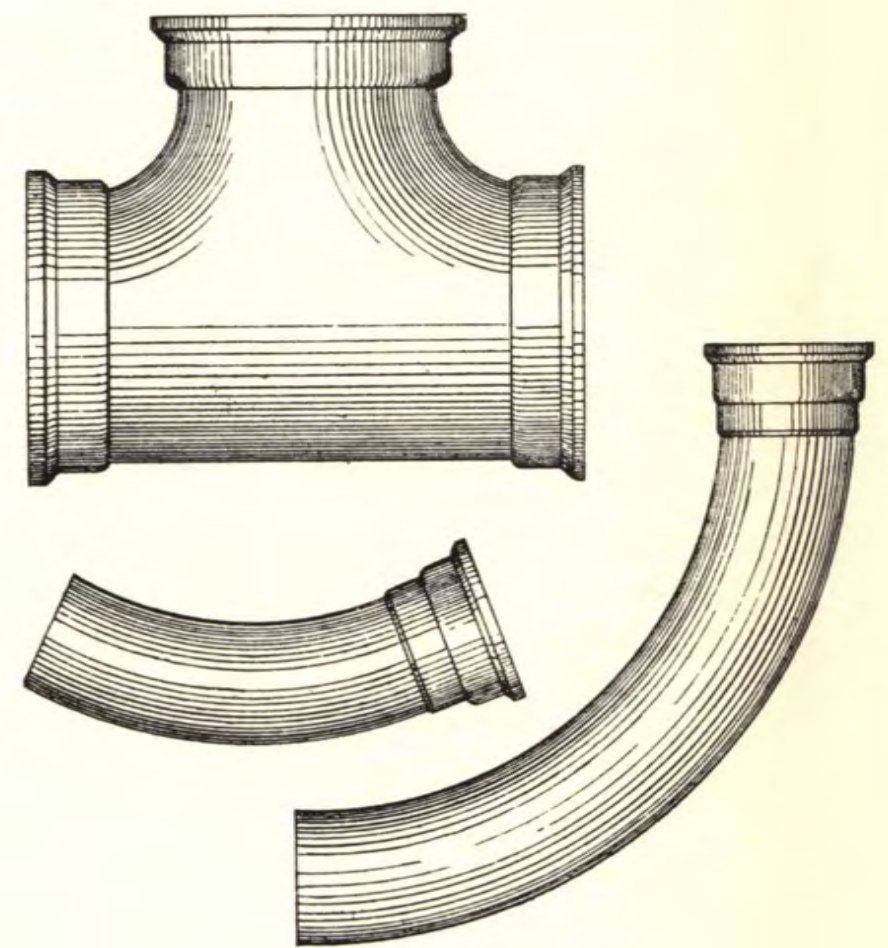

Fiy. 211.

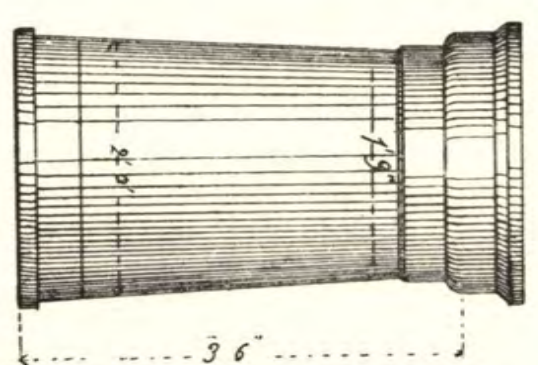

Fig. 213.

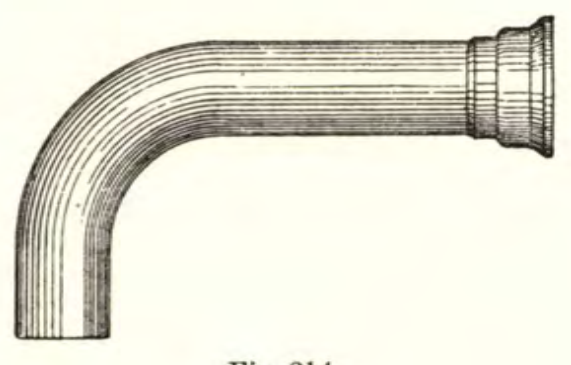

Fig. 214.

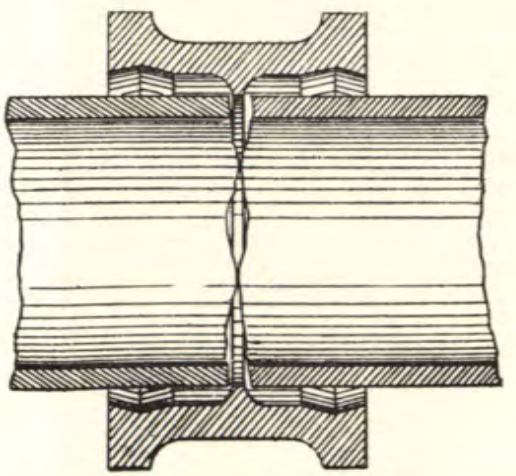

Fig. 215. 
spigots of pipes, and to specify the thickness and weights, allowing, in the case of the weights, a small margin (say, two or three per cent.) on either side, on account of the impossibility of casting pipes mathematically to a certain thickness. It is common to specify that, should the pipes be lighter than the weight mentioned, minus the allowance, they shall be condemned, and should they be heavier than the specified weight plus the allowance, the additional weight shall not be paid for.

There is something to be said for specifying merely the working pressures and test pressures that the pipes will be subjected to, allowing the pipe-founder to fill in the thicknesses and weights. The reason is that some pipe-founders prefer to use iron of greater tensile strength than others, reducing the thickness of the pipes accordingly. In such a case the engineer, in considering tenders, must be careful to observe that the thickness is really sufficient for safety, and that an unscrupulous tenderer has not reduced the thickness of the pipes to a dangerous degree in hopes that, by the reduction in price he can thereby allow, he may get the contract.

There is a good deal to be said, too, for allowing the tenderer to tender for the form of socket that he has been in the custom of making. A pipe-founder is just as likely to know a good form of socket from a bad, as most engineers; and we may be sure that, in the case of a pipe foundry, if the routine of the establishment has to be altered the alteration has to be paid for. Any pipe-founder can quote a lower price for a pipe of the form he has been accustomed to cast than one of a new form, at any rate, unless the quantity to be turned out be very large.

The lengths of pipes are commonly specified, those without the socket generally varying from 9 feet for 3-inch pipes to 12 feet for pipes of 18 inches diameter and over. There is some difference in practice, however, and here, again, a great deal is to be said for specifying the length of pipe-run of each diameter needed, allowing each tenderer to fill in the lengths himself. Some foundries are in the habit of turning out longer pipes than others. Belgian foundries, particularly, go in for extra long pipes. Of course, the advantage of a long pipe is that the number of joints is reduced, and the cost both of lead and labour. It seems a pity to so write specifications that the advantage may not be taken of long pipes, if, taking into consideration the saving in jointing, they are cheaper per yard run than short pipes; yet it would not do to so write specifications that all who cannot cast or have not 
been in the custom of casting long pipes, should be shut out from tendering. Should the long pipes cost more, as delivered, per yard run, than the shorter, the engineer can very easily calculate whether the saving in joints covers this extra cost or not.

All pipes should be cast vertically, in dry-sand moulds, without the use of chaplets, core nails, or any substitute therefor; the socket ends should be downwards; and there should be a sufficient head of metal above the actual pipe to insure compactness of grain of the spigot end. From one foot to two is sufficient. The flasks should remain unmoved for some time after the running of the metal, so that, by slow cooling of the semi-molten iron, all unequal contraction may, so far as is possible, be prevented.

All pipes must be free from air holes, cold shuts, cracks, and in fact all visible defects, and must be smooth both internally and externally. The metal of the pipes must be throughout of equal section, the transverse section being perfectly circular and the pipes quite straight.

It is usual to specify that certain letters, generally the initial letters of the name of the waterworks, be cast on the sockets of the pipes. The letters may, with advantage, be from 1 inch to 2 , or even 3 inches high, according to the size of the pipes, and may stand in relief from $\frac{1}{8}$ to $\frac{3}{16}$ inch.

Every pipe, as soon as possible after it has left the mouldif possible before it is cold-should be dressed and cleaned of all sand, dust, \&c., and then treated with Dr. Angus-Smith's composition. This is a varnish of coal tar, pitch, and oil. The varnish should be heated in a tank large enough to take the largest pipe to a temperature of about $400^{\circ} \mathrm{Fahr}$. It is sometimes specified that the pipes be dipped cold, and be left in the bath till they reach the same temperature as the iron varnish. It is, however, probably best to specify that they be heated also to about $400^{\circ} \mathrm{Fahr}$, and be dipped for five minutes. They are then removed and stood on end to drain. The surface of the coating should be quite black and retain a bright gloss. The coating should adhere so firmly to the surface of the pipe that it shall be impossible to remove it by mechanical means without removing some of the iron with it.

The reason why it is made a condition that the pipes be coated as soon as possible after they are cast is that, if they are not, there is a chance that they may rust, and the composition will not adhere over rust. This is a matter of great importance, for on the efficiency of the coating depends greatly, in some cases almost entirely, the life of the pipe. With really efficient coating, the life 
of a pipe may be indefinite. With imperfect coating a pipe will, in some soils, be completely eaten through in a few years.

Testing Pipes.-It is always specified that pipes be hydraulically tested to a certain pressure, and this is a most important matter. They should be tested to at least double the statical working-pressure - that is, to double the head there would be in the pipes whilst no water is being drawn off. It is better in all cases where there is any danger of ramming to add $100 \mathrm{lb}$. to the pressure corresponding to double the head. For whatever purpose waterworks pipes are to be used, even if they follow the hydraulic grade line, so that there is barely any pressure in them, they should be tested to $100 \mathrm{lb}$. per sq. in.

In testing pipes they are first filled with water, and it is important that they be quite filled; as, if there be no air, a pipe bursting will do so quite quietly on account of the comparative incompressibility of the water. If there be air in the pipe the latter may, if it bursts, go off with an explosion and harm may result. The pipe being filled, pressure is put on with a pump, being measured by a pressure gauge. When the specified pressure is reached it is maintained for several
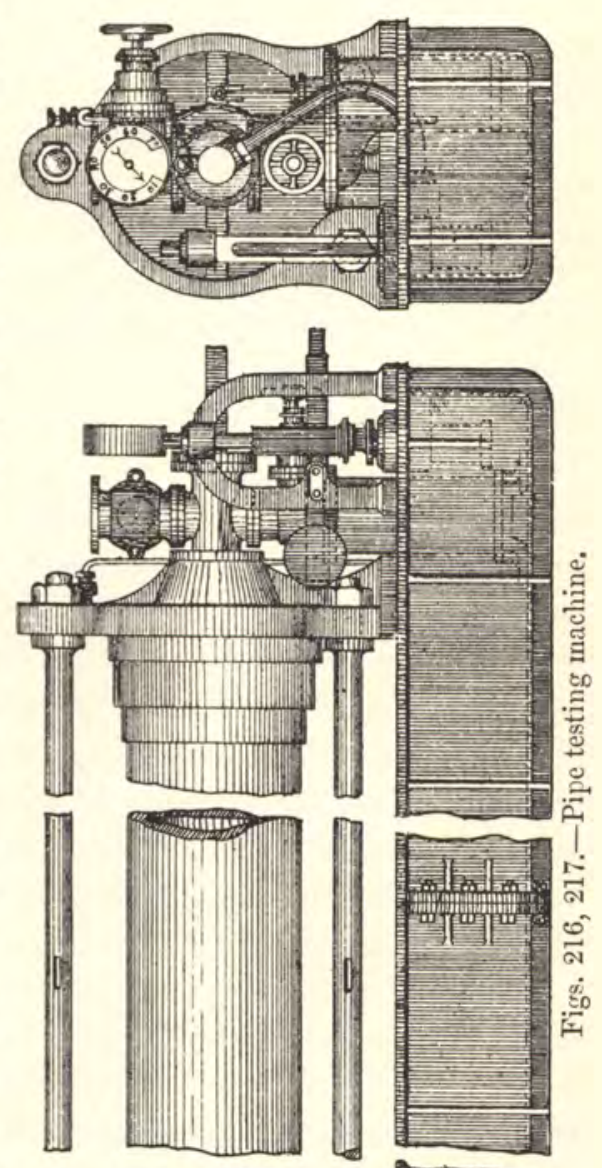
minutes, during which the inspector strikes the pipe repeatedly in different places with a hand hammer. There should be no leakage, not even a " sweating" or "weeping" of water through any part of the metal. 
Of course it is necessary, in testing, to close the ends of the pipes. In testing a few pipes two ordinary blank flanges may be used, through one of which a hole is bored to receive a pipe from a hand pump. The flanges are bolted together by long bolts outside the pipe, the joints being made with thick sheet rubber, and water being pumped in by a hand pump. It is well to stand clear of the ends of the bolts. The writer remembers a man having his leg broken by the violence with which a large nut flew off the end of a bolt that broke during the testing of a pipe.

If very many pipes are to be tested, it is a great convenience to have a machine such as that shown in Figs. 216, 217. This will need very little explanation. The water flows in by gravity by the large pipe, an air-valve being provided for the escape of air. When the pipe is filled the admission valve is elosed. Water is then pumped in by hand, a very little being necessary to raise the pressure greatly. Sometimes a pump, worked from shafting, is provided, the same water being used over and over again. There is a pressure-gauge to indicate the pressure, and it is unnecessary to state that before any large number of pipes are tested the inspector should satisfy himself that the gauge is indicating the true pressure. A gauge is as likely to indicate too low as too high a pressure. The writer remembers a case in which a pipefounder lost considerably before he found that the gauge was out of order and indicating much too low a pressure.

Some engineers specify that the pipes be tested with oil. It is difficult to see what is the exact advantage of this proceeding, and it is a somewhat expensive process, as, even if the oil be used over and over again as far as possible, there is sure to be some waste. The testing is also a very "messy" operation.

It is common to specify that an inspector appointed by the waterworks shall have free admission to the foundry during all working hours, and that he shall have such assistance as is necessary for testing and generally satisfying himself that the pipes are being turned out as they ought to be.

It is usual also to specify that if any pipe is condemned it is to be broken up, or that the distinguishing letters on the socket are to be chipped off, so that there is no chance that the pipe be slipped in amongst those that are passed; also that consecutive numbers be distinctly painted on all pipes passed. The inspector sees, or is supposed to see, all such breaking up of pipes, the chipping-off of letters, and the numbering of pipes. 
Iron and Steel Riveted Pipes. - It has already been mentioned that, although cast-iron may be considered as the standard material for waterworks pipes, various others are not infrequently used. Thus, for example, in America even wood was used not long ago, the pipes being built of longitudinal staves bound round with hoop iron. The adoption of such pipes seems rather a backward step, and we shall not consider them in detail here. In fact the only kind of pipes that seem in any way likely to compete with cast-iron pipes, for some time at least, are wrought-iron and steel riveted pipes, and these are the only ones that we propose to describe at any length here.

The advantages of these pipes over cast-iron pipes are obvious. They are much lighter, they are generally somewhat cheaper in first cost, and they are much cheaper in transit, and much more easily handled.

Roughly speaking, the tensile strength of wrought-iron is from two to three times that of cast-iron, and the tensile strength of good mild steel from three to four times. But the pipes may be made even less than one-half to one-quarter the weight of castiron pipes of the same diameter, to work at the same pressure. The reason is that it is not necessary to make anything like the percentage of allowance, over the thickness that would be got by merely taking a fair factor of safety, that it is necessary to make in the case of cast-iron pipes. The reason for this, again, is that there is no practical difficulty in making the pipes as thin as is desired, whilst cast-iron pipes cannot be cast under a certain thickness with any chance of even approximate uniformity of thickness. The wrought-iron and steel pipes are made out of rolled plates, which are nearly of absolutely uniform thickness. It is true that it is necessary to make allowance for the iron that is removed in punching the holes for riveting, but even this allowance is very much less, proportionally, than has to be made in the case of cast-iron pipes, especially in the case of those of moderate diameter.

Allowing a very ample factor of safety, allowing for some inequality in the thickness of the plates from which the pipes are made, and also allowing amply for the reduction of strength by the rivet-holes, the weight of mild steel pipes will be found to vary from about one-third to one-seventh that of cast-iron pipes.

The advantage in the matter of freight is, however, even in a higher ratio than this, as the pipes lend themselves more readily to "nesting" than do cast-iron pipes. This is particularly true 
when, as is often done, the pipes are shipped un-riveted, the riveting to be done at the place where they are to be used. In this case the plates are merely bent into form, and shells to be used even for the same size of pipe can be nested within each other, by slightly "springing" them. Breakage-an item that has always to be taken into consideration when cast-iron pipes are shipped-sometimes amounting to quite a large percentage of the whole-may be said not to occur at all in the case of wroughtiron or mild steel pipes.

In fact, were we only sure of one thing - namely, that the pipes are likely to have the same life as cast-iron pipes-there would be only one opinion as to the advisability of using them. We have, however, not sufficient evidence on this point at the present time. Wrought-iron is more prone to rust than cast-iron, mild steel more prone than wrought-iron, and there is only a fraction of the thickness of material to be rusted through in the case of steel or wrought-iron pipes that there is in the case of cast-iron.* Assuming the protective coating to be perfect, either cast-iron, wrought-iron, or steel pipes ought to last for ever, but it is too much to assume the absolute perfection of the coating. The fact that a line or two of wrought-iron pipes have been in use in America for thirty years, or somewhat more, without showing signs of deterioration, is not sufficient evidence of the capacity of wrought-iron or steel pipes to last nearly as long as cast-iron pipes.

This, however, is little more than the writer's private opinion, and not to be taken for much. There is no doubt that wroughtiron, and still more mild-steel riveted pipes, have been finding favour very rapidly with engineers within the last few years, and that great lengths of them have been laid down for waterworks. Moreover, it is always right to hear both sides of the question. The following is a quotation from a letter from one of the largest British manufacturing firms of such pipes :-

"We believe they" (mild-steel riveted pipes) "will last as long as cast-iron pipes, possibly longer under favourable circumstances. Cast-iron pipes sometimes become spongy, and decay very rapidly, while steel is not liable to this kind of deterioration. We have pipes now working most satisfactorily 24 inches diameter $\times \frac{1}{8}$-inch thick, conveying sewage. $\dagger$ Length of line 2 miles,

* See note 20, Appendix II.

$\dagger$ It is to be observed that the resistance of metal pipes to sewage must not be taken as a measure of their power of resisting the action of pure, or nearly pure, water. Sewage has the effect of quickly lining pipes with a greasy film, which 
laid in 1887, and there is no sign of wear upon them. Experience in the United States goes to prove that there is no danger or risk in using steel or wrought-iron pipes instead of cast-iron, and they have in some cases been in use for thirty-three or more years. Our bituminous coating is a perfect protection against corrosion,

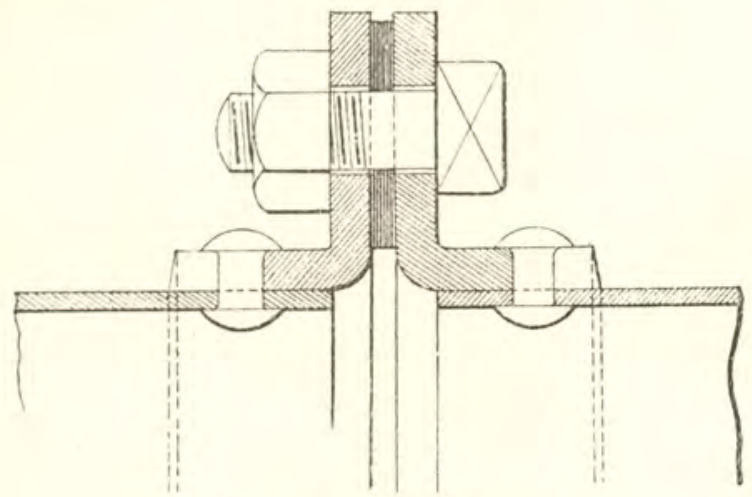

Fig. 218.- Stamped steel flanged joint.

and the only care that has to be observed is in seeing that the pipes are properly coated before they are laid in the track."

There are various methods of jointing these wrought-iron or steel pipes, and it should have been mentioned as one of the most decided advantages of them, that there are with them only about half as many joints as there are in the case of cast-iron pipes, the

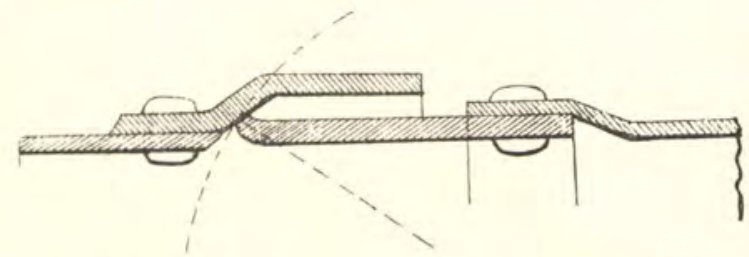

Fig. 219.-The Duncan patent joint for water-pipes.

mild-steel pipes being made in lengths up to 25 feet, exclusive of sockets. Moreover it is claimed that, where socket joints are used, only 75 per cent. as much lead is needed as with cast-iron joints, as the lead space can be made narrower. Fig. 218 shows a stamped steel flanged joint, which needs no explanation.

Fig. 219 illustrates one of a couple of socket joints that have

effectually prevents rusting. This fact does not, however, have any important bearing on the subject, as, so far as the rusting of pipes is concerned, action from the outside is to be more feared than that from the inside. 
been patented. It is known as the Duncan patent joint, and is thus described by Mr. D. J. Russell Duncan:*-

"The Duncan patent joint is better than the last" (one in which the end of the pipe itself is expanded into a socket, which is necessarily comparatively thin), " because the socket can be rolled of steel of greater thickness than the pipe, thereby giving greater strength when wanted. The socket is shrunk upon or riveted to the pipe, and, in some cases the pipes are expanded into the socket in the same manner, and by the same process as the expansion of boiler tubes into tube plates.

"A feature of this joint is the bearing surface of the spigot on the bottom of the socket. It is so designed that the surface of contact is spherical and allows the angular deviation, horizontal or

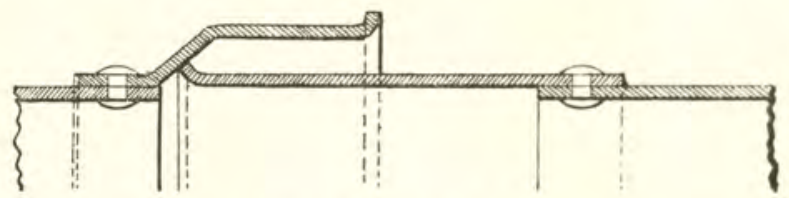

Fig. 220.-The Riley patent joint for water-pipes.

vertical, up to the limiting point, at which the spigot end of the pipe touches the extreme end of the mouth of the socket. The circle represents a sphere, and it will be seen that the bearing of the spigot on the socket is upon its surface."

Of the "Riley patent stamped steel socket and welded spigot" (Fig. 220), Mr. Duncan says :- “ The best joint on the socket-andspigot principle is a development of the two former " (that already described, and that mentioned as inferior to it), "and is known as the Riley patent stamped steel socket joint. The great advantage of this joint is the stiffness obtained at the mouth of the socket by the rim, which is favourable for caulking with lead. Stamped sockets are also truly cylindrical, and being without welded seams greater strength is obtained."

* See "Riveted Steel Pipes," by D. J. Russell Duncan, Assoc. M. Inst.C.E., M. Inst.M.E., Manager of the Steel Pipe Company, Ltd., Kirkcaldy, Scotland, read before the Eleventh Annual Convention of the American Waterworks Association, Philadelphia, Pa., April 16-19, 1891, for much valuable information about mild-steel pipes. 


\section{CHAPTER XXI.}

\section{Prevention of Waste of Water.}

ONE $_{\text {N }}$ the most troublesome things in connection with the administration of waterworks already established is the prevention or waste, or rather the minimizing of it, for some waste there will always be. In fact the administration of waterworks consists largely in a struggle against this insidious evil.

Causes of Waste.-There are various causes of the waste of public water. One is a misapprehension to the effect that a continual small stream of water along a house drain improves the sanitary condition of a house. This is a mistake. A short sudden rush at intervals has a beneficial effect in flushing drains, but a continual dribble has none. There is no use, therefore, in allowing small streams of water to flow continually down waterclosets, or other sanitary appliances. On the other hand it must be admitted that some of the regulations - in connection, for example, with the use of water-closets-are harmful from a sanitary point of view. By improvements in the form of waterclosets and of flushing apparatus, the former have been made quite self-cleansing with flushes of 2 gallons, or even of considerably less and the flush is often restricted to 2 gallons or less, appliances being insisted on that make it impossible to give a greater flush. The compilers of such regulations seem to have forgotten entirely that the function of the water is not to flush the closet only, but to flush the house-drain right to the sewer, however far off that may be. Except in the case of very short, well-laid drains of considerable fall and small diameter, 2 gallons is not enough to do this, and regulations ought, from a sanitary point of view, not only not to limit the quantity to 2 gallons, but should stipulate that it be considerably more.

This is not very much to the point, however, for it must be admitted that by far the greater part of the waste that takes 
place is due to sheer carelessness on the part of the consumers of water, often carelessness that can only be considered culpable, if it be borne in mind that the wilful waste of water supplied by waterworks is simply stealing. The water is actual public property if the works belong to the corporation; and even if they belong to a company, the water is public property in the sense that the price that each individual has to pay to the company must in great part depend on the consumption of the whole, including waste. It is undoubtedly the case that, in many towns of Europe, the water wasted has, at any rate until recently, when there has been much improvement in such matters, actually exceeded that used for legitimate purposes. It would appear that, in the case of American towns, the water wasted often many times exceeds that used legitimately.

It is not at all difficult to understand why the average householder is indifferent to the waste of water in his house, unless he has to pay for water by meter, as to be described hereafter. Any waste that he can individually make affects inappreciably the total consumption of water, and consequently, affects inappreciably the water rate. It is therefore a matter of indifference to him whether, for example, a tap be left running the whole night or not. There is more than this, however. Supposing that there is leakage from a pipe, or from any fitting, that does not cause actual inconvenience to the folks of the house, there may evidently be more than indifference in the matter of repairing this leakage, for the householder has to pay for the repairing, and beyond the satisfaction that may arise from a virtuous action performed he has no reward: It is evidently to his advantage to allow the leakage to continue. In the Northern States of America it is quite common to keep taps constantly running in winter, lest the water in the pipes should freeze, and in many ways water is used lavishly, if not actually wastefully.

A part, however, from this, a great deal of leakage takes place simply because it is difficult to appreciate how large a quantity of water is lost on account of an apparently very small leakage continuing through the whole twenty-four hours. It would astonish most people who see water merely dripping from a tap, or from a leaky pipe, to be told that the loss is very likely 3 to 4 cubic feet in twenty-four hours, or fully the average consumption of water of one individual! Yet, if a measuring glass be taken it will be found that from 2 to 3 ounces per minute of water may fall merely in the form of drops, and this corresponds to a large 
consumption in twenty-four hours for one person. It needs but a very small "dribble" to discharge 20 cubic feet of water in twenty-four hours, or, say, the quantity that ought to be consumed by an average household.

This matter of the great quantity of water that may be lost by a continual leakage is well illustrated by Mr. W. Hope, C.E. The annexed diagram (Fig. 221) is taken from a paper of his on the subject of the waste of water, ${ }^{*}$ and is described in his own words :-

The diagram "shows a lead pipe drilled with various sized holes, the burr on the inside not being removed. The actual number of gallons per day which passed through each hole under a pressure of $45 \mathrm{lbs}$. per square inch is noted on the drawing, together with the corresponding number of persons that quantity would supply at the exceptionally high rate of 15 gallons per head per day."

Some may not agree with $\mathrm{Mr}$. Hope that 15 gallons [say $2 \frac{1}{2}$ cubic feet] per head per day is an "exceptionally high rate" of consumption, even if the satisfactory results of the recent efforts to reduce consumption by prevention of waste be taken into consideration, but this does not make his illustration the less striking.

This matter of the waste of

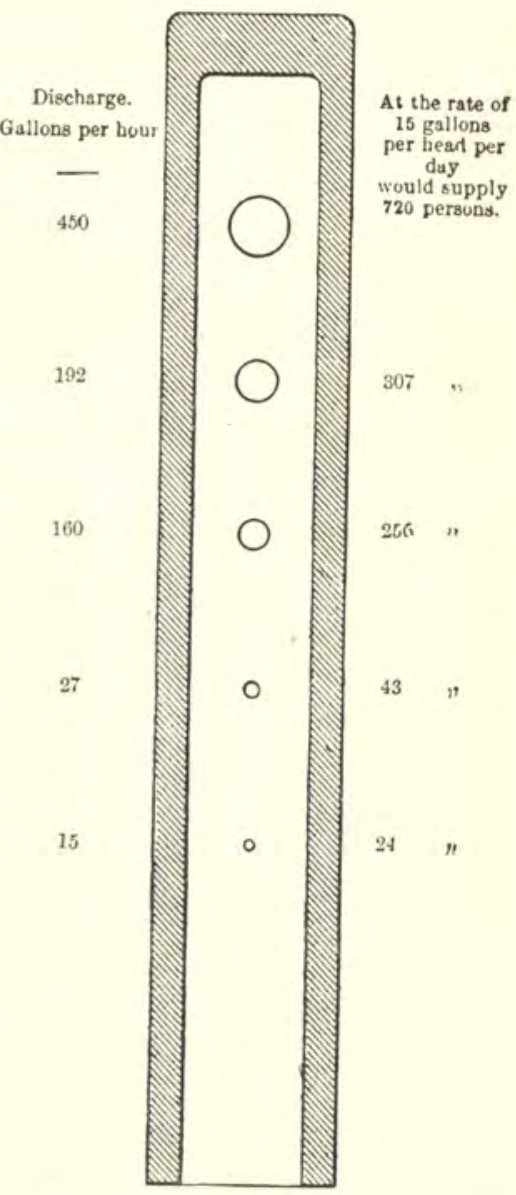

Fig. 221.-Results of experiments on the flow of water through circular holes in $\frac{1}{2}$ in. lead-pipe under pressure of $45 \mathrm{lbs}$. per sq. in., showing number of persons who might be supplied by the discharge through flaws of various sizes. water in houses is of much greater importance than that of waste from the mains of the waterworks. These mains are constructed by, and are under the supervision of,

* " The Waste of Water in Public Supplies, and Its Prevention," by William Hope, Assoc. Inst. C.E. Proceedings of Institution of Civil Engineers, vol, xc., session 1891-2, part iv. This interesting paper has been published in pamphlet form, and should be read by all who are interested in the question of the preven-
tion of waste of water. 
those whose evident interest it is to prevent leakage from them, and such leakage is kept within small limits without much difficulty.

Means of Preventing Waste.-The means that have been adopted to keep the leakage from house fittings within limits may be put under three heads, leaving out of consideration the adoption of the intermittent system of supply, which is practically now a thing of the past. With this system waterworks were more or less protected, inasmuch as water was not kept at pressure through the house system during the whole twenty-four hours, but was only turned on for a comparatively short timeoften not more than an hour or two-during which time cisterns within each house were filled up. Not only was the house system under comparatively small pressure, but it was necessary for the householder to keep leakage within some limits, unless he wanted to find that all the water in his cistern, or cisterns, had leaked away, and that he was waterless till the supply was turned on again. When the constant system was first tried in England, it had to be discontinued, the leakage being found to be so enormous. To get to the classification, however :-

(1) There is the system of enforcing the adoption of house fittings of a high class, and of many water-waste-preventing appliances, and the periodical inspection of the same. (2) There is the introduction of means, outside all houses, and entirely under the control of the officials of the waterworks, of finding out whether there is an excessive amount of leakage, or not; and, if there is, of localizing it, after which steps can readily be taken to put an end to it, the means which are now nearly always used being what is known as the " district meter system." (3) There is the custom of actually selling water by meter-that is to say, of charging each householder a sum just in proportion to the quantity of water that he uses, exactly as is commonly done in the case of gas.

Each of these means has resulted, under the direction of men of intelligence, in the reduction of leakage to such an extent that it may be said to have been abolished altogether in the most favourable cases, and there have been endless controversies as to which of the three systems is to be preferred. Before giving a brief résumé of the opinions expressed on the subject by those who appear best able to judge, it will be well to describe the three systems in a few words.

Enforced Adoption of particular House Fittings, with periodi- 
cal Inspection. - It is now common to enforce regulations to the effect that, in the case of new houses, none but fittings coming up to a certain standard may be used. Thus, for example, the materials that may be used for pipes, and the thicknesses that various diameters of pipes must have, are stipulated. Ball valves and taps may only be of such construction that their normal condition is that of water-tightness, instead of continual drip, as is the case with the common plug-tap of inferior make. Further than this, they are often so made that it is necessary to keep the hand on a knob, otherwise the flow of water immediately stops. Some valves are even so made, that they give out only a measured quantity of water when opened once, and have to be opened again to get more.

In connection with water-closets, innumerable inventions have been made to prevent or minimise waste. The commonest of these is the "water-waste-preventing cistern." This is a small cistern-commonly holding 2 gallons, a quantity that, as has already been said, the writer considers too small-filled through a ball valve that allows water to flow into it only very slowly, and so arranged that on pulling a handle the whole of the water is rapidly discharged, whether the handle be pulled for an instant only, or be held till all the water has drained away. After this the cistern fills up again slowly, taking several minutes, and in the case of cisterns of good design it is impossible to get another discharge till they are full again.

Various appliances have been designed to make it impossible to use more than a fixed quantity of water for each flushing of a closet, even when the supply is direct from high-pressure pipes, but the writer is not aware that any of them has been thoroughly successful. By the use of an appliance known as a "regulator valve " it is possible to adjust the flush of a closet approximately to any particular quantity, but this quantity may be either large
or small.

A great deal has been done by so arranging overflow pipes, discharge pipes, etc., that if there is a constant leakage it is discoverable, or even conspicuous, from the outside. In cisterns, particularly, the improvement has been very great. With the old arrangement having the waste pipe of the cistern connected directly with the drain or a soil pipe, and with the old plug ball-cocks, whose chronic condition was that of leakage, an indefinite amount of water might be lost without attracting the attention of anyone. Indeed, it was greatly this leakage of water invisibly into drains 
that made the first attempts to introduce the constant highpressure service system abortive.

Cisterns are much less used now than they were before the constant-supply system became prevalent, but when they are used, the waste or overflow pipe is allowed to project through the outer wall of the house. If there is any leakage in the ball valve, allowing water to run to waste, it makes itself conspicuous or even inconvenient, and is likely to be attended to at once.

The discharge pipes of sinks, baths, fixed basins, \&c., cannot be made quite so conspicuous as the "warning pipes" just mentioned, but it is now the universal custom to allow them to discharge over or into trapped gullies in the open air; and therefore a constant loss by way of one of them, such as will occur if a valve is leaky, is at any rate much more likely to be noticed than it was when the custom prevailed of connecting the discharge pipes of these appliances with drains or soil pipes.

When the constant service system is carried out completely, water-closets are supplied through water-waste-preventing cisterns, such as those described above, or through some other arrangement that makes it impossible that gas from the closets can be drawn into the pipes, even if the latter have to be emptied for repairing or for any other reason, and all other appliances are supplied directly by service pipes from the mains. In such a case it is evident that a burst pipe is liable to lead to very considerable loss by leakage. The commonest cause of burst pipes is the freezing of water in them. Water expands about 10 per cent. when it freezes, and a closed vessel that held the water cannot hold the whole of the ice without bursting, unless it has very elastic sides. Neither iron nor lead pipes can resist this bursting action.*

Care should be taken to so arrange pipes that they shall be well protected from frost. This is very easy in a country such as England, where the winters are mild. In countries with very severe climates, such as some of the Northern States of America, it is very difficult to prevent pipes from freezing, and it is a custom to allow water to flow through them continually, and to run to waste, to prevent freezing. Water passing in the form of

* It should be unnecessary to point out here that the old idea, that it is the thaw that bursts the pipes, is erroneous. It is only when the ice in them thaws that the water can escape, and, as the slight crack in a pipe burst by the freezing of the water in it nearly always escapes detection, it is only when the thaw comes that the water escapes, and a householder becomes aware that his pipes have burst. 
a current of even a comparatively moderate velocity through a pipe freezes at only a very low temperature.

Another cause of the bursting of pipes is the use of valves that shut suddenly. The concussion or "ram" that these result in is sometimes sufficient to burst pipes. Valves of this type should, therefore, be avoided where the working pressure is already considerable.

It will be at once evident that there is a great advantage in having a valve on the service pipe within the house, capable of closing off the whole water system of the house from the main, in a conspicuous and accessible place, so that the water may be shut off in a moment if a pipe bursts.

It is common, especially in some parts of England, to have something which very closely approaches the constant system, but has not the whole of its advantages, inasmuch as water is not drawn directly from the main. Instead of the numerous large and often nearly inaccessible cisterns that used to be customary, there are only two, and these of moderate size, placed in the attic. One is to supply water-closets, the other all other appliances in the house. The supply is constant, or only shut off occasionally for short intervals of time. Where the pressure in the mains is great such a system is likely to save leakage, because the pressure from the cisterns is less than that from the main would be. Moreover, it is possible to do something to prevent excessive waste by fixing a diaphragm with a small aperture in the rising main, or otherwise constricting the flow to one that will be more than sufficient to supply all the wants of the house during the twenty-four hours, but will not allow of reckless waste. The cistern must be large in this case, enough to provide the considerable quantity of water that has sometimes to be drawn within a short space of time-as, for example, in filling a bath.

On the whole, improvement in the construction and workmanship of fittings, and the adoption of a superior style of plumbing carried out under careful supervision, has probably done more to prevent the waste of water, or at any rate, to make its prevention possible, than anything else.

It is not sufficient to make regulations that all fittings within houses must be up to a certain standard. It is necessary, further, to ascertain by inspection that they are so, and that they remain so. For these reasons an essential part of any system of water supply, in which there is no means outside the houses of discovering leakage or waste, is the establishment of " house-to- 
house inspection." This is generally what is considered the most objectionable part of the system. Leaving on one side the cant about " every Englishman's house being his castle," it is at times inconvenient to have the inspector poking his nose into all parts of the premises; but what is of much more serious consideration than this is the fact that it is not always at all easy to discover leakages, and that it would need a perfect army of inspectors to do their work properly in a large town. It needs one man to every four or five thousand houses to make the necessary inspection very inefficiently, and this is about the number commonly employed. It would need many times more to make a really efficient inspection.

Detection of Leaking from the Outsides of Houses.-It is always, or nearly always, the case that means exist in connection with waterworks of recording, not only the total quantity of water that has been supplied during any day, but the rate at which it has been supplied at different times during the twentyfour hours. Where the water is pumped, the number of strokes that the pump makes during the twenty-four hours is a measure of the total quantity of the water that has been pumped, and, if the pumps are kept in good condition, should be a very fairly accurate one. When, however, as is common, the engines pump steadily into a reservoir, no idea is given of variation in consumption during the twenty-four hours. In the case of pumping into mains direct, it would be very easy to fit the engines with a recording instrument that would record not only the total number of revolutions made in any certain length of time, but that would record the rate of pumping during all times of the twenty-four hours, and this would constitute as good a system of keeping a check on the varying consumption as any other.

In the case of gravity systems, where the water is supplied direct from the source without the intervention of a service reservoir, and in all cases where water is supplied from a service reservoir, the water should be measured as it leaves the impounding reservoir, the intake, or the service reservoir.

When the water has not to be measured under pressure, but may be allowed to flow for some distance through an open channel, it is a comparatively easy matter to gauge it. This may be done simply by a notch board such as is illustrated and described at pages 25,26 . It will suggest itself to any engineer how apparatus could be designed to keep an automatic record of the height of water over the notch.

The following description of a very ingenious arrangement for 
measuring water in the open is taken from a paper on the Construction of the Yokohama Waterworks, by John Henry Tudsbery Turner, B.Sc., Assoc. M.I.C.E.* :- "The gauge through which the water passes from the depositing tank to the basin is a submerged vertical rectangular orifice 2 feet long by 6 inches high, with squared brass lips $\frac{1}{4}$ inch thick placed 2 feet 6 inches below the surface of the tank. The head of water above the orifice is measured by an automatic apparatus, consisting of two copper floats immersed in the water at the upper and lower sides

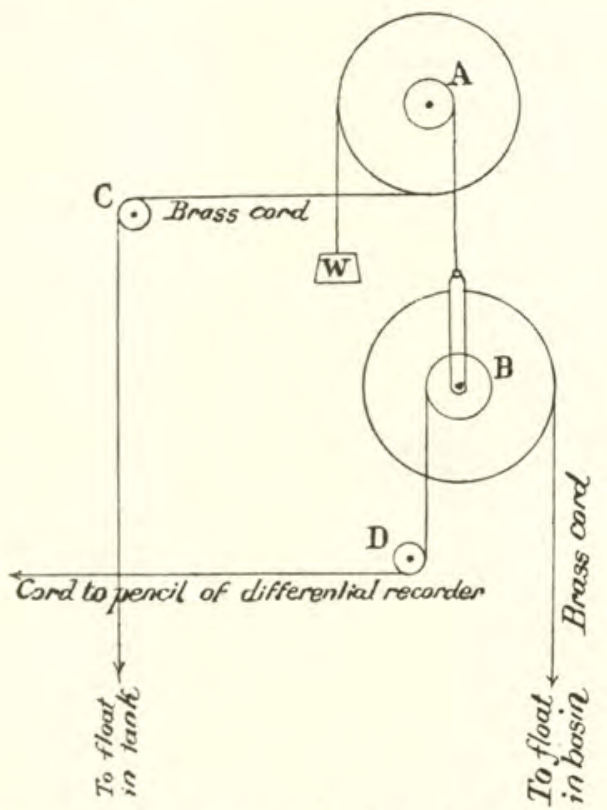

Fig. 222.-Arrangement of pulleys in water meter.

of the orifice respectively, which actuate a differential recorder and an integrator fixed in a gauge-house at the side of the tank. The discharge through the orifice is dependent on the head due to the difference of water-level on the upper and lower sides of the gauge, which difference is recorded by means of the floats.

"The relative motion of the floats is reduced to one-third for the differential recorder, which is of the revolving disc form. ${ }^{\dagger}$

"The arrangement of pulleys by which the recording pencil is actuated solely by the relative water-levels on the two sides of the orifice, without reference to the actual water-levels, is shown in Fig. 222. The diameters of the double pulley A, which turns

* Proceedings of Institution of Civil Engineers, vol. c., page 277.

+ See note 21, Appendix II. 
on a fixed axle, are 4 to 1 ; those of the double pulley, B, which turns on an axle suspended from $\mathrm{A}$, are 3 to 1 ; $\mathrm{c}$ and $\mathrm{D}$ are fixed guiding pulleys; $\mathrm{w}$ is a weight hung on the end of the continuous cord from the upper float round $\mathrm{C}$ and $\mathrm{A}$.

"The discharge through the orifice under the actual conditions of working was ascertained by experiment, and found to be very accurately expressed by the formula

$$
\mathrm{Q}=2,000 \sqrt{h} .
$$

Where $Q$ denotes gallons discharged per minute, and $h$ denotes the head of water in feet, namely, the difference in level between the surface of water on the inlet and outlet sides of the gauge.

When the water has to be measured under pressure, the measurement must be done by means of one or more meters, of the kind to be described hereafter. On page 63 is shown diagrammatically a set of three meters, any two of which are capable of measuring the maximum quantity of water that passes.

Of course the total amount of water used in twenty-four hours may be such as to indicate that there is waste, but a knowledge of the rate of consumption during the different times of the twenty-four hours is a much surer indication of the existence of waste. The reason is that, except in the case of certain manufacturing towns, the actual consumption falls to something very nearly zero, at some hour between midnight and the time that people begin to rise in the morning. In the case of manufacturing towns it is nearly always possible to estimate with fair accuracy the consumption that goes on even in the small hours of the morning. At some time during the early morning, the actual consumption will fall in ordinary cases to a very small fraction only of the average consumption. In fact, in the case of small towns, it will certainly fall, at least for short intervals of time, to zero. In the case of the manufacturing towns that we have been considering, it will fall to only a very little over the quantity constantly used, and, as already stated, is capable of at least approximate estimation. In either case, any great excess may be put down to waste, due either to leakage, or the leaving of taps, \&c., running. It is now merely a question of localizing this leakage.

District Meter System.-The system known under this title has proved most useful in facilitating the location of waste, particularly by leakage. In this system the town is divided into a number of districts, and the water is admitted into each through a certain kind of meter. The meter most commonly used for 
this purpose is a meter that keeps a record of the rate of consumption of water during all parts of the times of the twentyfour hours, in contradistinction to a meter that records the

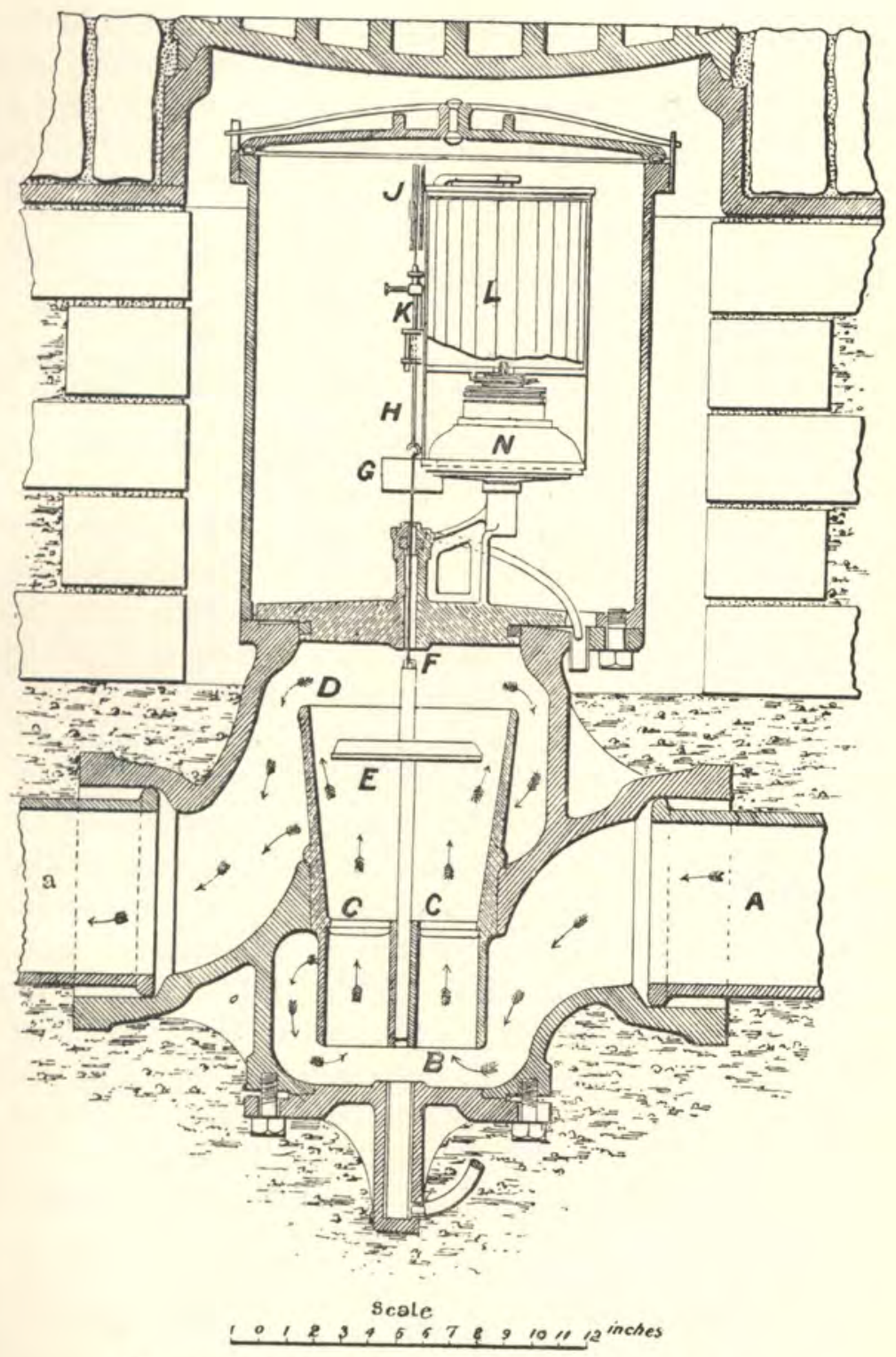

Fig. 223.-Mr. G. F. Deacon's "District" water meter.

quantity consumed in any particular period of time--that is to say an integrating meter. Meters originally designed for the latter kind of work have, however, been adapted to district meter work and it is claimed for them that they have the advantage that, 
besides the rate, it is always easy to read from them the total quantity of water that has been consumed in any particular length of time, whereas it is somewhat difficult with the differentiating form of meter.

To Mr. G. F. Deacon, M.I.C.E., we are indebted for the inception of the general idea of the district meter system, and also for the perfecting of a meter that is so simple and so efficient for the purpose for which it is designed, that it seems difficult to imagine a better.* An illustration of this meter is given on the preceding page (Fig. 223).

The flow of water from $A$, by B, C, D to a is indicated by the arrows. It may be stated that the only practical difficulty that was met with in designing the meter was that of obviating the disturbing effects of the "swirling" of the water. In the form of meter shown, this difficulty has been entirely overcome, partly by a series of veins at $\mathrm{B}, \mathrm{C}$.

The disc $\mathrm{E}$ tends to fall by gravity, in spite of the counterweight $\mathrm{G}$, the use of which is to keep the flexible wire $\mathrm{F}, \mathrm{J}, \mathrm{H}$ taut. If there is no flow of water, the disc falls down to $\mathrm{c}, \mathrm{c}$; but if water passes, the disc is forced upwards, and the greater the quantity that passes, the higher rises the disc, and the lower falls the weight $\mathrm{G}$ carrying with it the pencil $\mathrm{\kappa}$. The intervals corresponding to given increments of discharge-say 100 cubic feet per hour-are discovered by experiment, and paper, made to fit on the drum L, is ruled longitudinally at these intervals. The drum is carried round by a clock $\mathrm{N}$, and the pencil draws a curve, in which the ordinates are rate of consumption of water, and the abscissæ intervals of time. This will be made clear by reference to the diagrams (Figs. 224-231) in Plates XLII. and XLIII., which are reproduced from a paper on "The Constant Supply and Waste of Water," read before the Society of Arts, May 17th, 1882, by Geo. F. Deacon, M.I.C.E.†

The description of the method of actually working the district meter system will be best given in Mr. Deacon's own words :-

"I will now explain the modes in which the waste-water meter system is employed in practice, and in doing so I will take as an example the case of a town containing 100,000 persons. The number of waste-water meter districts into which such a town could be conveniently divided would depend entirely upon the arrangement of the water mains, but it would probably be fifty or

* See note 22, Appendix II.

$\dagger$ Journal of the Society of Arts, May 19, 1882. 
sixty. Upon the main supplying each such district, a wastewater meter is placed in such a manner that the whole of the water supplying that district passes through the meter. If in such a town, any system of inspection whatever has been adopted, there are probably not less than three inspectors. If they are fairly intelligent men, they may be retained, and no more will be required.

"Having fixed the meters and outside stopcocks upon the house-service pipes, if such stopeocks do not already exist, all ordinary systems of inspection are at once set aside. One inspector fixes blank diagrams at the rate of about thirty a day, and brings to the office as many diagrams from meters upon which they may have been placed from one to seven days before. Examples of such diagrams are shown by the faint lines in Figs. 224, 225, and 226. The diagrams shown by darker lines were taken from the same districts when much of the waste had been prevented. In a few days from the commencement of the work, the manager has before him the whole sixty diagrams, with the waste per hour visible at a glance, and with the waste in gallons per head, entered by the inspector or a clerk on the diagram, in the space left for the purpose, as shown in Fig. 227. He finds, probably to his surprise, that out of the sixty districts the diagrams show that in ten the waste per head is five times as great as in ten others, and that without any reason by which any divergence might have been anticipated. As a matter of fact, the divergence in the rate of waste per head, even in adjoining districts, of which the history is the same, and of which the external conditions are similar, is often greater than five to one.

"Instead of wasting the energy of his men upon all the districts in rotation, the manager now concentrates his attention upon the most wasteful ten; and with the worst of these he probably begins his work. Two inspectors receive orders at night to visit that district, and, in order that they may confine themselves to the right blocks of houses, and omit none, they are provided-in Liverpool, at least - with a small plan of the district, showing the houses supplied through the meter in question. Having reached the district between 11 and 12 o'clock p.m., one of two methods is adopted.

"By the first and most general method, the stopcocks are sounded in rotation, by using the ordinary stopcock turning-key as a stethoscope, and any stopcock through which water is heard to be running is shut off, the time and number being noted by the inspector. The shutting off and time of shutting off are simul- 
taneously recorded by the meter on the main, to which the inspectors have no access. On the pavement, above each stopcock so closed, the inspector marks a cross in chalk. If, after closing a stopcock, the sound continues, it is obviously caused by waste from the main, or between the stopcock and the main. It is then generally heard at several stopcocks, and by its relative loudness at each, an approximation is made to its position. The footway and the carriageway pavements are then sounded, until a spot of maximum noise is found. Here, again, a chalk mark is left, which rarely fails to show the position of a burst pipe or ferrule to the day inspector, who, with his labourer, visits the district on the following day. At the end of two to four hours the round of the whole district has been made, and the inspectors find themslves again not far from the meter. They next close the main-stop valve near the meter, and leave it closed for a minute or two. Commencing with this valve, they then reopen all the closed stopcocks, which are readily seen by the chalk marks, and return to the night office, where each inspector writes in copying ink on the left-hand side of a book the particulars of his inspection. By the second method-rarely necessary except when waste has already been very much reduced - the whole of the stopcocks are at first shut off without sounding. On the return journey, they are opened one by one, and sounded; the result is obviously to magnify the sound resulting from small leaks, supplied by cisterns with ball-taps.

"At 9 o'clock on the same morning the day inspector receives a press copy of the night inspector's reports. He visits those premises, and those only, in or under which waste is reported to be actually taking place, and the work of many days' inefficient houseto-house inspection is efficiently performed in one. He generally on the same evening writes in red ink, opposite the night inspector's report, the results of his examination. He also issues the necessary notices for repairs or renewals.

"On the same day, the manager or his clerk receives and records the meter diagram from the district in question. Such diagrams, taken after night inspections, are of the kind shown by faint lines on Figs. 228 and 229. He sees by the diagram the time during which the night inspectors were continuously engaged, and he sees the exact amount of useful work performed in that time. It would not be possible, even if the inspectors had access to the meter, to elude this knowledge. He sees, moreover, the total quantity of waste detected, and one month hence he will see by another diagram the result of the day inspector's efforts to stop it. 
GRAPHIC REPRESENTATION OF THE RATE OF SUPPLY DURING EACH INSTANT OF 24 HOURS IN A DISTRICT OF 1,933 PERSONS.

Fig.224

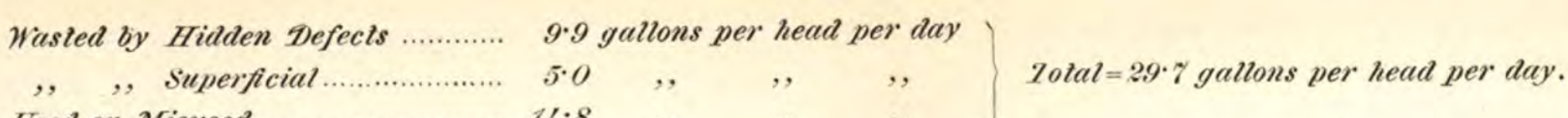

新

$\therefore$

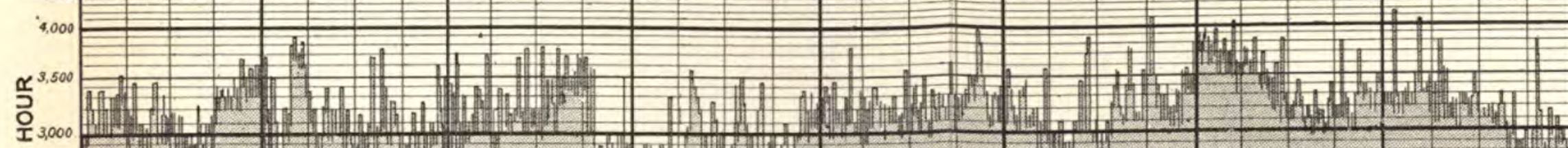

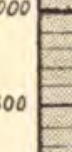

mina - in

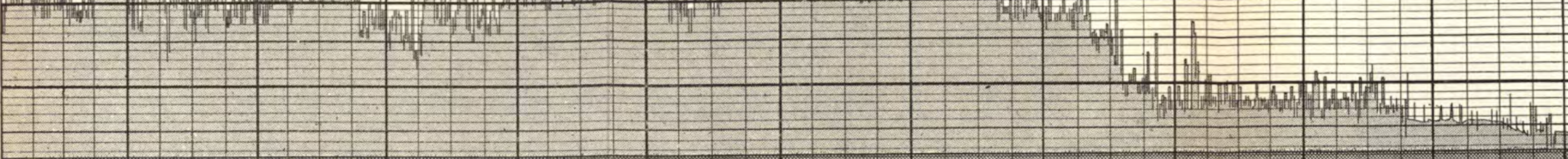

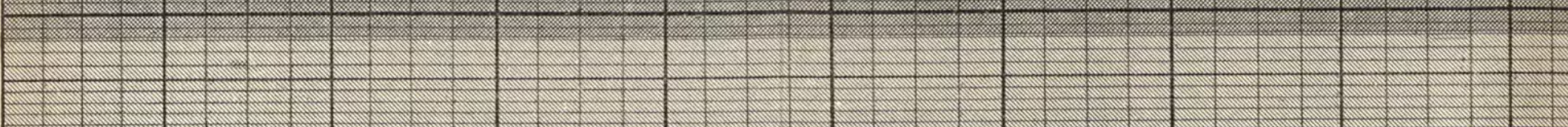

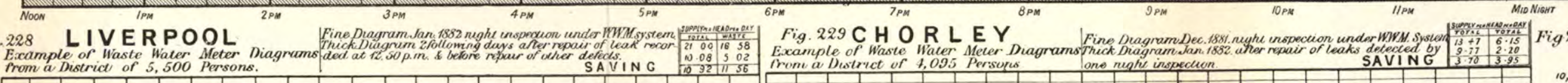

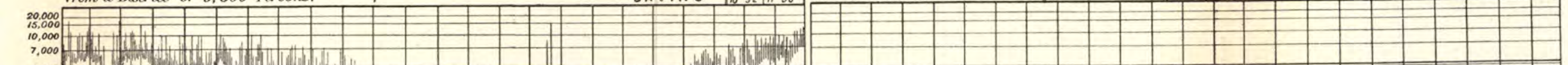

$=$ Mn

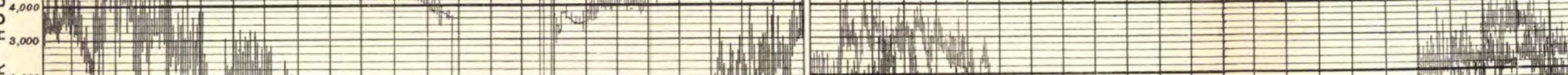

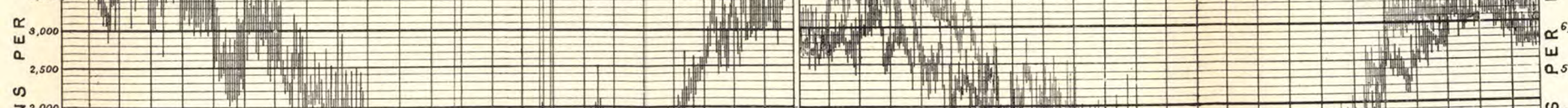

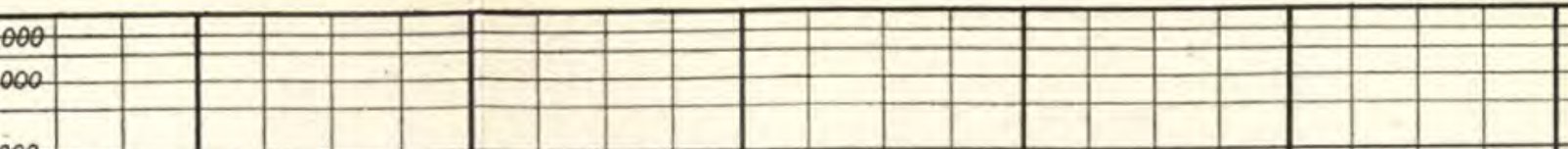



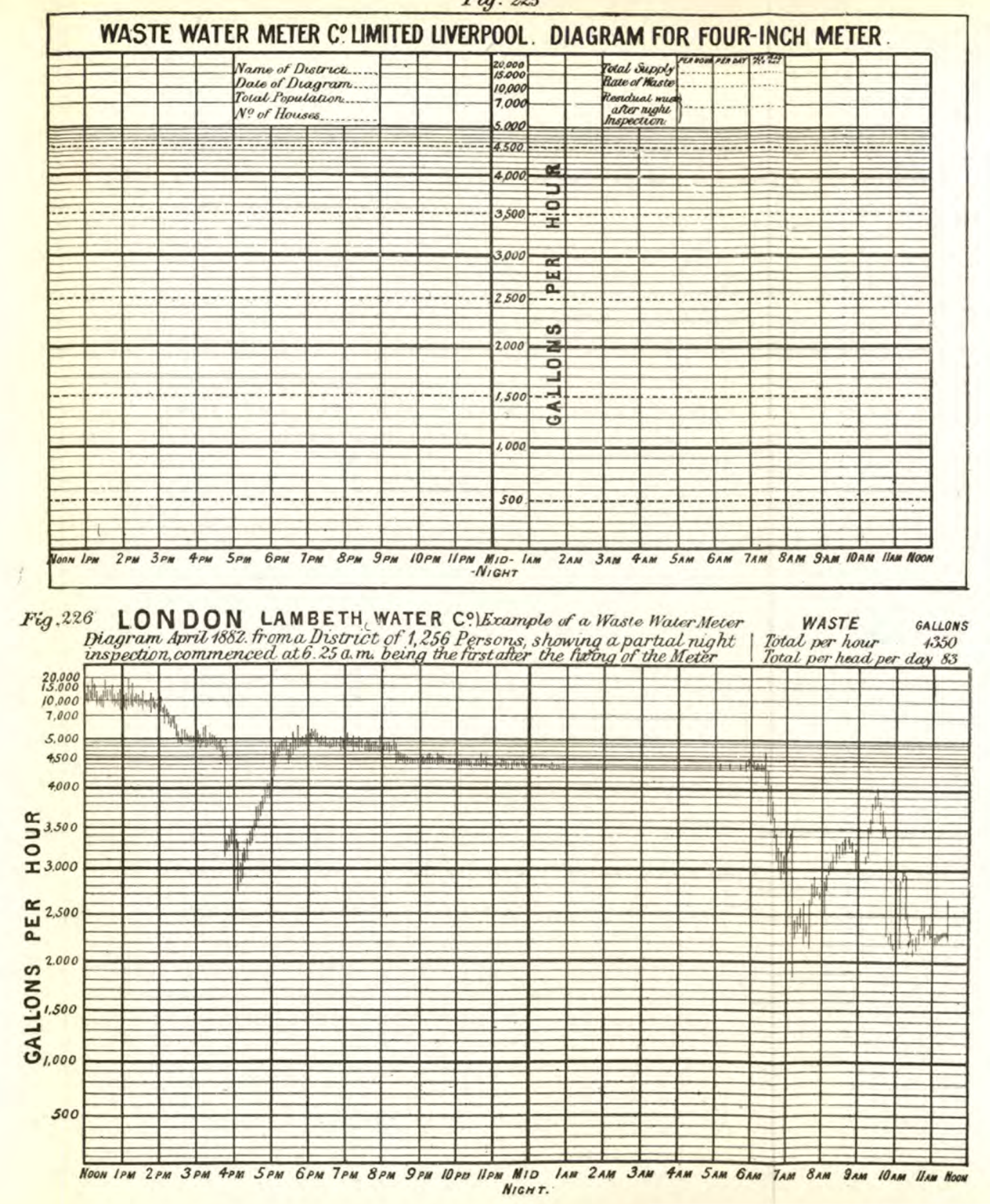

Fig. 231.

CONSTANT AND INTERMITTENT WATER SUPPLY, LIVERPOOL.

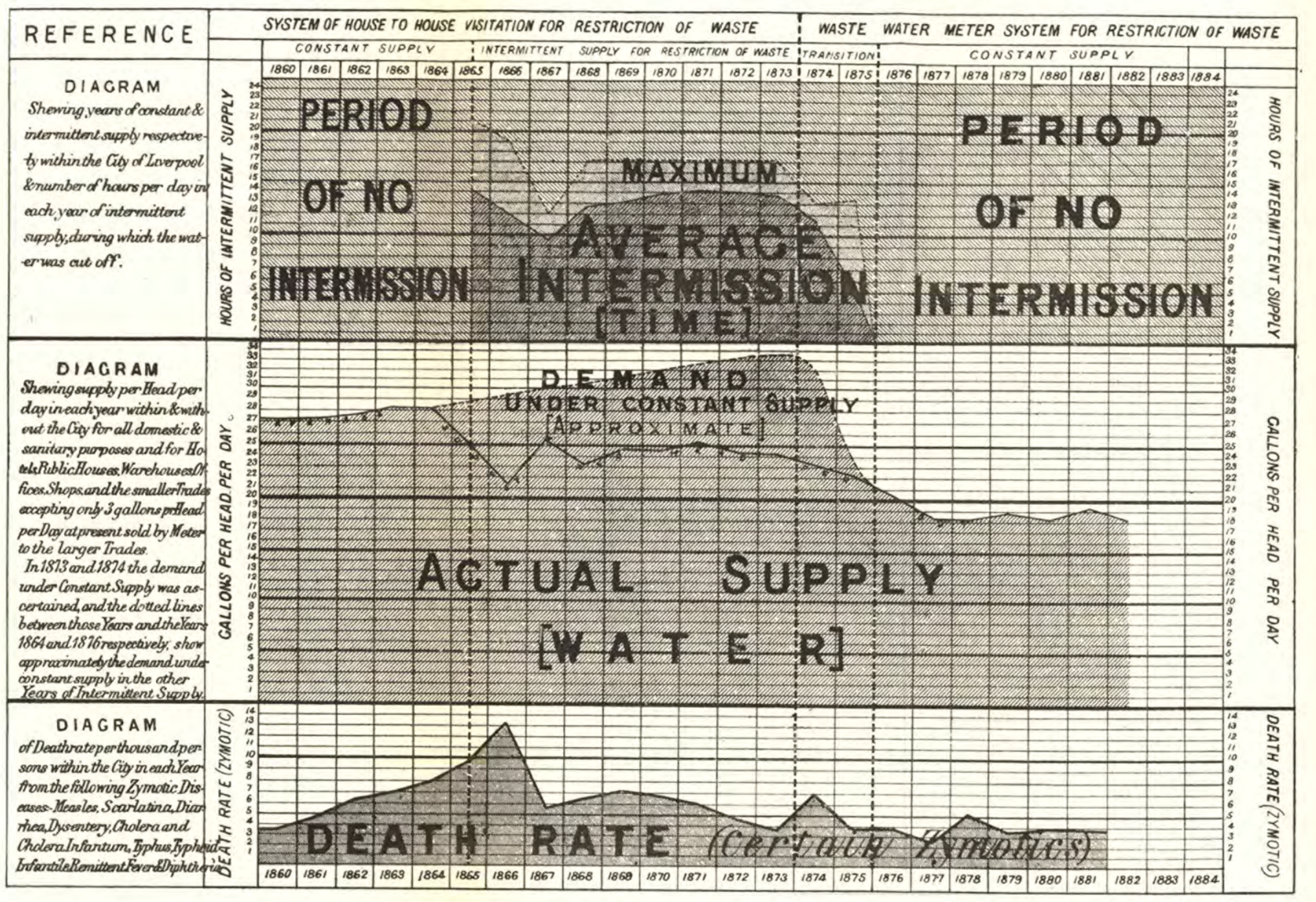


"It is readily seen that the secret of the success of this system, as compared with that of house-to-house inspection, is due to the facts-1st, - that the inspectors are always working in the most wasteful districts ; 2nd, - that the time occupied in inspection is greatly reduced; 3rd, - that the hidden as well as the superficial waste is detected.

"That the inspectors are always working in the most wasteful districts has already been shown. That the time occupied in inspection is greatly reduced may be shown as follows :-

" Under the ordinary system of house to-house visitation, one man, in one day, can inspect on the average the dwellings of about 180 persons. Under the waste-water meter system, the wages paid to him frequently suffice for the thorough inspection of the premises occupied by more than 1,000 persons.

"That the invisible as well as the visible waste is detected, has already been explained. This invisible waste frequently exceeds, on the average, one-half the whole waste, and where a thorough house-to-house inspection, occupying a given number of men a given time, and detecting a given quantity of waste, is followed by an inspection under the waste-water meter system, it is generally found that the same number of men suffice to detect two or three times the volume of waste in one-fifth the time. When in conjunction with this fact we take the additional advantage to the latter system of having the inspectors always engaged in the most wasteful districts, its relatively high efficiency is sufficiently obvious.

"Whatever results have been obtained by any other method could have been brought about by the method I advocate much more cheaply, both to the water authority and to the householder, and with far less trouble and annoyance to all concerned. This system has been applied within the last nine years to districts containing more than 1,500,000 persons.*

"The mode of preventing waste when detected is not affected by the manner of its detection. It will be agreed on all hands, that when it is decided to replace a fitting or pipe, that fitting or pipe should, like those to be used in new premises, be of the best possible kind, and should be fixed and adjusted in the best possible manner. A description of the fittings that have stood the test of time and experience would increase this paper to double its length.

* Since 1882, when Mr. Deacon's paper, from which the above is quoted, was read, the system has been applied to districts containing many times the number of
persons here indicated. 
I can, therefore, merely state that the soundness and efficiency of water fittings can only be determined by taking each to pieces, examining each part in detail, and finally testing the whole under pressure. Such an inquisition finds defects in a certain proportion of the fittings made by firms even of the highest and most deserved repute. It has been adopted in Liverpool with marked success.

"The fittings there used are such as encourage, rather than discourage, the proper use, while restricting the waste of water. No pea ferrules or other obstruction to the flow of water are permitted; no taps in which the duration of flow is limited are required, except for out-door stand pipes; and water-closets are not allowed to have new cisterns providing a flush of less than two gallons.

"The respectable local plumbers have been invited to sign an agreement to conform to the water regulations issued by the Corporation. The incentive to them to do so is the advertisement of their names on the backs of the waste-water notices. A plumber's name may at any time be erased if he fails to comply. In practice it is found that work is rarely performed except by men whose names appear in the list, and there is, therefore, no sale except for fittings tested and stamped by the proper officer of the Corporation."

There is some difficulty in working out the district meter system just described in cases where the "interlacing" system of distribution mains is adopted. It is quite possible, however, by a little ingenuity to get over this difficulty. It will have been observed that the district meter is really not brought into operation to measure water, except during the night, or at any rate need not be brought into operation. Where the "interlacing" system of distribution mains is adopted, it is not possible to divide a town into districts each of which is supplied by one inlet only. This has been fully explained in Chapter XVIII. As, however, it is necessary to take readings by the district meter during the night only, there is no objection to closing all the inlets but one to any particular district. At the inlet allowed to remain open there is a district meter. The only objection there can be to this arrangement is that, in the case of a fire in the district being "metered," there might be delay in opening the sluice valves that had been closed to isolate the district, with the effect that the water supplied to extinguish the fire would be only at the rate that could be obtained with a dead-end system. 
Sale of Water by Meter.-In this system the water used in every house is charged for at a uniform rate just as gas is, the price being, as a rule, from a few pence per thousand gallons upwards.

At first sight it might appear that there is little difference between this system and the district meter system-at any rate so far as the results are concerned. There is, however, a great difference. If the district meter system be properly carried out, leakage can be detected and stopped, but every inhabitant of the town is free to misuse water to any extent that he likes, and there are always many who use water extravagantly if there is no check on them. With the domestic meter system every householder has to pay for all water either used or misused in his house, and he naturally inclines to do all that he can to prevent the misuse.

The sale of water by meter has been customary for long in the case of factories or other establishments that use a disproportionately large quantity of water, and at first sight it might seem the simplest thing possible to apply the system to every house in a town, and that there are very decided advantages in so doing; but the matter is not so simple as it may at first appear, and there are some doubts as to its advantage. Those who are opposed to the sale of water by meter argue that the custom leads not only to a great reduction of the misuse of water, but is liable to lead people to stint themselves in the legitimate use of water, especially by the poorer people, who need particularly to be encouraged in the legitimate use of water, as it is with them that epidemics most commonly break out. To this the advocates of the complete domestic meter system reply that experience has proved that there is no harmful stinting in the use of water when people have to pay for it as for gas; that statistics point to a diminution of diseases commonly attributed to insanitary conditions where the sale of water by meter has been introduced. It is not to be argued from this that the diminution in the use of water arising from the introduction of the domestic system actually results in an improvement of the health of the people, but merely that it does not check the improvement proceeding on account of decided improvements in the general sanitary condition of a town.

A great and very palpable difficulty in the way of adopting the domestic meter system lies in the first cost. In some Continental cities where the average number of people to one house 
is very large - a notable case will be mentioned farther on-the first cost of meters may not be very great; but where, as in ordinary cases, there is one house to every six to eight people, the first cost of providing meters bears a very large proportion to the whole first cost of waterworks. It may increase the total cost of the works by 50 per cent. In a recent discussion on the meter system, it was stated that in a certain instance where it was tried the saving of water did not cover the interest on the first cost of meters, together with wear and tear and depreciation.

Then comes one more difficulty, which is that, in spite of all the ingenuity that has been spent on the matter-and it is very great -it can barely be said that a perfect meter has yet been invented-that is to say, there is no meter that has not some objectionable features, at least when used in certain cases. If we are to take the word of water-meter makers themselves, there is no meter approaching perfection. Each maker condemns the productions of every firm but his own, without stint, generally giving figures in support of his statements !

It would appear, at first sight, a very much simpler thing to design a meter to measure water, at a comparatively high pressure, than to measure so very light a fluid as coal gas, under a pressure corresponding to an inch or two of water, but it has not proved so.

Meters may be classified as positive and inferential. In a positive meter some vessel of known capacity, generally a cylinder, is filled and emptied as the water passes, and a record is kept of the filling and emptying. A positive meter is, in fact, a watermotor, with a counter to keep a record of the number of strokes or revolutions. In an inferential meter a vane, or fan, is caused to revolve by the velocity of flow of water. An inferential meter may be said to be the converse of a screw-propeller, with a counter to keep a record of the revolutions. It is, in fact, a kind of turbine.

Positive meters of the best designs are very exact in their measurements, whether the rate of flow be small or large. They are, however, of comparatively large size, are expensive, and some of them-some positive meters, not some of the best of themhave the efiect of putting considerable "back pressure" on the water, that is to say, of reducing the pressure to a very appreciable extent, and even in some cases of sticking altogether, when the flow of water is completely stopped.

Inferential meters of the best designs will measure water with all the degree of exactness that is necessary so long as the flow of 
water is not very small. (I say all the exactness that is necessary, because it seems to me that it is absurd, when the only alternative is no measurement whatever, to insist on extreme accuracy in the registration of water meters. If the registration is within 5 , or even 10, per cent. of the actual consumption it is near enough.)

The trouble with inferential meters is that there is always some small flow of water with which, or with anything less, the meter registers nothing whatever; and that, with flows not greatly more than those that will just bring the meter into operation, the measurement is very inaccurate, the flow indicated being always less than the actual flow.

Inferential meters can be made to measure, with all the accuracy that is necessary, the flow of water through a domestic tap of even small size. It is therefore possible, by the use of inferential meters, to measure all the water actually used, provided the constant supply system be adopted in its integrity, without any cisterns at all in houses, all water being drawn from the service pipes direct, through taps of such design that it is not easy to let them "dribble." A slight continual leakage-really wasting a large quantity of water-may, however, continue undetected by an inferential meter. There is also the difficulty with them that they will not register all the flow of water into cisterns. If only a moderate quantity of water is drawn from a cistern, the ball-valve falls but a very short distance, and the cistern is filled up merely by a dribble of water. Indeed, however much water is drawn off, the last part of the operation of filling up the cistern is by a dribble. Several arrangements have been worked out whereby, in the case of a cistern, the ballcock does not act till the water in the cistern is considerably lowered, when it suddenly opens " full bore," and discharges full bore till the cistern is filled up again. The writer is not, however, aware that these appliances have anywhere been extensively adopted. They all have the objection of reducing the useful storage capacity of a cistern, without of necessity reducing the average length of time that water stagnates in it, and if there is any apology for the storage of water in eisterns in houses, when the constant system is adopted, it is that it provides a certain storage of water that may be useful at the time of an emergency.

Inferential meters are generally compact in form and of comparatively low cost, and they do not put any appreciable back pressure on the water unless they are worked beyond their capacity. In this connection it must, however, be observed that 
some makers of meters advertise their sizes as capable of measuring quantities of water that they are not capable of measuring without considerably reducing the pressure. This is done to make their prices compare favourably

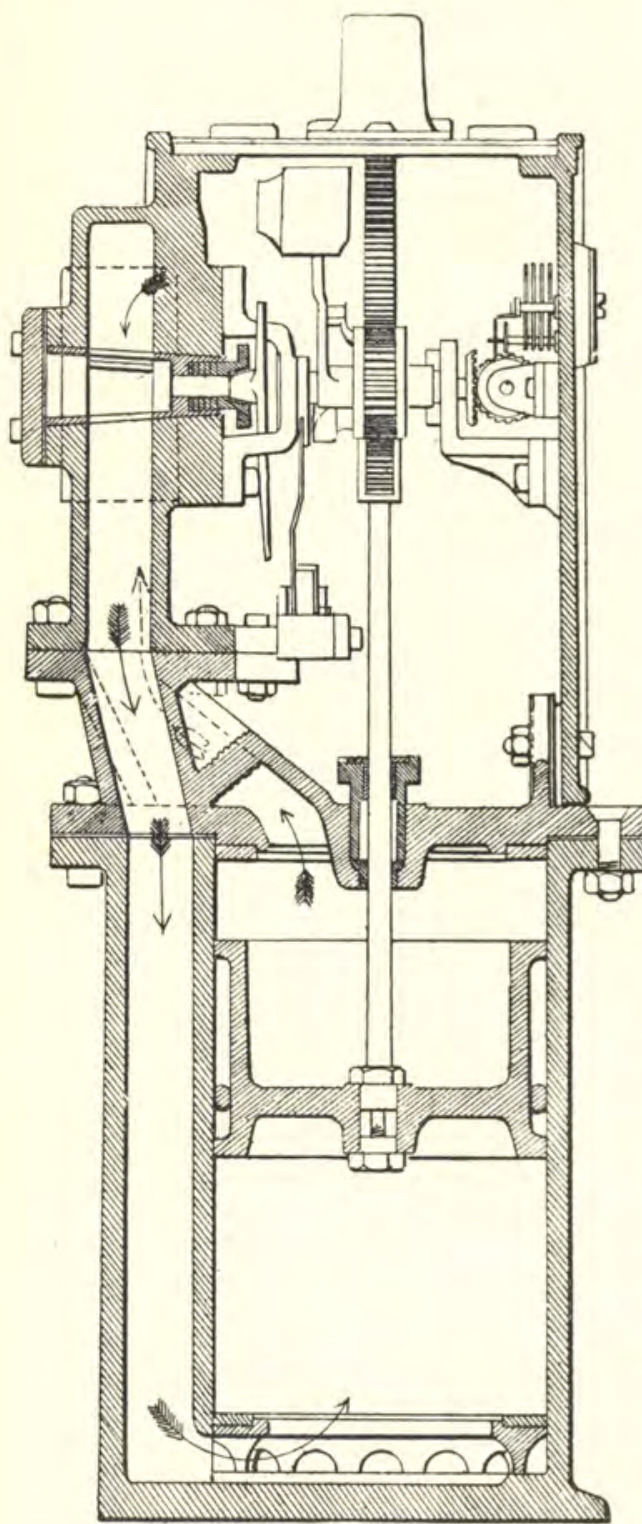

Fig. 232.-Kennedy's patent water meter. with those of other makers who are more scrupulous.

Kennedy's patent water meter, which is illustrated in section here (Fig. 232), may be taken as typical of positive meters. It will be seen that it consists essentially of a cylinder and piston. The piston is actuated by the water, and there is a train of wheels, with dials and pointers, that keep a record of the number of strokes made, exactly as in the case of an engine counter. The number of single strokes, multiplied by the capacity of the cylinder, less the clearance, and the cubic capacity of the piston is, of course, the consumption of water in any given time.

The first, or one of the first inventors of inferential meters were Messrs. Siemens and Halske, whose meter in its most recent form is illustrated by Figs. 233 and 234 . The arrows show the direction in which the water flows. The openings $\mathrm{B}, \mathrm{B}$, are tangential, and the water flowing through them causes the vanes to revolve with a velocity that ought to be proportionate to the discharge of water, that is so to all intents and purposes for any but very small discharges. The vanes actuate the spindle c, and this, in its turn, 
actuates the train of wheels at $\mathrm{D}$, which again actuate pointers, indicating on a dial the amount of water that has passed the
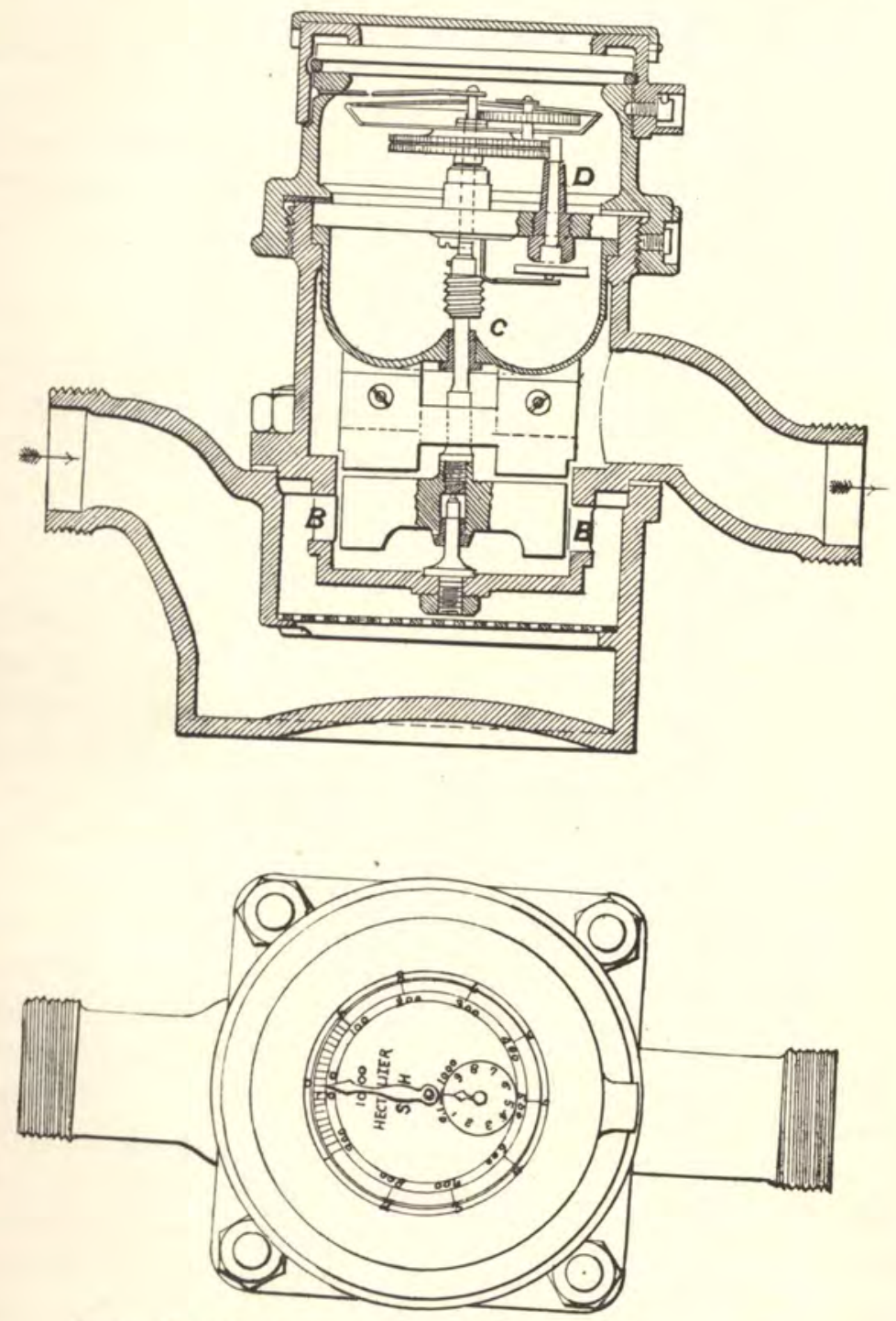

Figs. 233, 234.--Siemens and Halske's patent water meter.

meter in a given length of time. When it is taken into consideration that the drawings are two-fifths of full size, it will be seen how very compact this meter is.*

* The writer wishes it to be distinctly understood that he does not recommend the meters he has illustrated and briefly described to the exclusion of others. He kind, the first in the field. typical, and because he believes that each was, of its 
Many are the suggestions that have been made as to the means of doing away with the difficulties attending the application of the domestic meter system, and the objections that have been advanced against it. Thus, in connection with the statement that selling water by meter is likely to lead to a stinting in its legitimate use, it has been suggested that any quantity of water not exceeding that considered essential to health should be sold for the use of all inhabitants at a comparatively low rate, all used in excess of this at a higher rate. This suggestion seems a very reasonable one.

Again, in connection with the high first cost of meters, it has been suggested that municipalities or companies supplying water should obtain power to supply water by meter, and charge for it in proportion to the quantity used, but should not "meter" a whole town, but take advantage of the privilege of selling the water by meter only in those cases where it is suspected, or ascertained, that the consumption is much above the average. Certainly it would be a check on the extravagant consumption of water, if all consumers knew that, if they were extravagant with the water, they were liable to have a meter clapped on, and to be charged according to their consumption at a pretty stiff rate.

The gradual introduction of the domestic meter system in Berlin, from 1865 to 1885 , with the most marked success, gave a great stimulus to the sale of water in measured quantities. ${ }^{*}$ It is not, however, to be concluded that, because the system has been so successful in the case of Berlin, it will of necessity be successful in all other cases. There are certain circumstances that make the system particularly applicable in the case of Berlin, the principal of these being the fact of the existence of the "flat" system of residence. Families, with their servants, do not, as a rule, live in separate houses, but live each on a flat, or part of a flat, of a large house. The consequence is that there is an average of very nearly seventy people to each house. This means that there are about ten times as many as is usual, and as only one-tenth part the number of meters are necessary, the first cost is not much more than one-tenth what it would be in most cases.

Whatever may be said on one side or the other, the fact

* See "The Sale of Water by Meter in Berlin," by Henry Gill, M.I.C.E., Proceedings of Institution of Civil Engineers, vol. cvII. Figs. 233 and 234 are taken from this paper, which, with the discussion and correspondence printed with it, affords the fullest information that is, at the time of writing, to be had on this much disputed question of the sale of water by meter, or in accordance with some empirical standard. 
remains that the general adoption of the sale of water by domestic meters has greatly increased on the Continent of Europe during the last few years. To judge by the advertisements in technical periodicals, the use is increasing rapidly in America too. Domestic meters appear to have found less favour in England than in most other countries.

There are certain circumstances that point to the adoption of the domestic meter system in particular cases. One is that already indicated, that is to say the residence, on an average, of an unusually large number of people in each house.

Again when, on account of the great first cost of waterworks, or the high cost of working, it is necessary to collect, in one way or another, a comparatively large sum per head of population-in other words, if the water is unusually dear -it is evident that the meter system is more applicable than where water is cheap.

There are cases in which the general adoption of the domestic meter system is clearly advisable. Thus let us suppose the case of a town with a limited supply of water, the consumption increasing partly on account of increase of population, but undoubtedly also partly on account of the extravagant use, or the misuse, of water, not to mention leakage; and let us further suppose that the price of increasing the supply would be greatly more than the price of " metering" the town-or that, perhaps, it is prohibitive altogether: there can be no doubt that the general introduction of domestic meters would be the best step to take. The reason is that, by this means, the consumption can be reduced to a lower point than by any other means. 


\section{CHAPTER XXIl.}

\section{Various Appliances used in Connection with Waterworks.}

MANY of the most important appliances used in connection with waterworks-such as fire-hydrants, meters, and the likehave already been incidentally described at sufficient length, but there are others which have merely been mentioned or have not been mentioned at all. It seems necessary to give some description of the most important of them here.

Sluice Valves. - If number and first cost be a criterion, sluice valves-or, as they are commonly called in America, "gates"-must be considered as the most important subsidiary appliance that is used in connection with waterworks, except where the domestic meter system is introduced for all the houses, when the meters have the honourable position of being first in the matter of number and cost. The necessary number of sluice valves is particularly great where the interlacing system is adopted.

The general object in the use of sluice valves has been pretty fully described in the chapter on "Distribution Systems," and practice has resulted in the evolution of a form of sluice valve that is not much departed from by different designers or makers.

As long as a sluice valve fulfils certain conditions it is suited to its purpose. Thus it must not, when open, obstruct the flow of water in any way. This involves that, when open, it should leave a clear way of the full area of the pipe. Not only this, but sharp bends should be avoided, although the ill effects of these have, the writer thinks, been over-estimated. This puts the screwdown stop-valve type out of the question, and the type now universally adopted is the true sluice valve, in which a gate across the full bore of the water closes the valve, the gate being completely withdrawn from the bore of the pipe into a recess on opening the valve. 
Sluice valves should be perfectly water-tight when they are closed, and, moreover, should not be liable to "stick" if left for an indefinite length of time either open or closed. This involves the necessity of having at least one of every two parts that rub of brass or gun metal. That is to say, all rubbing parts must either be "brass to brass," or " brass to iron." "Iron to iron" is not permissible, as the result would probably be fast sticking through rusting up. The valve faces, and the seats on which these bear, should both be of gun-metal. The spindle also should be of gun-metal, although it is sometimes made of iron. In either case it should work in gun-metal bushes or liners.

Figs. 235 and 236 (Plate XLIV.) illustrate a good type of sluice valve.

There is often much difficulty in opening very large sluice
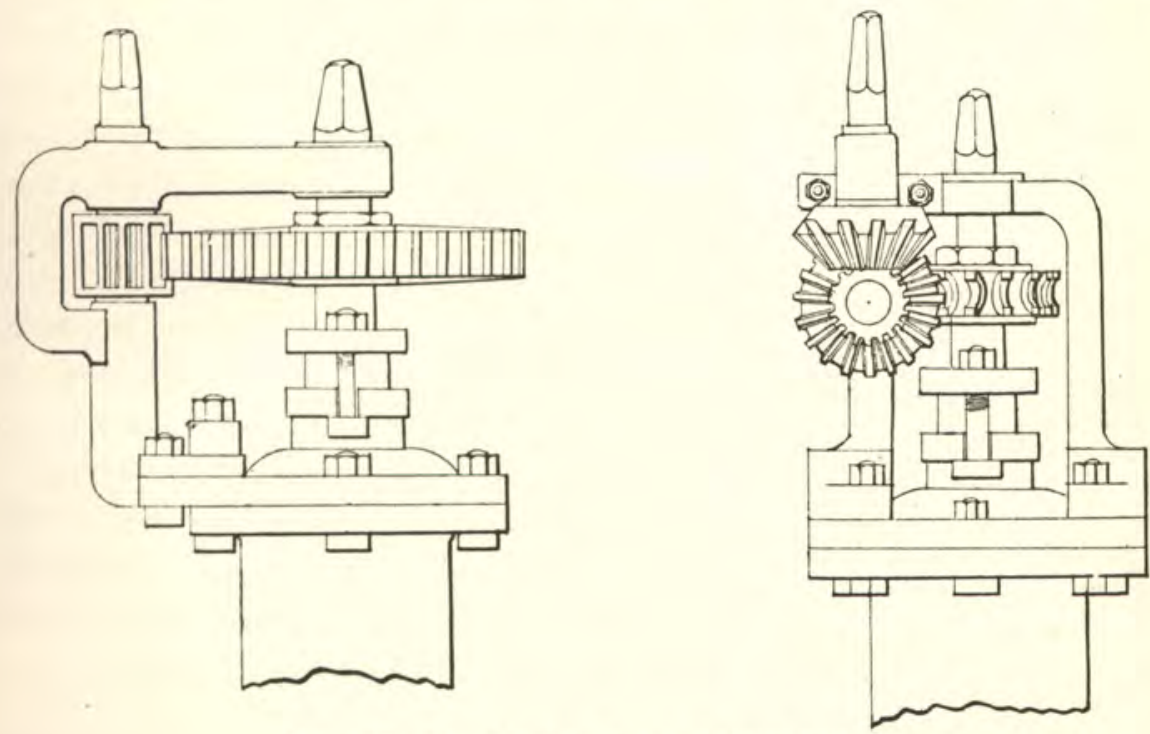

Figs. 237, 238.-Gear for opening sluice valves.

valves, entirely apart from any actual "sticking." This is especially so where the pressure is high, the friction caused by this pressure on the back of the slide being such that the force needed to open the valve, to such an extent that the difference of pressure on the two sides of the slide is nearly equalized, is very great.

Several arrangements have been devised for getting over this difficulty. In one of the neatest, a comparatively small slide works on the back of the large slide : the diameter of the small slide may, for example, be only one-third that of the pipe. The action is as follows :-On screwing the valve spindle to the right-in the direc- 
tion of the hands of a watch-the first effect is to open the small valve. Water flows through the aperture thus made with great velocity, not more than a few pounds of head at the most being, however, needed to produce this velocity. This few pounds of difference in pressure between the one side and the other of the great valve is not sufficient to cause much friction, and the effect of continuing to turn the spindle is to open the great valve.

Somewhat less neat, but nearly as effective, is the plan of having a by-pass with sluice valve, say one-third the diameter of

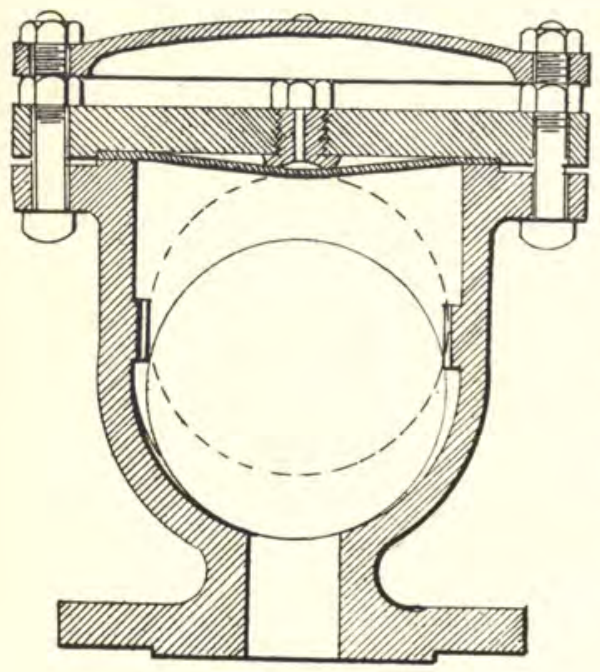

Fig. 239.-Air valve for waterpipe. the great valve. The small sluice valve is opened first, the great one afterwards.

An arrangement that is more common than either of these is to apply the force necessary to open the great valve through certain gearing, giving a man enough purchase to move it in spite of the pressure on the back. Such gear is illustrated in Figs. 237 and 238. Unless the water pressure is inconsiderable, such gear as this is advisable for all sizes of sluice valves above about 2 feet in diameter. For extraordinarily large valves, or even for such as are not extraordinarily large but have to work with an unusually high pressure, even more powerful gearing than that illustrated may be needed.

Air Valves.-At any place where a pipe rises over any eminence, however slight, air is liable to accumulate, and to interfere seriously with the flow of water. It is customary, especially on long lengths of pipe where such eminences occur, to fix an air valve - a simple automatic device whereby any air accumulating is allowed to escape.

All air valves are on the same principle. One which is illustrated here (Fig. 239) barely needs description. It will be seen that the whole arrangement consists of a ball in a cast-iron casing. The ball is made of some material lighter than water, and floats (as shown in dotted lines) as long as there is no air in the pipe, bearing against a rubber sheet or ring above it, and closing a small 
Plate XLIV.

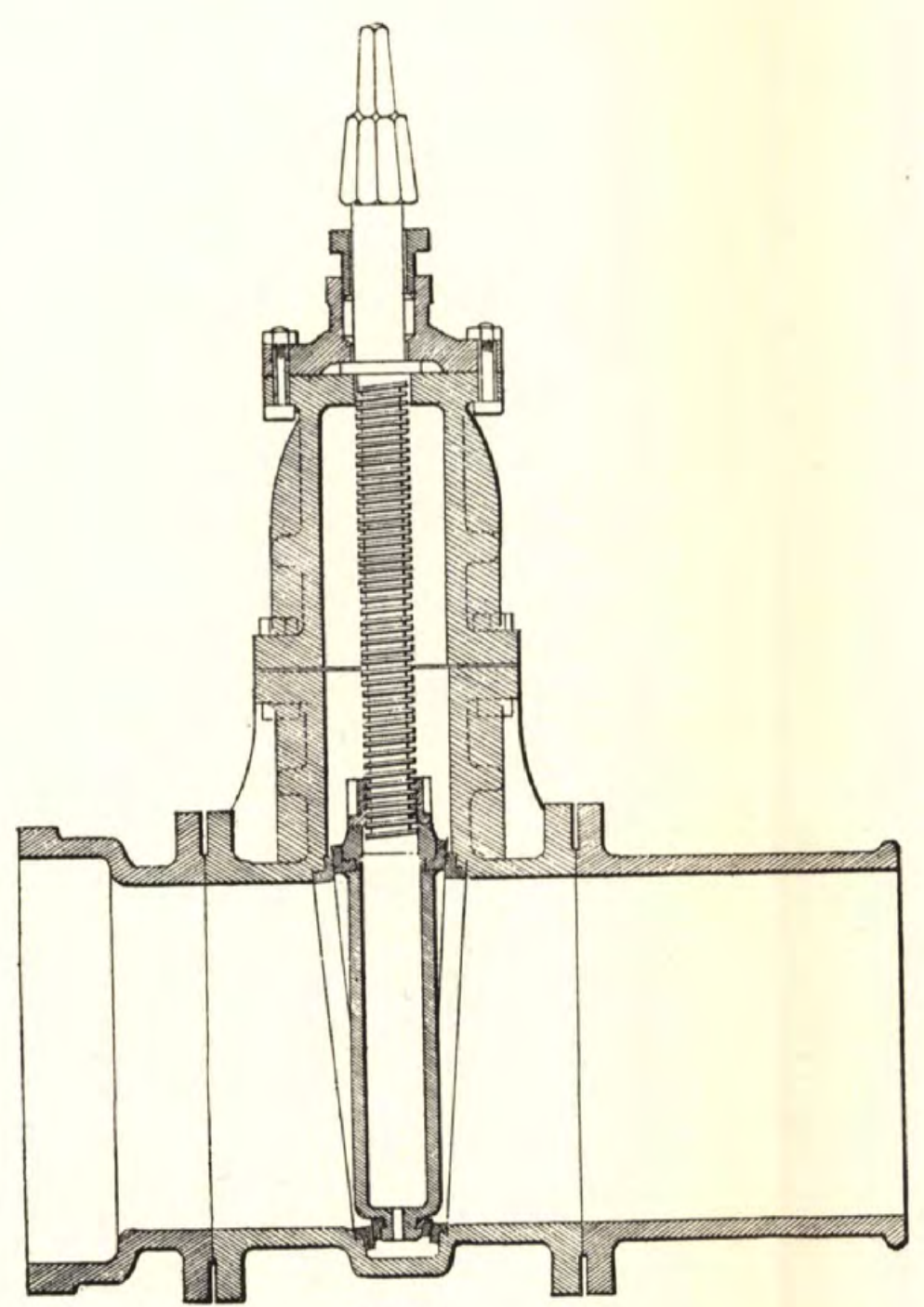

Fig. 235.

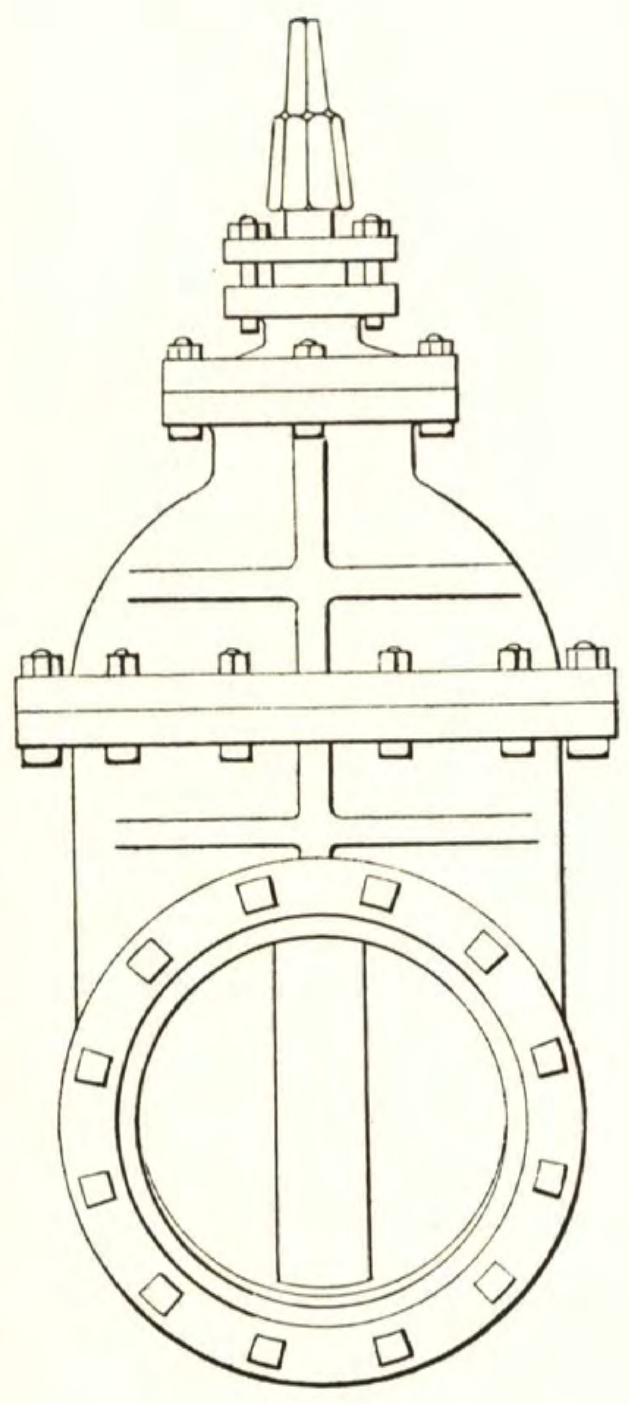

Fig. 236.

Sluice Valve.

[To face page 264. 
hole that can barely be seen in the cut. If any air accumulates in the pipe, it rises to the highest place to which it can get accessthat is to say, to the casing holding the ball. The ball has now no longer any support and falls, for the area of the hole is so small

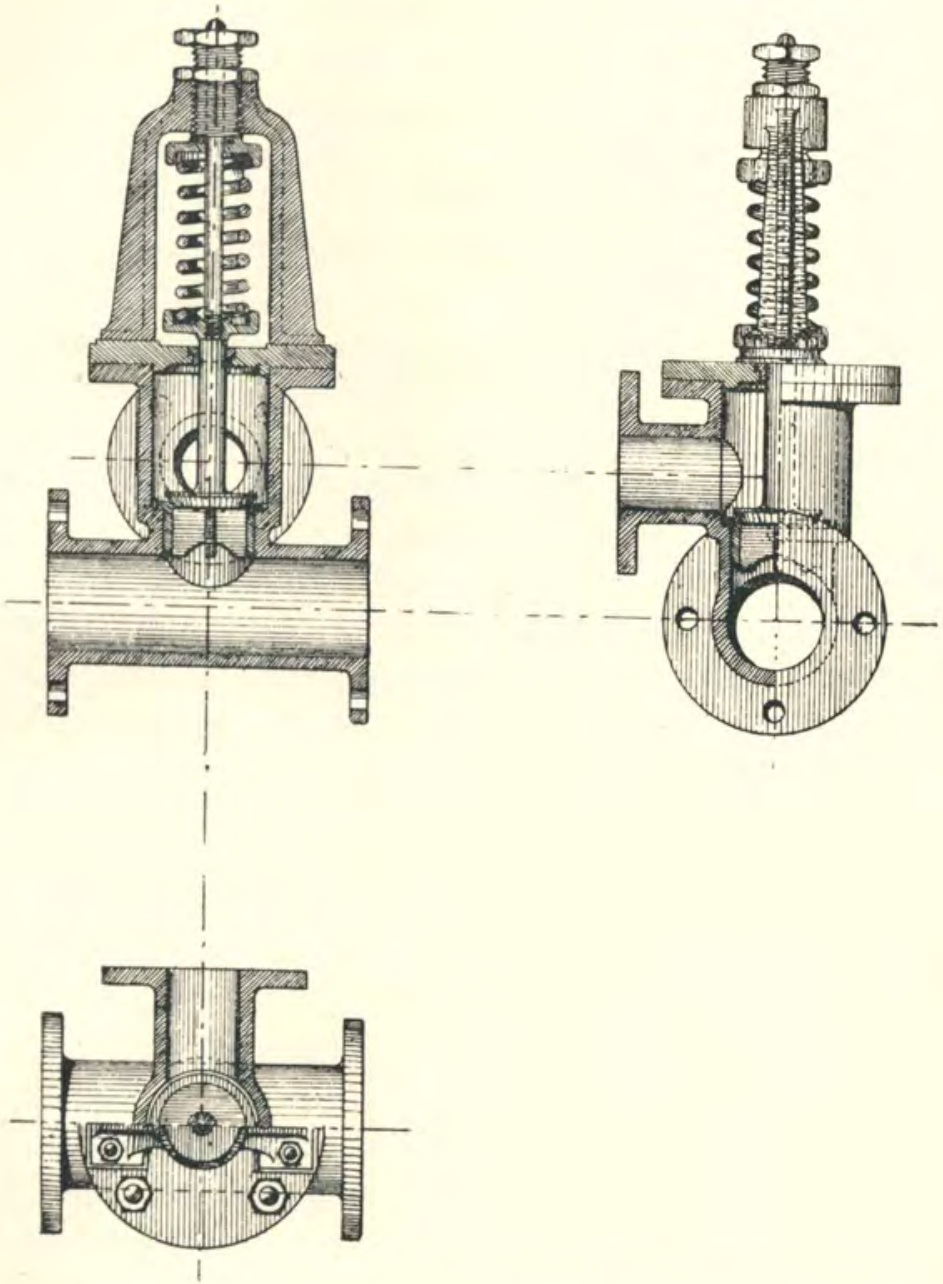

Figs. 240, 241, 242.-Spring and screw-down safety valve. Scale, $1 \frac{1}{2}$ in. to $1 \mathrm{ft}$.

that the pressure of the air will not sustain the ball. When the ball falls, the air is forced through the small hole till the water rises again and once more floats the ball and closes the opening.

Safety Valves.- “ Ramming," as a danger in connection with the flow of water in pipes, has already been mentioned (p. 225). It is particularly likely to show itself in the case of long pipes, with 
water running at any high velocity, if there is a reduction at all sudden in the velocity. As a safeguard against accidents by ramming, it is advisable to fix a safety valve at the lower end of any pipe where it is expected that the evil results of ramming may show themselves.

It is to be observed that a "dead-weight" safety valve is objectionable, as the inertia of the dead weight may allow of just as severe ramming as if there were no safety valve at all. There is not the same objection to a spring, and springs with screw-down arrangements are often used (Figs. 240, 241, 242).

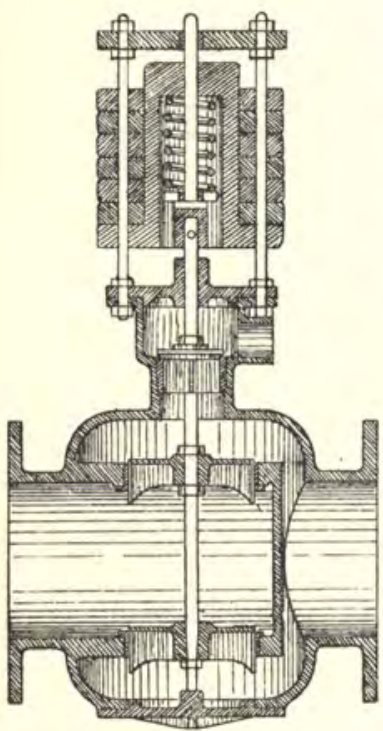

Fig. 243.-Large safety valve for use on water mains.

Some, however, like the idea of the "positiveness" of a weight, and it is possible to get the advantages of both a spring and a weight, by compressing the spring with the weight. In case of ramming, the spring is first compressed, then raises the weight. (Such a valve is illustrated in Fig. 243.) A safety valve to be of real service must be of large size, and there is the difficulty, with a valve of the form shown, that, especially in the case of pressures at all high, the springs must be very strong.

Fig. 243 shows a large safety valve designed by the writer and Mr. Hasegawa, in which these difficulties are overcome. It is intended for attachment to the lower end of a 20-inch main, several miles long, in which the velocity will be considerable, to be used in connection with the waterworks of Kobe, Japan. The arrangement consists of a balanced valve connected with a piston of considerably smaller area than either of the halves of the valve, actuating the balance valve in case the water pressure becomes great enough to lift the weights shown.

It is to be observed that such a valve would probably not be quite watertight. In the position in which it is to be fixed, at the lower end of a long pipe constantly discharging into a filter well, some leakage is of no consequence. Such leakage has simply to be carried to the filtering well.

Stand Posts, Drinking Fountains, \&c.-Drinking fountains in public places, for man and cattle, are familiar objects to all, and it would be superfluous to describe then here. 
Stand posts, or draw-off posts, are sometimes largely used in the poorer districts of towns to enable people who are too poor to have water carried into their houses to draw the supply they want. These people are commonly taxed a small sum for the privilege of drawing as much water as they need. As the water has all to be carried away from the stand-posts by hand, there is not likely to be any great waste. Very often pillar hydrants are used as draw-off posts, an additional small valve being attached; or rather, stand-posts perform the functions of both pillar hydrants and draw-off posts. If the catalogue of any maker of waterworks fittings be consulted, a number of designs for draw-off pillars will be found.

The stand pillar shown in Fig. 244 is from the catalogue of Messrs. J. Blakeborough and Sons, London. It has the advantage of being very cheap. It is not, however, as some more expensive posts are, fitted with a "self-closing" valve. The object of the self-closing valve is, of course, to prevent waste, by leaving the valve open after the drawing of water, so that there is a continuous flow. Such self-closing valves are certainly an advantage, but it will be seen that they are not as essential as might at first sight appear, if it is considered that stand-posts are generally purposely placed in somewhat conspicuous positions, and that a continuous flow is nearly sure to be very quickly noticed.

\section{Connection of Service Pipes with Mains.-} Service pipes-pipes, that is, leading water from the mains of waterworks into houses-are most

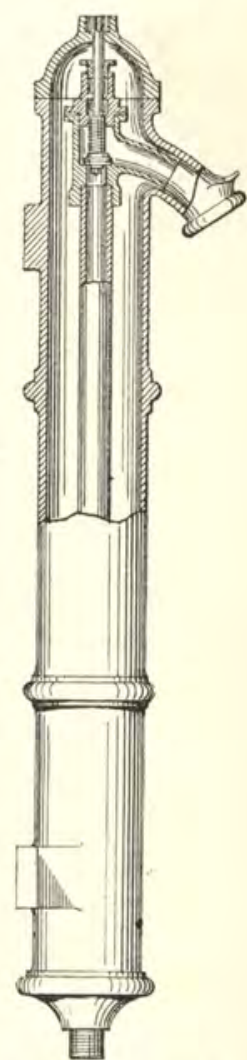

Fig. 244. - Blakeborough's stand pillar. commonly made of lead, spite of much that has been said and written about the possibility of lead poisoning from the use of such pipes. It is true that there are a few waters-very soft, and generally in other respects very pure-that have a continuous solvent action on lead, ${ }^{*}$ and that it is dangerous, in the case of such waters, to use lead pipes or lead-lined cisterns. Such waters are, however, very exceptional. The writer has not actually come across an instance of one. In nearly all cases the effect 
of the water is quickly to cover the lead with a thin film of an insoluble salt of lead, after which all further action ceases.

The great durability of lead, the ease with which it may be handled, and especially the facility there is, in the case of pipes, of bending it cold, make it commonly preferred for service pipes, although wrought iron is used to some extent (the writer believes) - -more in America than in other countries.

To make a connection between a cast-iron main and a service pipe of lead, a ferrule of brass is used. A hole is bored in the cast-iron pipe, and this hole is either "tapered" or screwed, according to the kind of ferrule that is to be used. Tapered ferrules are shown in the Figs. 245, 246. They are simply hammered into a coned hole in the cast-iron pipe.
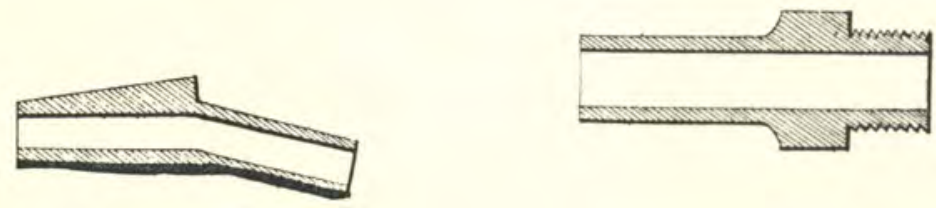

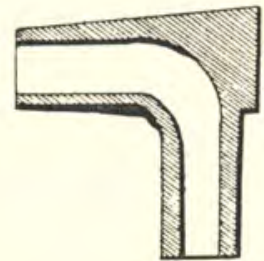

Figs. 245, 246.-Tapered ferrules for connecting waterpipes.

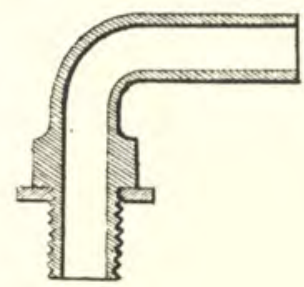

Figs. 247, 248.--Screwed ferrules for connecting waterpipes.

Screwed ferrules are illustrated in Fig. 247, 248. They are much to be preferred to tapered ferrules. In hammering a tapered ferrule into a pipe, there is always the possibility of splitting the latter, especially if it is thin. Moreover, if the water pressure be high, there is the chance that the ferrule will be driven out, though it must be admitted that such a thing very seldom takes place unless some other force be applied besides that of the water pressure. Even a slight tapping with a light hammer will, however, sometimes loosen a taper ferrule, when out it goes with the water pressure. It is conceivable that the vibration produced by heavy traffic overhead may act in the same way 
at times. In any case the screwed ferrule is to be preferred, and the difference in price is not great.

The ferrules illustrated are generally sent out ready "tinned," so that a lead pipe can quickly be attached to them by a wiped joint.

There are certain advantages in a ferrule, or coupling, that does not involve a soldered joint. These advantages will be particularly felt in remote countries, where it is difficult to get the services of skilled plumbers. Fig. 249 illustrates such a ferrule or coupling. It scarcely needs explanation. By coning out the end of the lead pipe a little, so as to give it the shape of a trumpet-mouth, and screwing home the nut, a watertight joint at once results. Sometimes "screw-down " or "plug"

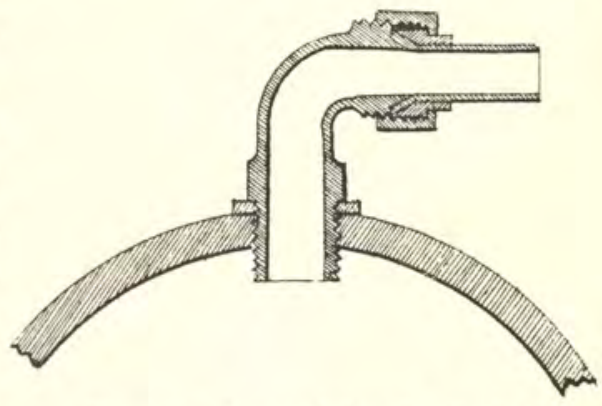

Fig. 249.- Screwed ferrule attached to waterpipe. ferrules are used. These form, in fact, a combination of a ferrule and a stopeock. One of the many forms of these is illustrated in connection with a pipe tapping tool on the next page.

Wrought-iron pipes may be screwed directly into the mains, though it would be better to have a brass coupling screwed at one end to enter the cast-iron pipe, at the other to receive either a coupling, a nipple, or the screwed end of a pipe.

Boring and Tapping Pipes under Pressure.-Naturally an attempt will be made, as waterworks come near to completion, to see that there is a ferrule inserted at every place where a service pipe is likely to be wanted before the pressure is finally turned on ; but it must often happen that after a time the need for further connection of service pipes with the mains occurs. With the intermittent system there is no difficulty. The pipe is bored and tapped, and the ferrule inserted during the hours that the water is "off." Even with the constant system it is a common custom to turn the water off a certain district during the small hours of the morning, to permit of the making of a connection, but this is a custom by no means to be encouraged, as will be understood if the possibility of the occurrence of a fire be taken into consideration.

The undesirability of shutting the water off a whole district to 
permit of the making of a single house connection has resulted in the invention of various ingenious machines, whereby it is possible, whilst a pipe is under pressure, to bore it, tap the hole, and screw in a ferrule. One such is illustrated here (Figs. 250, 251, 252), which will be readily understood with only a very short explana-

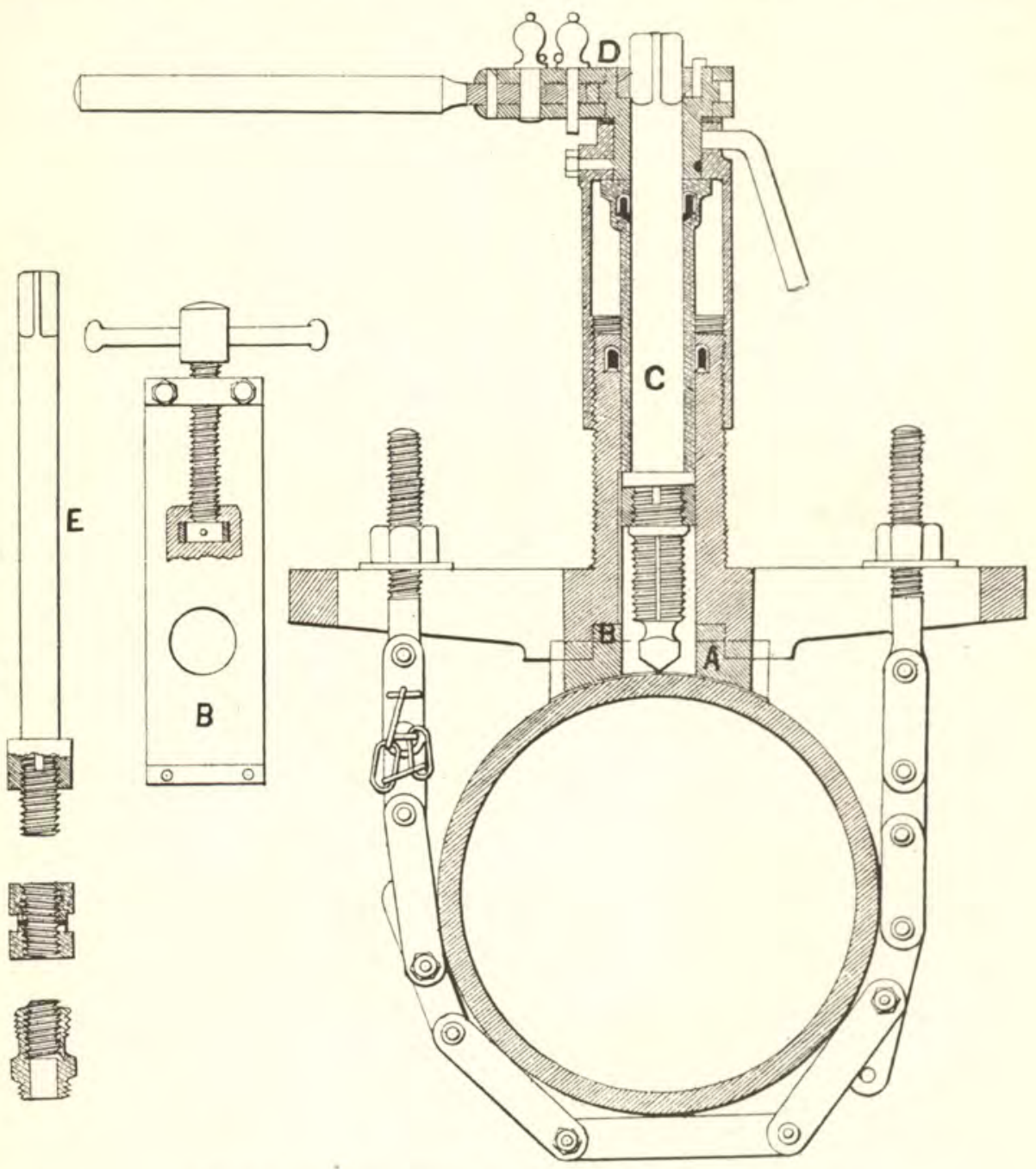

Figs. 250, 251, 252.-Gear for connecting pipes to mains.

tion. It will be seen at once how, by the aid of the chain, bolts, and nuts, the whole gear can be attached to a main where a connection has to be made. The packing-piece $\mathrm{A}$ has to be changed for different diameters of pipe. The rest of the gear does equally well for all diameters of pipe.

The slide $\mathrm{B}$, it should be understood, really forms a sluice valve, 
by means of which, after the hole has been bored, water can be shut off from the upper part of the apparatus.

The spindle c carries a combined drill and tap to be worked by the ratchet at D. Cup leathers prevent water from escaping around the sides of this spindle. The pipe is, of course, first drilled, then tapped. After this the drill and tap are withdrawn to such a height that the slide в can be closed, when the spindle bearing them is withdrawn altogether. It is then replaced by the spindle $\mathrm{E}, *$ by means of which the lower half of the patent stop valve ferrule can be screwed into the cast-iron pipe.

This ferrule is illustrated in Figs. 253 and 254. The plug A, when it is screwed down, closes the passage from в to $\mathrm{c}$; when it is raised, it leaves that passage open. At the time that the lower part of the ferrule is screwed into the pipe the plug a is screwed home.
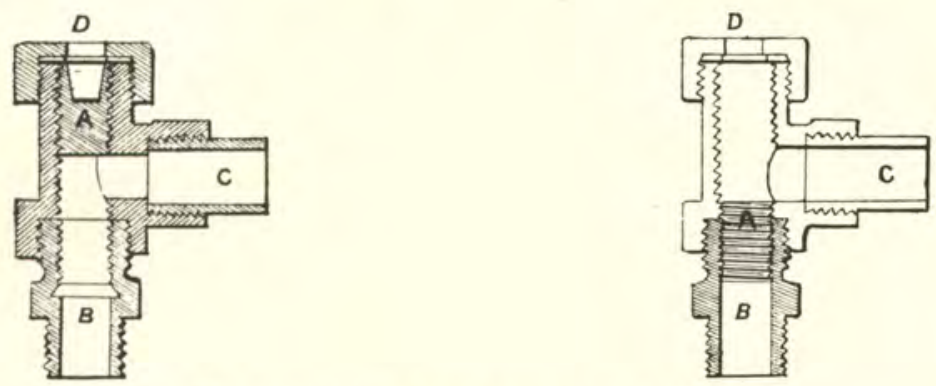

Figs. 253, 254.-Patent stop-valve ferrule.

The whole of the gear may now be removed, and the upper half of the ferrule may be screwed to the lower half.

The lead pipe is afterwards connected to c, and at any time the plug $\mathrm{A}$ is screwed upwards till it reaches the position seen on the left-hand side cut, when the passage from the main to the service pipe is clear. A cap, D, serves to prevent the possibility of a slight continuous leakage past the screw of the plug. If it is necessary to shut off the water from the service pipe at any time the plug can be screwed down again.

The gear here described is that known as Morris's apparatus, manufactured by Messrs. J. Stone \& Co., of London. It is certainly about the best of several gears all having the same object. The only objection that there can be to it, is that the combined drill and tap is an expensive tool liable to be broken just below the tap in careless hands. In another apparatus, of which

* By a mistake in the drawings, the spindles $\mathrm{C}$ and $\mathrm{E}$ are shown of different diameters. They are, of course, of the same diameter. 
the writer has not drawings by him, there are three separate spindles, one holding a drill, the next a tap, and the third the ferrule. The whole gear slides on a saddle in the direction of the axis of the main, and thus the drill first, then the tap, and finally the ferrule, are brought over the same point, and are actuated each by its special spindle. The difficulty of the combined tool is thus overcome, but it is naturally at a sacrifice in the matter of the portability of the gear.

In this chapter there have been described only a few out of almost innumerable appliances that have been specially designed in connection with waterworks. They are (the writer thinks) the most important. To describe all would be an interminable work. Any engineer who takes up waterworks practice will naturally provide himself with a collection of the catalogues of the well-known manufacturers whose specialty it is to provide fittings for waterworks, and from these he will get a very good idea of the numerous minor fittings. 


\section{APPENDIX I.}

Considerations concerning the Probable Effects of Earthquakes on Waterworks, and the Special Precautions to be taken in Earthquake Countries. By Professor John Milne, F.R.S.

Prefatory Note.-In different parts of this volume, principally in footnotes, will be found brief references to the effects of earthquakes on waterworks, but they are the merest references. Indeed, the writer does not know of any book or paper treating specially on this subject.

It is probably not too much to say that the greater part of all that is scientifically known about earthquake motion and its effects has come from Japan; and there is not much doubt that as that country is rapidly arlopting modern waterworks there will be, before long, practical examples of the effects of earthquakes on waterworks that will teach much to engineers as to the proper construction of such works in countries liable to earthquake shock; but in the meantime it is possible only to make deductions from theoretical reasoning and from the effects of earthquake on engineering structures generally.

It need scarcely be said that there is no man better able to make deductions of the kind referred to than Professor John Milne, as no man has a more thorough knowledge of the subject. I therefore consider it a matter of congratulation that Mr. Milne has acceded to my request that he write this Appendix, which will be found interesting and instructive to all engineers-not only to those who are specially engaged with waterworks.

W. K. Burton.

Although an engineer of waterworks, when laying pipes, building reservoirs, or erecting water-towers, is carrying out work peculiar to his own profession, the principles that should guide him so that the effects due to earthquakes may be minimized are practically the same as those 
that have been laid down for the guidance of engineering work in general.

The first point to which an engineer's attention may be directed, and a point that cannot be too strongly emphasized, is the selection of a site for the work to be carried out, where experience or experiment shows that the least quantity of motion is likely to be met with.

The history of all great earthquakes-as, for example, that of Lisbon in 1755 -has shown that certain districts have suffered severely whilst neighbouring districts have only suffered partially. One general rule is, that buildings founded upon hard material, which is generally the high ground, suffer less than those that are founded on soft, which is generally the low ground. The difference in motion that is experienced on hard ground, as compared with that experienced on soft, has very often been absolutely measured by seismographs, a fact that indicates the possibility of a seismic survey. Even within a small area, where to the eye the ground will appear to be uniform in character, it has been repeatedly shown that one part of it suffers more motion than another.

On wet and swampy ground, although the period of motion may be long, the amplitude is usually so great that stich ground is unsafe. Steep sloping ground is also bad, soft material often sliding down in consequence of the shaking. The edges of cliffs, scarps, and river banks are also dangerous sites, these forming free surfaces that swing back and forth through a range of motion so great that their outer faces are often completely detached from what is behind them.

For example, it would be unwise either to erect buildings or to lay a line of pipes close to and parallel with the edges of a river with steep banks, whereas a hundred yards back from these banks the situation might be comparatively safe.

The same remark applies to a sunk reservoir; for in the case of such a reservoir of large area, without an arched roof-such as a settling reservoir - it should be borne in mind that the retaining walls or sloping sides act as free surfaces with regard to earthquakes, especially when the reservoir is nearly or quite empty.

That great advantages can be gained by selecting a proper site is indicated by the fact that, in building regulations for districts where earthquakes are frequent-as, for example, in Manilla and Ischiaspecial references are made to the methods of founding on soft ground, and, in many cases, certain areas have been marked off as unsuitable for buildings of any description.

In making foundations, experiment and experience have shown 
that great advantages result from allowing the building to rise from a basement with an open area surrounding it, the motion at a distance, removed from the origin of a disturbance, being not unlike that of water-waves, the amplitude of motion of which is less beneath the surface than it is on the surface.

Regulations in certain parts of Italy respecting buildings require that, when they are erected on soft ground, the foundations should consist of a platform of masonry or concrete, to extend from 3 feet 2 inches to 4 feet 9 inches in every direction beyond the base of the building, the platform itself being, for a one-story building, 2.3 feet thick, and for a two-story building, 3.91 feet thick.

In Japan several buildings have been erected on what are called "free foundations," that is to say the buildings are carried on a layer of shot, or iron balls. On account of the movement experienced at the time of high winds, and also for other reasons, such construction is not to be recommended.

Another principle of great importance which is not to be neglected when designing high structures is that the stresses arising out of earthquake motion, that have to be contended against, are to a large extent applied horizontally. For example, ordinary archwork is condemned in Italy, Manilla, and other places where earthquakes are frequent, as being unsafe. In Ischia it is allowed underground, where the motion is less than on the surface; even in this case it is specified that the arches have a rise of one-third of their span, and that the minimum thickness at the crown shall be $\cdot 82$ foot (one brick) thick. The application of these figures to the construction of reservoirs with arched roofs will readily be understood.

In making dams for impounding reservoirs, it must not be forgotten that these may be subjected to a horizontal shaking, with the result, if they are made of loose material, that this may be disintegrated much in the same way as a pile of sand would be on a shaking table. For this reason it is better, in earthquake countries, to follow the English rather than the American practice in designing dams for impounding reservoirs. In connection with these dams it must be remembered that they may possibly be topped by waves caused by the earthquake motion. This is a strong argument for the adoption of a dwarf wall as a "breakwater" along the top of an earthwork dam in an earthquake country. It might be further advisable to pitch with stones the top and lower slope of the dam, as well as the upper slope, so that if it were merely a case of topping with a few waves in succession, there would not be the danger of cutting away of the earthwork that there would be without the pitching. 
In the construction of walls, whether for a building or for a water tower, we should remember that they should be both light and strong. The opinion sometimes held, that weight, in itself, actually gives strength, holding down a building, so to speak, is a complete delusion. The very contrary is true. Weight, or mass, in itself is a cause of weakness only. Lightness may be gained by the use of hollow bricks, strength by the use of good cement mortar, a cement joint having a tensile strength of perhaps $100 \mathrm{lbs}$. or more to the square inch, whilst a joint made with bad lime mortar may not have a tensile strength greater than 4 or 5 lbs. to the square inch.

The height to which walls are allowed to be carried in the Island of Ischia, for two-storied buildings, is 32.8 feet. Walls of 13 feet high, constructed of simple masonry, must have a thickness of not less than $2 \cdot 3$ feet.

The height to which an ordinary wall of good thickness can be carried with safety, depends upon the material of which it is constructed, and the weight of the top load it has to carry. An ordinary wall of uniform section, when moved backwards and forwards with sufficient rapidity, will finally snap at its base. Therefore it would seem that the strength of a wall ought to decrease from its base upwards.

As the result of experiments made in Japan, an outline for a column of square section may be obtained from the following formula :-

$$
y^{2}=\frac{10 g \mathrm{~F}}{a w} x
$$

Where

$x=$ half the horizontal dimension of any given section measured in inches whose distance from the top is $y$;

$w=$ the weight of a cubic inch of building material in lbs. (if brick is the material, it equals $\cdot 0608$ );

$\mathrm{F}=$ the force of cohesion, or the force upon 1 square inch of surface, which, when suddenly applied, produces fracture (in other words, the tensile strength per square inch when the force is applied suddenly);

$g=$ the acceleration due to gravity, in millimetres, which may be taken at 9660 ;

$a=$ the greatest acceleration per second, per second, measured in millimetres, which the structure may have to resist.

As an illustration, suppose

$a=1,000$ millimetres per second, per second;

$\mathrm{F}=5$ lbs. per square inch.

Then, taking our units in inches, $y^{2}=8,100 x$. The outline of such a figure is given in the accompanying diagram (Fig. 255).

Brick piers of this form, some of which are 110 feet high, were 
constructed by Mr. C. A. W. Pownell, M.I.C.E., for the railway over the Usui Pass in Japan.

If the section be rectangular, and the dimension perpendicular to the direction of motion be constant, as in a wall, then-

$$
y^{2}=\frac{4 g \mathrm{~F}}{a w} x .
$$

The equation gives a wall of zero thickness at the top-a thing that, of course, does not occur in practice. In the actual designing of walls according to this principle, the mean thickness - say the length of one brick-may be added to the hypothetical section got by the equation, or a sufficient length of the impractically thin top part of the section for a higher wall got by the equation may simply be cut off. In either case the section will be as near the theoretically correct one as practice demands.

On the occasion of the great earthquake of Japan, on October 28th, 1891, which overturned railway bridges and engineering structures generally, the greatest acceleration calculated was about 4,000 millimetres per second, per second, or say about 13 feet-in most cases it ran between 5 and 10 feet-per second, per second. These accelerations mean the same as a jerk such as would be produced if a building were standing on a truck, which began to move with velocities equal to the above numbers ; or if, moving with these velocities, it was suddenly stopped.

The third general principle not to be

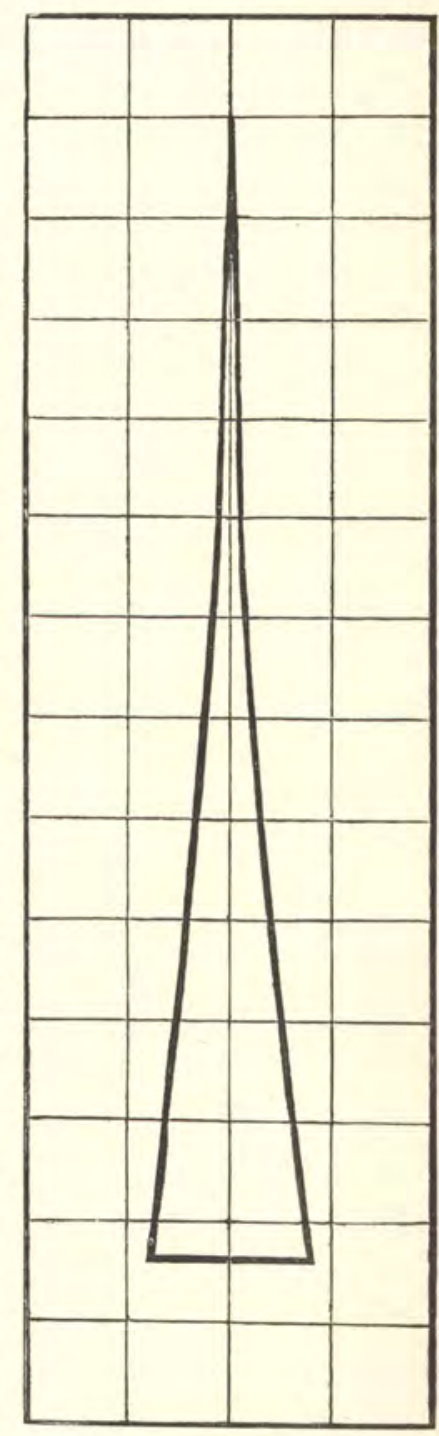

Fig. 255.-Diagram illustrating formula for strength of wall. forgotten is to keep centres of inertia as low as possible. For example, the upper parts of walls should carry only very light roofs, or else the roof should be free to move upon the wall. Water towers are about the worst structures that can be erected in earthquake countries. In the earthquake of 1891 in Japan, even the small water tanks which supply railway engines at 
stations were entirely destroyed on account of the inertia of their upper parts.

With regard to roofs and floors, all tie beams should extend at least $\frac{2}{3}$ into the thickness of the wall.

In erecting any structure, it must be remembered that its different parts, if not strongly tied together, will tend to vibrate in different periods, and in consequence of this want of syncronism in their motion they will be mutually destructive. For example, a brick chimney and a wooden building, if entirely free from each other, may stand with safety, but directly they come in contact, the wooden building almost invariably cuts the chimney in two and causes its collapse.

In putting up a building, either of two general principles may be followed. One is to make the structure light and flexible, like a wicker basket that may be shaken without damage; another is to make it strong and rigid, but at the same time also as light as possible. Here we approximate to a steel box, which will also resist considerable motion without suffering damage. One is cheap, but fragile and liable to decay and to destruction by fire; whilst the other one is expensive but lasting.

Perhaps the most important thing is to use only good materials, particularly good cement. *

* The subject of the effects of earthquakes on engineering structures in gen rral, and of the steps to be taken to minimise these effects, has been treated by the writer (John Milne) in vol. xiv. of the Transactions of the Seismological Society of Japan, and in the Minutes of the Proceedings of the Institution of Civil Engineers, vol. LxxiIr., pp. 278 et seq. 


\section{APPENDIX II.}

\section{Notes.}

THE criticisms and remarks in these notes attributed to Dr. E. Divers, F.R.S., were written in private letters to me, and were not intended for publication. I consider them, however, very valuable - even where I do not entirely agree with them-and I have persuaded Dr. Divers to allow them to be printed here.

W. K. Burton.

Note 1, page 12.-Service of water through lead pipes and cisterns. I have the following from Dr. Divers on this subject :-

"Outside the London and Paris basin, it is a very serious matter for the water engineer to consider that he may, with an otherwise excellent water, poison a town which has intrusted itself to his hands. There is some uncertainty in the matter, but you may venture thus far, and be of use to your readers :-

(1) Hard natural waters are seldom active on lead pipes in service.

(2) Soft potable natural waters owe their activity apparently to the presence of acids in minute quantities. Hence a soft water may be practically inactive in virtue of its freedom from acidity.

(3) Addition of a minute quantity of sodium carbonate destroys the activity of a water.

(4) Over-liming of water, by generating in it some sodium or potassium hydrate, is apt to make, or leave, a water active."

Note 2, page 15.- The writer recently read a paper in which to the humic acids of peaty water was attributed the property that some waters have of dissolving lead, making it dangerous to use lead pipes or lead-lined cisterns with such waters. Unfortunately he has 
lost his note of the paper, and can therefore neither refer the reader to it nor give the name of the author. It has always been somewhat of a mystery why some waters have this property of dissolving lead, others not; and if it could be definitely established that waters free from peat have not this property, the addition to our useful knowledge in connection with practical water supply would be great indeed.

Note 3, page 36.-Even as approximations, these values can be taken only when considering the comparatively small catchment areas that are likely to be utilized for the water supply of towns. In the case of the catchments of large streams, or rivers, a much smaller percentage only can be relied on.

Note 4, page 36.-Again, in the case of valleys in which snow lies for several months of the year, the flow of a river may fall nearly to zero towards the end of such a time, whilst, for some part of the spring, after the snow begins to melt, the flow of the river may be many times greater than the whole of the "precipitation" over the catchment area. In fact, all deductions of the flow of streams and rivers from the rainfall over the catchment area must be made, and

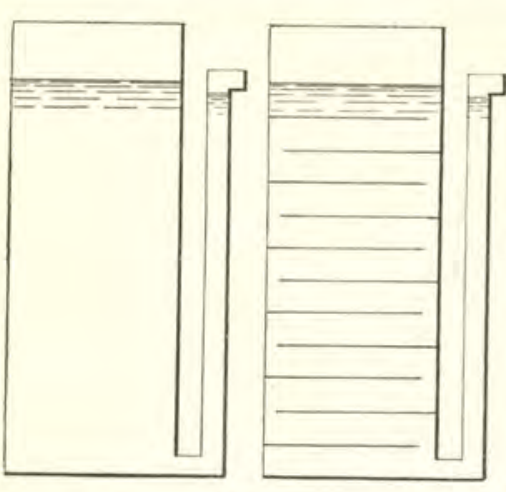

Fig. 256.-Illustration of Dr. Divers theory of sand filtration. used, only with the greatest caution and judgment; but the writer can certify that, when so used, they are of the greatest value, in the absence of actual gaugings spreading over a considerable time. This especially, considering how very inexact such gaugings often are.

Note 5, page 79.-Dr. Divers makes the following criticism of these statements, with the sketch reproduced here (Fig. 256):- "On the theory of filtration you are of course sound as far as you go, but you leave out the best part of the true theory. But on p. 82, the last paragraph on lime purification contains the essence of the true theory of sand or any other filtration, as contrasted with straining. If in twelve hours matters have just settled in the plain vessel shown in the sketch, then in one hour they will have settled in the vessel with eleven trays. Exchange the trays for 
the sand of a filter, and the fact remains. Rush the water through the filter, and, as you point out, the sediment is carried out of it. Hence so-called 'upward filtration,' or in reality drawing off water at nearly the same level as that of the surface of unfiltered water (vide side pipes)."

Note 6, page 80.-Dr. Divers has the following remarks on this paragraph :- " It has never been demonstrated that animal charcoal will completely oxidize organic matter, and it is against all experience that it should. Animal charcoal purification is familiar to the chemist, and is certainly known to be, though marvellous and unexplained, positively only 'absorption,' or temporary fixation of the matters to the charcoal, so that by appropriate washings with solvents these matters can be recovered afterwards. Hence the cause of the positive fact which you yourself refer to, that purer water following other water through a charcoal filter long enough in use becomes reduced in purity by the foul charcoal-it dissolves out the matters in the charcoal."

Note 7, page 81.-Dr. Divers has the following remarks on this paragraph:- "Spongy iron.-You are not justified in saying what you do. It or any metallic iron can only act chemically, and therefore by consumption and quantitatively to its effect; and if the water is flowing the local deposit of rust will be slight, and in any case will not protect the iron and water from each other. If the latter contain carbonic acid it will be active on iron; if not, probably not; but any iron, $a b$ initio very rusty, will suffer by use, not by rusting badly in running water, but by crusting by calcareous matter. There is no rationality in exalting nails and borings (oily and dirty from the drills*) at the expense of spongy iron clean from the furnace. Spongy iron chokes ; therefore it soon becomes useless."

Note 8, page 95.-Filtration through sand is better avoided than availed of, when not needed. The bed is a possible nidus for germs, and may become a veritable soil, unless the sand is nearly exclusively silicious. This remark does not apply to a regularly cleaned bed, but to one undisturbed for a long time.

* I believe cast-iron turnings and borings have, in practice, proved superior to spongy iron for the purpose of purifying water by agitating the iron and water together, and I consider this a rational reason for exalting the said turnings and borings. The oil and other dirt can readily be removed.-W. K. B. 
Note 9, page 100.—Concerning this, Dr. Divers remarks :- “The 'clean' here does not cover the point to be insisted on, which is, that the sand must be as nearly purely silicious as possible-inactive, that is, in furnishing mineral matters for food to vegetable organisms."

Note 10, page 113.--Dr. Divers says:-“"The fishy smell is due, with hardly a doubt, to trimethylamine formed by bacteria out of albuminous matters. . . I I should recommend aëration and sunning [of sand] in addition to washing [scouring] if feasible."

Note 11, page 116.-The following remarks with regard to the use of magnetic oxide of iron are by Dr. Divers:- "To Thomas Spencer [long dead] is due the merit of recognising the value of magnetite, and introducing porous fragments [not ' in a fine state of division '], obtained by calcination of spathic iron or other iron ores, into domestic filters and filter beds of waterworks. Unfortunately he called his preparation 'magnetic carbide,' because, from his mode of preparing it, it sometimes contained carbon. Frankland tried artificial magnetic oxide, which of course reacted with the water and was inapplicable, and this led him to discredit Spencer's oxide and Spencer's theory. But full experiments made by me for the Lancet established for so-prepared magnetic oxide a power equal to the finest charcoal, and a renovating property, when aërated occasionally, that is very remarkable. There is, however, this need for aerration, and that is the objection to the use of magnetic oxide of iron. It must be allowed to act on clear water, out of which it removes dissolved organic matter, and then it must be aërated by aërated water, or air itself, which means extensive disturbance of the filter. If we could make a filter bed all of porous magnetic oxide, and treat it as sand, the result would be admirable, but we cannot, on account of the expense and the weight due to the density of the material. . . . . At a time when I was acting as sanitary commissioner, I broke up a 'silicated carbon' filter, and found the interior packed with 'magnetic oxide' or 'carbide.' The fact was published at the time."

Note 12, page 123.-Dr. Divers remarks:- "I do not like the silver nitrate test. Why not use litmus paper? Red or violet must not become a marked blue. The silver nitrate will detect alkalinity in calcium hydrate; and suppose not enough lime has been added, the pale yellowish turbidity will detect the presence of calcium carbonate, but only in the very rare case of the entire absence of chlorides." 
Note 13, page 123.-Dr. Divers says further:- "The case does not depend on space alone; there is another thing. Usually, limed water settles well enough; but if not, or for any other reason the water is allowed to stand for many hours over or with the carbonate, carbonic acid will be taken up from the air, and some will go again into solution. But for this, settlers would be all that could be desired."

Note 14, page 124.- See Engineering for March 11th, 1892, page 318 , for a very interesting description of water-softening apparatus on a large scale, as adopted at Southampton. In this plant the water and lime are mixed in a tank or open reservoir of considerable size, and the carbonate of lime is afterwards removed by a large battery of filters much of the same pattern as those described here.

Note 15, page 126.--Dr. Divers says about this case of Perth:"Your illustration of Perth is, in my opinion, entirely wrongly interpreted - that is, against the facts and against your previous correct account that water may rise to a river, and not always go down from it ; and therefore your moralizing about Nature's work is as weak as all such moralising usually is. That sub-insular water is surely not purified by downward passage through the river bottom. It is the pure water from below."

Note 16, page 132.-If, instead of rows of columns, continuous partitions be built, supporting the arches-each partition having an arched opening at one end, and the arched openings being at alternate ends of the reservoir - the water will be kept well in motion, and all stagnation will be avoided.

Note 17, page 143.-In the case of very large waterworks, it is an economy to substitute open channels for pipes, in distributing the water as far as the filter beds. Open channels, for the purpose here indicated, are being adopted in Japan, by the author's advice, in both the Tokyo and the Osaka waterworks.

Note 18, page 182.-This is assuming the pipes to be coated with Angus-Smith's or some similar composition. With uncovered 
uncoated pipes, an incrustation of "tubercles" of an indefinite thickness, and having nob-shaped projections that enormously increase the friction of the water, forms. On the other hand, with proper coating, it often happens that no incrustation at all takes place. It is not safe, however, to determine the diameter of a pipe without making some allowance for incrustation.

Note 19, page 194.-A slight modification of this plan is as follows: Instead of making the pipes in one direction only mains, proportioning them to do all the work-making the pipes at right angles merely supplementary - the pipes in both directions at right angles may be made of equal diameter, each pipe being then looked on

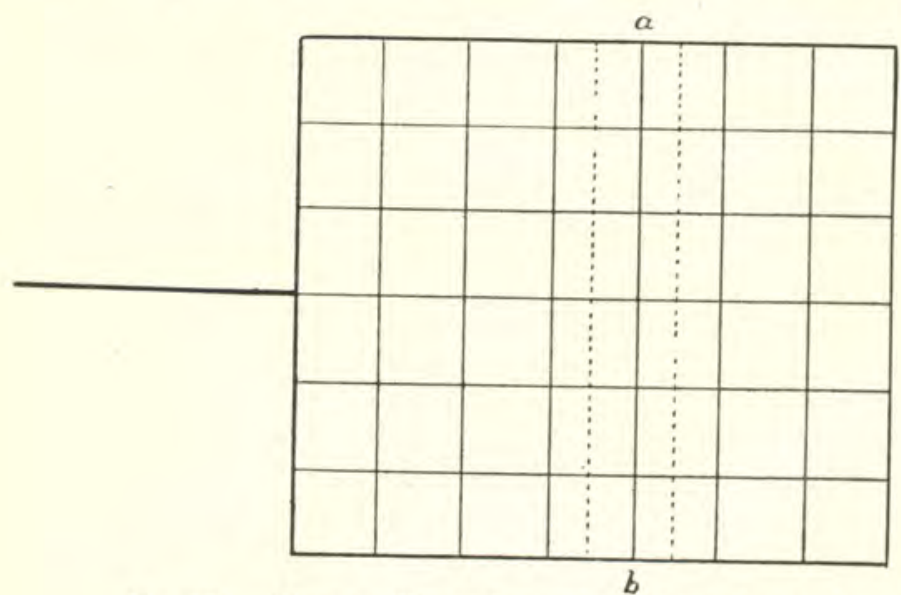

Fig. 257.-Diagram illustrating system of distribution for small distriet.

as a main. This arrangement is illustrated here (Fig. 257). In this case any pipe-as, for example, $a b$-is made of a diameter to serve only half the district marked out by the dotted lines, even considering it as supplied at both ends. One or the other of these modifications will be the most economical, according to the size of the district to be served by the "loop." A small district will probably be piped most economically by the modification shown in this note, the pipes being then, very likely, all of the minimum diameter used in the system, whereas a large district will probably be most economically piped by the system shown in Fig. 177 (page 193).

Note 20, page 236.-The difference between the thickness of cast-iron and of riveted steel pipes is relatively less the larger the pipes, so that the thinness of the latter is less likely to lead to serious 
results with large than with small pipes; and the convenience of steel pipes for very large sizes is so great, that the author has no hesitation in recommending them for such sizes in nearly all cases.

The only question is, What diameter constitutes a very large pipe ? It is difficult to answer, of course, but the author states provisionally that the convenience of steel pipes, as compared with cast-iron, begins to get so great in the case of such sizes as four feet and upwards, that he would certainly incline to adopt steel pipes in nearly every case where a pipe of four feet or upwards is needed ; and, as the thickness of steel pipes increases more rapidly with increase of pressure than does that of cast-iron pipes, it is evident that for high pressures any danger that there may be from thinness of the shell is less than for low pressures, and it seems at least likely that, in the case of what must be considered high pressures in waterworks practice-say 100 lbs. on the square inch and upwards-steel pipes might with advantage be used for all parts of the work, for diameters considerably less than four feet.

Note 21, page 247.- The writer has often visited the pumping station, at the intake for the Yokohama waterworks, where this gauging apparatus is fixed. He is of opinion that, if the discs were made larger and the motion were greater, the gauging would be much more precise. As the meter now works, the "shake" on the pencil, its holder, and other parts, is so great, relatively to the small radial motion, that a very appreciable error is introduced.

Note 22, page 250.-The "Venturi tube," which has long been used as a means of roughly estimating the velocity of air-currents, has recently been used as a water-meter. The Venturi tube is simply the Vena contracta. Its action depends on the fact that, if made carefully to a certain longitudinal section, the reduction of pressure at the contraction is a function of the velocity of water passing at that part of the tube. The simplicity - the fact, almost incredible at first, that no appreciable obstruction to the flow of water is causedand (so far as the writer can learn) the reliability of this meter, are such as to commend it for measuring water to be used for irrigation, for compensation, and for the like purposes; but it is not, unfortunately, suitable for a district meter. The first essential for a district meter is that it should be capable of measuring, with fair accuracy, the passage of small quantities of water. Now the Venturi meter will not register, with an approach to accuracy, velocities below about 
six inches per second, along the full section of the pipe, or say from one-quarter to one-tenth of the average velocity.

A desideratum at the present time for large mains is a "shunt" district meter (if the term is allowable) - that is to say, a meter through which not the whole but only a small fraction of the water has to pass. The difficulty with this is the same as with the Venturi meter. It would be easy to design such a "shunt" meter for moderately great and great velocities, but the writer does not know of any such meter that is suitable for small velocities, and he has been unable to design one that seems at all hopeful.

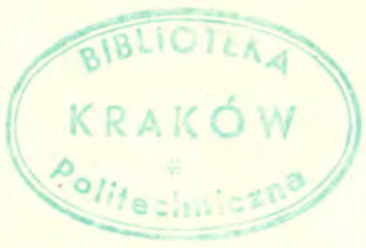




\title{
INDEX.
}

\begin{abstract}
* In those cases where a figure referring to a page is printed in large and conspicuous type, this indicates that the subject referred to is more fully treated on that page-or beginning at that page-than on any other.
\end{abstract}

A BEL, Sir Frederic, 118

Addington Hill reservoir, 133

Admission of water to filter beds, 110

Aërating sand of filter beds, 282

- magnetite, 282

Air-collecting vessel for syphon for emptying reservoirs, 62

Air pump for condensers, 151

_ for syphon for emptying reservoirs, 62,63

Air valves, 264

Air vessels for pumping engines, 161

for pumping machinery, 142

Allowance for increase of population, 20

_ for incrustation of pipes, 197

Alum for softening water, 12.

America, use of water meters in, 261

American pillar hydrant, 209

— screw-down hyc̉rants, 214

_ section of earthwork dam, 54 towns and cities, consumption of water in, 19

Analysis of water, 6

Anderson, William, 117

Angus-Smith (Dr.)'s composition for cestiron pipes, 232,283

Animal charcoal, action of on water, 80

Antwerp waterworks, 117

Apollinaris water, 11

Appliances used in connection with waterworks, 262

Apron of puddle, 69
Aqueduct bridges, 176

Aqueducts, 167

Arch principle in masonry dams, 73

Arched roof for clean water or service reservoirs, 132

_ roofs of reservoirs in earthquake countries, 274,275

Archimedean pump, 148

Archwork in earthquake countries, 275

Area of filter beds, 127

— of filtering surface, 95, 102

Ashlar masonry, valve towers, 61

Automatic valve for regulating filtering speed, 108

$\mathrm{B}^{\mathrm{ACTERIA}}, 129$

— as a purifier of water, 9

forming trimethylamine in sand of filter beds, 282 in water, 13

Bacteriological analysis, 7

Bacteriology in relation to filtering speed, 94

Ball hydrants, 212

- valves, 143

- $\quad$ - in houses, 243, 257

Bamboo pipes, 218

Basins, fixed, discharge pipes of, 244

Bateman, Mr. 176

Baths, discharge pipes of, 244,245

Beam engines, 150 
Belgian pipe foundries, 231

Bell-mouthed pipe for admitting water to filter beds, 111

- — for inlet to settling reservoir, 92

Berlin, sale of water at, 260

- waterworks, covered and open filters at, 94

Bishof, Professor Gustav, 117

Blakeborough and Sons, 267

Boiler chimneys, 164 - reserve for cases of fire, 207

Boilers, Cornish and Lancashire, 164

- - for pumping engines, 156, 163

locomotive and marine, 163,164

tubular, or water tube, 164

Bored and turued joints for cast-iron pipes, 220

Boring and tapping pipes under pressure, 269

Borings, trial, for impounding reservoirs, 48

Boulders for draining filter beds, 97, 98

Brass ferrule for connecting main and service pipe, 268

Breakwater on top of dams, 275

Breast-water wheels, 164

Breeches-pipe as stand-pipe, 141

Brick arches for roof of clean water or service reservoirs, 132

cellular floor for draining filter beds, 99

chimneys in earthquake countries, 278

in cement for covered conduits, 176

piers in earthquake countries, 276

Bridge at Usui Pass, Japan, 277

Brightmore, A. W., v.

Brighton water supply, 125

Brown, Bros. and Co., 184

Bucket-and-plunger pumps, 148

Bull pumping engines, 149

Burning vegetation within reservoir area, 69

Bursting of pipes by frost, 244

By-pass channels for impounding reservoirs, 68

for service or clean water reservoir, 129
By-pass for sluice valve, 264 pipes, 143, 144

By-passes for fire extinction, 206

By-wash for masonry dams, 75

— for reservoir, 54,64

CAPACITY (cubic), of reservoirs, 33 of impounding reservoirs, estimation of, 50

— of reservoir determined graphically, 39

of service or clean water reservoir, 128

of settling reservoirs, 83

of tanks of water towers, $13 \tilde{5}$

"Carbide of iron," 80

Carbonate of soda for softening water, 122

Carbonates of lime and magnesia in water, 11

Carbonic acid gas in water, 12,80

"Carfarel," 80

Carnot's law, 154

Casting pipes, 230

Cast-iron in tanks for water towers, 136

- pipes, 218, 219,

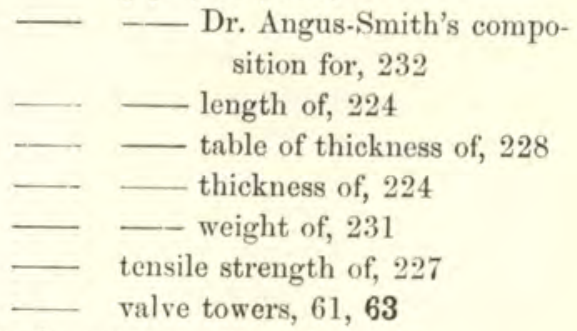

Catchment areas for waterworks,

— area of impounding reservoir, 48,65

Caulking lead joints, 221

Caustic lirne for softening water, 121

Cellular brick floor for draining filter beds, 99

Cement for settling reservoirs, 88

— for structures in earthquake countries, 278

for water pipes, 219

mortar for covered conduits, 176 
Cement mortar for masonry dams, 74

Centres of distribution, 199

Centrifugal pumps, 148

Chalk formation, 14

Channels, conduits, and pipes, flow of water in, 167 open, 169

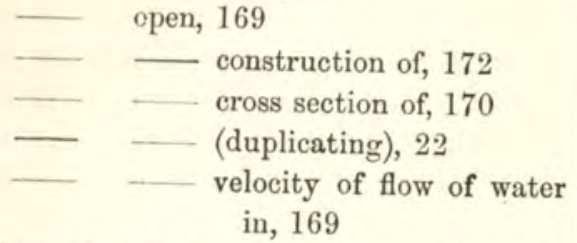

Charcoal, animal, action of on water, 80 , 281

Chemical analysis of water, 6

Chimneys for boilers, 164

- in earthquake countries, 277

Circular service or clean water reservoirs, 131

settling reservoirs, 87

Cireulating pump for condensers, 151, 162

Cisterns in houses, 188, 244, 245

lead-lined, 267

Clark's process for softening water, 11, $13,82,120$

__cale for hardness of water, 11, 123

Classification of waterworks, 42

Clay and gravel puddle, 59

- puddle, 57

Clean water or service reservoir, $42,44,45$, 127, 206

- capacity and position of, 128

- depth of, 131

— in middle of town, 200

or service reservoirs, connection with settling reservoirs and filter beds, 143

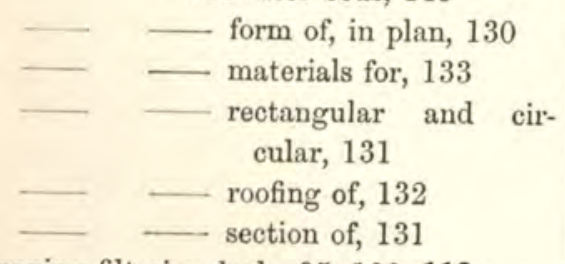

Cleaning filtering beds, 95, 100, 112

— settling reservoirs, $83,85,93$
"Clearance" in steam engines, 156

Closed conduits, 167, 174

Coal for steaming, 156

Coating pipes with varnish, 232

Compacting of sand in filter beds, 103

Compensation water, 63

Composition for coating cast-iron pipes, 232

Compound engines, 151, 156, 162

— - duty of, 157

Compounding pumping engines, 150, 155, 162

Concrete arches for roof of clean water or service reservoirs, 132

— dams, 51, 75

- for clean water or service reservoirs, 133

for covered conduits, 176

for lining of open channels, 173

for setting reservoirs, 88

Condensers, jet and surface, 151

Condensing engines, duty of, 157

pumping engines, 151

Conduits, flow of water in, 167

open, closed, "cut and cover," and tunnel, 167

Connecting pipes for settling reservoirs, filter beds, and clean water or service reservoirs, 143

Connection of service pipes with mains, 267

— of settling reservoirs, filter beds, and service or clean water reservoirs, 143

Constant service of water, 187, 242, 244, 245

- system of settlement of water, 83,84

Construction of earthwork dams, 53

— of masonry dams, 74

of open channels, 122

Consumption of water per head, 17

Contingencies in estimation of the capacity of reservoirs, 39

Contour lines for impounding reservoirs, 48

Controlling speed of pumping engines, 161

Cornish boilers, 164 
Cornish pumping engines, 149

Covered conduits, 174

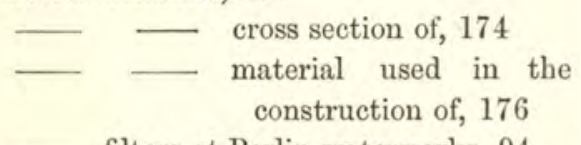

filters at Berlin waterworks, 94

Crank-shaft and fly-wheel pumping engines, 149, 155, 162

Crib-work dam, 69

Croes, James J. R., 73

Cross-section of covered conduits, 174

of open channels, 170

- of puddle trench, 56

Cultivated land, water from, 14

Culvert for discharge of water from reservoirs, 57,58

through masonry dams, 76

Jurrent meters, 30

Surved masonry dams, 73

"Cut and cover" conduits, 167, 175

Cylinders, high- and low-pressure, 156

$\mathrm{D}$

AILY maximum consumption of water, 20 rainfall, in graphic method of determining capacity of reservoir, 39

Dams, earthwork, construction of, 53

_ for impounding reservoirs in earthquake countries, 275

for impounding reservoirs, material of, earthen dams, masonry dams, 51

reservoir, 43

Dangerous waters, 14

Davis, Joseph P., 73

Deacon, G. F., M.I.C.E., 75, 136, 250

Deacon's district meter, 250

Dead-end distribution system, 191

Dead-weight safety valve, 266

Deep-well water, 14, 24

Delocre, Mons., 72

Depth, mean-hydraulic, 170

—— of filter beds, 97

— of impounding reservoirs, 48

of service or clean water reservoirs, 131
Depth of settling reservoirs, 83

— of waste weir, 66 of water over filtering sand, 100

Detection of leakage outside houses, 246

Determination of capacity of reservoirs, 34

Detritus carried by floods, 69

Diagrams of the discharge of water in pipes, 181, 197

Diameter of pipes between settling reservoirs, filter beds, and clean water or service reservoirs, 144

Diameters of large mains of distribution systems, 155

_ of overflow and waste pipes, 145 of smaller mains, 202

Diagramatic illustration of stand pipe and pumping engine, 141

Differential expansion gear, 161

Differentiating meter, 250

Direct pumping engines, 149

Discharge of water in pipes, tables and diagrams of, 181

through pipes, formulæ for, 178

Discharge pipes in houses, 243

Dissolved organic matter in water, 10, 12

Distillation of water, 77

Distribution centres, 199

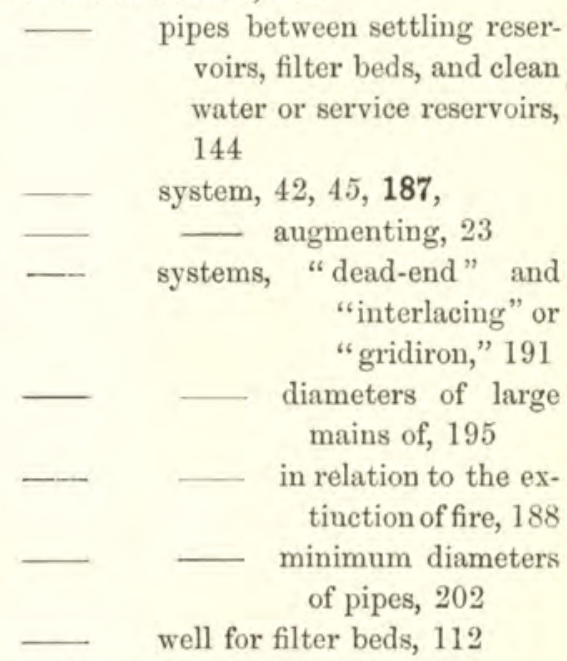

District meter, Deacon's, 250

— $\quad$ system, 18, 195, 248

meters, with interlacing distribution system, 254

Divers, Dr. E., vi., 80, 280, 281, 282, 283 
Domestic meter system, 255

- supply of water, 18

Double acting pumps, 148

- stand pipes, 141

Drain pipe for settling reservoirs, 93

Drainage of filter beds, 98

Draining settling reservoirs, 87

Drange, James, 75

Draw-off pipe for settling reservoir, 92 posts, 266

Drinking fountains, 266

Dry and wet well valve towers, 60

Dry-sand casting of pipes, 232

Duncan, D. J. Russell, 238

Duty of centrifugal pumps, 157

of high pressure, compound and triple expansion engines, 157 of pumping engines, 154

working at a varying speed, 162

of pumping machinery, testing, 162 of small engines, 159

Dwarf wall at top of earthwork dam, 65, 275

$\mathrm{E}^{\Delta}$

ARTHENWARE filters, 77

Earthquake countries, importance of " by-pass" pipes in, 145

Earthquake countries, precautions in connection with settling reservoirs in, 88

builüings in, 278

site of waterworks in, 274 effect of, on reservoir of Yokohama waterworks, 67 great, at Lisbon, 274

- $\quad$ of Japan (1891), 277

waves in reservoirs, 67

Earthquakes, effect of, on water towers, 136 - _ - on waterworks, vi., 273 - possible effect of, on earthwork dams of reservoirs, 67

Earthwork dams, 51, 52, 53

Easton, Edward, 125

Edinburgh waterworks, 200

Efficiency of boilers and engines, 156

of pumping engines, 207
Eiffel tower, 184

Eiselohr, Dr., 9

Electric motors for raising water, 165

Elevated reservoir, 207

— tanks, 134, 147, 201, 207

- - in earthquake countries, 277

Embanked open channels, 123

Engine foundations, 163

Engines for pumping, simple, compound, triple expansion (or tri-compound), and quadruple expansion, 151

—_ high pressure, 152, 162 pumping, 149, 153

$\longrightarrow \quad$ duty of, 154

steam pressure in, 55

English section of earthwork dams, 54

Estimation of capacity of impounding reservoirs, 50

Evaporation from water in reservoirs, 40 of water by coal, 156

Expansion gear, 159

differential, 161

of steam in pumping engines, 150

Extinction of fire, provision for, 205

Eytelwein's formula for the discharge of water in pipes, 181

HACTOR of safety for cast-iron pipes, 225

Fanning, v., 27, 29, 30, 31, 36, 64, 66, 69, 141, 168, 180, 189, 202, 203, 209, 214, 223,226

Faucet and spigot joints for cast-iron pipes, 219, 220, 229, 230

_ joints, steel, 238

Feed-water for boilers, 157

Ferrule, brass, for connecting main and service pipe, 268

for connecting service pipe with main, without soldering, 268

for use with machine for boring and tapping pipes under pressure, 271 
Ferrule, stop valve, 271

Ferrules (pea), in service pipes, 254

__ screw and tapered, for connecting main and service pipe, 268

"screw-down" and "plug," for connecting service pipes with mains, 269

Filling filter beds, 104

Filter beds, 42, 43, 44, 45, 85, 92, 93, 94

— adding to number of, 22

_- admission of water to, 110

arrangement of, 98

cleaning of, 112

connection with settling reservoirs and clean water or service reservoirs, 143

depth of, 97

distribution well for, 112

form of plan of, 96

regulating the flow of water into, 111

vertical section of, 102

Filtered water for filling filter beds, 104, 107

Filtering beds, number of, 95

— heating of water in, 101

head, 101, 103

— speed, 94, 127, 130

_— regulating, 104, 105

Filter press for filtering off carbonate of lime after softening water by Clark's process, 123

Filters, Pasteur's, 13

Filtration area, 127

best avoided when not necessary, 281

\section{- natural, 124}

__ of water by sand, 13,79

— theory of, 280

— through sand, $77,78,94$

Fire-clay pipes, 219

theory of, $\mathbf{7 9}, 280$

Fire extinction, boiler reserve necessary for, 207

distribution systems suitable for, 188

provision for, 205

provision of pumping, power for, 161
Fire extinction, reserve of pumping power for, 206

small mains to be proportioned with a view to fire extinction only, 202, 209

water to be provided for, 189

Fire hose, 189, 208, 210, 216

- hydrants, 190, 193, 202, 209

- $\quad$ - ball, sluice-valve and screwdown, 212

- $\quad$ - $\quad$ form and size of, 209

- _ locating, 203, 209

- - - prevention of freezing of, 216

- $\quad$ - requirements of, 209

- $\quad$ - $\quad$ size of, 209, 215

- $\quad$ - $\quad$ spacing and position, 208

- $\quad$ - $\quad$ stand-pipe, 212, 213

- $\quad$ - $\quad$ sunk and pillar, 209

- insurance by waterworks, 45

- jet nozzles, 216

- provision against, by high pressure in water mains, 183 in service or clean water reservoirs, 130

- provision for in water-tower tanks, 135 Fissuring of sand in filter beds, 103

Flanged joints for cast-iron pipes, 219

_ for steel pipes, steel flanged joints, 237

Flap valves for valve towers, 61

Floating pipe for drawing off water from settling reservoirs, 92 pipes, 143

Flood water in impounding reservoir, 68

Floor of filter beds, 98

— of settling reservoirs, 87

Flow of water in conduits, pipes, and open channels, 167

in pipes, 177, 182

Fluctuation in consumption of water, 19

Flushing water-closets, 243

Fly-wheel engines, 149, 155

Form of cross section of covered conduit, 174

of open channels, 170 of filter beds in plan, 96 
Form of filter beds in vertical section, 102 of fire hydrants, 209

of inlet and outlet pipes for settling reservoirs, 85, 92

of settling reservoirs, 87

Foundations for pumping engines, 163

— in earthquake countries, 274

— of earthwork dams, 51 of masonry dams, 74, 51

Fountains, drinking, 266

Frankland's experiments in the filtering of water, 282

Free foundations for buildings in earthquake countries, 275

Freeman, Mr., 190, 208

Freezing of hydrants, prevention of, 216 — of water in open channels, 171

— of water pipes, 240,244

Friction of water in pipes, 179

Frost cases for hydrants, 216

- protection of pipes from, 244

CALLERY for natural filtration, 125 U Gas engines for raising water, 165 Gases dissolved in water, 12

Gates on water pipes, 262

Gauge for measuring quantity of water filtered, 107

Gauging apparatus of Yokohama waterworks, 247,285

- springs, streams, and rivers, 24

Gearing for opening sluice valves, 264

for pumping machinery, 154

Geneva, lake of, 90

Gill, Henry, on sale of water in Berlin, 260

- on regulation of filtering speed, 105

Glasgow waterworks, 175,177

Glazed pipes, 168

Grade line, hydraulic, 178

Graphic method for determining capacity of reservoir, 37

Gravel, coarse and fine for filtering, 97 in filter beds, 99

Gravitation waterworks, 42

Gravity systems, 246

Great earthquake of Japan (1891), 277
"Gridiron" distribution system, 191, 284

Gun metal for sluice valves, 263

H AKODATE waterworks, Japan, 128

Halske's water meter, 258

Hardness of water, 11, 81

Hart, I. W., 136

Harwich sand for filtering, 97

Hasegawa, Mr., 266

Hassard, R., 176

Hatanomura waterworks, Japan, 95, 168

Hawksley, Sir John, formula for the capacity of storage reservoirs, 34

Head of impounding reservoir, works at, 54,57

necessary to produce flow of water in pipes, 179, 183

of water in filtering, 101, 103

— of water pumped against, 158

Hemans, W., 176

Hennell, Thomas, 27, 96, 148, 181

Hexagonal open channel, 172

High duty gear in pumping engines, 150

- level impounding reservoirs and intakes, 42

reservoir of the Tokyo waterworks, 204

reservoir, pumping into, 157,161

tanks, 42

pressure cylinders, 156

engines, 152, 155, 162

Hoggin for filtering, 97

duty of, 157

Hongkong waterworks, 75, 76, 176

Hongo reservoir, Tokyo, 204

Hope, W., 241

Horizontal pumps, 149

Horse-power of pumping engines, 152, 158

Hose from hydrants, 208, 210, 216 streams, 189

Hot-air engines for raising water, 165

House fittings, inspection of, 188, 243, 245

House to house inspection, 245

Houses, waste of water in, 241, 250 
Humber's Water Supply, v.

Humic acids as a solvent of lead, 279

Hunyani-yados water, 11

"Hurdy-gurdy" for raising water, 164

Hydrant stand pipe, 212, 213

Hydrants, ball, sluice valve, and screw down, 212

— fire, 190, 193, 202, 208

_ form and size of, 209

_ prevention of freezing of, 216

— requirements of, 209

— $\quad$ size of, 215

_ spacing and position, 208

sunk and pillar, 209

Hydrate of lime for softening water, 121

Hydraulic grade line, 168, 177, 178, 183, 185

$\begin{array}{ll}- & \text { gradient, } 191 \\ & \text { mean depth, } 170 \\ & \text { ram, } 165 \\ -\quad & \text { test for pipes, } 233\end{array}$

TE on open channel water, 171

Ideal impounding reservoir, 33

Idzu filtering sands, Japan, 100

Impounding reservoirs, 46, 127

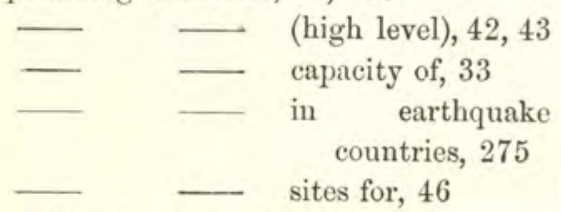

Impurities in water, 10

Increase of population, allowance for, 20, 196

Incrustation of pipes, 182, 283

Indicators, 159

— allowance for, 197

Inferential meters, 256

Inlet pipes for settling reservoirs, 85, 89

Inokichi, Professor A., vi.

Inorganic matter in water, 10

Inspection and repair of the valves of valve towers, 60

— of house fittings, 188, 242, 245 of pipes, 230, 234

Insurance against fire by waterworks, 4, 5
Intake, high level, 42

- pumping station, 43,45

Intakes, low level, 43

Integrating meter, 249

Intercepting sewers, 201

Interlacing distribution system, 191, 214, 254,284

Intermittent service of water, 187, 242

system of settlement of water, 83,84

Inverted syphon, 177

Iron (cast) turnings for purifying water, 118

_ for pipes, testing, 231

— for purifying water, 116

(granulated cast), for purifying water, 118

_ magnetic, oxide of, for purifying water, 116,

oxide of, in Japanese sands, 100

metallic, action of, on water, 80

for purifying water, 116, 117

ores, action of, on water, 80

oxide, magnetic, action of, on water, 80

spongy, action of, on water, $80, \mathbf{8 1}$, 281

to be used in pipe casting, 230

valve towers, 61,63

(wrought) for purifying water, 119

Irrigation, provision for, 37,38 ,

Isar river, 9

Ischia, 274, 275

Italian regulations anent earthquakes, 275

Iwata, I., 168

JAPANESE distribution system, 203

Japan, great earthquake of (1891), 277

- natural filtration in, 126

Jenkin, Fleeming, 109

Jet condensers, 151

Johnstown, U.S.A., 51 
Joints for cast-iron pipes, flanged, spiggot, and faucet, turned and bored, and jeints run with lead, 219, 220, 221

for steel pipes, 237

of pipes, spherical, 223

$K^{\mathrm{E}}$

ENNEDY'S patent water meter, 258

Kirkwood, James P., on regulation of filtering speed, 104

Kobe waterworks, Japan, 200, 266

Koch, Dr., 94

T AGGING steam cylinders, 163

Lakes as a source of supply, 24, 43

Lancashire boilers, 164

Lancet experiments in filtering water, 282

Large mains, diameters of, 195

— sluice valves, 263

steel pipes, $218,235,284$

Lead dissolved by humic acids, 279

— for service pipes, 267

joints for cast-iron pipes, 221

lined cisterns, 267

pipes, 218

Leakage from house fittings, 240, 245

_ from mains, 241

- _ from reservoirs, 40

in pipes outside of houses, 246

Leman, lake, 90

Length of east-iron pipes, 224

_ of steel pipes, 237

_ of stroke of pumps, 153

Lime carbonates in water, 11

- caustic and hydrate for softening water, 121

— for softening water, 13, 82, 120, 280

nitrates in water, 11

purification, 280

sulphates in water, 11

Line of pressure or resistance in masonry dams, 71

Lines of pipes in earthquake countries, 274

Lining of open channels, 173
Lisbon, great earthquake at, 274

Litmus paper, use of, as test for lime in softening water, 282

Liverpool, district meter system in, 254

- waterworks, 74

- water tower, 136

Locating fire hydrants, 203, 209

- hydrants, 203, 209

Loch Katrine waterworks, 175, 177

Locomotive boiler, 163, 164

London, growth of, 1

- Sanitary Protection Association, results of inspections for, 188

Loop pipes in distribution systems, 193, 284

Low-level intakes and service reservoirs, 43

- pressure cylinders, 156

MAGNESIA carbonates in water, 11

1 Magnesia nitrates in water, 11

Magnesia sulphates in water, 11

Magnetic " carbide," 282

— iron oxide, action of, on water, 80

- oxide of - iron for purifying water, 116, 282

oxide of iron in Japanese sands, 100

Magnetite for purifying water, 116, 282

Main, pumping directly witb, 157, 158, 161

Mains, connection of service pipes with, 267

_ large, diameters of, 195

__ leakage from, 241

— water pressure, 184

Manilla; 274, 275

Marine boilers, 163,164

—— engines, 154

Masonry dams, 51, 52, 71

— - curved, 73

for covered conduits, 176

valve towers, 61

Material for waterworks pipes, 219

- of masonry dams, 74 
Materials for clean water or service reservoirs, 133

for settling reservoirs, 88

_ for structures in earthquake countries, 278

- for the construction of covered conduits, 176

Maximum consumption of water (monthly, daily, and absolute), 20

_ discharge of streams, 31 rainfall, 33

Mean consumption of water, 20

- depth, hydraulic, 170

— depths of impounding reservoirs, 48

discharge of stream, 30

Means of preventing waste of water, 242, 250

Merryweather and Sons' hydrant, 210

Metallic iron, action of, on water, 80 for purifying water, 116, 117

- salts (poisonous) in water, 12

Meter, Deacon's district, 250

—_ (domestic) system, 255

- house at reservoir dams, 63

— sale of water by, 188, 242, 255

—_ (district) system, 248

Meters, 18

- district, 195

with interlacing distribution system, 254

— integrating and differentiating, 249,250

positive and inferential, 256

Mexican water supplies, 3

Micro-organisms as a purifier of water, 9

$$
\begin{gathered}
\text { in water, } 10,13,129 \\
\text { removed from water by } \\
\text { sand filtration, } 79
\end{gathered}
$$

Milne, Professor John, vi., 273

Minimum diameter of pipes for distribution systems, 202

flow of streams and rivers, 30

_ provision of water for fire extinction, 190

rainfall, 33

storage capacity for fire extinction, 206

Moji waterworks, Japan, 46, 47
Molesworth's formula for thickness of pipes, 226

Monolithic masonry dams, 75

Monthly maximum consumption of water, 20

—_ rainfall in graphic method of determining capacity of reservoirs, 39

Morris's apparatus for boring and tapping pipes under pressure, 271

Motors for raising water, 164

Muir's cellular brick floor, 99

Municipal work, supply of water a, 4

N

AGASAKI, determination of capacity of reservoirs at, 37

waterworks, Japan, 44, 47, 107,128

Natural filtration, 124

- - streams, self-purification of, 8

New River Company, 100

waterworks, 126

York City waterworks, 72

Niijima filtering sand, Japan, 100

Nitrate of silver for testing water after it

has been softened, 123,282

Nitrates of lime and magnesia in water, 11

Nominal horse power, 159

Non-condensing pumping engines, 151

Notch-board for gauging, 26, 246

Nozzles for fire jets, 216

Number of filtering beds, 95

of pumping engines to be adopted, 147

of settling reservoirs, 83

OIL test for pipes, 234

Open channels, construction of, 172

Open channels, cross section of, 170

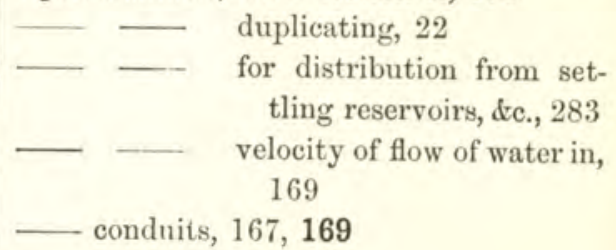


Open filters at Berlin waterworks, 94

Organic matter in water, 10

Osaka waterworks, Japan, 45, 108, 283

—_ _ bacteriological examination of filtered water, 94

Osumigori waterworks, Japan, 95 pumping engines, 147

Outlet pipes for settling reservoirs, 85, 89 Overflow for impounding reservoir, 54, 64 _ pipe for settling reservoirs, 93 pipes, 143, 145

- $\longrightarrow$ in houses, 243

Overshot water wheels, 164

Oxide of iron (magnetic) for purifying water, 116, 282

Oxygen as a purifier of water, 9

ADDY field water, 14, 16
Partitions in settling reserv

Pasteur's filters, 13, 77

Pea ferrules in service pipes, 254

Peatiness in water, 15,279

Peaty water, action of, on lead, 279

Pelton wheel for raising water, 164

Penarth Dock station, water softening and filtering apparatus at, 121

Percolation from reservoirs, 40

Perimeter, wetted, 170

Perth (Scotland), water supply of, 126, 283

Peruvian water supplies, 3

Pettenkofer, Professor von, 9

Pfeiffer, Dr., 9

Piers of bridges in earthquake countries, 276

Pillar hydrants, 209, 216, 267

Pipe casting, 230

- foundries, Belgian, 231

- inspecting, 230, 234

- joints, spherical, 223

- lines in earthquake countries, 274

- service, of lead, 267

- specifications, 230
Pipe tenders, 231

- testing, 233

Pipes, boring and tapping under pressure, 269

bursting through freezing of water, 244

cast-iron, 230, 284

Angus-Smith's composition for, 232

flanged and spiggot and socket joints, 219

length of, 224

table of thickness of, 228

thickness of, 224

weight of, 231

conduits and open channels, flow of water in, 167

discharge of water through, formulæ, 178

duplicating, 22

flow of water in, 177, 182

for connecting settling reservoirs, filter beds, and clean water or service reservoirs, 143

for discharge and overflow from houses, 243

incrustation of, 182

iron for, 230

material of, 218

of bamboo, 218

of cast iron, 218, 219

of lead, 218

of stoneware, glazed and vitrified, 168, 219

of wood, 218,235

of wrought iron and cement, 219

- — $\quad$ steel, 218, 235

riveted steel, 235,284

special, $\mathbf{T}$ pieces and $\boldsymbol{Y}$ pieces, 229

tables and diagrams of discharge of water in, 181

protection of, from frost, 244

water ram in, 225, 245

wrought iron and steel, weight of, 235

Piston pumps, 148

- speed of pumps, 153

Pitching inside slope of dam with stone, 53, 59 
Pitching top and outer slope of earthwork dams in earthquake countries, 275

Pitch varnish for coating pipes, 232

Pits, trial, for impounding reservoirs, 48

Plan of filter beds, 96

- of service or clean water reservoirs, 130

Plug ferrules for connecting service pipes with mains, 269

Plumbers in Liverpool, 254

Plumbing in houses, 245

Plunger pumps, 148

$$
\text { speed of pumps, } 153
$$

Poisonous metallic salts in water, 12

"Polarite" for purifying water, 80, 116

Population, increase of, allowance for, 20, 196

Portland cement concrete for clean water or service reservoirs, 133

— mortar for masonry dams, 74

Position and spacing of hydrants, 208

of inlet and outlet pipes for settling reservoirs, 85,89

of service or clean water reservoir, 128

Positive meters, 256

Posts for drawing water at, 266

Pownell, C. A. W., 277

Practical profiles of masonry dams, 72

Practical Sewage Purification, 86

Precipitation of sewage, 86

Preliminary works on impounding reservoirs, 47

Pressure, line of, in masonry dams, 71 of water in mains, 184

Pressures of steam in pumping engines, 155

Prevention of freezing in hydrants, 216

of waste of water, 239, 242

Private waterworks, 3

Profiles of masonry dams, practical and theoretical, 72

Puddle apron, 69

___ for settling reservoirs, 88

__ in open channels, 173

in the construction of clean water or service reservoirs, 133
Puddle trench for earthwork dams, 53, 56, 57

— wall for earthwork dams, 53, 58

thickness of, 54

with and without gravel, 59

Pullen, W. W. Fitzherbert, 121

Pulsometer pumps, 85, 163

Pump, centrifugal, 148

- - test for pipes, 233

valves, 149,159

Pumping engine boilers, 163

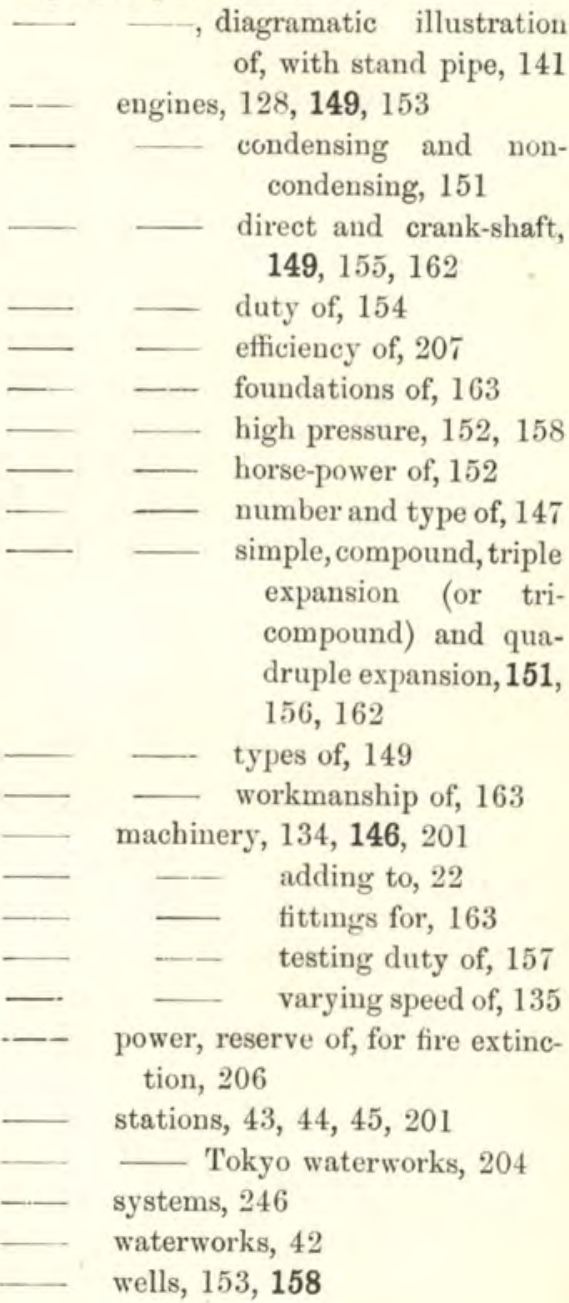

Pumps, air and circulating, for condensers, 151,162

for settling reservoirs, 85

plunges and piston, speed of, 153

pulsometer, 85, 163

length of suction of, 152 
Pumps, single acting, double acting, and bucket and plunger, 148

Purification of water, 77

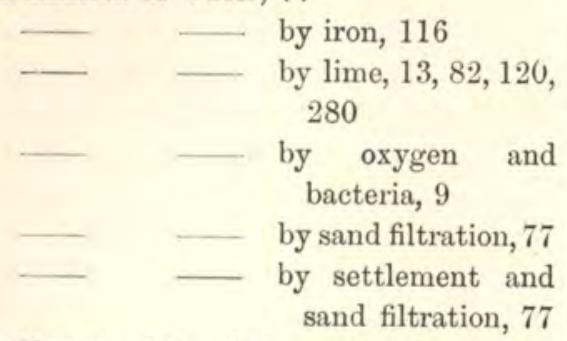

Purifier, revolving (for causing iron to act on water), 119

Purity of water, 13

$Q^{\prime}$ UADRUPLE expansion engines, 151, 152,156

Quaker-bridge dam, 72, 73, 74

Qualities, different, of water, 6

Quantity of water needed, 2

— of water to be provided, 17

$\mathrm{R}$

AINFALL in graphic method of determining capacity of reservoir, 39 maximum and minimum and average, 33

Rain-water, 14,15 phenomena of, 33

Ram, hydraulic, 165

Ramming of water in pipes, 225, 265

Rankine, Professor, 226

Rankine's profile of masonry dam, 72

Rate of filtration, 94, 127

Rectangular service or clean water reservoirs, 131

- settling reservoirs, 87

Red sandstone formation, 14

Reducing valve for constant discharge, 109

Regulating filtering speed, 104, 105

the discharge of water from reservoirs with masonry dams, 76
Regulating the flow of water into filter beds, 111

Regulator valve for water-closets, 243

Removal of surface vegetable soil from site of dam, 55

Repair of the valves of valve towers, 60

Repairs to distribution pipes, 191

Reserve of boiler power for cases of fire, 207

__ of pumping power for fire extinction, 206

Reservoir area, burning vegetation within, 69

— capacity, adding to, 22

- capacity of, determined graphically, 39

elevated, 207

high level, pumping into, $15 \pi$ 161

roofs in earthquake countries, 275

works at head of, 67

Reservoirs, impounding, 46

__ settling and service, 42,43

_ in earthquake countries, 274

__ of Tokyo waterworks, 204

_ service or clean water, 127

storage capacity of, 33

Resistance, line of, in masonry dams, 71

Retaining walls for settling reservoirs, 88

—_ _ - of reservoirs in earthquake countries, 274

Revolving purifier, for causing iron to act on water, 119

Rhone river, 90

Rice-field water, 14, 16

Rice fields, 7

Riley joint for steel pipes, 238

River Pollution Commissioners, classification of waters by, 14

River water to which sewage gains access, 14,15

Rivers as source of supply, 24,43

- gauging, 24, 28

minimum flow of, 30

Riveted wrought-iron and steel pipes, 218,235

Roman water supplies, 3

Roofing of clean water or service reservoirs, 132 
Roofs in earthquake countries, 277 of reservoirs, arched, in earthquake countries, 275

Rosebank ironworks, Edinburgh, 184

Rubble, concrete, for dams, 75

— for masonry dams, 74

"Rusting" turned and bored joints, 220

CAFETY valves for mains, 264

D Sakamoto, J., 108

Sakuma, K., 61

Sal ammoniac for turned and bored pipe joints, 220

Sale of water by meter, 188, 242, 255

Samples of water, taking for analysis, 8

Sand bed of filters, thickness of, 100

filtration, 13, 94

filtration, best avoided when not necessary, 281

— — for purifying water, 77 , 78

— $\quad$ theory of, 79

for filters, 100

silicious for filtration, 282

washing, 113

Sanitary considerations, 129

Sanitary Protection Association, results of inspections for, 188

Scott, General A. de C., 105

Scouring pipe for settling reservoirs, 93

Screw-down ferrules for connecting service pipes with mains, 269

- hydrants, 212, 214, 217

- safety valves, 265 stop valve, 262

Screw ferrules for connecting main and service pipe, 268

Section of clean water or service reservoir, 131

_ of earthwork dam, 54 of settling reservoirs, 87

Seismological Society of Japan, 278

Self-closing valves for stand-posts, 267

Self-purification of natural streams, 8

Service of water, constant and intermittent, 187, 242

Service or clean water reservoirs, 42,43 , $44,89,127,132$
Service or clean water reservoirs, capacity and position of, 128 connection with settling reservoirs and filter beds, 143

form of, in plan, 130 materials for, 133 rectangular and circular, 131

section of, 131

pipe, lead, 267

pipes, connection of with mains, 267

of wrought iron, 267

reservoirs, low level, 43

Selected material for reservoir dams, 55, 59

"Setting up" lead joints, 221

Settlement, constant and intermittent, 84

_ for purifying water, 77 of lime, 283

Settling reservoirs, $42,43,45,83$ reservoir at head of impounding reservoir, 69

form of, 87 depth of, 83 materials of, 88 number of, 83 positions of pipes, 89 section of, 87

Sewage, effect of, on pipes, 236

— in river water, 9,13 precipitation, 86

Sewers, 167

intercepting, 201

Shallow settling reservoirs, 84

wells, 1 well water, 14, 15

Shanghai waterworks, water tower at, 136 Shiba reservoir, Tokyo, 204

Shikene filtering sand, Japan, 100

Shimonoseki waterworks, Japan, 44, 47, 200

Shunk, William F., 73

Shunt meter, 286

Sides of filter beds, vertical and sloping, 102

of settling reservoirs, 88

Siemens and Halske's water meter, 258 
Silica in sands for filtration, 100

Silicated carbon filters, 282

Silicious sand for filtration, 282

Sill of waste weir, 65

Silting up of reservoirs, 67

Silver nitrate for testing water after it has been softened, 123,282

Simple pumping engines, 151

Single acting pumps, 148

Sinks, discharge pipes of, 244

Slagg, Charles, 49

Slate roofs for clean water or service reservoirs, 132

Sleeve for pipes, 229

sliding of earthwork dam, possibility of, 70

Sloping sides for filter beds, 102 of settling reservoirs, 88 walls of reservoirs in earthquake countries, 274

Sluice valve hydrants, 212,213

valves, 143, 262

for valve towers, 61

large, gearing for opening, 264

on distribution pipes, 191, 194

Small engines, duty of, 159

mains, diameters of, 202

Smith's (Angus) composition, 232, 283

Snow as affecting the flow of rivers and streams, 280

Soap test for hardness of water, 11

Socket and spiggot joints for cast-iron pipes, 219, 220, 229, 230

- _ joints, steel, 238

Sodium carbonate for softening water, 122

Softening water by the use of lime, 82 , 120

Soldered joints for pipes, 268

Source of supply, sufficiency of, 24

Southampton water-softening apparatus, 283

Spacing and position of hydrants, 208

Spare filter beds, 95

Special pipes, 229

provision for the extinction of fire, 205

Specifications for pipes, 230
Specifying for pumping machinery, 162

Speed of filtration, 94, 127, 130

$-\quad \longrightarrow \quad$ regulating, 104, 105 of piston or plunges of pumps, 153 of pumping engines, controlling, 161

machinery, variation in, 135

Spence, Peter, and Sons, 86

Spencer, Thomas, 282

Spherical pipe joints, 223

Spiggot and faucet joints for cast-iron pipes, 219, 220, 229, 231

Spongy iron, 117, 118 action of, on water, $80,81,281$

Spring safety valves, 265

— water, 414

Springs, gauging, 24

under dams, 56

Stability of a masonry dam, 71

-_- of earthwork dam, 54

Standard of measurement of water, 17

Stand-by pumping power, 45, 128, 135, 146, 161, 207

Stand pipe for drawing off water from settling reservoir, 92

- _ for hydrants, 212, 213

- pipes, 137, 139, 143, 201

- $\quad$ - and mains, 157, 161

- - pumping into, 157, 162

- posts, 266

Stanford pipes, 168

Steam jacketing of engines, 162

- pressures in pumping engines, 155 temperature of, 154

Steel and wrought-iron pipes, weight of, 235

— for purifying water, 119

pipes, 218, 235, 284

— joints of, 237

length of, 237

socket joints, 238

Stevenson's wave-height formula, 65

Stone and Co., London, 271

Stone-pitching for inside slope of dam, 53,59

- — for open channels, 173

Stoneware pipes, 167, 219

for draining filter beds, 99 
Stop-cocks on service pipes, 251

Stop valve ferrule, 271

-.. - screw-down, 262

Storage capacity of reservoirs, 33

- extra for fire extinction, 205 reservoirs, 24

Stored rain water, 14,15

Strasburg cathedral, 184

Stream as source of supply, 43

Streams, gauging, 24, 28

- minimum flow of, 30

Stroke of pumps, length of, 153

Sub-insular water, 283

Suction of pumps, 152, 158

Sufficiency of source of water supply, 24

Sulphates in water, 122

- of lime and magnesia in water, 11

Sunk hydrants, 209, 217

— reservoir in earthquake countries, 274

Sunning sand of filter beds, 282

Surface condensers, 151, 162

water from cultivated lands, 14, 15

_ vegetable soil, removal of from site of dam, 55

Survey for impounding reservoir, 48

Suspended inorganic matter in water, 10

- matter in natural streams, 67

Suspicious waters, 14

Syphon for emptying reservoirs, 58, 61, 62

— inverted, 177

—— well, 62,63

TABLE of thickness of cast-iron pipes,

Tables of discharge of water in pipes, 181

Taff vale railway company, water-softening at station of, 121

Tamagawa canal (Tokyo, Japan), 3

Tank, high level, pumping into, 157, 161

Tanks, elevated, 134, 147, 201, 207, 421
Tanks, elevated, in earthquake countries, 277

Tapered ferrules for connecting main and service pipe, 268

Tapping and boring pipes under pressure, 269

Taps and valves in houses, 243,245

Tar varnish for coating pipes, 232

Taylor, E. Brough, 181

\section{G. Midgley, 181}

Taylor's water-pipe discharge diagrams, 196, 199

Telescopic tube for regulating filtering speed, 107

$$
\text { hydrant, } 211
$$

Temperature of steam, 154

_ of water as affecting action of settling reservoirs, 89

Tenders for pipes, 231

Tensile strength of cast iron, 227

Test for water after it has been softened, 123

Testing iron for pipes, 230

- pipes, 233

- the duty of pumping machinery, 162

Theoretical profile of masonry dam, 72

Theory of filtration, 280

— of sand filtration, 79

Thickness of cast-iron pipes, 224

-
$\square$
$-\quad$ of puddle wall, 54
of sand bed of filters, 100
of top of masonry dam, 72
of wrought-iron and steel pipes,
235

Three-throw pumping engines, 150, 153, 156,162

Tile roofs for clean water or service reservoirs, 132

Tokyo, distribution system of waterworks, 204

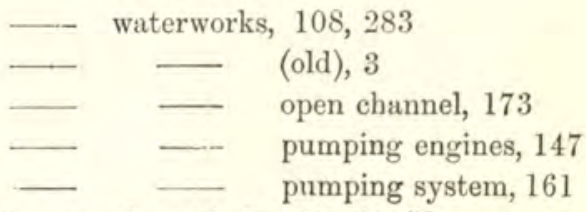

Tower, valve, $53,54,57,58,59$

for masonry dams, 76 
Towers, water, 134

_ _ $\quad$ in earthquake countries, 276,277

T pieces for pipes, 229

Trench under dam for discharge pipe from reservoirs, 56

Trial borings for impounding reservoirs, 47

- pits for impounding reservoirs, 48

Tri-compound engines, 151, 156, 164

- duty of, 157

Tri-compounding of engines, 155

Trimethylamine in sand of filter beds, 282

Triple expansion engines, 151, 156, 164

duty of, 157

Trumpet-mouthed pipe for admitting water to filter beds, 111

tubes for regulating filtering speed, 107

Tubercles in pipes, 284

Tubulous or water-tube boilers, 164

Tunnel conduits, 167

- for discharge pipes from reservoirs, 56,58

for natural filtration, 125 through masonry dams, 76

Tunnels (water) through impervious rock, 175

Turbines for raising water, 164

Turf for top and outside slope of dam, 53

Turned and bored joints for cast-iron pipes, 220

Turner, J. H. T., v., 247

Types of pumping engines to be adopted, 147,149

Typical system of waterworks, 143

Tytam waterworks, Hongkong, 75, 76, 176

T NGLAZED earthenware filters, 77

Upland streams as a source of supply, 24

Upland surface water, 14

Usui Pass bridge, Japan, 277
WALVE for regulating the flow of water into filter beds, 111

Valve-house at reservoir dam, 63

_ for impounding reservoir, 53

-_ for masonry dams, 76

Valve, automatic, for regulating filtering speed, 108

tower, $43,53,57,58,59$

—_ for masonry dams, 76

Valves, air, 264

— and taps in houses, 243, 245, 257 of pumps, 149, 159

— on by-passes, 206

_ self-closing, for stand-posts, 267 sluice, 262

Variable expansion gear, 159

Varnish for coating pipes, 232

Velocity of flow in drains of filter beds, 99,102 of water in covered conduits, 174

in open channels, 169

Vena contracta, 285

in pipes, 179

Ventilation of drains of filter beds, 102

Venturi tube meter, 285

Vertical casting of pipes, 232

- pumps, 149, 153

_ section of filter beds, 102

— sides for filter beds, 102

Vitrified pipes, 168

Vyrnwy reservoir, 74, 75 (and see Frontispiece)

WALKER's patent sand-washer, 113 Walker, Thomas, 133

Walls in earthquake countries, 277

Warning pipes, 244

Washing sand, 113

Waste of water, 18

cause of and prevention, 239,242

in houses, 241, 250

with constant service, 188

Waste pipes, 143, 145

from houses, 243 
Waste weir for masonry dams, 75 for reservoir, 54, 64

__ passing over dam, 64

Water analysis, 6 length and depth of, 66

—_ closets, $43,44,45,239$

discharge of in pipes (tables and diagrams of), 181

flow of, in conduits, pipes, and open channels, 167

—— in pipes, 177

- gauge (Turner's), 247

how admitted to filter beds, 110

meters, 18

motors for raising water, 164

over sand in filter beds, 98

pressure in mains, 184

quantity evaporated by coal, 156

rain, in pipes, $205,225,245$

selling by meter, 188, 242, 255

to be provided for extinction of fires, 189

towers, 134, 139, 147

in earthquake countries, 276,277

tube or tubulous boilers, 164

velocity of flow in pipes, 179

waste, cause of and prevention, 239 ,

242

- meter, 250

Water-waste preventing appliances, 242 cistern, 243, 244

Waterworks, site of, in earthquake countries, 224

_- $\quad$ typical system of, 143
Waves caused by earthquake motion, 67 , 275

— in impounding reservoirs, 65

— in relation to masonry dams, 72

Wells, pumping, 153, 158

- shallow, 1

Welsh coal, 156

Wergmann, Edward, Jr., 71, 72

West, C. D., vi

Wet and dry well-valve towers, 60

Wetted perimeter, 170

Wheels, water, 164

Wholesome waters, 14

Wiped joint for lead pipes, 268

Wood, James B., 27

Wooden pipes for waterworks, 2, 3, 18, 235

Wrought-iron and steel pipes, 218, 235

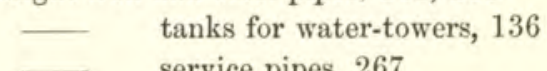

service pipes, 267

$\mathbf{Y}_{204}^{\text {ODOBASHI reservoir, Tokyo, Japan, }}$

Yokohama waterworks, effect of earthquake on, 67

$\longrightarrow \quad$ gaugingapparatus at, 247,285

Yoshimura, C., 37

$\mathbf{Y}$ pieces for pipes, 229

7 ERO, absolute, temperature of steam as measured from, 154

THE END. 


\section{CATALOGUE OF BOOKS}

INCLUDING NEW AND STANDARD WORKS IN

ENGINEERING: CIVIL, MECHANICAL AND MARINE; ELECTRICITY AND ELECTRICAL ENGINEERING; MINING, METALLURGY; ARCHITECTURE, BUILDING, INDUSTRIAL AND DECORATIVE ARTS; SCIENCE, TRADE AND MANUFACTURES; AGRICULTURE, FARMING, GARDENING; AUCTIONEERING, VALUING AND ESTATE AGENCY; LAW AND MISCELLANEOUS.

\section{CROSBY LOCKWOOD \& SON.}

MECHANICAL FNGINEERING, etc.

\section{K. Clark's Pocket-Book for Mechanical Engineers.}

THE MECHANICAL ENGINEER'S POCKET-BOOK OF TABLES, Engineering Practice. B "Railway Machinery," "By D. KINNEAR CLARK, M. Inst. C.E., Author of Small 8vo, 700 pages, 9 s. bound in flexible Second Edition, Revised and Enlarged, gilt edges.

\section{SUMMARY OF CONTENTS.}

Mathrmatical Tables.-Measurement of Surfaces and Solids.-English Weights and Measurgs.-French Metric Weights and Mrasures.-Foreign Weights - Fish Weights and

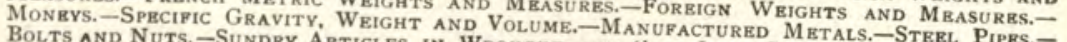
Bolts and Nuts.-Sundry Articles in Wrought and Cast Iron, Copper, Brass, - Sterd Pipes.Zinc.-Strength of Matrrials. - Strength of Timber. - Strength of Cast Iron, - Stren, Tin, of Wrovght Iron.-Strength of Stegl. - Tensimber.-STrength of Cast Iron.-STrength ANCE OF Stones And OTher BUUl, Shells.-Wire Rores and Hemp Ropes, - Chatns. - Riveted Joints in Boiler Plates, -Boiler Mrells,-Wire Ropes and Hemp Ropes, - Chains and Chain Cables,- Framing.-Hardiness of Mrtals, Alloys and Stones. - Labour of Animals. - Mrchanical Principles.-Gravity and Fale. of Bodies.-Accelerating and Retarding Forces.-Mill Gearing, Shafting, \&c.-TRansmission Stram.- Stram Engings and Bollers,- Ra Furls.-Warming, Ventilation, Cooking Stoves, Engings and Pumps.-Coan Engings,-W - Wter Power.-Sperd of Cutines, \& c.-Air in Motion,-Compressed Air.-Hot Air

$$
\text { * * OPInions of THE PRESS. }
$$

"Mr. Clark manifests what is an innate perception of what is likely to be useful in a pocketbook, and he is really unrivalled in the art of condensation. Very frequently we find the information on a given subject is supplied by giving a summary description of an experiment, and a statement of are rules given for several calculations, which steam table, occupying five-and-a-half pages; and there example, that on page 497 , for getting which rules cannot be found in other pocket-books, as, for weight of steam. It is ver getting at the quantity of water in the shape of priming in any known which this work supplies no difficult to hit upon any mechanical engineering subject concerning one word, it is an exceedingly information, and the excellent index at the end adds to its utility. one word, it is an exceedingly handy and efficient tool, possessed of which the engineer wil In saved many a wearisome calculation, or yet more wearisome hunt which the engineer will be treatises, and, as such, we can heartily recommend it to the idea that Mr. Clark's Pocket-book is only Molesworth in readers, who must not run away with contains what is not to be found in the other: and length with many subjects than Molesworth possibly could"-The Engine room and deais at more "It would be found difficult to colesworth possibly could."-The Engineer.

650 pages which should be more compress more matter within a similar compass, or produce a book of ciated bv mechanical engineers of all classes." "-Practical Engineer. reference. . . . Will be appre-

"Just the kind of work that practical men require to have near to them."-English Mechanic. 


\section{MR. HUTTON'S PRACTICAL HANDBOOKS.}

\section{Handbook for Works' Managers.}

THE WORKS' MANAGER'S HANDBOOK OF MODERN RULES,

TABLES, AND DATA, For Engineers, Millwrights, and Boiler Makers; Tool

Makers, Machinists, and Metal Workers; Iron and Brass Founders, \&c. By.

W. S. Hutron, Civil and Mechanical Engineer, Author of "The Practical En-

gineer's Handbook." Fourth Edition, carefully Revised and partly Re-written. In

One handsome Volume, medium 8vo, price $15 s$. strongly bound.

The Author having compiled Rules and Data for his own use in a great variety of modern engineering work, and having found his notes extremely usfful, decided to. bublish them-revised to date-believing that a practical work, suited to the DAILY REQUIREMENTS OF MODERN ENGINEERS, would be favourably received.

In the Fourth Edition the First Section has been re-uritten and improved by the addition of numerous Illustrations and new matter relating to STEAM ENGINES and GAS ENGines. The Second Section has been enlarged and Illustrated, and throughout the book a great number of emendations and alterations have been made, with the object of rendering the book more generally useful.

* * Opinions of the Press.

“The author treats every subject from the foint of view of one who has collected workshop notes for application in workshop practice, rather than from the theoretical or literary aspect. The volume contains. a great deal of that kind of information which is gained only by practical experience, and is seldom written in books." - Engineer.

'The volume is an exceedingly useful one, brimful with engineers' notes, memoranda, and rules, andi well worthy of being on every mechanical engineer's bookshelf." - Mechanical World.

"The information is precisely that likely to be required in practice. . . The work forms a desirable addition to the library not only of the works' manager, but of anyone connected with generas

engineering."-Mining fourval.
"A formidable mass of facts and figures, readily accessible through an elaborate index. . . . Such a volume will be found absolutely necessary as a book of reference in all sorts of 'works ' connected with. the metal trades." - Ryland's Iron Trades Circular.

"Brimful of useful information, stated in a concise form, Mr. Hutton's books have met a pressing. want among engineers. The book must prove extremely useful to every practical man possessing a copy."-Practical Engineer.

\section{New Manual for Practical Engineers.}

THE PRACTICAL ENGINEER'S HANDBOOK, Comprising a

Treatise on Modern Engines and Boilers, Marine, Locomotive, and Stationary.

And containing a large collection of Rules and Practical Data relating to recent

Practice in Designing and Constructing all kinds of Engines, Boilers, and other

Engineering work. The whole constituting a comprehensive Key to the Board of

Trade and other Examinations for Certificates of Competency in Modern Mechanical

Engineering. By WAlter S. HutTon, Civil and Mechanical Engineer, Author of

"The Works' Manager's Handbook for Engineers," \&c. With upwards of 370 .

Illustrations. Fourth Edition, Revised, with Additions. Medium 8vo, nearly $50 \mathrm{O}$ -

pp., price 18 s. strongly bound.

as?" This work is designed as a companion to the Author's "Works' Manager's. HANDBOOK." It possesses many new and original features, and contains, like its predecessor, a quantity of matter not originally intended for publication, but collected by the Author for his own use in the construction of a great variety of MODERN ENGINEERING: WORK.

The information is given in a condensed and concise form, and is illustrated by up. wards of 370 Woodcuts; and comprises a quantity of tabulated matter of great value to all engaged in designing, constructing, or estimating for ENGINES, BOILERS, and OTHER ENGINEERING WORK.

\section{* * Opinions of the Press.}

"We have kept it at hand for several weeks, referring to it as occasion arose, and we have not on a single occasion consulted its pages without finding the information of which we were in quest.' Athenoum.

"A thoroughly good practical handbook, which no engineer can go through without learning something that will be of service to him."-Marine Engineer.

" An excellent book of reference for engineers, and a valuable text-book for students ot engineering."-Scotsman.

"This valuable manual embodies the results and experience of the leading authorities on mechanical engineering."-Building News.

"The author has collected together a surprising quantity of rules and practical data, and has shown much judgment in the selections he has made. . . . There is no doubt that this boo

most useful of its kind published, and will be a very popular compendium."-Engineer.

"A nass of information, set down in simple language, and in such a form that it can be easily referred to at any time. The matter is uniformly good and well chosen, and is greatly elucidated by the illustrations. The book will find its way on to most engineers' shelves, where it will rank as one of

most useful books of reference."- Practical Engineer.
"Full of useful information, and should be found on the office shelf of all practical engineers."English Mechanic. 
MR. HUTTON'S PRACTICAL HANDBOOKS-continued.

\section{Practical Treatise on Modern Steam-Boilers.}

STEAM BOILER CONSTRUCTION. A Practical Handbook for Engineers, Boiler-Makers, and Steam Users. Containing a large Collection of Rules and Data relating to Recent Practice in the Design, Construction, and Working of all Kinds of Stationary, Locomotive, and Marine Steam-Boilers. By WALTER S. Hutron, Civil and Mechanical Engineer, Author of "The Works' Manager's Handbook," "The Practical Engineer's Handbook," \&c. With upwards of 300 Illustrations. Second Edition, medium $8 \mathrm{vo}, \mathbf{1} 8 \mathrm{~s}$. cloth.

THIS WORK is issued in continuation of the Series of Handbooks written by the Author, viz:- "The Works' Manager's HandBook" and "The PracticaI ENGINEER'S HANDBOOK," which are so highly appreciated by Engineers for the practical nature of their information; and is consequently written in the same style as those works.

The Author believes that the concentration, in a convenient form for easy reference, of such a large amount of thoroughly practical information on Steam-Boilers, will be of considerable service to those for whom it is intended, and he trusts the book may be deemed worthy of as favourable a reception as has been accorded to its predecessors.

\section{** Opinions of THe Press.}

"Every detail, both in boiler design and management, is clearly laid before the reader. The volume shows that boiler construction has been reduced to the condition of one of the most exact sciences; and such a book is of the utmost value to the fin de siecle Engineer and Works' Manager."-Marine
Engineer.

"There has long been room for a modern handbook on steam boilers; there is not that room now, because Mr. Hutton has filled it. It is a thoroughly practical book for those who are occupied in the
construction, design, selection, or use of boilers."-Engineer.

"The book is of so important and comprehensive a character that it must find its way into the libraries of every one interested in boiler using or boiler manufacture if they wish to be thoroughly informed. We strongly recommend the book for the intrinsic value of its contents." - Machinery Market.

"The value of this book can hardly be over-estimated. The author's rules, formula, \&c., are al very fresh, and it is impossible to turn to the work and not find what you want. No practical enginect
should be without it."-Colliery Guardian.

\section{Hutton's "Modernised Templeton."}

THE PRACTICAL MECHANICS' WORKSHOP COMPANION. Comprising a great variety of the most useful Rules and Formula in Mechanica: Science, with numerous Tables of Practical Data and Calculated Results for Facilitating Mechanical Operations. By William TempletoN, Author of "The Engineer's Practical Assistant," \&c. \&c. Sixteenth Edition, Revised, "Modernised, and considerably Enlarged by WALTER S. HutTon, C.E., Author of "The Works' Manager's Handbook," " The Practical Engineer's Handbook," \&c. Fcap. 8vo, nearly 500 pp., with 8 Plates and upwards of 250 Illustrative Diagrams, 6s. strongly bound for workshop or pocket wear and tear.

$$
\text { * Opinions of the PRFSS. }
$$

' In its modernised form Hutton's 'Templeton' should have a wide sale, for it contains much valuable information which the mechanic will often find of use, and not a few tables and notes which he might look for in vain in other works. This modernised edition will be appreciated by all who have learned to value the original editions of "Temp'eton." -English Mechanic.

"It has met with great success in the engineering workshop, as we can testify; and there are a great many men who, in a great measure, owe their rise in life to this little book." - Building Nezus.

"This familiar text-book - well known to all mechanics and engineers-is of essential service to the every-day requirements of engineers, millwrights, and the various trades connected with engineering and building. The new modernised edition is worth its weight in gold."-Bualding Nezw. (Second
Notice.) "This well-known and largely-used book contains information, brought up to date, of the sort so.
useful to the foreman and draughtsman. So much fresh information has been introduced as to constitute it practically a new book. It will be largely used in the office and workshop."

"The publishers wisely entrusted the task of revision of this popular, valuable, Mtchanical World. Mr. Hutton than whom a more competent to

\section{Templeton's Engineer's and Machinist's Assistant.}

THE ENGINEER'S, MILLWRIGHT'S, AND MACHINIST'S PRAC-

TICAL ASSISTANT. A collection of Useful Tables, Rules, and Data. By

William Templeton. Seventh Edition, with Additions. 18mo, 2s. $6 d$. cloth.

\section{** Opinions of the Press.}

"Occupies a foremost place among books of this kind. "A more suitable present to an apprentice to any of the mechanical trades could not possibly be made."-Building News.

"A deservedly popular work. It should be in the 'drawer' of every mechanic."-English Mechanic 


\title{
Foley's Office Reference Book for Mechanical Engineers.
}

THE MECHANICAL ENGINEER'S REFERENCE BOOK, for Machine and Boiler Construction. In Two Parts. Part I. General Engineering Data. Part II. Boiler Construction. With 51 Plates and numerous Illustrations. By Nelson Foley, M.I.N.A. Folio, $£ 55$ s. half-bound.

\section{Summary of Contents.}

PART 1.

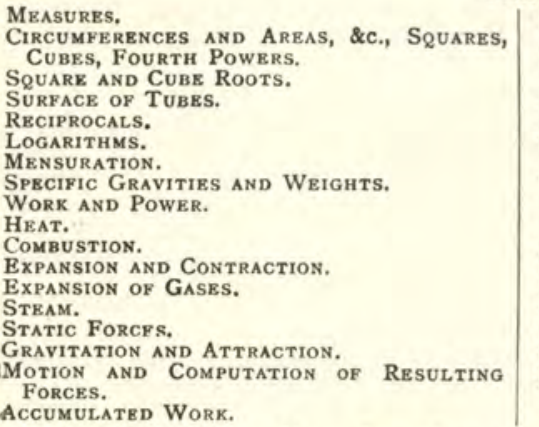

\author{
Centre and Radius of Gyration. \\ MOMENT OF INERTIA. \\ Centre of Oscillation. \\ ELECTRICITY. \\ Strength of Materials. \\ Elasticity. \\ Test SheEts of Metals. \\ Friction. \\ TRANSMISSION OF POWER. \\ Flow of Liquids. \\ FLow OF GASES. \\ Air Pumps, Surface Condensers, \&c. \\ SPEEd OF Steamships. \\ Propellers. \\ Cutring Tools. \\ FLANGES. \\ COPPER SheEts ANd TUBgs, \\ SCrews, Nuts, Bott Heads, \&c.
}

Various Recipes and Miscellaneous Matter.

With Diagrams for Valve-Ggar. Belting and Ropes, Discharge and Suction Pipgs Screw Propellers, and Copper Pipes.

Treating of, Power of Boilers.

PART II.

USEFul Ratios.

Notes ON Construction.

Cylindrical Botler Shells.

Circular Furnaces.

Fiat Plates.

STAYS.

GIRDERS.

Screws.

HyDRaulic TESTS.

Riveting.

Boiler Setring, Chrmens, and Mountings.

Fuels, \&c.

Examples of Botlers and Spgeds of SteamSHIPS.

With Diagrams fominal and Normal Horse Power.

\author{
* * Opinions of THe Press
}

"This anpears to be a work for which there should be a large demand on the part of mechanical engineers. It is no easy matter to compile a book of this class, and the labour involved is enormous, particularly when - as the author informs us - the majority of the tables and diagrams have been specially prepared for the work. The diagrams are exceptionally well executed, and generally constructed on the method adopted in a previous work by the same author. very numerous, and deal with a greater variety of subjects than will genecally be found in work tlus kind; they bave evidently been compiled with great care and are unusually complete. will the are unusually complete. All the information given appears to be well up to date. . . . It would be quite impossible within the limits at our disposal to even enumerate all the subjects treated; it should, however, be mentioned that the author does not confine himself to a mere bald statement of formula and laws, but in very many instances shows succinctly how these are derived. . . . The latter part of the book is devoted to diagrams relating to Boiler Construction, and to nineteen beautifully-executed plates of working drawinzs of boilers and their details. As samples of how such drawings should be got out, they may be cordially recommended to the attention of all young, and even some elderly, engineers. Altogether the book is one which every mechanical engineer may, with advantage to himself add to his library."-Industries.

"Mr. Foley is well fitted to compile such a work. . . . The diagrams are a great feature of the work. 1 Regarding the whole work, it may be very fairly stated that Mr. Foley has produced a volume which will undoubtedly fulfil the desire of the author and become indispensable to all mechanical engineers."-Marine Engineer.

"We have carefully examined this work, and pronounce it a most excellent reference book for the use of marine engineers."- Fournal of American Society of Naval Engineers.

"A veritable monument of industry on the part of Mr. Foley, who has succeeded in producing what is simpiy invaluable to the engineering profession."-Steamship.

\section{Coal and Speed Tables.}

A POCKET BOOK OF COAL AND SPEED TABLES, for Engineers and Steam-users., By NELSON FOLEY, Author of "The Mechanical Engineer's Reference Book." Pocket-size, 3s. 6d. cloth.

"These tables are designed to meet the requirements of every-day use; they are of sufficient scope for most practical purposes, and may be commended to engineers and users of steam."-Iron.

"This pocket-book well merits the attention of the practical engineer. Mr. Foley has compiled a very useful set of tables, the information contained in which is frequently required by engineers, coal consumers, and users of steam."-Iron and Coal Trades Reviezv. 


\section{Steam Engine.}

TEXT-BOOK ON THE STEAM ENGINE. With a Supplement on Gas Engines, and Part iI. on Heat Engines. By T. M. Goodeve, M. A., Barrister-at-Law, Professor of Mechanics at the Royal College of Science, London; Author of "The Principles of Mechanics," "The Elements of Mechanism," \&c. Twelfth Edition, Enlarged. With numerous Illustrations. Crown 8vo, 6s, cloth.

"Professor Goodeve has given us a treatise on the steam engine, which will bear comparison with anything written by Huxley or Maxwell, and we can award it no higher praise." - Engineer.

"Mr. Goodeve's text-bock is a work of which every young engineer should pussess himself." Mining fournal.

\section{Gas Engines.}

ON GAS ENGINES. With Appendix describing a Recent Engine with

Tube Igniter. By T. M. Goodeve, M. A. Crown 8vo, 2s. 6 d. cloth. [7ust published.

"Like all Mr. Goodeve's writings, the present is no exception in point of general excellence. It is a valuable little volume." -Mechanical World.

\section{Steam Engine Design.}

A HANDBOOK ON THE STEAM ENGINE, with especial Reference to Small and Medium-sized Engines. For the Use of Engine Makers, Mechanical Draughtsmen, Engineering Students, and Users of Steam Power. By Herman HAEDER, C.E. English Edition, Re-edited by the Author from the Second German Edition, and Translated, with considerable Additions and Alterations, by H. H. P. PowLes, A.M.I.C.E., M.I.M.E. With nearly I,100 Illustrations. Crown Svo, 9s. cloth.

"A perfect encyclopadia of the steam engine and its details, and one which must take a permanent place in English drawing-offices and workshops." - A Foreman Pattern-maker.

"This is an excellent book, and should be in the hands of all who are interested in the construction and design of medium-sized stationary enzines. . . . A careful study of its contenits and the arrangement of the sections leads to the conclusion that there is probably no other book like it in this country. The volume aims at showing the resulis of practic.l experience, and it certainly may claim a complete The volume aims at showing the resulis of practical experience, and it certainly may claim a complete
achievement of this idea."-Nature.

"There can be no question" as to its value. We cordially commend it to all concerned in the design and construction of the steam $t$ ngine. '-Mechanical World.

\section{Steam Boilers.}

A TREATISE ON STEAM BoIlers: Their Strength, Construction, and Economical Working. By R. Wilson, C.E. Fifth Edition. 12mo, 6s, cloth.

"The best treatise that has ever been published on steam boilers." - Engineer.

"The author shows himself perfect master of h's subject, and we heartily recominend all employing steam power to possess themselves of the wurk." - Ryland's Iron Trade Circular.

\section{Boiler Chimneys.}

BOILER AND FACTORY CHIMNEYS: Their Draught-Power and Stability. With a Chapter on Lightning Conductors. By RoBERT WILSON, A.I.C.E., Author of "A Treatise on Steam Boilers," \&c. Second Edition. Crown 8vc, 3s. 6 d. cloth.

"A valuable contribution to the literature of scientific building."-The Builder.

\section{Boiler Making.}

THE BOILER-MAKER'S READY RECKONER AND ASSISTANT.

With Examples of Practical Geometry and Templating, for the Use of Platers,

Smiths, and Riveters. By John CoukTney, Edited by D. K. Clark, M.I.C.E.

Third Edition, 480 pp., with r 40 Illustrations. Fcap. 8vo, $7 s$. half-bound.

"No workman or apprentice should be without this book."-Iron Trade Circular.

\section{Locomotive Engine Development.}

The Locomotive Engine ANd its Development. $\Lambda$ Popular Treatise on the Gradual Improvements made in Railway Engines between 1803 and 1893 . By Clement E. Stretton, C.E., Author of "Safe Railway Working," \&c. Second Edition, Revised and much Enlarged. With 95 Illustrations. Crown 8vo, $3 s .6$. cloth.

"Students of railway history and all who are interested in the evolution of the modern locomotive will find much to attract and entertain in this volume." - The Times.

"The anthor of this work is well known to the railway world, and no one, probably, has a better knowledge of the history and development of the locomotive. The volume betore us should be of value to ail connected with the railway system of this country." -Nature. 


\section{Fire Engineering.}

FIRES, FIRE-ENGINES, AND FIRE-BRIGADES. With a History of Fire-Engines, their Construction, Use, and Management ; Remarks on Fire-Proof Buildings, and the Preservation of Life from Fire ; Statistics of the Fire Appliances in English Towns; Foreign Fire Systems; Hints on Fire-Brigades, \&c. \&c. By Charles F. T. Young, C.E. With numerous Illustrations, $544 \mathrm{pp}$., demy 8vo, EI 4s. cloth.

"To such of our readers as are interested in the subject of fires and fire apparatus, we can most hisartily commend this book. It is really the only English work we now have upon the subject," ".

His "It displays much evidence of careful research, and $\mathrm{Mr}$. Young has put his facts neatly together. the conditions with which it is nectical details of the construction of steam fire engines, old and new, and the conditions with which it is necessary they should comply, is accurate and full." - Engineer.

\section{Estimating for Engineering Work, \&c.}

ENGINEERING ESTIMATES, COSTS, AND ACCOUNTS: A Guide to Commercial Engineering. With numerous Examples of Estimates and Costs of Millwright Work, Miscellaneous Productions, Steam Engines and Steam

Boilers ; and a Section on the Preparation of Costs Accounts. By A General Manager. Demy 8vo, i2s. cloth.

"This is an excellent and very useful book, covering subject-matter in constant requisition in every factory and workshop...... The book is invaluable, not only to the young engineer, but also to the estimate department of every works "-Builder.

anner, and bears thork unqualified praise. The information is given in a plain, straightforward every phrase of commercial engineering." every phrase of coinmercial engineering."-Mechanical World.

\section{Engineering Construction.}

PATTERN-MAKING : A Practical Treatise, embracing the Main Types of Engineering Construction and including Gearing, both Hand and Machine-made, Engine Work, Sheaves and Pulleys, Pipes and Columns, Screws, Machine Parts, Pumps and Cocks, the Moulding of Patterns in Loam and Greensand, \&c.; together with the methods of Estimating the weight of Castings; to which is added an Appendix of Tables for Workshop Reference. By A Foreman PATTERN-MAKer.

Second Edition, thoroughly Revised and much Enlarged. With upwards of 450

Illustrations. Crown 8vo, 7s.6d. cloth. [fust published.
[fus

"A well-written technical guide, evidently written by a man who understands and has practised what he has written about. . . We cordially recommend it to engineering students, young

journeymen, and others desirous of being initiated into the mysteries of pattern-making,"-Builder. thus rendering the work an excellent vade mecum for the apprentice who desires to become master of his
trade."-Engtish Mechanic.

\section{Dictionary of Mechanical Engineering Terms.}

\section{LOCKWOOD'S DICTIONARY OF TERMS USED IN THE PRACTICE}

OF MECHANICAL ENGINEERING, embracing those current in the Drawing Office,

Pattern Shop, Foundry, Fitting, Turning, Smiths', and Boiler Shops, \&c. \&c.

Comprising upwards of 6,000 Definitions. Edited by A Foreman PATTERN-

MAKER, Author of "Pattern Making." Second Edition, Revised, with Additions.
Crown 8vo, 7s. $6 d$. cloth.

"Just the sort of handy dictionary required by the various trades engaged in mechanical engineering. The practical engineering pupil will find the book of great value in his studies, and every foreman
engineer and mechanic should have a copv."-Builting Nerws. Mechanic.

"One of the most useful books which can be presented to a mechanic or student."-English

happy idea to combine with a but, to a certain extent, also a most valuable guide. It strikes us as a happy idea to combine with a definition of the phrase useful information on the subject of which it
treats."-Machinery Market. Mill Gearing.

TOOTHED GEARING : A Practical Handhook for Offices and Workshops. By, A Foreman PATtern MAKer, Author of "Pattern Making." "Lockwood's Dictionary of Mechanical Engineering Terms," \&c. With 184 Illustrations. Crown 8 vo, 6s. cloth.

\section{SUMMARY OF CONTENTS.}

Chap. I. Principles. - II. Formation of WhemLs.-Xi. Skew Bevels. -XII. Variable Tooth Profiles.-III. Proportions of TeEth. AND other GEars.-XIII. Diametrical PItch. -IV. Methods of Making ToOth Forms.- -XIV. The Odontograph. - XV. Pattern Forms, - VII, Beth. -VI. SOME Special Tooth Gears.-XVI. Machine Moulding Gears.Forms. - VII. BeVel Wheels. - VIII. Screw XVII. Machine Cut Gears.-XVIII. Propor"We - IX. Worm Gears, - X. Helical tion of WheEls.

heartily recommend it to book our unyualified praise for its throughness of treatment and we can Mechanical World. 


\section{Stone-working Machinery.}

STONE-WORKING MACHINERY, and the Rapid and Economical Conversion of Stone. With Hints on the Arrangement and Management of Stone Works. 'By M. Powis Bale, M.I.M.E. With Illustrations. Crown 8vo, $9 s$.

"The book should be in the hands of every mason or student of stonework."-Colliery Guardian.

"The book should be in the hands of every mason or student of stonework,"-Collier capital handbook for ail who manipulate stone for building or ornamental purposes."Machinery Market.

\section{Pump Construction and Management.}

PUMPS AND PUMPING: A Handbook for Pump Users. Being Notes on Selection, Construction, and Management. By M. Powis BALE, M.I.M.E., Author of "Woodworking Machinery," "Saw Mills," \&c. Second Edition, Revised. Crown 8vo, 2s. 6d. cloth.

"The matter is set forth as concisely as possible. In fact, condensation rather than diffuseness has been the aunor's aim throughout; yet he does not seem to have omitted anything likely to be of

use." - Fournal of Gas Lighting.

\section{Milling Machinery, \&c.}

MILLING MACHINES AND PROCESSES: A Practical Treatise on Shaping Metals by Rotary Cutters. Including Information on Making and Grinding the Cutters. By PAUL N. HASLUCK, Author of "Lathe-Work," "Handybooks for Handicrafts," \&c. With upwards of 300 Engravings, including numerous Drawings by the Author. Large crown 8 vo, 352 pages, 12s. $6 d$. cloth.

"A new departure in engineering literature. . . We can recommend this work to all interested in milling machines; it is what it professes to be--a practical treatise."-Engincer.

. A tho who are Already acquainted with the process as well as to tnose who contemplate its adoption." - Industries.

\section{Turning.}

LATHE-WORK : A Practical Treatise on the Tools, Appliances, and Processes employed in the Art of Turning. By PAUL N. HASLuck. Fourth Edition, Revised and Enlarged. Crown 8vo, 5 s. cloth.

"Written by an who knows not only how work ought to be done, but who also knows how to do it, and how to convey his knowledge to others. To all turners this book would be valuable." Engineering.

able. "To the student it will convey a great deal of useful information."-Engineer.

\section{Screw-Cutting.}

SCREW THREADS: And Methods of Producing Them. With numerous Tables and complete Directions for using Screw-Cutting Lathes. By PAUL N. HASLUCK, Author of "Lathe-Work," \&c. With Seventy-four Illustrations. Third Edition, Revised and Enlarged. Waistcoat-pocket size, Is. $6 d$. cloth.

"Full of useful information, hints and practical criticism. Taps, dies, and screwing tools generally are illustrated and their action described."- Mechantcal World.

are is a complete compendium of all the details of the screw-cutting lathe; in fact a multum-inbarvo on all the subjects it treats upon." -Carpenter and Builder.

\section{Smith's Tables for Mechanics, \&c.}

TABLES, MEMORANDA, AND CALCULATED RESULTS, FOR MECHANICS, ENGINEERS, ARCHITECTS, Builders, \&C. Selected and Arranged by FRANCIS SMITH. Fifth Edition. thoroughly Revised and Enlarged, with a New Section of Electrical Tables, Formule, \& Memoranda. Waistcoat-pocket size, Is. $6 d$. limp leather.

"It would, perhaps, be as difficult to make a small pocket-book selection of notes and formula to "It would, perhaps, be as difficult to make a small pocket-book selection lection may be looked upon as a successful attempt."-Engineer. ?

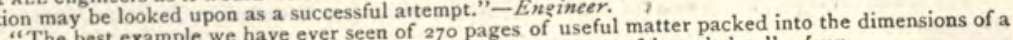
card-case."-Building News. "A veritable pocket treasury of knowledge."-Iron.

\section{French-English Glossary for Engineers, \&c.}

A POCKET GLOSSARY OF TECHNICAL TERMS: ENGLISHFRENCH, FRENCH-ENGLISH ; with Tables suitable for the Architectural, Engineering, Manufacturing, and Nautical Professions. By JOHN JAMES F LETCHER, Engineer and Surveyor. Second Edition, Revised and Enlarged, 200 pp. Waistcoat-poeket size, $1 s, 6 d$. limp leather.

"It is a very great advantage for readers and correspondents in France and England to have so large rarge a ntlo bers." - Architect.

The little book will be useful both to students and travellers. - Architect. cordially commend the book." - Mechanical World. 
Year-Book of Engineering Formulce, \&c.

THE ENGINEER'S YEAR-BOOK FOR 1894. Comprising Formulæ Rules, Tables, Data and Memoranda in Civil, Mechanical, Electrical, Marine and Mine Engineering. By H. R. KEMPE, A.M.Inst.C.E., M.I.E.E., Technical "A H undbook of Eler-in-Chief's Office, General Post Office, London, Author of \&c. With pages, $8 s$. leather. pages, 8s. leather.

[Fust published.

Engineer.

"The volume is distinctly in advance of most similar publications in this country."-Engineering. neers."-Saturfay Review. Nezus.

Teems with up-tordate $\because$ T

and The needs of the engineering profeerion could hars and convenient form. To say that it more tha could hardly be supplied in a more admirable, complete and that may justly be said of it."-Mining fournal.

"There is certainly room for the new comer, which

as formula and tables, It deserves to becomer, which supplies explanations and directions, as well Architect.

"Brings together withechnical annuals." -

by day. It is in every way admirably equipped, and is sure to prove successfun engineer has to use day The up-to-dateness of Mr. Kempe's compilation is to prove successful." - Scotsman.

people for whom the work is intended."-Glasgow Herald. Portable Engines.

THE PORTABLE ENGINE : ITS CONSTRUCTION AND MANAGE-

MENT: A Practical Manual for Owners and Users of Steam Engines generally. By

William Dyson Wansbrough. With 90 Illustrations. Crown 8 vo, $3 s .6 d$. cloth.

"This is a work of value to those who use steam machinery.
has a steam engine, on a farm or elsewhere."-Mark Lane Express. Should be read by every one do with their construction or use."-Timber Trades fournal.

be acquired by all intelligent owners and others who as $\mathrm{Mr}$. Wansbrough furnishes to the reader should "An excellent text-book of this useful form of engine. The steam engine."-Building Nevis.

deal of common-sense and practical wisdom."Iron and Steel.

"IRON AND STEEL": A Work for the Forge, Foundry, Factory, and Office. Containing ready, useful, and trustworthy Information for Ironmasters and their Stock-takers; Managers of Bar, Rail, Plate, and Sheet Rolling Mills ; Iron and Metal Founders; Iron Ship and Bridge Builders; Mechanicai, Mining. and Consulting Engineers; Architects, Contractors, Builders, and Professional Draughtsmen. By CHARLes HOARE, Author of "The Slide Rule," \&c. Eighth

"For comprehensiveness the bhout and considerably Enlarged. 32mo, 6s, leather.

"One of the best of the pocket books." not its equal." --Irnn.

"We cordially recommend this book." - English Mechanic.

and steel works." -Naval Science.

\section{Elementary Mechanics.}

CONDENSED MECHANICS. A Selection of Formulæ, Rules, Tables, and Data for the Use of Engineering Students, Science Classes, \&c. In accordance with the Requirements of the Science and Art Department. By W. G.

CRAWFORD Hughes, A.M.I.C.E. Crown 8 vo, 2s. $6 d$. cloth.

or are preparine for examination those who are either confronted with practical problems in their work, again."-Marine Engmerr. Steam.

THE SAFE USE OF STEAM. Containing Rules for Unprofessional

Steam-users. By an ENGINEer. Sixth Edition. Sewed, $6 d$.

by their rarity."-English Mechanic. Warming.

HEATING BY HOT WATER; with Information and Suggestions

on the best Methods of Heating Public, Private and Horticultural Buildings. By

"We confidently recommend Edition. With 96 Illustrations, crown $8 \mathrm{vo}, 2 s$. $6 d$. net. valuable little treatise." -The Piumber and Decorator. 


\section{THE POPULAR WORKS OF MICHAEL REYNOLDS}

\section{Locomotive-Engine Driving.}

("The ENGINe Driver's Friend").

LOCOMOTIVE-ENGINE DRIVING : A Practical Manual for Engineers

in Charge of Locomotive Engines. By Michael Reynolvs, Member of the Society of Engineers, formerly Locomotive Inspector, L. B. and S. C. R. Ninth

Edition. Including a KeY to the Locomotive ENGINe. With Illustrations and

Portrait of Author. Crown 8vo, 4s. 6 d. cloth.

"Mr. Reynolds has supplied a want, and has supplied it well. We can confidently recommend the book not only to the practical driver, but to everyone who takes an interest in the performance of loconotive engines." - The Engineer.

Mr. Reynolds has opened a new chapter in the literature of the dav. This admirable practical treatise, of the practical utility of which we have to speak in terms of warm commendation."-A thencum.

"Evidently the work of one who knows his subject thoroughly."-Railway Service Gazette.

"Were the cautions and rules given in the book to become part of the every-day working of our engine-drivers, we might have fewer distressing accidents to deplore."-Scotsman.

\section{Stationary Engine Driving.}

STATIONARY ENGINE DRIVING : A Practical Manual for Engineers in Charge of Stationary Engines. By Michakl Reynolds. Fifth Edition, Enlarged. With Plates and Woodcuts. Crown 8vo, 4s. 6 d. cloth.

"The author is thoroughly acquainted with his subjects, and his advice on the various points treated is clear and practical. . He has produced a manual which is an exceedingly useful one for the class for whom it is specially intended."-Engineering.

"Our author leaves no stone unturned. He is determined that his readers shall not only know something about the stationary engine, but all about it."-Engineer.

"An engineman who has mastered the contents of Mr. Keynolds's book will require but little actua experience with boilers and engines befo e he can be trusted to look after them."-English Mechanic.

\section{The Engineer, Fireman, and Engine-Boy.}

THE MODEL LOCOMOTIVE ENGINEER, FIREMAN, AND ENGINE-

BoY. Comprising a Historical Notice of the Pioneer Locomotive Engines and their

Inventors. By Michael Reynolds. With numerous lllustrations, and a fine

Fortrait of George Stephenson. Crown 8vo, 4 s. $6 d$. cloth.

"From tine technical knowledge of the author, it will appeal to the railway man of to-day more forcibly than anything written by Dr. Smiles. . . The volume contains information of a technical kind, and facts that every driver should be familiar with."-English Mechanic.

"We shouid be glad to see this book in the possession of everyone in the kingdom who has ever laid, or is to lay, hands on a locomotive engine."-Iron.

\section{Continuous Railwau Brakes.}

CONTINUOUS RAILWAY BRAKES: A Practical Treatise on the several Systems in Use in the United Kingdom : their Construction and Performance. With copious I!lustrations and numerous Tables. By MICHAEL REYNOLDS.

Large crown 8vo, 9s. cloth.

"A popular explanation of the different brakes. It will be of great assistance in forming public opinion, and will be studied with benefit by those who take an interest in the brake."-English Mechanic.

"Written with sufficient technical detail to enable the principal and relative connection of the various parts of each particular brake to be readily grasped." - Mechanical World.

\section{Engine-Driving Life.}

ENGINE-DRIVING LIFE : Stirring Adventures and Incidents in the

Lives of Locomotive Engine-Drivers. By Michael Reynolns. Third and

Cheaper Edition. Crown 8vo, Is. $6 d$, cloth.

[Fust published.

"From first to last perfectly fascinating. Wilkie Collins's most thrilling conceptions are thrown into the shade by true incidents, endless in their variety, related in every page." - North British Mail.

"Anyone who wishes to get a real insight into railway life caunot do better than read "Engine. Driving Life' for himself, and if he once takes it up he will find that the author's enthusiasm and real luve of the engine-driving profession will carry him on till he has read every page." - Saturday Review.

\section{Pocket Companion for Enginemen.}

THE ENGINEMAN'S POCKET COMPANION and Practical Educator for Enginemen, Boiler Attendants, and Mechanics. By Michael Reynolds,

With Forty-five Illustrations and numerous Diagrams. Third Edition, Revised.

Royal $18 \mathrm{mo}, 3 s .6 d$. strongly bound for pocket wear.

"This admirable work is well snited to accomplish its object, being the honest workmanship of a competent engineer."-Glasgow Herald.

"A most meritorious work, giving in a succinct and practical form all the information an engineminder desirous of mastering the scientific princ ples of his daily calling would require." - The Miller.

"A boon to those who are striving to become efficient mechanics." - Daily Chronicle. 


\section{CIVIL ENGINEERING, SURVEYING, etc.}

\section{MR. HUMBER'S VALUABLE ENGINEERING BOOKS. The Water-Supply of Cities and Towns.} A COMPREHENSIVE TREATISE ON THE WATER-SUPPLY OF Cities AND TOWNS. By William Humber, A.-M. Inst. C.E., and M. Inst، M.E., Author of "Cast and Wrought Iron Bridge Construction," \&c. \&c. Illustrated with 50 Double Plates, I Single Plate, Coloured Frontispiece, and upwards of 250 Woodcuts, and containing 400 pages of Text. Imp. 4 to, $£ 66$ s. elegantly and substantially half-bound in morocco.

\section{List of Contents.}

I. Historical. SKetch of Some of the Means | XIII. Distribution of Water.-XIV. Meters THAT HAVE BEEN ADOPTED FOR THE SUPPLY OF WATER TO Citiks AND TOWNS.-II. WATER AND THE Foreign MATter USUALly associated WITH IT.--III. RAINFALl AND EVAPORATION.IV. SPRINGS AND THE WATER-BEARING FORMATIONS OF VARIOUS DISTRICTS.-V. MEASUREMENT AND ESTIMATION OF THE FLOW OF WATER.VI. ON THE SElection OF THE SOURCE OF SUPPLY.-VII. WELLS. - VIII. KESERVOIRS.IX. The Purification of Water.-X. Pumps. -XI. Pumping Machinery.-XiI. Conduits. -

SERVICE PIPES THE LAW AND ECONOMY OF WATER WORKS.XVI. Constant AND INTERMITTENT SUPPLY, XVII. DESCRIPTION OF PLATES, - ApPENDICES, GIVING TABLES OF RATES OF SUPPLY, VELOcITIES, \&c. \&C., TOGETHER WITH SPECIFICATIONS OF SEVERAL WORKS ILLUSTRATED, AMONG WHICH WILL BE FOUND: ABERDEEN, BIDEFORD, Canterbury, DUndee, Halifax, Lambeth, ROTHERHAM, DUBLIN, AND OTHERS.

"The most systematic and valuable work upon water supply hitherto produced in English, or in any other language. . . . Mr. Humber's work is characterised almost throughout by English, or in any much more distinctive of French and German than of English technical treatises." "Ey an exhaustiveness "We can congratulate Mr. Humber German than of English technical treatises." - Enginecr.

a subject so impurtant as the water supply of cities and drawings of executed works, and amply of cities and towns. The plates, fifty in number, are mostly prawings of executed works, and alone would have commanded the attention of every engimeer whose
practice may lie in this branch of the profession."-Builder.

\section{Cast and Wrought Iron Bridge Construction.}

A COMPLETE AND PRACTICAL TREATISE ON CAST AND WROUGHT IRON BRIDGE CONSTRUCTION, including Iron Foundations. In Three Parts-Theoretical, Practical, and Descriptive. By William Humber, A.-M. Inst. C.E., and M. Inst. M.E. Third Edition, revised and much improved, with 115 Double Plates (20 of whicn now first appear in this edition), and numerous

Additions to the Text. In 2 vols., imp. 4 to, $£ 616 s .6 d$. half-bound in morocco.

"A very valuable contribution to the standard literature of civil engineering. In addition to elevations, plans, and sections, large scale details are given, which very much enhance the instructive worth of those illustrations."- Crvil Engineer and Architect's fournal.

"Mr. Humber's stately volumes, lately issued - in which the most important bridges erected during the last five years, under the direction of the late Mr. Brunel, Sir W. Cubitt, Mr. Hawkshaw, Mr. Page, Mr. Fowler. Mr. Hernans, and others among our most eminent engineers, are drawn and specified in
great detail."-Engineer.

Strains, Calculation of.

A HANDY BOOK FOR THE CALCULATION OF STRAINSIN GIRDERS AND SIMILAR STRUCTURES AND THEIR STRENGTH. Consisting of Formulæe and Corresponding Diagrams, with numerous details for Practical Application, \&c. By William Humber, A.-M. Inst. C.E., \&c. Fifth Edition. Crown 8vo, with nearly 100 Woodcuts and 3 Plates, $7 s .6$. cloth.

"The formula are neatly expressed, and the diagrams good."-Athenaum.

"We heartily commend this really handy book to our engineer and architect readers." - English

\section{Barlow's Strength of Materials, Enlarged by Humber.}

A TREATISE ON THE STRENGTH OF MATERIALS; with Rules for application in Architecture, the Construction of Suspension Bridges, Railways, \&c. By Peter Barlow, F.R.S. A New Edition, revised by his Sons, P. W. BARLOW, F.R.S., and W. H. BARLOW, F.R S.; to which are added, Experiments by HodgKinson, FAIRBAIRN, and KIRKALDY; and Formulæ for Calculating Girders, \&c. Arranged and Edited by WM. HUMEer, A.-M. Inst. C.E. Demy 8 vo, 400 pp., with 19 large Plates and numerous Woodcuts, I 85 . cloth.

"Valuable alike to the student, tyro, and the experienced practitioner, it will always rank in future, as it has hitherto done, as the standard treatise on that particular subject." - Engineer.

"There is no greater authority than Barlow."-Building News.

"As a scientific work of the first class, it deserves a foremost place on the bookshelves of every' 


\section{MR. HUMBER'S GREAT WORK ON MODERN ENGINEERING.}

Complete in Four Volumes, imperial 4to, price $\oint_{12}$ 12s. half-morocco. Each volume sold separately as follows :-

A RECORD OF THE PROGRESS OF MODERN ENGINEERING. FiRST Series. Comprising Civil, Mechanical, Marine, Hydraulic, Railway, Bridge, and other Engineering Works, \&c. By William Humber, A.-M. Inst. C.E., \&c. Imp. 4 to, with 36 Double Plates, drawn to a large scale, Photographic Portrait of John Hawkshaw, C.E., F.R.S., \&c, , and copious descriptive Letterpress, Specifications, \&c., $\{3$ 3s. half-morocco.

\section{List of the Plates and Diagrams.}

Victoria Station and Roof, L. B. \& S. C. R. (8 PLATES): SOUTHPORT PIER (2 PLATES); VICTORIA STATION AND ROOF, L. C. \& D. AND G. W. R. (6 PLATES); ROOF OF CREMORNE MUSIC Hall; Bridge OVER G. N. RAILWAY; RoOF OF

Bridge over the Thames, West London EXTENStON RaILWAY (5 PLATES); A RMOUR Plates': SUSPENSION BRIDGE. THAMES (4 PLATES); THE Allen ENGine; SUSPENSIÓN BRIDGe, AvoN STATION, DUTCH RHENISH RAIL (2 PLATES);

"Handsomely lithographed and printed. It will find favour with many who desire to preserve in a permanent form copies of the plans and specifications prepared for the guidance of the contractors for many important engineering works."-Engineer.

Humber's Progress of MOdern Engineering. Second Series. Imp. 4to, with 36 Double Plates, Photographic Portrait of Robert Stephenson, C.E., M.P., F.K.S., \&c., and copious descriptive Letterpress, Specifications, \&c., Ł3 3 s. half-morocco.

\section{List of the Plates and Diagrams.}

Birkenhead Docks, Low Water Basin (IS plates); Charing Cross Station Roof. C. C. Railway (3 plates); Digswell Viaduct, Great NORTHE BN RALWAY: RoBbERY WOOD VIADUCt, Great Northern RALWAY; Iron Permanent WAY; CLYDACH VIADUCT; MERTHYR, TREDEGAR, WAY; CLYDACH VIADUCT; MERTHYR, TREDEGAR,
AND ABERGAEN RA RAILAY; EBBW VIADUCT,

"Mr. Humber has done the profession good and true service, by the fine collection of examples he has here brought before the profession and the public."-Practical Mechanic's fournal.

HUMBER'S PROGRESS OF MODERN ENGINEERING. THIRD SERIES. Imp. 4to, with 40 Double Plates, Photographic Portrait of J. R. M'Clean, late Pres. Inst. C.E., and copious descriptive Letterpress, Specifications, \&c., $633^{s .}$ half-morocco.

\section{Iist of the Plates and Diagrams.}

Main Drainage, Metropolis.-North Side.MAP SHOWING INTERCEPTION OF SEWERS; Middee Level Sewer (2 Plates); Outfall SEWER, Bridge OVER RiVer LeA (3 plates); OUTYALt. SEWER, BRIDGE OVSR MARSH LANE, NORTH WOOLWICH RAILWAY, AND BOW AND Barking Railway Junction; OUtfall Sewer, BRIDGE OVER BOW AND BARKING RAILWAY BRIDGE OVER OUTFALL SEWER, BRIDGE OVER 3 PLATES); OUTFALL SEWER, BRIDGE OVER OUTYALL. SEWER RESERVOIR (2 PLATES); OUT: FALE SEWER, TUMBLING BAY AND OUT,ET; Outrall. Sewer, Penstocks. South Side.OUTFAlL SEWER, BERMONDSEY BRANCH (2

PLATES); OUtFall SEwer, ResRrvotr AND OUTLET (4 plates); OUtFall Sewer, Filth HoIst: Sections of SEWERS (NORTH AND SOUTH SIDES).

Thames Embankment.-Section of River WALL; STBAMBOAT PIER, WESTMINSTER (2 Plates); Landixg Stairs betweEn Charing Cross and Waterloo Bridges; York Gate (2 PLATES); OVERFLow AND OUTLET AT SAvoY STREet Sewer (3 Platrs); Steamboat PIER, WATKRLOO BRIDGE (3 PLATES): JUNCTION OF, WEWERS, PLANS AND SEctions; GULLIES, HLANS, AND SECrIOYS; ROLLING Stock; GRANITE AND IRON FORTS.

"The drawings have a constantly increasing value, and whoever desires to possess clear representacions of the two great works carried out by our Metropolitan Board will obtain Mr. Humber's volume."-Engineer.

HUMBER'S PROGRESS OF MODERN ENGINEERING: FOURTH SERIES. Imp. 4to, with 36 Double Plates, Photographic Portrait of John Fowler, late Pres. Inst. C.E., and copious descriptive Letterpress, Specifications, \&c., $£ 33^{\text {s. hall- }}$ morocco.

\section{List of the Plates and Diagrams.}

Abbey Mills Pumping Station, Main DrainAGE, MEtropolis (4 PLATES); Barrow Docks (S plates); Manguis Viaduct, Santiago and Valparaiso Railway (2 plates); Adam's Locomotive, St. Helen's Canal Railway (2 plates); Cannon Street Station Roof, Charing Cross Railway (3 plates); Road BRIDGE OVER THE RIVER MOKA (2 PLATES);

TELEGRAPHIC APPARATUS FOR MESOPOTAMIA;

Viaduct ovgr the River Wye, MidLand RaILway (3 plates); St. Germans Viaduct, CornWALL RAILWAY (2 PLATES); WROUGHT-IRON CYLL RAR For DiviNG BeLL; MILLWALL Docks CYLINDER FOR DIVING BELL; MILLWALL DOCKS (6 PLATES); MILROY'S PATENT EXCAVATOR; Harbours, POKTs, aND BREaKwaters (3 PLATES).

"We gladly welcome another year's issue of this valuable publication from the able pen of Mr. Humber. The accuracy and general excellence of this work are well known, while its usefulness in giving the measurements and details of some of the late it examples of engineering, as carried out by the most eminent men in the profession, cannot be too hig hly prized."-Artizan. 


\section{Statics, Graphic and Analytic.}

GRAPHIC AND ANALYTIC STATICS, in their Practical Application to the Treatment of Stresses in Roofs, Solid Girders, Lattice, Bowstring, and Suspension Bridges, Braced Iron Arches and Piers, and other Frameworks. By R. Hudson Graham, C.E. Containing Diagrams and Plates to Scale. With numerous Examples, many taken from existing Structures. Specially arranged for Class-work in Colleges and Universities. Second Edition, Revised and Enlarged. $8 \mathrm{vo}, 16 s$. cloth.

"Mr. Graham's book will find a place wherever graphic and analytic statics are used or studied." Engineer.

"The work is excellent from a practical point of view, and has evidently been prepared with much care. The directions for working are ample, and are illustrated by an abundance of well-selected
examples. It is an excellent text-book for the practical draughtsman." - Athenawm.

\section{Practical Mathematics.}

MATHEMATICS FOR PRACTICAL MEN : Being a Common-place

Book of Pure and Mixed Mathematics. Designed chiefly for the Use of Civil Engineers, Architects and Surveyors. By OLINTHUS GREgory, LL.D., F.R.A.S., Enlarged by HeNRY LAw, C.E. Fourth Ed., carefully revised by J. R. Young,

formerly Professor of Mathematics, Belfast College. With $1_{3}$ Plates, 8vo, f $_{1}$ Is. cloth. "The engineer or architect will here find ready to his hand rules for solving nearly every mathematical
difficulty that may arise in his practice. The difficulty that may arise in his practice. The rules are in all cases explained by means of examples, in "wich every step of the process is clearly worked out."-Builder.

"One of the most serviceable books for practical mechanics.

student, and a Text-book for him who, having to refresh his memory upon them."-Building News.

\section{Hydraulic Tables.}

HYDRAULIC TABLES, CO-EFFICIENTS, AND FORMULA for Finding

the Discharge of Water from Orifices, Notches, Weirs, Pipes, and Rivers. With

New Formulæ, Tables, and General Information on Rain-fall, Catchment-Basins,

Civil Engineer, Me, Water Supply for Towns and Mill Power. By JoHN Neville,

Civil Engineer, M.R.I.A. Third Edition, carefully revised, with considerable

Additions. Numerous lllustrations. Crown 8vo, 14s. cloth.

avoidable failures, and assist them to select work connected with hydraulic engineering. the readiest means of successfully carrying out any given "It is, of all English bo engineering."-Mining fournal.

good arrangement of the matter, the subject, the one nearest to completeness . . . From the good arrangement of the matter, the clear explanations and abundance of * From the displayed from first to above all, the thorough acquaintance with both theory and construction, which is displayed from first to last, the book will be found to be an acquisition." - Archilect.

\section{Hydraulics.}

HYDRAULIC MANUAL. Consisting of Working Tables and Explanatory Text. Intended as a Guide in Hydraulic Calculations and Field Operations.

By Lowis , D'A. JACKson, Author of "Aid to Survey Practice," "Modern

"The author has had. Fourth Edition, Enlarged. Large crown 8vo, 16s, cloth.

the facts which have come under his notice, in hydraulic engineering and has been a careful observer of constructed a mave come under his notice, and from the grest mass of material at his command he has constructed a manual which may be accepted as a trustworthy guide to this branch of the engineer's prodevelopment of this important subject,"-Engineering. "Thent of this important subject."-Engineering.

"The standard work in this department of mechanics,"-Scotsman.

adoption of recent experiments; the work is its freedom from what is superannuated, and its thorough experiments."-Nature.

\section{Drainage.}

ON THE DRAINAGE OF LANDS, TOWNS, AND BUILDINGS. BY G. D. DEMPSEY, C.E., Author of "The Practical Railway Engineer," \&c.

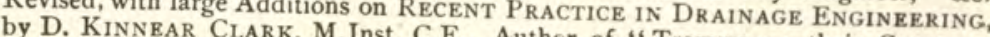
by D. KINNEAR CLARK, M.Inst. C.E., Author of "Tramways : their ConstrucEngineers," \&c. "A Manual of Rules, Tables, and Data for Mechanical

"The news," \&c. Second Edition, Corrected. Fcap. 8vo, 5s. cloth.

grasp and accuracy. of detail for which they's excellent work is characterised by the comprehensive Athencum. ts a wor

making that branch of engineering in drainage engineering, the book is to be commended to all who are

"A that branch of engineering science their special study."-Iron. Building News. 
Water Storage, Conveyance, and Utilisation.

WATER ENGINEERING: A Practical Treatise on the Measurement, Storage, Conveyance, and Utilisation of Water for the Supply of Towns, for Mill Power, and for other Purposes. By CharLes SlaGG, Water and Drainage Engineer, A.-M.Inst.C.E., Author of "Sanitary Work in the Smaller Towns, and in Villages," \&c. With numerous Illustrations. Crown 8vo, $7 s .6 d$. cloth.

"As a small practical treatise on the water supply of towns, and on some applications of waterpower, the work is in many respects excellent."-Engineering.

"The author has collated the results deduced from the experiments of the most eminent authorities, and has presented them in a compact and practical form, accompanied by very clear and detailed explanations. . . The application of water as a motive power is treated very carefully and exhaustively."-Builder.

"For anyone who desires to begin the study of hydraulics with a consideration of the practical applications of the science there is no better guide." - A rchitect.

\section{River Engineering.}

RIVER BARS: The Causes of their Formation, and their Treatment by "Induced Tidal Scour;" with a Description of the Successful Reduction by this Method of the Bar at Dublin. By I. J. MANn, Assist. Eng. to the Dublin Port and Docks Board. Royal 8vo, 7s. 6d. cloth.

"We recommend all interested in harbour works-and, indeed, those concerned in the improvements of rivers generally - to read Mr. Mann's interesting work on the treatment of river bars."-Engineer.

\section{Trusses.}

TRUSSES OF WOOD AND IRON. Practical Applications of Science in Determining the Stresses, Breaking Weights, Safe Loads, Scantlings, and Details of Construction. With Complete Working Drawings. By William

Griffiths, Surveyor, Assistant Master, Tranmere School of Science and Art. Oblong 8vo, 4s. 6d. cloth.

"This handy little book enters so minutely into every detail connected with the construction of roof trusses that no student need be ignorant of these matters."-Practical Engineer.

\section{Railway Working.}

SAFE RAILWAY WORKING: A Treatise on Railway Accidents, their Cause and Prevention; with a Description of Modern Appliances and Systems. By Clement E. Stretton, C.E., Vice-President and Consulting Engineer, Amalgamated Society of Railway Servants. With Illustrations and Coloured Plates. Third Edition, Enlarged. Crown 8vo, $3 s .6 d$. cloth.

"A book for the engineer, the directors, the managers ; and, in short, all who wish for information on railway matters will find a perfect encyclopedia in 'Safe Railway Working.' "-Railway Review.

"We commend the remarks on railway signalling to all railway managers, especially where a uniforn. code and practice is advocated."-Herepath's Railway fourual.

"The author may be congratulated on having collected, in a very convenient form, much valuable information on the principal questions affecting the safe working of railways." - Railway Engineer.

\section{Oblique Bridges,}

A PRACTICAL AND THEORETICAL ESSAY ON OBLIQUE BRIDGES.

With 13 large Plates. By the late GeORGe WATSON BuCK, M.I.C.E. Third Edition, revised by his Son, J. H. WATSON Buck, M.I.C.E.; and with the addition of Description to Diagrams for Facilitating the Construction of Oblique Bridges, by W. H. BARLow, M.I.C.E. Royal 8vo, I2s. cloth.

"The standard text-book for all engineers regarding skew arches is $\mathrm{Mr}$. Buck's treatise, and it would be impossible to consult a better."-Engineer.

"Mr. Buck's treatise is recognised as a standard text-book, and his treatment has divested the subject of many of the intricacies supposed to belong to it. As a guide to the engineer and architect, on a confessedly difficult subject, Mr. Buck's work is unsurpassed."-Building Nerws.

\section{Tunnel Shafts.}

THE CONSTRUCTION OF LARge TUNNEL ShafTS: A Prac-

tical and Theoretical Essay. By J. H. WATsON BUCK, M. Inst. C.E., Resident Engineer, London and North-Western Railway. Illustrated with Folding Plates, royal 8vo, 12s. cloth.

"Many of the methods given are of extreme practical value to the mason, and the observations on the form of arch, the rules for ordering the stone, and the construction of the templates, will be found of considerable use. We commend the book to the engineering profession."-Building News.

"Will be regarded by civil engineers as of the utmost value, and calculated to save much time and obviate many mistakes." - Collierv Guardian. 


\section{Student's Text-Book on Surveying.}

PRACTICAL SURVEYING: A Text-Book for Students preparing for

Examinations or for Survey-work in the Colonies. By GEORGE W. U SILL, A.M.I.C.E., Author of "The Statistics of the Water Supply of Great Britain." With 4 Lithographic Plates and upwards of 330 Illustrations. Third Edition, Revised and Enlarged. Including Tables of Natural Sines, Tangents, Secants, \&c. Crown $8 \mathrm{vo}, 7 s .6 d$. cloth; or, on THIN PAPER, bound in limp leather, gilt
edges, rounded corners, for pocket use, price $12 s .6 d$.

"The best forms of instruments are described as to their construction, uses and modes of employment, and there are innumerable hints on work and equipment such as the author, in his experience as surveyor, draughtsman and teacher, has found necessary, and which the student in "The latest will find most serviceable."-Engineer.

that the student will find it a better guide than on surveying, and we have no hesitation in saying that the student will find it a better guide than any of its predecessors. . . Deserves to be recognised as the first book which should be put in the hands of a pupil of Civil Engineering, and every gentleman of education who sets out for the Colonies would find it well to have a copy." -
Architect.

\section{Survey Practice.}

AID TO SURVEY PRACTICE : for Reference in Surveying, LevelJing, and Setting-out; and in Route Surveys of Travellers by Land and Sea. With Tables, Illustrations, and Records. By Lowis D'A. JACKson, A.M.I.C.E.,
Author of "Hydraulic Manual," "Modern Metrology," \&c. Second Edition,

Enlarged. Large crown 8vo, 12s. 6 d. cloth.

"Mr. Jackson has produced a valuable vade-mecum for the surveyor. We can recommend this book as containing an admirable supplement to the teaching of the accomplished surveyor."-Athenaum. matured instructions afforded in its pages."-Colliery to place it in their libraries, and study well the"The author afforded in its pages." - Colliery Guardian.

a clear and lucid style of writing, renders the book a very useful one." - Builder. Surveying, Land and Marine.

LAND AND MARINE SURVEYING, in Reference to the Preparation of Plans for Roads and Railways; Canals, Rivers, Towns' Water Supplies ; Docks and Harbours. With Description and Use of Surveying Instruments. By

W. DAVIS HASKOLL, C.E., Author of "Bridge and Viaduct Construction," \&c.

Second Edition, Revised, with Additions. Large crown 8vo, 9 s. cloth.

feeling assured that it will more than repay a careful study,"-Mechanical World. "A most useful and well ar ranged oook for the aid of a student. We World.

a carefully-written and valuable text-book. It enjoys a well-deserved. We can strongly recommend it as.

"This volume cannot fail to prove of the utmost practical ntility. It may be surveyors."-Bwilder. all students who aspire to become clean and expert surveycal utility. It may be safely recommended to Field-Book for Engineers.

THE ENGINEER'S, MINING SURVEYOR'S, AND CONTRACTOR'S

FIELD-Book. Consisting of a Series of Tables, with Rules, Explanations of Systems, and use of Theodolite for Traverse Surveying and Plotting the Work with minute accuracy by means of Straight Edge and Set Square only; Levelling with the Theodolite, Casting-out and Reducing Levels to Datum, and Plotting Sections in the ordinary manner: Setting-out Curves with the Theodolite by Tangential Angles and Multiples with Right and Left-hand Readings of the Instrument; Settingout Curves without Theodolite on the System of Tangential Angles by Sets of Tangents and Offsets; and Earthwork Tables to 8o feet deep, calculated for every 6 inches in depth. By W. DAvis HASKolL, C.E. With numerous Woodcuts.

Fourth Edition, Enlarged. Crown 8vo, I2s, cloth.

"The book is very handy; the separate tables of sines and tangents to every minute will make it useful for many other purposes, the genuine traverse tables existing all the same."-Athenaum.

and the amount of valuable in engineering field operations will estimate the importance of such a work with the accuracy and fulness of those given in this volume,"-Railiway set of reliable tables prepared Levelling.

A TREATISE ON THE PRINCIPLES AND PRACTICE OF LEVELLING. Showing its Application to purposes of Railway and Civil Engineering in the Construction of Roads; with Mr. TELFORD's Rules for the same. By FREDERICK W. Simms, F.G.S., M. Inst. C.E. Seventh Edition, with the addition of LAw's. Practical Examples for Setting-out Railway Curves, and TrAUTWINE's Field Practice of Laying-out Circular Curves. With 7 Plates and numerous Woodcuts,

8 vo, $8 s .6 d$. cloth.

"THE text-book on levelling in most" of our engineering schools and colleges."-Engineer. members, by bringing ont the present euition of service to the profession, especially to the younger 


\section{Trigonometrical Surveying.}

AN OUTLINE OF THE METHOD OF CONDUCTING A TRIGONOMETRICAL SURVEY, for the Formation of Geographical and Typographical Maps and Plans, Military Reconnaissance, LEVELLING, \&c., with Useful Problems, Formulæ, and Tables. By Lieut.-General FroME, R.E. Fourth Edition, Revised and partly Re-written by Major-General Sir CHARLES WARREN, G.C.M.G., R.E. With I9 Plates and 115 Woodcuts, royal $8 \mathrm{vo}, \mathrm{I} 6 \mathrm{~s}$. cloth.

"The simple fact that a fourth edition has been called for is the best testimony to its merits. No "The simple fact that a fourth edition he position so well and so steadily maintained by this work. Sir Charles Warren has revised the entire work, and made such additions as were necessary to bring every portion of the contents up to the present date."-Broad Arrow.

\section{Field Fortification.}

A TREATISE ON FIELD FORTIFICATION, The Attack of Fortresses, Military Mining, and Reconnoitring. By Colonel 1. S. MaCaulay, late Professor of Fortification in the R.M.A., Woolwich. Sixth Edition, crown 8vo, with separate Atlas of 12 Plates, 12s. cloth.

\section{Tunnelling.}

PRACTICAL TUNNELLING. Explaining in detail the Setting-out of the Works, Shaft-sinking, and Heading-driving, Ranging the Lines and Levelling under Ground, Sub-Excavating, Timbering, and the Construction of the Brickwork of Tunnels, with the amount of Labour required for, and the Cost of, the various portions of the work. By FREDERICK W. SIMMS, F.G.S., M. Inst. C.E. Third Edition, Revised and Extended by D. KINNEAR CLARK, M.Inst.C.E. Imp. 8vo, with 2I Folding Plates and numerous Wood Engravings, 3os. cloth.

"The estimation in which Mr. Simms's book on tunnel ing has been held for over thirty years cannot be more truly expressed than in the words of the late Professor Rankine :- "The best source of information on the subject of tunnels is Mr. F. W. Simms's work on Practical Tunnelling." "-Arckitect. immensely to the valiue of the book." -Engineer.

\section{Tramways and their Working.}

TRAMWAYS: THEIR CONSTRUCTION AND WORKING. Embracing a Comprehensive History of the System; with an exhaustive Analysis of the Various Modes of Traction, including Horse Power, Steam, Cable Traction, Electric Traction, \&c. ; a Description of the Varieties of Rolling Stock ; and ample Details of Cost and Working Expenscs. New Edition, Thorougbly Revised, and Including the Progress recently made in Tramway Construction, \&c. \&c. By D. KINNEAR CLARK, M. Inst. C.E. With numerous Illustrations and Folding Plates. In One Volume, $8 \mathrm{vo}, 700$ pages. Price about 25 s. [Nearly ready.

"All interested in tramways must refer to it, as all railway engineers have turned to the author's work 'Railway Machinery." -Engineer.

"An exhaustive and practical work on tramways, in which the histnry of this kind of locomotion, and a description and cost of the various modes of laying tramways. are to be found."-Biildine Nezes.

"The best form of rails, the best morle of construction, and the best mechanical appliances, are so fairly iudicated in the work under review that any engineer ahout to construct a tramway will be enabled at once to obtain the practical information which will be of most service to him."-Athenaum.

\section{Curves, Tables for Setting-out.}

TABLES OF TANGENTIAL ANGLES AND MULTIPLES FOR SETTING-OUT CuRVEs from 5 to 200 Radius. By Alexander Beazeley, M.Inst.C.E. Fourth Edition. Printed on 48 Cards, and sold in a cloth box, waistcoat-pocket size, 3 s. $6 d$.

"Each table is printed on a small card, which, being placed on the theodolite, leaves the hands free to manipulate the instrument - no small advantage as regards the rapidity of work."-Engineer.

"Very handy a man may know that all his day's work must fall on two of these cards, which he puts nto his own card-case, and leaves the rest behind."-A thencum.

\section{Earthwork.}

EARTHWORK TABLES. Showing the Contents in Cubic Yards of Embankments, Cuttings, \&c., of Heights or Depths up to an average of 80 feet. By Joseph Broadbent, C.E., and Francis CAMPIN, C. E. Crown Svo, 5 s. cloth.

"The way in which accuracy is attained, bv a simple division of each cross section into three elements, two in which are constant and one variable, is ingenious." - Atheneum. 


\section{Heat, Expansion by.}

EXPANSION OF STRUCTURES BY HEAT. By JOHN KEILY, C.E., late of the Indian Public Works and Victorian Railway Departments. Crown 8vo,
3 s. 6 . cloth.

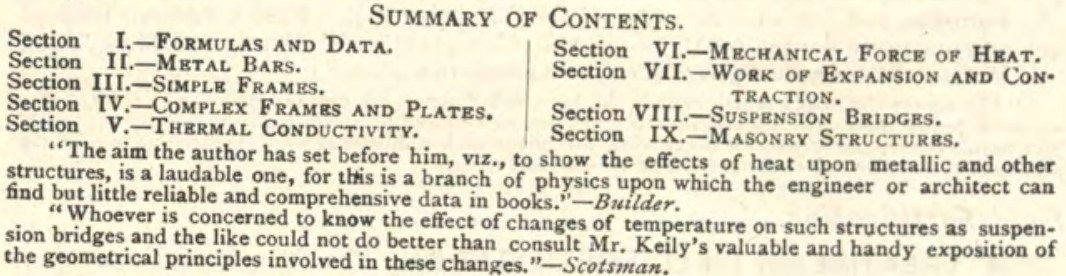

\section{Earthwork, Measurement of.}

A Manual on Earthwork. By Alex. J. S. Graham, C.E. With numerous Diagrams. Second Edition. $18 \mathrm{mo}, 2 s .6 d$. cloth.

"A great amount of practical information very admirably arranged, and available for rough estimates, as well as for the more exact calculations required in the engineer's and contractor's offices." $-A$ rtizan.

\section{Strains in Ironwork.}

THE STRAINS ON STRUCTURES OF IRONWORK; with Practical Remarks on Iron Construction. By F. W. SHEILDS, M. Inst. C.E. Second Edition, with 5 Plates. Royal 8vo, $5^{s}$. cloth.

"The student cannot find a better little book on this subject."-Engineer.

\section{Cast Iron and other Metals, Strength of.}

A PRACTICAL ESSAY ON THE STRENGTH OF CAST IRON and other Metals. By THOMAS TREDGOLD, C.E. Fifth Edition, including HODGKINSON's Experimental Researches. 8vo, I2s. cloth.

\section{Oblique Arches.}

\section{A PRACTICAL TREATISE ON THE CONSTRUCTION OF OBLIQUE}

ARCHES. By JoHn HART. Third Edition, with Plates. Imperial $8 \mathrm{vo}$, 8s. cloth.

\section{Girders, Strength of.}

GRAPHIC TABLE for Facilitating the Computation of the Weights of Wrought Iron and Steel Girders, \&c., for Parliamentary and other Estimates. By J. H. Watson Buck, M. Inst. C.E. On a Sheet, $2 s .6 d$.

\section{Water Supply and Water-Works.}

A PRACTICAL TREATISE ON THE WATER SUPPLY OF TOWNS AND THE CONSTRUCTION OF WATER-WORKS. By W. K. BURTON, A.M.Inst.C.E., Professor of Sanitary Engineering in the Imperial University, Tokyo, Japan, and Consulting Engineer to the Tokyo Water-Works. With an Appendix on WATERWORKS IN COUNTRIES SUBJECT TO EARTHQUAKES, by JOHN MILNE, F.R.S., Professor of Mining in the Imperial University of Japan. With numerous Plates
and Illustrations. 


\section{MARINE ENGINEERING, SHIPBUILDING, NAVIGA. TION, etc.}

\section{Pocket-Book for Naval Architects and Shipbuilders.}

THE NAVAL ARCHITECT'S AND SHIPBUILDER'S POCKET-BOOK OF FORMULA, RULES, AND TABLES, AND MARINE ENGINEER'S AND SURVEYOR'S HANDY Book of Reference. By Clement MACkrow, Member of the Institution of Naval Architects, Naval Draughtsman. Fifth Edition, Revised and Enlarged to 700 pages, with upwards of 300 Illustrations. Fcap., 12s. 6d. strong'y bound in leather.

\section{Summary OF CONTENTS.}

Signs and Symbols, Decimal Fractions,TRIGONOMETY.- Practical GEOMETRY,-MENSURATION. - CENTRES AND MOMENTS OF FIGURES. - MOMENTS OF INERTIA AND RADII OF GYRATTON. - Algesraical Expressions por Simpson's Rules. - Mechanical Principles. - Centre of Gravity, - Laws of Motion.-DisplaceMENT, CENTRE OF BUOYANCY, - CENTRE OF GRAVITY OF SHIP'S HULL.-STABILITY CURVES AND Metacentres.-SEA AND SHALlow-WATER Waves.-Rolling of SHIPS.-PROPUlsion AND Resistance of Vessels, - SPEED Trials, SAILING, CENTRe OF EFfort, - Distances DOWN RIVERS, COAST LINES, - STEERING AND RUDDERS OF VESSELS, - LAUNCHING CALCULATIONS AND VELOCITIES.-WEIOHT OP MATERIAL AND GEAR,-GUN PARTICURARS AND WEIGHE. AND GEAR,-GUN PARTICULARS AND WEIGHT. - STANDARD GAUges.- RIVETED JoINTS AND RIVETING. - STRENGTH AND TEStS OF MATERIALS.-BINDING AND SHEARING STRESSES, ETC. -Strength of Shafting, Pillars, Wheels, etc. - Hydraulic Data, etc. - Contc SEC. TIONS, Catenarian CuRYes, - MEchanicat POWERS, WORK, - BOARD OF TRADE REGULA. TIONS FOR BOLLERS AND ENGISES, - BOARD OF TRADE REGUL

ADE REgulations FOR SHIPS, - LlOYD's

RULES FOR BOILERS.-Lloyd's WEIGHT OF Chains.-Lloyd's SCANTLINGS FOR SHIPS. DATA of ENGINes AND VESSELS,-SHIPS' FitTINGS AND TESTS.-SEASONING PRESERVING TIMBER-MEASUREMENT OF TIMBER,-ALLOYS, Paints, Varnishes.-Data for Stowage.ADMIRALTY Transport Regulations.-RULEs FOR HORSE-POWER, SCREW Propellers, etc.Percentages for Butt Straps, etc.-PartiCULARS OF YACHTS.-MASTING AND RIGgING Vessels.-Distances of Foreign Ports.TONNAGE TABLES, - VOCABULARY OF FRENCH AND ENGLISH TERMS.-ENGLISH WEIGHTS AN, MEAsures. FOREIS WNGLISH WETGHTS AN, ME -Decimal Equivalents,-Foreign Monex.Discount and Wage TABles.-USeful NumBERS AND READY RECKONERS. - TABLES OF Circular measures. - Tables of Areas of AND CIRCUMFERENCES OF CIRCLES, - TABLES OF Areas of Segments of Circles, - Tables of SQUARES AND CUBES AND ROOTS OF NUMBERS. -TABLES OF LOGARITHMS OF NumBers. TABLES OP HYPERBOTI L TABLES OF HYPERBOLIC LOGARITHMS.-TABLES of Natural Sines, TAngents, etc.-Tables of Logarithmic Sines, Tangents, etc.

"In these days of advanced knowledge a work like this is of the greatest value. It contains a specific purpose that has ever unhesitatingly say that it is the most valuable compilation for its specific purpose that has ever been printed. No naval architect, engineer, surveyor, or seaman, " or iron shipbuilder, can afford to be without this work."-Nautical Magasine.

"Should be used by all who are engaged in the construction or design of vessels. . . Will be found to contain the most useful tables and formula required by shipbuilders, carefully collected from the best authorities, and put together in a popular and simple form."-Engineer.

"The professional shipbuilder has now, in a convenient and accessible form, reliable data for solving many of the numerous problems that present themselves in the course of his work." -Iron.

"There is no doubt that a pocket-book of this description must be a necessity in the

trade. The a necessity in the shipbuildin trade.... The volume contains a mass of useful information clearly expressed and presented in a handy form."-Marine Engineer.

\section{Marine Engineering.}

MARINE ENGINES AND STEAM VESSELS: A Treatise on. By

ROBERT MURRAY, C.E. Eighth Edition, thoroughly Revised, with considerable Additions by the Author and by George CARLISLE, C.E., Senior Surveyor to the Board of Trade at Liverpool. $12 \mathrm{mo}, 5 \mathrm{~s}$. cloth boards.

"Well adapted to give the young steamship engineer or marine engine and boiler maker a general introduction into his practical work."-Mechanical World.

"We feel sure that this thorougbly revised edition will continue to be as popular in the future as it has been in the past, as, for its size, it contains more useful information than any similar treatise." -Industries.

"As a compendious and useful guide to engineers of our mercantile and royal naval services, wa should say it cannot be surpassed."-Building News.

"The information given is both sound and sensible, and well qualified to direct yorng sea-going hands on the straight road to the extra chief's certificate. . Most usetul to surveyors, inspectors, draughtsmen, and all young engineers who take an interest in their profession."-Glasgow Heraid.

"An indispensable manual for the student of marine engineering."-Liverpool Mcrcury.

\section{Electric Lighting of Ships.}

ELECTRIC SHIP LIGHTING: A Handbook on the Fractical Fitting and Running of Ship's Electrical Plant, for the Use of Shipowners and Buiders, Marine Electricians and Sea-going Engineers in Charge. By J. W. URQUHART, Author of "Electric Light," "Dynamo Construction," \&c. With numerous Iliu, trations, Crown 8 vo, 75 . $6 d$. cloth. 


\section{Pocket-Book for Marine Engineers.}

A POCKET-BOOK OF USEFUL TABLES AND FORMULF FOR MARINE ENGINEERS. By Frank PROCTOR, A.I.N.A. Third Edition. Royal $32 \mathrm{mo}$, leather, gilt edges, with strap, 4 .

"We recommend it to our readers as going far to supply a long-felt want."-Naval Science.

"A most useful companion to all marine engineers."-United Service Gazetie.

\section{Introduction to Marine Engineering.}

ELEMENTARY ENGINEERING: A Manual for Young Marine Engineers and Apprentices. In the Form of Questions and Answers on Metals, Alloys, Strength of Materials, Construction and Management of Marine Engines and Boilers, Geometry, \&c. \&c. With an Appendix of Useiul Tabies. By JoHN SHERREN BREWER, Government Marine Surveyor, Hongkong. Second Edition, Revised, small crown 8 vo, $2 s$. cloth.

"Contains much valuable information for the class for whom it is intended, especially in the chapters on the management of boilers and engines."-Nautical Magazine.

"A useful introduction to the more elaborate text books."-Scotsman. "To a student who has the requisite desire and
Brewer offers decidedly useful help."-A thenaum.

\section{Navigation.}

Practical navigation. Consisting of The Sailor's Sea-Book, by JAMES GRKENWOOD and W. H. ROSSER; together with the requisite Mathematical and Nautical Tables for the Working of the Problems, by Henky LAw, C.E., and Professor J. R. Young. Illustrated. 12mo, 7 s. strongly half-bound.

\section{Drawing for Marine Engineers.}

LOCKIE'S MARINE ENGINEER'S DRAWING-BOOK. Adapted to the Requirements of the Board of Trade Examinations. By JoHN Lockie, C.E. With 22 Plates, Drawn to Scale. Royal 8vo, 3s. 6d. cloth.

"The student who learns from these drawings will have nothing to unlearn." -Engineer.

".The examples chosen are essentially practical, and are such as should prove of service to engineers generally, while admirably fulfilling their specific purpose."-Mechanical World.

\section{Sailmaking.}

The ART AND Science of SAIlmaking. By Samuel B. Sadler, Practical Sailmaker, late in the employment of Messrs. Ratsey and Lapthorne, of Cowes and Gosport. With Plates and other Illustrations. Small 4to, 12s. $6 d$. cloth.

\section{Summary of Contents.}

Chap, I. The Materials used and their -Vi. On Allowances,-Vil. Calculation of

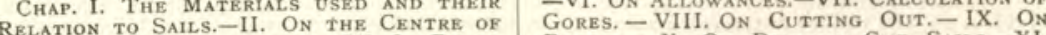
Relation TO SAll Measuring.-IV. ON Draw- Roping. --X. ON Diagonal-Cut Sails.-Xi. EFFORT. - III. ON MEASUR OF CLOTHS REQUIRED. CONCLUDING REMARKS.

"This work is very ably written, and is illustrated by diagrams and carefully-worked calculations. The work should be in the hands of every sailmaker, whether employer or employed, as it cannot fail to assist them in the pursuit of their important avocations." -Isle of Wight Herald.

"This extremely practical work gives a complete education in all the branches of the manufacture, cutting out, roping, seaming, and goring. It is copiously illustrated, and will form a first-rate text-book and guide."-Portsmouth Times.

The author of this work has rendered a distinct service to all interested in the art of sailmaking. The subject of which he treats is a congenial one. Mr. Sadler is a practical sailmaker, and has devoted years of careful observation and study to the subject; and the results of the experience thus gained he has set forth in the volume before us." - Steamship.

\section{Chain Cables.}

CHAIN CABLES AND CHAINS. Comprising Sizes and Curves or

Links, Studs, \&c., Iron for Cables and Chains, Chain Cable and Chain Making, Forming and Welding Links, Strength of Cables and Chains, Certificates for Cables, Marking Cables, Prices of Chain Cables and Chains, Historical Notes, Acts of Parliament, Statutory Tests, Charges for Testing, List of Manufacturers of Cables, \&c. \&c. By Thomas W. Traill, F.E.R.N., M.Inst.C.E., EngineerSurveyor-in-Chief, Board of Trade, Inspector of Chain Cable and Anchor Proving Establishments, and General Superintendent, Lloyd's Committee on Proving Establishments. With numerous Tables, Illustrations, and Lithographic Drawings.

Folio, £2 2s. cloth, bevelled boards.

"It contains a vast amount of valuable information. Nothing seems to be wanting to make it a com. plete and standard work of reference on the subject."-Nawtical Magazine. 


\section{MINING AND METALLURGY.}

\section{Mining Machinery.}

MACHINERY FOR METALLIFEROUS MINES: A Practical Treatise for Mining Engineers, Metallurgists and Managers of Mines. By E. HENRY 12s. 6d, cloth., F.G.S. Crown 8vo, 580 pp., with upwards of 300 Illustrations. 12s. 6 d. cloth.

[Fust published.

good service. Davies, in this handsome volume, has done the advanced student and the manager of mines and plates are good."-Athenowm. . Frome good. -Athenatum.

and aturact the attention of the student as he peruses the characteristics which excite the confidence mended. By its publication the literature connected with the page. The work may safely be recom-

reputation of its author enhance 1 ." -Mining Gournal.

appliances. His work carries internal evidence of the author's best of everything in modern mining of the great merits of the book. Throughout his the author's impartiality, and this constitutes ene reliable experience." - Iron and Steel Trades' his work the criticisms are based on his own or other

"The uork deals with nearly every class of mal.

required in connection with metalliferous mining of machinery or apparatus likely to be met with or meuding."-Prastical Engineer. "Invaluable to mining engias

Denver, Colorado, U.S.A.

\section{Metalliferous Minerals and Mining.}

A TREATISE ON METALLIFEROUS MINERALS AND MINING.

By D. C. DAvies, F.G.S., Mining Engineer, \&c., Anthor of "A Treause on Slate and Slate Quarrying." Fifth Edition, thoroughly Revised and much Enlarged,

by his Son, E. HeNry Davies, M.E., F.G.S. With about r 50 Illustrations.
Crown 8 vo, 12s. $6 d$ cloth. "Nis companion and his guide." - Mining Fournal.
" Feader, interested in mines, can have a better book for

" We are doing our readers a service in calling their attention to this valuable work."-Mining World. also very interesting to the general public." the geologist, the practical miner, and the metallurgist; but "As a history of the present state of mining

supplies an actual want." - Athenumen.

\section{Earthy Minerals and Mining.}

A TREATISE ON EARTHY AND OTHER MINERALS AND MINING.

By D. C. DAviES, F.G.S., Author of "Metalliferous Minerals," \&c. Third

With about roo Illusts. Enlarged, by his Son, E. Henry Davis,, M.E., F.G.S.

We do not rementher

amount of information packed in equally convenientish work on mining matters that contains the same

"We should be inclined to rank it as among the - Acalemy.

manuals which have recently appeared."-British Ouarterly pest $^{\circ}$ of the handy technical and trades Metalliferous Mining in the United Kingdom.

BRITISH MINING: A Treatise on the History, Discovery, Practical

Development, and Future Prospects of Metalliferous Mines in the United Practical

By RoBert Hunt, F.R.S., Keeper of Mining Records; in the United Kingdom.

tionary of Arts, Manufactures, and Mines," \&c Records; Editor of "Ure's Dic-

Illustrations. Second Edition, Revised. Super-royal Upwards of 950 pp., with 230

"One of the most valuable works of reference of Super-royal 8vo, $\mathrm{K}_{2} 2 \mathrm{~s}$. cloth.

Records of the United Kingdom, has had opportunities for such a times. Mr. Hunt, as Keeper of Mining has evidently made the most of them. ment of the mario the most of them. - . The language and style adopted are good, and the, and "The book is, in fact, a treasure-house of statistical scientific." - Engineering. of no other work embodying so great a mass of matter of this kind. Were this the only merit development of the mining and metallurgical it indispensable in the library of everyone interested in the "A mass of the mining and metallurgical industries of this country."-Athenaum.

cerested in our great mineral industries."-Engineer. and of the greatest value to those who may be in.

Underground Pumpingtries. - Engineer.

Mround Pumping Machy.

MINE DRAINAGE: Being a Complete and Practical Treatise on

Direct-Acting Underground Steam Pumping Machinery, with a Description of a

of their Action, the Mode of Engines, their General Utility and the Special Sphere

other forms of Pumping Machinery Application, and their merits compared with

"Will be highly esteemed by colliery owners and lessees, mining engel. 8vo, I5s. cloth. who require to be acquainted with the best means of lecurees, mining engineers, and students generally able work, and stands almost alone in the literature of securing the drainage of mines. It is a most valu. "Much valuable almost alone in the literature of steam pumping machinery."-Colliery Guardian. lation amongst practical men and purchasers of machinery is throughly worthy of an extensive circu- 


\section{Prospecting for Gold and other Metals.}

THE PROSPECTOR'S HANDBOOK: A Guide for the Prospector and Traveller in Search of Metal-Bearing or other Valuable Minerals. By J. W: Anderson, M.A. (Camb.), F.R.G.S., Author of "Fiji and New Caledonia." Fifth Edition, thoroughly Revised and Enlarged. Small crown 8vo, 3s. 6d. cloth.

"Will supply a much felt want, especially among Colonists, in whose way are so often thrown many mineralogical specimens the value of which it is difficult to determine."-Engineer.

"How to find commercial minerals, and how to identify them when they are found, are the leading points to which attention is directed. The author has managed to pack as much practical detail into his pages as would supply material for a book three times its size."-Mining fournal.

\section{Mining Notes and Formulce.}

NOTES AND FORMULA FOR MINING STUDENTS. By JOHN

Herman Merivale, M.A., Certificated Colliery Manager, Professor of Mining in the Durham College of Science, Newcastle-upon-Tyne. Third Edition, Revised and Enlarged. Small crown 8vo, 2s. 6d. cloth.

"Invaluable to anyone who is working up for an examination on mining subjects." - Coal Iron and Trades' Reviezv.

"The author has done his work in an exceedingly creditable manner, and has produced a bnok that will be of service to students, and those who are practically engaged in miuing operations," Engineer.

\section{Handybook for Miners.}

THE MINER'S HANDBOOK: A Handy Book of Reference on the subjects of Mineral Deposits, Mining Operations, Ore Dressing, \&c. For the Use of Students and others interested in Mining matters. Compiled by JOHN MILNE, F.R.S., Professor of Mining in the Imperial University of Japan.

Revised Edition. Fcap. 8vo, 7s. 6d. leather. [Yust published.

"Professor Milne's handbook is sure to be received with favour by all connected with mining, and will be extremely popular among students." - Athenoum.

\section{Miners' and Metallurgists' Pocket-Book.}

A POCKET-BOOK FOR MINERS AND METALluRgists. Comprising Rules, Formulx, Tables, and Notes, for Use in Field and Office Work. By F. Danvers Power, F.G.S., M.E. Fcap. 8vo, 9s. leather, gilt edges.

"This excellent book is an admirable example of its kind, and ought to find a large sale amongst English-speaking prospectors and mining engineers."-Engineering.

"Miners and metallurgists will find in this work a useful vaae-mecum containing a mass of rules, formula, tables, and various other information, the necessity for reference to which occurs in their daily rinties."-Iron.

\section{Mineral Surveying and Valuing.}

THE MINERAL SURVEYOR AND VALUER'S COMPLETE GUIDE.

Comprising a Treatise on Improved Mining Surveying and the Valuation of

Mining Properties, with New Traverse T ables. By WM. Lintern. Third Edition,

Enlarged. $12 \mathrm{mo}$, 4 s. cloth. Review.

"Mr. Lintern's book forms a valuable and thoroughly trustworthy guide."-Iron and Coal Trades"

\section{Asbestos and its Uses.}

ASBESTOS: Its Properties, Occurrence, and Uses. With some Account of the Mines of Italy and Canada. By Robert H. Jones. With Eight Collotype Plates and other lilustrations. Crown 8vo, I2s. 6d. cloth.

"An interesting and invaluable work."-Colliery Guardian.

\section{Explosives.}

A HANDBOOK ON MODERN EXPLOSIVES. Being a Practical Treatise on the Manufacture and Application of Dynamite, Gun-Cotton, NitroGlycerine and other Explosive Compounds. Including the Manufacture of Collodion-Cotton. By M. EIssler, Mining Engineer and Metallurgical Chemist, Author of "The Metallurgy of Gold," "The Metallurgy of Silver," \&c. With about 100 Illustrations. Crown 8vo, 10s. 6 d. cloth.

"Useful not only to the miner, but also to officers of both services to whom blasting and the use of explosives generally may at any time become a necessary auxiliary."-Nature.

"A vetitable mine of information on the subject of explosives employed for military, minirg and blasting purposcs."-Army and Navy Gazette. 


\section{Colliery Management.}

THE Colliery MANAger's HandBOOK: A Comprehensive Treatise on the Laying-out and Working of Collieries, Designed as a Book of Reference for Colliery Managers, and for the Use of Coal-Mining Students preparing for First-class Certificates. By CALEB PAMely, Mining Engineer and Surveyor; Member of the North of England Institute of Mining and Mechanical Engineers; and Member of the South Wales Institute of Mining Engineers. With nearly 500 Plans, Diagrams, and other Illustrations. Second Edition, Revised, with Additions, medium 8 vo, about $700 \mathrm{pp}$. Price $\delta \mathrm{I} 5$ s. strongly bound.

\section{SumMary OF CONTENTS.}

GEOLOGY.

Search yor Coat.

Mineral Leases and other Holdings.

SHAFT SINKING.

SHAFT SINKING.

Fitting Up the Shaft and Surface ArRANGEMENTS.

Steam Boilers aNd their Fittings.

TIMBERING AND WALLING.

NARROW WORK AND METHODS OF WORKING.

Underground Conveyance.

DRAINAGE.

The Gases met With in Mines; Ventthation.

$$
\text { * * OpInions of the PRESS. }
$$

ON THE Friction of Air in Mines.

The Priestman OH Engine; Petroleum and Natural Gas.

SURVeying and PlanNing.

SAFETY LAMPS AND FIRE-DAMP DETECTORS.

SUNDRY AND INCIDENTAL OPERATIONS AND APPLIANCES.

Colliery EXPLOSIONS.

Miscellaneous Questions and Answers.

Appendix: SUMMARY OF REPORT OF H.M. COMMISSIONERS ON ACCIDENTS IN MINES.

"Mr. Pamely has not only given us a comprehensive reference bonk of a very high order. suitable to the requiremests of mining engineers and colliery managers, but at the same time bas provided mining students with a class-book that is as interesting as it is instructive."-Colliery Manager.

"Mr. Pamely's work is eminently suited to the purpose for which it is intended-being clear, interesting, exhaustive, rich in detail, and up to date, giving descriptions of the very latest machines in every department. . . . A mining engineer could scarcely go wrong who followed this work."-Colliery Guardian.

ratian.

This is the most complete 'all-round' work on coal-mining published in the English language. . .

library of coal-mining books is complete without it "-Colierv En yineer (Scranton, Pa., U.S.A.).

$\because$ Mr. Pamely's work is in all res jects worthy of our admiration. No person in any responsible position connected with mines should be without a copy." - Westminster Review.

\section{Coal and Iron.}

THE COAL AND IRON INDUSTRIES OF THE UNITED KINGDOM. Comprising a Description of the Coal Fields, and of the Principal Seams of Coal, with Returns of their Produce and its Distribution, and Analyses of Special Varieties. Also, an Account of the occurrence of Iron Ores in Veins or Seams; Analyses of each Variety ; and a History of the Rise and Progress of Pig Iron Manufacture. By Richard Meade, Assistant Keeper of Mining Records. With Maps 8vo, $£$ I 8s. cloth.

"The book is one which must find a place on the shelves of all interested in coal and iron production, and in the iron, steel, and other metallurgical industries."-Engineer.

"Of this book we may unreservedly say that it is the best of its class which we have ever met. . . . A book of reference which no one engaged in the inon or coal trades should omit from his library."-Iron and Coal Trades' Review.

\section{Coal Mining.}

COAL AND COAL MINING, A Rudimentary Treatise on. By the late Sir WARINGTon W. SMYTH, M.A., F.R.S., \&c., Chief Inspector of the Mines of the Crown. Seventh Edition, Revised and Enlarged. With numeruus Illus. trations, $12 \mathrm{mo}, 4 s$. cloth boards.

"As an outline is given of every known coal-fieldi in this and other countries, as well as of the principal methods of working, the book will doubtless interest a very large number of readers."-Mining fournal.

\section{Subterraneous Surveying.}

SUBTERRANEOUS SURVEYING, Elementary and Practical Treatise on; with and without the Magnetic Needle. By Thomas Fenwick, Surveyor of Mines, and Thomas BAKer, C.E. Illustrated. 12mo, 3 s. cloth boards.

\section{Granite Quarrying.}

GRANITES AND OUR GRANITE INDUSTRIES. By GEORge F. HARris, F.G.S., Membre de la Société Belge de Géologie, Lecturer on Economic Geology at the Birkbeck Institution, \&c. With Illustrations. Crown 8 vo, 2s. $6 d$. cloth.

"A clearly and well-written manual for persons engaged or interested in the granite industry."Scotsman.

"An interesting work, which will be deservedly esteemed."-Colliery Guardian.

"An exceedingly interesting and valuable monograph on a subject which has hitherto reccived unaccountably little attention in the shape of systematic literary trestment." - Scottish Leader. 


\section{Gold, Metallurgy of.}

THE MetalluRgy OF Gold: A Practical Treatise on the Metallurgical Treatment of Gold-bearing Ores. Including the Processes of Concentration and Chlorination, and the Assaying, Melting, and Refining of Gold. By M. EIssLer, Mining Engineer and Metallurgical Chemist, formerly Assistant Assayer of the U.S. Mint, San Francisco. Third Edition, Revised and greatly Enlarged.

With 187 Illustrations. Crown $8 v o, 12 s .6 d$. cloth.

"This book thoroughly deserves its title of a 'Practical Treatise'. The whole process of gold milling, from the breaking of the quartz to the as say of the bullion, is described in clear and orderly narrative and with much, but not too much, fulness of detail."-Saturday Review.

"The work is a storehouse of information and valuable data, and we strongly recommend it to. all professional men engaged in the gold-mining industry."-Mining fournal.

\section{Silver, Metallurgy of.}

THE METAlluRgy OF Silver: A Practical Treatise on the

Amalgamation, Roasting, and Lixiviation of Silver Ores. Including the Assaying, Melting, and Refining of Silver Bullion. By M. EISsLer, Author of "The MetalJurgy of Gold," \&c. Second Fdition, Enlarged. With 150 Illustrations. Crown 8 vo, 10s. 6d. cloth.

"A practical treatise, and a technical work which we are convinced will supply a long felt want amongst practical men, and at the same time be of value to students and others indirectly connected with the industries."-Mining fournal.

"From first to last the book is thoroughly sound and reliable."-Colliery Guardian.

"For chemists, practical miners, assayers, and investors alike, we do not know of any work on the subject so handy and yet so comprehensive."-Glasgow Herald.

\section{Lead, Metallurgy of.}

THE Metallurgy of ARgentiferous LeAd: A Practical

Treatise on the Smelting of Silver-Lead Ores and the Refining of Lead Bullion.

Including Reports on various Smelting Establishments and Descriptions of Modern

Smelting Furnaces and Plants in Europe and America. By M. Eissler, M.E.,

Author of "The Metallurgy of Gold," \&c. Crown ðvo, 400 pp., with 183 Illustrations, 12s. $6 d$. cloth.

"The numerous metallurgical processes, which are fully and extensively treated of, embrace all the stages experienced in the passage of the lead from the various natural states to its issue from the refinery as an article of commerce." - Practical Engineer.

"The present volume fully maintains the reputation of the anthor. Those who wish to obtain a thorough insight into the present state of this industry cannot do better than read this volume, and all mining engineers cannct $f$ ail to find many useful hints and suggestions in it." -Industries.

"It is most carefully written and illustrated with capital drawings and diagrams. In fact, it is the work of an expert for experts, by whom it will be prized as an indispensable text-book." - Bristol Mencury.

\section{Iron, Metallurgy of.}

METALLURGY OF IRON. Containing History of Iron Manufacture,

Methods of Assay, and Analyses of Iron Ores, Processes of Manufacture of Iron and Steel, \&c. By H. Bauerman, F.G.S., A.R.S.M. With numerous Illustrations. Sixth Edition, Revised and Enlarger. $12 \mathrm{mo}, 5^{\mathrm{s} .} 6 \mathrm{~d}$. cloth.

"Carefully written, it has the merit of brevity and conciseness, as to less important points ; while all material matters are very fully and thoroughly entered into." - Standard.

\section{Iron Mining.}

THE IRON ORES OF GREAT BRITAIN AND IRELAND: Their

Mode of Occurrence. Age and Origin, and the Methods of Searching for and

Working Them. With a Notice of some of the Iron Ores of Spain. By J. D.

KendalL, F.G.S., Mining Engineer. With Plates and Illustrations. Crown 8vo,

16s. cloth.

"The author has a thorough practical knowledge of his subject, and has supplemented a careful study of the available literature by unpublished information derived from his own observations. The result is a very useful volume which cannot fail to be of value to all interested in the iron industry of the country."-Industries.

"Constitutes a systematic and carefal acconnt of our present knowledge of the origir and occurrence of the iron ores of Great Britain, and embraces a description of the means employed in reaching and working these ores."-Iron.

"Mr. Kendall is a great authority on this subject and writes from personal observation."Colliery Guardian.

"Mr. Kendall's book is thorougbly well done. In it there are the outlines of the history of ore mining in every centre and there is everything that we want to know as to the character of the ores of each distri't their commercial value and the cost of working them."-Iron and Sieel Trades fournul. 


\section{ELECTRICITY, ELECTRICAL ENGINEERING, ETC.}

\section{Electrical Engineering.}

THE ELECTRICAL ENGINEER'S POCKET-BOOK OF MODERN

Rules, formule, TABles, and Data. By H. R. KemPe, M. Inst. E.E., A. M. Inst. C.E., Technical Officer, Postal Telegraphs, Author of "A Handbook of Electrical Testing," \&c. Second Edition, Thoroughly Revised, with Additions.

With numerous Illustrations, royal $32 \mathrm{mo}$, oblong, $5 \mathrm{~s}$. leather.

"There is very little in the shape of formulæ or data which the electrician is likely to want in a hurry which cannot be found in its pages."-Practical Engineer.

"A very useful book of reference for daily use in practical electrical engineering and its various applications to the industries of the present day."-Iron.

"It is the best book of its kind."-Electrical Engineer. trician.

Well arranged and compact. The Electrical Engineer's Pocket-Book is a good one."-Elec. Review.

\section{Electric Lighting.}

ELECTRIC LIGHT FITTING: A Handbook for Working Electrical

Engineers, embodying Practical Notes on Installation Management. By J. W.

URQUHART, Electrician, Author of "Electric Light," \&c. With numerous Illusts.

Second Edition, Revised, with Additional Chapters. Crown 8vo, 5 s. cloth.

"This volume deals with what may be termed the mechanics of electric lighting, and is addressed to men who are already engaged in the work, or are training for it. The work traverses a great deal of ground, and may be read as a sequel to the same author's useful work on 'Electric Light." "-Electrician.

"This is an attempt to state in the simplest language the precautions which should be adopted in installing the electric light, and to give information for the guidance of those who have to run the plant when installed. The book is well worth the perusal of the workman, for whom it is written."Electrical Review.

"We have read this book with a good deal of pleasure. We believe that the book will be of use to practical workmen, who will not be alarmed by finding mathematical formula which they are unable to understand." - Electrical Plant.

"Eminently practical and useful. ..... Ought to be in the hands of everyone in charge of an electric light plant."-Electrical Engineer.

"Mr. Urquhart has succeeded in producing a really capital book, which we have no hesitation
"Mrich in recommending to working electricians and electrical engineers."-Mechanical World.

\section{Electric Light.}

ELECTRIC LIGHT: Its Production and Use, Embodying Plain Directions for the Treatment of Dynamo-Electric Machines, Batteries, Accumulators, and Electric Lamps. By J. W. UrQUhART, C.E., Author of "Electric Light Fitting," "Electroplating," \&c. Fifth Edition, carefully Revised, with Large Additions and 145 Illustrations. Crown $8 \mathrm{vo}, 7 \mathrm{~s} .6 \mathrm{~d}$. cloth.

"The whole ground of electric lighting is more or less covered and explained in a very clear and concise manner."-Electrical Retiew.

"Contains a good deal of very interesting information, espesially in the parts where the author gives dimensions and working costs."-Electrical Engineer.

"A miniature vade-mecum of the salient tacts connected with the science of electric lighting." Electrician.

"You cannot for your purpose have a better book than "Electric Light,' by Urquhart." - Engineer.

"The book is by far the best that we have yet met with on the subject." - Athenaum.

\section{Construction of Dynamos.}

DYNAMO CONSTRUCTION : A Practical Handbook for the Use of Engineer Constructors and Electricians-in-Charge. Embracing Framework Building, Field Magnet and Armature Winding and Grouping, Compounding, \&c. With Examples of leading English, American, and Contınental Dynamos and Motors. By J. W. URQUHART, Author of "Electric Light," "Electric Light Fitting," \&c. With upwards of Ioo Illustrations, crown 8vo, $7 s$. $6 d$. cloth.

"Mr. Urquhart's book is the first one which deals with these matters in sucn a way that the engineering student can understand them. The book is very readable, and the author leads his readers up to difficult subjects by reasonably simple tests." - Engineering Review.

"The author deals with his subject in a style so popular as to make his volume a han tbook of great practical value to engineer contractors and electricians in charge of lighting installations." - Scotsman.

"'Dynamo Construction' more than sustains the high character of the author's previ us publications. It is sure to be widely read by the large and rapidly-increasing number of practical electricians." - Glasgow Herald.

"A book for which a demand has long existed."-Mechanical World. 


\section{A New Dictionary of Electricity.}

THE STANDARD ELECTRICAL DICTIONARY. A Popular Dictionary of Words and Terms Used in the Practice of Electrical Engineering. Containing upwards of 3,00o Definitions. By T. O'CONNOR SLOANE, A.M., Ph.D., Author of "The Arithmetic of Electricity," \&c. \&c. Crown 8vo, 630 pp., 350 Illustrations, $75.6 d$. cloth.

fust published.

"The work has many attrac'ive features in it, and is, beyond doubt, a well put together and use. $\mathrm{ful}$ publication. The amount of ground covered may be gathered from the fact that in the index about 5,000 references will be found. The inclusion of such comparatively modern words as 'im. pedence,' 'reluctance,' \&c., shows that the author has desired to be up to date, and indeed there are other indications of carefulness of compilation. The work is one which does the author great credit and it should prove of great value, especially to students."-Electrical Review.

"We have found the book very complete and reliable, and can, therefore, commend it beartily."

"Very complete and conta'ns a large amount of useful information."-Industries.

"An encyclopædia of electrical science in the compass of a dictionary. Thtries.

is sound and clear. The book is well pring information given confidently recommended." -Builder.

"We hail the appearance of this little work as one which will meet a want that has been keenly felt for some time. The author is to be congratulated on the excellent manner in which he has accomplished his task." - Practical Engineer.

"The volume is excellently printed and illus:rated, and should form part of the library of every one who is directly or indirectly connected with electrical matters."-Hardware Trade fournal.

\section{Electric Lighting of Ships.}

ELECTRIC SHIP-LIGHTING: A Handbook on the Practical Fitting and Running of Ship's Electrical Plant. For the Use of Shipowners and Builders, Marine Electricians, and Sea-going Engineers in Charge. By J. W. URQUHART,

C.E., Author of " Electric Light," \&c. With 88 Illusts., crown 8vo, 7s.6 d. cloth.

"The subject of ship electric lighti ig is one of vast importance in these daye, and Mr. Urqubart is to be bighly complimented for p'acing such a valuable work at the service cf the practical marine eiectrician."-The Steamship.

"Distinctly a book which of its kind stands almost alone, and for which there should be a demand,"-Electrical Review.

\section{Electric Lighting.}

THE ELEMENTARY PRINCIPLES OF ELECTRIC LIGHTING. By

Alan A. CAMPBell Swinton, Associate I.E.E. Third Edition, Enlarged and

Revised. With Sixteen Illustrations. Crown 8 vo, Is. $6 d$. cloth.
"Anyone who desires a short and thoroughly clear exposition of the elementary principles of electric-lighting cannot do better than read this little work." - Bradford Observer.

\section{Dynamic Electricity.}

THE ELEMENTS OF DYNAMIC ELECTRICITY AND MAGNETISM. By Philip Atrinson, A.M., Ph.D., Author of "Elements of Static Electricity," "The Elements of Electric Lighting," \&c. \&c. Crown 8vo, 4I7 Pp., with 120 Illustrations, 10s. $6 d$. clcth.

\section{Electric Motors, \&c.}

THE ELECTRIC TRANSFormation OF POWER and its Application by the Electric Motor, including Electric Railway Construction. By P. ATKINSON. A.M., Ph.D., Author of "The Elements of Electric Lighting," \&c. With 96 Illustrations. Crown 8vo, 7s. $6 d$. cloth.

\section{Dynamo Construction.}

HOW TO MAKE A DYNAmO: A Practical Treatise for Amateurs. Containing numerous Illustrations and Detailed Instructions for Constructing a Small Dynamo to Produce the Electric Light. By ALFred CrofTs. Fourth Edition, Revised and Enlarged. Crown 8vo, 2s. cloth.

"The instructions given in this unpretentious little book are sufficiently clear and explicit to enable any amateur mechanic possessed of average skill and the usual tools to be found in an amateur's workshop, to build a practical dynamo machine."-Electrician.

\section{Text-Book of Electricity.}

THE STUDENT'S TEXT-BOOK OF ELECTRICITY. By H. M. NOAD, Ph.D., F.R.S. New Edition. With Introduction and Additional Chapters by W. H. PREECE, M.I.C.E. Crown 8vo, 12s. $6 d$. cloth.

\section{Electricity.}

A MANUAL OF ELECTRICITY : including Galvanism, Magnetism, Dia-Magnetism, Electro-Dynamics, \&c. By H. M. NOAD, Ph.D., F.R.S. Fourth Edition (1859). $8 \mathrm{vo}, \therefore \mathrm{I}$ 4s, cloth. 


\section{ARCHITECTURE, BUILDING, etc.}

\section{Building Construction.}

PRACTICAL BUILDING CONSTRUCTION: A Handbook for

Students Preparing for Examinations, and a Book of Reference for Persons Engaged in Building. By John PARnell Allen, Surveyor, Lecturer on Building Construction at the Durham College of Science, Newcastle-on-Tyne. Medium 8vo, 450 pagee, with $\mathrm{I}, 000$ Illustrations. 12s. $6 \mathrm{~d}$. cloth. [Fust published.

"This volume is one of the most complete expositions of buildıng construction we have seen. It contains all that is necessary to prepare students for the various examinations in building construccion."-Bvilding Nezws.

The author depends nearly as much on his diagrams as on his type. The pages sugzest the hand of a man of experience in hirilding operations-and the volume must be a blessing to many seachers as well as to students "-The A rchitect.

"This volume promises to be the recognised hanthook in all advanced classes where building construction is taught from a practical, point of view. We strongly commend the book to the notice of all teachers of building construction."-Teihnical World.

"The work is sure to prove a fornidable rival to great and small competitors alike, and bids fair to take a permanent place as a favourite students' text-book. The large numter of illustrations deserve particular mention for the great merit they possess for purposes of reference, in exactly corse:ponding to convenient scales." - Gour. Inst. Brit. Archts.

\section{Concrete.}

CONCRETE : ITS NATURE AND USES. A Book for Architects, Builders, Contractors, and Clerks of Works. By GeORGE L. SuTClifFe, A.R.I.B.A. 350 pages, with numerous Illustrations. Crown 8vo, 7s. 6d. cloth.

"The author treats a difficult subject in a lucid manner. The manual fills a long felt gap. It is careful and exhaustive : equally useful as a student's guide and an architect's book of selerence."Fournal of Royal Instituti $n$ of British Architects.

"There is room for this new bnok, which will probably be for some time the standard work on the subject for a buil/er's purpose." - Glaspow Herald.

"A thoroughly useful and compreheasive work." - Brit'sh Architect.

\section{Mechanics for Architects.}

THE MECHANICS OF ARCHITECTURE : A Treatise on Applied

Mechanics, especially Adapted to the Use of Architects. By E. W. TARN, M. A.,

Author of "The Science of Building," \&c. Second Edition, Enlarged. Illus-

trated with I25 Diagrams. Crown 8vo, 7s. 6d. cloth. [Fust published.
[Fuld

"The book is a very useful and helpful manual of architectural mechanics, and really contains sufficient to enable a ca'eful and painstaking student to grasp the principle; bearing upon the majority of building problems. . Mr. Tarn has added, by this volume, to the debt of gratitude which is owing to him by architectural students for the many valuable works which he has produced for their use."-The Builder.

"The mechanics in the volume are really mechanics, and are harmoniously wrought in with the distinctive professional matter proper to the subject. I he diagrams and type are commendably clear."-The Schoolmaster.

\section{The New Builder's Price Book, 1894.}

LOCKWOOD'S BUILDER'S PRICE BOOK FOR 1894. A Com-

prehensive Handbrok of the Latest Prices and Data for Builders, Architects,

Engineers, and Contractors. Re-constructed, Re-written, and Greatly Enlarged.

By Francis T. W. Miller. 700 closely-printed pages, crown 8vo, 4 s. cloth.

"This book is a very useful one, and shouid find a place in every English office connected with the building and engineering professions."-Industries.

"An excellent book of reference,"-Architect.

"In its new and revised form this Price Book is what a work of this kind should be-comprehensive, reliable, well arranged, legible, and well bound."-British A rchitect.

\section{Designing Buildings.}

THE DESIGN OF BUILDINGS: Being Elementary Notes on the

Planning, Sanitation and Ornamentive Formation of Structures, based on Modern Practice. Illustrated with Nine Folding Plates. Ry W. WuoDLEy, Assistant Master, Metropolitan Drawing Classes, \&c. Demy 8vo, 6s. cloth. [Just published.

\section{Sir William Chambers's Treatise on Civil Architecture.}

THE DECORATIVE PART OF CIVIL ARCHITECTURE. By Sir William Chambers, F.R.S. With Portrait, Illustrations, Notes, and an Examination of Grecian Architecture, by Joseph Gwilt, F.S.A. Revised and Edited by W. H. Leeds. 66 Plates, 4to, 21 s. cloth. 


\section{Villa Architecture.}

A HANDY BOOK OF VILLA ARCHITECTURE : Being a Series of Designs for Villa Kesidences in various Styles. With Outline Specifications and Estimates, By C. WICKES, Architect, Author of "The Spires and Towers of England," \&c. 6I Plates, 4to, $\oint_{\text {I }}$ I I $s$. $6 d$. half-morocco, gilt edges.

"The whole of the designs bear evidence of their being the work of an artistic architect, and they will prove very valuable and suggestive,"-Building News.

\section{Text-Book for Architects.}

THE ARCHITECT'S GUIDE : Being a Text-book of Useful Information for Architects, Engineers, Surveyors, Contractors, Clerks of Works, \&c.

\&c. By Frederick Rogers, Architect. Third Edition. Cr. 8vo, 3s. 6d. cloth. find a As a text-book of useful information for architects, engineers, surveyors, \&c., it would be hard to find a handier or more complete little volume."-Standard.

\section{Taylor and Cresy's Rome.}

THE ARCHITECTURAL ANTIQUities OF ROME. By the late

G. L. TAYLor, Esq., F.R.I.B.A., and EdWard Cresy, Esq. New Edition, thoroughly Revised by the Rev. ALEXANDER TAYLOR, M.A. (son of the late G. L. Taylor, Esq.), Fellow of Queen's College, Oxford, and Chaplain of Gray's Inn. Large folio, with 130 Plates, $\{33$ s. half-bound. which cannot be bettered."-Architect.

\section{Linear Perspective.}

ARChItectural PERspective. The whole Course and Operations of the Draughtsman in Drawing a Large House in Linear Perspective. Illustrated by 39 Folding Plates. By F. O. FerGuson. 8vo, 3s. $6 d$. boards.

"It is the most intelligible of the treatises on this ill-treated subject that I have met with." E. INGKeSS BELL, EsQ., in the R.I.B.A. Fowrnal.

\section{Architectural Drawing.}

PRACTICAL RULES ON DRAWING, for the Operative Builder and Young Student in Architecture. By George Pyne. With 14 Plates, 4to, 7s. $6 d$. boards.

\section{Vitruvius' Architecture.}

THE ARCHITECTURE OF MARCUS VITRUVIUS POLLIO. Translated by JOSEPH GWILT, F.S.A., F.R.A.S. New Edition, Revised by the Translator. With 23 Plates, fcap. $8 \mathrm{vo}, 5^{s}$. cioth.

\section{Designing, Measuring, and Valuing.}

THE STUDENT'S GUIDE TO THE PRACTICE OF MEASURING AND VALUING ARTIFICERS' WORK. Containing Directions for taking Dimen. sions, Abstracting the same, and bringing the Quantities into Bill, with Tables of Constants for Valuation of Labour, and for the Calculation of Areas and Solidities. Originally edited by EDWARD DOBSON, Architect. With Additions by E. WYNDhaM TARN, M.A. Sixth Edition. With 8 Plates and 63 Woodcuts. Crown 8vo, $7 s .6 d$. cloth.

"This edition will be found the most complete treatise on the principles of measuring and valuing artificers' work that has yet been published." - Building Newus.

\section{Pocket Estimator and Technical Guide.}

THE POCKET TECHNICAL GUIDE, MEASURER, AND ESTIMATOR FOR BUILDERS AND SURVEYORS. Containing Technical Directions for Measuring Work in all the Building Trades, Complete Specifications for Houses, Roads, and Drains, and an Easy Method of Estimating the parts of a Building collectively.

By A. C. BEATON. Sixth Edition. Waistcoat-pocket size, Is. $6 d$. gilt edges.
"No builder, architect, surveyor, or valuer should be without his 'Beaton." "-Building Nezus.

\section{Donaldson on Specifications.}

THE HANDBOOK OF SPECIFICATIONS; or, Practical Guide to the Architect, Engineer, Surveyor, and Builder, in drawing up Specifications and Contracts for Works and Constructions. Illustrated by Precedents of Buildings actually executed by eminent Architects and Engineers. By Professor T. L. DonAlDSon, P.R.I.B.A., \&c. New Edition, in One large Vol., 8vo, with upwards of $\mathrm{I}, 000$ pages of Text, and 33 Plates, $£$ I I I $s, 6 d$. cloth.

" to say that Donaldson's 'Handbord, and more valuable still as a book of precedents. . . Suffice is 


\section{Bartholomew and Rogers' Specifications.}

SPECIFICATIONS FOR PRACTICAL ARCHITECTURE. A Guide to the Architect, Engineer, Surveyor, and Builder. With an Essay on the Structure and Science of Modern Buildings. Upon the Basis of the Work by ALFRED BARTHOLOMEW, thoroughly Revised, Corrected, and greatly added to by FREDERICK

Rogers, Architect. Third Edition, Revised, with Additions. 8vo, 15s. cloth.

"The collection of specifications prepared by Mr. Rogers on the basis of Bartholomew's work is too well known to need any recommendation from us. It is one of the books with which every young architect must be equipped." - Architect.

\section{Construction.}

THE SCIENCE OF BUILDING: An Elementary Treatise on the Principles of Construction. By E. Wyndham TARN, M.A., Architect. Third Edition, Revised and Enlarged, with 59 Engravings. Fcap. 8vo, 4s. cloth.

"A very valuable book, which we strongly recommend to all students."-Builder.

\section{House Building and Repairing.}

THE HOUSE-OWNER'S ESTIMATOR; or, What will it Cost to Build, Alter, or Repair? A Price Book for Unprofessional People, as well as the Architectural Surveyor and Builder. By J. D. Simon. Edited by F. T. W. Miller, A.R.I.B.A. Fourth Edition. Crown 8vo, $3 s .6 d$. cloth.

"In two years it will repay its cost a hundred times over."-Field.

\section{Cottages and Villas.}

COUNTRY AND SUBURBAN COTTAGES AND VILLAS: How to Ylan and Build Them. Containing 33 Plates, with Introduction, General Explanations, and Description of each Plate. By James W. Bogue, Architect, Author of "Domestic Architecture," \&c. 4to, 10s. 6d. cloth.

\section{Building; Civil and Ecclesiastical.}

A BOOK ON BUILDING, Civil and Ecclesiastical, including Church Restoration; with the Theory of Domes and the Great Pyramid, \&c. By Sir EdmUnd BecKeTt, Bart., LL.D., F.R.A.S. Second Edition. Fcap. 8vo, 5 s. cloth.

"A book which is always amusing and nearly always instructive."-The Times.

\section{Sanitary Houses, etc.}

THE SANITARY ARRANGEMENT OF DWELLING-HOUSES: A Hand book for Householders and Owners of Houses. By A. J. WAllis-TAYLER, A.M.Inst. C.E. With numerous Illustrations. Crown 8 vo, $2 s .6 d$. cloth.

\section{Ventilation of Buildings.}

[Just published.

VENTILATION. A Text-Book to the Practice of the Art of Venti-

lating Buildings. Py W. P. BUCHAN, R.P. 12mo, $4 s$ cloth.

"Contains a great amount of useful practical information, as thoroughly interesting as it is technically reliable," "-British Architect.

\section{The Art of Plumbing.}

PLUMBING. A Text-Book to the Practice of the Art or Craft of the Plumber. By W. P. Buchan, R.P. Sixth Edition, Enlarged. I $2 \mathrm{mo}, 4 s$, cloth.

"A text book which may be safely put in the hands of every young plumber."-Builder.

\section{Geometry for the Architect, Engineer, \&c.}

PRACTICAL GEOMETRY, for the Architect, Engineer, and Mechanic. Giving Rules for the Delineation and Application of various Geometrical Lines, Figures, and Curves. By E. W. TARN, M.A., Architect. 8vo, 9s, cloth.

"No book with thesane objects in view has ever been published in which the clearness of the rules aid down and the illustrative diagrams have been so satisfactory." -Scotsman.

\section{The Science of Geometry.}

THE GeOMETRY OF COMPASSES; or, Problems Resolved by the mere Description of Circles, and the use of Coloured Diagrams and Symbols. By Oliver Byrne. Coloured Plates. Crown 8vo, 3 s. $6 d$. cloth. 


\section{CARPENTRY, TIMBER, etc.}

\section{Tredgold's Carpentry, Revised and Enlarged by Tarn.}

THE ELEMENTARY PRINCIPLES OF CARPENTRY: A Treatise on the Pressure and Equilibrium of Timber Framing, the Resistance of Timber, and the Construction of Floors, Arches, Bridges, Roofs, Uniting Iron and Stone with Timber, \&c. To which is added an Essay on the Nature and Properties of Timber, \&c., with Descriptions of the kinds of Wood used in Building; also numerous Tables of the Scantlings of Timber for different purposes, the Specific Gravities of Materials, \&c. By THOMAS TREDGoLD, C.E. With an Appendix of Specimens of Various Roofs of Iron and Stone, Illustrated. Seventh Edition, thoroughly Revised and considerably Enlarged by $\mathbf{E}$. WYNDHAM TARN, M.A., Author of "The Science of Building," \&c. With 6r Plates, Portrait of the Author, and several Woodcuts. In One large Vol., 4to, 25s. cloth.

"Ought to be in every architect's and every builder's library."-Builder.

The author's whose monumental excellence must commend it wherever skilful carpentry is concerned. The author's principles are rather confirmed than impaired by time. The additional plates are of great
intrinsic value."--Building News. Woodworking Machinery.

WOODWORKING MACHINERY: Its Rise, Progress, and Construction. With Hints on the Management of Saw Mills and the Economical Conversion of Timber. Illustrated with Examples of Recent Designs by leading English, French, and American Engineers. By M. Pow'IS BALE, A.M. Inst,C.E., M.I.M.E. Second Edition, Revised, with large Additions, large crown 8vo, 440 pages, $9 s$. cloth. [Yust published.

"Mr. Bale is evidently an expert on the subject, and he has collected so much intormation that his book is all-sufficient for builders and others engaged in the conversion of timber." - Architect. "The most comprehensive compendium of wood-working machinery we have seen. 'The author is a
thorough master of his subject."-Building Nerws.

\section{Saw Mills.}

SAW MILLS: Their Arrangement and Management, and the

Economical Conversion of Timber. (A Companion Volume to "Woodworking

Machinery.") By M. Powis BAl.e. Crown 8vo, 10s. 6d. cloth.

"The ar mi istration of a large sawing establishment is discussed, and the subject examined from a financial stanopoint. Hence the size, shape, order, and disposition of saw-mills and the like are gone into in detail, and the course of the timber is traced from its reception to its delivery in its converted state. We could not desire a more complete or practical treatise."-Builder.

\section{Nicholson's Carpentry.}

THE CARPENTER'S NEW GUIDE ; or, Book of Lines for Carpenters; comprising all the Elementary Principles essential for acquiring a knowledge of Carpentry. Founded on the late PETER NICHOLSON's standard work. A New Edition, Revised by ARTHUR AshPITEL, F.S.A. Together with Practical Rules on Drawing, by George Pyne. With 74 Plates, 4 to, $\&^{I}$ Is, cloth.

\section{Handrailing and Stairbuilding.}

A PRACTICAL TREATISE ON HANDRAILING: Showing New and Simple Methods for Finding the Pitch of the Plank, Drawing the Moulds, Bevelling, Iointing-up, and Squaring the Wreath. By George Colcisgs. Second Edition, Revised and Enlarged, to which is added A Treatise on STAIR"WUILDING. With Plates and Diagrams. 12mo, 2s. 6d. cloth limp.

"Will be found of practical utility in the execution of this difficuit branch of joinery."-Builder. "Almost every difficult ohase of this somewhat intricate branch of joinery is elucidated by the aid
of plates and explanatory letterpress." -Furniture Gnzette.

\section{Circular Work.}

CIRCULAR WORK IN CARPENTRY AND JOINERY: A PraCtical Treatise on Circular Work of Single and Double Curvature. By GEORGE Collings. With Diagrams. Second Edition, $\mathrm{I} 2 \mathrm{mo}, 2 s$. $6 d$. cloth limp.

"An excellent example of what a book of this kind should be. Cheap in price, clear in definition, and practical in the examples selected."-Builaer.

\section{Handrailing.}

HANDRAILING COMPLETE IN EIGHT LESSONS. On the Square-

Cut System. By J. S. GoldTHORP, Teacher of Geometry and Building Construction at the Halifax Mechanic's Institute. With Eight Plates and over 150 Practical

Exercises. 4to, 3\% $6 d$. cloth.

"Likely to b of considerable value to joiners and others who take a vride in good work. The arrangement of the book is excellent. We heart ly commend it to teachers and students." - Timbır
Trades Fournal. 


\section{Timber Merchant's Companion.}

THE TIMBER MERCHANT'S AND BUILDER'S COMPANION. Containing New and Copious Tables of the Reduced Weight and Measurement of Deals and Battens, of all sizes, from One to a Thousand Pieces, and the relative Price that each size bears per Lineal Foot to any given Price per Petersburgh Standard Hundred; the Price per Cube Foot of Square Timber to any given Price per Load of 50 Feet ; the proportionate Value of Deals and Battens by the Standard, to Square Timber by the Load of 50 Feet ; the readiest mode of ascertaining the Price of Scantling per Lineal Foot of any size, to any given Figure per Cube Foot, \&c. \&c. By William Dowsing. Fourth Edition, Revised and Corrected. Cr. 8vo, $3^{s}$. cloth. "Everything is as concise and clear as it can possibly be made. There can be no doubt that every timber merchant and builder ought to possess it."-Hull Advertiser.

"We are glad to see a fourth edition of these admirable tables, which for correctness and simplicity of arrangement leave nothing to be desired."-Timber Trades' Fournal.

\section{Practical Timber Merchant.}

THE PRACTICAL TIMBER MERCHANT: Being a Guide for the use of Building Contractors, Surveyors, Builders, \&c., comprising useful Tables for all purposes connected with the Timber Trade, Marks of Wood, Essay on the Strength of Timber, Remarks on the Growth of Timber,.\&c. By W. Richardson. Fcap. 8 vo, 3s. 6d. cloth.

"This handy manual contains much valuable information for the use of timber merchants, builders, foresters, and all others connected with the growth, sale, and manufacture of timber."-Fonrual of Forestry.

\section{Timber Freight Book.}

THE TIMBER MERCHANT'S, SAW MILLER'S, AND IMPORTER'S

FREIGHT BOOK AND ASSISTANT. Comprising Rules, Tables, and Memoranda relating to the Timber Trade. By WILLIAM RICHARDSON, Timber Broker; together with a Chapter on Speeds of Saw Mill Machinery by M. Powis Bale M.I.M.E., \&c. $12 \mathrm{mo}, 3 s$. 6 d. cloth boards

"A very useful manual of rules, tables, anc memoranda relating to the timber trade. We recommend it as a compendium of calculation to all timber measurers and merchants, and as supplying a real want in the trade."-Building News.

\section{Packing.Case Makers, Tables for.}

PACKING-CASE TABLES; showing the number of Superficial Feet in Boxes or Packing-Cases, from six inches square and upwards. By W. RICHARDson, Timber Broker. Third Edition. Oblong 4 to, $3 s .6 d$. cloth.

"Invaluable labour-saving tables."-Ironmonger. "Will save much labour and calculation."-Grocer.

\section{Superficial Measurement.}

THE TRADESMAN'S GUIDE TO SUPERFICIAL MEASUREMENT.

Tables calculated from $\mathbf{I}$ to 200 inches in length, by $\mathbf{I}$ to 108 inches in breadth.

For the use of Architects, Surveyors, Engineers, Timber Merchants, Builders, \&c.

By James Hawkings. Fourth Edition. Fcap., 3s. $6 d$. cloth.

"A useful collection of tables to facilitate rapid calculation of surfaces. The exact area of any surface of which the limits have been ascertained can be instantly determined. The book will be found of the greatest utility to all engaged in building operations." - Sc Jtsman.

"These tables will be found of great assistance to all who require to make calculations in superficial measurement."-English Mechanic.

\section{Forestry.}

THE ELEMENTS OF FORESTRY. Designed to afford Information concerning the Planting and Care of Forest Trees for Ornament or Profit, with suggestions upon the Creation and Care of Woodlands. By F. B. Hough. Large crown 8 vo, IOs. cloth.

\section{Timber Importer's Guide.}

THE TIMBER IMPORTER'S, TIMBER MERCHANT'S, AND BUILDER'S STANDARD GUIDE. By RICHARD E. GRandy. Comprising:-An Analysis of Deal Standards, Home and Foreign, with Comparative Values and Tabular Arrangements for fixing Net Landed Cost on Baltic and North American Deals, including all intermediate Expenses, Freight, Insurance, \&c. \&c. ; together with copious Information for the Retailer and Builder. Third Edition, Revised. 12mo, 2s. cloth limp.

" Everything it pretends to be : built up gradually, it leads one from a forest to a treenail, and throws in, as a makeweight, a host of material cencerning bricks, columns, cisterns, \&c."-English Mechanic. 


\section{DECORATIVE ARTS, etc.}

\section{Woods and Marbles, Imitation of.}

SCHOOL OF PAINTING FOR THE IMITATION OF WOODS AND MARBLES, as Taught and Practised by A. R. VAN DER BURG and P. VAN DEK BURG, Directors of the Rotterdam Painting Institution. Royal folio, $18 \frac{1}{2}$ by $12 \frac{1}{2}$ in., Illustrated with 24 full-size Coloured Plates; also 12 plain Plates, comprising 154 Figures. Second and Cheaper Edition. Price $f$ I 11s. $6 d$.

\section{List of Plates.}

I. VARIOUS TOOLS REQUired For WOOD Painting.-2,3. Walnut; Preliminary Stages OF GRAINING AND FINISHED SPECIMEN - TOOLS USED FOR MARBLE PAINTINO AND MET. TOOLS MANIPULATION, 5 , 6 . ST. REMI MAR OF MANIPULATION. - 5, 6. ST. REMI MARBLE; Earlier Operations and Finished Specimen, 7. Methods of Sketching Different Grains, KNots, \&c. -8, 9. Ash: Preliminary Stages ANd Finished Specimen.-10. Methods of Sketching Marble Grains.-11, 12. Breche Marble; Preliminary Stages of WorkiNo AND FINISHED SPECIMEN-I3 MAPLE METHODS OP PRODU'S-EYE MAPLE; PRE GRAINS. -14, 15. BIRD's-EYE MAPLe; PRELIMINARY Stages and Finished Specimen.-If. Methods OF SKetching the Different SPECies of White Marble.-17, 18. White Marble; Pre-

liminary Stages of Process and Finished SPECIMEN.-19. MAHOGANY; SPECIMENS OF VARtous Grains and Methods of Manipulation,20, 21. MAHOganY; EARLIER Stages AND FINISHED SPECIMEN.-22, 23 24. SiEnNA MARBLE VARIETIES OF GRAIN, PreLIMINARY Stages AND Finished SPECIMEN.-25, 26, 27. JUNIPER Wood Methods of Producing Grain, \&C.; Pretimi NARY STAGES AND FINISHED SPECIMEN $-28,29$ 30, VERT DE MER MARBLE; VARIETIES 29 GRAIN AND ME GRAIN AND METHODS OF WORKING, UNFINISHED AND Finished SPECIMENS.-31, 32, 33. OAK : VArieties of Grain, Tools EMployed and Methods of Manipulation, Preliminary Stages ANd Finished SPECIMEN, $-34,35,36$ WAULSORT MARBLE: VARIETIES OF GRA UNFINISHED AND FINISHED SPECIMENS.

"Those who desire to attain skill in the art of painting woods and marbles will find advantage in consulting this book. . . Some of the Working Men's Clubs should give their young men the opportunity to study it."-Bivilder.

"A comprehensive guide to the art. The explanations of the processes, the manipulation and management of the colours, and the beautifully executed plates will not be the least vafuable to the student who aims at making his work a faithful transcript of nature."-Building News.

\section{Wall Paper.}

Wall PAPER Decoration. By Arthur Seymour Jennings,

Author of "Practical Paper Hanging." With numerous Illustrations. Demy 8vo.

House Decoration.

[n preparation.

ELEMENTARY DECORATION: A Guide to the Simpler Forms of Everyday Art. Together with PRACTICAL HOUSE DECoration. By JAMrs W.

FACEY. With numerous Illustrations. In One Vol., $5^{5}$. strongly half-bound.

House-Painting, Graining, etc.

HOUSE-PAINTING, GRAINING, MARBLING, AND SIGN WRITING,

A Practical Manual of. By Ellis A. DAvidson. Sixth Edition. With Coloured Plates and Wood Engravings. I $2 \mathrm{mo}, 6 s$. cloth boards.

"A mass of information, of use to the amateur and of value to the practical man."-English Mechanic.

\section{Decorators, Receipts for.}

THE DECORATOR'S ASSISTANT: A Modern Guide to Decorative Artists and Amateurs, Painters, Writers, Gilders, \&c. Containing upwards of 600 Receipts, Rules and Instructions; with a variety of Information for General Work connected with every Class of Interior and Exterior Decorations, \&c.,

Fifth Edition, Revised. I 52 pp., crown 8vo, Is. in wrapper.

"Full of receipts of value to decorators, painters, gilders, \&c. The book contains the gist of larger treatises on colour and technical processes. It would be difficult to meet with a work so full of varied information on the painter's art." -Building Nezw.

\section{Moyr Smith on Interior Decoration.}

ORNAMENTAL INTERIORS, ANCIENT AND MODERN. By J. MOYR SMITH. Super-royal 8vo, with Thirty-two full-page Plates and numerous smaller Illustrations, handsomely bound in cloth, gilt top, $18 \mathrm{~s}$.

"The book is well illustrated and handsomelv got up, and contains some true criticism and a good many good examples of decorative treatment." -The Builder. 


\section{British and Foreign Marbles.}

MARBLE DECORATION and the Terminology of British and Foreign

Marbles. A Handbook for Students. By GEORGE H. BLAGROVE, Author of

"Shoring and its Application," \&c. With 28 Illustrations. Cr. 8vo, 3s. 6d. cloth.

"This most useful and much wanted handbook should be in the hands of every architect and builder."-Building World.

"A carefully and usefully written treatise; the work is essentially practical."-Scotsman.

\section{Marble Working, etc.}

MARBLE AND MARBLE WORKERS: A Handbook for Architects, Artists, Masons, and Students. By ARTHUR LeE, Author of "A Visit to Carrara," "The Working of Marble," \&c. Small crown 8vo, 2s. cloth.

"A really valuable addition to the technical literature of architects and masons."-Building News.

\section{DELAMOTTE'S WORKS ON ILLUMINATION AND ALPHABETS.}

A PRIMER OF THE ART OF ILLUMINATION, for the Use of Beginners; with a Rudimentary Treatise on the Art, Practica: Directions for its Exercise, and Examples taken from Illuminated MSS,, printed in Gold and Colours. By F. Delamotte. New and Cheaper Edition. Small 4to, 6s. ornamental boards.

"The examples of ancient MSS, recommended to the student, which, with much good sense, the author chooses from collections accessitle to all, are selected with judgment and knowledge, as well as taste."-Athencum.

ORNAMENTAL ALPHABETS, Ancient and Mediæval, from the Eighth Century, with Numerals ; including Gothic, Church-Text, large and small, German, Italian, Arabesque, Initials for Illumination, Monograms, Crosses, \&c. \&c., for the use of Architectural and Engineering Draughtsmen, Missal Painters, Masons, Decorative Painters, Lithographers, Engravers, Carvers, \&c. \&c. Collected and Engraved by F. Delamotre, and printed in Colours. New and Cheaper Edition. Royal $8 \mathrm{vo}$, oblong, 2s. 6 d. ornamental boards.

"For those who insert enamelled sentences round gilded chalices, who blazon shop legends over shopdoors, who letter church walls with pithy sentences from the Decalogue, tnis book will be useful." Athenaum.

EXAMPLES OF MODERN ALPHABETS, Plain and Ornamental, including German, Old English, Saxon, Italic, Perspective, Greek, Hebrew, Court Hand, Engrossing, Tuscan, Riband, Gothic, Rustic, and Arabesque ; with several Original Designs, and an Analysis of the Roman and Old English Alphabets, large and small, and Numerals, for the use of Draughtsmen, Surveyors, Masons, Decorative Painters, Lithographers, Engravers, Carvers, \&c. Collected and Engraved by F. Delamotte, and printed in Colours. New and Cheaper Edition. Koyal 8vo, oblong, $2 s .6 d$. ornamental boards.

"There is comprised in it every possible shape into which the letters of the alphabet and numerals can be formed, and the talent which has been expended in the conception of the various plain and ornamental letters is wonderful." - Standard.

MEDIÆVVAL ALPhABETS AND INITIALS FOR ILLUMINATORS. By F. G. Delamotte. Containing 21 Plates and Illuminated Title, printed in Gold and Colours. With an Introduction by J. WILLIS BROOKS. Fourth and Cheaper Edition. Small 4 to, 4 s. ornamental boards.

"A volume in which the letters of the alphabet come forth glorified in gilding and all the colours of che prism interwoven and intertwined and intermingled." - Sun,

\section{THE EMBROIDERER'S BOOK OF DESIGN. Containing Initials,} Emblems, Cyphers, Monograms, Ornamental Borders, Ecclesiastical Devices, Mediæval and Modern Alphabets, and National Emblems. Collected by F. DeLAMOTTE, and printed in Colours. Oblong royal $8 \mathrm{vo}, \mathrm{I} s .6 d$. ornamental wrapper.

"The book will be of great assistance to ladies and young children who are endowed with the art of plying the needle in this most ornamental and useful pretty work."-East Anglian Times.

\section{Wood Caruing.}

INSTRUCTIONS IN WOOD-CARVING FOR AMATEURS; with Hints

on Design. By A Lady. With Ten Plates. New and Cheaper Edition. Crown 8 vo, 2s. in emblematic wrapper.

"The handicraft of the wood-carver, so well as a book can impart it, may be learnt from 'A Lady's publication."-Athenoum. 


\section{NATURAL SCIENCE, etc. \\ The Heavens and their Origin. \\ THE VISIBLE UNIVERSE : Chapters on the Origin and Construc- tion of the Heavens. By J. E. Gore, F.R.A.S., Author of "Star Groups," \&c. Illustrated by 6 Stellar Photographs and 12 Plates. Demy 8vo, 16s. cloth. \\ "A valuable and lucid summary of recent astronomical theorv, rendered more valuable and attractive by a series of stellar photographs and other illustrations."-The Times. \\ "In presenting a clear and concise account of the present state of our knowledge, Mr. Gore has made a valuable addition to the literature of the subject." - . Nature. \\ "Mr. Gore's 'Visible Universe' is one of the finest works on astronomical science that has recently appeared in our language. In spirit and in method it is scientific from cover to cover, but the style is so clear and attractive that it will be as acceptable and as readable to those who make no scientific preten- sions as to those who devote themselves sf ecially to matters astronomical."-Leeds Mercury. \\ "As interesting as a novel, and instructive withal; the text being made still more luminous by stellar photographs and other illustrations. . . . A most valuable book."-Manchester Examiner.}

\section{The Constellations.}

STAR GROUPS: A Student's Guide to the Constellations. By J.

Ellard Gore, F.R.A.S., M.R.I.A., \&c., Author of "The Visible Universe,"

"The Scenery of the Heavens." With 30 Maps. Small 4 to, 5 s. cloth, silvered.

"A knowledge of the principal constellations visible in our latitudes may be easily acquired from the thirty maps and accompanying text contained in this work."-Nature.

"The volume contains thirty maps showing stars of the sixth magnitude-the usual naked-eye limit - and each is accompanied by a brief commentary, adasted to facilitate recognition and bring to notice objects of special interest. For the purpose of a preliminary survey of the 'midnight pomp' of the heavens, nothing could be better than a set of delineations averaging scarcely twenty square inches in area, and including nothing that cannot at once be identified."-Saturday Reviezv.

"A very compact and handy guide to the constellations." - Athenoum.

\section{Astronomical Terms.}

AN ASTRONOMICAL GLOSSARY ; or, Dictionary of Terms used in Astronomy. With Tables of Data and Lists of Remarkable and Interesting Celestial Objects. By J. Ellard Gore, F.R.A.S., Author of "The Visible Universe," \&c. Small crown 8vo, 2s. 6d. cloth.

"A very useful little work for beginners in astronomy, and not to be despised by more advanced students." -The Times.

"A very handy book . . the utility of which is much increased by its valuable tables of astronomical data."-The Athencum.

"Astronomers of all kinds will be glad to have it for reference."-Guardian.

\section{The Microscope,}

THE MICROSCOPE : Its Construction and Management. Including

Technique, Photo-micrography, and the Past and Future of the Microscope. By

Dr. Henri van Heurck, Director of the Antwerp Botannical Gardens. English

Edition, Re-Edited and Augmented by the Author from the Fourth French Edition, and Translated by WYNne E. BAXTER, F.R.M.S., F.G.S., \&c. A bout 400 pages, with Three Plates and upwards of 250 Woodcuts, imp. $8 \mathrm{vo}, 18$ s., cloth gilt.

"This is a translation of a well-known work, at once popular and comprehensive, on the structure, mechanism, and use of the microscope."-Times.

"The translation is as felicitous as it is accurate."-Nature.

\section{Astronomy.}

ASTRONOMY. By the late Rev. Robert Main, M.A., F.R.S. Third Edition, Revised by WILliam THYNNE LyNn, B.A., F.R.A.S., formerly of the Royal Observatory, Greenwich. 12mo, 2s. cloth limp.

"A sound and simple treatise, very carefully edited, and a capital book for beginners." - Knoweledge.

"Accurately brought down to the requirements of the present time by Mr.Lynn." - Educational Times.

\section{Recent and Fossil Shells.}

A MANUAL OF THE MOLLUSCA : Being a Treatise on Recent and Fossil Shells. By S. P. WoodWARD, A.L.S., F.G.S., late Assistant Palæontologist in the British Museum. With an Appendix on RECENT AND FossiL ConCHOLOGICal Discoveries by Ralph Tate, A.L.S., F.G.S. Illustrated by A. N. WaterHOUSE and JOSEPH WILSON LOWRY. With 23 Plates and upwards of 300 Woodcuts. Keprint of Fourth Edition (1880). Crown 8vo, 7s. 6d. cloth.

"A most valuable storehouse of conchological and geological information."-Science Gossip.

Geology and Genesis.

THE TWIN RECORDS OF CREATION ; or Geology and Genesis, their Perfect Harmony and Wonderful Concord. By G. W. V. LE VAuX. 8vo, 5s. cl.

"A valuable contribution to the evidences of Revelation, and disposes very conclusively of the arguments of those who would set God's Works against God's Word. No real difficulty is shirked, and no
so $\mathrm{L}_{\mathrm{L}}$ his ry is left unexposed."-7 he Kcck. 


\section{DR. LARDNER'S COURSE OF NATURAL PHILOSOPHY.}

THE HANDBOOK OF MECHANICS. Enlarged and almost re-written by Benjamin Loewy, F.R.A.S. With 378 Illustrations. Post 8 vo, 6 s. cloth.

"The perspicuity of the original has been retained, and chapters which had become obsolete have been replaced by others of more modern character. The explanations throughout are studiously popular, and care has been taken to show the application of the various branches of physics to the industrial arts, and to the practical business of life."-Mining fournal.

"Mr. Loewy has carefully revised the book, and brought it up to modern requirements." - Nature. subject than Dr. Lardner a and Mr. New exponents more able or better skilled in the art of popularising the subject than Dr. Lardner : and Mr. Loewy is doing good service in fitting this treatise, and the others
of the series, for use at the present time."-Scotsman.

THE HANDBOOK OF HYDROSTATICS AND PNEUMATICS. New Edition, Revised and Enlarged by BENJAMIN LOEWY, F.R.A.S. With 236 Illustrations. Post 8vo, 5s. cloth.

"For those "who desire to attain an accurate knowledge of physical science without the profound methods of mathematical investigation,' this work is not merely intended, but well adapted."-Chemical

"The volume before us has been carefully edited, augmented to nearly twice the bulk of the former edition, and all the most recent matter has been added. . . It is a valuable text-book."-Nature. English Mechanic.
"Candidates for pass examinations will find it, we think, specially suited to their requirements."-

THE HANDBOOK OF HEAT. Edited and almost entirely re-written by Benjamin Loewy, F.R.A.S., \&c. II 7 Illustrations. Post 8 vo, 6 s. cloth. "The style is always clear and precise, and conveys instruction without leaving any cloudiness or
lurking doubts behind."-Engineering.

"A most exhaustive book on the subject on which it treats, and is so arranged that it can be understood by all who desire to attain an accurate knowledge of physical science. . . Mr. Loewy has included all the latest discoveries in the varied laws and effects of heat." -Standard.

"A complete and handy text-book for the use of students and general readers." $-E_{n g l i s h}$ Mechanic.

THE HANDBOOK OF OPTICS. By Dionysius LaRdner, D.C.L., formerly Professor of Natural Philosophy and Astronomy in University College, London. New Edition. Edited by T. Olver Harding, B. A. Lond., of University College, London. With 298 Illustrations. Small 8 vo, 448 pages, 5 s. cloth.

"Written by one of the ablest English scientific writers, beautifully and elaborately illustrated." -Mechanic's Magazine.

THE HANDBOOK OF ELECTRICITY, MAGNETISM, AND ACOUSTICS,

By Dr. LARDNER. Ninth Thousand. Edited by Geo. CAREY FOSTER, B.A., F.C.S. With 400 Illustrations. Small 8 vo, 5 s. cloth.

"The book could not have been entrusted to anyone better calculated to preserve the terse and lucid style of Lardner, while correcting his errors and bringing up his work to the present state of
scientific knowledge."-Popular Science Review.

THE HANDBOOK OF ASTRONOMY. Forming a Companion to the "Handbook of Natural Philosophy." By Dionysius LARDNer, D.C.L., formerly Professor of Natural Philosophy and Astronomy in University College, London. Fourth Edition. Revised and Edited by EDWIN DUNKIN, F.R.A.S., Royal Observatory, Greenwich. With 38 Plates and upwards of Ioo Woodcuts. In One Vol., small $8 \mathrm{vo}, 550$ pages, 9 s. $6 d$. cloth.

"Probably no other book contains the same amount of information in so compendious and wellarranged a form-certainly none at the price at which this is offered to the public."-Athencum.

"We can do no other than pronounce this work a most valuable manual of astronomy, and we strongly recommend it to all who wish to acquire a general-but at the same time correct-acquaintance with this sublime science."-Quarterly Fournal of Science.

" One of the most deservedly popular books on the subject . . : We would recommend not only the student of the elementary' principles of the science, but him who aims at mastering the higher and mathematical branches of astronomy, not to be without this work beside him." - Practical Maguzine.

\section{Geology.}

RUDIMENTARY TREATISE ON GEOLOGY, PHYSICAL AND

HISTORICAL. Consisting of "PHYSICAL GEOLOGY," which sets forth the Leading Principles of the Science ; and "H Istorical Geology," which treats of the Minera! and Organic Conditions of the Earth at each successive epoch, especial rcference being made to the British Series of Rocks. By RALPH TATE, A.L.S., F.G.S., \&c. \&c. With 250 Illustrations. I $2 \mathrm{mo}, 5 \mathrm{~s}$. cloth boards. "The fulness of the matter has elevated the book into a manual. Its information is exhaustive and
well arranged."- Sehool Board Chronicle. 


\section{DR. LARDNER'S MUSEUM OF SCIENCE AND ART.}

\section{THE MUSEUM OF SCIENCE AND ART. Edited by Dionysius} LARDNER, D.C.L., formerly Professor of Natural Philosophy and Astronomy in University College, London. With upwards of 1,200 Engravings on Wood. In 6 double volumes, $f_{\mathrm{I}} \mathrm{I}$ s., in a new and elegant cloth binding; or handsomely bound in half morocco, $31 s$. $6 d$.

\section{** Opinions of the Press.}

"This series, besides affording popular but sound instruction on scientific subjects, with which the humblest man in the country ought to be acquainted, also undertakes that teaching of "Common Things" which every well wisher of his kind is anxious to promote. Many thousand copies of this serviceable publication have been printed, in the belief and hope that the desire for instruction and improvement widely prevails; and we have no fear that such enlightened faith wil meet with disappointment." The Times.

"A cheap and interesting publication, aiike informing and attractive. The papers combine subjects of importance and great scientific knowledge, considerable inductive powers, and a popular style of treatment."-Spectator.

"The 'Museum of Science and Art' is the most valyable contribution that has ever been made to the scientific instruction of every class of society."-Sir DAvID BREWSTER, in the North British Review.

"Whether we consider the liberality and beauty of the illustrations, the charm of the writing, or the durable interest of the matter, we must express our belief that there is hardly to be found among the new books one that would be welcomed by people of so many ages and classes as a valuable present." Examiner.

*** Separate books formed from the above, suitable for Workmen's Libraries, Science Classes, \&re.

Common Things Explained. Containing Air, Earth, Fire, Water, Time, Man, the Eye, Locomotion, Colour, Clocks and Watches, \&c. 233 Illustrations, cloth gilt, $5^{s}$.

The Microscope. Containing Optical Images, Magnifying Glasses, Origin and Description of the Microscope, Microscopic Ubjects, the Solar Microscope, Micro. scopic Drawing and Engraving, \&c. 147 Illustrations, cloth gilt, $2 s$.

Popular Geology. Containing Earthquakes and Volcanoes, the Crust of the Earth, \&c. 201 Illustrations, cloth gilt, 2s. $6 d$.

Popular Physics. Containing Magnitude and Minuteness, the Atmosphere, Meteoric Stones, Popular Fallacies, Weather Prognostics, the Thermometer, the Barometer, Sound, \&c. 85 Illustrations, cloth gilt, $2 s, 6 d$.

Steam and its Uses. Including the Steam Engine, the Locomotive, and Steam Navigation. 89 Illustrations, cloth gilt, $2 s$.

Popular Astronomy. Containing How to observe the Heavens. The Earth, Sun, Moon, Planets. Light, Comets, Eclipses, Astronomical Influences, \&c. I82 Illus. trations, cloth gilt, 4 s. 6 d.

The Bee and White Ants: Their Manners and Habits. With Ilfustrations of Animal Instinct and Intelligence. 135 Illustrations, cloth gilt, 2s.

The Electric Telegraph Popularized. To render intelligible to all who can Read, irrespective of any previous Scientific Acquirements, the various forms of Telegraphy in Actual Operation. Ioo Illustrations, cloth gilt, Is. $6 d$.

\section{Dr. Lardner's School Handbooks.}

NATURAL PHILOSOPHY FOR SCHOOLS. By Dr. LARDNER. 328

Illustrations. Sixth Edition. One Vol., 3s. 6d. cloth.

"A very convenient class-book for junior students in private schools. It is intended to convey, in clear and precise terms, general notions of all the principal divisions of Physical Science." - British Quarterly Review.

ANIMAL PHYSIOLOGY FOR SCHOOLS. By Dr. LARDNER. With 190 Illustrations. Second Edition. One Vol., 3s. 6d. cloth.

"Clearly written, well arranged, and excellently illustrated."-Gardener's Chronicle.

\section{Lardner and Bright on the Electric Telegraph.}

THE Electric TElegraph. By Dr. Lardner. Revised and Re-written by E. B. BRIGHT, F.R.A.S. I40 Illustrations. Small 8vo, $2 s .6 d$. cloth.

"One of the most readable books extant on the ElectricTelegraph."-English Mechanic. 


\section{CHEMICAL MANUFACTURES, CHEMISTRY, etc.}

\section{Chemistry for Engineers, etc.}

ENGINEERING CHEMISTRY : A Practical Treatise for the Use of Analytical Chemists, Engineers, Iron Masters, Iron Founders, Students and others. Comprising Methods of Analysis and Valuation of the Principal Materials used in Engineering Work, with numerous Analyses, Examples and Suggestions. By $\mathrm{H}$. Joshua Phillips, F.I.C., F.C.S., Formerly Analytical and Consulting Chemist to the Great Eastern Railway. Second Edition, Revised and Enlarged. Crown 8vo, $400 \mathrm{pp}$., with Illustrations, ros. 6d. cloth. [ 7 ust published. "In this work the author has rendered no small service to a numerous body of practical men.

The analytical methods may be pronounced most satisfactory, being as accurate as the despatch required of engineering chemists permits."-Chemical News.

Those in search of a handy treatise on tbe subject of analytical chemistry as applied to the every-day requirements of workshop practice will find this volume of great assistance." -Iron.

The first attempt to bring forward a Chemistry specially written for the use of engineers, and we have no besitation whatever in saying that it should at once be in the possession of every railway engineer."-The Railway Engineer.

The book will be very useful to those who require a handy and concise résumé of approved methods of analysing and valuing metals, oils, fuels, \&c. It is, in fact, a work for chemists, a guide to the routine of the engineering laboratory. ... The book is full of good things. As a handbook of téchnical analysis, it is very welcome."-Builder.

"Considering the extensive ground which such a subject as Engineering Chemistry covers, the work is complete, and recommends itself to both the practising analyst and the analytical student."Chemical Trade fournal.

"The analytical methods given are, as a whole, such as are likely to give rapid and trustworthy results in experienced hands. . . There is much excellent descriptive matter in the work, the chapter on 'Oils and Lubrication' being specially noticeable in this respect." - Engineer.

\section{The Alkali Trade, Manufacture of Sulphuric Acid, \&c.}

A MANUAL OF THE ALKALI TRADE, including the Manufacture of Sulphuric Acid, Sulphate of Soda, and Bleaching Powder. By JoHn Lomas, Alkali Manufacturer, Newcastle-upon-Tyne and London. With 232 Illustrations and Working Drawings, and containing 390 pages of Text. Second Edition, with Additions. Super-royal 8vo, fI Ios. cloth.

"This book is written by a manufacturer for manufacturers. The working details of the most approved forms of apparatus are given, and these are accompanied by no less than 232 wood engravings, all of which may be used for the purposes of construction. Every step in the manufacture is very fully described in this manual, and each improvement explained."-Athenaum.

"We rind not merely a sound and luminous explanation of the chemical principles of the trade, but a notice of numerous matters which have a most important bearing on the successful conduct of alkali works. but which are generally overlooked by even experienced technological authors."-Chemical Review.

\section{The Blowpipe.}

THE BLOWPIPE IN CHEMISTRY, MiNERALOgY, AND GEOLOGY. Containing all known Methods of Anhydrous Analysis, many Working Examples, and Instructions for Making Apparatus. By Lieut.-Colonel W. A. Ross, R.A., F.G.S. With 120 Illustrations. Second Edition, Revised and Eniarged. Crown 8 vo, 5s. cloth.

"The student who goes conscientiously through the course of experimentation here laid down will gain a better insight into inorganic chemistry and mineralogy than if he had 'got up' any of the best text-books of the day, and passed any number of examinations in their contents."-Chemical Nerus.

\section{Commercial Chemical Analysis.}

THE COMMERCIAL HANDBOOK OF CHEMICAL ANALYSIS; or, Practical Instructions for the determination of the Intrinsic or Commercial Value of Substances used in Manufactures, in Trades, and in the Arts. By A. Normandy, Editor of Rose's “Treatise on Chemical Analysis." New Edition, to a great extent re-written by HENry M. NOAD, Ph.D., F.R.S. With numerous lllustrations. Crown $8 \mathrm{vo}, 12 s, 6 d$. cloth.

"We strongly recommend this book to our readers as a guide, alike indispensable to the housewife as to the pharmaceutical practitioner." - Medical Times.

Essential to the analysts appointed under the new Act. The most recent resilts are given, and the work is well edited and carefully written."-Nature.

\section{Dye-Wares and Colours.}

THE MANUAL OF Colours AND DYe-WARES: Their Properties, Applications, Valuations, Impurities, and Sophistications. For the use of Dyers, Printers, Drysalters, Brokers, \&c. By J. W. Slater. Second Edition, Revised and greatly Enlarged, crown 8vo, 7s. 6d. cloth.

"A complete encyclopadia of the materia tinctoria. The information given respecting each article is full and precise, and the methods of determining the value of articles such as these, so liable to sophis. tication, are given with clearness, and are practical as well as valuable." - Chemist and Druggist.

"There is no other work which covers precisely the same ground. To students preparing for examinations is dyeing and printing it will prove exceedingly useful,"-Chemical News. 


\section{Modern Brewing and Malting.}

A HANDYBOOK FOR BREWERS: Being a Practical Guide to the Art of Brewing and Malting. Embracing the Conclusions of Modern Research which bear upon the Practice of Brewing. By Herbert Edwards Wright.

M.A. Crown 8 vo, 530 pp., I2s. $6 d$, cloth.

"May be consulted with advantage by the student who is preparing himself for examinational tests, while the scientific brewer will find in it a résumé of all the most important discoveries ot modern times. The work is written throughout in a clear and concise manner, and the author takes great care to discriminate between vague theories and well-established facts."-Brewers' fournal.

"We have great pleasure in recommending this handybook, and have no hesitation in saying that it is one of the best-if not the best-which has yet been written on the subject of beer-brewing in this country, it should have a place on the shelves of every brewer's library."-Brewer's Guardian.

"Aithough the requirements of the student are primarily considered, an acquaintance of half-an. hour's duration cannot fail to impress the practical brewer with the sense of having found a trustworthy suide and practical counsellor in brewery matters."-Chemical Trade Fournal.

\section{Analysis and Valuation of Fuels.}

FUELS: SOLID, LIQUID, AND GASEOUS: Their Analysis and

Valuation. For the Use of Chemists and Engineers. By H. J. PHILLIPS, F.C.S.,

Formerly Analytical and Consulting Chemist to the Great Eastern Railway.

Second Edition, Revised and Enlarged. Crown 8 vo, 5 s. cloth.

"Ought to have its place in the laboratory of every metallurgical establishment, and wherever fuel is used on a large scale."-Chemical News.

"Cannot fail to be of wide interest, especially at the present time."-Railway News.

\section{Pigments.}

THE ARTISTS' MANUAL OF PIgMENTS. Showing their Composition, Conditions of Permanency, Non-Permanency, and Adulterations; Effects in Combination with Each Other and with Vehicles; and the most Reliable Tests of Purity. Together with the Science and Arts Department's Examination Questions on Painting. By H. C. Standage. Second Edition, crown $8 v o, 2 s .6 d$. cloth.

"This work is indeed multum-in-parvo, and we can, with good conscience, recommend it to all who come in contact with pigments, whether as makers, dealers, or users." - Chemical Review,

\section{Gauging. Tables and Rules for Revenue Officers, Brewers, \&c.}

A POCKET BOOK OF MENSURATION AND GAUGING : Containing

Tables, Rules, and Memoranda for Revenue Officers, Brewers, Spirit Merchants, \&c.

By J. B. MANT (Iniand Revenue). Second Edition, Revised. 18mo, 4s. leather.

"This handy and useful book is adapted to the requirements of the Inland Revenue Department. and will b? a favourite book of reference. The range of subjects is comprehensive. and the arrangement simple and clear."-Civilian. "Should be in the hands of every practical brewer."-Brewers' fournal.

\section{INDUSTRIAL ARTS, TRADES AND MANUFACTURES.}

\section{Cotton Spinning.}

COTTON MANUFACTURE: A Manual of Practical Instruction in the Processes of Opening, Carding, Combing, Drawing, Doubling and Spinning of Cotton, and the Methods of Dyeing and Preparing Goods for the Market. For the Use of Operatives, Overlookers and Manufacturers. By JOHN LISTER, Technical Instructor, Pendleton. With numerous Illustrations. 8vo, $7 s, 6 d$. cloth.

\section{Flour Manufacture, Milling, etc.}

['fust published.

Flour MANufacture: A Treatise on Milling Science and Prac-

tice. By FRIEDRICH KICK, Imperial Regierungsrath, Professor of Mechanical Technology in the Imperial German Polytechnic Institute. Prague. Translated from the Second Enlarged and Revised Edition with Supplement. By H. H. P. Powl.ES, Assoc. Memb. Institution of Civil Engineers. Nearly 400 pp. Illustrated with 28 Folding Plates, and 167 Woodcuts. Roy. $8 \mathrm{vo}, 25$ s. cloth.

"This valuable work is, and will remain, the standard authority on the science of milling. . . : The miller who has read and digested this work will have laid the foundation, so to speak, of a successful career; he will have acquired a number of general principles which he can proceed to apply. In this handsome volume we at last have the accepted text-book of modern milling in good, sound English, which has little, if any, tuace of the German idiom."-The Miller.

"The appearance of this celebrated work in English is very opportune, and British millers will, we are sure, not be slow in availing themselves of its pages." -Millers' Gazette. 
Agglutinants.

CEMENTS, PASTES, GLues AND Gums: A Practical Guide to the

Manufacture and Application of the various Agglutinants required in the Building,

Metal-Working, Wood-Working, and Leather-Working Trades, and for Workshop,

Laboratory or Office Use. With upwards of 900 Recipes and Formulæ. By H. C.

STANDAge, Chemist. Crown 8 vo, $2 s .6 d$. cloth.

[7ust published.

"We have pleasure in speaking favourably of this volume. So far as we have had experience, which is not inconsiderable, this manual is trustworihy." - Athenoxum.

"As a revelation of what are considered trade secrets, this book will arouse an amount of curiosity among the large number of industries it touches." - Daily Chronicle.

found."-Oil and Colourmaion of recipes it would be strange if a cement for any purpose cannot be Soap-making.

THE ART OF SOAP-MAKING: A Practical Handbook of the

Manufacture of Hard and Soft Soaps, Toilet Soaps, \&c. Including many New

Processes, and a Chapter on the Recovery of Glycerine from Waste Leys. By

Alexander Watt. Fourth Edition, Enlarged. Crown 8vo, 7s. 6d. cloth.

boiler who wishes to understand the theorv merely to the technological student, but to the practical soap. " A thoroughly practical treatise on an art which has almical Nezes.

gratu'ate the aughly practical treatise on an art which has almnst uo literature in onr Janguage. We conPaper Making.

PRACTICAL PAPER-MAKING: A Manual for Paper-makers and

Owners and Managers of Paper-Mills. With Tables, Calculations, \&c. By G.

Clapperton, Paper-maker. With Illustrations of Fibres from Micro-photographs.

Crown 8 vo, 5 s. cloth.

[fust published.

"The author caters for the requ'rements of responsible mill hands, apprentices, \&c., whilst his manual will be found of great service to students of technology, as well as to veteran paper-makers and mill owners. The illustraxions form an excellent f fature."-The World's Paber Trade Review. book."-Paper Making. Paper Making.

THE ART OF PAPER MAKING: A Practical Handbook of the

Manufacture of Paper from Rags, Esparto. Straw, and other Fibrous Materials.

Including the Manufacture of Pulp from Wood Fibre, with a Description of the Machinery and Appliances used. To which are added Details of Processes for Recovering Soda from Waste Liquors. By ALEXANDER WATT, Author of "The Art of Soap-Making." With Illustrations. Crown $8 \mathrm{vo}, 7 \mathrm{~s} .6 \mathrm{~d}$. cloth.

"It may be regarded as the standard work on the subject. The book is full of valuable informa. tion. The 'Art of Paper-making,' is in every respect a model of a text-book, either for a technical class, or for the private student."-P.sper and Printing Trades fournal.

\section{Leather Manufacture.}

THE ART OF LEATHER MANufacture: Being a Practical

Handbook, in which the Operations of Tanning, Currying, and Leather Dressing are fully Described, and the Principles of Tanning Explained, and many Recent Processes Introduced; as also Methods for the Estimation of Tannin, and a

Description of the Arts of Glue Boiling, Gut Dressing, \&c. By Alexander

WATT, Author of "Soap-Making," \&c. Second Edition. Crown Svo, 95. cloth. "A sound, comprehensive treatise on tanning and its accessories. The book is an eminently valuable
production, which redounds to the credit of both author and publishers."-Chemical Review.

\section{Boot and Shoe Making.}

THE ART OF BOOT AND SHOE-MAKING: A Practical Hanc?. book, including Measurement, Last-Fitting, Cutting-Out, Closing and Making, with a Description of the most approved Machinery Employed. By JoHN B."

LENo, late Editor of St. Crispin, and The Boot and Shor-Maker. 12mo, 2s. cloth.

"This excellent treatise is by far the best work ever written. The chapter on clicking, which shows how waste may be prevented, will save fifty times the price of the book."-Scottish Leather.Trader.

\section{Dentistry Construction.}

MECHANICAL DENTISTRY: A Practical Treatise on the Construction of the various kinds of Artificial Dentures. Comprising also Useful Formulæ, Tables, and Receipts for Gold Plate, Clasps, Solders, \&c. \&c. By C. HunTer.

Third Edition. With roo Wood Engravings. Crown 8vo, 3s. 6d. cloth.

"We can strongly recommend Mr. Hut.'er's treatise to all students preparing for the profession of dentistry, as well as to every mechanical dentist."-Dublin Yournal of Medical Science. 


\section{Wood Engraving.}

WOOD ENGRAVING: A Practical and Easy Introduction to the Study of the Art. By William Norman Brown. Second Edition. With numerous Tllustrations. $12 \mathrm{mo}, \mathrm{I} s .6 d$. cloth limp.

"The book is clear and complete, and will be useful to anyc.ue wanting to understand the first elevients of the beautitul art of wood engraving."-Graphic.

Horology.

A TREATISE ON MOdern HOROlOGY, in Theory and Practice. Translated froin the French of CLAUDIUS SAUNiER, ex-Director of the School of Horology at Macon, by Julien TripPLin, F.R.A.S., Besancon Watch Manufacturer, and EDWARD RIGG, M.A., Assayer in the Royal Mint. With Seventy. eight Woodcuts and Twenty-two Coloured Copper Plates. Second Edition. Super-royal 8 vo, $£_{2} 2 s$. cloth; $£_{2}$ Ios. half-calf.

"There is no horological work in the English language at all to be compared to this production of M. Saunier's for clearness and completeness. It is alike good as a guide for the student and as a reference for the experienced horologist and skilled workman." - Horological fournal.

"The iatest, the most complete, and the most reliable of those literary productions to which continental watchmaker are indebted for the me hanical superiority over their Euglish brethrea-in fact, the Book of Books, is M. Saunier's 'Treause.' "-Watchmaker, feweller, and Silversmith.

\section{Watchmaking.}

THE WATCHMAKER'S HANDBOOK. Intended as a Workshop

Companion for those engaged in Watchmaking and the Allied Mechanical Arts.

Translated from the French of CLAUDIUS SAUNiER, and considerably enlarged by

JULIEN TRIPPLIN, F.R.A.S., Vice-President of the Horological Institute, and

EDWARD Rigg, M.A.. Assayer in the Royal Mint. With numerous Woodcuts and Fourteen Copper Plates. Third Edition. Crown 8vo, 9s. cloth.

"Each part is truly a treatise in itself. The arrangement is good and the language is clear and concise. It is an admirable gude for the young watchmaker."- Enginecring.

- It is impossible to speak too highly of its excellence. It fulfils every requirement in a handbook intended for the use of a workman. Should be found in every workshop." - Watch and Clockmaker.

"This book contains an immense number of practical details bearing on the dauly occupation of a watchmaker."-Watchmaker and Metalworker (Chicago).

\section{Watches and Timekeepers.}

A HISTORY OF WATCHES AND OTHER TIMEKEEPERS. By

JAMES F. KENDAL, M.B.H. Inst., Is. $6 d$. boards; or $2 s .6 d$. cloth, gilt.

Mr. Kendal's book, for its size, is the best which has yet appeared on this subject in the English language."-Industries.

Open the book where you may, there is interesting matter in it concerning the ingenious devices of the ancient or modern horologer. The subject is treated in a liberal and entertaining spirit, as might be expected of a historian who is a master of the craft."-Saturday Revietw.

\section{Electroiysis of Gold, Silver, Copper, \&c.}

ELECTRO-DEPOSITION : A Practical Treatise on the Electrolysis of Gold, Silver, Copper, Nickel, and other Metals and Alloys. With descriptions of

Voltaic Batteries, Magneto and Dynamo-Electric Machines, Thermopiles, and of

the Materials and Processes used in every Department of the Art, and several

Chapters on Electro-Metallurgy. By Alexander Watt, Author of

"Electı-Metallurgy," \&c. Third Edition, Revised. Crown 8vo, 9s., cloth.

"Eminently a book for the practical worker in electro-deposition. It contains practical descriptions of methods, processes and materials, as actually pursued and used in the workshop."-Engincer.

\section{Electro-Metallurgy.}

Electro-Metallurgy: Practically Treated. By Alexander

WATT, Author of "Electro-Deposition," \&c. Ninth Edition, including the most recent Processes. 12mo, 4 s, cloth boards.

"Fr secution of electroplating." -1ron.

\section{Working in Gold.}

THE JEWELLER'S ASSISTANT IN THE ART OF WORKING IN

GOLD: A Practical Treatise for Masters and Workmen, Compiled from the

Experience of Thirty Years' Workshop Practice. By George E. GEE, Author of

"The Goldsmith's Handbook," \&c. Crown 8vo, 7s. 6d. cloth.

"This manual of technical education is apparently destined to be a valuable auxiliary to a handicraft which is certainly capable of great improvement."-The Times.

"Very useful in the workshop, the knowiedge is practical, having been accuired by long experience. and all the recipes and directions are guaranteed to be successful." - Yeweller and Aetalworker. 


\section{Electroplating.}

ELECTROPLATING: A Practical Handbook on the Deposition of Copper, Silver, Nickel, Gold, Aluminium, Brass, Platinum, \&c. \&c. ; with Descriptions of the Chemicals, Materials, Batteries, and Dynamo Machines used in the Art. By J. W. Urquhart, C.E., Author of "Electric Light," \&c. Third Edition, Revised, with Additions, Numerous Illustrations. Crown 8vo, 5 s. cloth.

"An excellent practical manual."-Engineering.

"An excellent work, giving the newest information."-Horological fournal.

\section{Electrotyping.}

ELECTROTYPING : The Reproduction and Multiplication of Printing

Surfaces and Works of Art by the Electro-deposition of Metals. By J. W.

URQUHART, C.E. Crown 8 vo, 5 s. cloth.

"The book is thoroughly practical ; the reader is, therefore, conducted through the leading laws of electricity, then through the metals used by electrotypers, the apparatus, and the depositing processes, up to the final preparation of the work,"-Art fournal.

\section{Goldsmiths' Work.}

THE Goldsmith'S HANDBOOK. By George E. Gee, Jeweller,

\&c. Third Edition, considerably Enlarged. 12mo, $3 s .6 d$. cloth boards.

"A good, sound educator, and will be generally accepted as an authority."-Horological Yournal.

\section{Silversmiths' Work,}

THE Silversmith'S HANDBOOK. By George E. Gee, Jeweller,

\&c. Second Edition, Revised, with numerous Illusts. I2mo, 3s. $6 d$. cloth boards.

"The chief merit of the work is its practical character. The workers in th: trade will speedily discover its merits when they sit down to study it."-English Mechanic. * * The above two works together, slrongly half-bound, price 7 s.

\section{Bread and Biscuit Baking.}

THE BREAD AND BISCUIT BAKER'S AND SUGAR-BOILER'S

ASSISTANT. Including a large variety of Modern Recipes. With Remarks on the Art of Bread-making. By RoBert Wells, Practical Baker. Second Edition, with Additional Recipes. Crown 8vo, 2s. cloth.

"A large number of wrinkles for the ordinary cook, as well as the baker."-Saturday Review.

\section{Confectionery for Hotels and Restaurants.}

THE PASTRYCOOK AND CONFECTIONER'S GUIDE. For

Hotels, Restaurants, and the Trade in general, adapted also for Family Use.

By ROBERT WBLLS, Author of "The Bread and Biscuit Baker's and Sugar Boiler's

Assistant." Crown 8vo, 2s. cloth.

"We cannot speak too highly of this really excellent work. In these days of keen competition our readers caznot do better than purchase this book."-Baker's Times.

\section{Ornamental Confectionery.}

ORNAMENTAL CONFECTIONERY: A Guide for Bakers, Confectioners and Pastrycooks; including a Variety of Modern Recipes, and Remarks on Decorative and Coloured Work. With I29 Original Designs. By ROBERT Wells, Practical Baker, Author of "The Bread and Biscuit Baker's and Sugar-Boiler's Assistant," \&c. Crown 8vo, cloth gilt, $5^{s}$.

A valuable work, practical, and should be in the hands of every baker and confectioner. The Ilustrative designs are alone worth treble the amount charged for the whole work." -Baker's Times.

\section{Flour Confectionery.}

THE MOdERN Flour CONFECTIONER, Wholesale and Retail. Containing a large Collection of Recipes for Cbeap Cakes, Biscuits, \&c. With

Remarks on the Ingredients Used in their Manufacture. To which are added Recipes for Dainties for the Working Man's Table. By Robert Wells, Author of "The Bread and Biscuit Baker," \&c. Crown 8vo, 2s. cloth.

"The work is of a decidedly practical character, and ia every recipe regard is had to economical working."-North British Daily Mail.

\section{Laundry Work.}

LAUNDRY MANAGEMENT. A Handbook for Use in Private and

Public Laundries. Including Descriptive Accounts of Modern Machinery and Appliances for Laundry Work. By the EDITOR of "The Laundry Journal." With numerous Illustrations. Second Edition. Crown 8vo, 2s. 6d. cloth.

"This book should certainly occupy an honoured place on the shelves of all housekeepers who wish to keep themselves au courant of the newest appliances and methods." $-T h e$ Queen. 


\section{HANDYBOOKS FOR HANDICRAFTS.}

\section{Editor of "Work' BY PAUL N. HASLUCK.}

'(New Series), Author of "Lathe Work," " Milling Machines," \&c.

Crown $8 \mathrm{vo}$, 144 pages, cloth, price 1s. each.

These HANDYBOOKs have been zuritten to supply information for WORKMEN STUDENTs, and AMATEURS in the several Handicrafts, on the actual PRACTICE of the We the several CRAFTS. In describing the processes employed, and the manipulation of material, workshop terms are used; workshop practice is fully explained; and the text is freely illustrated with drawings of modern tools, afpliances, and processes.

THE METAL TURNER'S HANDYBOOK. A Practical Manual for

Workers at the Foot-Lathe. With over 100 Illustrations. Price Is.

"The book will be of service alike to the amateur and the artisan turner. It displays thorough
knowledge of the subject."-Scotsman.

\section{THE WOOD TURNER'S HANDYBOOK. A Practical Manual for}

Workers at the Lathe. With over Ioo Illustrations. Price Is.

sought in vain for a manual of this special industry."-Mechanical Worltude of workmen have hitherto

THE WATCH JOBBER'S HANDYBOOK. A Practical Manual on

Cleaning, Repairing, and Adjusting. With upwards of roo Illustrations. Price $1 s$. inexpensive work."-Clerkenwell Chronicle.

THE PA

the ConstruR MAKER'S HANDYBOOK. A Practical Manual on

A most valnaction of Patterns for Founders. With upwards of Ioo Illustrations. Is.

THE

TE MECHANIC'S WORKSHOP HANDYBOOK. A Practical Manual on Mechanical Manipulation, embracing Information on various Handicraft Processes. With Useful Notes and Miscellaneous Memoranda. Comprising about 200 Subjects. Price Is. "A very clever and useful book, which should be found in every workshop; and it should cer-
tainly find a place in all technical schools."-Saturday Review.

THE MODEL ENGINEER'S HANDYBOOK. A Practical Manual on the Construction of Model Steam Engines. With upwards of 100 Illustrations. Is. "Mr. Hasluck has produced a very good little book."-Builder.

THE CLOCK JOBBER'S HANDYBOOK. A Practical Manual on Cleaning, Repairing, and Adjusting. With upwards of roo Illustrations. Price Is. It is of nestimable service to those commencing the trade."-Coventry Standard.

THE CABINET WORKER'S HANDYBOOK. A Practical Manual on the Tools, Materials, Appliances, and Processes employed in Cabinet Work. With upwards of 100 Illustrations. Price Is.

"Mr. Hasluck's thoroughgoing little Handybook is amongst the most practical guides we have seen for beginners in cabinet-work."-Saturday Revicw.

THE WOODWORKER'S HANDYBOOK OF MANUAL INSTRUCTION. Embracing Information on the Tools, Materials, Appliances and Processes Employed in Woodworking. With IO4 Illustrations. Price Is.
[Fust published. THE METALWORKER'S HANDYBOOK. With upwards of roo Illus-
trations.

In preparation.

\section{Opinions of the PRESS.}

"Written by a man who knows, not only how work ought to be done, but how to do it, and how to convey his knowledge to others."-Engineering.

"Mr. Hasluck writes admirably, and gives complete instructions."-Engineer.

"Mr. Hasluck combines the experience of a practical teacher with the manipulative skill and scientific knowledge of processes of the trained mechanician, and the manuals are marvels of what can be produced at a popular price."-Schoolmaster.

". Helpful to workmen of all ages and degrees of experience."-Daily Chronicle.

Practical, sensible, and remarkably cheap."-fourna! of Education.

"Concise, clear, and practical."-Saturday Review. 


\section{COMMERCE, COUNTING-HOUSE WORK, TABLES, etc.}

\section{Commercial Education.}

LESSONS IN COMMERCE. By Professor R. Gambaro, of the

Koyal High Commercial School at Genoa. Edited and Revised by JAM ES GAULT,

Professor of Commerce and Commercial Law in King's College, London. Crown

8 vo, 3s. 6d. cloth.

"The publishers of this work have rendered considerable service to the cause of commercial education by the opportune production of this volume. . The work'is peculiarly acceptable to English readers and an admirable addition to existing class books. In a phrase, we think the work attains its object in furnishing a brief account of those laws and customs of British trade with which the commercial man interested therein should be familiar."-Chamber of Commerce fournal.

"An invaluable guide in the hands of those who are preparing for a commercial career, and, in fact the information it contains on matters of business should be impressed on every one."-Counting Howse.

\section{Foreign Commercial Correspondence.}

THE FOREIGN COMMERCIAL CORRESPONDENT: Being Aids

to Commercial Correspondence in Five Languages-English, French, German,

Italian, and Spanish. By Conrad E. BAKER. Second Edition. Cr. 8vo, $3 s .6 d$. cl.

"Whoever wishes to correspond in all the languages mentioned by Mr. Baker cannot do better than study this work, the materials of which are excellent and conveniently arranged. They consist not of entire specimen letters, but-what are far more useful-short passages, sentences, or phrases expressing the same general idea in various forms."-Athenaum.

"A careful examination has convinced us that it is unusually complete, well arranged and reliable. The book is a thoroughly good one."-Schoolmaster.

\section{Accounts for Manufacturers.}

FACTORY ACCOUNTS: Their Principles and Practice. A Handbook for Accountants and Manufacturers, with Appendices on the Nomenclature of Machine Details ; the Income Tax Acts ; the Rating of Factories ; Fire and Boiler Insurance; the Factory and Workshop Acts, \&c., including also a Glossary of Terms and a large number of Specimen Rulings. By EMILE GARCKe and J. M. Fells. Fourth Edition, Revised and Enlarged. Demy 8 vo, 250 pages. $6 s$. strongly bound.

"A very interesting description of the requirements of Factory Accounts. . The principle of assimilating the Factory Accounts to the general commercial books is one which we thoroughly agree with."-Accountants' Yournal.

"Characterised by extreme thoroughness. There are few owners of factories who would not derive great benefit from the perusal of this most admirable work."-Local Government Chronicle.

\section{Intuitive Calculations.}

THE COMPENDIOUS CALCULATOR; or, Easy and Concise Methods

of Performing the various Arithmetical Operations required in Commercial and Business Transactions, together with Useful Tables. By DaniEL O'GoRMan.

Corrected and extended by Prof. J. R. Young. Twenty-seventh Edition, Revised by

C. NOR RIS. Fcap. 8vo, $2 s .6 d$. cloth limp; or, $3 s .6 d$. strongly half-bound in leather.

"It would be difficult to exaggerate the usefulness of a book like this to everyone engaged in commerce or manufacturing industry. It is crammed full of rules and formulæ for shortening and employing calculations." - Knowledse.

\section{Modern Metrical Units and Systems.}

MODERN METROLOGY: A Manual of the Metrical Units and

Systems of the present Century. With an Appendix containing a proposed English System. By Lowis D"A. JACKson, A.-M. Inst. C.E., Author of "Aid to Survey Practice," \&c. Large crown 8vo, i2s. 6d. cloth.

"We recommend the work to all interested in the practical reform of our weights and measures."

\section{The Metric System and the British Standards.}

A SERIES OF METRIC TABLES, in which the British Standard

Measures and Weights are compared with those of the Metric System at present in

Use on the Continent. By C. H. Dowl.ing, C. E. 8vo, ros. 6 d. strongly bound.

"Mr. Dowling's Tables are well put together as a ready reckoner for, the conversion of one system into the other,"-Athenaum.

\section{Iron and Metal Trades' Calculator.}

THE IRON AND METAL TRADES' COMPANION: For expeditiously ascertaining the Value of any Goods bought or sold by Weight, from Is. per cwt. to I1 $2 s$. per cwt., and from one farthing per pound to one shilling per pound. By Thомas DownIE. Strongly bound in leather, $=96 \mathrm{pp}$., $9 s$.

"A most useful set of tables, nothing like them before existed."-Building News.

"Although specially adapted to the iron and metal trades, the tanles will be found useful in every cther business in which merchandise is bought and sold by weight."-Railway. News. 


\section{Chadwick's Calculator for Numbers and Weights Combined.}

THE NUMBER, WEIGHT, AND FRACTIONAL CALCULATOR. Containing upwards of 250,000 Separate Calculations, showing at a glance the value at 422 different rates, ranging from $\frac{1}{2} \frac{1}{8}$ th of a Penny to 20 s. each, or per cwt., and 620 per ton, of any number of articles consecutively, from 1 to 470 .-Any number of cwts., qrs., and lbs., from I cwt. to 470 cwts.-Any number of tons, cwts., qrs., and lbs., from $\mathrm{I}$ to $\mathrm{r}, 000$ tons. By William CHadwick, Public Accountant. Third Edition, Revised and Improved. 8vo, price 18s. strongly bound for Office wear and tear.

$\sum$ Is adapted for the use of Accountants and Auditors, Railway Companies, Canal Companies, Shippers, Shipping Agents, General Carriers, Sc. Ironfounders, Brassfounders, Metal Merchants, Iron Manufacturers. Ironmongers, Engineers, Machinists, Boiler Makers, Millwrights, Roofing, Bridgc and Girder Makers, Colliery Proprietors, Sic. Timber Merchants, Builders, Contractors, Architects, Surveyors, Auctioneers, Valuers, Brokers, Mill Owners and Manufacturers, Mill Furnishers, Merchants, and General Wholesale Tradesmen. Also for the Apportionment of Mileage Charges for Railway Traffic.

*** Opinions of thr. Press.

"It is as easy of reference for any answer or any number of answers as a dictionary, and the references are even more quickly made. For making up accounts or estimates the book must prove invaluable to all who have any considerable quantity of calculations involving price and measure in any combination to do."-Engineer.

"The most conplete and practical ready reckoner which it has been our fortune yet to see. It is difficult to imagine a trade or occupation in which it could not be of the greatest use, either in saving human labour or in checking work. The publishers have placed within the reach of every commercial man an invaluable and unfailing assistant."-The Miller.

"The most perfect work of the kind yet prepared."-Glasgow Herald.

\section{Harben's Comprehensive Weight Calculator.}

THE WEIGHT CALCULATOR: Being a Series of Tables upon a

New and Comprehensive Plan, exhibiting at one Reference the exact Value of any

Weight from $\mathrm{I}$ lb. to $\mathrm{I} 5$ tons, at 300 Progressive Rates, from $\mathbf{I} d$. to $168 \mathrm{~s}$. per cwt., and containing 186,000 Direct Answers, which, with their Combinations, consisting of a single addition (mostly to be performed at sight), will afford an aggregate of 10,266,000 Answers; the whole being calculated and designed to ensure correctness and promote despatch. By Henry Harben, Accountant. Fourth Edition, carefully corrected. Royal 8vo, strongly half-bound, $£ \mathrm{I} 5 s$.

"A practical and useful work of reference for men of business generally ; it is the best of the kind we have seen."-Ironmonger.

"Of priceless value to business men. It is a necessary book in all mercantile offices."--Sheffield Independent.

\section{Harben's Comprehensive Discount Guide.}

THE DISCOUNT GUIDE. Comprising several Series of Tables for the use of Merchants, Manufacturers, Ironmongers, and others, by which may be ascertained the exact Profit arising from any mode of using Discounts, either in the Purchase or Sale of Goods, and the method of either Altering a Rate of Discount, or Advancing a Price, so as to produce, by one operation, a sum that will realise any required profit after allowing one or more Discounts: to which are added Tables oi Profit or Advance from $\mathbf{I}_{4} \frac{1}{4}$ to 90 per cent., Tables of Discount from $\mathbf{I}_{4} \frac{1}{4}$ to $98 \frac{3}{4}$ per cent., and Tables of Commission, \&c., from $\frac{1}{5}$ to 10 per cent. By HENRY HAKBEN, Accountant, Author of "The Weight Calculator," New Edition, carefully Revised and Corrected. Demy 8 vo, 544 pp., $£$ I $5^{s}$. half-bound.

"A book such as this can only be appreciated by business men, to whom the saving of time means saving of money. We have the high authority of Professor J. K. Young that the tables throughout the work are constructed upon strictly accurate principles. The work is a model of typographical clearness, and must prove of great value to merchants, manufacturers, and general traders." - British Traie Fournal.

\section{Iron Shipbuilders' and Merchants' Weight Tables.}

IRON-PLATE WEIGHT TABLES: For Iron Shipbuilders, Engineers, and Iron Merchants. Containing the Calculated Weights of upwards of 150,000 different sizes of Iron Plates from 1 foot by 6 in. by $\frac{1}{4}$ in. to ro feet by 5 feet by $\mathbf{I}$ in. Worked out on the basis of $40 \mathrm{lbs}$. to the square foot of Iron of $\mathbf{I}$ inch in thickness. Carefully compiled, and thoroughly Revised by H. BurLinsON and W. H. Simpson. Oblong 4to, $25^{s}$. half-bound.

"This work will be found of great utility. The authors have had much practical experience ot what is wanting in making estumates, and the use of the book will save much time in making elaborate calculations."-English Mechanic. 


\section{AGRICULTURE, FARIMING, GARDENING, etc.}

\section{Dr. Fream's New. Edition of "The Standard Treatise on Agriculture." Fream's New Edition COMPLETE GRAZIER AND FARMER'S AND CATTLE
THE CREDER'S ASSISTANT: A Compendium of Husbandry. Originally Written by
BREE William YouATT. Thirteenth Edition, entirely Re-written, considerably En- larged, and brought up to the Present Requirements of Agricultural Practice, by WiLLIAM FreAM, LL.D., Steven Lecturer in the University of Edinburgh, Author of "The Elements of Agriculture," \&c. 'Royal 8vo, I, roo pp., with over $45^{\circ}$ IIlustrations. Price $f$ I Is. $6 d$. strongly and handsomely bound.}

\section{EXtract From PUBLishers' Advertisement.}

"A treatise that made its original appearance in the first decade of the century, and that enters apon its Thirteenth edition before the century has run its course, has undoubtedy established its The phenomenal progress of the last dozen years 作 (t) be re-written and for this undertaking the Publishers were fortunate enough to have been services of Dr. FREAM, whose bigh attainments in all matters pertaining to agriculture have been so emphatically recognised by the highest professional and official authorities. In carrying out ho editorial duties, Dr. FreAm bas been favoured with valuable contributions, H. Rew, Prof. SHELDON, Mr. AXE, Mr. E. Brown, Dr. Bernard Dyer, Mr. W.

J. SINCLAIR, Mr. SANDERS SPENCER, and others.

"As regards the illustrations of the work, no pains have been spared to make them Grazier." sentative and characteristic as possible, so as to be practically useful to the Farmer and

\section{SUMMARY OF CONTENTS.}

Book I. On the Varieties, Bregding, RearING, FATTENING AND MANAGEMKNT OF CATTLE. Bookil. ON The Economy and Management OF THE DATRY.

Book III. ON THE BreEding, Rearing, and MANAGEMENT OF HORSES.

BoOK IV. ON THE BrEEDING, REARING, AND FATteniNg OF SHEEP.

BOoK V. ON THE BREeding, ReArING, AND FATTENING OP SWINE. Fook VI, ON THE Diseases of Lrve Stock.

Book VII. ON the Breeding, Rearing, AND Management of Poultey.

BOOK VIII, ON PAPM OFFICES AND IMPLEMENTS OF HUSBANDRY.

Book IX. ON the Culture and ManageMENT OF Grass Lands.

Book $X$ On the Cultivation and ApplicaBOOK X. ON THE CULSE AND ROOTS.

TION OF GRASSE, PULSES AND THEIR APPLIBOOK XI. ON MANURES AND CROPS.

CATION TO GRASS LAND AND CROPS.

\section{* Opinions of the Press on the New Edition.}

* "Dr. Fream is to be congratulated on the successful attempt he has madry. We believe that which will at once become the standard classic of the farm practice of the country. We. . The it will be found that it has no compeer among the many works at present well-known bull, New Year's illustrafions are admirable, while the frontispiece, which

Gift, bred by the Queen, is a work of art."-The Times. "The book must be recognised as occupying the proud position of the most exha

reference in the English language on the subject with which it deals."-Athenaum,

"The most comprehensive guide to modern farm practice that exists in the English language to-day.

The book is one that ought to be on every farm and in the library of every land vaner,"-Mark Lane Express.

"In point of exbaustiveness and accuracy the work will certainly hold a pre-eminent and unique position among books dealing with scientitic

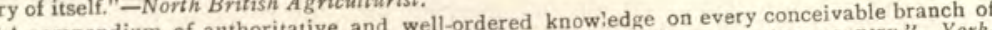
"A compendive stock farmer; probably without an equal in this or any otner country."-Yorkthe work of

shire Post.

"The best and brightest guide to the practice of husbandry : one that has no superior- In every section we might truly say-among the agriculrural literature now before the public. "Dell's Weekly Messenger.

\section{British Farm Live Stock.}

FARM LIVE STOCK OF GREAT BRITAIN. By RoBert Wallace, F.L.S., F.R.S.E., \&c.; Professor of Agriculture and Rural Economy in the University of Edinburgh. Third Edition, thoroughly Revised and considerably Enlarged. With over 120 Phototypes of Prize Stock. Demy 8vo, 384 pp., with 79 Plates and Maps. Price 12s. 6d., cloth.

Plack of Great "A really complots lo fikely to way to the suelves of every country gentleman's Britain, and one whicl

"The latest edition of "Farm Live Stock of Great Britain' is a production to be proud of, and which its author has rendered to agricultural science."-

"The book is very attractive, . . and we can scarcely imagine the existence of
"The would not like to have a copy of this beautiful and useful work."-Mark Lame Express a concise history and "A work which will long be regarded as a standard authority whe we 


\section{Dairy Farming.}

BRITISH DAIRYING : A Handy Volume on the Work of the DairyFarm. For the Use of Technical Instruction Classes, Students in Agricultural Commissioner of the Cana Dairy-Farmer. By Prof. J. P. SHELDON, late Special Farm and the Dairy," \&c. Wian Government, Author of "Dairy Farming," "The "May be confidently recommended as a useful hlustrations. Crown 8vo, 2s. $6 d$. cloth. atte.
. British Agriculturist.

"It is the soundest little work we have yet seen on the subject."-The Times.

Dairy Manual.

MILK, CHEESE AND BUTTER: A Practical Handbook on

their Properties and the Processes of their Production. Including a Chapter on Principal of the Western Dairy Institute from Milk. By JOHN OLIVER, late 200 Illustrations, Crown Dairy Institute. Berkeley. With Coloured Plates and
Agricultural Facts and Figures.
[Gust published.

\section{NOTE-BOOK OF AGRICULTURAL FACTS AND FIGURES FOR

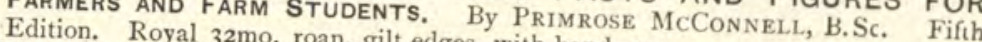
"Literally teems with $32 \mathrm{mo}$, roan, gilt edges, with band, $4 s$.

agriculture."-North British Agriculturist. Small Farming.

SYSTEMATIC SMALL FARMING; or, The Lessons of my Farm.

Being an Introduction to Modern Farm Practice for Small Farmers. By ROBERT

Illustrations, crown 8vo, 6s. cutlines of Modern Farming," \&c. With numerous

cloth

read with pleasure, and accert as a guide."-Field.

\section{Modern Farming.}

OUtLines OF MOdern Farming. By R. SCOTt Burn. Soils,

Management of Dairy, Pigs, and Farming Economy-Cattle, Sheep, and Horses-

\&c. Sixth Edition. In one vol, I, 250 - Utilization of Town-Sewage, Irrigation,

"The aim of the author has been to make his work., half.bound, profusely Illustrated, $12 s$. this aim he has succeeded to a degree which his work at once comprehensive and trustworthy, and in

\section{Agricultural Engineering.}

FARM ENGINEERING, THE COMPLETE TEXT-BOOK OF. Com.

prising Draining and Embanking; Irrigation and Water Supply; Farm Roads, ments and Machines; Agricultural Surveying, one vol., I, I 50 pages, half-bound, with

"Written with great care, half-bound, with over 600 Illustrations, $12 s$

well; we have found him a very trustworthy guide whereve and ability. The author has done his work will be of great value to agricultural students,"-Mark

\section{Agricultural Text-Book.}

THE FIELDS OF GREAT BRITAIN : A Text-Book of Agriculture.

Advanced Students. By HuGH Corence and Art Department. For Elementary and

Revised, with Additions. I $8 \mathrm{mo}, 2 s, 6 d$,

"A most comprehendrons. $18 \mathrm{mo}, 2 s .6 d$. cloth.

"It is a long time since we have giving a mass of information."-A gricultural Economist.

vast and useful fund of knowledge." - Educational Times. pleased us more, or which contains such a Tables for Farmers, \&c.

TABLES, MEMORANDA, AND CALCULATED RESULTS for Farmers,

New System of Farmal Students, Surveyors, Land Agents, Auctioneers, \&c. With a

Third Edition, Revised.

"Weighing less than I oz, and 272 pp., waistcoat-pocket size, limp leather, Is. $6 d$.

facts and calculations which has never before, in such hace than a match box, it contains a mass of tion on the farm is dealt with. The work may be taken as form, been obtainable. Every opera. tables having been revised by Dr. Fream. We taken as thoroughly accurate, the whole of the 
The Management of Bees.

BEES FOR PLEASURE AND PROFIT: A Guide to the Manipulation of Bees, the Production of Honey, and the General Management of the Apiary. By G. Gordon SAMSON. With numerous Illustrations. Crown 8vo, is, cloth. "The intending bee-keeper will find exactly the kind of information required to enable him to make a successful start with his hives. The author is a thoroughly coinpetent teacher, and his book may be commended." - Morning Post.

\section{Farm and Estate Book-keeping.}

BOOK-KEEPING FOR FARMERS AND ESTATE OWNERS. A

Practical Treatise, presenting, in Three Plans, a System adapted for all Classes of Farms. By Johnson M. Woodman, Chartered Accountant. Second Edition,

Revised. Crown $8 \mathrm{vo}, 3 s .6 d$. cloth boards; ; or, $2 s .6 d$. cloth limp.

"The volume is a capital study of a most important subject."-Agricultural Gazetite.

"The young farmer, land agent, and surveyor will find Mr. Woodman's treatise more than repay its cost and study." - Building News.

\section{Farm Account Book.}

WOODMAN'S YEARLY FARM ACCOUNT BOOK. Giving a Weekly

Labour Account and Diary, and showing the Income and Expenditure under each Department of Crops, Live Stock, Dairy, \&c. \&c. With Valuation, Profit and Loss Account, and Balance Sheet at the end of the Year. By JoHNSON M. WoodMAN, Chartered Accountant, Author of "Bookkeeping for Farmers." Folio, 7s. $6 d$. half-bound.

"Contains every requisite form for keeping farm accounts readily and accurately." - Agriculture.

Early Fruits, Flowers and Vegetables.

THE FORCING-GARDEN ; or, How to Grow Early Fruits, Flowers, and Vegetables. With Plans and Estimates for Building Glasshouses, Pits and Frames. With Illustrations. By SAMUEL Wood. Crown 8vo, $3 s$. $6 d$. cloth.

"A good book, and fairly fills a place that was in some degree vacant. The book is written with great care, and contains a great deal of valuable teaching."-Gardeners' Magazine.

\section{Good Gardening.}

A Plain Guide to GOOD GaRdening; or, How to Grow Vegetables, Fruits, and Flowers. By S. WoOD. Fourth Edition, with considerable Additions, \&c., and numerous Illustrations. Crown 8vo, $3 s .6 d$. cloth.

"A very good book, and one to be highly recommended as a practical guide. The practical directions are excellent."-Athenaum.

"May be recommended to young gardeners, cottagers, and specially to amateurs, for the plain, simple, and trustworthy information it gives on common matters too often neglected." -Gardeners' Chronicle.

\section{Gainful Gardening.}

MULTUM-IN-PARVO GARDENING; or, How to make One Acre of Land produce $£ 620$ a-year, by the Cultivation of Fruits and Vegetables; also, How to Grow Flowers in Three Glass Houses, so as to realise $£_{1} 176$ per annum clear Profit. By SAMUEL WOOD, Author of "Good Gardening," \&c. Fifth and Cheaper Edition, revised, with Additions. Crown 8vo, is. sewed.

"We are bound to recommend it as not only suited to the case of the amateur and gentleman's gardener, but to the market grower."-Gardeners' Magazine.

\section{Gardening for Ladies.}

\section{THE LADIES' MULTUM-IN-PARVO FLOWER GARDEN, AND}

Amateurs' Complete Guide. With Illusts. By S. Wood. Cr. 8 vo, 3 s. $6 d$. cloth.

"This volume contains a good deal of sound, common-sense instruction."-Florist.

"Full of shrewd hints and useful instructions, based on a lifetime of experience."-Scotsman.

Receipts for Gardeners.

GARDEN RECEIPTS. Edited by Charles W. Quin. i 2 mo, is. $6 d$. cloth limp.

"A useful and handy book, containing a good deal of valuable information."-Athenaum.

\section{Market Gardening.}

MARKET AND KITCHEN GARDENING. By Contributors to "The Garden." Compiled by C. W. SHAW, late Editor of "Gardening Illustrated." $12 \mathrm{mo}, 3$ s. $6 d$. cloth boards.

"The most valuable compendiuin of kitchen and market-garden work published."-Farmer.

\section{Cottage Gardening.}

COTTAGE GARDENING; or, Flowers, Fruits, and Vegetables for Small Gardens. By E. HOBDAY. I2mo, Is. 6 d. cloth limp.

Contains much use'ul information at a small charge." -Glasgow Ferald. 


\section{AUCTIONEERING, VALUING, LAND SURVEYING, ESTATE AGENCY, etc.}

\section{Auctioneer's Assistant.}

THE APPRAISER, AUCTIONEER, BROKER, HOUSE AND ESTATE AGENT AND VALUER'S POCKET ASSISTANT, for the Valuation for Purchase, Sale, or Renewal of Leases, Annuities and Reversions, and of property generally; with Prices for Inventories, \&c. By John Wheeler, Valuer, \&c. Sixth Edition, Re-written and greatly Extended by C. Norkis, Surveyor, Valuer, \&c. Royal $32 \mathrm{mo}$, 5 s. cloth.

"A neat and concise book of reference, containing an admurable and clearly-arranged list of prices for inventories, and a very practical guide to determine the value of furniture, \&c."-Standard.

$\mathrm{C}$ ntains a large quantity of varied and useful information as to the valuation for purchase, sale, or renev al of leases, annuities and reversions, and of propertv generally, with prices for inventories, and a guide to determine the value of interior fittings and other effects."-Builder.

\section{Auctioneering.}

AUCTIONEERS: THEIR DUTIES AND LIABILITIES. A Manual of Instruction and Counsel for the Young Auctioneer. By RoBERT SQUiBBS, Auctioneer. Second Edition, Revised and partly Re-written. Demy 8vo, 12s. 6d. cloth. ** Opinions of the Press.

"The standard text-book on the topics of which it treats."-Athenaum.

"The work is one of general excellent character, and gives much information in a compendions and satisfactory form."-Builder.

"May be recommended as giving a great deal of information on the law relating to auctioneers, in a very readable form." - Law founal.

"Auctioneers may be congratulated on having so pleasing a writer to minister to their special needs."-Solicitors' fournal.

"Every auctioneer ought to possess a copy of this excellent work."-Ironmonger.

"Of great value to the profession. . . We readily welcome this book from the fact that it treats the subject in a manner somewhat new to the profession."-Estates Gasette.

\section{Inwood's Estate Tables.}

TABLES FOR THE PURCHASING OF ESTATES, FREEHOLD, COPYHOLD, OR LEASEHOLD; ANNUITIES, ADVOWSONS, \&C., and for the Renewing of Leases held under Cathedral Churches, Colleges, or other Corporate bodies, for Terms of Years certain, and for Lives; also for Valuing Reversionary Estates, Deferred Annuities, Next Presentations, \&c. ; together with SMART's Five Tables of Compound Interest, and an Extension of the same to Lower and Intermediate Rates. By W. INwooD, 24th Edition, with considerable Additions, and new and valuable Tables of Logarithms for the more Difficult Computations of the Interest of Money, Discount, Annuities, \&c., by M. FÉDOR ThomAn, of the Société Crédit Mobilier of Paris. Crown 8vo, 8s. cloth.

"Those interested in the purchase and sale of estates, and in the adjustment of compensation cases, as well as in transactions in annuities, life insurances, \&c., will find the present edition of eminent

service."-Engineering. large additional contributions by M. Fédor Thoman, whose carefully-arranged Tables cannot fail to be of the utmost utility."-Mining Fournal.

\section{Agricultural Valuer's Assistant.}

the Agricultural Valuer's Assistant. A Practical Handbook on the Valuation of Landed Estates ; including Rules ant Data for Measuring and Estimating the Contents, Weights and Values of Agricultural Produce and Timber, and the Valaes of Feeding Stuffs, Manures, and Labour; with Forms of Tenant-Right Valuations, Lists of Local Agricultural Customs, Scales of Compensation under the Agricultural Holdings Act, \&c. \&c. By ToM BRIGHT, Agricultural Surveyor. Second Edition, much Enlarged. Crown 8vo, 5s. cloth.

"Full of tables and examples in connection with the valuation of tenant-right, estates, labour, contents and weights of timber, and farm produce of all kinds." - Agricultural Gazette.

"An eminently practical handbook, full of practical tables and data of uadoubted interest and value to surveyors and auctioneers in preparing valuations of all kinds."-Farmer.

\section{Plantations and Underwoods.}

POLE PLANTATIONS AND UNDERWOODS: A Practical Handbook on Estimating the Cost of Forming, Renovating, Improving, and Grubbing Plantations and Underwoods, their Valuation for Purposes of Transfer, Rental, Sale or Assessment. By TOM BRIGHT, Author of "The Agricultural Valuer's Assistant," \&c. Crown 8vo, 3s. 6d. cloth.

"To valuers. foresters and agents it will be a welcome aid."-North British Agriculturist.

"Well calculated to assist the valuer in the discharge of his duties, and of undoubted interest and use both to surveyors and auctioneers in preparing valuations of all kinds." - Kent Herald. 
Hudson's Land Valuer's Pocket-Book.

THE LAND VALUER'S BEST ASSISTANT: Being Tables on a very much improved Plan, for Calculating the Value of Estates. With Tables for reducing Scotch, Irish, and Provincial Customary Acres to Statute Measure, \&c. By R. Hudson, C.E. New Edition. Royal $32 \mathrm{mo}$, leather, elastic band, $4 s$.

"Of incalculable value to the country gentleman and professional man."-Farmers' Gournal.

Ewart's Land Improver's Pocket-Book.

THE LAND IMPROVER'S POCKET-BOOK OF FORMULE, TABLES, AND MEMORANDA required in any Computation relating to the Permanent Improvement of Landed Property. By JOHN EWART, Land Surveyor and Agricultural Engineer. Second Edition, Revised. Royal 32mo, oblong, leather, gilt edges, with elastic band, $4 \mathrm{~s}$.

"A compendious and handy little volume." - Spectator.

Complete Agricultural Surveyor's Pocket-Book. THE LAND VALUER'S AND LAND IMPROVER'S COMPLETE POCKET-BOoK. Being the above Two Works bound together. Leather, with strap, $7 s .6 d$.

House Property.

HANDBOOK OF HOUSE PROPERTY: A Popular and Practical Guide to the Purchase, Mortgage, Tenancy, and Compulsory Sale of Houses and Land, including the Law of Dilapidations and Fixtures: with Examples of all kinds of Valuations, Useful Information on Building and Suggestive Elucidations of Fine Art. By E. L. TARBUCK, Architect and Surveyor. Fifth Edition, Enlarged. $12 \mathrm{mo}, 5 s$. cloth.

"The advice is thoronghly practical,"-Law Fournal.

"For all who have dealings with house property, this is an indispensable guide."-Decoration.

"Carefully brought up to date, and much improved by the addition of a division on Fine Art.

- . . A well-written and thoughtful work."-Land Agent's Record.

\section{LAW AND MISCELLANEOUS.}

\section{Private Bill Legislation and Provisional Orders.}

HANDBOOK FOR THE USE OF SOLICITORS AND ENGINEERS

Engaged in Promoting Private Acts of Parliament and Provisional Orders, for the authorization of Railways, Tramways, Works for the Supply of Gas and Water, and other undertakings of a like character. By L. LivingSTON MACASSEY, of the Middle Temple, Barrister-at-Law, and Member of the Institution of Civil Engineers ; Author of "Hints on Water Supply." Demy 8vo, 950 pp., 25s. cloth.

"The author's double experience as an engineer and barrister has enabled him to approach the subject alike from an engineering and legal point of view."-Local Government Chronizie.

\section{Law of Patents.}

PATENTS FOR INVENTIONS, AND HOW TO PROCURE THEM Compiled for the Use of Inventors, Patentees and others. By G. G. M. HARDINGHAM, Assoc. Mem. Inst. C.E., \&c. Demy 8vo, is. 6d. cloth.

Labour Disputes.

CONCILIATION AND ARBITRATION IN LABOUR DISPUTES: A Historical Sketch and Brief Statement of the Present Position of the Question at Home and Abroad. By J. S. JEANs, Author of "England's Supremacy," \&c. Crown 8vo, 200 pp., 2s. $6 d$. cloth.

[fust published.

Pocket-Book for Sanitary Officials.

THE HEALTH OFFICER'S POCKET-BOOK: A Guide to Sanitary Practice and Law. For Medical Officers of Health, Sanitary Inspectors, Members of Sanitary Authorities, \&c. By EDWARd F. Willoughby, M.D. (Lond.), \&c., Author of "Hygiene and Public Health" Fcap. 8vo, 7s. 6d., cloth, red edges, rounded corners.

[Fust published.

"A mine of condensed information of a pertinent and useful kind on the various subjects of which it treats. The matter seems to have been carefully compiled and arranged for facility of reference, and it is well illustrated by diagrams and woodcuts. The different subjects are succinctiy but fully and scientifically dealt with."-The Lancet.

"Ought to be welcome to those for whose use it is designed, since it practically boils down a reference library into a pocket volume. . . . It combines, wita an uncommon degree of efficiency, the qualities of accuracy, conciseness and comprehensiveness." - Scotsman.

"An excellent publication, dealing with the scientific, technical and legal matters connected with the duties of medical officers of health and sanitary nspectors. The work is replete witn information."-Local Government fournal. 


\section{A Complete Epitome of the Laws of this Country.}

EVERY MAN'S OWN LAWYER: A Handy-Book of the Principles of Law and Equity. By A BARRISTER. Thirty-first Edition, carefully Revised, and including the Legislation of 1893. Comprising (amongst other Acts) the Voluntary Conveyances Act. 1893; the Married Women's Property Act, I8s3; the Trustee Act, 1893; the Savings Bank Act, 1893 ; the Barbed Wire Act, 1893 ; the Industrial and Provident Societies' Act, 1893 ; the Hours of Labour of Railway Servants Act, 1893; the Fertiliser and Feeding Stuffs Act, 1893, etc., as well as the Betting and Loans (Infants) Act, 1892; the Gaming Act, 1892; the Shop Hours Act, 1892 ; the Conveyancing and Real Property Act, 1892 ; the Sinall Holdings $\mathrm{Acl}, 1892$; and many other new Acts. Crown 8vo, 700 pp., price $6 \mathrm{~s} .8 \mathrm{~d}$. (saved at every consultation !), strongly bound in cloth. [Fust published.
[Fuld *** The Book will be found to comprise (amongst other matter) -

The Rights and WRONGS OF INDIVIDUALS-LAN LLORD AND TENANTVENDORS AND PURCHASERS-PARTNERS AND Agents-COMPANIES AND ASSOCIATIONS-MASTERS, Servants AND Workmen-Leases and Mortgages-Libel. ANd Slander-Contracts and Agreements-Bonds and Bills of SaleCheques, Bills and Notes-Railway and SHIPPING LAW-BANKRUPTCY and INSURANCE-Borrowers, LENDERs AND SURETIES-CrIMINAL LAW-PARLiAMENTARY ElEctions-COUNTY COUNCILS-MUNICIPAL CORPORATIONS-PARISH Law, Churchwardens, etc.-Public Health aNd Nuisances-COPYRight and Patents-Trade Marks and Designs-Husband and Wife, Divorce, ETc.TRUSTEES AND EXECUTORS-GUARDian AND WARD, INFANTS, ETC.-Game Laws and Sporting-Horses, Horse-dealing and Dogs-INNKeEpers, Licensing, ETC.-Forms of Wills, Agreements, ETC. ETC.

D The object of this work is to enable those who consult it to help themselves to the law; and thereby to dispense, as far as possible, with professional assistance ana advice. There are many wrongs and grievances which persons submit to from time to time through not knowing how or where to apply for redress; and many persons have as great a dread of a lawyer's office as of a lion's den. With this book at hand it is believed that many a SIX-AND-EIGHTPENCE may be saved; many a wrong redressed; many a right reclaimed; many a law suit avoided; and many an evil abated. The work has established itself as the standard legal adviser of all classes, and has also made a reputation for itself as a useful book of reference for lawyers residing at a distance from law libraries, who are glad to have at hand a work embodying recent decisions and enactments.

$$
\text { *** Opinions of the Press. }
$$

"It is a complete corle of English Law written in plain language, which all can understand. .

Should be in the hauds of every business nuan, and all who wish to abolish lawyers' bills." - Weekly Times.

"A usefnl and concise epitome of the law, compiled with considerable care."-Law Magazine.

"A complete digest of the most useful facts which constitute English law."-Globe.

"This excellent handbook. . . . Admirablv done, admirably arranged, and admirablv cheap."-
eeds Mercury.

"A concise, cheap, and complete epitome of the English law. So plainly written that he who runs may read, and he who reads may understand." - Figaro.

"A dictionarv of legal tacts well Ditt together. The book is a very useful one."- Spectator. "A work which has long been wanted, wnich is thoroughlv well done, and which we most cordially
recommend."-Sunday Times.

"The latest edition of this popular book ought to be in every business establishment, and on every library table." - Skeffield Post. Life.

"A complete epitome of the law; thoroughly intelligible to non-professional readers." $-B e l l$ 's

\section{Legal Guide for Pawnbrokers.}

THE PAWNBROKERS', FACTORS' AND MERCHANTS' GUIDE TO THE LAW OF LOANS AND PLEDGES. With the Statutes and a Digest of Cases. Hy
H. C. FOLKARD, Esq., Barrister-at-Law. Fcap. 8vo, 3s. 6 , cloth.

\section{The Law of Contracts.}

LABOUR CONTRACTS: A Popular Handbook on the Law of Contracts for Works and Services. By David GibBons. Fourth Edition, with Appendix
of Statutes by T. F. UtrLey, Solicitor. Fcap. 8vo, 3s. 6d. cloth.

The Factory Acts.

SUMMARY OF THE FACTORY AND WORKSHOP ACTS (1878-1891),

For the Use of Manufacturers and Managers. By EMile GARCKE and J. M.

Fells. (Reprinted from "FACTORY Accounts.") Crown 8vo, 6d. sewed. 


\title{
Teteale's Lilloimentary Series.
}

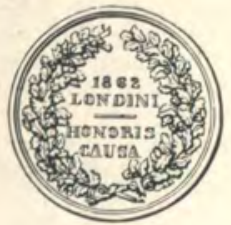

\author{
London, I862, \\ THE PRIZE ME D A L \\ Was awarded to the Publishers of \\ “W E A L E'S SERIES."
}

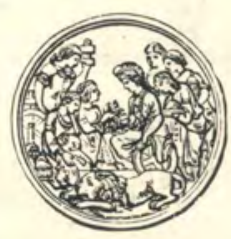

A NEW LIST OF

\section{WEALE'S SERIES \\ OF \\ RUDIMENTARY \\ SCIENTIFIC WORKS.}

tw "WEALE'S SERIES includes Text-Books on almost every branch of Science and Industry, comprising such subjects as Agriculture, Architecture and Building, Civil Engineering, Fine Arts, Mechanics and Mechanical Engineering, Physical and Chemical Science, and many miscellaneous Treatises. The whole are constantly undergoing revision, and new editions, brought up to the latest discoveries in scientific research, are constantly issued. The prices at which they are sold are as low as their excellence is assured."-American Literary Gazette.

"Amongst the literature of technical education, WEALE'S SERIEs has ever enjoyed a high reputation, and the additions being made by Messrs. Croser LockwooD \& SOrt render the series even more complete, and bring the information upon the several subjects down to the present time."-Mining fournal.

" Any persons wishing to acquire knowledge cannot do better than look through WEALE'S SERIES and get all the books they require. The Series is indeed an inexhaustible mine of literary wealth."-The Metropolitan.

“WEALE'S SERIES has become a standard as well as an unrivalled collection of treatises in all branches of art and science."-Public Opinion.

“'The excellence of WEALE'S SERIES is now so well appreciated that it would be wasting our space to enlarge upon their general usefulness and value."-Builder.

"It is not too much to say that no books have ever proved more popular with or more useful to young engineers and others than the excellent treatises comprised in Weale's Series." - Engineer.

"The volumes of WEALE'S SERIES form one of the best collections of elementary technical books in any language." - Architect.

"A collection of technical manuals which is unrivalled."-Weekly Dispatch.

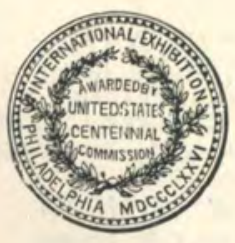

Mhiladelphia, 1876 , THE PRIZE M E D L Was awarded to the Publishers for Books : Rudimentary Scientific, "WEALE'S SERIES," \&c.

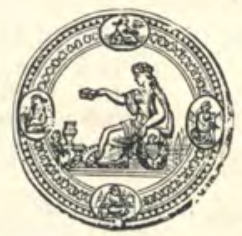

\section{CROSBY LOCKWOOD \& SON,}

7, STATIONERS' HALL COURT, LUDGATE HILL, LONDON, E C. 


\title{
WEALE'S RUDIMENTARY SCIENTIFIC SERIES.
}

\begin{abstract}
** The volumes of this Series are freely Illustrated with Woodcuts, or otherwise, where requisite. Throughout the following List it must be understood that the books are bound in limp cloth, unless otherwise stated; but the volumes marked with a I may also be had strongly bound in cloth boards for $6 d$. extra.

$N . B$. - In ordering from this List it is recommended, as a means of facilitating business and obviating error, to quote the numbers affixed to the volumes, as well as the titles and prices.
\end{abstract}

\section{CIVIL ENGINEERING, etc.}

3x. WELLS AND WELL-SINKING. By John Geo. Swindell, A.R.I.B.A., and G. R. Burnel., C.E. Revised Edition. With a New Appendix on the Qualities of Water. Illustrated. . . . . . 2/o

"Solid practical information, written in a concise and lucid style. The work can be recommended as a text-book for all surveyors, architects, \&c."-Iron and Coal Trades Review.

35. THE BLASTING AND QUARRYING OF STONE, for Building and other Purposes. With Remarks on the Blowing up of Bridges. By Gen. Sir J. Burgoyne, K.C.B. . . . * $\quad$. 16

43. TUBULAR AND OTHER IRON GIRDER BRIDGES, describing the Britannia and Conway Tubular Bridges. With a Sketch of Iron Bridges, \&c. By G. DRYSDALE DEMPSEY, C.E. Fourth Edition . 2/o

44. FOUNDATIONS AND CONCRETE WORKS. With Practical Remarks on Footings, Planking, Sand, Concrete, Béton, Pile-driving, Caissons, and Cofferdams. By E. DoBson, M.R.I.B.A. Seventh Edition ? I/6

6. LAND AND ENGINEERING SURVEYING. For Students and Practical Use. By T. BAKER, C.E. Fifteenth Edition, revised and corrected by J.R. Young, formerly Professor of Mathematics, Belfast College. Illustrated with Plates and Diagrams . . . . 2/o!

80*. EMBANKING LANDS FROM THE SEA. With Examples and Particulars of actual Embankments, \&c. By JoHN Wiguins, F.G.S. · 2/o

81. WATER WORKS, for the Supply of Cities and Towns. With a Description of the Principal Geological Formations of England as influencing Supplies of Water; and Details of Engines and Pumping Machinery for raising Water. By SAMUEL HUGHES, F.G.S., C.E. Enlarged Edition. . 4/of

"Every one who is debating how his village, town, or city shall be plentifully supplied with pure water should read this book." - Newcastle Courant.

ri. SUBTERRANEOUS SURVEYING. By THOMAS FENwick. Also the Method of Conducting Subterraneous Surveys without the use of the Magnetic Needle, and other modern Improvements. By T. BAKER, C.E. 2/6

118. CIVIL ENGINEERING IN NORTH AMERICA, A Sketch of. By David Stevenson, F.R.S.E., \&c: Plates and Diagrams. . 3/o

167. A TREATISE ON THE APPLICATION OF IRON TO THE CONSTRUCTION OF BRIDGES, ROOFS, AND OTHBR WORKS By FRANCIS CAMPIN, C.E. Fourth Edition . . . . 2/6

"For numbers or young engineers the book is just the cheap, handy, first guide they want."Middlesbrough Weekly News. "Remarkably accurate and well written."-Artizan.

197. ROADS AND STREETS (THE CONSTRUCTION OF), in Two Parts: I. THE ART OF CONSTRuCting Common/Roads, by H. LAW, C.E.. Revised by D. Kinnear Clark, C.E.; IIJ ReCent Practice: Including Pavements of Stone, Wood, and Asphalte. By D. K. CLARK, C.E. 4/6t

"A bool: which every borough surveyor and engineer must possess, and which will be of considerable service to architects, builders, and property owners generally." - Building News.

203. SANITARY WORK IN THE SMALLER TOWNS

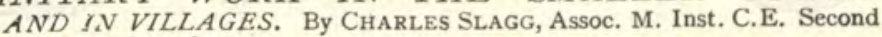
Edition, enlarged

"This is a very useful book. There is a great deal of work required to be done in the smaller towns and villages, and this little volume will help those who are willing to do it."-Builder. 
Civil Engineering, etc., continued.

212. THE CONSTRUCTION OF GAS WORKS, and the Manu-

facture and Distribution of Coal Gas. By S. Hughes, C.E. Re-written by

WILLIAM RicharDS, C.E. Eighth Edition, with important Additions $.5 / 6 \ddagger$

"Will be of infinite service alike to manufacturers, distributors, and consumers."-Foreman Engineer

2r3. PIONEER ENGINEERING: A Treatise on the Engineering

Operations connected with the Settlement of Waste Lands in New Countries.

By EDWARD DoBson, A.I. C.E. With numerous Plates. Second Edition . 4/6

"Mr. Dobson is familiar with the difficulties which have to be overcome in this class of work, $4 / 6 \pm$ much of his advice will be valuable to young engineers proceeding to our colonies." - Eng ineering. 216. MATERIALS AND CONSTRUCTION: A Theoretical and Practical Treatise on the Strains, Designing, and Erection of Works of

"No better exposition of the practical application of the principles of construction revised. $2 / 0$ † published to our knowledge in such a cheap comprehensive form." - -Building News. 219. CIVIL ENGINEERING. By HeNRY LAw, M. Inst. C.E. Including a Treatise on Hydraulic EngINEERING by G. R. Burnell, M.I.C.E. Seventh Edition, revised, WITH LARGE ADDITIONS ON RECENT PRACTICE by D. KINNEAR CLARK, M. Inst. C.E. $6 s .6 d$., cloth boards $\cdot 7 / 6$

"An admirable volume, which we warmly recommend to young engineers."-Builder.

260. IRON BRIDGES OF MODERATE SPAN: Their Construction and Erection. By HAMILTON WELDON PENDRED, late Inspector of

Ironwork to the Salford Corporation. With 40 Illustrations .
"Students and engineers should obtain this book for constant and practical use."-Colliery Guardian

268. THE DRAINAGE OF LANDS, TOWNS, AND BUILD.

INGS. By G. D. DEMPSEY, C.E. Revised, with large Additions on Recent Edition, corrected

\section{MECHANICAL ENGINEERING, etc.}

33. CRANES, the Construction of, and other Machinery for Raising Heavy Bodies for the Erection of Buildings, \&c. By JOSEPH GLYNN, F.R.S. $x / 6$

34. THE STEAM ENGINE. By Dr. LARDNER. Illustrated . x/6

59. STEAM BOILERS: Their Construction and Management.

By R. ARMSTRONG, C.E. Illustrated

"A mass of information suitable for beginners."-Design and Work.

82. THE POWER OF WATER, as applied to drive Flour Mills, and to give motion to Turbines and other Hydrostatic Engines. By JOSEPH GLYNN, F.R.S., \&c. New Edition, Illustrated . . . . . . 2/

98. PRACTICAL MECHANISM, and Machine Tools. By T.

BAKER, C.E. With Remarks on Tools and Machinery, by J. NASMYTH, C.E. $2 / 6$

r39. THE STEAM ENGINE, a Treatise on the Mathematical

Theory of, with Rules and Examples for Practical Men. By T. BAKER, C.E. x/6

"Teems with scientific information in reference to the steam-engine.-Design and Work.

r64. MODERN WORKSHOP PRACTICE, as applied to Marine,

Land, and Locomotive Engines, Floating Docks, Dredging Machines, Bridges,

" Whip-building, \&c. By J. G. WiNToN. Fourth Edition, Illustrated . : $3 / 6 \ddagger$ himself to a higher position, this clearly written and practical treatise will be a great help."-Scotsman, 165. IRON AND HEAT, exhibiting the Principles concerned in the

Construction of Iron Beams, Pillars, and Girders, By J. ARMOUR, C.E. 2/6

"A very useful and thoroughly practical little volume."-Mining fournal,

r66. POWER IN MOTION: Horse-power Motion, Toothed-Wheel

Gearing, Long and Short Driving Bands, Angular Forces, \&c. By JAmEs

ARMOUR, C.E. With 73 Diagrams. Third Edition
"The value of the knowledge imparted cannot well be over-estimated." Newcastle Weekly Chron."

r7x. THE WORKMAN'S MANUAL OF ENGINEERING

$D R A W I N G$. By JOHN MAXTON, Instructor in Engineering Drawing.

Royal Naval College, Greenwich. Seventh Edition. 30o Plates and Diagrams $3 / 6 \ddagger$
"A copy of it should be kept for reference in every drawing office." 
Mechanical Engineering, etc., continued.

190. STEAM AND THE STEAM ENGINE, Stationary and Portable, An Elementary Treatise on. Being an Extension of the Treatise on the Steam Engine of Mr. J. Sewell. By D. K. Clark, C. E. Third Edition $3 / 6 \$$

"Every essential part of the subject is treated of competently, and in a popular style."-Iron.

200. FUEL, ITS COMBUSTION AND ECONOMY. Consisting of an Abridgment of "A Treatise on the Combustion of Coal and the Prevention of Smoke." By C. W. Williams, A.I.C.E. With extensive Additions by D. KINNEAR CLARK, M. Inst. C.E. Third Edition, corrected $3 / 6 \pm$ "Students should buy the book and read it, as one of the most complete and satisfactory treatises on" the combustion and economy of fuel to be had." $-E$ ngineer.

202. LOCOMOTIVE ENGINES, A Rudimentary Treatise on. By G. D. DEMPSEY, C.E. With large Additions treating of the Modern Locomotive, by D.K. CLARK, M. Inst. C.E. With numerous Illustrations . $3 / 0 \ddagger$

"A model of what an elementary technical book should be."-Academy.

211. THE BOILERMAKER'S ASSISTANT in Drawing, Templating, and Calculating Boiler Work, \&c. By J. Courtney, Practical Boilermaker. Edited by D. K. CLARK, C.E. Third Edition, revised . 2/o

"With very great care we have gone through the 'Boilermaker's Assistant,' and have to say that io has our unqualified approval. Scarcely a point has been omitted." - Foreman Engineer.

217. SEWING MACHINERY: Its Construction, History, \&c. With full Technical Directions for Adjusting, \&c. By J. W. URQUHART, C.E. $2 / 0$

"A full description of the principles and construction of the leading machines, and minute instructions as to their management."-Scotsman.

223 MECHANICAL ENGINEERING. Comprising Metallurgy, Moulding, Casting, Forging, Tools, Workshop Machinery, Mechanical Manipulation, Manufacture of the Steam Engine, \&c. By FRANCIS CAMPIN, C.E. . $2 / \epsilon_{\ddagger}$

"A sound and serviceable text-book, quite up to date."-Building News.

236. DETAILS OF MACHINERY. Comprising Instructions for the Execution of various Works in Iron in the Fitting-Shop, Foundry, and

"Aoiler-Yard. By FRANCIS CAMPIN, C.E.

237. THE SMITHY AND FORGE, including the Farrier's Art and Coach Smithing. By W. J. E, Crane. Second Edition, revised . . 2/6‡ "The first modern English book on the subject. Great pains have been bestowed by the author
upon the book ; shoeing smiths will find it both useful and interesting."-Builder.

239. THE SHEET-METAL WORKER'S GUIDE: A Practical Handbook for Tinsmiths, Coppersmiths, Zincworkers, \&c., with 46 Diagrams and Working Patterns. By W.J. E. CRANE. Second Edition, revised. $x / 6$

"The author has acquitted himself with considerable tact in choosing his examples, and with no less ability in treating them."-Plumber.

25x STEAM AND MACHINERY MANAGEMENT: A Guide to the Arrangement and Economical Management of Machinery, with Hints on Construction and Selection. By M. POWIS BALE, M.Inst.M.E. . . $2 / 6$ ?

"Of high practical value."-Colliery Guardian.

"Gives the results of wide experience."-Lloyd's Newspaper.

254. THE BOILER-MAKER'S READY RECKONER, with Examples of Practical Geometry and Templating for the Use of Platers, Smiths, and Riveters. By John Courtney. Edited by D. K. Clark, M.I.C.E. Second Edition, revised, with Additions . . . . . . . . 4/o

*** Nos. 211 and 254 in One Vol., half-bound, entitled "THE BoIlermaker'S REAdYReckoner and Assistant." By J. Courtney and D. K. Clark. Price $7 s$.

"A most useful work. No workman or apprentice should be without it."-Iron Trade Circular.

255. LOCOMOTIVE ENGINE-DRIVING. A Practical Manual for Engineers in charge of Locomotive Engines. By MICHAEL REYNOLDS, M.S.E. Eighth Edition: 3s. 6d. limp; cloth boards . . . . . 4/6

"We can confidently recommend the book, not only to the practical driver, but to everyone who takes an interest in the performance of locomotive engines. - The Enginer.

256. STATIONARY ENGINE-DRIVING. A Practical Manual for Engineers in charge of Stationary Engines. By MICHAEL REYNOLDS, M.S.E. Fourth Edition. 3s. $6 d$. limp; cloth boards . . . . 4/6

"The author is thoroughly acquainted with his subjects, and has produced a manual which is an exceedingly useful one for the class for whom it is specially intended." - Engineering.

The + indicates that these vols. may be had strongly bound at $6 d$. extra. 
MINING, METALLURGY, etc.

4. MINERALOGY, Rudiments of. By A. Ramsay, F.G.S.

Third Edition, revised and enlarged. Woodcuts and Plates.?. $36 \ddagger$

"The author throughout has displayed an intimate knowledge of his subject, and great facility in imparting that knowledge to others. The book is of great utility."-Mining fournal.

I17. SUBTERRANEOUS SURVEYING, with and without the Magnetic Needle. By T. FEnWICK and T.BAKER, C.E. Illustrated . ${ }_{2} / 6 \ddagger$

«33. METALLURGY OF COPPER: An Introduction to the Methods of Seeking, Mining, and Assaying Copper. By R. H. LAM BorN. 2/6I

«35. ELECTRO-METALLURGY, Practically Treated. By AlExANDER WATT. Ninth Edition, enlarged and revised. With Additional Illustrations, and including the most Recent Processes . [Fust published. 3/6‡

"From this book both amateur and artisan may learn everything necessary."-Iron.

ะ72. MINING TOOLS, Manual of. By William Morgans, Lecturer on Practical Mining at the Bristol School of Mines . . . 2/6

${ }_{172 *}$.MINING TOOLS, ATLAS of Engravings to Illustrate the above, containing 235 Illustrations of Mining Tools, drawn to Scale. 4to. . 4/6

"Students, Overmen, Captains, Managers, and Viewers may gain practical knowledge and useful hints by the study of Mr.' Morgans' Manual." - Colliery Guardian.

176. METALLURGY OF IRON. Containing History of Iron

Manufacture, Methods of Assay, and Analyses of Iron Ores, Processes of Manufacture of Iron and Steel, \&c. Bv H. BAuerman, F.G.S., A.R.S.M. With numerous Illustrations. Sixth Edition, revised and enlarged . . . . 5/oł

"Carefully written, it has the merit of brevity and conciseness, as to less important points; while all material matters are very fully and thoroughly entered into."-Standard.

180. COAL AND COAL MINING, A Rudimentary Treatise on.

By the late Sir WARINGTON W.SMYTH, M.A., F.R.S., \&c., Chief Inspector

of the Mines of the Crown. Seventh Edition, revised and enlarged . 3/6I

"Every portion of the volume appears to have been prepared with much care, and as an outline is given of every known coal-field in this and other countries, as well as of the two principal methods of working, the book will doubtless interest a very large number of readers."-Mining fournal.

195. THE MINERAL SURVEYOR AND VALUER'S COMPLETE GUIDE. Comprising a Treatise on Improved Mining Surveying and the Valuation of Mining Properties, with New Traverse Tables. By W. LINTERN, Mining and Civil Engineer. Third Edition, with an Appendix on Magnetic and Angular Surveying, with Records of the Peculiarities of Needle Disturbances. With Four Plates of Diagrams, Plans, \&c.

"Contains much valuable information, and is thoroughly trustworthy" -Iron \& Coal Trades Review. 214. SLATE AND SLATE QUARRYING, Scientific, Practica!, and Commercial. By D. C. DAviEs. F.G.S., Mining Engineer, \&c. With numerous Illustrations and Folding Plates. Third Edition

"One of the best and best-balanced treatises on a special subject that we have met with."Engineer.

264. A FIRST BOOK OF MINING AND QUARRYING, with

the Sciences connected therewith, for Primary Schools and Self Instruction. By T. H. Collins, F.G.S., Lecturer to the Miners' Association of Cornwall and Devon. Second Edition, with additions.

"For those coner. $\mathrm{I} / 6$ the hands of their schoolmasters."-Iron.

\section{ARCHITECTURE, BUILDING, etc.}

a6. ARCHITECTURE-ORDERS-The Orders and their Esthetic Principles. By W. H. LeEds. Illustrated . . . . . x/6

7. ARCHITECTURE-STYLES-The History and Description of the Styles of Architecture of Various Countries, from the Earliest to the Present Period. By T. TAlbot Bury, F.R.I.B.A., \&c. Illustrated . . 2/0 ** Orders and Styles of Architecture, in One Vol., 3 s. 6 d.

18. ARCHITECTURE-DESIGN-The Principles of Design in Architecture, as deducible from Nature and exemplified in the Works of the Greek and Gothic Architects. By EDW. LACY GARBETT, Architect. Illastrated 2,6

"We know no work that we would sonner recommend to an attentive reader desirous to obtain clear views of the nature of architectural art. The book is a valuable one."-Butder.

** The three preceding Works in One handsome Vol., half bound, entitled "MODERN ARCHITECTURE," price $6 s$.

The indicates that these vols. may be had strongly bound at 6 d. extra. 
Architecture, Building, etc., continued.

22. THE ART OF BUILDING, Rudiments of. General Principles of Construction, Strength and Use of Materials, Working Drawings, Specifications, \&c. By EDWARD DOBSON, M.R.I.B.A., \&c. .

"A good book for practical knowledge, and about the best to be obtained." - Building Nerus. 25. MASONRY AND STONECUTTING: The Principles of Masonic Projection and their application to Construction. By E. DoBsos; M.R.I.B.A.

2. COTTAGE BUILDING. By C. Bruce Allen. Eleventh Ed,,with Chapter on Economic Cottages for Allotments, by E. E. ALLEN,C.E. 2/o

45. LIMES, CEMENTS, MORTARS, CONCRETES, MASTICS, PLASTERING, \&.C. By G. R. BURNELL, C.E. Thirteenth Edition $1 / 6$

57. WARMING AND VENTILATION of Domestic and Public Buildings, Mines, Lighthouses, Ships, \&c. By Charles Tomlinson, F.R.S. 3/o

m. ARCHES, PIERS, BUTTRESSES, \&o.: Experimental Essays on the Principles of Construction in. By William BLAND . . $x / 6$

116. THE ACOUSTICS OF PUBLIC BUILDINGS; or, The Principles of the Science of Sound applied to the purposes of the Architect and Builder. By 'T. ROGER SMITH, M.R.I.B.A., Architect. Illustrated . 1/6

127. ARCHITECTURAL MODELLING IN PAPER, The Art of. By T. A. Richardson. With Illustrations, engraved by O. JEWITT ${ }^{2} / 6$

"A valuable aid to the practice of architectural modelling."-Builder's Weekly Reporter.

128. VITRUVIUS-THE ARCHITECTURE OF MARCUS VITRUVIUS POLLO. In Ten Books. Translated from the Latin by JOSEPH GWILT, F.S.A., F.R.A.S. With 23 Plates . . . . ${ }^{5}$.

N.B.-This is the only Edition of VITRUVIUS procurable at a moderate price.

130. GRECIAN ARCHITECTURE, An Inquiry into the Principles of Beauty in ; with an Historical View of the Rise and Progress of the Art in Greece. By the EARL OF ABERDEEN.

"** The two preceding Works in One handsome Vol, half bound, entitled "ANCIENT ARCHITECTURE," price $6 s$.

332. DWELLING-HOUSES, The Erection of, Illustrated by a Perspective View, Plans, Elevations, and Sections of a Pair of Villas, with the Specification, Quantities, and Estimates. By S. H. Brooks, Architect . 2/6

r56. QUANTITIES AND MEASUREMENTS, in Bricklayers', Masons', Plasterers', Plumbers', Painters', Paperhangers', Gilders', 'Smiths', Carpenters' and Joiners' Work. By A. C.'BEATON, Surveyor. I. I/6

"This book is indispensable to builders and their quantity clerks."-English, Mechanic.

175. LOCKWOOD'S BUILDER'S PRICE BOOK FOR I 894. A Comprehensive Handbook of the Latest Prices and Data for Builders. Architects, Engineers, and Contractors, Re-constructed, Re-written, and greatly Enlarged. By FrANCIS T. W. MILLER, A.R.I.B.A. 700 pages. . 4.0

182 CARPENTRY AND JOINERY-The Elementary PrinCIPLES OF CARPENTRY. Chiefly composed from the Standard Work of THOMAS TREDGOLD, C.E. With Additions, and a TREATISE ON JOINERY by E. W. TARN, M.A. Fifth Edition, Revised and Extended $.36 \mp$

18*. CARPENTRY AND JOINERY. ATLAS of 35 Plates to accompany and illustrate the foregoing book. With Descriptive Letterpress. 4to $6 / 0$

"These two volumes form a conplete treasury of carpentry and joinery, and should be in the hands of every carpenter and joiner in the empire."-Iron.

185. THE COMPLETE MEASURER; setting forth the Measurement of Boards, Glass, Timber and Stone. By R. HORTON. Fifth Edition. 4\%

*** The above, strongly bound in leather, price $5^{s}$.

187. HINTS TO YOUNG ARCHITECTS. By GeORge Wightwick, Architect, Author of "The Palace of Architecture," \&c., \&c. Fifth Edition, revised and enlarged by G. Huskisson Guillaume. Architect. $3 / 6 \ddagger$

"A copy ought to be considered as necessary a $₹$ urchase as a box of instruments."-A rchitect.

The \pm indicales that these vols. may be had strongly bound at $6 d$. extra. 
Architecture, Building, etc., continued.

188 HOUSE PAINTING, GRAINING, MARBLING, AND SIGN WRITING: With a Course of Elementary Drawing, and a Collection of Useful Receipts. By Ellis A. DAvidson. Sixth Edition. Coloured Plates '5/0

"A mass of information of use to the amateurand bof strongly bound, 6 s.

18. THE RUDIMENTS OF PR of value to the practical man."-English Mechanic.

General Principles of Bricklaying.

Pointing; Paving, Tiling, \&c. By A Arch Drawing, Cutting, and Setting :

"The young bricklayer will find it infinitely ADaluall HAMMOND. With 68 Woodcuts : $\mathbf{r}_{i}^{\prime} 6$

rgr. PLUMBING: A Text-Book to the Practice Herala.

Craft of the Plumber. With Chapters the Practice of the Art or

By WM. PATON BUChAN, R. P., Sanitary Engineer. Sixth Edition Ventilation.

enlarged, with 380 Illustrations
A text-book which may be safely put into the hands of every young plumber, and which will also be found useful by architects and medical professors."-Bunds of every young plumber, and which will also 192. THE TIMBER IMPORTER'S TIM

AND BUILDER'S STANDARD' TIMBER MERCHANT'S,

"Everything BUILDER'S STANDARD GUIDE. By R. E. GRANDY.

in, as a makeweight, a host of material concerning bricks, columns, fisterest to a treenail, and throws 206. A BOOK ON BUILDING bricks, columns, cisterns, \&c."-English Mechanic.

EDMund Beckett, Bart., LL.D., Civil and Ecclesiastical. By Sir

Watches and Bells," \&c. 'Second "Edition., F.R.A.S., Author of "Clocks and

"A book which is always amusing and neariy always instructive" $-\dot{\text { Times. }} . \quad . \quad .4 / 6 \pm$

226. THE JOINTS MADE AND USED BY B

By WYVILL J. CHRISTY, Architect. With

"The work is deserving of high commendation."-Builder. . . . . . . . *

228. THE CONSTRUCTION OF ROOFS, OF WOOD AND

$I R O N$ : Deduced chiefly from the Works of Robison, Tredgold, and Humber.
By E. WYNDHAM TARN, M.A., Architect. Second Edition, revised

"Mr. Tarn is so thoroughly master of his subject, that although the treatise is founded on the works of others. he has given it a distinct value of his own. It will be found valuable by all students." - Builder. 229. ELEMENTARY DECORATION: As applied to Dwelling
Houses, \&c. By JAMES W.

"The principles which ought to guid. FACEY. Illustrated "The principles which ought to guide the decoration of dwelling-houses are clearly set forth, and
elucidated by examples; while full instructions are given to the learner." $-S$ cotsman. 257. PRACTICAL HOUSE DECORATION."-Scotsman.

Art of Ornamental Painting, A Guide to the the Principles of Decorative Design.

* Nos, 229 and 257 in One hand Design. By JAMES W. FACEY

TION,

TION, ELEMENTARY AND PRACTICAL," price 5 s.

230. A PRACTICAL TREATISE ON HANDRAILING;

Showing New and Simple Methods. By. GEo. Collings. Second Edition.

"will be found of practical a TREATISE ON STAIRBUILDING. With Plates , $2 / 6$

247. BUILDING ESTATES: A Treatise on the Development,

Sale, Purchase, and Management of Building Land. By F. MAITLAND.

"This book should undoubtedly be added to the library of . . 2/o

building land."-Land Agent's Record.

248. PORTLAND CEMENT FOR USERS. By HENRY FAIJA,

A.M. Inst. C.E. Third Edition, Corrected

"Supplies in a small compass all that is necessary to be known by users of cement" " . . . $2 / 0$

252. BRICKWORK: A Practical Treatise, embodying the Generalding News. and Higher Principles of Bricklaying, Cutting and Setting tion of Geometry to

" Contains all that a young tradesman or student By F. WALKER.

259. GAS FITTING : A Practical needs to learn from books."-Bwilding News. With 121 Illustrations

"Contains all the requisite information for the . . . 2/6† It is written in a simple practical style, and we heartion successful fitting, of houses with a gas service, \&c.

It is written in a simple practical style, and we heartily recommend it."-Plumber and Decorator. 253. THE TIMBER MERCHANT'S, SAW MILLER'S, AND IMPORTER'S FREIGHT BOOK AND ASSISTANT. By WILLIAM

"A compendium of calculations which supplies a real want in the trade."-Building News. $310 !$

The $f$ indicates that these vols. may be had strongly bound at $6 d$. extra. 
Architecture, Building, etc., continued.

23. THE PRACTICAL BRICK AND TILE BOOK. Com-

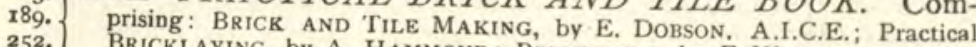
252. BRICKLAYING, by A. HAMmond; BRICKWORK, by F. WALKER. 550 pp.

258. CIRCULAR WORK IN CARPENTRY A ND TOINERY. A Practical Treatise on Circular Work of Single and Double Curvature. By "Cheap in price, clear ings. Second Edition . . . . . . . . . . .

"Cheap in price, clear in definition, and practical in the examples selected." - Builder.

26r. SHORING, and Its Application: A Handbook for the Use of Students. By George H. BLAgrove. With $3 \mathrm{r}$ lllustrations, , , $/ 6$

"We recommend this valuable treatise to all students."-Building News.

265. THE ART OF PRACTICAL BRICK CUTTING AND SETTING. By ADAM HAMMOND. With 90 Engravings .

267. THE SCIENCE OF BUILDING: An Elementary Treatise on the Principles of Construction. By E. WYNDHAM TARN, M.A. Lond. Third Edition, revised and enlarged. . . . $3 / 6 \pm$

27r. VENTILATION: A Text Book to the Practice of the Art of Ventilating Buildings. By W. P. BUCHAN, R. P., Author of "Plumbing," \&c. With r7o Illustrations
[Fust published. 3/6士

272. ROOF CARPENTRY; Practical Lessons in the Framing of Wood Roofs. For the Use of Working Carpenters. By GEO. Coltrngs, Author of "Handrailing and Stairbuilding," \&c.

273. THE PRACTICAL PLASTERER: A Compendium of Plain and Ornamental Plaster Work. By WILFRED KEMP . [fust published. 2]-
[foll

\section{SHIPBUILDING, NAVIGATION, etc.}

51. NAVAL ARCHITECTURE: An Exposition of the Elementary Principles. By James PEAke, H.M. Dockyard, Portsmouth $.3 / 6 \ddagger$

53*. SHIPS FOR OCEAN AND RIVER SER VICE, Elementary and Practical Principles of the Construction of. By HAKON A. SOMMERFELDT. I/6

$53^{* *}$. AN ATLAS OF ENGRAVINGS to Illustrate the above. Twelve large folding Plates. Royal 4 to, cloth.

54. MASTING, MAST-MAKING, AND RंGGING OF SHIPS. Also Tables of Spars, Rigging, Blocks; Chain, Wire, and Hemp Ropes, \&c., relative to every class of vessels. By ROBERT KIPPING, N.A. $2 / 0$

54. IRON SHIP-BUILDING. With Practical Examples and Details. By John Grantham, Fifth Edition

55. THE SAILOR'S SEA BOOK: A Rudimentary Treatise o 4/ Navigation. By JAMES GREENWOOD B. A. With and Coloured Plates. New and enlarged Edition. By W. H. Rosser . 2/6t

"Is perhaps the best and simplest epitome of navigation ever compiled. - Field.

55 PRACTICAL NAVIGATION. Consisting of ThE SaILOR's

$\&$ SEA-BOOK, by JAMES GREENWOOD and W. H. Rosser; together with

204. Mathematical and Nautical Tables for the Working of the Problems, by Henry LAw, C.E., and Prof. J. R. Young. Half-bound in leather . , $/ 0$

"A vast amount of information is contained in this volume, and we fancy in a very short time that it will be seen in the library of almost everv ship or yacht afloat."-Hunt's Yachting Magazine.

8o. MARINE ENGINES AND STEAM VESSELS. By R. MURray, C.E. Eighth Edition, thoroughly Revised, with Additions by the Author and by George CARLisle, C.E.

"An indispensable manual for the student of marine engineering."-Liverpool Mercury. . . 4/6士

THE FORMS OF SHIPS AND BOATS. By W. BLAND. Seventh Edition, revised, with numerous Illustrations and Models.

99. NAVIGATION AND NAUTICAL ASTRONOMY, in

Theory and Practice. By Prof. J. R. Young. New Edition. Illustrated . 2/6
"A very complete, thorough. and useful manual for the young navigator."-Observatory.

ro6. SHIPS' ANCHORS, a Treatise on. By GEORGE COTSELL. $1 / 6$

249. SAILS AND SAIL-MAKING. With Draughting, and the Centre of Effort of the Sails. Also, Weights and Sizes of Ropes; Masting, Rigging, and Sails of Steam Vessels, \&c. By ROBERT KIPPING, N.A.

I55.

THE ENGINEER'S GUIDE TO THE ROYAL AND MERCANTILE NAVIES. By a PRACTICAL ENGINEER. Revised by D. F. M'CARThY, late of the Ordnance Surver Office, Southampton . 3/o

E The + indicates that these vols. may be had strongly bound at $6 d$. extra. 


\title{
AGRICULTURE, GARDENING, etc. \\ o** A COMPLETE READY RECKONER FOR THE AD.
} MEASUREMENT OF LAND, \&c. By A. ARMAN. Third Edition, revised and extended by C. NOR RIS, Surveyor, Valuer, \&c. . . . . 2/o

"A very useful book to all who have land to measure."-Mark Lane Express.

Should be in the hands of all persons having any connection with land."-Irish Farm.

131. MILLER'S, CORN MERCHANT'S, AND FARMER'S $R E A D Y$ RECKONER. Second Edition, revised, with a Price List of

Modern Flour Mill Machinery, by W. S. HuTTON, C.E. . . . . 2/o perfect'y adapted to indispensable vade mecum. Nothing has been spared to make the book complete and perfect:v adapted to its special purpose. '-Miller.

r40. SOILS, MANURES, AND CROPS. (Vol. I. OUTLINES of MODERN FARMing.) By R. SCOTt BURN. Woodcuts. . . . . 2/o

r4r. FARMING AND FARMING ECONOMY, Historical and Practical. (Vol. II. Outlines of Modern Farming.) By R. Scott Burn. 3/o

"Eminently calculated to enlighten the agricultural communitv on the varied subjects of which it treats ; hence it should find a place in every farmer's library."-City Press.

142. STOCK; CATTLE, SHEEP, AND HORSES. (Vol. III.

OUtlines of Modern Farming.) By R. Scott Burn. Woodcuts. $2 / 6$

"The author's grasp of his subject is thorough, and his grouping of facts effective. . . . We commend this excellent treatise." - Weekly Dispatch.

145. DAIRY, PIGS, AND POULTRY. (Vol. IV. Outlines of

MONERN FARming.) By R. SCOTT BURn. Woodcuts... . $2 / 0$

"We can testify to the clearness and intelligibility of the matter, which has been compiled from the best authorities."-London Review.

146. UTILIZATION OF SEWAGE, IRRIGATION, AND RECLAMATION OF WASTE LAND. (Vol. V. OUTLINES OF MODERN FARMing.) By R. SCOTT BURN. Woodcuts 2/6

"A work containing valuable information, which will recommend itself to all interested in modern farming." - Field.

ז4.) OUTLINES OF MODERN FARMING. By R. SCOTT

142. BURN, Author of "Landed Estates Management," "Farm Management,"

145. and Editor of "The Complete Grazier." Consisting of the above Five 146. Volumes in One, 1,250 pp., profusely Illustrated, half-bound .

\author{
. $12 / 0$
}

The aim of the anthor has been to make his work at once comprehensive and trustworthy, and in

"She has succeeded to a degree which entitles him to much credit." - Morning Advertiser.

"Should find a place in every farmer's library."-City Press.

No farmer should be without it."-Banbury Guardian.

177. FRUIT TREES, The Scientific and Profitable Culture of. From the French of M. DU BREUIL. Fourth Edition, carefully Revised by GeORGE GlenNY. With 187 Woodcuts . . . . . . . 3/6士

"The book teaches how to prune and train fruit trees to perfection."-Field.

198. SHEEP: The History, Structure, Economy, and Diseases of. By W. C. SPOONER, M.R.V.C., \&c. Fifth Edition, with fine Engravings, including Specimens of New and Improved Breeds. $366 \mathrm{pp}$.

"The book is decidedly the best of the kind in our language."-Scotsman.

201. KITCHEN GARDENING MADE EASY. Showing the best means of Cultivating every known Vegetable and Herb, \&c., with directions for management all the year round. By GEO. M. F. GLENNY. Illustrated $1 / 6 \neq$

"This book will be found trustworthy and useful." - North British Agriculturist.

207. OUTLINES OF FARM MANAGEMENT. Treating of the General Work of the Farm ; Stock: Contract Work ; Labour, \&c. By R. SCOTT BURn, Author of "Outlines of Modern Farming," \&c. . . 2/6‡

"The book is eminently practical, and may be studied with advantage by beginners in agriculture, while it contains hints which will be useful to old and successful farmers."-Scotsman. 208. OUTLINES OF LANDED ESTATES MANAGEMENT:

Treating of the Varieties of Lands, Methods of Farming, the Setting-out of

Farms, \&c. ; Roads, Fences, Gates, Irrigation, Drainage, \&c. By R. S. BuRN. 2/6t "A complete and comprehensive outline of the duties appertaiaing to the management of landed estates." - Fournal of Forestry.

*** Nos. 207 \& 208 in One Vol., handsomely half-bound, entitied "OUTLINES of LANDED Estates and Farm Management." By Robert Scott Burn. Price $6 s$.

The $\ddagger$ indicates that these vols. may be had strongly bound at 6 d. extra. 
Agriculture, Gardening, etc., continued.

209. THE TREE PLANTER AND PLANT PROPAGATOR:

With numerous Illustrations of Grafting, Layering, Budding, Implements,

Houses, Pits, \&c. By S. WooD, Author of "Good Gardening," \&c. . . 2/0

"Sound in its teaching and very comprehensive in its aim. It is a good book."-Gardeners' Magazine.

"The instructions are thoroughly practical and correct."-North British Agriculturist.

2x. THE TREE PRUNER: Being a Practical Manual on the Pruning of Fruit Trees, including also their Training and Renovation, also treating of the Pruning of Shrubs, Climbers and Flowering Plants. With numerous Illustrations. By SAMUEL WOOD, Author of "Good Gardening," \&c. I/6

"A useful book, written by one who has had great experience."-Mark Lane Express.

"We recommend this treatise very highly."-North British Agriculturist.

*Nos, 209 \& 2 ro in One Vol., handsomely half-bound, entitled "THE TREE. Planter, Propagator and Pruner." By Samuel Wood. Price $35.6 d$.

218. THE HAY AND STRAW MEASURER: New Tables for the Use of Auctioneers, Valuers, Farmers, Hay and Straw Dealers, \&c., forming a complete Calculator and Ready Reckoner. By JOHN STEELE . 2/o

"A most useful handbook. It should be in every professional office where agricultural valuations are conducted."-Land Agent's Record.

222. SUBURBAN FARMING : A Treatise on the Laying-out and Cultivation of Farms, adapted to the Produce of Milk, Butter and Cheese, Eggs, Poultry, and Pigs. By the late Prof. JOHN DonAlDson. With Additions, illustrating Modern Practice, by R. SCOTT BURN. With numerous Illustrations $3 / 6$ t

"An admirable treatise on all matters connected with dairy farms." - Live Stock Fournal.

231. THE ART OF GRAFTING AND BUDDING. By Charles Baltet. With Illustrations . . . . . . . $2 / 6$ *

"The one standard work on this subject."-Scotsman.

232. COTTAGE GARDENING; or, Flowers, Fruits, and Vegetables for Small Gardens. By E. HoвdAY . . . . . . . I/6

"Definite instructions as to the cultivation of small gardens." - Scotsman.

"Contains much useful information at a small charge."-Glasgow Herald.

233. GARDEN RECEIPTS. Edited by Charles W. Quin.

"A singularly complete collection of the principal receipts needed by gardeners." - Farmer.

"A useful and handy book, containing a good deal of valuable information."-Athenoum.

234. MARKET AND KITCHEN GARDENING. By C. W.

SHAw, late Editor of "Gardening Illustrated"

"The most valuable compendium of kitchen and market-garden work published."-Farmer.

"A most comprehensive volume on market and kitchen-gardening."-Mark Lane Express.

$D R A I N I N G A N D E M B A N K I N G$. A Practical Treatise.

By John SCOTT, late Professor of Agriculture and Rural Economy at the Royal Agricultural College, Cirencester. With 68 Illustrations .

"A valuable handbook to the engineer, as well as to the surveyor,"-Land.

"A valuable handbook to the engineer, as well as to the surveyor," -Land Agent's Record.

240. IRRIGATION AND WATER SUPPL Y: A Practical Treatise on Water Meadows, Sewage Irrigation, Warping, \&c. ; on the Construction of Wells, Ponds and Reservoirs, \&c. By Prof. J.Scotr. With 34 Illusts, $x / 6$

"A valuable and indispensable book for the estate manager and owner."-Forestry.

"Well worth the study of all farmers and landed proprietors."-Building Neves.

24r. FARM ROADS, FENCES, AND GATES: A Practical Treatise on the Roads. Tramways, and Waterways of the Farm; the Principles of Enclosures; and the different kinds of Fences, Gates, and Stiles. By Professor JoHN Scotr. With 75 Illustrations . . . 1/6

"Mr. Scott's treatise will be welcomed as a concisely compiled handbook."-Building News.

"A useful practical work, which should be in the hands of every farmer."-Farmer.

FARM BUILDINGS: A Practical Treatise on the Buildings necessary for various kinds of Farms, their Arrangement and Construction, with Plans and Estimates. By Prof: JOHN SCOTT. With ro5 Illustrations . 2/o

. No one who is called upon to design farm-buildings can afford to be without this work."-Builder "This book ought to be in the hands of every landowner and agent." -Kelso Chronicle,

$B A R N$ IMPLEMENTS AND MACHINES. Treating of the Application of Power to the Operations of Agriculture; and of the various Machines used in the Threshing-barn, in the Stock-yard, Dairy, \&c. By Professor JOHN SCOTT. With 123 Illustrations . 
Agriculture, Gardening, etc., continued.

244. FIELD IMPLEMENTS AND MACHINES: With Principles and Details of Construction and Points of Excellence, their Management, \&c. By Prof. JOHN ScOTT. With $13^{8}$ Illustrations . . . . 2/0

245. AGRICULTURAL SURVEYJNG: A Treatise on Land Surveying, Levelling, and Setting-out; with Directions for Valuing and Reporting on Farms and Estates. By Prof. J. ScoTr. With 62 Illustrations $x / 6$

239. ) FARM ENGINEERING : By Professor John ScotT. Com-

to prising the above Seven Volumes in One, 1,150 pages, and over 600 Illustrations. 245.) Half.bound

A copy of this work should be treasured up in every library where the owner thereof is in any way connected with land." - F arm and Home.

250. MEAT PRODUCTION: A Manual for Producers, Distribu-

tors, and Consumers of Butchers' Meat. By JoHn EWART.

265. BOOK-KEEPING FOR FARMERS AND ESTATE OWNERS. A Practical Treatise, presenting, in Three Plans, a System adapted for all classes of Farms. By J. M. WoodMAN, Charterea Accountant. $2 / 6$
Third Edition, revised

** The above in cloth boards, strongly bound, $3 s .6 \dot{d}$.

$"$ Will be found of great assistance by those who intend to commence a system of book-keeping, the author's examples being clear and explicit, and his explanations full and accurate."-Live Stock fow nal.

\section{MATHEMATICS, ARITHMETIC, etc.}

32. MATHEMATICAL INSTRUMENTS, a Treatise on ; Their Construction, Adjustment, Testing, and Use concisely Explained. By J. F. HeAther, M.A., of the Royal Military Academy, Woolwich. Fourteenth Edition, Revised, with Additions, by A. T. WALMrSLEY, M.I.C.E., Fellow of the Surveyors' Institution. Original Edition, in I vol., Illustrated. . .

$\because$ *In ordering the above, be careful to say "Original Edition," or give the number in the Series (32), to distinguish it from the Enlarged Edition in 3 vols. (Nos.168-9-70).

76. DESCRIPTIVE GEOMETR $Y$, an Elementary Treatise on ; with a Theory of Shadows and of Perspective, extracted from the French of G. MoNGE. To which is added a Description of the Principles and Practice of Isometrical Projection. By J. F. HEATHer, M.A. With I $_{4}$ Plates . 2

78. PRACTICAL PLANE GEOMETRY: giving the Simplest Modes of Constructing Figures contained in one Plane and Geometrical Construction of the Ground. By J. F. HeAther, M.A. With $2{ }_{5}$ Woodcuts . 2/o

"The author is well-known as an experienced professor, and the volume contains as complete a collection of problems as is likely to be required in ordinary practice."-Architect.

83. COMMERCIAL BOOK-KEEPING. With Commercial Phrases and Forms in English, French, Italian, and German. By JAMES HADDON, M.A., formerly Mathematical Master, King's College School . I/6

84. ARITHMETIC, a Rudimentary Treatise on: with full Explanations of its Theoretical Principles, and numerous Examples for Practice. For the Use of Schools and for Self-Instruction. By J. R. YounG, late Professor of Mathematics in Belfast College. Eleventh Edition . . I/6

84*A KEY TO THE ABOVE. By J. R. YounG . . . . ×/6

85. EQUATIONAL ARITHMETIC, applied to Questions of Interest, Annuities, Life Assurance, and General Commerce; with various Tables by which all Calculations may be greatly facilitated. By W. HIPSLEY. 2/o

86. ALGEBRA, the Elements of. By James HadDon, M.A., formerly Mathematical Master of King's College School. With Appendix, containing Miscellaneous Investigations, and a collection of Problems . 2/o

86*.A KEY AND COMPANION TO THE ABOVE. 'An extensive repository of Solved Examples and Problems in Illustration of the various Expedients necessary in Algebraical Operations. By J. R. Young.

88. EUCLID, The Elements of : with many Additional Proposi-

\& tions and Explanatory Notes; to which is prefixed an Introductory Essay on

8. Logic. By Henry Law, C.E.

88. Euchid, The First Three Books, By Henry LAw, C.E. . . . , 1/6

89. Enclin, Books 4. 5, 6, т1, 12. Bv HeNRY LAw. C.E. . . . . $1 / 6$ IT The indicates that these vols, may be had strongly bound a 6 d. extra. 
Mathematics, Arithmetic, etc., continued.

90. ANALYTICAL GEOMETRY AND CONIC SECTIONS, a Rudimentary Treatise on. By JAMEs HANn. A New Edition, re-written and enlarged by Professor J. R. YounG.

"The author's style is exceedingly clear and simple, and the book is well adapted for the beginner and those who may be ubliged to have recourse to seli-tuition."-Engineer.

9r. PLANE TRIGONOMETRY, the Elements of. By James HANN, formerly Mathematical Master of King's College, London . . I

92. SPHERICAL TRIGONOMETRY, the Elements of. By James Hann. Revised by Charles H. Dowling, C.E. . . . . $1 / 0$

*** Or with " The Elements of Plane Trigonometry," in One Volume, 2s, $6 d$.

93. MENSURATION AND MEASURING, for Students and Practical Use. With the Mensuration and Levelling of Land for the purposes of Modern Engineering. By T. BAKER, C. E. New Ed. by E. Nugent, C. E. r/6

ror. DIFFERENTIAL CALCULUS, Elements of the. By W.S. B. Woolhouse, F.R.A.S., \&c. . . . . . . . . . . $1 / 6$

zo2. INTEGRAL CALCULUS. By Homersham Cox, B.A. r/o

r36. ARITHMETIC, Rudimentary, for the Use of Schools and SelfInstruction. By JAmes Haddon, M.A. Revised by AвRAHAM AkMAN - I/6

r37. A KEY TO THE ABOVE. By A. ARMAN . . . . . ז/6

r68. DRAWING AND MEASURING INSTRUMENTS. Including - I. Instruments employed in Geometrical and Mechanical Drawing, and in the Construction, Copying, and Measurement of Maps and Plans. II. Instruments used for the purposes of Accurate Measurement, and for Arithmetical Computations. By J. F. HEATHER, M.A. - Feweller and Metal Worker.

«69. OPTICAL INSTRUMENTS. Including (more especially) Telescopes, Microscopes, and Apparatus for producing copies of Maps and Plans by Photography. By J. F. HeAther, M.A. Illustrated . . . r/6

"An excellent treatise."-British fournal of Photography.

r7o. SURVEYING \& ASTRONOMICAL INSTRUMENTS. Including-I. Instruments used for Determining the Geometrical Features of a portion of Ground. II. Instruments employed in Astronomical Observations. By J. F. Heather, M.A. Illustrated . . . . . . I

"A good, sensible, useful book."-School Board Chronicle.

** The above three volumes form an enlargement of the Author's original work, "Mathematical Instruments": price 2s. (See No. 32 in the Series.)

168. MATHEMATICAL INSTRUMENTS: Their Construction, 168. Adjustment, Testing and Use. Comprising Drawing, Measuring, Optical, 169. Surveying, and Astronomical Instruments. By J. F. HeAther, M.A. 170. Enlarged Edition, for the most part entirely re-written. The Three Parts as above, in One thick Volume . . . . $4 / 6+$

"An exhaustive treatise, belonging to the well-known Weale's Series. Mr. Heather's experience well qualifies him for the task he has so ably fulfilled."-Engineering and Building Times.

45. THE SLIDE RULE, AND HOW TO USE IT. Containing full, easy, and simple Instructions to perform all Business Calculations with unexampled rapidity and accuracy. By ChARLES HoAre, C.E. With a Slide Rule, in tuck of cover. Fitth Edition. . . . . . 2/6士

196. THEORY OF COMPOUND INTEREST AND ANNUI.

TIES ; with Tables of Logarithms for the more Difficult Computations of Interest, Discount, Annuities, \&c., in all their Applications and Uses for Mercantile and State Purposes. By FEDOR ThOMAN, of the Société Crédit Mobilier, Paris. Fourth Edition, carefully revised and corrected . . 4/0

"A very powerfill work, and the author has a very remarkable command of his subject."-Professor A de Morgan. "We recommend it to the notice of actuaries and accountants."-A thenerum.

$\leftarrow$ The $\ddagger$ indicales that these vols. may te had strongty bound at 6 d. extra. 
Mathematics, Arithmetic, etc., continued.

199. THE COMPENDIOUS CALCULATOR (Intuitive Calculations); or, Easy and Concise Methods of Performing the various Arithmetical Operations required in Commercial and Business Transactions; together with Useful Tables, \&c. By DANIEI. O'Gorman. Twenty-seventh Edition, carefully revised by C. NORRIS.

$*$ * The above strongly half-bound, price $3^{5 .} 6 d$.

"It would be difficult to exaggerate the usefulness of this book to everyone engaged in commerce or manufacturing industry. It is crammed full with rules and formula for shortening and employing calculations in money, weights and measures, \&e. of every sort and description."-Knowledge.

204. MATHEMATICAL TABLES, for Trigonometrical, Astronomical, and Nautical Calculations; to which is prefixed a Treatise on Logarithms. By H. LAW, C.E. Together with a Series of Tables for Nav1. gation and Nautical Astronomy. By Professor J. R. Young. New Edition 4/o

204.* LOGARITHMS. With Mathematical Tables for Trigonometrical, Astronomical, and Nautical Calculations. By HENRY LAw, C.E. Revised Edition. (Forming part of the above work.). . . . . $3 / 0$

221. MEASURES, WEIGHTS, AND MONEYS OF ALL NATIONS, and an Analysis of the Christian, Hebrew, and Mahometan Calendars. By W.S. B. WOOLHOUSE, F.R.A.S., F.S.S. Seventh Edition, 2/6!

"A work necessary for every mercantile office."-Building Trades Yournal.

227. A TREATISE ON MATHEMATICS, as applied to the Constructive Arts. By FraNCIS CAMPIN, C.E., \&c. Second Edition . 3/ot

"Should be in the hands of everyone connected with building construction."-Builder's Weekly Reporter.

\section{PHYSICAL SCIENCE, NATURAL PHILOSOPHY, etc.}

x. CHEMISTRY, for the Use of Beginners. By Prof.Geo. Fownes,

F.R.S. With an Appendix on the Application of Chemistry to Agriculture. I/o

2. NATURAL PHILOSOPHY, for the Use of Beginners. By Charles Tomlinson, F.R.S. . . . . . . . . . $ז / 6$

6. MECHANICS: Being a concise Exposition of the General Principles of Mechanical Science, and their Applications. By ChARLES TOMLINSON, F.R.S.

7. ELECTRICITY; showing the General Principles of Electrical Science, and the Purposes to which it has been applied. By Sir W. SNow HARRIS, F.R.S., \&c. With considerable Additions by R.SABINE, C.F., F.S.A. $1 / 6$

7*. GALVANISM. By Sir W. Snow Harris. New Edition, revised, with considerable Additions, by ROBErt SABINE, C.E. . . r r/6

8. MAGNETISM. By Sir W. Snow Harris. New Edition, revised and enlarged by H. M. NOAD, Ph.D. With 165 Woodcuts. $3 / 6 \ddagger$

"The best popular exposition of magnetism, its intricate relations and complicating effects, with which we are acquainted."-School Board Chronicle.

x. THE ELECTRIC TELEGRAPH: its History and Progress ; with Descriptions of some of the Apparatus. By R. SABINE, C.E., F.S.A., \&c. 3/o

"Essentially a practical and instructive work."-Daily Telegraph.

12. PNEUMATICS, including Acoustics and the Phenomena of Wind Currents, for the Use of Beginners. By CharLes TomLinson, F.R.S. Fourth Edition, enlarged. Illustrated.

72. MANUAL OF THE MOLLUSCA: A Treatise on Recent and Fossil Shells. By Dr. S. P. WoodwaRD, A.L.S. With Appendix by RALPH TATE, A.L.S., F.G.S. With numerous Plates and 300 Woodcuts. cloth boards, gilt

"A storehouse of conchological and geological information."-Hardwicke's Science Gossip.

"An important work, with such additions as complete it to the present time."-Land and Water.

96. ASTRONOMY. By the late Rev. Robert Main, M.A., F.R.S., formerly Radcliffe Observer at Oxford. Third Edition, revised and corrected to the Present Time, by William Thynne Lynn, B.A., F.R.A.S.

"A sound and simple treatise, very carefully edited, and a capital book for beginners."-Knowledge.

97. STATICS AND DYNAMICS, the Principles and Practice of; embracing also a clear development of Hydrostatics, Hydrodynamics, and Central Forces. By T. BAKE, C.E. Fourth Edition . . . . . I

E The indicates that these vols, may be had strongly bound at 6 d. extra. 


\section{MISCELLANEOUS VOLUMES.}

36. A DICTIONARY OF TERMS Used in ARCHITECTURE, BUILDING, ENGINEERING, MINING, METALLURGY, ARCHAEOLOGY, the FINE ARTS, EOC. By JOHN WEALE. Sixth Edition. Edited by ROBT. HUNT, F.R.S., Keeper of Mining Records, Editor of "Ure's Dictionary." Numerous Illustrations . . . . . . . 5/0 *** The above, strongly bound in cloth boards, price 6 s.

"The best small technological dictionary in the language."-A rcinitect.

"The absolute accuracy of a work of this character can only be judged of after extensive consultation and from our examination it appears very correct and very complete."-Mining fournal.

$"$ There is no need now to speak of the excellence of this work; it received the approval of the community long ago. Edited now by Mr Robert Hunt, and published in a cheap, handy form, it will be of the utmost service as a book of reference scarcely to be exceeded in value." -Scotsman.

50. THE LAW OF CONTRACTS FOR WORKS AND

SERVICES. By DAvid GiBBONs. Fourth Edition, with Appendix of

Statutes by T. F. UTTLEY, Solicitor. Cloth boards

"A very compendious, full and intelligible digest of the working and results of the law, in regard to all kinds of contracts between parties standing in the relation of employer and employed."-Builder.

"This exhaustive manual is written in a clear, terse, and pleasant style, and is just the work for masters and servants alike to depend upon for constant reference."-Metropolitan.

112. MANUAL OF DOMESTIC MEDICINE. By R. Gooding, B.A., M.D. Intended as a Family Guide in all cases of Accident and Emergency. Third Edition, carefully revises. "The author has, we think, performed a useful service by placing at the disposal of those situated, by unavoidable circumstances, at a distance from medical aid, a reliable and sensible work in which professional knowledge and accuracy have been well seconded by the ability to express himself in ordinary untechnical language." - Public Health.

\section{2.* MANAGEMENT OF HEALTH. A Manual of Home} and Personal Hygiene. By the Rev. JAmes BAIRD, B.A.

"The author gives sound instructions for the preservation of health."-A thenaum.

"It is wonderfully reliable, it is written with excellent taste, and there is instruction crowded into every page."-English Mechanic.

150. LOGIC, Pure and Applied. By S. H. Emmens. Third Edition $1 / 6$

"This admirable work should be a text-book not only for schools, students and philosophers, for all literatetirs and men of science, but for those concerned in the practical affairs of hife, \&c." - The Newus.

153. SELECTIONS FROM LOCKE'S ESSAYS ON THE HUMAN UNDERSTANDING. With Notes by S. H. EMmENS . . . 2/o

154. GENERAL HINTS TO EMIGRANTS. Containing Notices of the various Fields for Emigration. With Hints on Preparation for Emigrating, Outfits, \&c., Useful Recipes, Map of the World, \&c. . . . 2/o

157. THE EMIGRANT'S GUIDE TO NATAL. By RoBERT JAMES MANn, F.R.A.S., F.M.S. Second Edition, revised. Map . . 2/0 193. HANDBOOK OF FIELD FORTIFICATION. By Major W. W. KNOLLYS, F.R.G.S. With 163 Woodcuts . . . . . $3 / 0 \ddagger$

"A well-timed and able contribution to our military literature. . . The author supplies, in a clear business style, all the information likely to be practically useful." -Chambers of Commerce Chronicle.

194. THE HOUSE MANAGER: Being a Guide to Housekeep-

ing, Practical Cookery, Pickling and Preserving, Household Work, Dairy Management, the Table and Dessert, Cellarage of Wines, Home-brewing and Wine-making, the Boudoir and Dressing-room, Travelling, Stable Economy, Gardening Operations, \&c. By AN OLD HouSEKEEPER . . . 3/6

"We find here directions to be discovered in no other book, tending to save expense to the pocket, as well as labour to the head."- Fohn Bull.

"Quite an Encyclopæedia of domestic mattere. We have been greatly pleased with the neatness and lucidity of the explanatory details."-Court Circular.

r94. ) HOUSE BOOK(The). Comprising: I. The House Manager. I.2. By an Old Housekeeper. II. DoMestic Medicine. By Ralph Gooding,

\& M.D. III. Management of Health. By James Baird. In One Vol.,

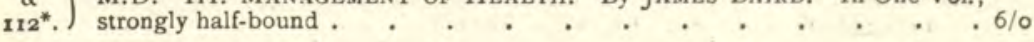

The Thindicates that these vols. may be had strongly bound at 6 d. extra. 